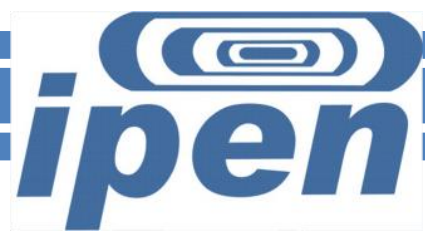

AUTARQUIA ASSOCIADA À UNIVERSIDADE DE SÃO PAULO

\title{
FERRAMENTA PARA ANÁLISE DE DESEMPENHO AMBIENTAL NA GERAÇÃO DE ENERGIA ELÉTRICA
}

\section{FLÁVIO AUGUSTO BARRELLA}

Tese apresentada como parte dos requisitos para obtenção do Grau de Doutor em Ciências na Área de Tecnologia Nuclear - Aplicações.

Orientador:

Prof. Dr. GORO HIROMOTO 


\section{((G)

AUTARQUIA ASSOCIADA À UNIVERSIDADE DE SÃO PAULO

\section{FERRAMENTA PARA ANÁLISE DE DESEMPENHO AMBIENTAL NA GERAÇÃO DE ENERGIA ELÉTRICA}

\section{FLÁVIO AUGUSTO BARRELLA}

Tese apresentada como parte dos requisitos para obtenção do Grau de Doutor em Ciências na Área de Tecnologia Nuclear - Aplicações.

Orientador:

Prof. Dr. GORO HIROMOTO 


\section{DEDICATÓRIA}

Dedico este trabalho à:

Dora e Lourenço (in memorium)

Xyko

Mirela

Carmen

Raul

Por ser esta a ordem em que entraram em minha vida! 


\section{AGRADECIMENTOS}

Ao Professor Doutor Goro Hiromoto, pela sua majestosa orientação;

Aos Professores Doutores Luiz Antonio Mai, Álvaro Luiz Guimarães Carneiro, Roberto Vicente e Orlando Rodrigues Jr., pelas valorosas sugestões tanto na Qualificação quanto no Seminário de Área;

Ao IPEN, por ter me dado a oportunidade de desenvolver este trabalho;

À minha família, a qual se privou de tantas coisas, para que eu pudesse atingir meus objetivos;

Aos colegas de trabalho, que me ajudaram em momentos críticos e

A todos aqueles que direta ou indiretamente contribuíram para a realização deste trabalho. 


\section{EPÍGRAFE}

"Tudo que é, é, ou em si ou em outra coisa."

Spinoza (Ética)

"O homem é o que ele é."

Sigmund Freud (O Ego e o ld)

"A tecnologia deveria ser utilizada como seletor da qualidade de vida e não como acelerador do ritmo de vida."

Flávio Barrella 


\title{
FERRAMENTA PARA ANÁLISE DE DESEMPENHO AMBIENTAL NA GERAÇÃO DE ENERGIA ELÉTRICA
}

\author{
FLÁVIO AUGUSTO BARRELLA
}

\begin{abstract}
RESUMO
A produção de energia elétrica é intimamente vinculada ao seu consumo. Ela acompanha o consumo, pois os processos de produção não armazenam energia e o ponto ótimo se dá quando não se tem nem excesso nem falta da quantidade de energia produzida em relação à consumida. Por sua vez, o consumo de energia elétrica está relacionado ao padrão de crescimento e desenvolvimento da nação. Inúmeras evidências, associando o consumo de energia elétrica ao produto interno bruto e outros índices de desenvolvimento, são encontrados na literatura, os quais mostram claramente esta justa correlação.

Por outro lado, o total de energia elétrica produzida é o resultado da soma das produções individuais das diversas fontes de recursos, tais como: gás natural, carvão vapor, hídricas, produtos de cana, eólica e urânio. Este é um cenário típico de produtores e consumidores, em que os produtores concorrem, entre si, para suprir a demanda. Qualquer variação na produção de um é compensada pela produção dos outros, a fim de se manter a demanda atendida na exata medida de suas necessidades.

Neste trabalho foram desenvolvidas uma metodologia original e uma ferramenta de simulação, no aplicativo MATLAB®, e estabelecidos parâmetros e indicadores ambientais para auxiliar a tomada de decisões quanto ao direcionamento de investimentos na área de produção de energia elétrica, mostrando como minimizar os efeitos nocivos ao meio ambiente e acompanhar o crescimento da demanda simultaneamente. São utilizadas técnicas e metodologias consagradas, tais como a Avaliação do Ciclo de Vida, a Contabilidade Emergética, a Análise Estatística, a Teoria de Sistemas sobre a base de dados oficial do governo brasileiro, isto é, a matriz $27 \times 47$ do relatório anual Boletim Energético Nacional (BEN) do Ministério das Minas e Energia (MME), fornecendo uma visão holística e otimizada do setor energético nacional e em particular da área de energia elétrica.
\end{abstract}

Alguns temas polêmicos como o efeito da utilização da área florestal para a produção de energia elétrica e o esgotamento de reservas energéticas são discutidos no final deste trabalho.

Palavras chave: ACV, Emergia, BEN, Matriz Energética. 


\title{
A TOOL FOR ANALYSIS OF ENVIRONMENTAL PERFORMANCE IN ELECTRICITY GENERATION
}

\author{
FLÁVIO AUGUSTO BARRELLA
}

\begin{abstract}
The production of electricity is closely linked to its consumption. It follows the consumption, because the production processes do not stock up energy and the optimum point is when it does not have over or less quantity of energy produced according to its consumption. In turn, energy consumption is related to the level of growth and development of the nation. A lot of evidence associating energy consumption to gross domestic product and other development indicators are found in the literature, which clearly shows this correlation.

On the other side, there are several sources of resources from which is produced electric power, such as: natural gas, steam coal, hydro, sugarcane waste, wind and uranium in amounts that together supply the need consumption required all the time and could supply more than the required amount. This presented scenario is a typical example of producers and consumers, where producers compete to supply demand, and any variation in one of them is offset by the production of others, in order to get demand attended in the exact extent of their needs.

In this work were developed a methodology and a tool, and also parameters were set to help decision making regarding guidelines for investments in the production of electricity, directing to minimize harm to the environment and at the same time meet the growing of the demand. Techniques and traditional methods were used, such as Life Cycle Assessment, Emergy Accounting, Statistical Analysis, the System Theory on the official database of the Brazilian government, that is, the $27 \times 47$ matrix of the Annual Report National Energy Bulletin (BEN) of Ministry of Mines and Energy (MME), providing an holistic and optimized overview in the energy national sector and in particular the electric power sector.

Some controversial issues as the effect of using the forest for the production of electricity and the depletion of energetic reserves are discussed at the end of this work.
\end{abstract}

Keywords: LCA, Emergy, BEN, Energy Matrix. 


\section{SUMÁRIO}

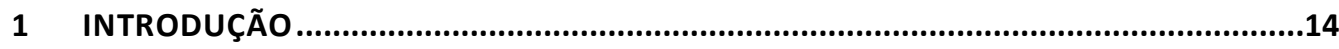

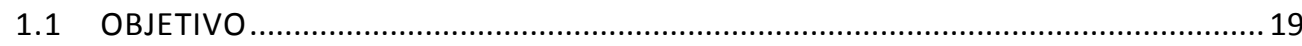

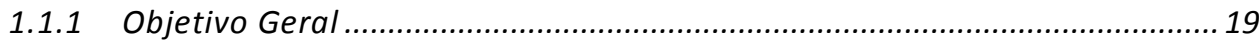

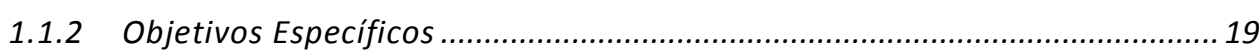

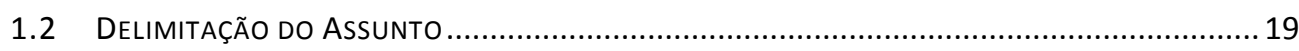

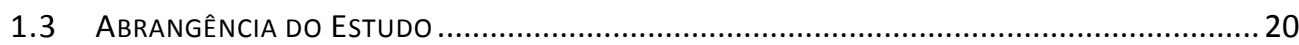

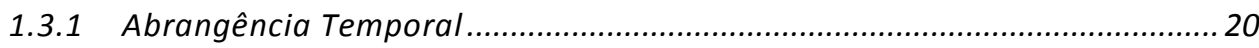

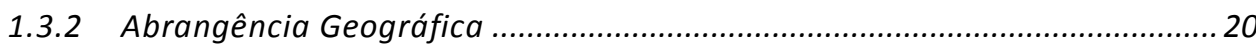

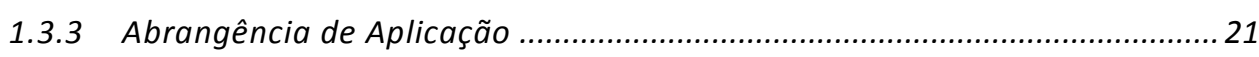

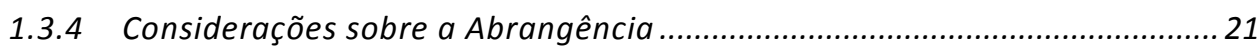

1.3.5 Análises e discussões não contempladas por este estudo..............................21

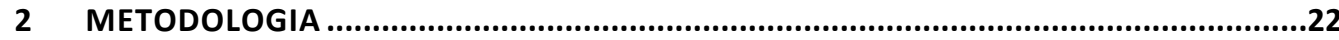

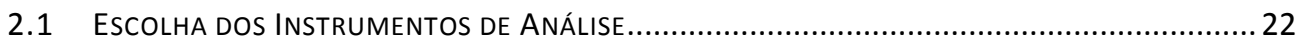

2.1.1 O BEN - Balanço Energético Nacional ........................................................2 23

2.1.1.1 Unidade Funcional utilizada no BEN................................................................24

2.1.1.2 Descrição das linhas e colunas da matriz $27 \times 47$.................................................25

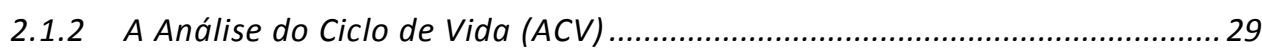

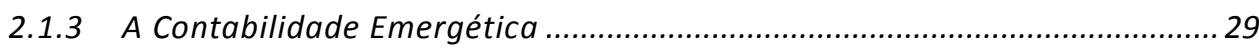

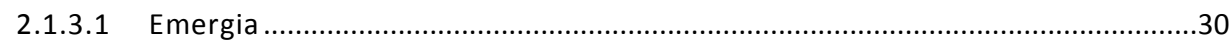

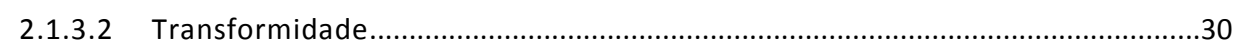

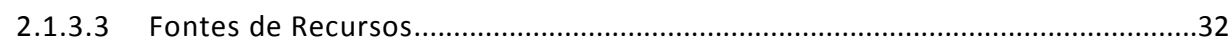

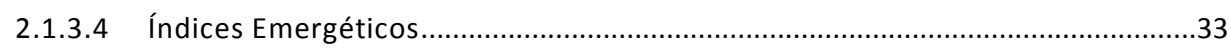

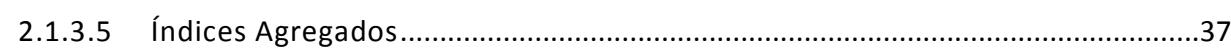

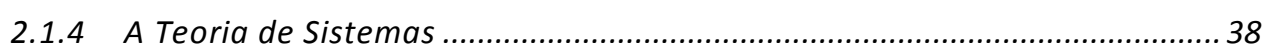

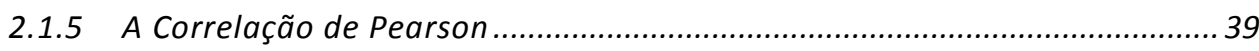

2.2 ESCOLHA DAS FONTES DE RECURSOS A SEREM UTILIZADAS ................................................... 45

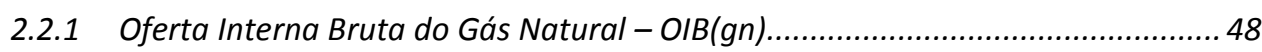

2.2.2 Oferta Interna Bruta do Carvão Vapor - OIB(cv).................................................. 49

2.2.3 Oferta Interna Bruta de Energia Hídrica - OIB(eh)........................................... 49

2.2.4 Oferta Interna Bruta dos Produtos de Cana - OIB(pc) ....................................... 50

2.2.5 Oferta Interna Bruta da Energia Eólica - OIB(ee) ............................................... 51

2.2.6 Oferta Interna Bruta da Energia Nuclear - OIB(en) ............................................51

2.2.7 Transformidades das Fontes de Recursos .................................................... 52

2.2.8 Análise de sensibilidade .................................................................................. 53

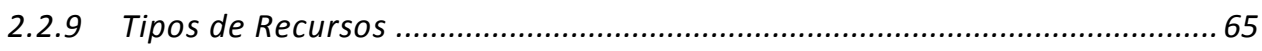

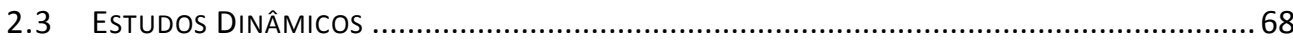




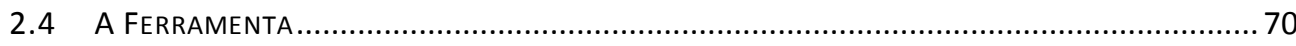

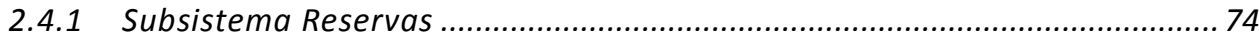

2.4.2 Subsistema Extração-Produção................................................................. 77

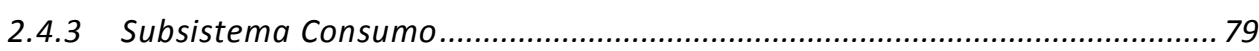

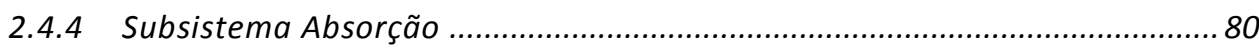

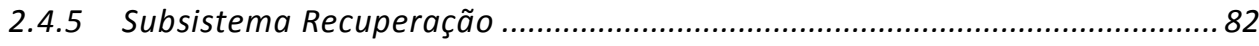

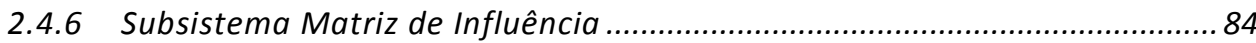

2.4.7 Subsistema Energia Corrigida.................................................................. 85

2.4.8 Subsistema de Obtenção dos Índices Emergéticos........................................ 86

2.4.9 Cálculo dos valores e gráficos de simulações ............................................91

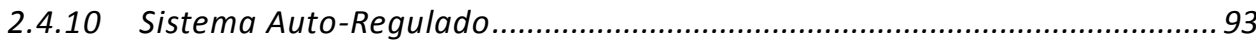

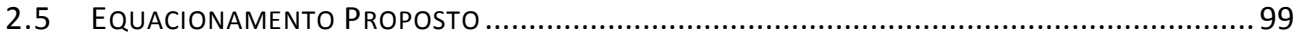

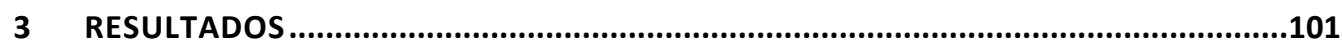

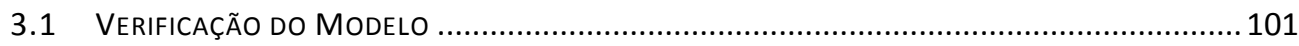

3.2 COMPORTAMENTO DO MODELO COM PERTURBAÇÕES ................................................... 103

3.2.1 Comportamento com perturbações de curto prazo ......................................... 103

3.2.2 Comportamento do modelo com perturbações de médio prazo.......................... 106

3.3 OBTENÇÃo DOS ÍNDICES COM E SEM PERTURBAÇÕES .................................................. 113

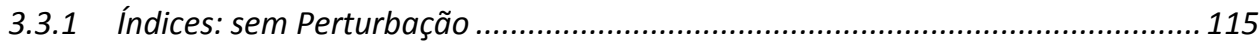

3.3.2 Índices: Perturbação na fonte de Gás Natural ................................................ 116

3.3.3 Índices: Perturbação na fonte de Carvão Vapor............................................. 117

3.3.4 Índices: Perturbação na fonte de recursos Hídricos .......................................... 118

3.3.5 Índices: Perturbação na fonte de recursos Produtos de Cana ............................. 119

3.3.6 Índices: Perturbação na fonte de recursos Eólica............................................. 120

3.3.7 Índices: Perturbação na fonte de recursos Nucleares ..................................... 121

3.3.8 Índices: Perturbação combinada Hídrica e Nuclear 1 ........................................ 122

3.3.9 Índices: Perturbação combinada Hídrica e Nuclear 2 ......................................... 123

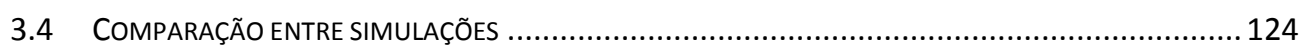

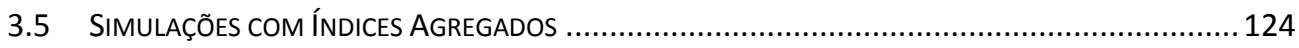

3.5.1 Índices Agregados Médios: sem Perturbação .............................................. 125

3.5.2 Índices Agregados Médios: Perturbação na fonte de Gás Natural ...................... 125

3.5.3 Índices Agregados Médios: Perturbação na fonte de Carvão Vapor................... 126

3.5.4 Índices Agregados Médios: Perturbação na fonte de recursos Hídricos ............. 127

3.5.5 Índices Agregados Médios: Perturbação na fonte de Produtos de Cana ........... 127

3.5.6 Índices Agregados Médios: Perturbação na fonte de recursos Eólica .................. 128

3.5.7 Índices Agregados Médios: Perturbação na fonte de recursos Nucleares .......... 129

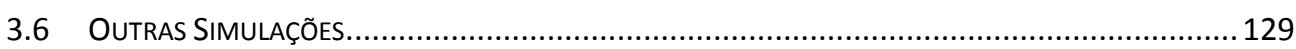

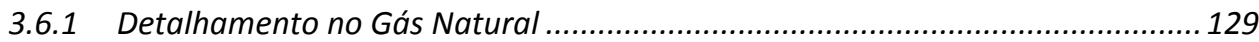


3.6.2 Índices Agregados Médios: Gás Natural com Reserva llimitada ....................... 132

3.6.3 Recursos Hídricos e de Produtos de Cana..................................................... 134

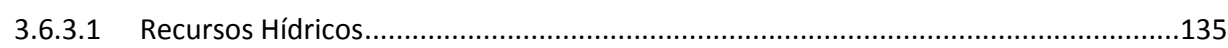

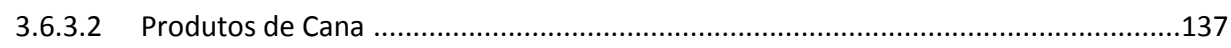

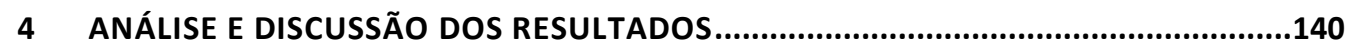

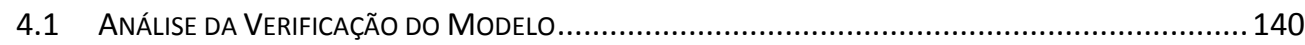

4.2 ANÁlISE DO COMPORTAMENTO DO MODELO COM PERTURBAÇÕES ................................... 141

4.3 ANÁLISE DA OBTENÇÃO DOS ÍNDICES COM E SEM PERTURBAÇÕES .................................... 142

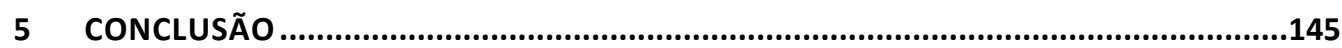

6 SUGESTÕES DE CONTINUIDADE DO TRABALHO..................................................146

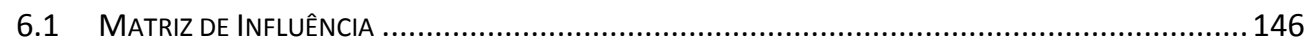

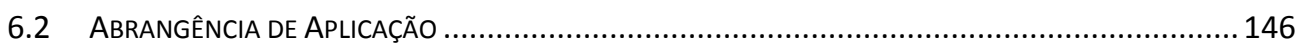

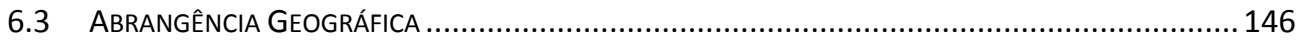

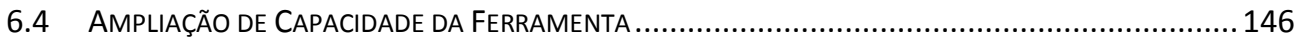

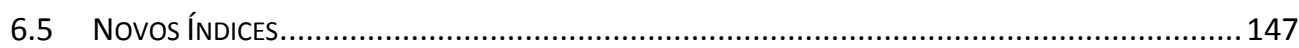

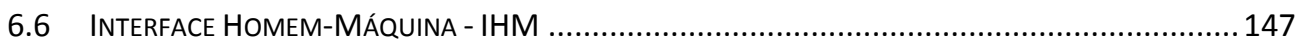

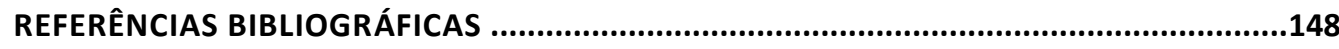

APÊNDICE A - SENSIBILIDADE DOS ÍNDICES EYR, ELR E EIS EM RELAÇÃO À F..............152

APÊNDICE B - SIMULAÇÕES ÍNDICES AGREGADOS ...................................................155

ANEXO A - ANEXO E DO CAPÍTULO 9 DO BEN2005 .................................................189

ANEXO B - CÁLCULOS DAS COMPONENTES EMERGÉTICAS .....................................195 


\section{LISTA DE TABELAS}

TABELA1 - FATORES DE CONVERSÃO PARA TEP MÉDIO .24

TABELA2 - DESCRIÇÃO DAS COLUNAS DA MATRIZ 27X47. 27

TABELA 3 - DESCRICÃO DAS LINHAS DE OFERTA DA MATRIZ 27X47....

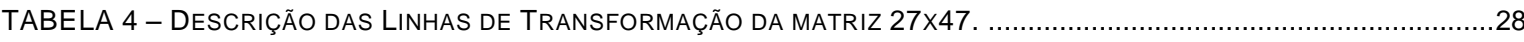

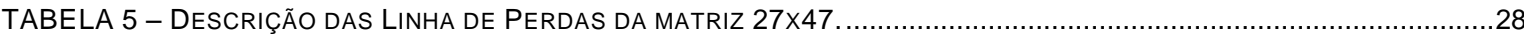

TABELA 6 - DESCRIÇÃO DAS LINHAS DE CONSUMO DA MATRIZ 27X47.

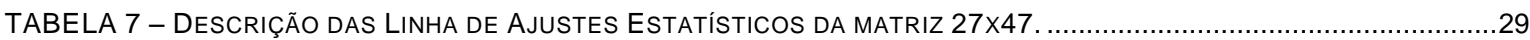

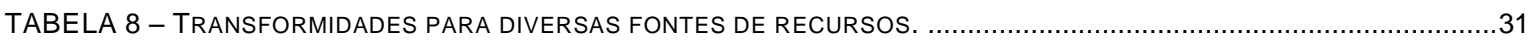

TABELA 9 - PARTICIPAÇÃO DE CADA FONTE DE RECURSO NA GERAÇÃO DE ENERGIA ELÉTRICA. ...................................46

TABELA 10 - PARCELAS DE RECURSOS RENOVÁVEIS, NÃO RENOVÁVEIS E PAGOS POR FONTE DE RECURSO....................53

TABELA 11 - R, N E F E ÍNDICES EMERGÉTICOS PARA 4 PLANTAS DE GERAÇÃO DE ENERGIA ELÉTRICA, COM A

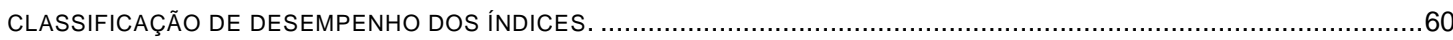

TABELA 12 - CLASSIFICAÇÃO DAS PLANTAS DE ENERGIA COM E SEM O SERVIÇO DO MEIO AMBIENTE .............................62

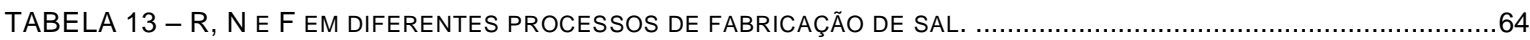

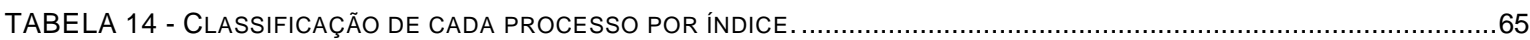

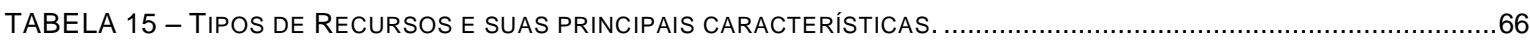

TABELA 16 - SUBSISTEMAS SUAS ENTRADAS, SAÍDAS E PARÂMETROS INTERNOS.

TABELA 17 - ÍNDICES EMERGÉTICOS DAS FONTES DE RECURSO UTILIZADAS................................................................8

TABELA 18 - CLASSIFICAÇÃO DAS REGIÕES DO DIAGRAMA TERNÁRIO. ..............................................................

TABELA 19 - COMPARAÇÃO DOS RESULTADOS BEN2004 E PROJEÇÃO. ................................................................102

TABELA 20 - COMPARATIVO DOS RESULTADOS BEN2009 E SIMULAÇÃO. ...........................................................102

TABELA 21 - RESULTADOS DE SIMULAÇÃO: SEM PERTURBAÇÃO; COM PERTURBAÇÕES INDIVIDUAIS E COMBINADAS......124

TABELA 22 - ÍNDICES AGREGADOS: RESULTAdOS DE SIMULAÇÃO COM E SEM PERTURBAÇÃO. .....................................133

TABELA 23 - RESULTADOS COM E SEM OS SERVIÇOS DO MEIO AMBIENTE PARA OS RECURSOS HÍDRICOS.....................137

TABELA 24 - RESULTADOS COM E SEM OS SERVIÇOS DO MEIO AMBIENTE PARA OS PRODUTOS DE CANA. .......................139 


\section{LISTA DE FIGURAS}

FIGURA1 - INTERRELAÇÕES ENTRE AS DISCIPLINAS CONSIDERADAS. FONTE: O AUTOR. ............................................22

FIGURA 2 - AS DIVERSAS ETAPAS DO PROCESSO ENERGÉTICO DA MATRIZ 27X47 ...................................................2

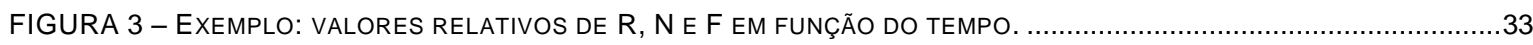

FIGURA 4 - EXEMPLO: ÍNDICES EIS, ELR E EYR EM FUNÇÃO DO TEMPO.

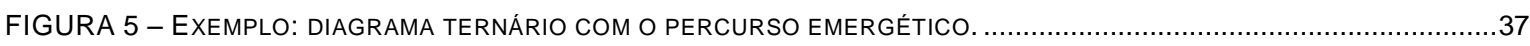

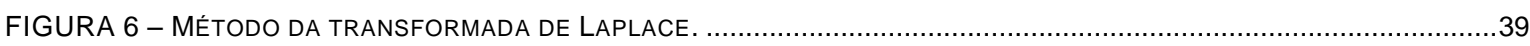

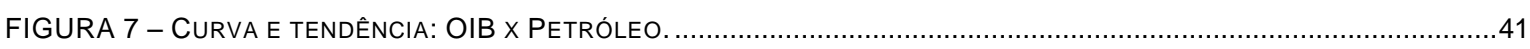

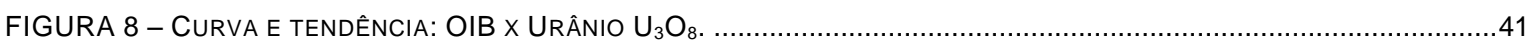

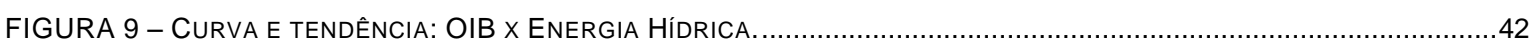

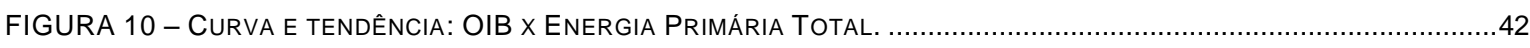

FIGURA 11 - MATRIZ DE CORRELAÇÃO ENTRE COLUNAS SELECIONADAS DA MATRIZ 27X47 DO BEN .............................43

FIGURA 12 - CURVAS DE CORRELAÇÃO DE PRODUÇÃO DE ENERGIA: ANOS CONSECUTIVOS, DE 2, 3, 5 E 10 ANOS..........44

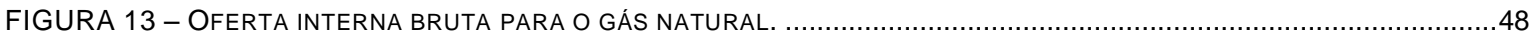

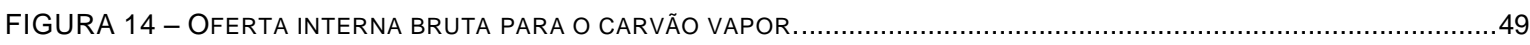

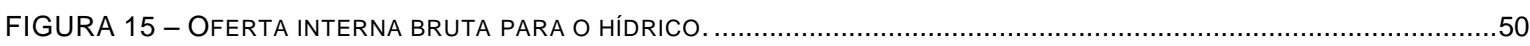

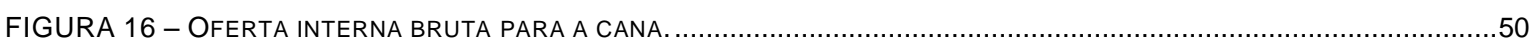

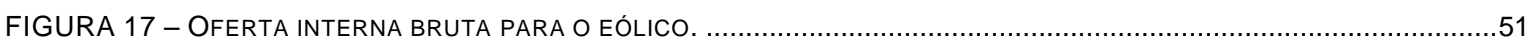

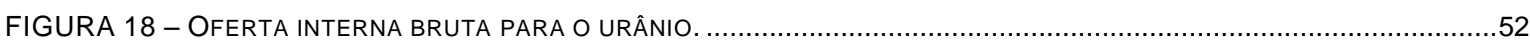

FIGURA 19 - DIAGRAMA TERNÁRIO E CURVAS EYR, ELR, EIS E S F, SENSIBILIDADE EM RELAÇÃO À F...........................55

FIGURA 20 - DIAGRAMA TERNÁRIO E CURVAS EYR, ELR, EIS E $S_{F}$, SENSIBILIDADE EM RELAÇÃO À F, NO PONTO 1......56

FIGURA 21 - DIAGRAMA TERNÁRIO E CURVAS EYR, ELR, EIS E S F, SENSIBILIDADE EM RELAÇÃO À F, NO PONTO 2.......56

FIGURA 22 - DIAGRAMA TERNÁRIO E CURVAS EYR, ELR, EIS E S F, SENSIBILIDADE EM RELAÇÃO À F, NO PONTO $3 . . . . .57$

FIGURA 23 - DIAGRAMA TERNÁRIO E CURVAS EYR, ELR, EIS E SF, SENSIBILIDADE EM RELAÇÃO À F, NO PONTO $4 . \ldots . . .57$

FIGURA 24 - DIAGRAMA TERNÁRIO E CURVAS EYR, ELR, EIS E SF, SENSIBILIDADE EM RELAÇÃO À F, NO PONTO $5 \ldots . . . .58$

FIGURA 25 - DIAGRAMA TERNÁRIO E CURVAS EYR, ELR, EIS E S F, SENSIBILIDADE EM RELAÇÃO À F, NO PONTO $6 . . . . .58$

FIGURA 26 - DIAGRAMA TERNÁRIO E CURVAS EYR, ELR, EIS E $S_{F}$, SENSIBILIDADE EM RELAÇÃO À F, NO PONTO $7 \ldots . . . .59$

FIGURA 27 - DIAGRAMA TERNÁRIO E CURVAS EYR, ELR, EIS E S $S_{F}$, SENSIBILIDADE EM RELAÇÃO À F, NO PONTO 8......59

FIGURA 28 - DIAGRAMA TERNÁRIO COM AS PLANTAS DE ENERGIA ELÉTRICA, SEM E COM SERVIÇO DO MEIO AMBIENTE...63

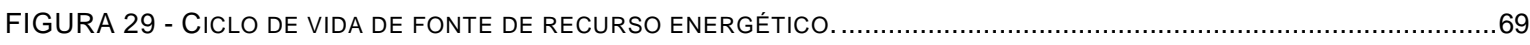

FIGURA 30 - CICLO DE VIDA DE FONTES DE RECURSOS COM RECUPERAÇÃO INDEPENDENTE DA ABSORÇÃO. ...................69

FIGURA 31 - DIAGRAMA DE BLOCOS GERAL DA FERRAMENTA DE ANÁLISE: A) BLOCOS DAS FONTES DE RECURSOS; B)

GERAÇÃO DOS RESULTADOS; C) GERAÇÃO DOS ÍNDICES EMERGÉTICOS ........................................................70

FIGURA 32 - INTERRELAÇÃO ENTRE BLOCOS DE UMA DAS FONTES DE RECURSOS.......................................................71

FIGURA 33 - DIAGRAMA DE BLOCOS INTERNO REFERENTE AO ACV DE UMA DAS FONTES DE RECURSOS.........................72

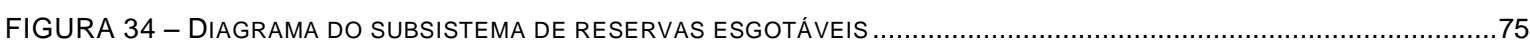

FIGURA 35 - DIAGRAMA DO SUBSISTEMA DE RESERVAS NÃO ESGOTÁVEIS ….............................................................76

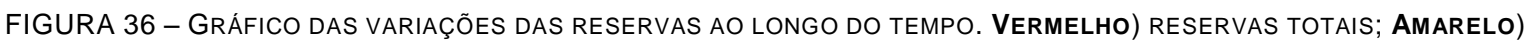

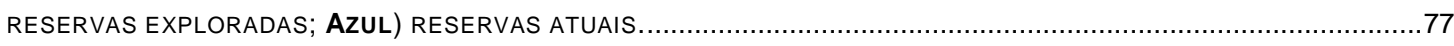

FIGURA 37 - DIAGRAMA DO SUBSISTEMA DE EXTRAÇÃO-PRODUÇÃO …...................................................................77

FIGURA 38 - GRÁFICOS DE PRODUÇÃO, A) VERMELHO: PRODUÇÃO LIVRE NO CICLO; AMARELO: PRODUÇÃO NO CICLO; B)

VERMELHO: PRODUÇÃO LIVRE ACUMULADA; AMARELO: PRODUÇÃO ACUMULADA ….............................................78

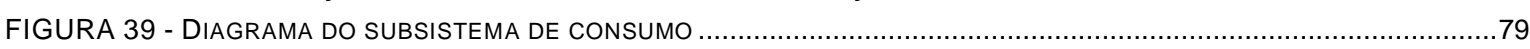

FIGURA 40 - GRÁFICOS DE CONSUMO, A) VERMELHO: CONSUMO LIVRE NO CICLO; AMARELO: CONSUMO NO CICLO; B) VERMELHO: CONSUMO LIVRE ACUMULADO; AMARELO: CONSUMO ACUMULADO

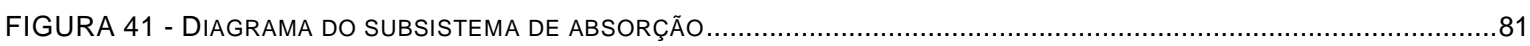

FIGURA 42 - GRÁFICOS DE ABSORÇÃO; A) ABSORÇÃO NO CICLO; B) VERMELHO: ABSORÇÃO LIVRE ACUMULADO;

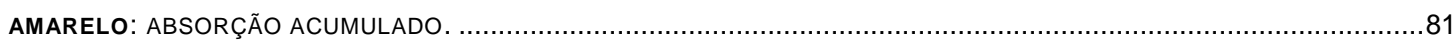

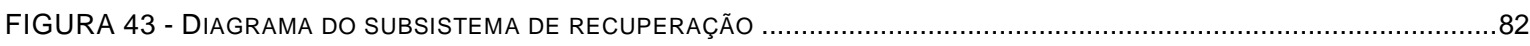

FIGURA 44 - GRÁFICOS DE RECUPERAÇÃO; A) RECUPERAÇÃO NO CICLO; B) RECUPERAÇÃO ACUMULADO. .....................83

FIGURA 45 - DIAGRAMA DE BLOCOS DO VETOR REFERENTE A UMA FONTE DE RECURSOS DA MATRIZ DE INFLUÊNCIA. .....84

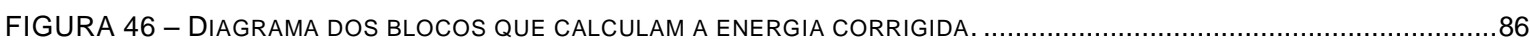

FIGURA 47 - DIAGRAMA DOS BLOCOS GERADOR DOS ÍNDICES EMERGÉTICOS. ...........................................................8 
FIGURA 48 - DIAGRAMA TERNÁRIO A) PERCURSO EMERGÉTICO B) REGIÕES.

FIGURA 49 - DIAGRAMA DE BLOCOS PARA CÁLCULO DOS VALORES ENERGÉTICOS.

FIGURA 50 - EXEMPLO DE GRÁFICO DE DELTAS DE PRODUÇÃO, PRODUÇÃO POR FONTE DE RECURSO E PRODUÇÕES COM E SEM PERTURBAÇÃO.

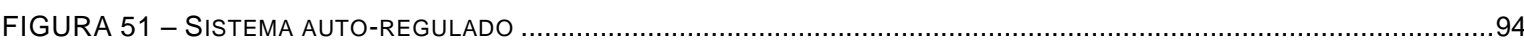

FIGURA 52 - CAIXA DE DIÁLOGO PARA ENTRADA DE PERTURBAÇÃO NO SISTEMA …………...................................95

FIGURA 53 - GRÁFICOS DE PRODUÇÃO COM PERTURBAÇÃO EM SOMENTE UMA FONTE DE RECURSO: A) DELTA DE PRODUÇÃO; B) PRODUÇÃO POR FONTE DE RECURSOS E C) PRODUÇÃO TOTAL COM E SEM PERTURBAÇÃO.................97

FIGURA 54 - GRÁFICOS DE PRODUÇÃO COM PERTURBAÇÃO EM TODAS AS FONTES DE RECURSO: A) DELTA DE PRODUÇÃO; B) COMPORTAMENTO DO SISTEMA COM PERTURBAÇÃO E C) COMPORTAMENTO DO SISTEMA SEM PERTURBAÇÃO. ....98

FIGURA 55 - PRODUÇÃO SEM PERTURBAÇÃO POR FONTE DE RECURSO PARA VALIDAÇÃO DO MODELO (ATÉ 2009). .......101

FIGURA 56 - GRÁFICOS DE PRODUÇão SEM PERTURBAÇÃo (ATÉ 2027): A) DELTA DE PRODUÇão; B) PRODUÇÃO POR FONTE DE RECURSO E C) COMPORTAMENTO DO SISTEMA SEM PERTURBAÇÃO.

FIGURA 57 - GRÁFICOS DE PRODUÇÃO COM PERTURBAÇÃO DE 15000 TEP, NA FONTE NUCLEAR, EM 2020 (ATÉ 2027): A) DELTA DE PRODUÇÃO; B) PRODUÇÃO INDIVIDUAL E C) COMPORTAMENTO DO SISTEMA COM PERTURBAÇÃO.............105

FIGURA 58 - GRÁFICOS DE PRODUÇÃO SEM PERTURBAÇÃO: A) DELTA DE PRODUÇÃO; B) PRODUÇÃO INDIVIDUAL E C) COMPORTAMENTO DO SISTEMA SEM PERTURBAÇÃO.

FIGURA 59 - GRÁFICOS DE PRODUÇÃO COM PERTURBAÇÃO DE 15000 TEP, NA FONTE NUCLEAR, EM 2015 (ATÉ 2040): A) DELTA DE PRODUÇÃO; B) PRODUÇÃO INDIVIDUAL E C) COMPORTAMENTO DO SISTEMA COM PERTURBAÇÃO.............108

FIGURA 60 - GRÁFICOS DE PRODUÇÃo COM PERTURBAÇÃO DE 15000 TEP, NA FONTE HÍDRICA, EM 2015 (ATÉ 2040): A) DELTA DE PRODUÇÃO; B) PRODUÇÃO INDIVIDUAL E C) COMPORTAMENTO DO SISTEMA COM PERTURBAÇÃO.............109

FIGURA 61 - GRÁFICOS DE PRODUÇÃo COM PERTURBAÇÕES INDIVIDUAIS ENTRE 2015 E 2030 (ATÉ 2040): A) DELTA DE PRODUÇÃO; B) PRODUÇÃO INDIVIDUAL E C) COMPORTAMENTO DO SISTEMA COM PERTURBAÇÃO...........................110

FIGURA 62 - GRÁFICOS DE PRODUÇÃO COM PERTURBAÇÃO DE 15000, NA FONTE GÁS NATURAL, EM 2018 (ATÉ 2040): A) DELTA DE PRODUÇÃO; B) PRODUÇÃO INDIVIDUAL E C) COMPORTAMENTO DO SISTEMA COM PERTURBAÇÃO.............111

FIGURA 63 - GRÁFICOS DE PRODUÇÃo SEM PERTURBAÇÃO, COM ESGOTAMENTO DE GÁS NATURAL: A) DELTA DE PRODUÇÃO; B) PRODUÇÕES INDIVIDUAIS E C) COMPORTAMENTO DO SISTEMA SEM PERTURBAÇÃO.

FIGURA 64 - GRÁFICOS DOS ÍNDICES DE DESEMPENHO (ESQUERDA) E ÍNDICES DE DESEMPENHO COM MARCAÇÃO DOS

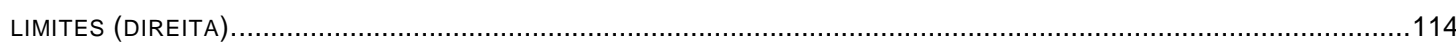

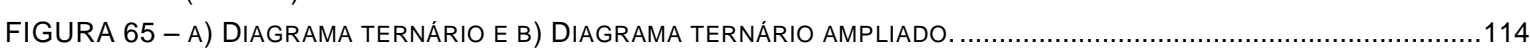

FIGURA 66 - ÍNDICES: SUSTENTABILIDADE, IMPACTO AMBIENTAL E RENDIMENTO, SEM PERTURBAÇÃO.........................115

FIGURA 67 - PERCURSO EMERGÉTICO SEM PERTURBAÇÃO. ................................................................................115

FIGURA 68 - ÍNDICES: EIS, ELR E EYR, COM PERTURBAÇÃO NA FONTE DE GÁS NATURAL DE 10000 TEP...................116

FIGURA 69 - PERCURSO EMERGÉTICO COM PERTURBAÇÃo NA FONTE DE GÁs NATURAL DE 10000 TEP.......................116

FIGURA 70 - ÍNDICES: EIS, ELR E EYR, COM PERTURBAÇÃO NAS FONTE DE RECURSO CARVÃO DE 10000 TEP...........117

FIGURA 71 - PERCURSO EMERGÉTICO COM PERTURBAÇÃO NA FONTE DE ENERGIA CARVÃO DE 10000 TEP. .................117

FIGURA 72 - ÍNDICES: EIS, ELR E EYR, COM PERTURBAÇÃO NA FONTE DE ENERGIA HÍDRICA DE 10000 TEP...............118

FIGURA 73 - PERCURSO EMERGÉTICO COM PERTURBAÇÃO NA FONTE DE ENERGIA HÍDRICA DE 10000 TEP..................118

FIGURA 74 - ÍNDICES: EIS, ELR E EYR, COM PERTURBAÇÃO NAS FONTE DE RECURSO CANA DE 10000 TEP. ..............119

FIGURA 75 - PERCURSO EMERGÉTICO COM PERTURBAÇÃO NA FONTE DE ENERGIA CANA DE 10000 TEP.......................119

FIGURA 76 - ÍNDICES: EIS, ELR E EYR, COM PERTURBAÇÃO NAS FONTE DE RECURSO EÓLICO DE 10000 TEP. ...........120

FIGURA 77 - PERCURSO EMERGÉTICO COM PERTURBAÇÃO NA FONTE DE ENERGIA EÓLICA DE 10000 TEP. ...................120

FIGURA 78 - ÍNDICES: EIS, ELR E EYR, COM PERTURBAÇÃO NA FONTE DE RECURSOS NUCLEAR DE 10000 TEP..........121

FIGURA 79 - PERCURSO EMERGÉTICO COM PERTURBAÇÃO NA FONTE DE ENERGIA NUCLEAR DE 10000 TEP. ...............121

FIGURA 80 - ÍNDICES: EIS, ELR E EYR, COM PERTURBAÇÃO COMBINADA NAS FONTES DE RECURSOS HÍDRICA DE 10000

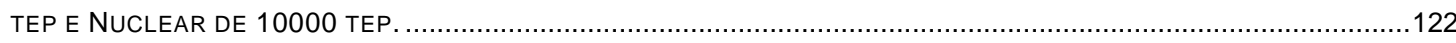

FIGURA 81 - PERCURSO EMERGÉTICO COM PERTURBAÇÕES NAS FONTES DE ENERGIA HÍDRICA DE 10000 TEP E NUCLEAR

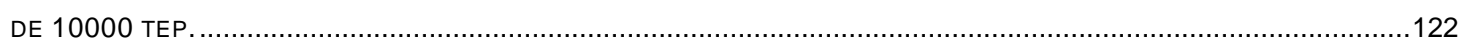

FIGURA 82 - ÍNDICES: EIS, ELR E EYR, COM PERTURBAÇÃO COMBINADA NAS FONTES DE RECURSOS HÍDRICA DE 5000

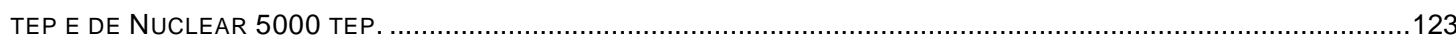

FIGURA 83 - PERCURSO EMERGÉTICO COM PERTURBAÇÕES NAS FONTES DE ENERGIA HÍDRICA DE 5000 TEP E NUCLEAR DE 5000 TEP.

FIGURA 84 - ÍNDICES AGREGADOS: EIS, ELR E EYR, SEM PERTURBAÇÃO......................................................125

FIGURA 85 - ÍNDICES AGREGADOS: EIS, ELR E EYR, COM PERTURBAÇÃO NAS FONTE DE RECURSO GÁS NATURAL DE

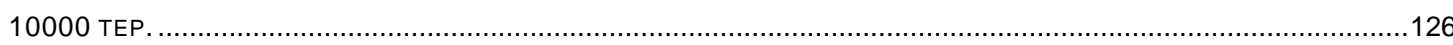

FIGURA 86 - ÍNDICES AGREGAdos: EIS, ELR E EYR, COM PERTURBAÇÃo NA FONTE DE CARVÃO, DE 10000 TEP.......126 
FIGURA 87 - ÍNDICES AGREGAdOS: EIS, ELR E EYR, COM PERTURBAÇÃO NA FONTE HÍDRICA, DE 10000 TEP. 127

FIGURA 88 - ÍNDICES AGREGADOS: EIS, ELR E EYR, COM PERTURBAÇÃO NA FONTE DE CANA, DE 10000 TEP.

FIGURA 89 - ÍNDICES AGREGADOS: EIS, ELR E EYR, COM PERTURBAÇÃO NA FONTE EÓLICA, DE 10000 TEP.

FIGURA 90 - ÍNDICES AGREGADOS: EIS, ELR E EYR, COM PERTURBAÇÃO NA FONTE NUCLEAR, DE 10000 TEP. .129

FIGURA 91 - ÍNDICES: EIS, ELR E EYR, COM PERTURBAÇÃO NA FONTE DE GÁS NATURAL DE 10000 TEP E FALSO AUMENTO DE RESERVAS.

FIGURA 92 - PERCURSO EMERGÉtICO: PERTURBAÇÃo NO GÁS NATURAL DE 10000 TEP E FALSO AUMENTO DE RESERVAS.

FIGURA 93 - ÍNDICES: EIS, ELR E EYR, SEM PERTURBAÇÃO ATÉ 2050 PARA O GÁS NATURAL.

FIGURA 94 - PERCURSO EMERGÉTICO: SEM PERTURBAÇÃo ATÉ 2050, PARA O GÁS NATURAL.

FIGURA 95 - ÍNDICES: EIS, ELR E EYR, COM PERTURBAÇÃO DE 10000 TEP NO ANO DE 2015 E SIMULAÇÃO ATÉ 2050 PARA O GÁS NATURAL.

FIGURA 96 - PERCURSO EMERGÉtICO: PERTURBAÇÃO DE 10000 TEP NO ANO DE 2015 E SIMULAÇÃO ATÉ 2050, PARA O GÁS NATURAL.

FIGURA 97 - ÍNDICES: EIS, ELR E EYR, COM PERTURBAÇÃO COMBINADA NAS FONTES DE RECURSOS HÍDRICA DE 10000 TEP E NUCLEAR DE 10000 TEP.

FIGURA 98 - ÍNDICES: EIS, ELR E EYR, COM O SERVIÇO DO MEIO AMBIENTE PARA RECURSOS HÍDRICOS. ...................136

FIGURA 99 - PERCURSO EMERGÉTICO COM SERVIÇO DO MEIO AMBIENTE, RECURSOS HÍDRICOS...............................136

FIGURA 100 - ÍNDICES: EIS, ELR E EYR, COM SERVIÇO DO MEIO AMBIENTE PARA PRODUTOS DE CANA......................138

FIGURA 101 - PERCURSO EMERGÉTICO COM SERVIÇO DE MEIO AMBIENTE, RECURSO DE PRODUTO DE CANA...............138 


\section{INTRODUÇÃO}

A alocação de investimentos para a geração de energia elétrica tem-se tornado cada vez mais crítica no que se refere à utilização dos recursos necessários, quer sejam financeiros, quer sejam ambientais.

Há uma sensação de disputa entre os vários segmentos da sociedade para sensibilizar e convencer que suas soluções são as melhores para o coletivo e ainda corretas, tanto do ponto de vista econômico, quanto social e ambiental.

Governos, investidores, a comunidade científica, ambientalistas, ecologistas e a sociedade em geral têm muito discutido o assunto sem que se consiga chegar a um consenso que atenda as expectativas de cada grupo.

Desenvolvimentistas fazem a análise da geração de energia elétrica utilizando-se diversas metodologias que avaliam os aspectos de impacto ambiental: (ULGIATI, ODUM e BASTIANONI, 1994) - análise emergética da produção de energia elétrica na Itália; (ULGIATI, BROWN e MARCHETTINI, 1995) - avaliação da sustentabilidade por meio da utilização de índices emergéticos; (SILVA, 2003) - análise do controle de gastos ambientais; (ULGIATI, BARGIGLI e RAUGEL, 2004) - análise ambiental do fluxo de importações e exportações internacional. Ainda sugerem a utilização de índices de impacto ambiental, renovabilidade e sustentabilidade: (ULGIATI, ODUM e BASTIANONI, 1994) - índices de carga ambiental, sustentabilidade, investimento emergético e rendimento emergético; (ULGIATI, BROWN e MARCHETTINI, 1995) - definição de critérios para os valores dos índices emergéticos; (BROWN e ULGIATI, 1997) - avaliação dos efeitos de mitigação dos impactos ambientais nos índices emergéticos; (ULGIATI e BROWN, 1998) - análise de índices emergéticos em ecosistemas feitos pelo homem; (POPP, HOAG e HYATT, 2001) - análise conjunta de índices ambientais; (RONCHI, FEDERICO e MUSMECI, 2002) análise integrada de indicadores de sustentabilidade, na Itália; (SPANGENBERG, 2002) - proposição do prisma de sustentabilidade, para análise de desenvolvimento sustentável. 
Dentre as diversas formas de análise utilizam-se metodologias de avaliação do ciclo de vida - ACV (GIANNETTI e ALMEIDA, 2006), que considera que a cadeia de produção e consumo passa pelas fases de extração/exploração, produção, consumo, absorção dos rejeitos e emissões e o serviço de recuperação executado pela natureza, fechando assim o ciclo.

Técnicas e metodologias desenvolvem critérios para direcionar a produção de bens e serviços, como o Projeto para o Meio Ambiente (PMA) (GRAEDEL e ALLENBY, 1995; GIANNETTI, BARRELLA e ALMEIDA, 2006), onde todas as fases desde a produção até o descarte final são planejadas de forma a alcançarem o mínimo de agressão ao meio ambiente.

Estudos na área da ecologia industrial (GRAEDEL e ALLENBY, 1995; SEAGER e THEIS, 2002; GIANNETTI e ALMEIDA, 2006), nos quais a produção de bens e serviços é estudada em seu conjunto regional ou setorial, aproveitando e reaproveitando a sinergia que possa existir nessa proximidade geográfica ou de setor. Assim estudando esse conjunto, de forma sistêmica. Muito do que poderia ser desperdício em processos produtivos individuais pode ser aproveitado em outra parte do próprio sistema, diminuindo o impacto para fora do sistema.

Metodologias de contabilidade emergética (ULGIATI, ODUM e BASTIANONI, 1994; PATTEN, 1995; JÖRGENSEN, NIELSEN e MEJER, 1995; ODUM, 1996; ODUM e PETERSON, 1996; BASTIANONI e MARCHETTINI, 1997; ORTEGA, 2004; GIANNETTI e ALMEIDA, 2006) que estudam não só a energia final associada a um bem ou serviço, mas também todo o histórico de gasto energético despendido no processo de se obter esses bens ou serviços, e dessa forma são capazes de comparar, para um mesmo bem ou serviço, qual dos processos produtivos gasta menos energia, impactando menos o meio ambiente.

Governos se guiam por decisões estratégicas que consideram a disponibilidade de recursos, o crescimento ou a diminuição da dependência externa e os fatores econômicos (BEN, 2005). Ainda nessa linha de atuação, os acordos multilaterais, interesses políticos internacionais e pressões entre governos interferem na tomada de decisões referentes às direções de investimentos na área de energia. 
Investidores fixam-se nos ganhos econômicos, financeiros e de produtividade. Raramente interesses outros são levados em consideração na tomada de decisões em onde investir.

A comunidade científica se dedica à análise do rendimento energético e alguns estudos avaliam em conjunto aspectos econômicos, ambientais e estratégicos quando aplicados a uma ou outra fonte específica de recursos (ALVIN, EIDELMAN e FERREIRA, 2007).

A utilização de diversos recursos para a geração de energia elétrica é passível de diferentes avaliações e depende do conjunto de critérios do objeto que está sendo analisado. Os modelos adotados para tomada de decisões, quanto às matrizes energéticas, ou consideram questões econômico-financeiras ou ficam restritos às análises de impactos ambientais.

Faz-se necessário, diante das novas realidades de desempenho social, econômico e de responsabilidade ambiental a apresentação de um modelo de tomada de decisões (BARRELLA, 2004; ALMEIDA, BARRELLA e GIANNETTI, 2005; BARRELLA, ALMEIDA e GIANNETTI, 2005; GIANNETTI, BARRELLA e ALMEIDA, 2006) para a análise da matriz energética, que compare os custos e os benefícios das diversas fontes de recursos (ODUM, 2000; BROWN e ULGIATI, 2002; ULGIATI e BROWN, 2002; BUSICO, 2003; INTERNATIONAL ATOMIC ENERGY AGENCY, 2005) e que, além dos aspectos puramente econômicos (PORTER e LINDE VAN DER, 1995; SHRIVASTAVA, 1995; SHARMA e VREDENBURG, 1998; CLEVELAND, KAUFMANN e STERN, 2000) ou da produção (YANG, LI, et al.,2003; SARKIS, 1995; HEIZER e RENDER, 1996; HORNBORG, 1998; BASTIANONI e MARCHETTINI, 2000; ALMEIDA, BUENO, et al., 2004), levem também em consideração simultaneamente os aspectos ambientais.

Esta simultaneidade analítica quer seja dos aspectos ambientais, produtivos e econômicos, quer seja da análise do conjunto das fontes de recursos, não está desenvolvida dentro da literatura acadêmica levantada neste trabalho.

Discussões em fóruns, simpósios e congressos só agravam as diferenças de pontos de vista dos vários grupos que, usualmente, tem como 
característica o corporativismo marcante. Assim, em vez de se obter soluções que caminhem no sentido de melhorar a utilização dos recursos energéticos, há uma fixação de posições em defesa, por exemplo, de suas corporações em detrimento de uma busca de solução comum (CICCHI, 2006; KUSTER e SOUZA, 2006), onde o mote é o da eficiência energética (SZWARC, 2006; SHALDERS, 2006).

Ou ainda, há os que adotam a postura da eficiência e renovabilidade das reservas, sem levar em conta a disputa por espaços da cultura de alimentos (SALES, 2006; SPALDING, 2006).

Há aqueles que, em defesa do baixo lançamento de emissões de gases efeito estufa e sem levar em conta o avanço em direção ao desmatamento das florestas, defendem a utilização irrestrita da energia hidrelétrica (ZANCAN, 2006; TORRES, 2006).

Outra vertente ressalta a disponibilidade e não dependência externa dos recursos de carvão, mesmo com altas emissões de gases efeito estufa (ZIMMERMAN, 2006).

Outros ainda, não destacam as questões de segurança, em defesa das reservas estratégicas e do crescimento econômico (PINHEIRO DA SILVA, 2006), onde somente o aspecto de emissões zero na produção é ressaltado, sem a devida advertência de riscos com a segurança e o destino do lixo nuclear, por exemplo.

Esta situação acarreta em maior indecisão nas tomadas de decisões pertinentes aos investimentos adequados na definição da matriz energética futura.

Neste cenário, neste trabalho propõe-se desenvolver uma ferramenta que sirva de modelo para análise e auxílio à tomada de decisões no âmbito da matriz energética nacional, no que concerne à produção de energia elétrica, para análise de várias fontes em conjunto e suas mútuas influências.

Analisando o histórico da última década dos requisitos ambientais e econômicos percebe-se que esses dois aspectos têm-se apresentado como forças concorrentes e excludentes. Em benefício de um, parece sempre, que 
o outro sofre algum prejuízo. Assim o é, quando se designam isenções fiscais para empresas ambientalmente responsáveis ou ainda pelo aumento da produção implicando em maior agressão ao ambiente.

Quando a produção industrial estava em seus primórdios, com níveis de produção pequenos e os recursos energéticos abundantes e baratos, não eram perceptíveis os malefícios ao meio ambiente dos efeitos de utilização desses recursos, com eficiências mínimas, nem era importante se prever o esgotamento dos recursos em poucas décadas.

Hoje, tendo o cenário se alterado drasticamente, com 0 esgotamento dos recursos energéticos naturais, o crescimento vertiginoso da produção, os objetivos empresariais de globalização na busca, cada vez mais, de lucros crescentes e o cuidado com o meio ambiente na pauta de discussão, as forças da sociedade, nem sempre equilibradas, brigam por espaço tendo objetivos diversos e não conciliatórios.

Essa concorrência e disputa por espaços não necessariamente deve ocorrer para que se mantenha a produção e ao mesmo tempo não seja isto motivo de restrições inumeráveis.

Dentro dessa abordagem, o termo sustentabilidade obteve um significado amplo, podendo atender a todos os lados simplesmente adjetivando-a e gerando termos como sustentabilidade econômica, sustentabilidade ambiental, sustentabilidade energética e assim por diante.

No contexto deste trabalho, entende-se que a sustentabilidade não deve permitir adjetivações, pois só se é sustentável quando se é sustentável por completo. Não se concebe, sobre o mesmo objeto, sustentabilidade em uma direção e não sustentabilidade em outras direções, como um edifício que é sustentável energeticamente e estruturalmente não o é. 


\subsection{OBJETIVO}

\subsubsection{Objetivo Geral}

Como contribuição original, este trabalho propõe um modelo de análise para auxílio à tomada de decisões quanto ao direcionamento e distribuição dos investimentos pela matriz energética nacional.

Ainda como contribuição original faz a análise do desempenho dos índices ambientais, aplicando o modelo proposto, na comparação de alternativas de produção de energia elétrica, com a utilização de diferentes fontes de recursos.

\subsubsection{Objetivos Específicos}

Apresentar uma metodologia de análise comparativa para a geração de energia elétrica abrangente que considera os pontos de vista ambiental, econômico-financeiro, produtividade, disponibilidade de recursos e estratégicos.

Apresentar uma ferramenta que atenda os princípios da metodologia proposta de avaliação ambiental, e que considera e abrange as metodologias de avaliação utilizadas.

Apresentar diferentes cenários para exercitar o uso da ferramenta e fazer a análise e a verificação de sua usabilidade no âmbito da geração de energia elétrica.

\subsection{Delimitação do Assunto}

Este trabalho está delimitado ao aspecto de produção e consumo de energia elétrica relatada na matriz energética $27 \times 47$ do relatório do Balanço Energético Nacional (BEN) do Ministério de Minas e Energia (MME) do Governo Brasileiro (BEN, 2005). 


\subsection{Abrangência do Estudo}

A abrangência desse estudo está limitada por três dimensões: temporal, geográfica e de aplicação.

\subsubsection{Abrangência Temporal}

A abrangência temporal envolve o estudo entre os anos de 1970 e 2009, referentes à série histórica do BEN, sendo que entre 1970 e 2004 os dados serão utilizados para a definição do modelo que descreve as várias fontes de recursos energéticos e entre os anos de 2005 e 2009, aproximadamente $10 \%$ da série histórica, são utilizados para validação do próprio modelo.

A partir daí são efetuadas duas análises: uma de curto prazo entre os anos de 2010 e 2027, acompanhando o plano decenal do governo brasileiro e mais 10 anos; e outra até o ano de 2040, num horizonte de 70 anos, desde 1970.

\subsubsection{Abrangência Geográfica}

A abrangência geográfica, de aplicação da ferramenta neste trabalho, limitar-se-á à área geográfica do Brasil. Como alguns recursos fazem parte do rol daqueles que estão na pauta do comércio exterior, redundando em importações e exportações, tais como: energia hidrelétrica com Itaipu -, petróleo, gás e recentes esforços para exportação de etanol para os EUA entre outros, os parâmetros a estudados são os da oferta interna bruta (OIB) e das reservas internas de recursos.

Com a análise ficando restrita à OIB e às reservas internas, as influências advindas do comércio exterior ficam blindadas e ao mesmo tempo se permite uma análise conjunta menos complexa, privilegiando 0 entendimento das conclusões. 


\subsubsection{Abrangência de Aplicação}

Este trabalho limitar-se-á às aplicações de fontes de recursos energéticos que resultam em produção de energia elétrica.

Como algumas das fontes de recursos servem tanto para a geração de combustíveis motrizes, usados na área de transporte, como também na produção de energia elétrica, eles serão considerados, quando pertinente.

\subsubsection{Considerações sobre a Abrangência}

O estudo poderá, em algum momento, ultrapassar os limites determinados tanto de abrangência geográfica quanto de abrangência de aplicação, pois o seu foco, o Brasil, não é um sistema fechado e isolado no planeta.

\subsubsection{Análises e discussões não contempladas por este estudo}

Não está contemplada no escopo deste trabalho a análise de cada uma das fontes de recursos energéticos que não são utilizadas para a produção de energia elétrica.

Ressalte-se ainda, que este trabalho concentra o foco na produção de energia elétrica e não no consumo, dado que o consumo de energia elétrica não considera como essa energia foi produzida, isto é, diversas fontes de recursos energéticos podem ser utilizadas indistintamente para um mesmo consumo. 


\section{METODOLOGIA}

\subsection{Escolha dos Instrumentos de Análise}

Este estudo aborda o tema energético sob diferentes pontos de vista, reunindo-os com um objetivo comum venha ser alcançado; assim diversas disciplinas apóiam e sustentam cada parte do trabalho e uma visão holística e sistemática se apresenta ao final.

A estrutura do trabalho é apresentada na figura 1; estão presentes as áreas do conhecimento que o fundamentam: contabilidade emergética, análise do ciclo de vida, teoria de sistemas e controle e análise estatística. Também são apresentados os principais instrumentos para o equacionamento, metodologias e procedimentos adotados.

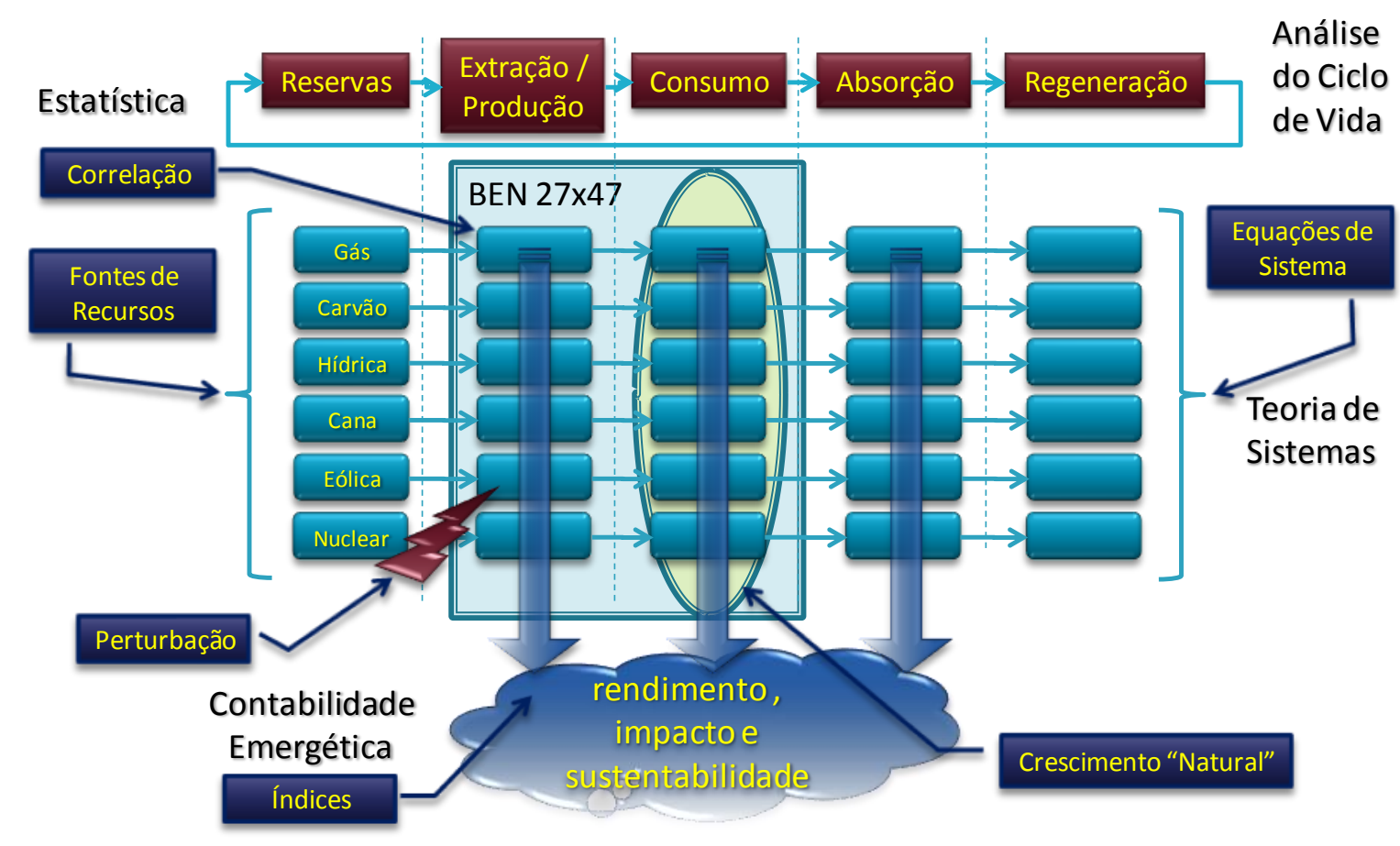

FIGURA1 - Interrelações entre as disciplinas consideradas. Fonte: o autor

$\mathrm{Na}$ figura 1 estão apresentadas as relações entre as várias disciplinas, a metodologia geral a ser adotada e as restrições de ordem 
econômico-social impostas pelos estudos de correlação aplicados à produção e ao consumo de energia.

O topo da figura 1 mostra um diagrama que contém os blocos extração / exploração, produção, consumo, absorção e regeneração, que incorporam o conceito da análise do ciclo de vida.

Para os equacionamentos dos ciclos de vida de cada fonte de recurso utilizar-se-á equações integrais e diferenciais que serão convertidas para o domínio das freqüências complexas por meio da transformada de Laplace (DORF, 2008).

No centro da figura 1 estão representados os ciclos de vida para cada uma das fontes de recursos.

Os blocos de extração / produção e consumo estão contidos no retângulo que indica a utilização da base de dados do BEN, onde são efetuados os estudos de correlação. Nos estudos estatísticos aplicados à produção e ao consumo utilizar-se-á a correlação de Pearson.

Três setas descendentes indicam os blocos que fornecem informações para que sejam calculados os indicadores, que neste trabalho, são obtidos dos blocos de extração / produção para o cálculo dos índices emergéticos. Para o cálculo dos índices de desempenho utilizar-se-á a contabilidade emergética;

\subsubsection{O BEN - Balanço Energético Nacional}

O relatório do Balanço Energético Nacional (BEN) do Ministério de Minas e Energia (MME) do Governo Brasileiro é uma publicação que compila todos os dados energéticos do Brasil e apresenta e analisa em profundidade o período referente ao ano anterior à sua publicação (BEN, 2005). 


\subsubsection{Unidade Funcional utilizada no BEN}

Todas as células utilizadas na matriz energética do Balanço Energético Nacional utilizam como unidade funcional tep x 1000 (milhares de toneladas equivalentes de petróleo).

A tabela 1 apresenta o resumo de conversão de tep para algumas das outras principais unidades energéticas.

Recomenda-se a observação das considerações sobre conversões de unidades que estão incluídas neste trabalho (Anexo A) reproduzido integralmente do relatório do Balanço Energético Nacional referente ao ano de 2005 (BEN, 2005), onde são apresentadas em detalhes todas as conversões e outras considerações referentes às variações nos valores de conversão ao longo do tempo.

TABELA1 - Fatores de conversão para tep médio

\begin{tabular}{lcccccc}
\hline FONTE & UNIDADE & $\mathbf{1 9 9 1}$ & $\mathbf{1 9 9 4}$ & $\mathbf{1 9 9 7}$ & $\mathbf{2 0 0 0}$ & $\mathbf{2 0 0 3}$ \\
\hline PETRÓLEO & $\mathrm{m}^{3}$ & 0,889 & 0,889 & 0,893 & 0,889 & 0,89 \\
GÁS NATURAL ÚMIDO & $10^{3} \mathrm{~m}^{3}$ & 0,993 & 0,993 & 0,993 & 0,993 & 0,993 \\
GÁS NATURAL SECO & $10^{3} \mathrm{~m}^{3}$ & 0,88 & 0,88 & 0,88 & 0,88 & 0,88 \\
CARVÃO VAPOR 3100 kcal/kg & $\mathrm{t}$ & 0,295 & 0,295 & 0,295 & 0,295 & 0,295 \\
CARVÃO VAPOR 4700 kcal/kg & $\mathrm{t}$ & 0,445 & 0,445 & 0,445 & 0,445 & 0,445 \\
CARVÃO VAPOR 6000 kcal/kg & $\mathrm{t}$ & 0,57 & 0,57 & 0,57 & 0,57 & 0,57 \\
CARVÃO METALÚRGICO NACIONAL & $\mathrm{t}$ & 0,642 & 0,642 & 0,642 & 0,642 & 0,642 \\
CARVÃO METALÚRGICO IMPORTADO & $\mathrm{t}$ & 0,74 & 0,74 & 0,74 & 0,74 & 0,74 \\
URÂNIO U3O8 & $\mathrm{kg}$ & 10,139 & 10,139 & 10,139 & 10,139 & 10,139 \\
OUTRAS RENOVÁVEIS & $\mathrm{tep}$ & 1 & 1 & 1 & 1 & 1 \\
HIDRÁULICA & $\mathrm{MWh}$ & 0,086 & 0,086 & 0,086 & 0,086 & 0,086 \\
CALDO DE CANA & $\mathrm{t}$ & 0,06 & 0,06 & 0,06 & 0,061 & 0,062 \\
ÓLEO DIESEL & $\mathrm{m}^{3}$ & 0,871 & 0,871 & 0,871 & 0,851 & 0,848 \\
ÓLEO COMBUSTÍVEL MÉnIO & $\mathrm{m}^{3}$ & 0,972 & 0,972 & 0,972 & 0,959 & 0,959 \\
GÁS LIQUEFEITO DE PETRÓLEO & $\mathrm{m}^{3}$ & 0,616 & 0,616 & 0,616 & 0,612 & 0,611 \\
GÁS DE COQUERIA & $10^{3} \mathrm{~m}^{3}$ & 0,43 & 0,43 & 0,43 & 0,43 & 0,43 \\
GÁS CANALIZADO RIO DE JANEIRO & $10^{3} \mathrm{~m}^{3}$ & 0,38 & 0,38 & 0,38 & 0,38 & 0,38 \\
URÂNIO CONTIDO NO UO2 & $\mathrm{kg}^{3}$ & 73,908 & 73,908 & 73,908 & 73,908 & 73,908 \\
ELETRICIDADE & $\mathrm{MWh}^{3}$ & 0,086 & 0,086 & 0,086 & 0,086 & 0,086 \\
CARVÃO VEGETAL & $\mathrm{t}$ & 0,646 & 0,646 & 0,646 & 0,646 & 0,646 \\
ÁLCOOL ETÍLICO ANIDRO & $\mathrm{m}^{3}$ & 0,534 & 0,534 & 0,534 & 0,534 & 0,534 \\
OUTROS ENERGÉTICOS DE PETRÓLEO & $\mathrm{m}^{3}$ & 0,889 & 0,889 & 0,893 & 0,889 & 0,89 \\
\hline
\end{tabular}

Fonte: BEN2005

Ressalte-se que os valores de conversão variam ao longo do tempo para algumas das fontes de recursos devido a fatores de recálculo e ajustes 
energéticos, bem como variações nas eficiências e qualidade das fontes, conforme apresentado na tabela 1.

Nas simulações realizadas neste trabalho serão impostas ao sistema perturbações de 5000 a 15000 tep, equivalentes a $430 \mathrm{MW}$ a 1,3 GW. Estes valores são da ordem de grandeza de usinas médias de produção de energia elétrica, tais como: usina hidrelétrica de Itá (1,4 GW); usina nuclear de Angra III (1,3 GW); Usina de carvão de Jorge Lacerda (857 MW); conjunto de usinas de produtos de cana de Baldin e Baia Formosa (500 MW); usina de gás natural de Araucária (485 MW) e a previsão de 14 parques eólicos para 2011 (510 MW). Estes valores têm como base o próprio relatório do BEN e são estimados como entrada de novas produções de energia ao longo de um ano.

\subsubsection{Descrição das linhas e colunas da matriz 27x47}

O BEN apresenta ainda, além dos resultados do ano anterior, os dados históricos desde 1970, ano em que se iniciou sua publicação, projetando a evolução para os anos seguintes. Em sua edição de 2005, o BEN apresenta a seguinte organização de capítulos:

- Análises Energéticas e Dados Agregados

- Oferta e Demanda de Energia por Fonte (1989-2004)

- Consumo de Energia por Setor (1989-2004)

- Comércio Externo de Energia (1989-2004)

- Balanços de centros de Transformação (1989-2004)

- Recursos e Reservas Energéticas (1974-2004)

- Energia e Socioeconomia (1989-2004)

- Dados Energéticos Estaduais (2004)

- Anexos

- Capacidade Instalada

- Dados Mundiais de Energia

- Estrutura Geral do BEN

- Tratamento das Informações

- Unidades

- Balanços Energéticos Consolidados 
Destaque especial deve ser feito para 0 anexo Balanços Energéticos Consolidados, Matrizes de consolidação do BEN, contendo os fluxos de energia das fontes primárias e secundárias, unidade tep, em Poderes Caloríficos Inferiores $(\mathrm{PCl})$, do qual é parte integrante e principal a matriz 27x47.

Para um melhor entendimento dos fundamentos do relatório, segue reprodução de parte da introdução do BEN2005:

"O Balanço Energético Nacional - BEN 2005 (Ano-Base 2004) completa trinta anos de existência, divulgando informações relativas ao binômio Oferta-Consumo de fontes de energia, nas suas formas primárias e secundárias, obtidas junto aos diversos agentes produtores e consumidores de energia.

A base de dados que dá suporte às edições do BEN, contempla, desde 1970, os fluxos físicos anuais de quarenta e nove formas e grupos de energia, nas atividades (47 ao todo) de produção, estoques, comércio externo, transformação, distribuição e consumo nos setores econômicos." (BEN, 2005)

Dessa maneira, a matriz composta por 27 colunas e 47 linhas está organizada de modo permitir a visualização conjunta do panorama energético nacional, conforme a figura 2 e o texto de seu anexo $\mathrm{B}$, aqui reproduzidos.

“...suficientemente geral, de forma a permitir a obtenção de adequada configuração das variáveis físicas próprias do setor energético.

A matriz BALANÇO ENERGÉTICO, síntese da metodologia, expressa o balanço das diversas etapas do processo energético: produção, transformação e consumo, conforme figura e conceituação apresentados a seguir." (BEN, 2005) 


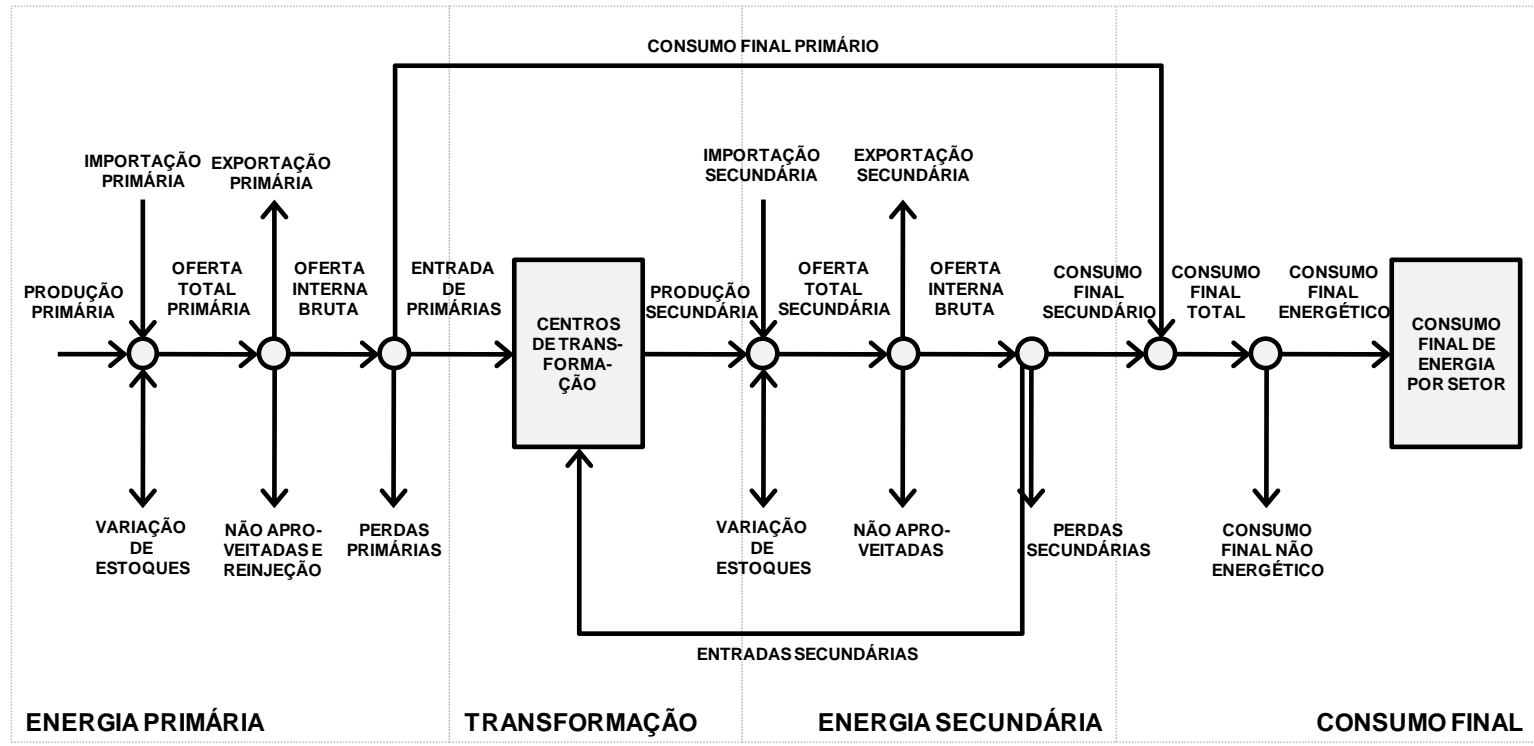

FIGURA 2 - As diversas etapas do processo energético da matriz 27×47.

Fonte: adaptado do BEN2005

\section{a) Descrição das colunas}

As colunas estão divididas em duas partes principais e três colunas de totalizações parciais e geral, colunas 10, 26 e 27, conforme tabela 2, como segue:

Recursos Energéticos Primários, colunas de 1 a 9 , que se referem àqueles recursos que da extração / exploração podem ser utilizados diretamente para o consumo ou como insumo para produção de recursos energéticos secundários, e

Recursos Energéticos Secundários, colunas de 11 a 25, que se relacionam às fontes de recursos energéticos obtidos da transformação dos recursos energéticos primários.

TABELA2 - Descrição das colunas da matriz $27 \times 47$.

\begin{tabular}{ll}
\hline Coluna & Descrição \\
\hline de $\mathbf{1}$ a $\mathbf{9}$ & Fontes primárias de energia \\
$\mathbf{1 0}$ & Totalização da energia primária \\
de $\mathbf{1 1}$ a $\mathbf{2 5}$ & Fontes secundárias de energia \\
$\mathbf{2 6}$ & Totalização da energia secundária \\
$\mathbf{2 7}$ & Totalização Geral \\
\hline
\end{tabular}




\section{b) Descrição das Linhas}

As linhas estão divididas em cinco partes, conforme as tabelas 3, 4, 5, 6 e 7, como segue:

Produção - relacionada às quantidades produzidas, importação exportação e ofertas de recursos energéticos, linhas de 1 a 8 ;

Transformações - relacionada às transformações de energia primária em secundária, linhas de 9 a 9.10;

Perdas - relacionadas às perdas de processos, linha 10;

Consumo - relacionado com o consumo por aplicação e por setor, como por exemplo, transporte e na própria indústria de geração de energia, linhas 11 a $11.2 .8 \mathrm{e}$

Ajustes - relacionados aos ajustes estatísticos, linha 12.

TABELA 3 - Descrição das Linhas de Oferta da matriz 27x47.

\begin{tabular}{cl}
\hline Linha & Definição \\
\hline $\mathbf{1}$ & Produção \\
$\mathbf{2}$ & Importação \\
$\mathbf{3}$ & Variação de Estoques \\
$\mathbf{4}$ & Oferta Total \\
$\mathbf{5}$ & Exportação \\
$\mathbf{6}$ & Não Aproveitada \\
$\mathbf{7}$ & Re-injeção \\
$\mathbf{8}$ & Oferta Interna Bruta \\
\hline
\end{tabular}

TABELA 4 - Descrição das Linhas de Transformação da matriz 27x47.

\begin{tabular}{cl}
\hline Linha & Definição \\
\hline $\mathbf{9}$ & Total de Transformações \\
de 9.1 a 9.9 & Centros de Transformações \\
$\mathbf{9 . 1 0}$ & Outras Transformações \\
\hline
\end{tabular}

TABELA 5 - Descrição das Linha de Perdas da matriz 27x47.

\begin{tabular}{cl}
\hline Linha & Definição \\
\hline $\mathbf{1 0}$ & Perdas na Distribuição e Armazenagem \\
\hline
\end{tabular}


TABELA 6 - Descrição das Linhas de Consumo da matriz 27x47.

\begin{tabular}{cl}
\hline Linha & Definição \\
\hline 11 & Consumo Final \\
$\mathbf{1 1 . 1}$ & Consumo Final Não Energético \\
$\mathbf{1 1 . 2}$ & Consumo Final Energético \\
$\mathbf{1 1 . 2 . 1}$ & Consumo Final do Setor Energético \\
$\mathbf{1 1 . 2 . 2}$ & Consumo Final Residencial \\
$\mathbf{1 1 . 2 . 3}$ & Consumo Final Comercial \\
$\mathbf{1 1 . 2 . 4}$ & Consumo Final Público \\
$\mathbf{1 1 . 2 . 5}$ & Consumo Final Agropecuário \\
$\mathbf{1 1 . 2 . 6}$ & Consumo Transportes Total \\
$\mathbf{1 1 . 2 . 7}$ & Consumo Final Indústria Total \\
$\mathbf{1 1 . 2 . 8}$ & Consumo Não Identificado \\
\hline
\end{tabular}

TABELA 7 - Descrição das Linha de Ajustes Estatísticos da matriz 27×47.

\begin{tabular}{cl}
\hline Linha & Definição \\
\hline 12 & Ajustes \\
\hline
\end{tabular}

\subsubsection{A Análise do Ciclo de Vida (ACV)}

A escolha da ACV mostra-se útil para a realização de análise de impactos ambientais, principalmente quando considera parcelas de absorção e regeneração da energia produzida e consumida. Nos estudos dos ciclos de vida ficam evidenciadas as diversas naturezas das fontes de recursos no que se referem a sua renovabilidade e, por conseguinte, o seu esgotamento futuro.

Os desenvolvimentos sistêmicos, neste trabalho, consideram a realimentação natural dos recursos energéticos envolvidos. As premissas de utilização da análise de ciclo de vida estão posicionadas e melhor detalhadas no capítulo referente aos índices dinâmicos.

\subsubsection{A Contabilidade Emergética}

A escolha da contabilidade emergética também se mostra útil para a análise do desempenho ambiental na produção e ainda na avaliação da sustentabilidade dos processos e produtos. Esta metodologia, além de levar 
em consideração os aspectos ambientais, inclui os aspectos econômicos, representados pelas energias pagas, numa mesma análise (ODUM, 1996).

Nesta metodologia inserem-se as definições de emergia e de transformidade, das fontes de recursos, necessárias para a obtenção de um produto, bem ou serviço, bem como definições de uma simbologia para utilização nos diagramas de energia, de uma álgebra própria e de índices calculados a partir das relações entre os tipos das fontes de recursos que compõem o sistema estudado (ODUM, 1996).

\subsubsection{Emergia}

A emergia pode ser entendida como a memória da energia ou energia total incorporada em um produto, bem ou serviço. A grafia "eMergia" enfatiza este ponto.

Emergia é a quantidade de energia necessária, de forma direta ou indireta, para obter um produto, bem ou serviço, em um determinado processo, sendo sua unidade geralmente expressa em joule de energia solar (seJ). O uso de uma única unidade para a qual são convertidos os diversos tipos de energia permite somar todas as contribuições de energia utilizadas para a obtenção de um determinado produto, bem ou serviço (ODUM, 1996).

\subsubsection{Transformidade}

Define-se a transformidade como a quantidade de energia solar empregada, diretamente ou indiretamente, na obtenção de um joule de um determinado produto (bem ou serviço), sendo sua unidade expressa geralmente em joule de energia solar por joule (se $/ \mathrm{J})$. Pode ser entendida como um fator de conversão entre a Energia e a Emergia de um produto. Fornece assim a medida da concentração de emergia e pode ser considerada como um indicador do inverso da eficiência de um eco-sistema.

Os valores de emergia e transformidade dependem do material e da energia utilizados nas diversas etapas para a obtenção do produto, bem 
ou serviço e, por este motivo, variam de acordo com a matéria prima selecionada, com o tipo de energia empregado na produção, com a eficiência do sistema produtivo e com a qualidade da mão de obra empregada. A tabela 8 apresenta valores de transformidades para as principais fontes de recursos.

TABELA 8 - Transformidades para diversas fontes de recursos.

\begin{tabular}{|c|c|c|c|c|c|c|}
\hline ITEM & ANO & LUGAR & UNIDADE & $\begin{array}{l}\text { TRANSFOR- } \\
\text { MIDADE* }^{\star}\end{array}$ & OBSERVAÇÃO & REFERÊNCIA \\
\hline Luz Solar & 2000 & Mundo & $\mathrm{seJ} / \mathrm{J}$ & $1,00 \times 10^{0}$ & Por definição & $\begin{array}{l}\text { Odum, 2000, } \\
\text { Folio \#1 }\end{array}$ \\
\hline $\begin{array}{l}\text { Circulação de } \\
\text { Ventos }\end{array}$ & 2000 & Mundo & $\mathrm{seJ} / \mathrm{J}$ & $2,45 \times 10^{3}$ & $\begin{array}{l}\text { Circulação de ventos global } \\
0,4 \text { watts } / \mathrm{m}^{2}\left(\left(0,4 \mathrm{~J} / \mathrm{m}^{2} / \mathrm{s}\right)\right. \\
\left(3,15 \times 10^{7} \mathrm{~s} / \text { ano }\right) \\
\left(5,12 \times 10^{14} \mathrm{~m}^{2} / \text { terra }\right)= \\
\left.6,45 \times 10^{21} / \text { ano }\right)\end{array}$ & $\begin{array}{l}\text { Odum, } 2000, \\
\text { Folio \#1 }\end{array}$ \\
\hline $\begin{array}{l}\text { Média } \\
\text { Geopotencial } \\
\text { Fluvial }\end{array}$ & 2000 & Mundo & seJ/J & $4,70 \times 10^{4}$ & $\begin{array}{l}\text { Elevação média, } 875 \mathrm{~m} \\
\left(\left(39,6 \times 10^{12} \mathrm{~m}^{3} / \mathrm{ano}\right)\right. \\
\left(1000 \mathrm{~kg} / \mathrm{m}^{3}\right)\left(9,8 \mathrm{~m} / \mathrm{s}^{2}\right) \\
\left.(875 \mathrm{~m})=3,4 \times 10^{20} \mathrm{~J} / \mathrm{ano}\right)\end{array}$ & $\begin{array}{l}\text { Odum, 2000, } \\
\text { Folio \#1 }\end{array}$ \\
\hline Eólico, Cinético & 1983 & EUA & $\mathrm{seJ} / \mathrm{J}$ & $6,63 \times 10^{2}$ & $\begin{array}{l}\text { Tabela 10.2, Fluxo } \\
\text { Emergético nos EUA, de } \\
\text { Odum et al., } 1987\end{array}$ & $\begin{array}{l}\text { Odum, 1996, } \\
\text { contabilidade }\end{array}$ \\
\hline Eletricidade & 1996 & Padrão & $\operatorname{seJ} / \mathrm{J}$ & $2,00 \times 10^{5}$ & $\begin{array}{l}\text { Padronizado em 1983, pg. } \\
147\end{array}$ & $\begin{array}{l}\text { Odum, 1996, } \\
\text { contabilidade }\end{array}$ \\
\hline $\begin{array}{l}\text { Produção de } \\
\text { Carvão }\end{array}$ & 1983 & EUA & $\operatorname{seJ} / \mathrm{J}$ & $3,98 \times 10^{4}$ & $\begin{array}{l}\text { Tabela 10.2, Fluxo } \\
\text { Emergético nos EUA, de } \\
\text { Odum et al., } 1987\end{array}$ & $\begin{array}{l}\text { Odum, 1996, } \\
\text { contabilidade }\end{array}$ \\
\hline $\begin{array}{l}\text { Produção de } \\
\text { Óleo }\end{array}$ & 1983 & EUA & $\operatorname{sed} / \mathrm{J}$ & $5,30 \times 10^{4}$ & $\begin{array}{l}\text { Tabela } 10.2 \text {, Fluxo } \\
\text { Emergético nos EUA, de } \\
\text { Odum et al., } 1987\end{array}$ & $\begin{array}{l}\text { Odum, 1996, } \\
\text { contabilidade }\end{array}$ \\
\hline $\begin{array}{l}\text { Produção de Gás } \\
\text { Natural }\end{array}$ & 1983 & EUA & $\operatorname{sed} / \mathrm{J}$ & $4,80 \times 10^{4}$ & $\begin{array}{l}\text { Tabela 10.2, Fluxo } \\
\text { Emergético nos EUA, de } \\
\text { Odum et al., } 1987\end{array}$ & $\begin{array}{l}\text { Odum, 1996, } \\
\text { contabilidade }\end{array}$ \\
\hline $\begin{array}{l}\text { Produção de } \\
\text { Urânio }\end{array}$ & 1983 & EUA & $\mathrm{seJ} / \mathrm{J}$ & $1,79 \times 10^{3}$ & $\begin{array}{l}\text { Tabela 10.2, Fluxo } \\
\text { Emergético nos EUA, de } \\
\text { Odum et al., } 1987\end{array}$ & $\begin{array}{l}\text { Odum, 1996, } \\
\text { contabilidade }\end{array}$ \\
\hline Etanol & 1984 & Brazil & $\operatorname{seJ} / \mathrm{J}$ & $8,80 \times 10^{4}$ & $\begin{array}{l}\text { Tabela C } 5 \text { em Odum } \\
\text { (1996) fornece } 6 \times 10^{4}\end{array}$ & $\begin{array}{c}\text { Odum, } 1984 \\
1849-1855\end{array}$ \\
\hline
\end{tabular}

* Aplicar fator 1,68 para itens calculados antes de 2000.

Fonte: Ulgiati e Brown (2004)

Para um determinado produto, o valor da transformidade está dentro de uma faixa de valores que dependem de como foi obtido aquele produto: processo de produção, região em que foi produzida, origem da matéria prima, tipo da mão de obra, amortização de investimento. Essa faixa de valores está delimitada entre um valor mínimo de transformidade, o qual abaixo dele não é possível obter-se o produto, e um valor máximo, acima do qual a obtenção do produto torna-se economicamente inviável (ODUM, 1996). 


\subsubsection{Fontes de Recursos}

As fontes de recursos que participam em qualquer processo podem ser divididas em três classes: renováveis, não renováveis e provenientes da economia. Esta divisão é fundamental para o estudo emergético e a interrelação dos processos com o meio-ambiente.

Os recursos renováveis $(\mathbf{R})$ são retirados do ambiente local em relação ao sistema, objeto de estudo, e como o próprio nome diz, têm a capacidade de renovação temporal e espacial mais rápida que o seu consumo. Encontram-se nessa classe a energia solar, geotérmica, gravitacional, dos ventos e da chuva.

Segundo Ulgiati e Brown (1998), os fluxos renováveis são: (i) limitados, não é possível aumentar a taxa do fluxo no sistema; (ii) gratuitos, geralmente estão disponíveis sem custo, podendo incorrer somente em custos para a sua extração e (iii) disponíveis localmente.

Os recursos não renováveis $(\mathbf{N})$ são armazenados na natureza localmente no sistema estudado, porém seu consumo é mais rápido do que a capacidade que o meio ambiente tem de renovação desse recurso. Nessa classe encontram-se as fontes de recursos naturais como o carvão e o petróleo.

As florestas e a água potável, dependendo da taxa de exploração, podem ainda ser classificados como recursos não renováveis. Segundo Ulgiati e Brown (1998), os fluxos não renováveis são: (i) de estoques limitados, pode-se aumentar a sua taxa de utilização, mas a quantidade total disponível é finita na mesma escala de tempo do sistema; (ii) nem sempre gratuitos, algumas vezes incorre-se em custos, pagos pela sua exploração; (iii) disponíveis localmente.

Os recursos pagos (F), advindos da economia, são associados a bens e serviços ou a recursos não renováveis provenientes de outras regiões fora dos limites do sistema estudado e que, como característica principal, incorrem em custos econômicos. Os fluxos vindos da economia ou fluxos de retro-alimentação são: (i) de estoques limitados, da mesma forma que os 
fluxos não renováveis; (ii) nunca gratuitos; (iii) nunca disponíveis localmente, sendo sempre importados (ULGIATI e BROWN, 1998).

A figura 3 apresenta a título de exemplo ilustrativo um gráfico hipotético que mostra a evolução temporal de utilização de recursos, por classe: $\mathrm{R}, \mathrm{N}$ e $\mathrm{F}$, em valores relativos. Note-se que a qualquer instante a soma dos valores de $\mathrm{R}, \mathrm{N}$ e $\mathrm{F}$ é igual à unidade.

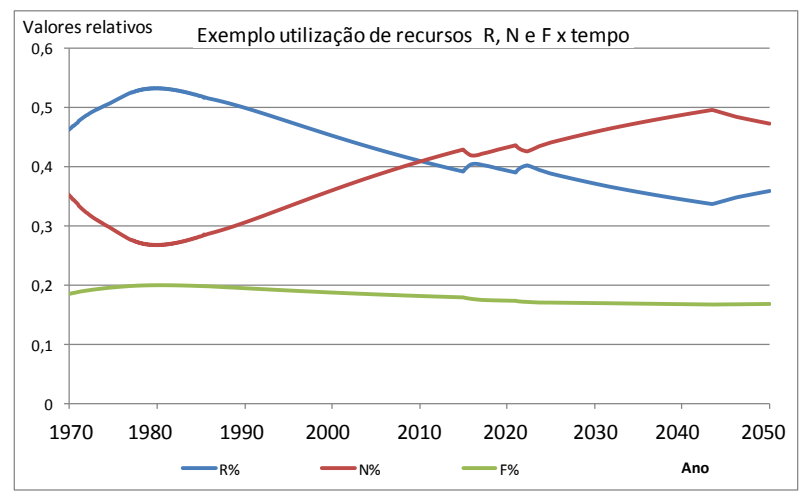

FIGURA 3 - Exemplo: valores relativos de R, N e F em função do tempo.

\subsubsection{4 Índices Emergéticos}

Os principais índices adotados para a análise emergética utilizam como variáveis os valores de emergia das fontes de recursos e denotam uma série de características que auxiliam a avaliação do sistema estudado quanto ao seu desempenho econômico-ambiental, quanto à sua agressividade ao meio ambiente e sua eficiência de produção.

$O$ rendimento emergético (EYR) é obtido pela emergia total do produto $(\mathrm{Y}=\mathrm{R}+\mathrm{N}+\mathrm{F})$, dividida pela emergia de entrada do setor econômico $(F)$, conforme apresentada na equação (1):

$$
E Y R=\frac{Y}{F}=\frac{R+N+F}{F}
$$

Este índice reflete a habilidade do processo de utilizar recursos locais (ULGIATI e BROWN, 2002), mas não diferencia recursos renováveis de não renováveis. 
Segundo Brown e Ulgiati (2002), valores de EYR abaixo de 5 devem ser considerados como indicativos de fontes de energia secundária e materiais primários como cimento e aço. Fontes de energia primária usualmente têm valores de EYR maiores que 5. Além disso, processos que têm rendimento emergético menor que 2 não fornecem qualquer contribuição que possa ser considerada como fonte de energia e representam produtos de consumo ou etapas na transformação das fontes de energia reais.

A carga ambiental (ELR) é definida como a relação entre emergia de entrada proveniente do sistema econômico $(F)$, e do recurso local não renovável $(\mathrm{N})$, e a emergia do recurso local renovável $(R)$, conforme apresentada na equação (2):

$$
E L R=\frac{N+F}{R}
$$

Este índice mostra um balanço entre os investimentos locais renováveis e não renováveis. Um valor alto de ELR indica uma utilização intensiva dos recursos não renováveis.

Segundo Brown e Ulgiati (2002), valores baixos de ELR, aproximadamente 2, são indicativos de baixo impacto ambiental ou processos que usam uma grande área para diluir o impacto. Valores de ELR maiores que 10 são indicativos de impacto ambiental relativamente alto e aqueles entre 2 e 10 podem ser considerados como impactos moderados. Valores extremamente altos de ELR podem ser o resultado de investimentos econômicos em um ambiente relativamente pequeno, com entradas derivadas de energias não renováveis muito concentradas.

O índice de sustentabilidade (EIS, ESI ou SI) é dado pela relação entre o rendimento emergético e o índice de carga ambiental, conforme apresentada na equação (3):

$$
E I S=\frac{E Y R}{E L R}=\frac{\frac{Y}{F}}{\frac{N+F}{R}}
$$


O conceito de sustentabilidade fica atrelado à maximização de EYR, rendimento emergético e a minimização de ELR, impacto ambiental, ou seja, máximo aproveitamento do investimento econômico com um mínimo de impacto nos recursos locais. O índice mostra se o processo fornece uma contribuição economicamente apropriada para o usuário em relação à pressão ambiental.

Segundo Brown e Ulgiati (2002) valores de EIS menores que 1 são indicativos de produtos ou processos que não são sustentáveis em longo prazo. Sistemas com valores maiores que 1 indicam produtos e processos que dão contribuições sustentáveis do ponto de vista da economia e da ecologia. Sustentabilidade em médio prazo pode ser caracterizada por um EIS entre 1 e 5 ao passo que produtos e processos com sustentabilidade em longo prazo têm SI maiores que 5 .

Outros índices emergéticos como o investimento emergético (EIR), o porcentual de emergia renovável ou renovabilidade (\%R), e a densidade de fluxo emergético (ED), apresentados respectivamente nas equações (4), (5) e (6), não serão utilizados neste trabalho, embora possam fazer parte de implementações futuras da ferramenta.

$$
\begin{aligned}
& E I R=\frac{F}{N+R} \\
& \% R=\frac{R \times 100}{R+N+F}=\frac{R \times 100}{Y} \\
& E D=\frac{\dot{E}_{m}}{\text { Área }}
\end{aligned}
$$

Os índices selecionados, para fazer a análise de desempenho ambiental, foram o de sustentabilidade (EIS), carga ambiental (ELR) e rendimento emergético (EYR), por serem os mais significativos na análise global. O gráfico da figura 4 apresenta um exemplo hipotético de variação desses índices ao longo do tempo, fornecendo uma idéia de como é o comportamento de cada um deles em relação aos outros. 


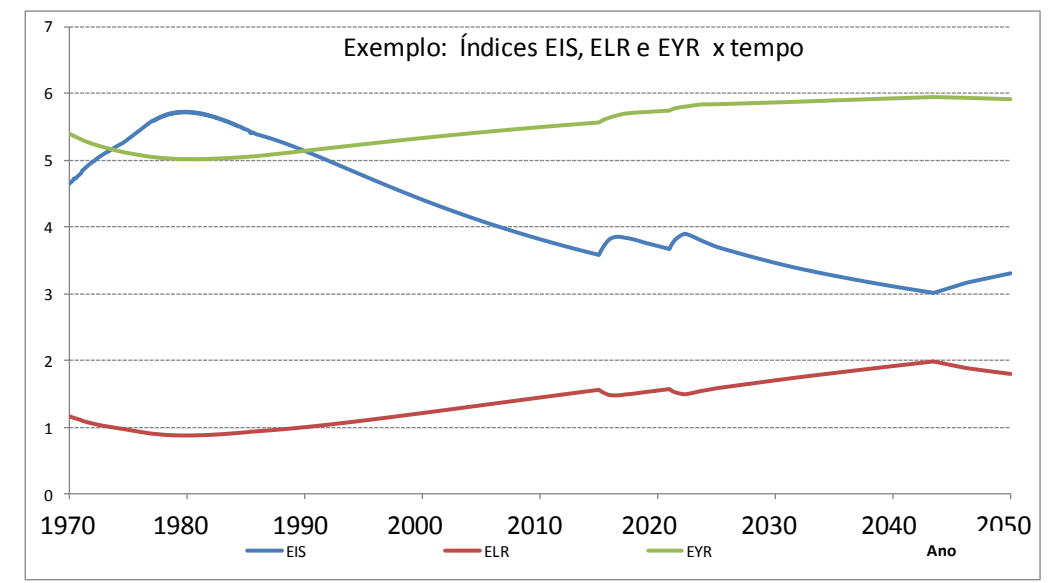

FIGURA 4 - Exemplo: Índices EIS, ELR e EYR em função do tempo.

O diagrama ternário, uma ferramenta gráfica, desenvolvida por Barrella (2004) para visualização dos principais índices emergéticos, foi também utilizado neste trabalho para visualização e análise dos índices dinâmicos, e o percurso emergético, conforme ilustrado na figura 5 .

A representação de produtos ou processos, segundo Barrella (2004), fica conforme segue:

"A representação dos produtos ou processos no diagrama ternário utiliza uma conversão de coordenadas triangulares para coordenadas cartesianas; dessa forma, se utiliza como coordenadas triangulares os valores de $\bar{R}, \bar{N} e \bar{F}$ e se faz as transformações para um sistema de coordenadas cartesianas com origem na mediana da base do triângulo por meio das equações:

$$
\mathrm{x}_{\mathrm{a}}=\frac{2 \times \overline{\mathrm{F}}+\overline{\mathrm{R}}-1}{\sqrt{3}} \text { e } \mathrm{y}_{\mathrm{a}}=\overline{\mathrm{R}}
$$




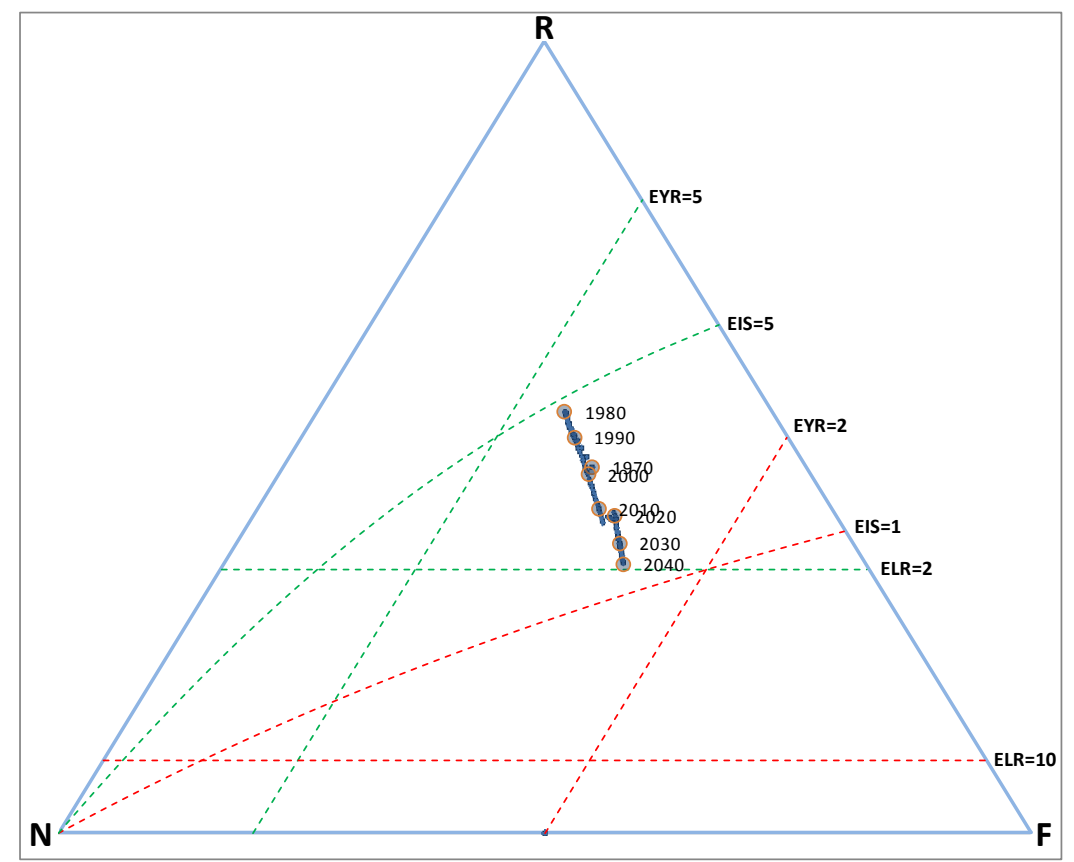

FIGURA 5 - Exemplo: diagrama ternário com o percurso emergético.

\subsubsection{5 Índices Agregados}

Os índices emergéticos apresentados na seção anterior, quando analisados no tempo e sobre o volume total de produções, indicam os valores de desempenho acumulados pela produção ao longo do tempo. Embora esta seja uma medida válida quando se deseja avaliar o histórico, para avaliações de fenômenos que variam rapidamente com o tempo, os valores históricos podem mascarar os resultados.

Por outro lado, se considerarmos somente os valores emergéticos de cada ciclo, qualquer alteração no ciclo vai representar variações grandes nos índices, fornecendo informação de difícil visualização para a tendência dos índices ao longo do tempo.

Neste trabalho, foi desenvolvido um procedimento de cálculo,

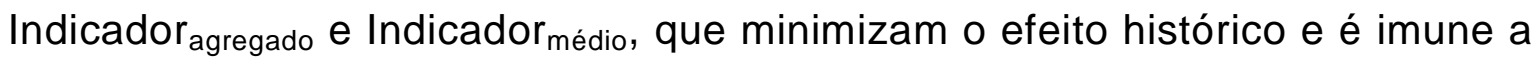
variações ciclo a ciclo. 


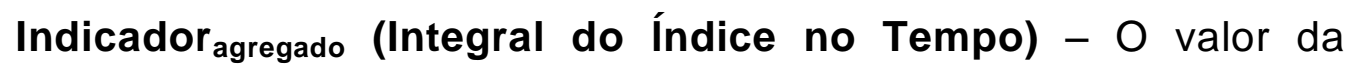
integral do índice no tempo pode ser obtido por meio das somas sucessivas dos valores em cada ciclo do índice, conforme equação (7).

$$
\text { Indicador }_{\text {agregado }}=\sum_{1}^{\mathrm{n}} \text { Indicador }_{\text {ciclo }}(7)
$$

Indicador médio (Valor Médio no período do Índice Agregado) - 0 valor médio é obtido dividindo-se a integral do índice pelo número de ciclos que se fez a contagem. Assim obtém-se um índice que representa em cada ciclo a média de todos os ciclos anteriores, conforme equação (8).

$$
\text { Indicador }_{\text {médio }}=\frac{1}{\mathrm{n}} \sum_{1}^{\mathrm{n}} \text { Indicador }_{\text {ciclo }}
$$

\subsubsection{A Teoria de Sistemas}

A teoria de sistemas de controle aplicada neste trabalho fornece uma visão holística e facilita a busca de caminhos ótimos para sistemas complexos. Optou-se pela utilização das equações da teoria de sistemas em Laplace por sua clara harmonização com 0 instrumental para 0 desenvolvimento da ferramenta de simulação (DORF, 2008).

O uso do aplicativo de software Simulink, incluído no pacote Matlab (MATHWORKS, 2008), permite que o sistema seja descrito por meio de uma edição gráfica pela união de blocos funcionais constantes da vasta biblioteca do Simulink. Permite, ainda, a definição de novos blocos funcionais e a sua inclusão na biblioteca, bem como o agrupamento de blocos formando blocos maiores e permitindo a visão do sistema em diversos níveis de abstração.

A aplicação de transformadas, em particular a de Laplace, tem sua justificativa na simplificação das equações diferenciais e integrais que regem as leis naturais. Dessa forma, sem perda do rigor matemático, as manipulações dos dados ficam evidentes e consistentes (DORF e SVOBODA, 
2008). A figura 6 apresenta o método da transformada de Laplace que, embora tenha um caminho mais longo - transformar, resolver e antitransformar - do que a resolução das equações diferenciais e integrais, se mostra mais rápida e simples.

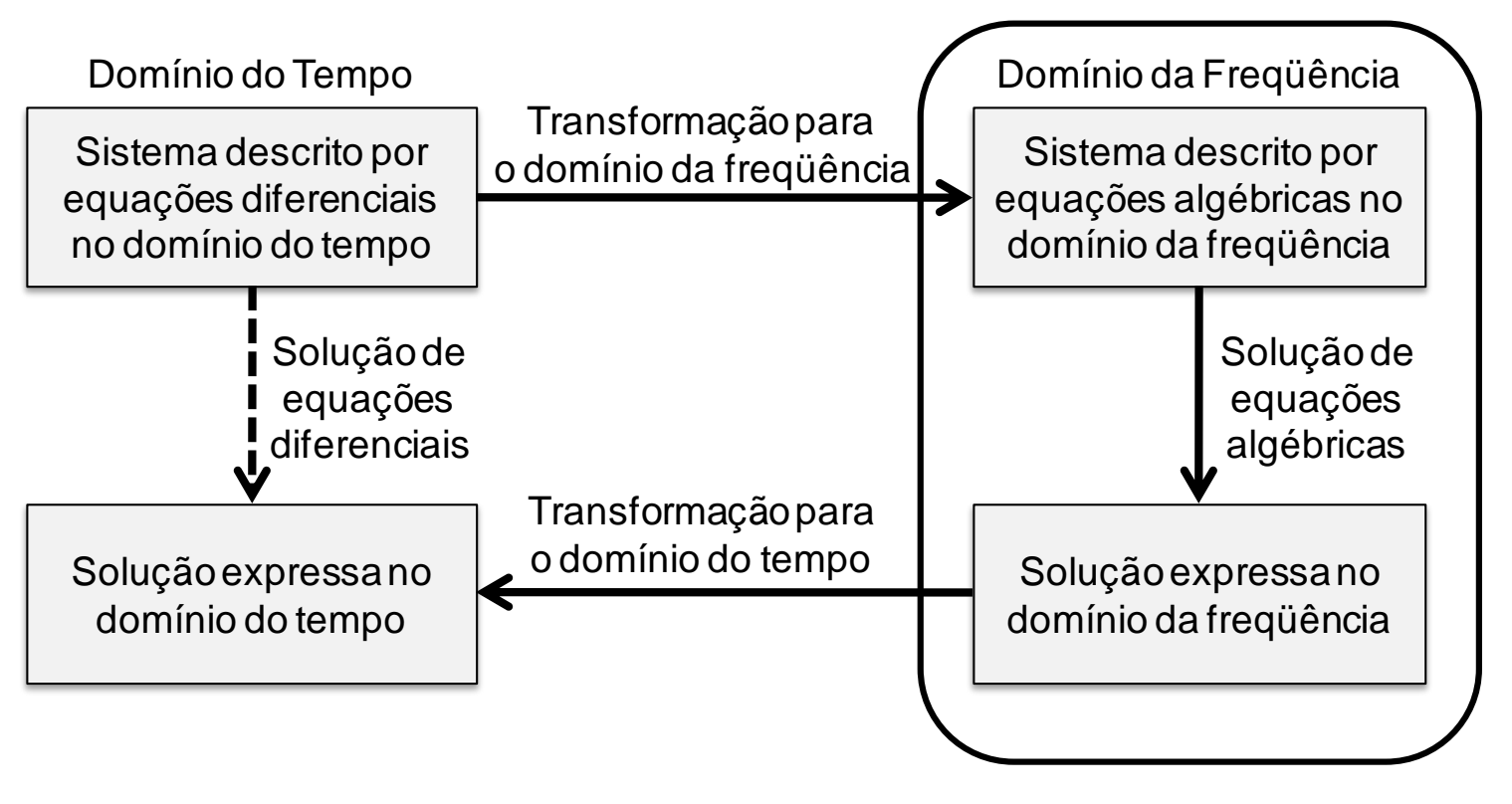

FIGURA 6 - Método da transformada de Laplace.

Fonte: adaptado de DORF e SVOBODA (2008)

\subsubsection{A Correlação de Pearson}

A estatística, indispensável neste tipo de estudo, pois, permite assegurar a confiabilidade dos resultados obtidos. No caso, optou-se pela utilização da correlação de Pearson entre outras opções tais como, $\tau$ de Kendall ou correlação de Spearman, por ela se mostrar suficiente para sustentar os conceitos aqui desenvolvidos.

Como premissa, considerou-se que a matriz energética é a representação das operações econômicas, produtivas e de consumo de toda a atividade que envolve a exploração de energia em suas mais diversas formas e dentro de uma sociedade inserida na economia de mercado. Assim sendo, entende-se que não haverá decreto, que não seja totalmente drástico, que possa induzir mudanças comportamentais de consumo acima de certa medida (BEM, 2005). 
Podem-se induzir comportamentos e privilegiar ações, porém as mudanças de real impacto ocorrem numa sucessão de pequenas mudanças de período para período.

Com base nessa premissa adotou-se como limite de mudanças possíveis um valor mínimo de correlação entre as produções de energia contidas nas matrizes de $27 \times 47$ do BEN, entre 1970 e 2004, com intervalos de $1,2,3,5$ e 10 anos.

Este estudo de correlação foi feito utilizando-se as colunas de recursos primários e secundários para as linhas de produção e de consumo total, ou seja, todas as colunas de recursos e as linhas de 1 à 13 , apresentadas na seção 2.1.1.2, página 27.

A partir do levantamento do valor de correlação entre as matrizes desde 1970 até 2004 nos intervalos especificados, conclui-se que, independente de regime político, incentivos, situação econômica global, política e investimentos no setor e outros parâmetros do cotidiano, o valor de correlação nunca foi menor que 0,970, o qual foi adotado como referência para verificação dos desvios das curvas simuladas pela ferramenta, conforme apresentado na figura 12 .

Mesmo em fases de mudanças profundas no país como o regime militar, a volta a democracia, a crise do petróleo, os planos Bresser, Collor e outros, abrangidas no histórico da matriz 27×47, de 1970 a 2004, a análise demonstra que os efeitos na correlação entre matrizes nunca foi menor que 0 valor adotado como referencial.

A menos que grandes mudanças das relações econômico-sociais ocorram, há uma tendência de que o valor de correlação seja mantido acima de algum valor que significa a dificuldade de mudança espontânea.

Foi feita uma projeção de crescimento para os anos de 2009 até 2017, para cada célula, linha / coluna, da matriz energética, escolhendo-se a curva que melhor se ajustou aos dados. Assim, se não existir nenhuma perturbação no sistema, obtém-se as matrizes energéticas projetadas para os anos de 2009 a 2017. 
Nas figuras de 7 a 10, estão apresentados os gráficos, com a curva de tendência calculada, para as células da oferta interna bruta. Os exemplos a seguir são para a Produção de Energia Primária. A escala nas ordenadas está em tep x 1000 .

Junto à curva de tendência está representada a expressão algébrica da curva e o valor do quadrado do coeficiente de correlação de Pearson $\left(R^{2}\right)$, descrito pela seguinte expressão:

$$
R=\frac{\sum(x-\bar{x}) \cdot(y-\bar{y})}{\sqrt{\sum(x-\bar{x})^{2} \cdot(y-\bar{y})^{2}}}
$$

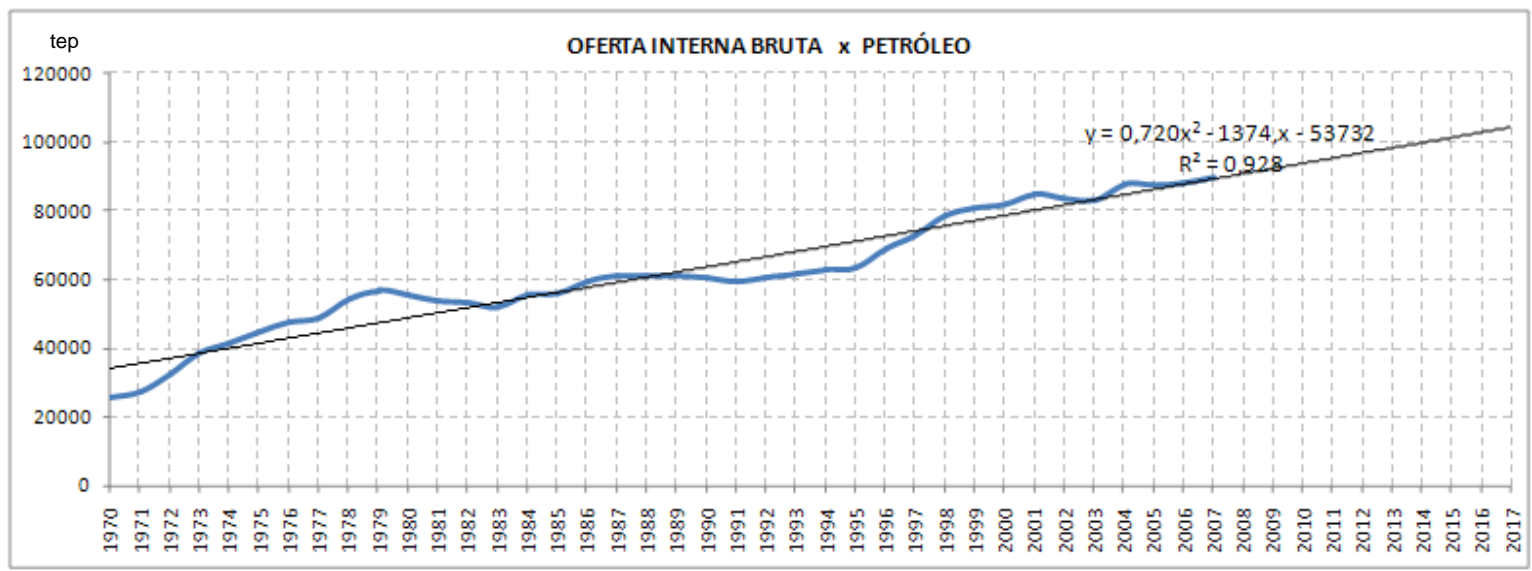

FIGURA 7 - Curva e tendência: OIB x Petróleo.

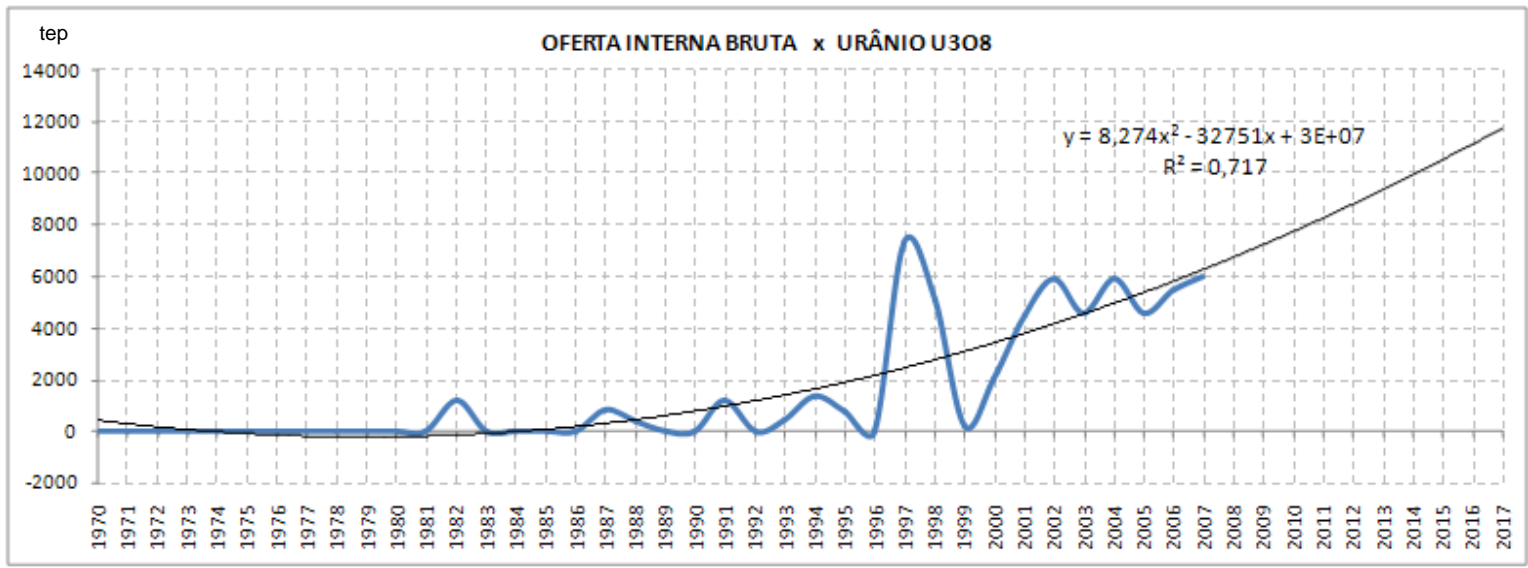

FIGURA 8 - Curva e tendência: OIB x Urânio $\mathrm{U}_{3} \mathrm{O}_{8}$. 


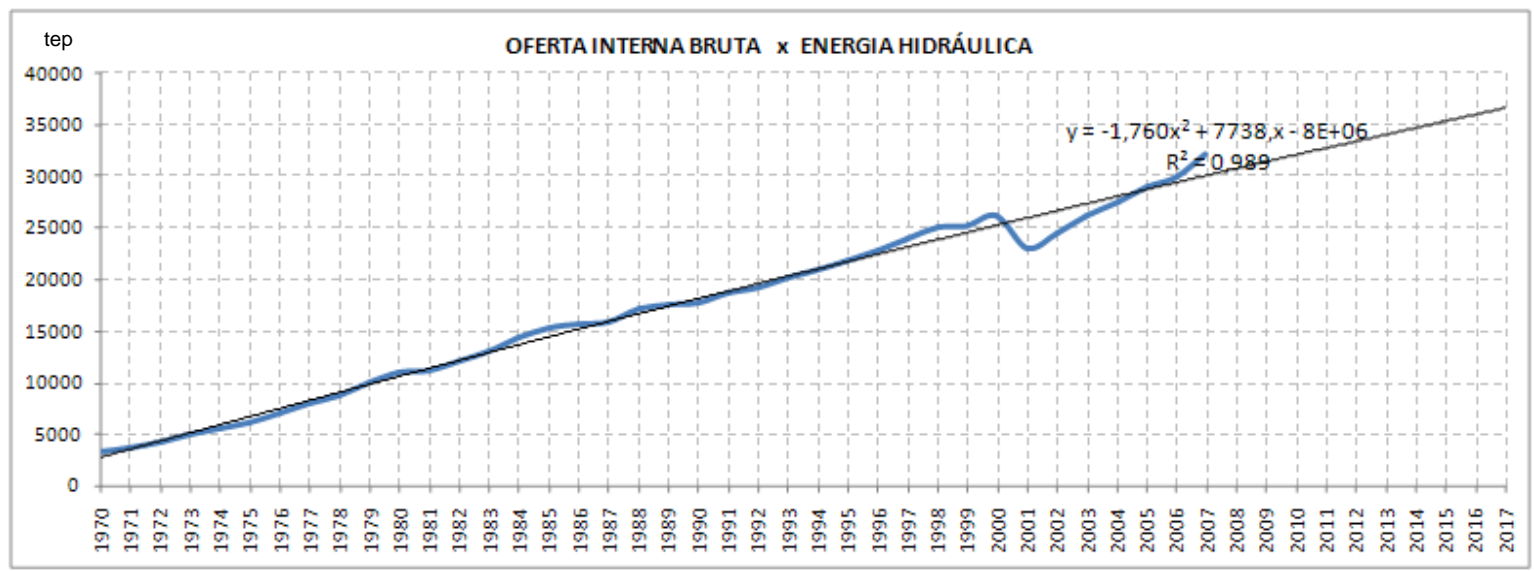

FIGURA 9 - Curva e tendência: OIB x Energia Hídrica.

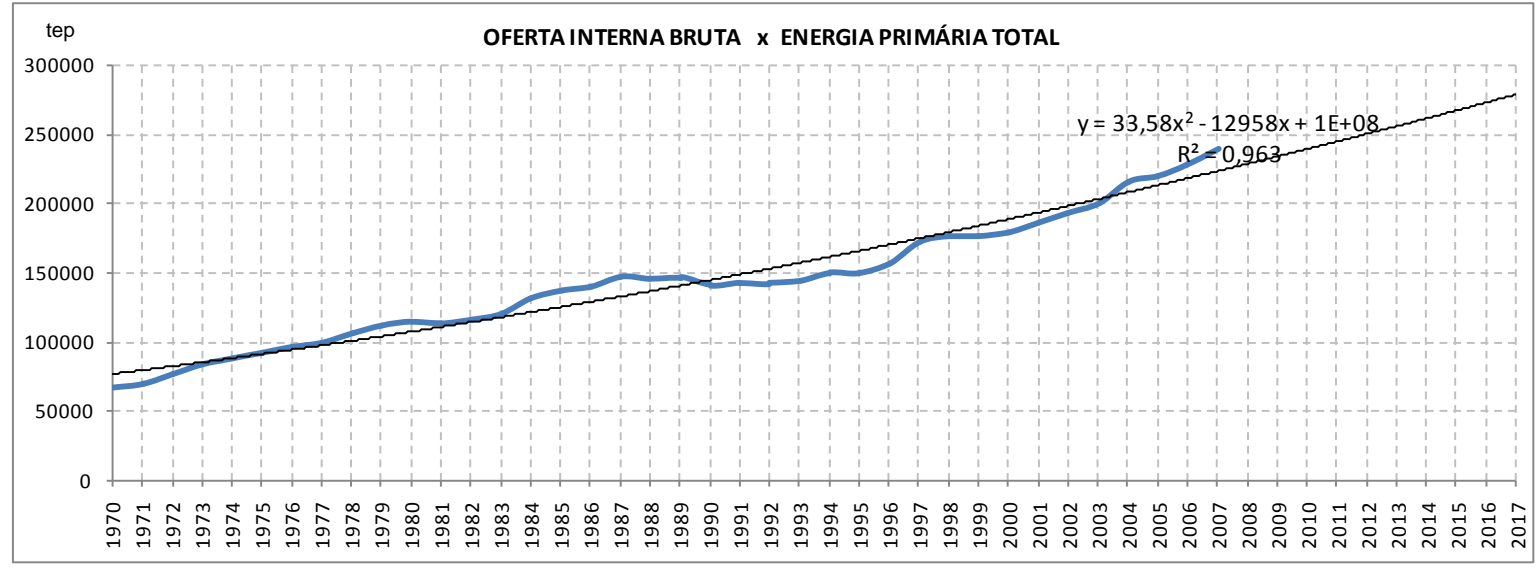

FIGURA 10 - Curva e tendência: OIB x Energia Primária Total.

Nos gráficos apresentados, destaca-se o caso em que o coeficiente $R^{2}$ não tem valor elevado, referente ao urânio. Esse fato pode ser creditado principalmente a dois fatores: i) o baixo valor da produção e ii) investimentos realizados em um período curto de tempo e sem continuidade.

Por outro lado, na figura 11 encontram-se tabelados os valores de correlação de Pearson das matrizes de 1970 a 2017, entre as colunas de fontes de recursos, referentes à produção de energia elétrica. As células mais escuras mostram valores de correlação maiores e as colunas mais claras valores de correlação menores. Pode-se notar que a maioria de células apresenta coloração mais escura, evidenciando o grau de correlação maior entre as colunas das matrizes selecionadas. 
Porém, os valores das correlações entre colunas ficam entorno do valor de 0,75 . Isto nos indica que tanto as produções quanto os consumos dos principais insumos energéticos para a produção de energia elétrica tem uma correlação ao longo do tempo também razoavelmente forte.

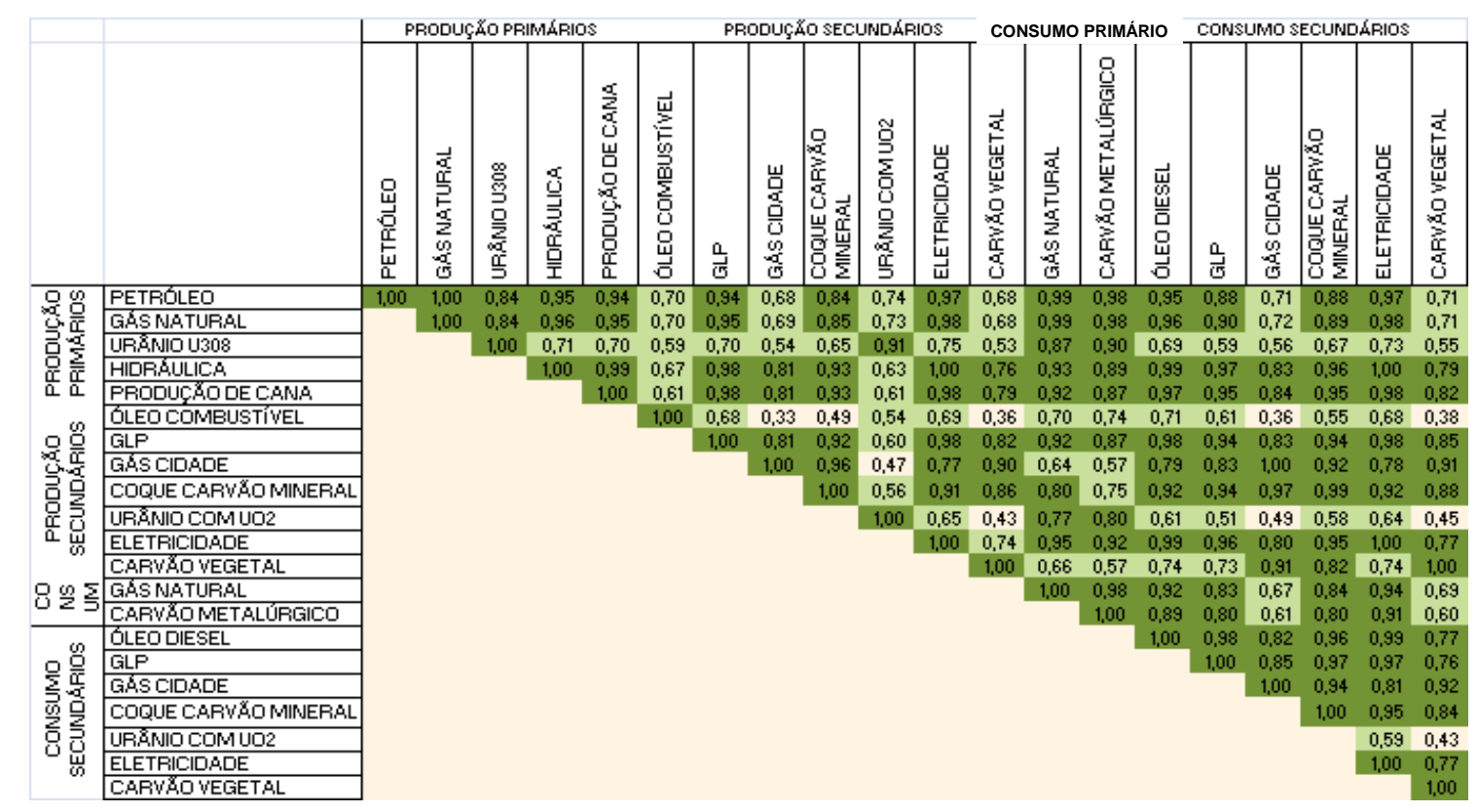

FIGURA 11 - Matriz de Correlação entre colunas selecionadas da Matriz 27x47 do BEN

Mesmo com essa variável não tendo um valor de auto-correlação alto, não afeta os valores de correlação quando analisadas todas as fontes de recursos em conjunto. Isto indica que mesmo com variações individuais, em cada uma das fontes de recursos, globalmente os valores de correlação não são significativamente afetados, como apresentado na figura 12 .

Estes dados foram compilados no período de 1970 à 2017, sendo que entre 1970 à 2009 os dados são históricos e entre 2010 à 2017 os dados são os das curvas de tendências. O gráfico da figura 12 mostra os valores de correlações globais entre dois anos seguidos, e ainda com intervalos de dois, três, cinco e dez anos.

Notar que mesmo num horizonte de variações de 10 em 10 anos as correlações obtidas não apresentaram valores menores que 0,970. 


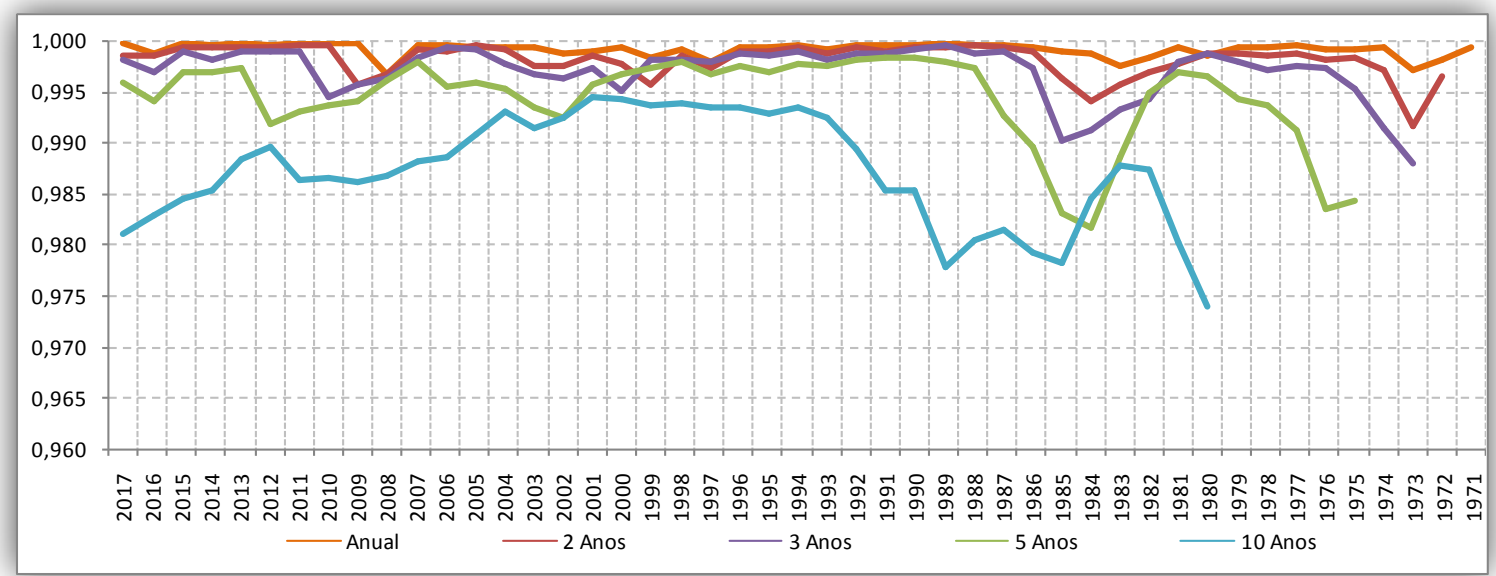

FIGURA 12 - Curvas de correlação de produção de energia: anos consecutivos, de 2, 3, 5 e 10 anos.

Este fato indica que variações na oferta de produção das fontes de recursos individuais têm pouca influência na oferta global, que segue uma curva de crescimento própria que pode ser relacionada com outros fatores como, por exemplo, a riqueza da nação traduzida no produto interno bruto (ALVIN, EIDELMAN e FERREIRA, 2007).

Isso permite também, no equacionamento para os comportamentos de produção de energia, fazer duas considerações:

i) Se o total da oferta segue uma lei própria independente das partes, toda vez que houver um crescimento de uma das fontes de recursos implica numa pressão para o decréscimo das outras fontes de recursos que compõem a combinação de recursos e vice-versa.

ii) Essa disputa entre vários tipos de fontes de recursos para suprir a oferta total necessária para o consumo deve ter diferentes medidas de influência umas nas outras. Assim o crescimento de produção numa determinada fonte de recursos influencia, com parcelas diferentes, no decréscimo das outras, para que o total se mantenha acompanhando a curva de crescimento natural.

Essas duas considerações servem de base para a definição sistêmica da ferramenta, na qual se constituiu um modelo que, com base 
numa lei de crescimento total, faz com que as fontes individuais tenham variações livres ou forçadas, ditas perturbações, sem que o total seja afetado.

Assim sendo, incorporou-se na ferramenta uma matriz de influências que permite determinar em qual medida cada acréscimo ou decréscimo numa determinada fonte de recursos influência em todas as outras fontes, definida como matriz de influências.

\subsection{Escolha das fontes de recursos a serem utilizadas}

A aplicação desse estudo dar-se-á nos principais recursos utilizados para geração de energia. Em princípio não serão classificados em recursos renováveis e não renováveis, pois esta classificação apóia-se nos conceitos e estudos estáticos, entretanto podem-se identificar grupos afins, conforme segue:

- Fósseis: Petróleo, Gás, Carvão;

- Hídricos: Bacias Fluviais, Oceanos;

- Bioenergéticos: Etanol, Outras fontes de Biomassa;

- Alternativos: Vento, Calor Geotérmico, Energia Solar;

- Nuclear;

A ferramenta desenvolvida, em seu estado atual, suporta até seis fontes diferentes de recursos energéticos. Esta foi uma decisão de implementação, em que se procurou ter um número suficiente de fontes de recursos para testar a ferramenta e ainda ser factível de ser executada na maioria dos computadores pessoais atuais. O tempo de simulação é de aproximadamente 2 minutos e o tamanho do arquivo de simulação tem aproximadamente 1 GByte.

Sendo 'n' o número de fontes de recursos, o crescimento do tempo de simulação é proporcional a $\mathrm{n}^{2}$, pois, a cada fonte de recursos considera em sua entrada a saída de todas as outras fontes de recursos e o tamanho do arquivo de simulação é proporcional a $n$, pois, a cada fonte de recursos 
deve ser acrescentado na ferramenta um subsistema equivalente a cada uma das fontes de recursos.

Cabe salientar que como o desenvolvimento da ferramenta é modular, pode-se expandi-la para quantas fontes de recursos se deseje, sem que haja alterações nos conceitos e simulações aqui realizadas.

As principais fontes de recursos que participam na formação da matriz energética nacional estão descritas na tabela 9. Embora algumas delas não sejam componentes significativas na produção de eletricidade, foram mantidas na tabela para efeito de comparação entre as fontes de recursos.

TABELA 9 - Participação de cada fonte de recurso na geração de energia elétrica.

\begin{tabular}{|c|c|c|c|c|c|}
\hline Fonte Primária & $\begin{array}{c}\text { Fonte } \\
\text { Secundária }\end{array}$ & $\begin{array}{c}\text { parcela } \\
\text { usada para } \\
\text { geração de } \\
\text { energia } \\
\text { elétrica - } \\
\text { pública }\end{array}$ & $\begin{array}{c}\text { parcela usada } \\
\text { para geração } \\
\text { de energia } \\
\text { elétrica - } \\
\text { privada }\end{array}$ & $\begin{array}{l}\text { parcela de } \\
\text { geração de } \\
\text { energia } \\
\text { elétrica em } \\
\text { relação ao } \\
\text { total - pública }\end{array}$ & $\begin{array}{l}\text { parcela de } \\
\text { geração de } \\
\text { energia } \\
\text { elétrica em } \\
\text { relação ao } \\
\text { total - privada }\end{array}$ \\
\hline Gás Natural* & & $14,5 \%$ & $5,4 \%$ & $8,4 \%$ & $3,2 \%$ \\
\hline Carvão Vapor* & & $80,2 \%$ & $2,3 \%$ & $5,3 \%$ & $0,2 \%$ \\
\hline Energia Hidráulica* & & $96,3 \%$ & $3,7 \%$ & $80,7 \%$ & $3,1 \%$ \\
\hline Lenha & & $0,0 \%$ & $0,4 \%$ & $0,0 \%$ & $0,4 \%$ \\
\hline Produtos de Cana* & & $0,0 \%$ & $4,9 \%$ & $0,0 \%$ & $4,4 \%$ \\
\hline Outros (Eólico/Solar)* & & $0,3 \%$ & $32,5 \%$ & $0,1 \%$ & $5,9 \%$ \\
\hline Petróleo & Óleo Diesel & $1,9 \%$ & $0,3 \%$ & $4,3 \%$ & $0,6 \%$ \\
\hline Petróleo & Óleo Combustível & $0,5 \%$ & $0,3 \%$ & $1,1 \%$ & $0,7 \%$ \\
\hline Gás Natural & Gás Cidade & $0,0 \%$ & $0,7 \%$ & $0,0 \%$ & $0,4 \%$ \\
\hline Urânio $\mathrm{U}_{3} \mathrm{O}_{8}{ }^{*}$ & Urânio $\mathrm{UO}_{2}$ & $53,8 \%$ & $0,0 \%$ & $7,2 \%$ & $0,0 \%$ \\
\hline Outras & Outras & $0,0 \%$ & $0,3 \%$ & $0,0 \%$ & $0,8 \%$ \\
\hline
\end{tabular}

As colunas contemplam as parcelas utilizadas para geração de energia elétrica de cada recurso e as parcelas relativas ao total de energia, tanto para o setor público quanto para o setor privado.

Pela observação da tabela 9, podem-se adotar critérios de corte que delimitam as fontes de recursos que podem ser desconsideradas sem prejuízos para as simulações, como segue:

1. Embora o óleo diesel e o óleo combustível estejam presentes na geração de eletricidade com um valor considerável de 
aproximadamente $5 \%$, em relação à produção de petróleo os valores são muito menores, o que significa que alterações na quantidade de utilização dessas fontes não vão alterar a quantidade total de utilização do petróleo enquanto recurso primário.

2. Os valores de produção do recurso lenha, gás cidade e de outras secundárias do petróleo são pequenos, quer seja na quantidade percentual destinada para energia elétrica do recurso, quer seja no porcentual sobre o total de energia elétrica produzida.

3. No setor de transportes, há que considerar a migração de utilização de recursos fósseis, com os quais têm fortes ligações, para a utilização de energia elétrica que pode ou não ser gerada através de recursos fósseis. Já se observam subáreas do setor de transportes que se desvinculam dos combustíveis fósseis, como por exemplo, transporte ferroviário, metrô e ainda, mais recentemente, esforços da indústria automobilística para viabilizar os seus projetos de carro elétrico.

4. Dessa forma, das onze fontes que participam na geração de energia elétrica somente seis serão consideradas como objeto de estudo deste trabalho: Gás Natural, Carvão Vapor, Energia Hidráulica, Produtos da Cana, Eólica e Urânio.

As funções que descrevem o comportamento da produção, para as fontes de recursos selecionadas, com base nas curvas de tendências, bem como os seus respectivos gráficos, estão apresentadas nas figuras das próximas sessões.

Para o equacionamento efetuou-se uma mudança de variável independente, de " $\boldsymbol{x}$ " para "1970+u", em razão de que no simulador os tempos são contados a partir de 0 , que é o tempo inicial.

A curva de tendência foi obtida a partir dos dados do BEN de 1970 até 2004. Efetuou-se a escolha do tipo de função levando-se em 
consideração três fatores: i) $O$ valor de correlação $R^{2}$; ii) a diferença entre os valores reais e os valores da curva de tendência para os anos de 2005 a 2009 e iii) os valores de produção são totais, pois a emergia de subprodutos é igual ao do produto - álgebra emergética (ODUM 1996).

Mesmo em detrimento a um valor de máximo $\mathrm{R}^{2}$, em alguns casos, optou-se pela utilização de uma curva mais próxima dos valores reais no intervalo 2005 a 2009, tais como o carvão e produtos de cana.

A escolha das curvas de tendência não afeta os resultados das simulações dado que a ferramenta deve se auto ajustar a variações individuais.

\subsubsection{Oferta Interna Bruta do Gás Natural - OIB(gn)}

Neste caso obteve-se uma função polinomial de segundo grau

$$
\begin{aligned}
O I B(g n) & =19,58853309 \times(1970+u)^{2}-77.436,17475459 \times(1970+u) \\
& +75.529 .409,09116460
\end{aligned}
$$

O gás natural teve uma queda no ano de 2009, relativa à crise mundial e assim espera-se que nos próximos anos uma retomada de ritmo deve ser realizada. O gráfico da figura 13 mostra as evoluções da curva real de produção e a curva de tendência.

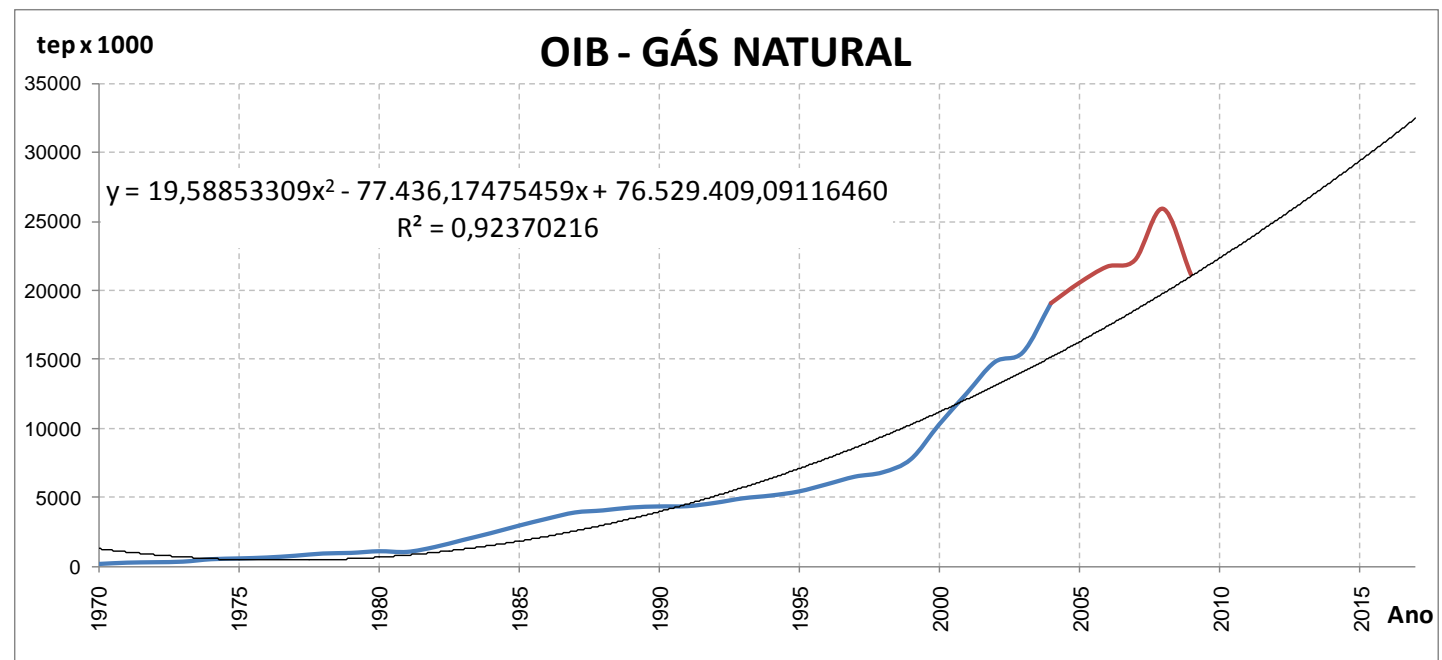




\subsubsection{Oferta Interna Bruta do Carvão Vapor - OIB(cv)}

Neste caso obteve-se uma função polinomial de primeiro grau $O I B(c v)=52,04291115 \times(1970+u)-101.636,77457065$

O carvão vapor também teve uma queda nos anos de 2008 e 2009, parte relativa à crise mundial e parte pelo aumento de outras fontes de recursos concorrentes. O gráfico da figura 14 mostra as evoluções da curva real de produção e a curva de tendência.

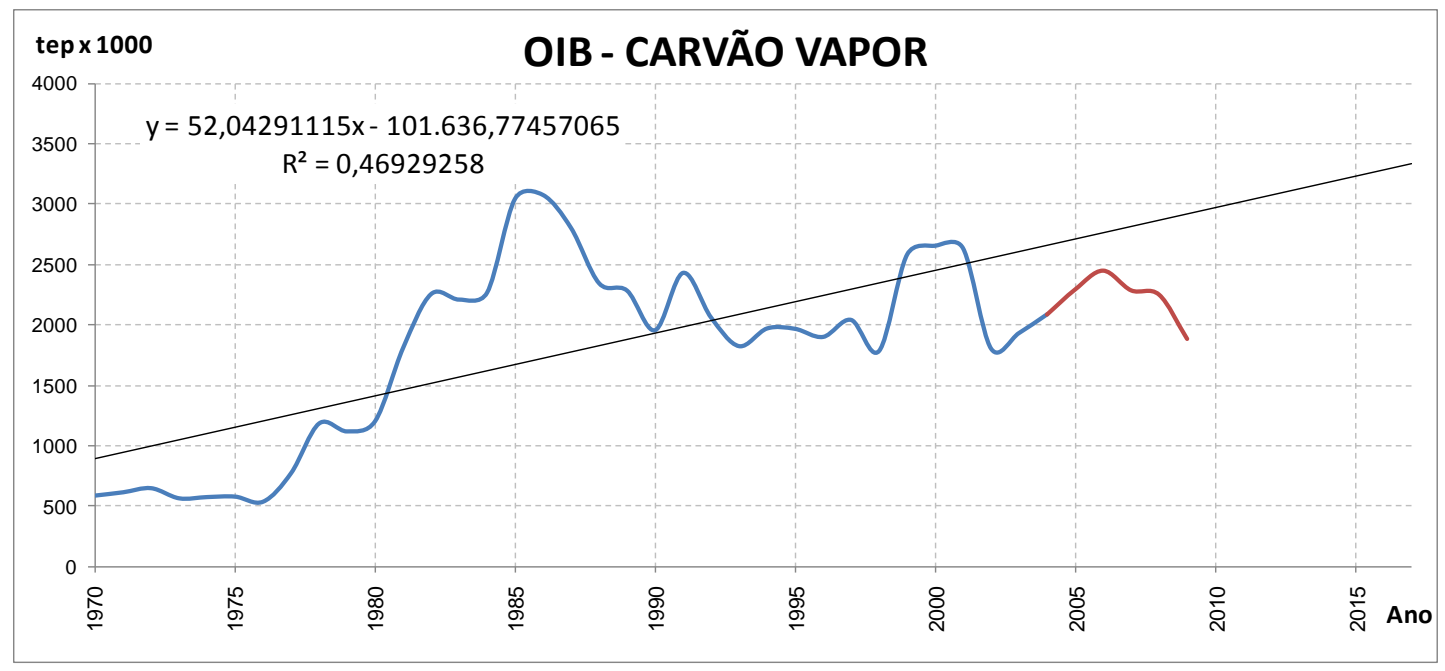

FIGURA 14 - Oferta interna bruta para o carvão vapor.

\subsubsection{Oferta Interna Bruta de Energia Hídrica - OIB(eh)}

Neste caso obteve-se uma função polinomial de primeiro grau

$O I B(e h)=727,43548217 \times(1970+u)-1.429 .723,70879914$

O gráfico da figura 15 mostra as evoluções da curva real de produção e a curva de tendência. 


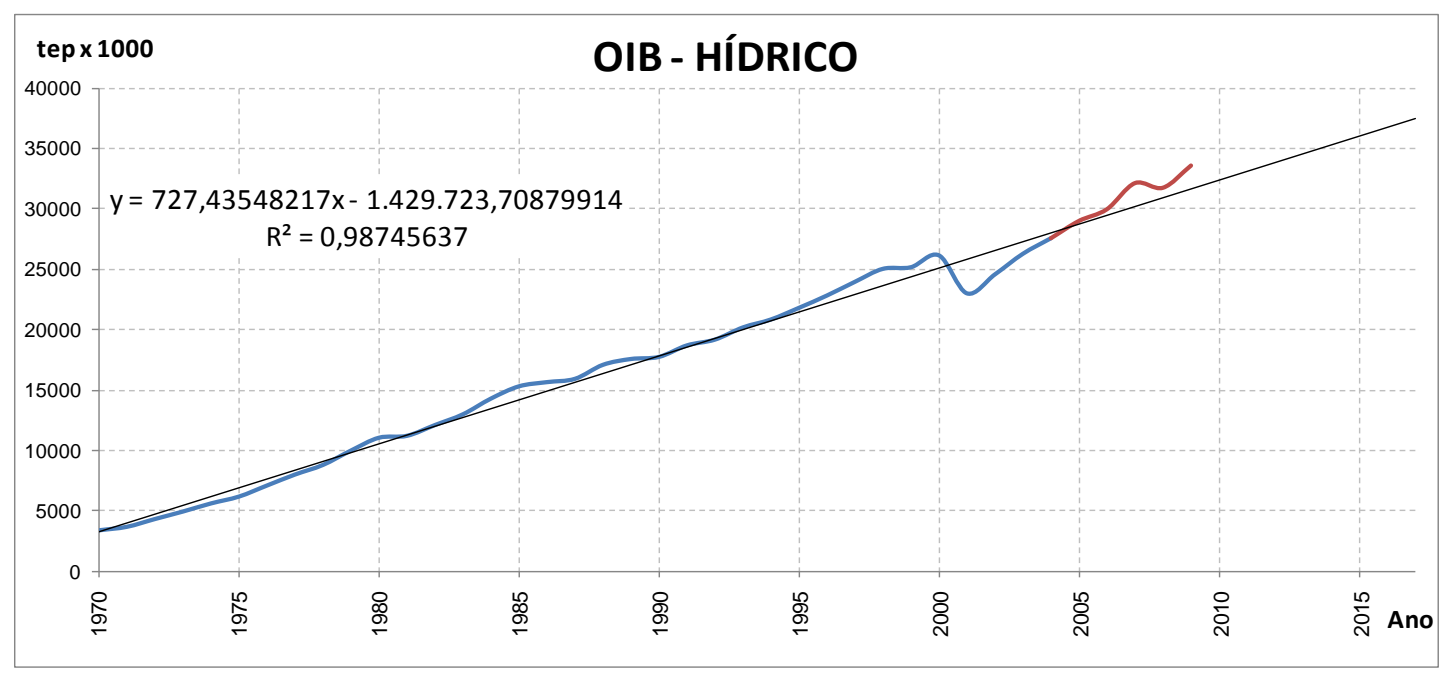

FIGURA 15 - Oferta interna bruta para o hídrico.

\subsubsection{Oferta Interna Bruta dos Produtos de Cana - OIB(pc)}

Neste caso obteve-se uma função polinomial de primeiro grau

$O I B($ cana $)=762,15636813 \times(1970+u)-1.498 .489,97482418$

O gráfico da figura 16 mostra as evoluções da curva real de produção e a curva de tendência.

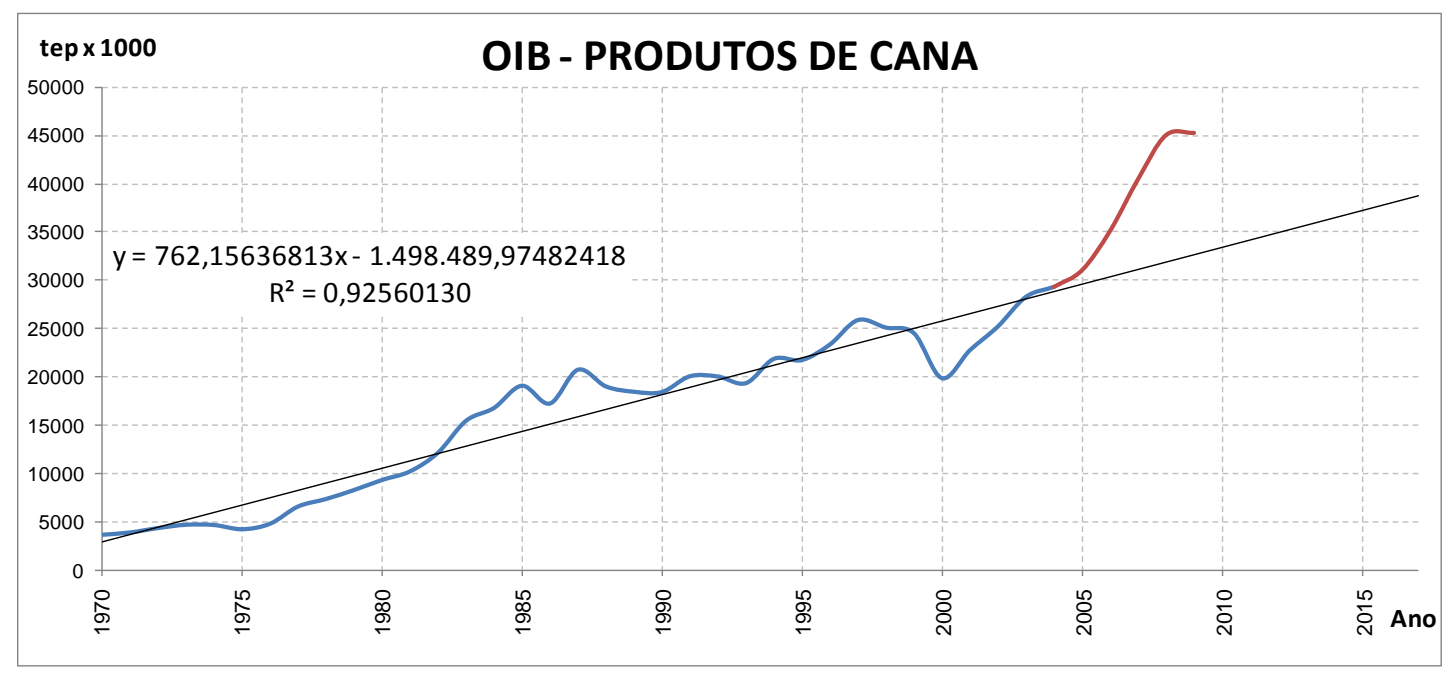

FIGURA 16 - Oferta interna bruta para a cana. 


\subsubsection{Oferta Interna Bruta da Energia Eólica - OIB(ee)}

Neste caso obteve-se uma função polinomial de segundo grau

$$
\begin{gathered}
\text { OIB }(\text { eól })=4,10203557 \times(1970+u)^{2}-16146,23079105 \times(1970+u) \\
+15888749,37147380
\end{gathered}
$$

O gráfico da figura 17 mostra as evoluções da curva real de produção e a curva de tendência.

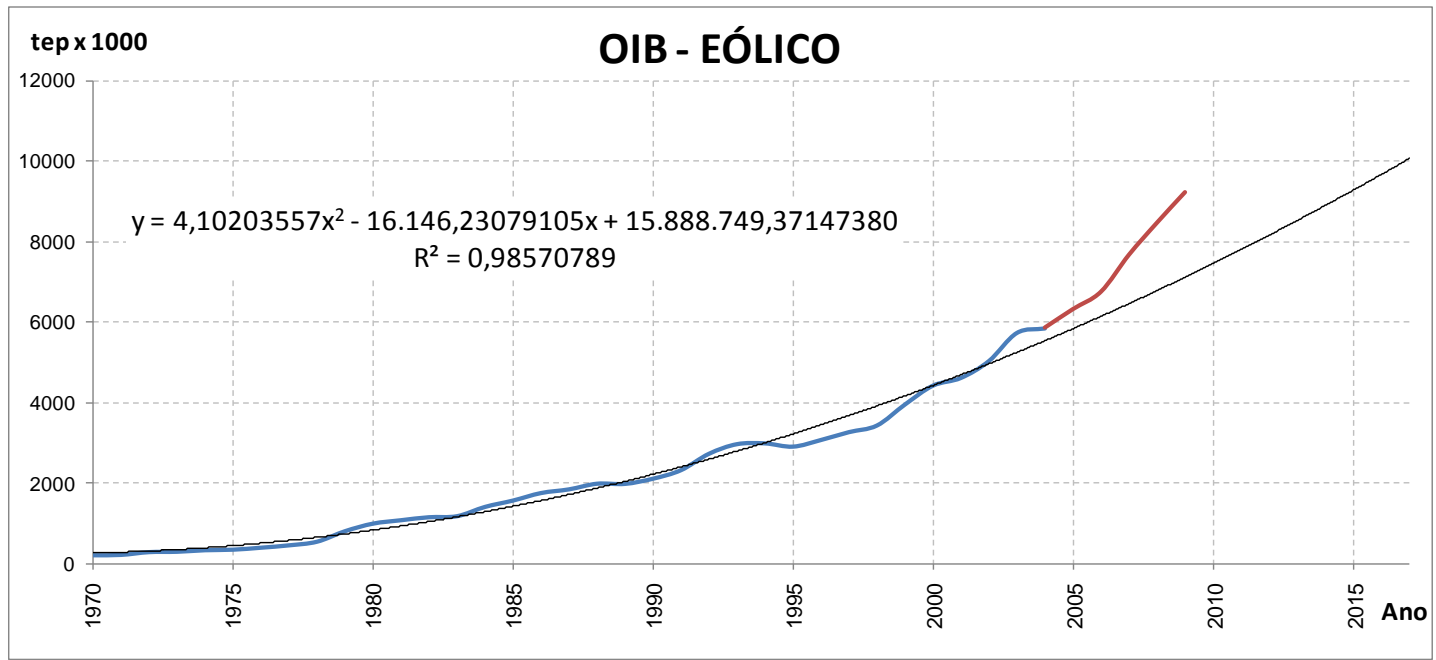

FIGURA 17 - Oferta interna bruta para o eólico.

\subsubsection{Oferta Interna Bruta da Energia Nuclear - OIB(en)}

Neste caso obteve-se uma função polinomial de primeiro grau

$O I B(u r a ̂ n)=140,62565369 \times(1970+u)-278.230,76531764$

O gráfico da figura 18 mostra as evoluções da curva real de produção e a curva de tendência. 


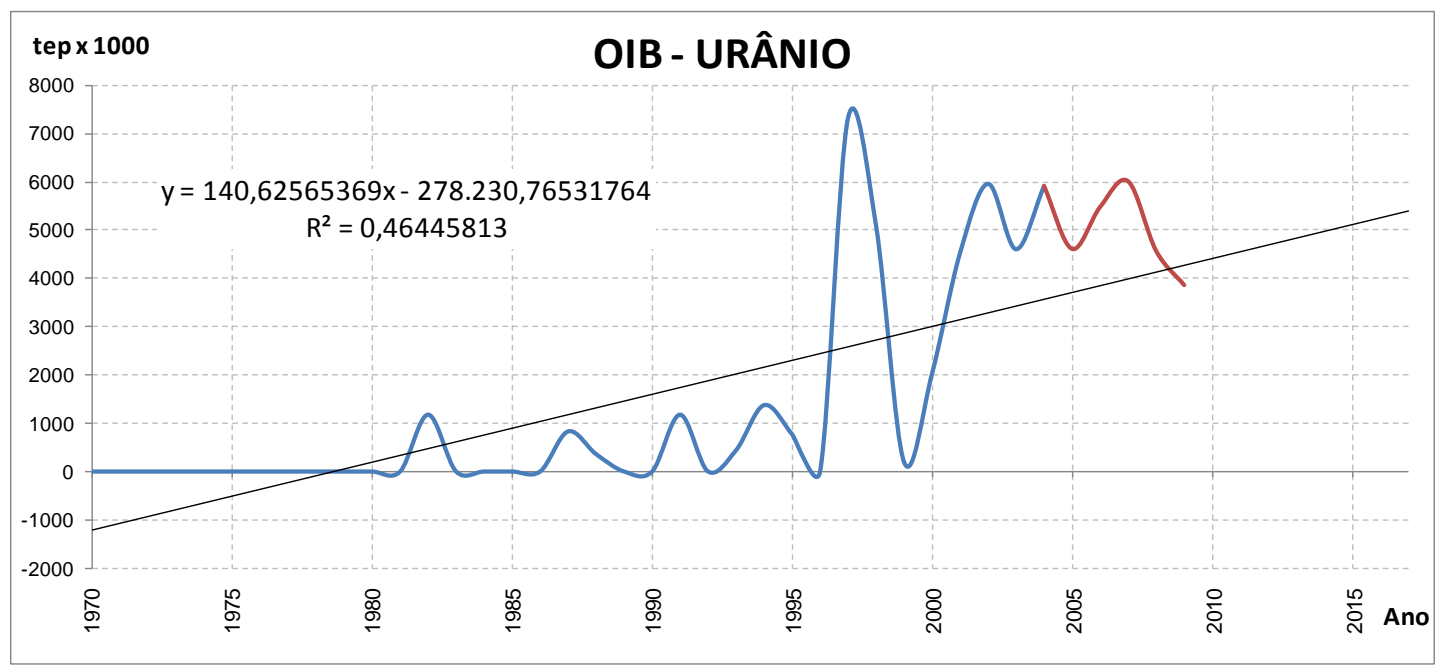

FIGURA 18 - Oferta interna bruta para o urânio.

\subsubsection{Transformidades das Fontes de Recursos}

Os valores de transformidades que foram utilizados nos cálculos emergéticos para as fontes de recursos selecionadas foram obtidos na literatura e em estudos acadêmicos, conforme apresentados no anexo B.

Não foram encontrados dados de valores emergéticos calculados para o caso das plantas de energia elétrica para o Brasil. Dessa forma, foram utilizados os valores encontrados na literatura, embora calculados para localidades específicas, mesmo com o conhecimento que tanto as quantidades emergéticas, quanto as parcelas referentes a cada uma das categorias de fontes de recursos, podem ter variações quando se muda o cenário do cálculo. Essas limitações não têm grande influência na validação do método, nem tampouco a verificação do funcionamento da ferramenta, conforme discutido na seção 2.2.8 - análise de sensibilidade.

Os cálculos emergéticos para as plantas de energia de gás natural, carvão, eólica e hídrica foram extraídas de Brown e Ulgiati (2002); para a planta de energia nuclear, de Kindberg (2007) e International Atomic Energy Agency (2005); para os produtos de cana, de Alonso-Pippo et al. (2004). Os cálculos dos valores emergéticos estão apresentados no Anexo B.

$\mathrm{Na}$ tabela 10 estão apresentados os valores de transformidades na geração de energia elétrica a partir das fontes de recursos por unidade de 
milhões de Watt (MW) gerada e feita a conversão para milhões de toneladas equivalentes de petróleo $\left(\right.$ tep $\left.\times 10^{6}\right)$. Estão apresentadas, também, as parcelas emergéticas relativas de recursos renováveis, não renováveis e pagos, para cada uma das seis fontes de recursos.

TABELA 10 - Parcelas de recursos renováveis, não renováveis e pagos por fonte de recurso.

\begin{tabular}{lccccc}
\hline Fonte de Recurso & $\begin{array}{c}\text { Transformidade } \\
{[\mathbf{s e j} / \mathrm{j}]}\end{array}$ & $\begin{array}{c}\text { Transformidade } \\
\text { [sej/tep] }\end{array}$ & $\mathbf{R}_{\text {normal }}$ & $\mathbf{N}_{\text {normal }}$ & $\mathbf{F}_{\text {normal }}$ \\
\hline Gás Natural & $1,70 \mathrm{E}+05$ & $4,06 \mathrm{E}-06$ & 0,078 & 0,770 & 0,152 \\
Carvão Vapor & $1,71 \mathrm{E}+05$ & $4,09 \mathrm{E}-06$ & 0,088 & 0,729 & 0,182 \\
Energia Hidráulica & $6,23 \mathrm{E}+04$ & $1,49 \mathrm{E}-06$ & 0,688 & 0,181 & 0,131 \\
Produtos de Cana & $6,97 \mathrm{E}+04$ & $1,67 \mathrm{E}-06$ & 0,677 & 0,026 & 0,297 \\
Urânio $\mathrm{UO}_{2}$ & $4,81 \mathrm{E}+04$ & $1,15 \mathrm{E}-06$ & 0,399 & 0,519 & 0,082 \\
Eólico & $6,21 \mathrm{E}+04$ & $1,48 \mathrm{E}-06$ & 0,866 & 0,000 & 0,134 \\
\hline
\end{tabular}

\subsubsection{Análise de sensibilidade}

Nos processos globalizados hoje em prática, principalmente nas grandes corporações e setores macro-econômicos, os meios de produção não se diferenciam substancialmente a não ser pelos requisitos de ordem econômica tais como, os valores da mão de obra, dos impostos, da infraestrutura e das distâncias de transporte, entre outros.

Do ponto de vista de fornecimento de máquinas e equipamentos para a produção de energia elétrica, poucas empresas trans-nacionais tais como ABB, Alstom, Andritz, Areva, GE, IMPSA, Suez, Toshiba-Westinghouse e Voith-Siemens, são responsáveis pelo fornecimento de mais de $85 \%$ de todo parque produtivo mundial.

Por outro lado, o setor produtivo de energia elétrica no Brasil, público e privado, tem acompanhado a evolução tecnológica mundial, introduzindo em seu parque produtivo equipamentos com grau de atualidade igual ao utilizado em outras partes do mundo.

Neste contexto, os meios produtivos de energia elétrica, quando vistos sob o ponto de vista da contabilidade emergética, têm as parcelas de 
recursos renováveis e não renováveis semelhantes, independente do local de produção.

Por exemplo, o volume de recurso hídrico para produção de certa quantidade de energia elétrica para uma planta de energia que utiliza uma turbina de bulbo no Brasil ou em outro lugar é muito semelhante. Também a composição dos materiais para a fabricação de tais turbinas são bastante similares.

Já as parcelas de emergia contabilizadas para de mão de obra (M), serviços (S), recursos importados e advindos da economia, têm variações de país para país. Para efeito dos índices contidos neste trabalho, todos estes são incorporados na parcela de recursos pagos $(F)$.

Assim sendo, a transposição do cálculo emergético de um determinado bem ou produto de uma localidade para outra se dá com um acréscimo ou decréscimo na parcela de recursos pagos, mantendo-se a relação entre $\mathrm{N}$ e R.

Esse efeito pode ser verificado através da análise do diagrama ternário de emergia. Na reta de sensibilidade em relação à componente $\mathrm{F}$ (BARRELLA, 2004), todos os pontos que representam produtos ou bens localizados no diagrama ternário, quando submetidos a um acréscimo na componente de recursos pagos, são atraídos para novos pontos mais próximos do vértice $F$, conforme figura 19 .

$\mathrm{Na}$ figura 19, o ponto A representa um determinado produto com determinada composição de recursos R, N e F. Quando ocorre uma mudança de valor somente na parcela $F$, mantendo a relação de $N$ e $R$, o ponto deslocado que representa a nova posição do produto com a composição alterada é A'. Esse novo ponto A' está situado sobre a reta que liga o vértice $F$ ao ponto $A$, que é denominada de linha da sensibilidade emergética em relação à $F\left(S_{F}\right)$. Na mesma figura estão desenhadas as linhas que representam os valores de ELR, EYR e EIS para o ponto A. Quaisquer dois pontos sobre uma mesma linha têm o mesmo valor de índice. 


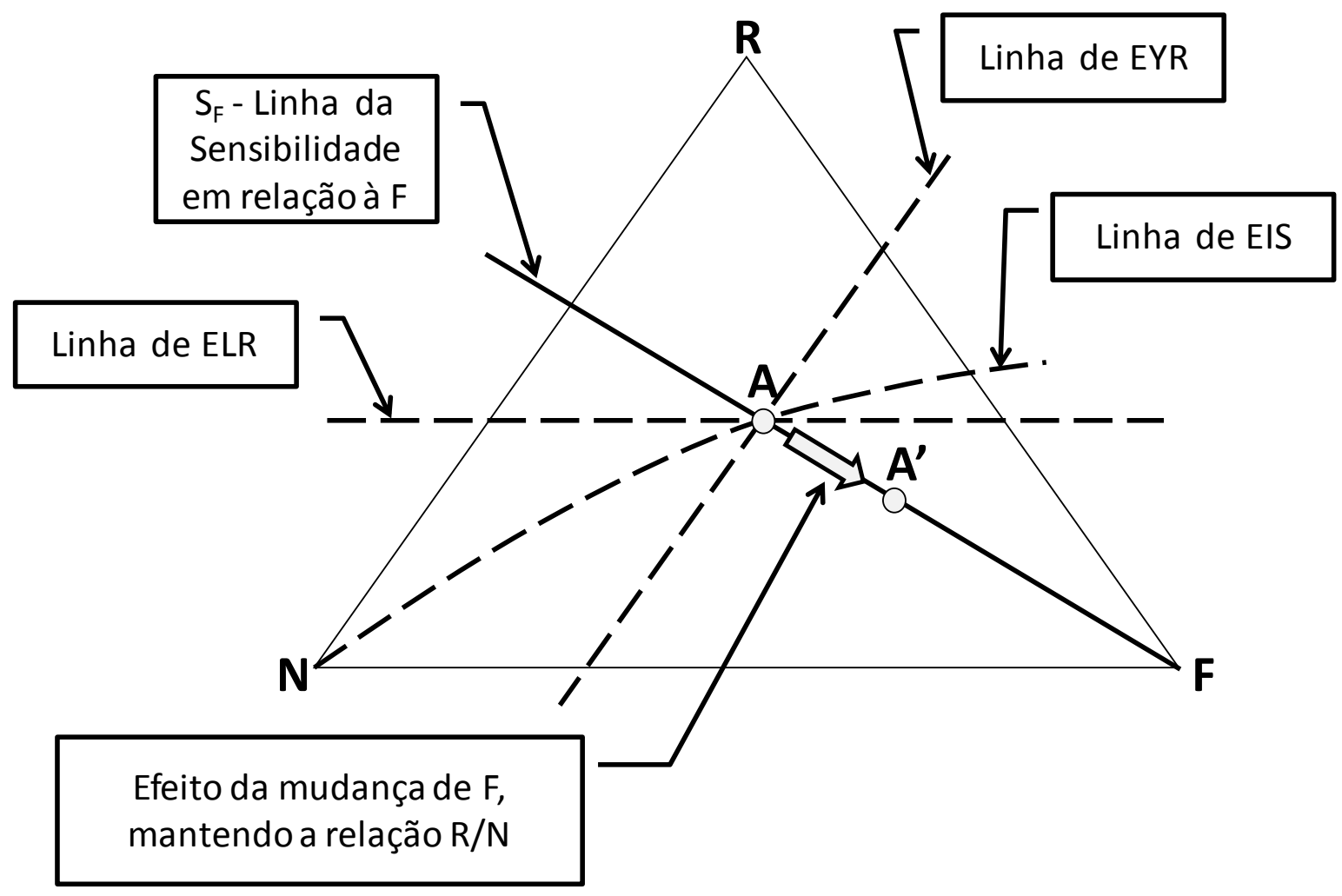

FIGURA 19 - Diagrama ternário e curvas EYR, ELR, EIS e $S_{F}$, sensibilidade em relação à $F$.

Análise 1 - Variação dos índices emergéticos para mudanças de F por um fator constante igual a 2

Nas figuras de 20 a 27 estão apresentados os casos para um conjunto de 4 pontos típicos, pontos 1, 3, 5 e 7, e para o novo conjunto de pontos 2, 4, 6 e 8, respectivamente obtidos a partir do primeiro conjunto pela variação de $\mathrm{F}$ por um fator igual a 2 .

Pode-se observar, pela seqüência das figuras 20 a 27, que a ordem de classificação por índice, linhas ELR, EYR e EIS, não se altera do primeiro conjunto de pontos para o segundo conjunto de pontos. 


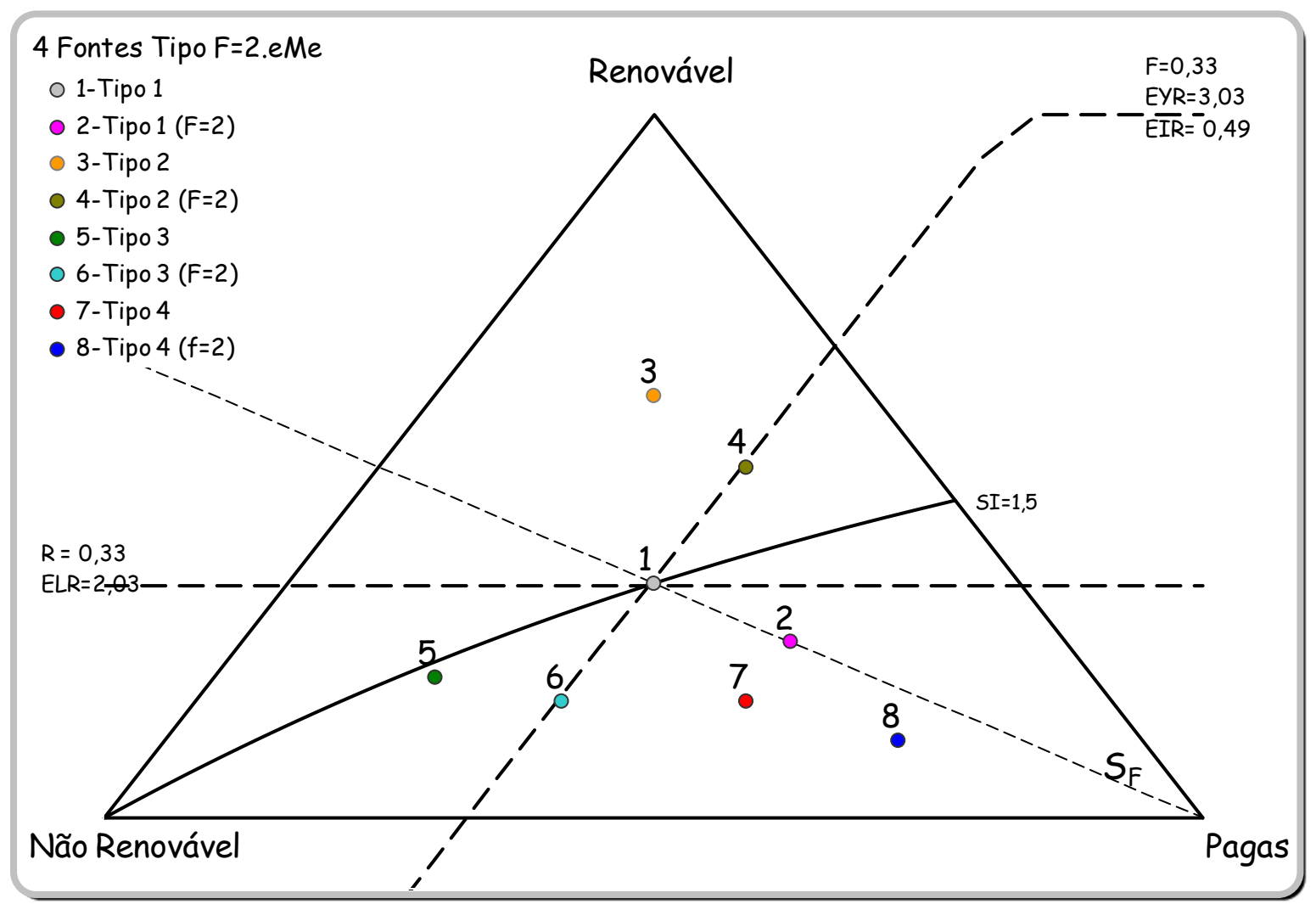

FIGURA 20 - Diagrama ternário e curvas EYR, ELR, EIS e $S_{F}$, sensibilidade em relação à $F$, no ponto 1.

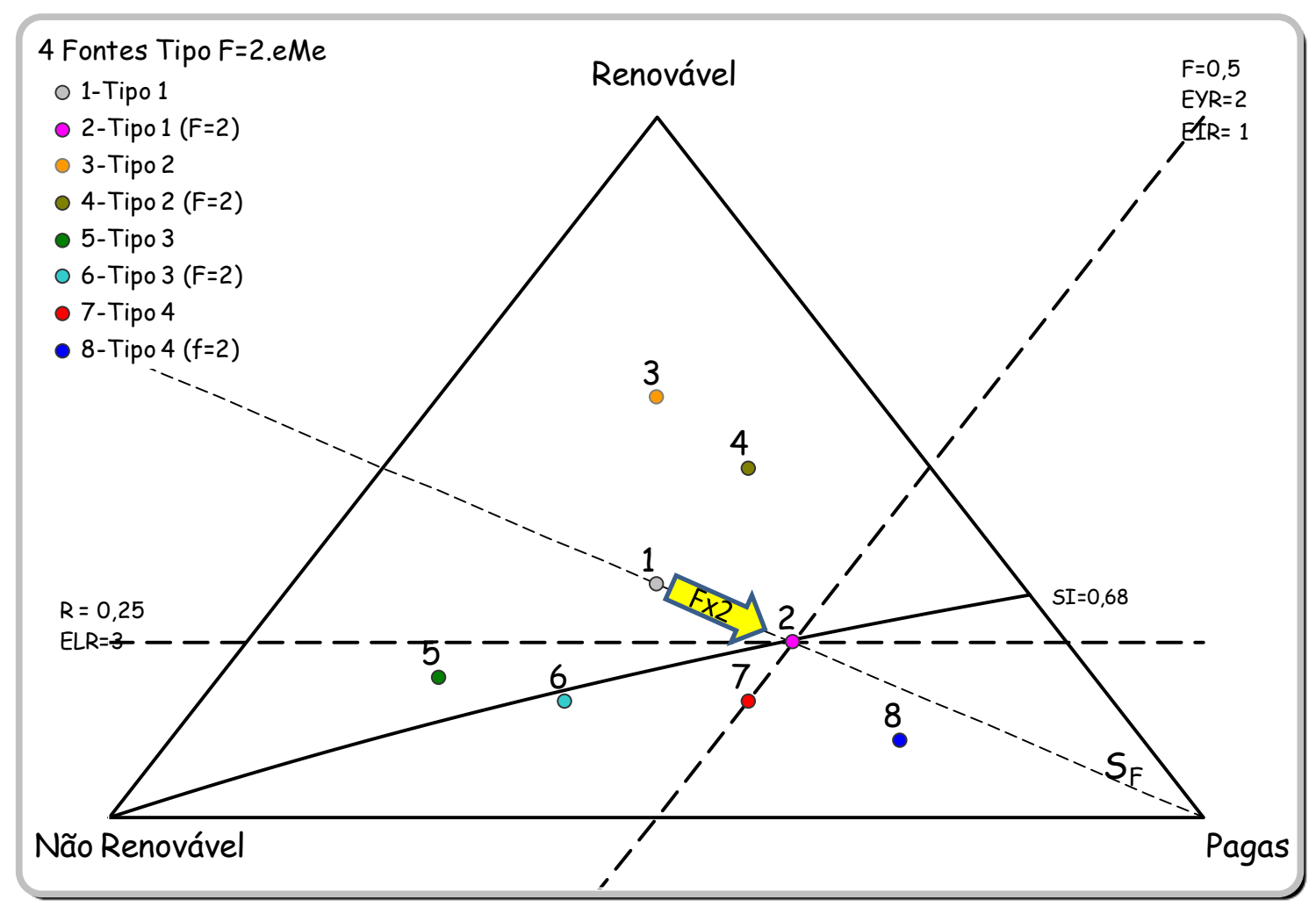

FIGURA 21 - Diagrama ternário e curvas EYR, ELR, EIS e $S_{F}$, sensibilidade em relação à $F$, no ponto 2. 


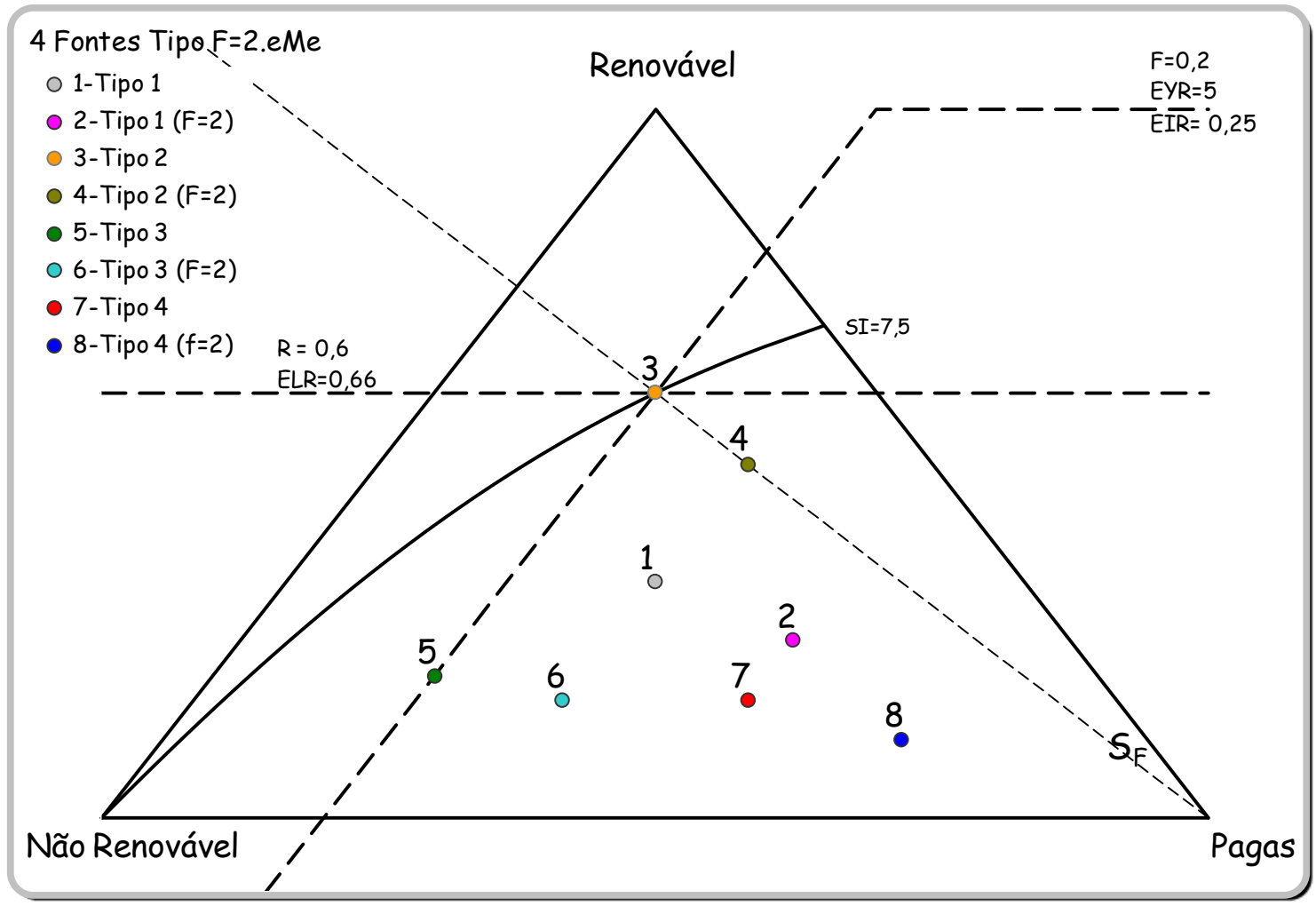

FIGURA 22 - Diagrama ternário e curvas EYR, ELR, EIS e $S_{F}$, sensibilidade em relação à $F$, no ponto 3.

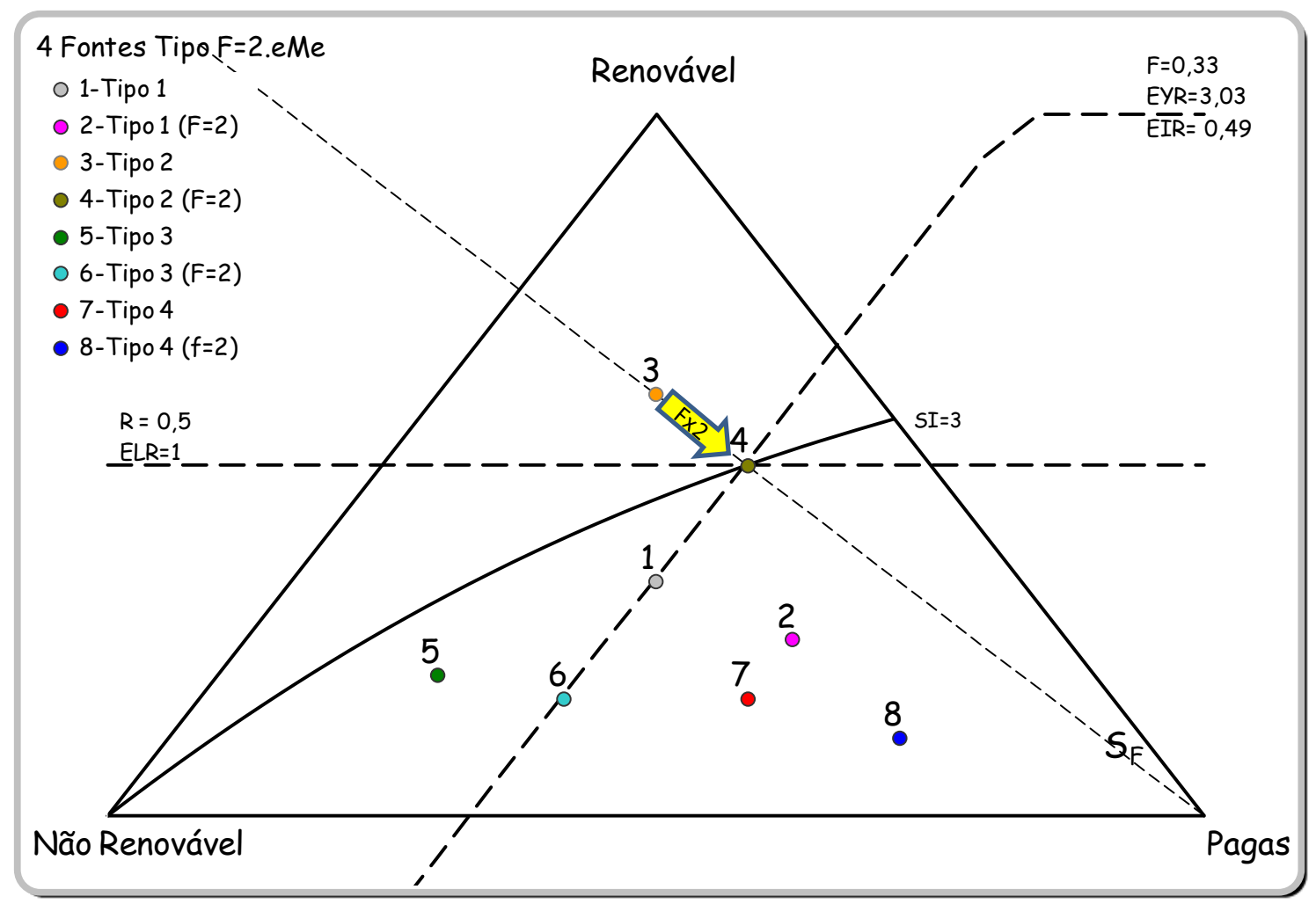

FIGURA 23 - Diagrama ternário e curvas EYR, ELR, EIS e $S_{F}$, sensibilidade em relação à $F$, no ponto 4. 


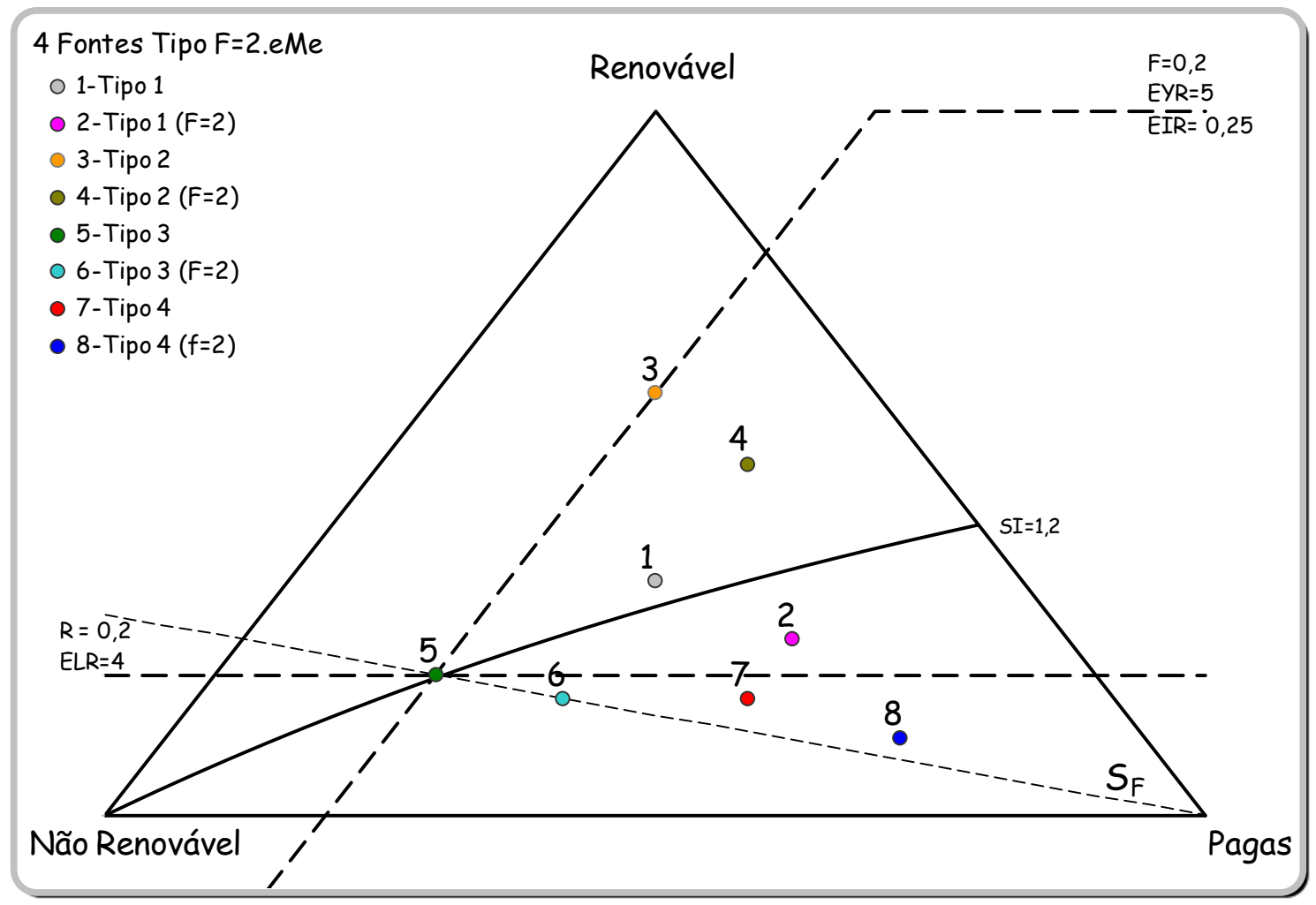

FIGURA 24 - Diagrama ternário e curvas EYR, ELR, EIS e $S_{F}$, sensibilidade em relação à $F$, no ponto 5.

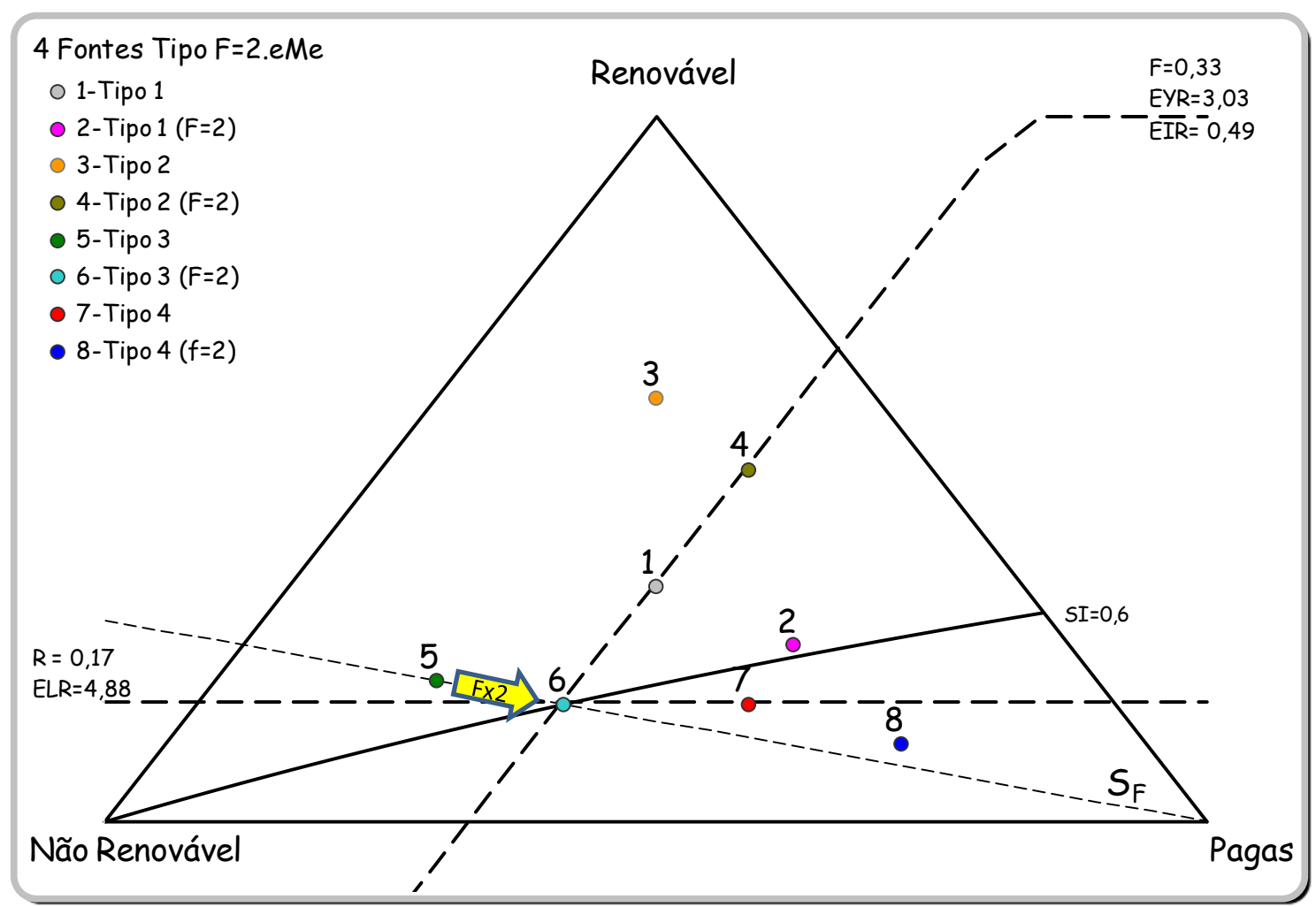

FIGURA 25 - Diagrama ternário e curvas EYR, ELR, EIS e $S_{F}$, sensibilidade em relação à $F$, no ponto 6. 


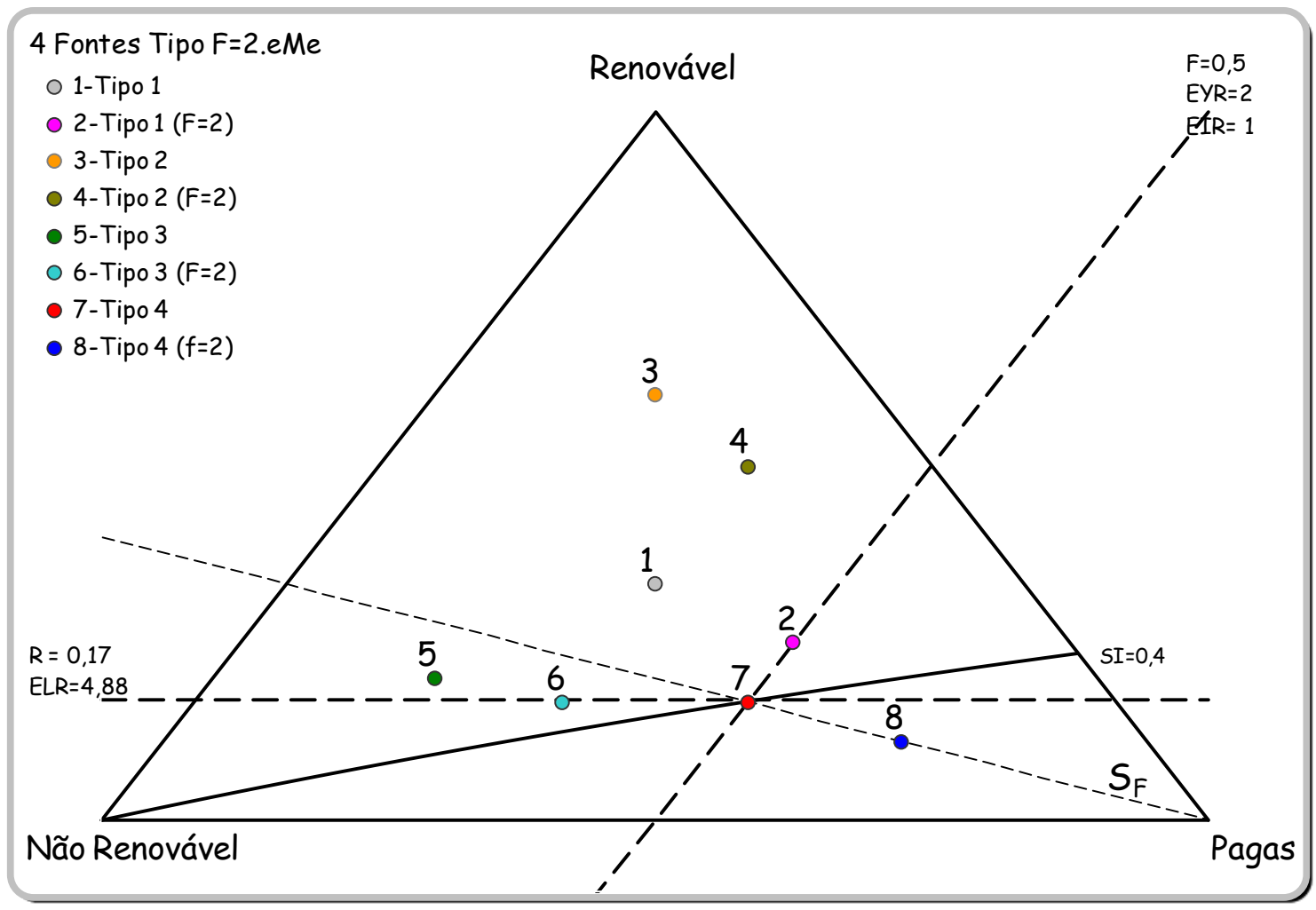

FIGURA 26 - Diagrama ternário e curvas EYR, ELR, EIS e $S_{F}$, sensibilidade em relação à $F$, no ponto 7.

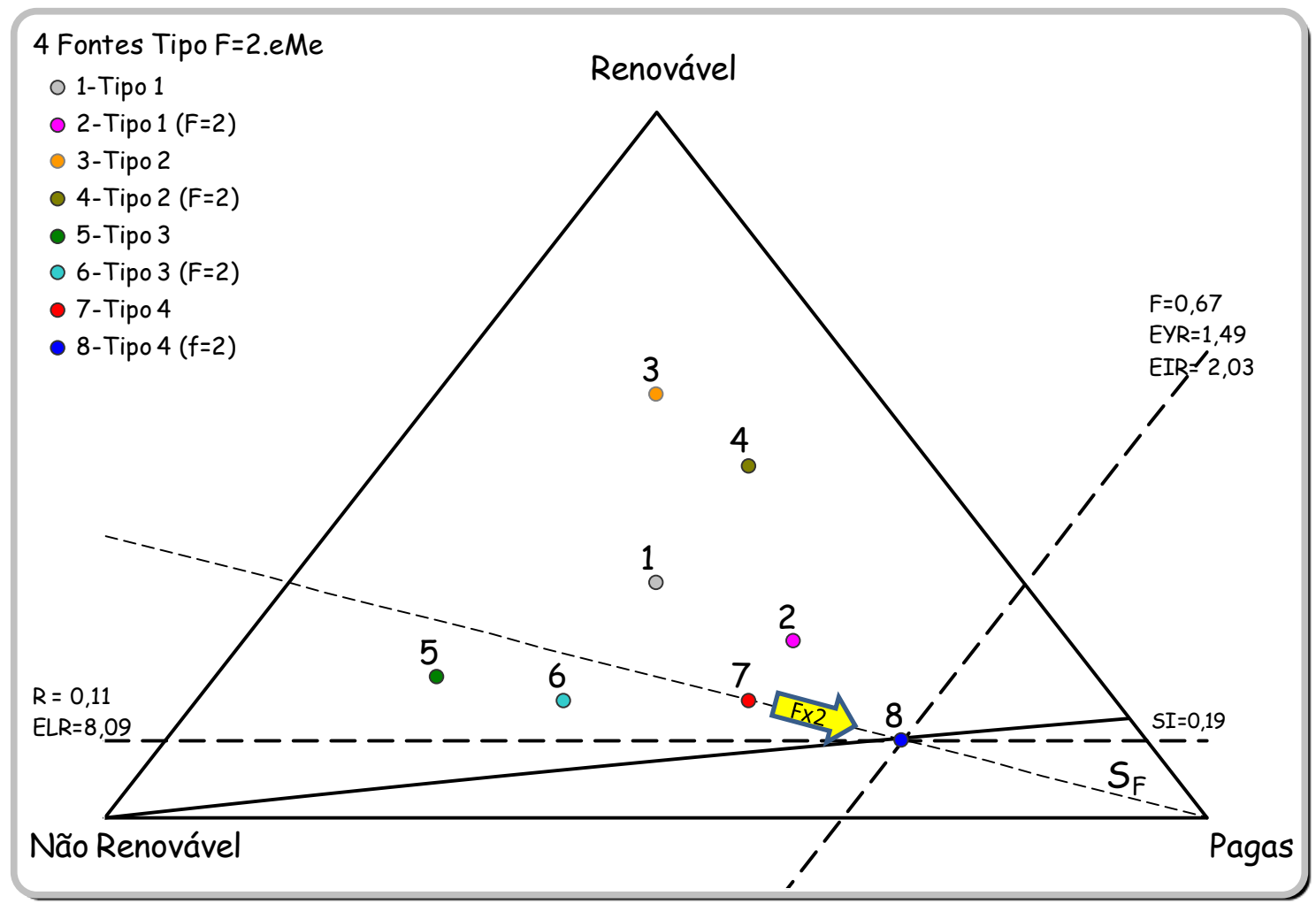

FIGURA 27 - Diagrama ternário e curvas EYR, ELR, EIS e $S_{F}$, sensibilidade em relação à $F$, no ponto 8. 
As simulações, apresentadas nas figuras de 20 a 27, indicam que embora os valores dos índices mudem com a variação de $F$, isso não implica na alteração da ordem classificatória quanto ao desempenho dos índices da contabilidade emergética.

No apêndice A estão apresentados os valores de composição $R, N$ e $F$, além dos índices para os pontos de 1 a 8 , bem como as expressões analíticas da sensibilidade emergética dos índices ELR, EYR e EIS em relação à componente $F$.

Análise 2 - Variação dos índices emergéticos para mudanças de $F$ considerando o serviço do meio ambiente

Outro exemplo de análise de sensibilidade pode ser feito sobre 0 estudo de Ulgiati e Brown (2002). Nesse artigo é feita uma comparação para seis tipos diferentes de processos de produção de energia elétrica (Eólica, Geotérmica, Hidrelétrica, Gás, Óleo e Carvão). Os índices emergéticos são comparados com os índices alterados, para quatro delas, (Geotérmica, Gás, Óleo e Carvão) pela incorporação de uma parcela adicional na componente $F$ referente ao serviço do meio ambiente necessário para diluir e mitigar as emissões geradas pelas plantas de energia. Os valores das componentes $R$, $\mathrm{N}$ e $\mathrm{F}$, e os respectivos índices, estão mostrados na tabela 11.

TABELA 11 - R, N e F e índices emergéticos para 4 plantas de geração de energia elétrica, com a classificação de desempenho dos índices.

\begin{tabular}{|c|c|c|c|c|c|c|c|c|}
\hline & \multicolumn{4}{|c|}{ Original } & \multicolumn{4}{|c|}{ Modificada } \\
\hline & GEO & GÁS & CARVÃO & ÓLEO & $\begin{array}{c}\text { GEO } \\
(F \times 2,57)\end{array}$ & $\begin{array}{c}\text { GÁS } \\
(\mathrm{Fx} 1,62)\end{array}$ & $\begin{array}{l}\text { CARVÃO } \\
\text { (Fx2,51) }\end{array}$ & $\begin{array}{c}\text { ÓLEO } \\
(F \times 1,91)\end{array}$ \\
\hline \multicolumn{9}{|l|}{ Recursos } \\
\hline Renovável [seJ] & $3,36 \times 10^{19}$ & $2,72 \times 10^{19}$ & $3,68 \times 10^{20}$ & $3,12 \times 10^{20}$ & $3,36 \times 10^{19}$ & $2,72 \times 10^{19}$ & $3,68 \times 10^{20}$ & $3,12 \times 10^{20}$ \\
\hline Não Renovável [seJ] & $4,61 \times 10^{18}$ & $2,68 \times 10^{20}$ & $3,05 \times 10^{21}$ & $3,32 \times 10^{21}$ & $4,61 \times 10^{18}$ & $2,68 \times 10^{20}$ & $3,05 \times 10^{21}$ & $3,32 \times 10^{21}$ \\
\hline Pagas [seJ] & $1,00 \times 10^{19}$ & $5,28 \times 10^{19}$ & $7,63 \times 10^{20}$ & $1,13 \times 10^{21}$ & $2,57 \times 10^{19}$ & $8,57 \times 10^{19}$ & $1,92 \times 10^{21}$ & $2,16 \times 10^{21}$ \\
\hline \multicolumn{9}{|l|}{ Índices } \\
\hline EYR & 4,8 & 6,59 & 5,48 & 4,21 & 2,49 & 4,45 & 2,78 & 2,68 \\
\hline ELR & 0,44 & 11,79 & 10,36 & 14,26 & 0,90 & 13,00 & 13,50 & 17,56 \\
\hline EIS & 11,09 & 0,56 & 0,53 & 0,30 & 2,76 & 0,34 & 0,21 & 0,15 \\
\hline \multicolumn{9}{|l|}{ Classificação (Ranking) } \\
\hline $\mathrm{R}_{\mathrm{EYR}}$ & 3 & 1 & 2 & 4 & 4 & 1 & 2 & 3 \\
\hline $\mathrm{R}_{\mathrm{ELR}}$ & 1 & 3 & 2 & 4 & 1 & 2 & 3 & 4 \\
\hline$R_{\text {EIS }}$ & 1 & 2 & 3 & 4 & 1 & 2 & 3 & 4 \\
\hline
\end{tabular}


Os acréscimos na componente $F$ para cada caso foram muito diferentes, indo de 1,6 para o gás até 2,6 para a planta eólica. Na tabela 11 ainda foram acrescentadas três linhas referentes à classificação por índice de cada uma das plantas.

Observa-se que mesmo com fatores de $\mathrm{F}$ muito variados houve pouca mudança de posição entre as condições de antes e depois da consideração do serviço do meio ambiente. Assim duas inversões de posição foram auferidas:

i) A troca de posição, $3^{\circ}$ e $4^{\circ}$ lugares, no índice EYR, para as plantas GEO e ÓLEO. Isso acorreu em virtude de que os valores de EYR, antes da aplicação do fator multiplicativo, estarem próximos $\left(E Y R_{G E O}=\right.$ 4,80 e $E Y R_{\text {ÓLEO }}=4,21$ ) e os fatores de multiplicação de $\mathrm{F}$ serem bastante diferentes $\left(x F_{G E O}=2,68\right.$ e $\left.x F_{O L E O}=1,90\right)$. Verifica-se que ainda que trocadas as posições, os novos EYRs ainda se conservaram muito próximos $\left(E Y R_{\text {novoGEO }}=2,49\right.$ e $\left.E Y R_{\text {novó́ } L E O}=2,68\right)$.

ii) A troca de posição, $2^{\circ}$ e $3^{\circ}$ lugares, no índice ELR, para as plantas GÁS e CARVÃO. Isso ocorreu em virtude de que os valores de ELR, antes da aplicação do fator multiplicativo, estarem próximos $\left(E L R_{G A ́ s}=\right.$ 11,79 e ELR ${ }_{\text {CARVÃo }}=10,36$ ) e os fatores de multiplicação de F serem bastante diferentes $\left(x F_{G A ́ S}=1,6\right.$ e $\left.x F_{C A R V A ̃ O}=2,5\right)$. Verifica-se que ainda que trocadas as posições, os novos ELRs ainda se conservaram muito próximos $\left(E L R_{\text {novoGÁs }}=13,00\right.$ e EYR $\left.R_{\text {novoCARVÃo }}=13,50\right)$.

A classificação geral pode ser feita por grau de informação que cada índice traz. Fez-se uma média ponderada de classificações, levando-se em consideração o grau de agregação de informação de cada índice, com pesos para os índices EIS, ELR e EYR iguais a 3, 2 e 1, respectivamente, . O resultado pode ser verificado na tabela 12 , onde consta a ordem geral de classificação para as plantas de energia. 
TABELA 12 - classificação das plantas de energia com e sem o serviço do meio ambiente

\begin{tabular}{|c|c|c|c|c|c|c|c|c|}
\hline GEO & \multicolumn{4}{|c|}{ SEM O SERVIÇO DO MEIO AMBIENTE } & \multicolumn{4}{|c|}{ COM O SERVIÇO DO MEIO AMBIENTE } \\
\hline Índice & $\begin{array}{c}\text { Clas. por } \\
\text { índice }\end{array}$ & $\begin{array}{l}\text { Peso do } \\
\text { índice }\end{array}$ & Pontuação & $\begin{array}{l}\text { Clas. } \\
\text { Geral }\end{array}$ & $\begin{array}{c}\text { Clas. por } \\
\text { índice }\end{array}$ & $\begin{array}{l}\text { Peso do } \\
\text { índice }\end{array}$ & Pontuação & $\begin{array}{l}\text { Clas. } \\
\text { Gera }\end{array}$ \\
\hline EYR & 3 & 1 & \multirow{3}{*}{8} & \multirow{3}{*}{10} & 4 & 1 & \multirow{3}{*}{9} & \multirow{3}{*}{10} \\
\hline ELR & 1 & 2 & & & 1 & 2 & & \\
\hline ESI & 1 & 3 & & & 1 & 3 & & \\
\hline GÁS & \multicolumn{4}{|c|}{ SEM O SERVIÇO DO MEIO AMBIENTE } & \multicolumn{4}{|c|}{ COM O SERVIÇO DO MEIO AMBIENTE } \\
\hline Índice & $\begin{array}{c}\text { Clas. por } \\
\text { índice }\end{array}$ & $\begin{array}{l}\text { Peso do } \\
\text { índice }\end{array}$ & Pontuação & $\begin{array}{l}\text { Clas. } \\
\text { Geral }\end{array}$ & $\begin{array}{c}\text { Clas. por } \\
\text { índice }\end{array}$ & $\begin{array}{l}\text { Peso do } \\
\text { índice }\end{array}$ & Pontuação & $\begin{array}{l}\text { Clas. } \\
\text { Gera }\end{array}$ \\
\hline EYR & 1 & 1 & \multirow{3}{*}{13} & \multirow{3}{*}{20} & 1 & 1 & \multirow{3}{*}{11} & \multirow{3}{*}{20} \\
\hline ELR & 3 & 2 & & & 2 & 2 & & \\
\hline ESI & 2 & 3 & & & 2 & 3 & & \\
\hline ÓLEO & \multicolumn{4}{|c|}{ SEM O SERVIÇO DO MEIO AMBIENTE } & \multicolumn{4}{|c|}{ COM O SERVIÇO DO MEIO AMBIENTE } \\
\hline Índice & $\begin{array}{c}\text { Clas. por } \\
\text { índice }\end{array}$ & $\begin{array}{l}\text { Peso do } \\
\text { índice }\end{array}$ & Pontuação & $\begin{array}{l}\text { Clas. } \\
\text { Geral }\end{array}$ & $\begin{array}{c}\text { Clas. por } \\
\text { índice }\end{array}$ & $\begin{array}{l}\text { Peso do } \\
\text { índice }\end{array}$ & Pontuação & $\begin{array}{l}\text { Clas. } \\
\text { Gera }\end{array}$ \\
\hline EYR & 4 & 1 & \multirow{3}{*}{24} & \multirow{3}{*}{40} & 3 & 1 & \multirow{3}{*}{23} & \multirow{3}{*}{40} \\
\hline ELR & 4 & 2 & & & 4 & 2 & & \\
\hline ESI & 4 & 3 & & & 4 & 3 & & \\
\hline CARVÃO & \multicolumn{4}{|c|}{ SEM O SERVIÇO DO MEIO AMBIENTE } & \multicolumn{4}{|c|}{ COM O SERVIÇO DO MEIO AMBIENTE } \\
\hline Índice & $\begin{array}{c}\text { Clas. por } \\
\text { índice }\end{array}$ & $\begin{array}{l}\text { Peso do } \\
\text { índice }\end{array}$ & Pontuação & $\begin{array}{l}\text { Clas. } \\
\text { Geral }\end{array}$ & $\begin{array}{c}\text { Clas. por } \\
\text { índice }\end{array}$ & $\begin{array}{l}\text { Peso do } \\
\text { índice }\end{array}$ & Pontuação & $\begin{array}{l}\text { Clas. } \\
\text { Gera }\end{array}$ \\
\hline EYR & 2 & 1 & \multirow{3}{*}{\multicolumn{2}{|c|}{15}} & 2 & 1 & \multirow{3}{*}{17} & \multirow{3}{*}{ 3은 } \\
\hline ELR & 2 & 2 & & & 3 & 2 & & \\
\hline ESI & 3 & 3 & & & 3 & 3 & & \\
\hline
\end{tabular}

Nota-se claramente, observando-se a tabela 12, que além da classificação geral não ser alterada, a pontuação das plantas de energia elétrica, sem e com o serviço do meio ambiente ficaram próximas, mesmo com a aplicação de fatores sobre as componentes $F$ muito diferentes.

O efeito de mudança de valores de $\mathrm{F}$ mantendo-se a relação entre $\mathrm{R}$ e N foi apresentado graficamente por Almeida, Barrella e Giannetti (2004). O diagrama ternário da figura 28 apresenta um resumo da análise feita. 


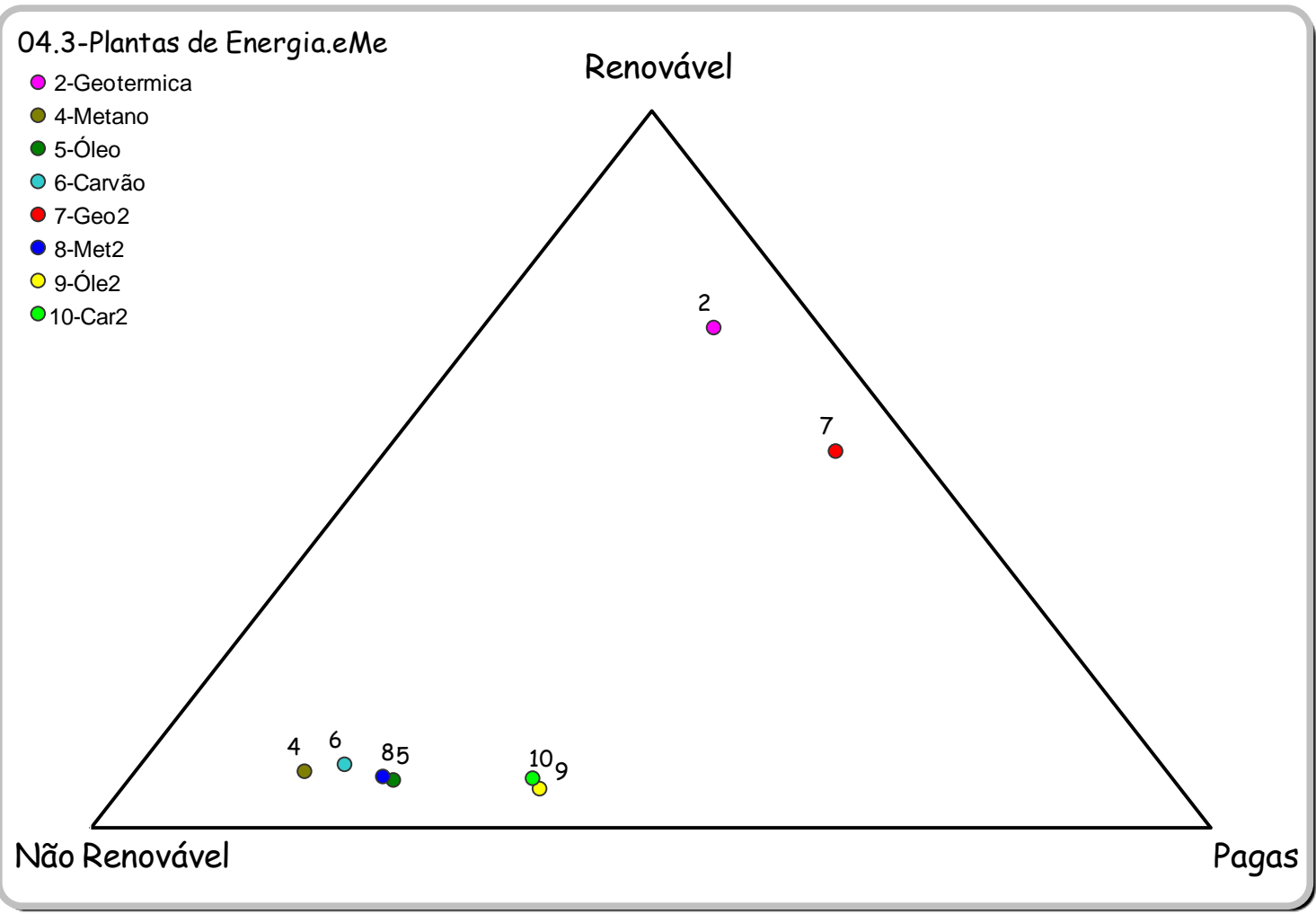

FIGURA 28 - Diagrama ternário com as plantas de energia elétrica, sem e com serviço do meio ambiente.

Na figura 28 os pontos 2, 4, 5 e 6 se referem às plantas GEO, GÁs, ÓLEO e CARVÃO sem o serviço do meio ambiente e os pontos 7, 8, 9 e 10 às plantas GEO, GÁS, ÓLEO e CARVÃO com o serviço do meio ambiente respectivamente.

Análise 3 - Variação dos índices emergéticos para mudanças de $\mathrm{F}$ por mudança de processo de produção

Um terceiro exemplo encontra-se descrito por Laganisa e Debelijakb (2006), onde é feito um estudo de sensibilidade para a produção de sal em vários processos diferentes, redundando em indicadores também diferentes. A tabela 13 apresenta os resultados obtidos pela simulação dos processos. 
TABELA 13 - R, N e F em diferentes processos de fabricação de sal.

\begin{tabular}{|c|c|c|c|c|c|c|c|}
\hline & $\begin{array}{c}\text { Bomba } \\
\text { eólica } \\
\text { original }\end{array}$ & $\begin{array}{c}\text { Bomba à } \\
\text { motor }\end{array}$ & $\begin{array}{c}\text { Fluxo } \\
\text { geotérm. }\end{array}$ & $\begin{array}{c}2 \times \text { menor } \\
\text { evap. }\end{array}$ & $\begin{array}{c}\text { 10x mais } \\
\text { chuva }\end{array}$ & $\begin{array}{l}2 \mathrm{x} \text { mais } \\
\text { trabalho } \\
\text { humano }\end{array}$ & $\begin{array}{c}2 \times \text { menos } \\
\text { trabalho } \\
\text { humano }\end{array}$ \\
\hline$R\left(x 10^{15}\right.$ seJ) & 2,926 & 2,922 & 2,938 & 1,697 & 3,126 & 3,342 & 2,713 \\
\hline$M\left(x 10^{14}\right.$ seJ $)$ & 2,037 & 2,857 & 2,037 & 2,037 & 2,037 & 2,857 & 2,857 \\
\hline$S\left(x 10^{15}\right.$ seJ) & 3,992 & 3,988 & 3,992 & 3,992 & 3,992 & 7,762 & 2,101 \\
\hline eM total $\left(x 10^{15}\right.$ seJ) & 7,121 & 7,196 & 7,133 & 5,892 & 7,321 & 11,389 & 5,099 \\
\hline Sal total (g) & 5851188 & 5851188 & 5851188 & 3117185 & 4109557 & 5851188 & 5851188 \\
\hline Sal total nos resíduos de salmoura & 6991070 & 6991070 & 6991070 & 3724451 & 4910148 & 6991070 & 6991070 \\
\hline TF sal $\left(x 10^{9} \mathrm{seJ} / \mathrm{g}\right)$ & 1,046 & 1,047 & 1,047 & 1,624 & 1,533 & 1,673 & 0,749 \\
\hline TF sal nos resíduos de salmoura $\left(\times 10^{8} \mathrm{se} / \mathrm{g}\right)$ & 9,626 & 9,642 & 9,642 & 14,948 & 14,113 & 10,540 & 6,894 \\
\hline$N / R$ & 0,070 & 0,098 & 0,069 & 0,120 & 0,065 & 0,085 & 0,105 \\
\hline ELR & 1,434 & 1,462 & 1,428 & 2,473 & 1,342 & 2,408 & 0,880 \\
\hline EYR & 1,697 & 1,684 & 1,649 & 1,404 & 1,745 & 1,415 & 2,136 \\
\hline EIS & 1,184 & 1,151 & 1,191 & 0,568 & 1,300 & 0,588 & 2,428 \\
\hline \multirow[t]{2}{*}{ Densidade de empower $\left(\times 10^{11} \mathrm{se} / / \mathrm{m}^{2}\right)$} & 3,705 & 3,744 & 3,711 & 3,065 & 3,809 & 5,925 & 2,653 \\
\hline & $\begin{array}{c}\text { R no } \\
\text { trabalho } \\
\text { humano }= \\
5 \%\end{array}$ & $\begin{array}{c}\text { R no } \\
\text { trabalho } \\
\text { humano = } \\
20 \%\end{array}$ & $\begin{array}{c}\text { Área } 2 x \\
\text { maior }\end{array}$ & $\begin{array}{l}2 \mathrm{x} \text { mais } \\
\text { combust. }\end{array}$ & $\begin{array}{c}\text { Sem } \\
\text { combust. }\end{array}$ & $\begin{array}{l}2 \times \text { mais } \\
\text { combustív } \\
\text { el para a } \\
\text { bomba à } \\
\text { motor }\end{array}$ & $\begin{array}{l}2 \times \text { menor } \\
\text { valor de } \\
\text { emdollar }\end{array}$ \\
\hline $\mathrm{R}\left(\mathrm{x} 10^{15}\right.$ seJ $)$ & 2,704 & 5,406 & 5,406 & 2,923 & 2,926 & 2,972 & 2,915 \\
\hline$M\left(x 10^{14}\right.$ seJ $)$ & 2,037 & 2,037 & 2,037 & 5,147 & 0,5593 & 3,669 & 2,037 \\
\hline $\mathrm{S}\left(\times 10^{15}\right.$ seJ) & 4,213 & 3,992 & 3,992 & 3,988 & 3,992 & 3,988 & 3,891 \\
\hline eM total $\left(\times 10^{15}\right.$ seJ) & 7,121 & 9,601 & 9,601 & 7,425 & 3,973 & 7,277 & 7,01 \\
\hline Sal total (g) & 5851188 & 5851188 & 10132663 & 5851188 & 5851188 & 5851188 & 5851188 \\
\hline Sal total nos resíduos de salmoura & 6991070 & 6991070 & 12106628 & 6991070 & 6991070 & 6991070 & 6991070 \\
\hline TF sal $\left(x 10^{9} \mathrm{seJ} / \mathrm{g}\right)$ & 1,046 & 1,046 & 0,814 & 1,091 & 1,023 & 1,069 & 1,030 \\
\hline TF sal nos resíduos de salmoura $\left(\times 10^{8} \mathrm{seJ} / \mathrm{g}\right)$ & 9,626 & 9,626 & 7,498 & 10,044 & 9,423 & 9,841 & 9,48 \\
\hline$N / R$ & 0,075 & 0,060 & 0,038 & 0,176 & 0,019 & 0,126 & 0,07 \\
\hline ELR & 1,634 & 1,113 & 0,776 & 1,541 & 1,383 & 1,490 & 1,405 \\
\hline EYR & 1,612 & 1,898 & 2,288 & 1,649 & 1,722 & 1,671 & 1,711 \\
\hline SI & 0,987 & 1,704 & 2,949 & 1,070 & 1,245 & 1,121 & 1,218 \\
\hline Densidade de empower $\left(\times 10^{11} \mathrm{seJ} / \mathrm{m}^{2}\right)$ & 3,705 & 3,705 & 2,497 & 3,863 & 3,628 & 3,786 & 3,647 \\
\hline
\end{tabular}

Fonte: adaptado de Laganisa e Debeljakb (2006)

Os processos de produção analisados no referido artigo apresentados nas colunas da tabela 13 , se diferenciam em diversos fatores, caso a caso, como seguem:

- Substituição de bomba eólica por bomba a motor;

- Diferentes porcentagens de energia renovável por trabalho humano;

- Diferentes quantidades de emprego de maquinário;

- Diferentes intensidades de evaporação e diferentes quantidades de precipitação;

- Diferentes quantidades de combustíveis consumidos e máquinas envolvidas;

A partir da tabela 13, apresentada no artigo, foi montada uma tabela auxiliar, tabela 14 , de classificação dos processos. 
TABELA 14 - Classificação de cada processo por índice.

\begin{tabular}{cccccccccccccccc}
\hline & $\begin{array}{c}\text { Bomba eólica } \\
\text { original }\end{array}$ & $\begin{array}{c}\text { Bomba à } \\
\text { motor }\end{array}$ & $\begin{array}{c}\text { Fluxo } \\
\text { geotérmico }\end{array}$ & $\begin{array}{c}\text { 2x menor } \\
\text { evaporação }\end{array}$ & 10x mais chuva & $\begin{array}{c}\text { 2x mais trabalho } \\
\text { humano }\end{array}$ & $\begin{array}{c}\text { 2x menos } \\
\text { trabalho } \\
\text { humano }\end{array}$ \\
Índices Valores Clas. Valores Clas. Valores Clas. & Valores & Clas. & Valores & Clas. & Valores & Clas. & Valores & Clas. \\
\hline ELR & 1,434 & 4 & 1,462 & 5 & 1,428 & 3 & 2,473 & 7 & 1,342 & 2 & 2,408 & 6 & 0,880 & 1 \\
EYR & 1,697 & 3 & 1,684 & 4 & 1,649 & 5 & 1,404 & 7 & 1,745 & 2 & 1,415 & 6 & 2,136 & 1 \\
EIS & 1,184 & 4 & 1,151 & 5 & 1,191 & 3 & 0,568 & 7 & 1,300 & 2 & 0,588 & 6 & 2,428 & 1 \\
\hline
\end{tabular}

\begin{tabular}{|c|c|c|c|c|c|c|c|c|c|c|c|c|c|c|}
\hline \multirow[b]{2}{*}{ Índices } & \multicolumn{2}{|c|}{$\begin{array}{l}R \text { no trabalho } \\
\text { humano }=5 \%\end{array}$} & \multicolumn{2}{|c|}{$\begin{array}{l}\mathrm{R} \text { no trabalho } \\
\text { humano }=20 \%\end{array}$} & \multicolumn{2}{|c|}{ Área 2x maior } & \multicolumn{2}{|c|}{$\begin{array}{l}2 \times \text { mais } \\
\text { combustível }\end{array}$} & \multicolumn{2}{|c|}{ Sem combustível } & \multicolumn{2}{|c|}{$\begin{array}{c}\text { 2x mais } \\
\text { combustível } \\
\text { para a bomba à } \\
\text { motor }\end{array}$} & \multicolumn{2}{|c|}{$\begin{array}{l}2 \times \text { menor valor } \\
\text { de emdollar }\end{array}$} \\
\hline & Valores & Clas. & Valores & Clas. & Valores & Clas. & Valores & Clas. & Valores & Clas. & Valores & Clas. & Valores & Clas. \\
\hline ELR & 1,634 & 7 & 1,113 & 2 & 0,776 & 1 & 1,541 & 6 & 1,383 & 3 & 1,490 & 5 & 1,405 & 4 \\
\hline EYR & 1,612 & 7 & 1,898 & 2 & 2,288 & 1 & 1,649 & 6 & 1,722 & 3 & 1,671 & 5 & 1,711 & 4 \\
\hline EIS & 0,987 & 7 & 1,704 & 2 & 2,949 & 1 & 1,070 & 6 & 1,245 & 3 & 1,121 & 5 & 1,218 & 4 \\
\hline
\end{tabular}

Observa-se na tabela 14 que as posições relativas dos índices permaneceram constantes, independentemente do processo, exceto uma inversão de EYR, com valores muito próximos, nas posições 3,4 e 5 , denotando a robustez dos índices e a sensibilidade em relação às variações dos componentes de entrada.

Com base nos três exemplos apresentados neste estudo, adotaram-se os valores emergéticos encontrados na literatura. É esperado uma influência menor nas componentes $\mathrm{R}, \mathrm{N}$ e $\mathrm{F}$ devido à transposição de local e tempo, e as diferenças que possam existir para os casos reais não irão alterar a classificação relativa dos meios produtivos de energia elétrica.

\subsubsection{Tipos de Recursos}

Os recursos energéticos têm características muito dessemelhantes e devem ser consideradas quanto às suas diferentes naturezas. Assim os equacionamentos para cada um dos recursos devem ser criteriosamente avaliados. A tabela 15 apresenta um resumo das principais características de cada tipo de recurso a ser considerado neste estudo. 
TABELA 15 - Tipos de Recursos e suas principais características.

\begin{tabular}{|c|c|c|c|c|c|c|}
\hline $\begin{array}{l}\text { Tipo de } \\
\text { Recurso }\end{array}$ & Tipo de Uso & $\begin{array}{c}\text { Características } \\
\text { das Reservas }\end{array}$ & Localidade & $\begin{array}{l}\text { Emissões e } \\
\text { Impactos }\end{array}$ & Absorção* & Recuperação \\
\hline Petróleo & $\begin{array}{l}\text { Eletricidade e } \\
\text { Transporte } \\
\text { Calor Industrial }\end{array}$ & Atual + Novas & $\begin{array}{c}\text { Extração } \neq \\
\text { Produção }\end{array}$ & $\begin{array}{c}\text { Alto } \\
\text { Acumulativo }\end{array}$ & Baixa & Zero \\
\hline Gás & $\begin{array}{l}\text { Eletricidade e } \\
\text { Transporte } \\
\text { Calor Industrial }\end{array}$ & Atual + Novas & $\begin{array}{c}\text { Extração } \neq \\
\text { Produção }\end{array}$ & $\begin{array}{c}\text { Alto } \\
\text { Acumulativo }\end{array}$ & Baixa & Zero \\
\hline Hidro & Eletricidade & Total de Bacias & $\begin{array}{l}\text { Extração = } \\
\text { Produção }\end{array}$ & $\begin{array}{l}\text { Baixo + Uso } \\
\text { Intensivo }\end{array}$ & Alta & Anual \\
\hline Urânio & Eletricidade & Atual + Novas & $\begin{array}{c}\text { Extração } \neq \\
\text { Produção }\end{array}$ & $\begin{array}{c}\text { Baixo } \\
\text { Acumulativo }\end{array}$ & Baixa & Zero \\
\hline Biomassa & $\begin{array}{l}\text { Eletricidade e } \\
\text { Transporte }\end{array}$ & Total de Terras & $\begin{array}{c}\text { Extração } \neq \\
\text { Produção }\end{array}$ & $\begin{array}{l}\text { Baixo +Uso } \\
\text { Intensivo }\end{array}$ & Alta & Anual \\
\hline Eólico & Eletricidade & Fluxo & $\begin{array}{l}\text { Extração = } \\
\text { Produção }\end{array}$ & $\begin{array}{c}\text { Baixo + } \\
\text { Implantação }\end{array}$ & Alta & Fluxo Máximo \\
\hline Solar & $\begin{array}{l}\text { Eletricidade, } \\
\text { Transporte e } \\
\text { Aquecimento }\end{array}$ & Fluxo & $\begin{array}{l}\text { Extração = } \\
\text { Produção }\end{array}$ & $\begin{array}{c}\text { Baixo + } \\
\text { Implantação }\end{array}$ & Alta & Fluxo Máximo \\
\hline
\end{tabular}

*absorção menor que $1 \%$ da produção num ciclo

\section{Fonte de Recurso}

Os três principais usos para as fontes de recursos são: transporte - o qual majoritariamente está apoiado na utilização de recursos fósseis; aquecimento - como combustível para alto-fornos e caldeiras; e aquecimento - como combustível na geração da energia elétrica.

\section{Tipo de Reserva}

As reservas, como já discutido anteriormente, têm como características sua esgotabilidade, sua renovabilidade, e a sua obtenção a partir de fluxos não controláveis.

\section{Localização das Reservas}

No aspecto de independência de localidade de extração em relação à produção, algumas fontes de recursos têm suas reservas em localização independente da sua utilização, como por exemplo, o carvão vapor e o 
urânio. Por outro lado, algumas fontes só podem produzir energia no local em que está disponível o recurso; isto pode tornar a operação não viável economicamente, as quais, em alguns casos se exigem altos custos de transporte da energia elétrica, como por exemplo, nas hidrelétricas, biomassas, eólicas e solares.

\section{Impacto Gerado pelo Uso}

Recursos do tipo eólico e solar, os quais tem o menor impacto de operação, estão limitados pelo fluxo máximo contínuo, pois não se tem controle sobre a fonte de energia e a quantidade extrativa de suas reservas. Outros, como o fóssil, em que o controle da extração é decidido pelo grau de investimento e necessidade, além de alto impacto tem suas reservas limitadas e não há recuperação em horizonte de tempo, senão em escala de milhões de anos.

Vale ressaltar que algumas fontes de recurso, como a eólica e solar, têm baixo impacto de operação, porém relativo impacto na implantação, devendo assim ser levado em consideração o tempo de vida de operação antes de novas implantações ou atualizações de plantas já implementadas.

\section{Capacidade de Absorção}

O meio ambiente tem uma determinada capacidade de absorção das emissões e resíduos gerados na produção. A causa do impacto ambiental é a diferença entre a quantidade de descarte de emissões e resíduos e a capacidade de absorção do meio ambiente. Ainda o aproveitamento do que foi absorvido, pelo meio ambiente, pode ou não ser re-transformado em recursos energéticos, como por exemplo, a reciclagem da água.

\section{Capacidade de Recuperação}

Quanto à capacidade de renovação, recursos como os bioenergéticos devem ser considerados como praticamente recuperáveis a cada ciclo, enquanto recursos fósseis, dado o seu tempo de formação de pelo 
menos alguns milhões de anos, para efeito prático, devem ser considerados como não recuperáveis. Recursos, como a energia solar, que têm fluxo constante e não controlável, podem ter seus fluxos aproveitados, considerando a eficiência dos conversores, porém, não são recuperáveis.

\subsection{Estudos Dinâmicos}

O modelo de análise do ciclo de vida para os recursos energéticos está subdividido em cinco subsistemas básicos: Reservas, Extraçãoprodução, Consumo, Absorção e Recuperação. As inter-relações entre os subsistemas, no nível de abstração geral, estão apresentadas na figura 29 (LOPES, 2003).

Não estão consideradas as emissões e descartes gerados durante o consumo da energia, dado que, em se tratando de energia elétrica, qualquer que seja a fonte de recursos não há diferenciação no consumo.

Goldemberg (2009) ${ }^{1}$ afirma que:

\section{"...O elétron que chega na sua casa é indistinto, não podendo ser identificado se veio de Itaipú, de Tucuruí ou ainda de Angra dos Reis..."}

Isso não altera em essência o estudo dos índices, pois independente de sua utilização, os índices aqui estudados estarão atrelados na geração da energia e não no seu consumo. Para isso admite-se que a produção segue a tendência de consumo, não se importando para qual fim será utilizada essa energia produzida.

A análise da produção tem relevância na consideração de volumes de atendimentos, porém nesta fase o foco é em relação à quantidade de emissões e descartes por unidade de energia produzida.

${ }^{1}$ GOLDEMBERG, J. Entrevista à Heródoto Barbeiro, CBN Brasil, Rádio CBN, São Paulo, 8 de janeiro de 2009. 


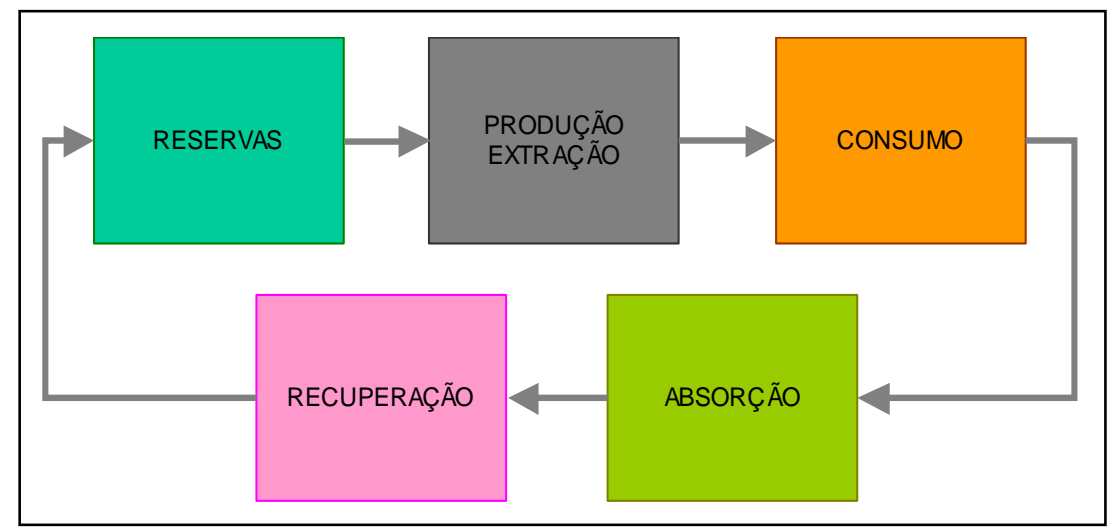

FIGURA 29 - Ciclo de vida de fonte de recurso energético.

Um diagrama alternativo ao da figura 29 pode ser utilizado quando a recuperação das reservas independe da absorção no ciclo, ficando, portanto, o ciclo de vida aberto, conforme apresentado na figura 30 .

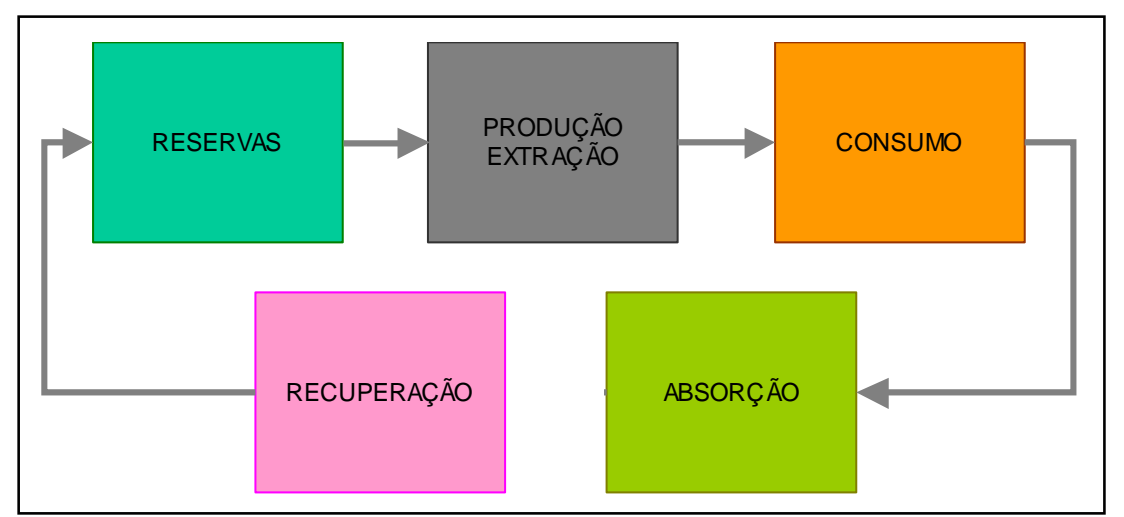

FIGURA 30 - Ciclo de vida de fontes de recursos com recuperação independente da absorção.

Este é o caso de reservas de fontes de recursos por fluxo como a eólica e a solar. Ainda fontes de recursos como hídricas e produtos de cana, que são intermediárias entre por fluxo e por esgotamento, também podem ser consideradas neste diagrama, já que a parte de esgotamento é muito menor que a recuperação, no estado de exploração atual.

Esses dois comportamentos sistêmicos estão contemplados no desenvolvimento dos procedimentos de cálculo e simulações. 


\subsection{A Ferramenta}

Para este trabalho foi desenvolvida uma ferramenta de análise utilizando-se 0 aplicativo Simulink®, contido no pacote MATLAB®, e complementada com a inclusão de alguns gráficos desenvolvidos no aplicativo Excel® (MICROSOFT, 2008).

Para a ferramenta foi utilizada uma base de tempo que gera 700 ciclos para os 70 anos de simulação, de 1970 a 2040, cada ciclo representando um décimo de ano.

A visão geral do sistema, em termos de diagramas de blocos, está apresentada na figura 31 .

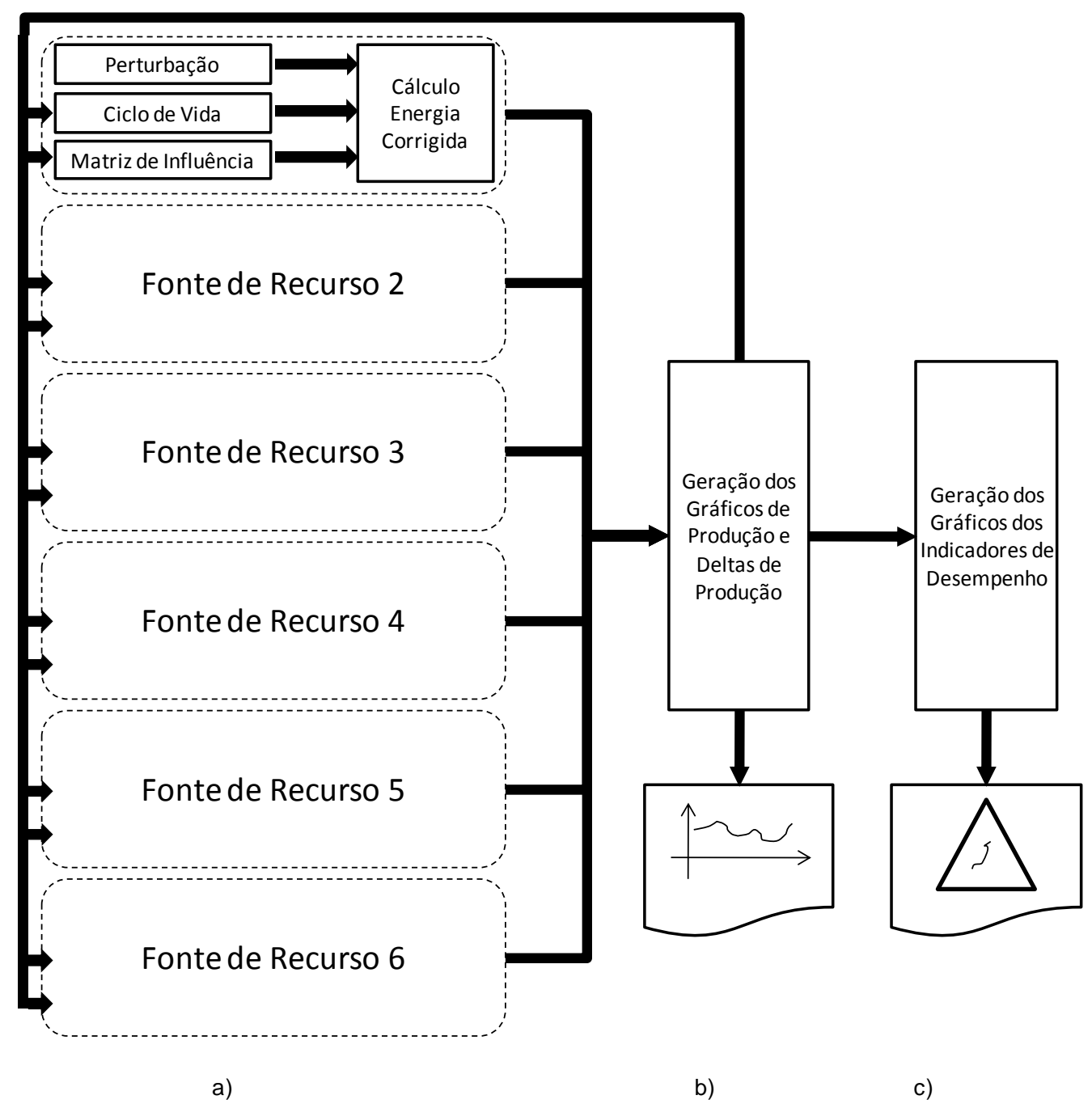

FIGURA 31 - Diagrama de blocos geral da ferramenta de análise: a) blocos das fontes de recursos; b) geração dos resultados; c) geração dos índices emergéticos 
No exemplo da figura 32 está apresentado o detalhe da interrelação entre os blocos referentes a uma das fontes de recursos, Gás Natural. Em destaque, na parte esquerda superior da figura 32 aparece o bloco, denominado Gás, que representa o ciclo de vida para esta fonte de recurso, a ser detalhada posteriormente. Como entrada deste bloco a função de energia corrigida, que representa a energia realmente produzida num ciclo e duas saídas que são referentes à produção de gás natural sem correção, porém com as restrições de consumo e de reservas, e a fórmula de crescimento da produção de energia a partir do gás natural, sem restrições.

Na parte superior direita da figura 32 o bloco referente aos cálculos da energia livre de restrições produzida no ciclo, energia realmente produzida, a diferença entre elas e o quociente da diferença pelo total produzido. Estes cálculos são realizados a partir das entradas de energia que é gerada a partir do ciclo de vida da fonte de recurso, dos deltas de cada uma das outras fontes de recursos e de perturbações impostas pela simulação, dada pelo bloco perturbação.

$\mathrm{Na}$ parte central da figura 32 está o bloco referente à parte da matriz de influência que permite a simulação, levando-se em consideração as influências de acréscimos e decréscimos de produção, de uma determinada fonte de recurso em outras fontes por meio de uma ponderação matricial.

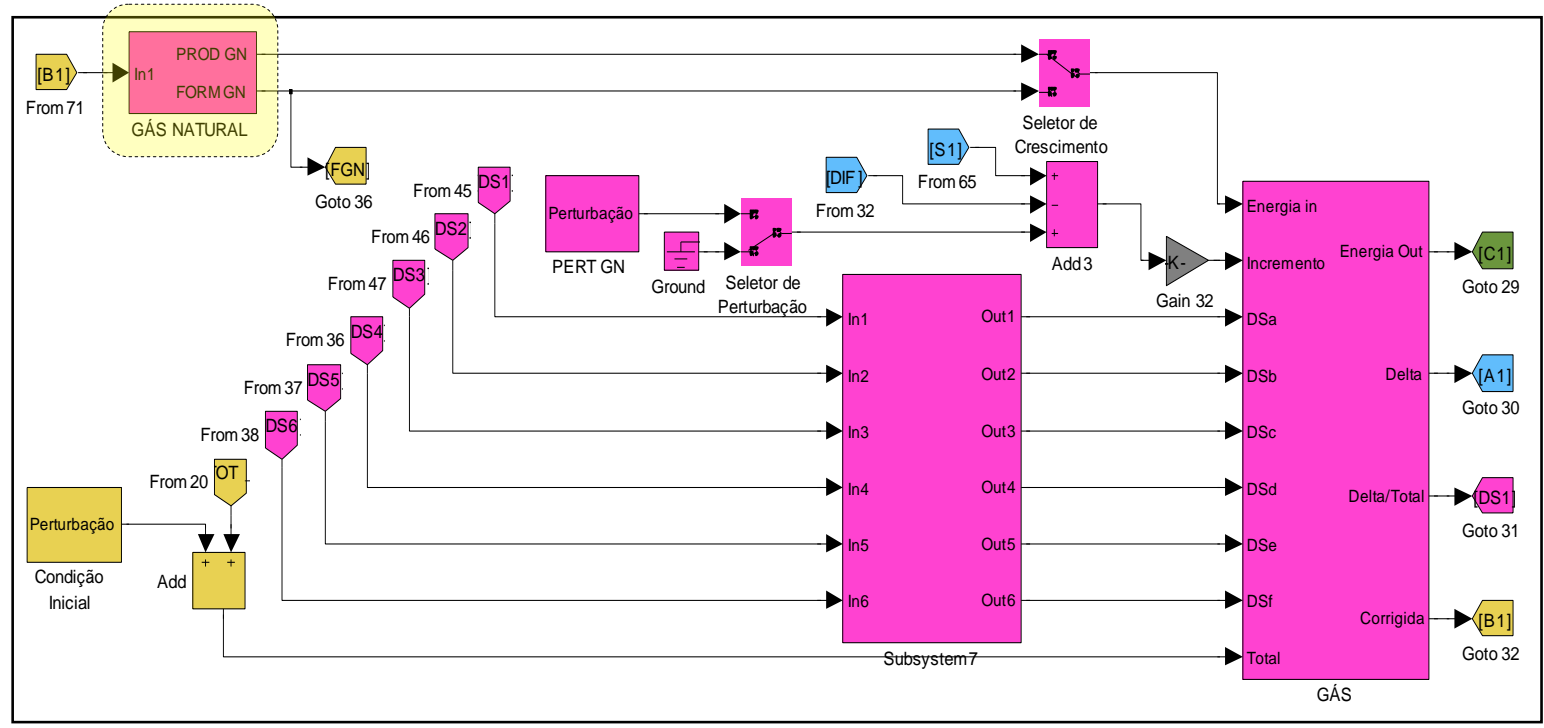

FIGURA 32 - Interrelação entre blocos de uma das fontes de recursos. 
A figura 33 apresenta o diagrama de blocos interno do subsistema referente ao ACV da fonte de gás natural. Outros cinco subsistemas semelhantes representam cada uma das outras fontes de recurso.

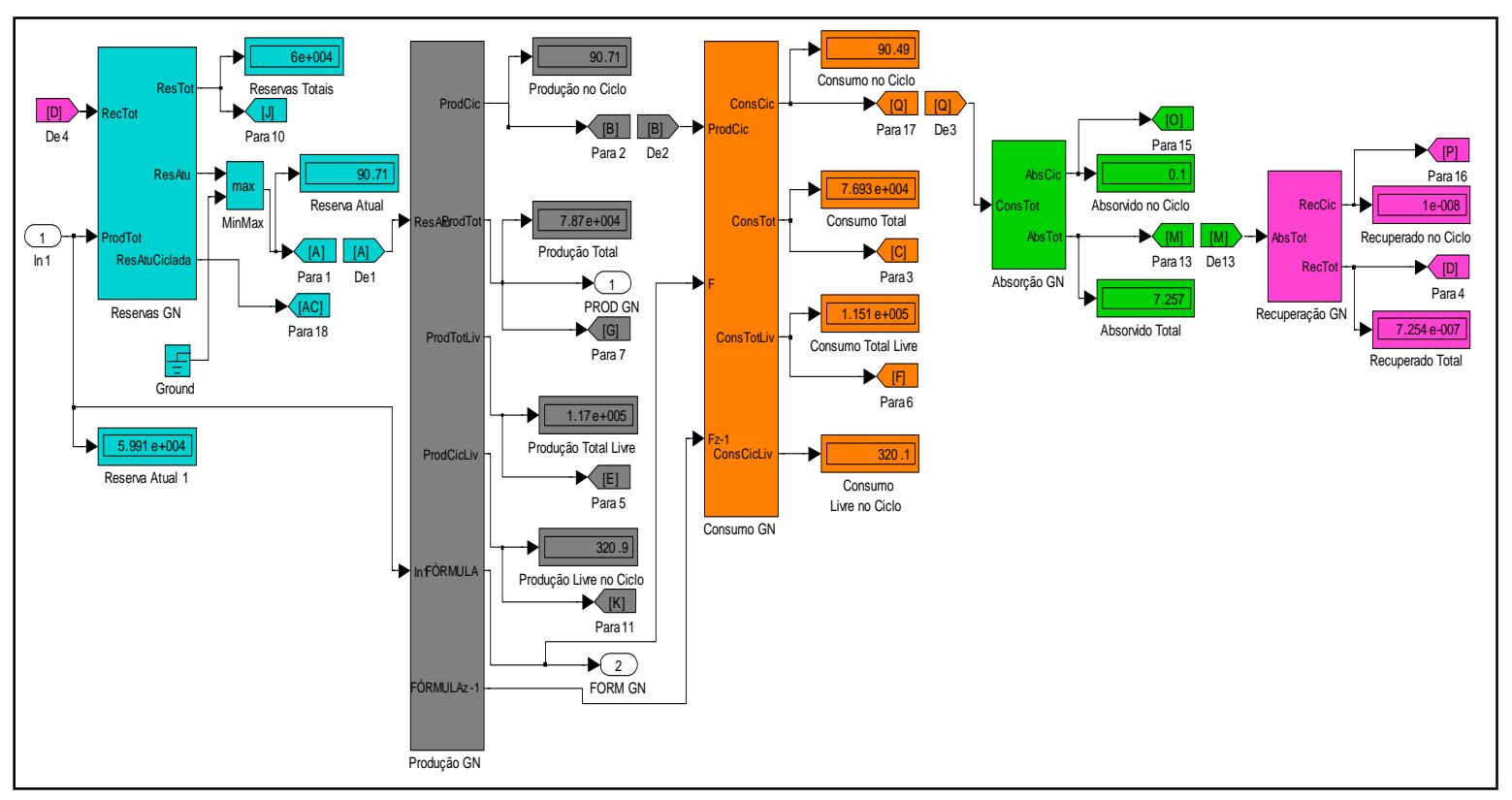

FIGURA 33 - Diagrama de blocos interno referente ao ACV de uma das fontes de recursos.

Os subsistemas referentes ao ciclo de vida são: reservas, extraçãoprodução, consumo, absorção e recuperação. Cada subsistema representando uma fase do ciclo de vida gera a sua saída a partir de sua entrada e de acordo com sua função de transferência e parâmetros internos.

A tabela 16 apresenta as principais entradas e saídas de cada bloco. 
TABELA 16 - Subsistemas suas entradas, saídas e parâmetros internos.

\begin{tabular}{|c|c|c|c|}
\hline Subsistema & Entradas & Saídas & Parâmetros Internos \\
\hline Reservas & $\begin{array}{l}\text { Recuperado Total } \\
\text { Produção Total }\end{array}$ & $\begin{array}{l}\text { Reserva Total } \\
\text { Reserva Atual } \\
\text { Reserva Atual no Ciclo }\end{array}$ & $\begin{array}{l}\text { Reserva Inicial } \\
\text { Reserva Final } \\
\text { Taxa de Descobrimento de Novas } \\
\text { Reservas }\end{array}$ \\
\hline $\begin{array}{l}\text { Produção / } \\
\text { Extração }\end{array}$ & $\begin{array}{l}\text { Reserva Atual+ } \\
\text { Fórmula de Produção } \\
\text { Fórmula de Produção } z^{-1}\end{array}$ & $\begin{array}{l}\text { Produção no Ciclo } \\
\text { Produção Total } \\
\text { Produção Total Livre } \\
\text { Fórmula de Produção } \\
\text { Fórmula de Produção } z^{-1}\end{array}$ & $\begin{array}{l}\text { Produção Inicial } \\
\text { Produção Final } \\
\text { Taxa de crescimento de Produção }\end{array}$ \\
\hline Consumo & $\begin{array}{l}\text { Produção no Ciclo } \\
\text { Fórmula de Produção } \\
\text { Fórmula de Produção } z^{-1}\end{array}$ & $\begin{array}{l}\text { Consumo no Ciclo } \\
\text { Consumo Total } \\
\text { Consumo Total Livre } \\
\text { Consumo no Ciclo Livre }\end{array}$ & $\begin{array}{l}\text { Consumo Inicial } \\
\text { Consumo Final } \\
\text { Taxa de crescimento de Consumo }\end{array}$ \\
\hline Absorção & Consumo Total & $\begin{array}{l}\text { Absorvido Total } \\
\text { Absorvido no Ciclo }\end{array}$ & $\begin{array}{l}\text { Absorção Inicial } \\
\text { Absorção Final } \\
\text { Taxa de crescimento da Cap. } \\
\text { Absorção }\end{array}$ \\
\hline Recuperação & Absorvido Total & $\begin{array}{l}\text { Recuperado Total } \\
\text { Recuperado no Ciclo }\end{array}$ & $\begin{array}{l}\text { Recuperação Inicial } \\
\text { Recuperação Final } \\
\text { Taxa de crescimento da Cap. } \\
\text { Recuperação }\end{array}$ \\
\hline
\end{tabular}

Nas linhas estão apresentados os subsistemas - reservas, extração-produção, consumo, absorção e recuperação; nas colunas estão apresentados os sinais para cada subsistema: entradas - as entradas de cada subsistema; saídas - as saídas de cada subsistema e parâmetros internos - parâmetros adotados.

$\mathrm{Na}$ tabela 16 são utilizadas as seguintes nomenclaturas para denominação dos sinais de entrada, saídas e internos dos blocos:

- CICLO - adotado o ciclo de décimo de ano;

- ATUAL - o valor no ciclo atual;

- INICIAL - o valor no ciclo inicial da simulação;

- TOTAL - a integração do valor até o presente ciclo;

- TOTAL LIVRE - o valor de integração caso não existissem restrições.

O caminho natural do ciclo de vida do recurso é como nascedouro no subsistema de reservas, passando para a extração-produção, pelo consumo, pela absorção pelo meio ambiente e pela recuperação do meio ambiente gerando novamente a fonte de recurso. Cada um dos subsistemas está detalhado separadamente, nos próximos itens. 


\subsubsection{Subsistema Reservas}

O subsistema reserva considera as reservas atuais, a taxa de crescimento de descobertas de novas reservas, a recuperação do meio ambiente gerando reservas adicionais e a extração-produção reduzindo as reservas totais. Como saídas temos o valor das reservas a cada ciclo e as reservas totais ao longo do tempo.

Como o estudo engloba uma grande diversidade de recursos, as reservas iniciais podem significar, por exemplo, no caso do petróleo, as reservas identificadas no presente momento e, no caso da biomassa, o total alcançável de área agriculturável destinada ao cultivo de insumos energéticos.

Existem três categorias diferentes de reservas para as diferentes fontes de recursos energéticos. Assim, no caso de petróleo, gás e urânio, uma quantidade finita de recursos está disponível na natureza, e o horizonte de que a natureza possa produzir mais recursos é distante. $O$ homem retira partes desse recurso diminuindo a quantidade de reservas. Definiram-se, neste trabalho, esses recursos como sendo de reservas esgotáveis.

Outro tipo de recurso é o de aproveitamento por fluxos contínuos. Nesta categoria encontram-se a energia eólica, solar e geotérmica. A característica desses recursos é que, dentro de um período de tempo, a natureza disponibiliza uma quantidade desses recursos e o homem a aproveita ou não. Não há como utilizar mais recursos do que a natureza disponibiliza por unidade de tempo, embora num horizonte distante de tempo, essas reservas sejam inesgotáveis.

O terceiro tipo pode ser classificado como inesgotáveis ou esgotáveis, dependendo da intensidade de sua utilização; são, por exemplo, os hídricos e os produtos de cana. Neste caso, o homem cria uma situação de exploração dentro de uma disponibilidade de recursos que disputa o seu uso para outras aplicações que não como fonte de recursos energéticos. Por exemplo, além de terem limites de exploração, as áreas em que se pode fazer plantação de cana disputam lugar com áreas de plantio de alimentos para o homem e pasto para gado. Ainda um segundo exemplo, no caso dos 
recursos hídricos, a utilização da água está limitada e disputa espaço com a água de irrigação e consumo e com as florestas. Neste caso, após se chegar ao limite de exploração, corre-se o risco de se ter a reserva em cada ciclo diminuída em função da intensidade de uso dessas fontes de recursos.

A figura 34 apresenta o diagrama geral de blocos para 0 subsistema reservas do tipo esgotável. Na parte da esquerda do diagrama estão os blocos de reservas hoje conhecidas, representada pelo bloco "Reservas Iniciais" e a previsão de novas descobertas, que somadas às reservas iniciais, são representadas pelo bloco "Reservas Totais". Estes blocos se interconectam a um bloco de novas descobertas. Essa interligação é feita através do bloco $Z^{-400}$, que fornece o tempo de atraso e o bloco $\frac{1}{s+1}$, que fornece a taxa de crescimento.

O cálculo do valor das reservas, no ciclo e atuais, é feito considerando, além das reservas totais, o volume de reservas recuperado e a quantidade gasta na produção.

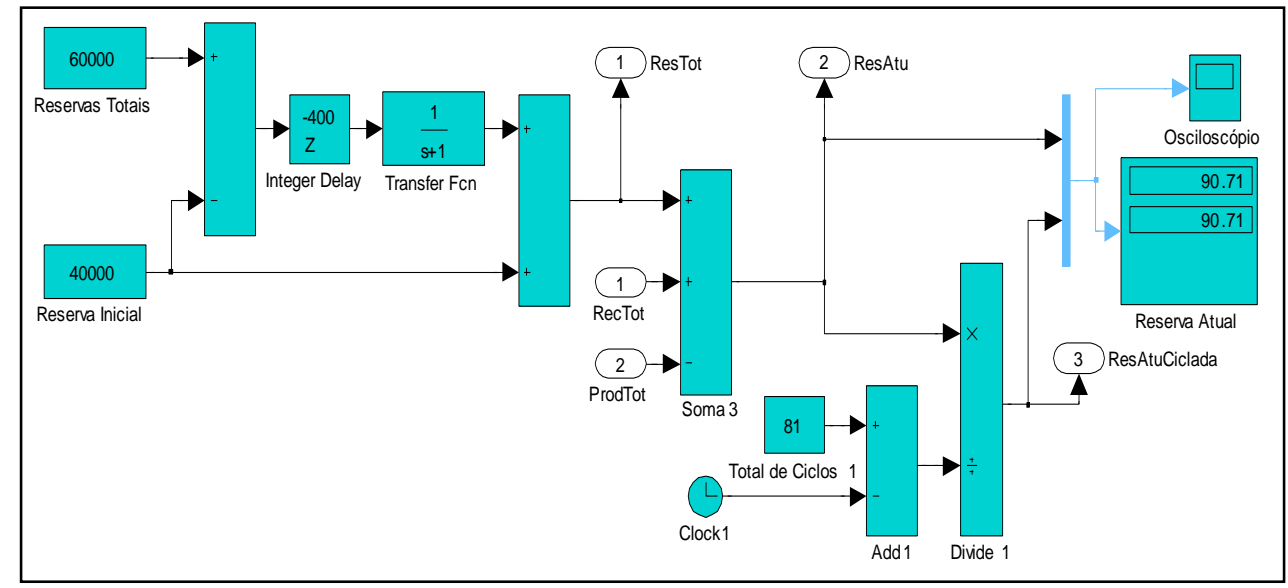

FIGURA 34 - Diagrama do subsistema de reservas esgotáveis

A figura 35 apresenta o diagrama geral de blocos para 0 subsistema reservas do tipo não esgotável, por fluxo contínuo. As quantidades de reservas atuais e totais se referem à capacidade de extração dessas reservas durante um ciclo. A principal diferença deste diagrama para 
o de reservas esgotáveis é que o cálculo das reservas atuais é feito com a produção no ciclo anterior e não ao montante de produção acumulado.

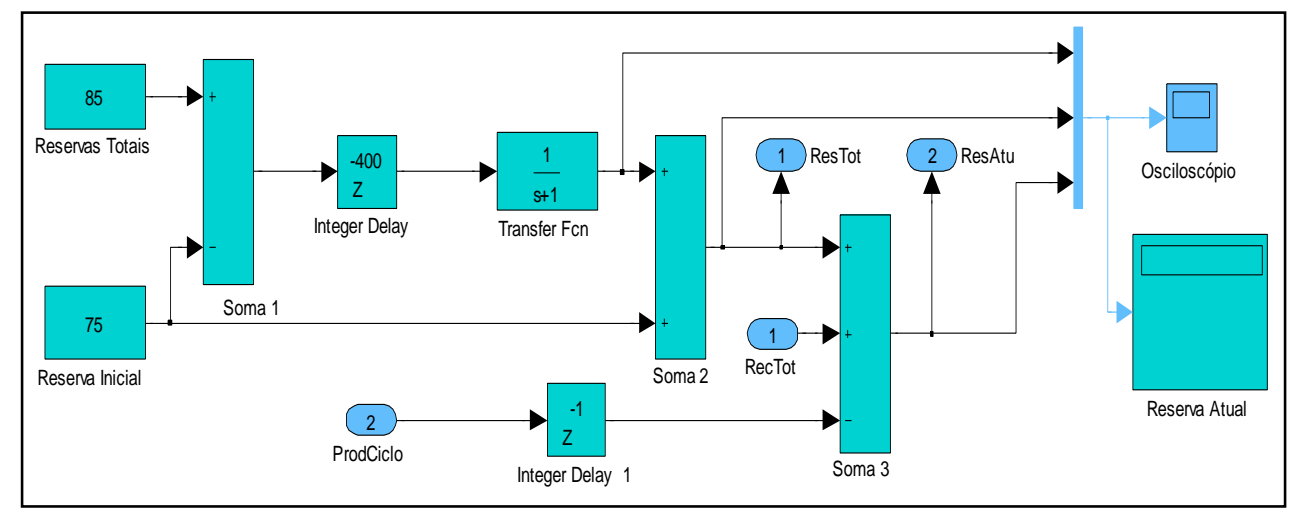

FIGURA 35 - Diagrama do subsistema de reservas não esgotáveis

No gráfico da figura 36, pode-se observar um exemplo de simulação para reservas do tipo esgotável. Existe um crescimento inicial das reservas e, portanto, o valor das reservas atuais cresce. Ainda, verifica-se que mesmo com novas reservas, se a sua exploração for intensiva, o valor das reservas atuais reduz-se a zero ao longo do tempo. Neste exemplo adotou-se a premissa que não há entrada de novas reservas por recuperação do meio ambiente, dentro do horizonte de tempo do estudo, como é o caso das reservas fósseis.

As equações (9) e (10) representam o cálculo das reservas totais e reservas atuais para uma determinada fonte de energia.

$$
\begin{gathered}
\text { Reserva }_{\text {Total }}=\text { Reserva }_{\text {Inicial }}+\frac{\text { Reserva }_{\text {Final }}-\text { Reserva }_{\text {Inicial }}}{\text { Taxa } \cdot s+1} \\
\text { Reserva }_{\text {Atual }}=\text { Reserva }_{\text {Total }}+\text { Recuperação }_{\text {Total }}-\text { Produção }_{\text {Total }}
\end{gathered}
$$




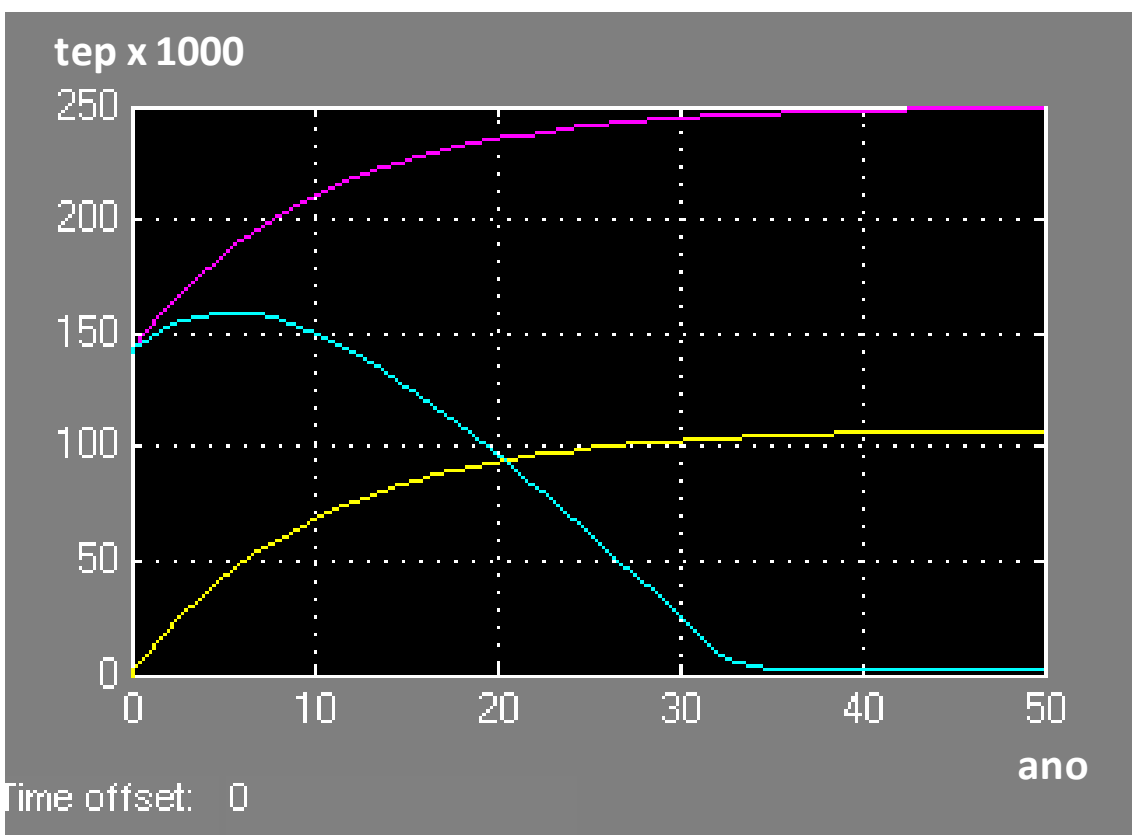

FIGURA 36 - Gráfico das variações das reservas ao longo do tempo. Vermelho) reservas totais; Amarelo) reservas exploradas; Azul) reservas atuais.

\subsubsection{Subsistema Extração-Produção}

A figura 37 apresenta o diagrama de blocos para o subsistema extração-produção. Este subsistema considera a extração-produção atual e a taxa de crescimento da extração-produção limitada pela quantidade de reservas disponíveis. Como saídas se tem o valor de extração-produção a cada ciclo e o valor integrado ao longo do tempo.

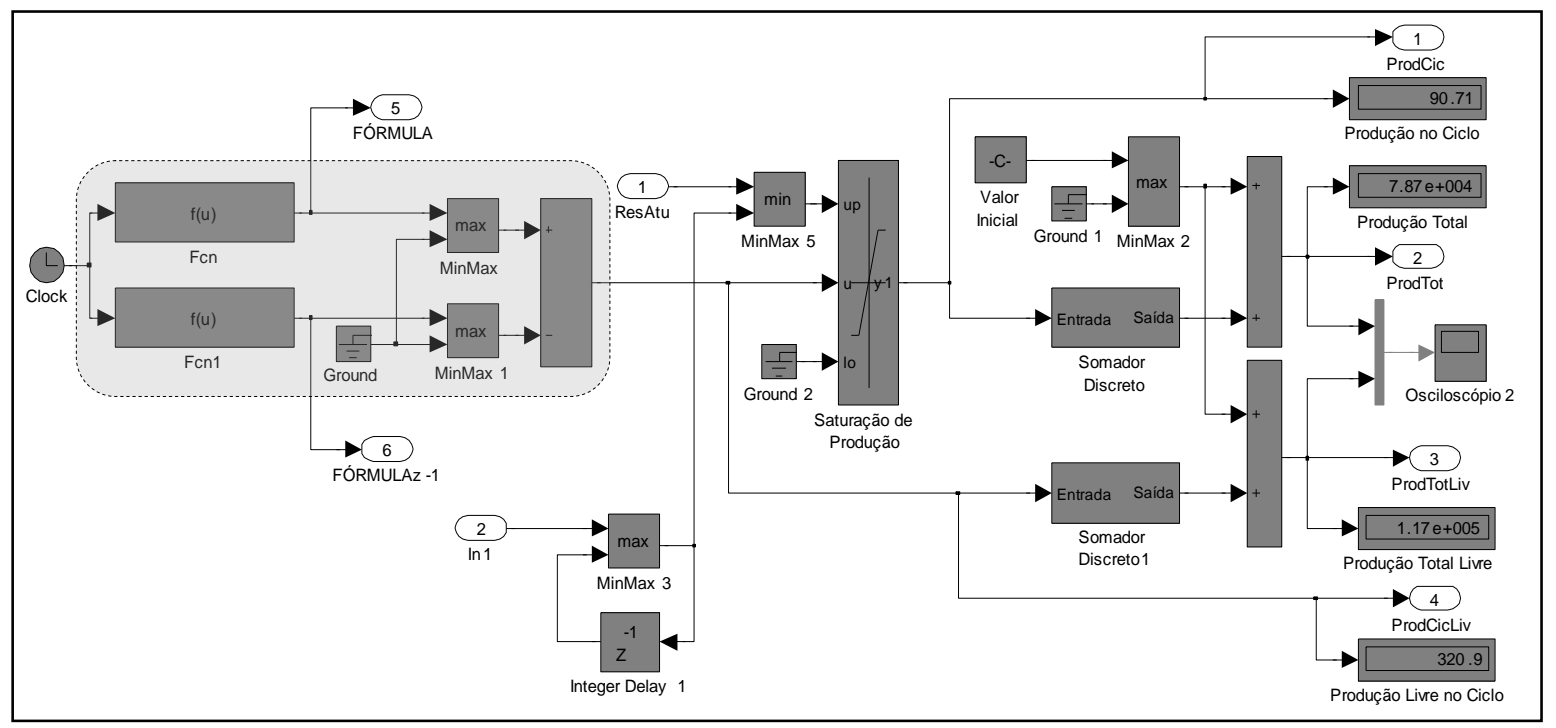

FIGURA 37 - Diagrama do subsistema de extração-produção 
O valor gerado de produção por ciclo, em destaque à esquerda do diagrama, é feito através da diferença das expressões [f(u)], que representam a equação de produção conforme obtida na tabela resumo do BEN, da curva de tendência para cada fonte de recurso, no ciclo atual e no ciclo anterior, onde u é a variável representativa de ciclo (tempo).

Os gráficos da figura 38 apresentam um exemplo da evolução de produção de energia de uma determinada fonte de recursos considerando dois casos: com reservas ilimitadas e com a limitação de reservas para a produção no ciclo (figura 38a) e a produção acumulada (figura 38b).

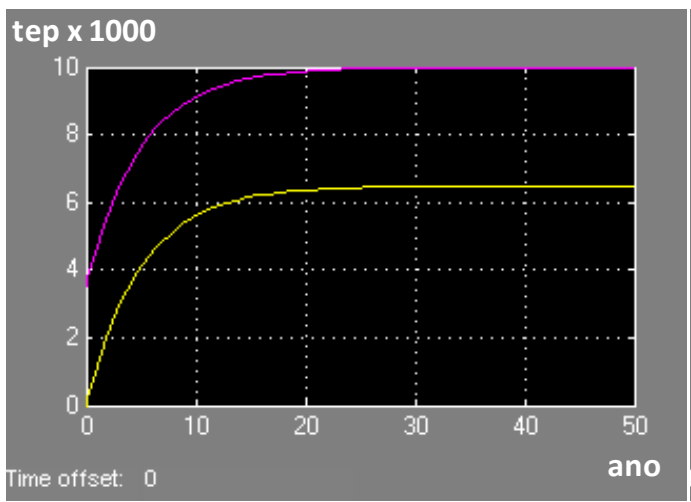

a)

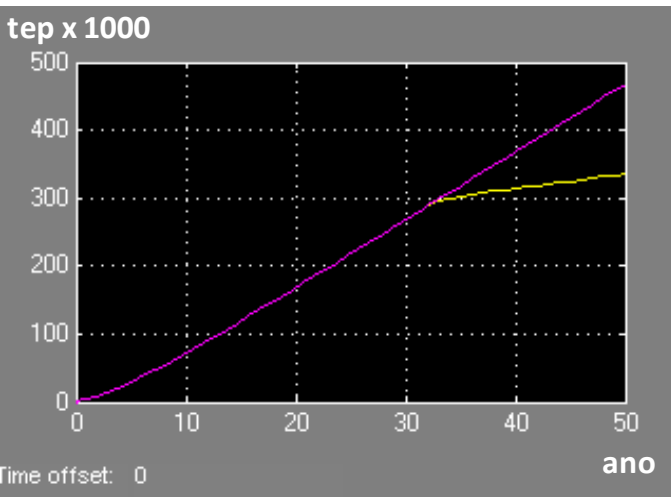

b)

FIGURA 38 - Gráficos de produção, a) vermelho: produção livre no ciclo; amarelo: produção no ciclo; b) vermelho: produção livre acumulada; amarelo: produção acumulada

As equações (11) representam o cálculo das produções no ciclo, produções totais, produções no ciclo livre e produções totais livre para uma determinada fonte de energia.

$$
\begin{gathered}
\text { Produção }_{\text {Ciclo }}=\min \left(\text { Produção }_{\text {Atual }}+\frac{\text { Produção }_{\text {Final }}-\text { Produção }_{\text {Atual }}}{\text { Taxa } \cdot s+1} ; \text { Reserva }_{\text {Atual }}\right) \\
\text { Produção }_{\text {Total }}=\int \text { Produção }_{\text {Ciclo }} \cdot d t \\
\text { Produção }_{\text {CicloLivre }}=\text { Produção }_{\text {Atual }}+\frac{\text { Produção }_{\text {Final }}-\text { Produção }_{\text {Atual }}}{\text { Taxa } \cdot s+1}
\end{gathered}
$$$$
\text { Produção }_{\text {TotalLivre }}=\int \text { Produção }_{\text {CicloLivre }} \cdot \mathrm{dt}
$$ 


\subsubsection{Subsistema Consumo}

O subsistema consumo considera as reservas atuais e a taxa de crescimento de consumo limitada pela extração-produção. Como saídas, o subsistema fornece o valor de consumo a cada ciclo e integrado ao longo do tempo. A figura 39 apresenta o diagrama de blocos para o subsistema consumo.

O bloco "Gain1", em destaque no diagrama, possibilita limitar o consumo a um valor menor que a produção, representando, além de perdas do sistema em armazenamento e outros, o desejo de se obter reservas estratégicas.

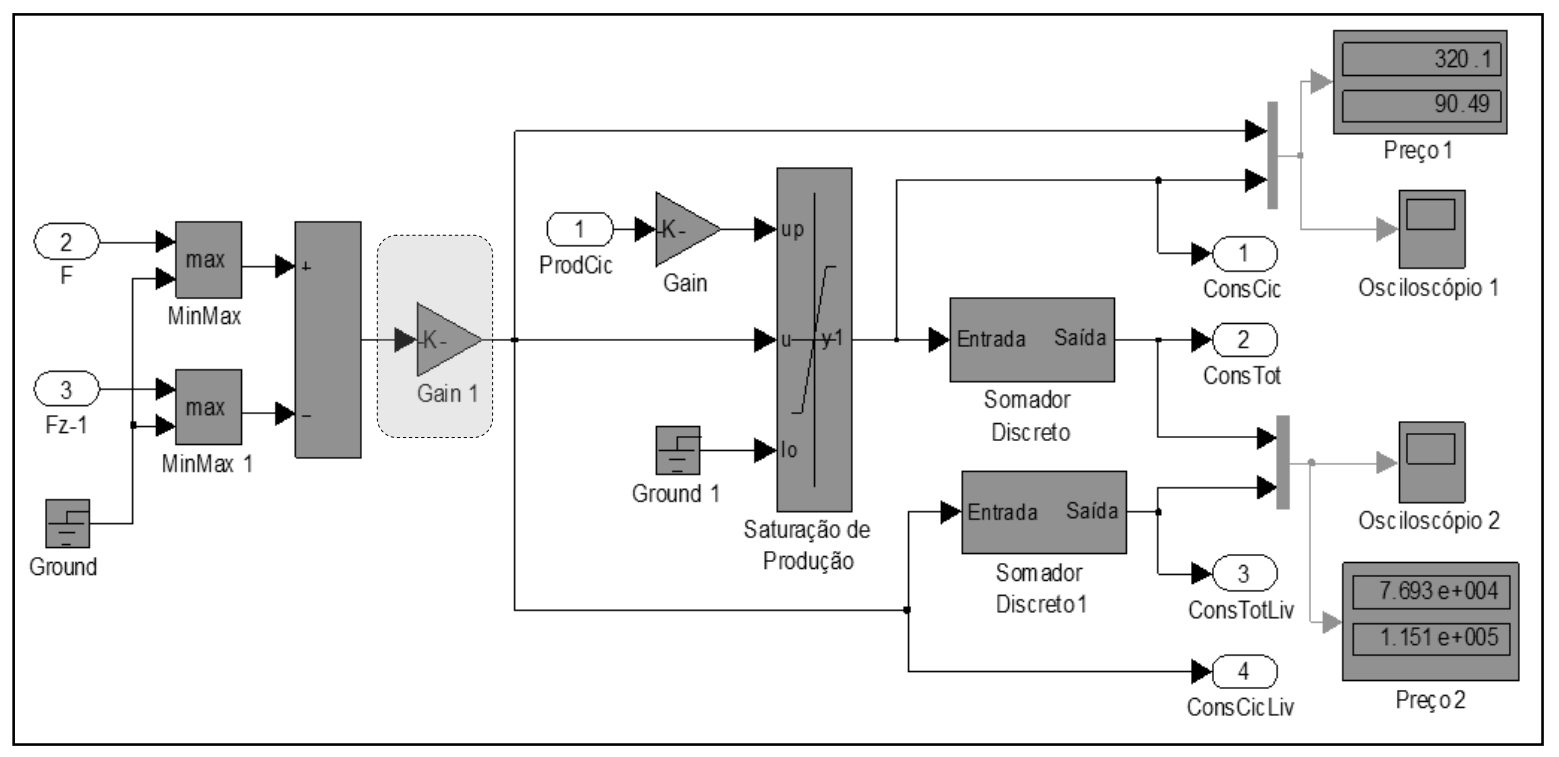

FIGURA 39 - Diagrama do subsistema de consumo

Os gráficos da figura 40 apresentam um exemplo da evolução do consumo de energia de uma determinada fonte de recursos considerando dois casos: com reservas ilimitadas e com a limitação de reservas para o consumo no ciclo (figura 40a) e consumo acumulado (figura 40b). 


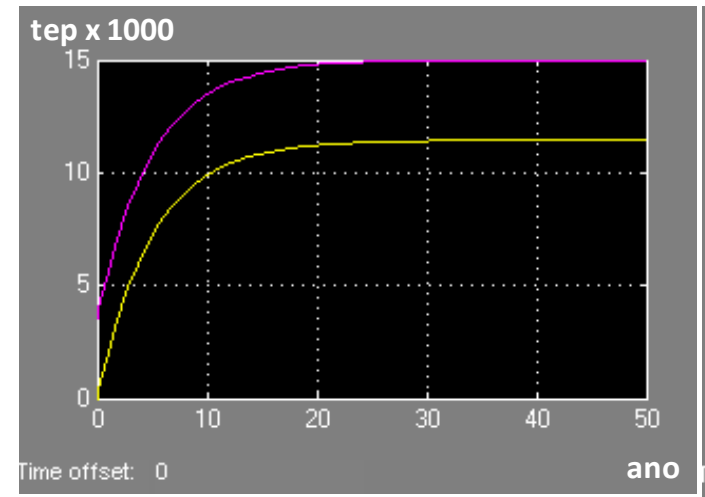

a)

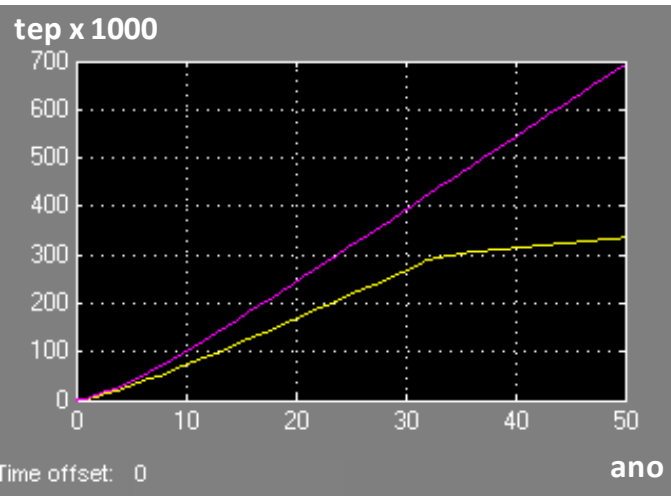

b)

FIGURA 40 - Gráficos de consumo, a) vermelho: consumo livre no ciclo; amarelo: consumo no ciclo; b) vermelho: consumo livre acumulado; amarelo: consumo acumulado.

As equações (12) representam o cálculo dos consumos no ciclo, totais, no ciclo livre e totais livre para uma determinada fonte de energia.

$$
\begin{gathered}
\text { Consumo }_{\text {Ciclo }}=\min \left(\text { Consumo }_{\text {Atual }}+\frac{\text { Consumo }_{\text {Final }}-\text { Consumo }_{\text {Atual }}}{\text { Taxa } \cdot \mathrm{s}+1} ; \text { Produção }_{\text {Ciclo }}\right) \\
\text { Consumo }_{\text {Total }}=\int \text { Consumo }_{\text {Ciclo }} \cdot \mathrm{dt} \\
\text { Consumo }_{\text {CicloLivre }}=\text { Consumo }_{\text {Atual }}+\frac{\text { Consumo }_{\text {Final }}-\text { Consumo }_{\text {Atual }}}{\text { Taxa } \cdot \mathrm{s}+1} \\
\text { Consumo }_{\text {TotalLivre }}=\int \text { Consumo }_{\text {CicloLivre }} \cdot \mathrm{dt} \quad \text { (12) }
\end{gathered}
$$

\subsubsection{Subsistema Absorção}

O subsistema absorção considera a absorção inicial, a taxa de crescimento de absorção e é alimentado pelo consumo no ciclo. Como saídas, o subsistema fornece o valor absorvido a cada ciclo e integrado ao longo do tempo. A figura 41 apresenta o diagrama de blocos para o subsistema absorção. 


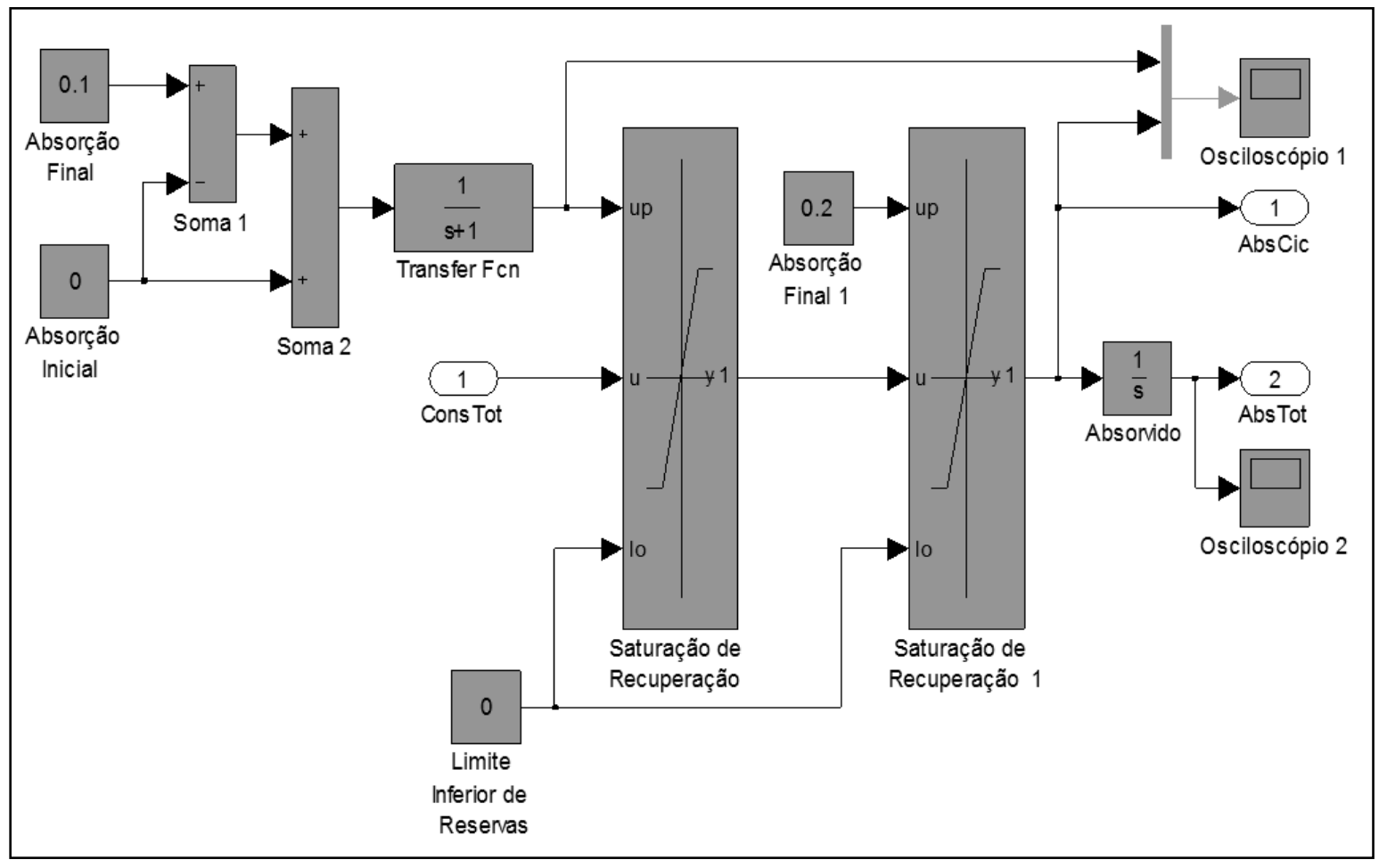

FIGURA 41 - Diagrama do subsistema de absorção

Os gráficos da figura 42 apresentam um exemplo da evolução de absorção de uma determinada fonte de recursos considerando dois casos: com reservas ilimitadas e com a limitação de reservas para a absorção no ciclo (figura 42a) e absorção acumulada (figura 42b).

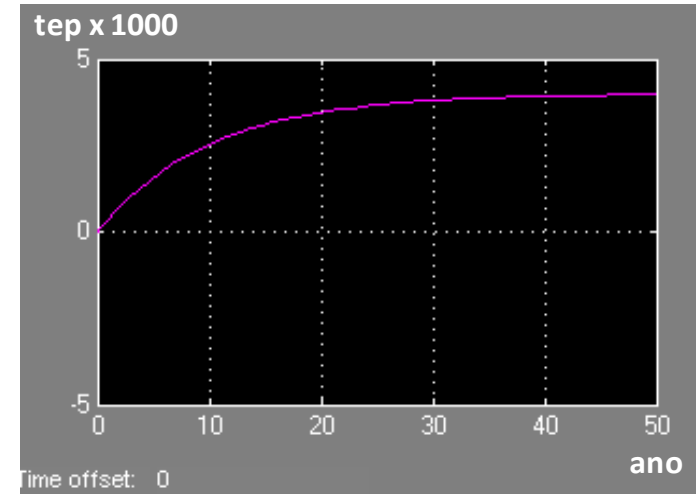

a)

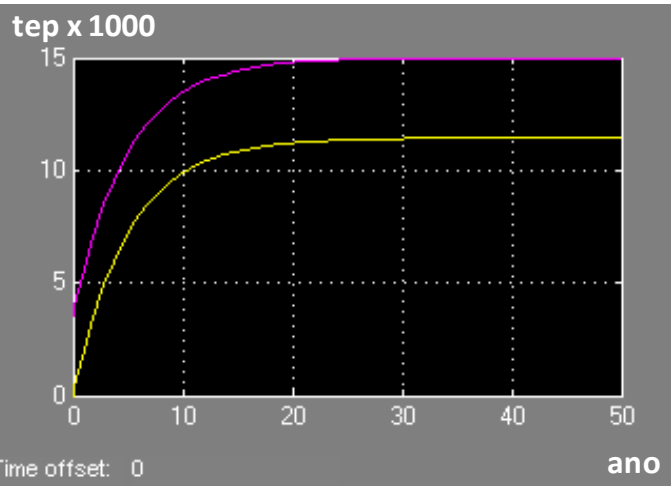

b)

FIGURA 42 - Gráficos de absorção; a) absorção no ciclo; b) vermelho: absorção livre acumulado; amarelo: absorção acumulado. 
As equações (13) representam o cálculo das absorções no ciclo e totais para uma determinada fonte de energia.

$$
\begin{gathered}
\text { Absorção }_{\text {Ciclo }}= \\
=\min \left(\max \left(0 ; \text { Consumo }_{\text {Total }}\right) ; \text { Absorção }_{\text {Inicial }+} \frac{\text { Absorção }_{\text {Final }}-\text { Absorção }_{\text {Atual }}}{\text { Taxa } \cdot s+1}\right) \\
\text { Absorção }_{\text {Total }}=\int \text { Absorção }_{\text {Ciclo }} \cdot \mathrm{dt} \quad \text { (13) }
\end{gathered}
$$

\subsubsection{Subsistema Recuperação}

O subsistema recuperação considera a recuperação atual, a taxa de crescimento de recuperação e é alimentado pela quantidade absorvida no ciclo. Como saídas o subsistema fornece o valor recuperado a cada ciclo e integrado ao longo do tempo. A figura 43 apresenta o diagrama de blocos para o subsistema recuperação.

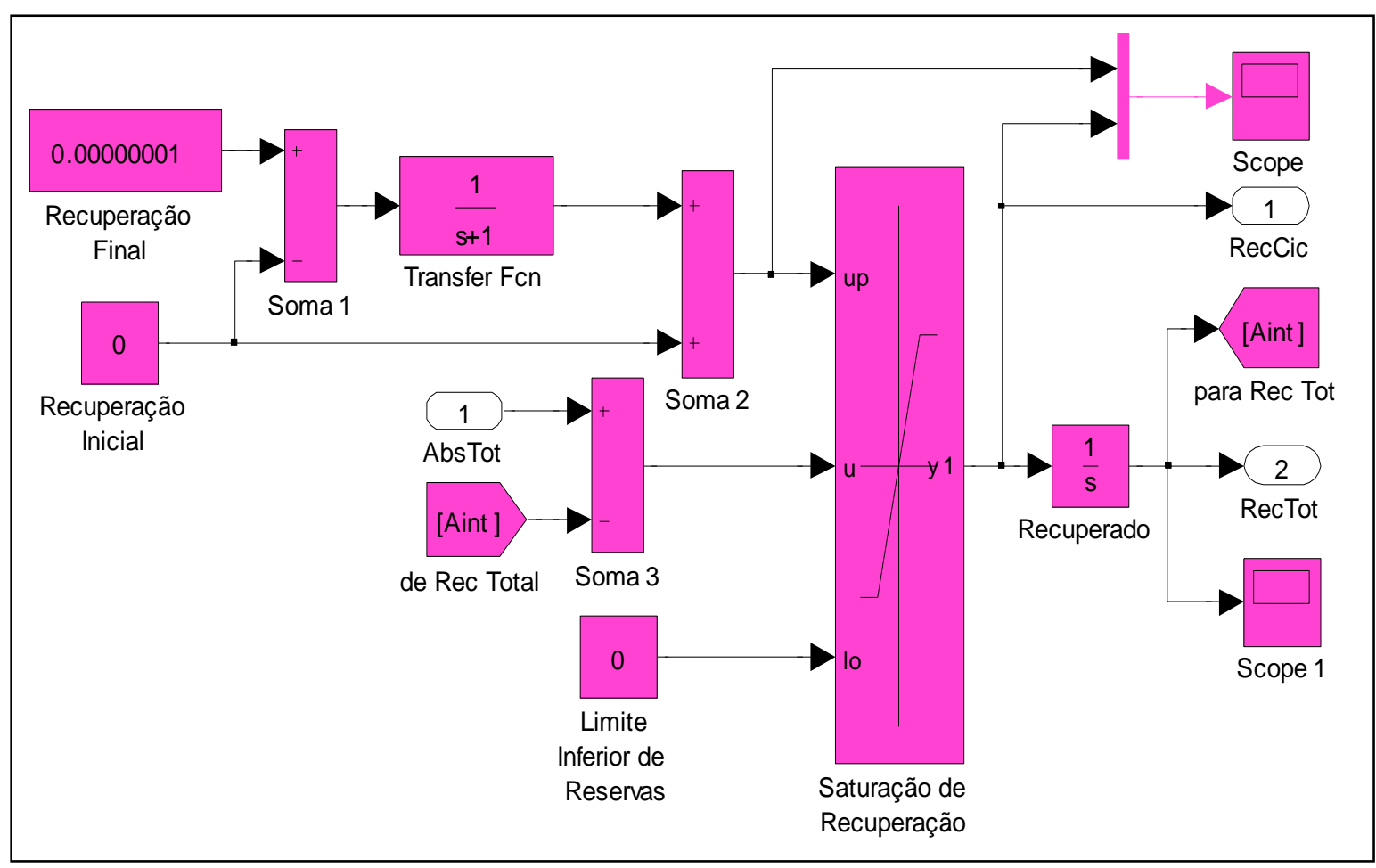

FIGURA 43 - Diagrama do subsistema de recuperação 
No caso de recuperação inexistente, como é o caso das fontes de recursos fósseis, os parâmetros nos blocos "Recuperação Inicial" e "Recuperação Final" estão configurados com valores muito baixos, da ordem de $10^{-8}$, fato que não afeta os cálculos e mantém o diagrama inalterado.

A diferença básica dos diagramas de recursos esgotáveis para os não esgotáveis é a realimentação de recuperação total (Aint), que deve ser desligada da entrada do bloco de saturação de recuperação, nos casos de recursos não esgotáveis, pois a quantidade de novas reservas independe da quantidade já recuperada no passado.

Os gráficos da figura 44 apresentam um exemplo da evolução de recuperação de uma determinada fonte de recursos considerando dois casos: com reservas ilimitadas e com a limitação de reservas para a recuperação no ciclo (figura 44a) e recuperação acumulada (figura 44b).

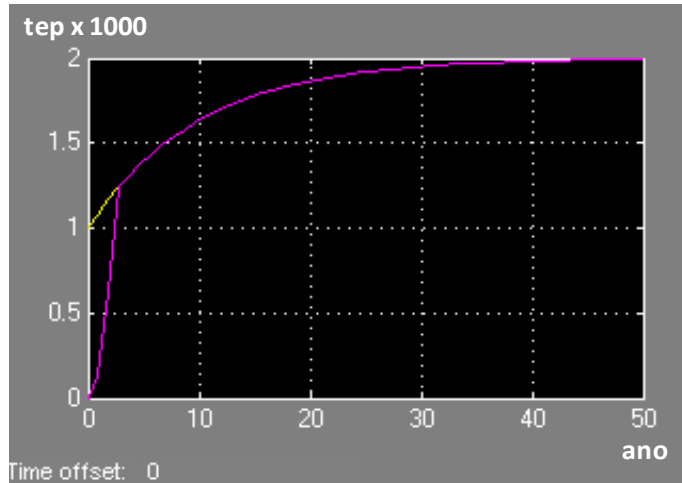

a)

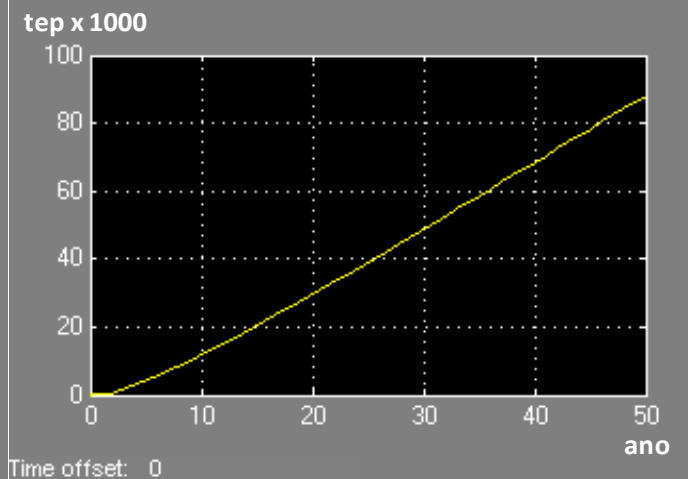

b)

FIGURA 44 - Gráficos de recuperação; a) recuperação no ciclo; b) recuperação acumulado.

As equações (14) representam o cálculo das recuperações no ciclo, totais, no para uma determinada fonte de energia.

$$
\begin{gathered}
\text { Recuperação }_{\text {Ciclo }}= \\
=\min \left(\max \left(0 ; \operatorname{Recuperação}_{\text {Total }}\right) ; \operatorname{Recuperação}_{\text {Inicial+ }} \frac{\text { Recuperação }_{\text {Final }}-\text { Recuperação }_{\text {Atual }}}{\text { Taxa } \cdot \mathrm{s}+1}\right)
\end{gathered}
$$

$$
\text { Recuperação }_{\text {Total }}=\int \text { Recuperação }{ }_{\text {Ciclo }} \cdot \mathrm{dt}
$$




\subsubsection{Subsistema Matriz de Influência}

A ferramenta está equipada com blocos da matriz de influência, distribuída de tal forma que, cada coluna (vetor) está associada a uma fonte de recursos, o que permite o estudo de como a variação de produção de uma determinada fonte de recursos influencia nas outras.

Cenários podem ser mudado com a parametrização da matriz de influências, a qual pela escolha adequada dos coeficientes de influência, de fonte para fonte, redunda em influências que consideram outros fatores, tais como custo e mercado.

A figura 45 apresenta o diagrama de blocos de cada vetor referente a cada uma das fontes de recursos. O bloco "Matriz de Influência" calcula as variações de produção para cada fonte de recurso com base nos coeficientes de influência.

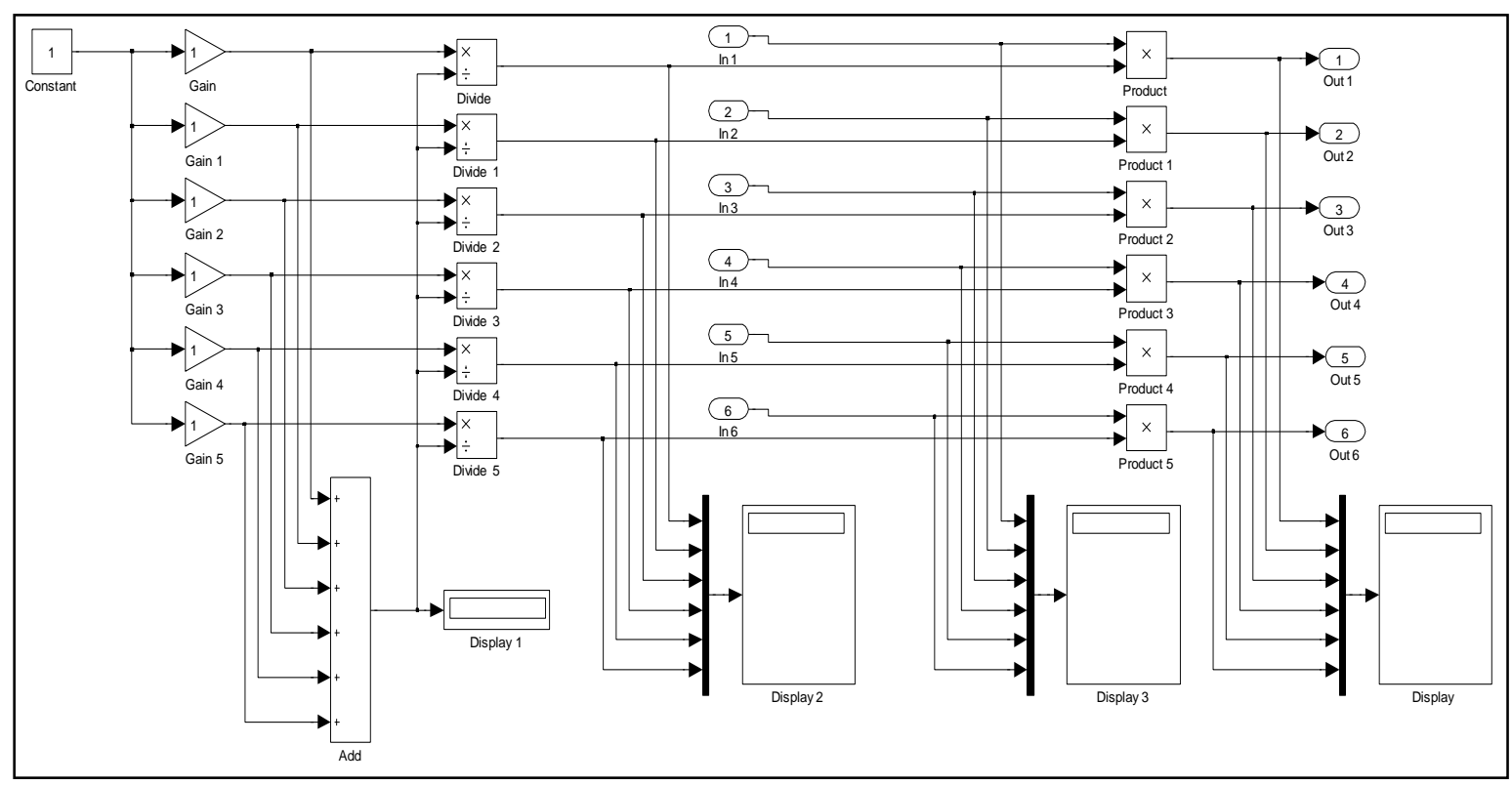

FIGURA 45 - Diagrama de blocos do vetor referente a uma fonte de recursos da matriz de influência.

Justifica-se a introdução desse subsistema na ferramenta, pois cada fonte de recurso pode ter diferentes influências, umas sobre as outras, devido as seguintes condições: 
Econômicas - Quando a proteção de investimento e do mercado é o direcionador para definição de parcelas de produção por fonte de recursos;

Políticas - Quando há programas de beneficiamento, de cunho político, para determinados setores produtivos de energia;

Sociais - Quando há a opção pelo atendimento dos anseios da sociedade, mesmo sem justificativas técnicas;

Regulatórios - Quando as regras de produção, como por exemplo, onde haja definições de produção primária e secundária, regulamentam o modus operandi no que se refere à produção de energia.

Para efeito deste trabalho, considerou-se que cada acréscimo na produção de uma determinada fonte de recursos irá influenciar no decréscimo de produção nas outras fontes, na exata proporção do valor de produção de cada uma em relação ao total da produção, isto é, com os coeficientes de influência neutros.

\subsubsection{Subsistema Energia Corrigida}

A energia corrigida é o valor da energia efetivamente produzida, levando-se em consideração as perturbações e realimentações sistêmicas. A ferramenta conta com blocos para o cálculo da energia produzida corrigida em função da própria produção, das reservas e de perturbações impostas em outras fontes de recursos, conforme apresentado na figura 46. 


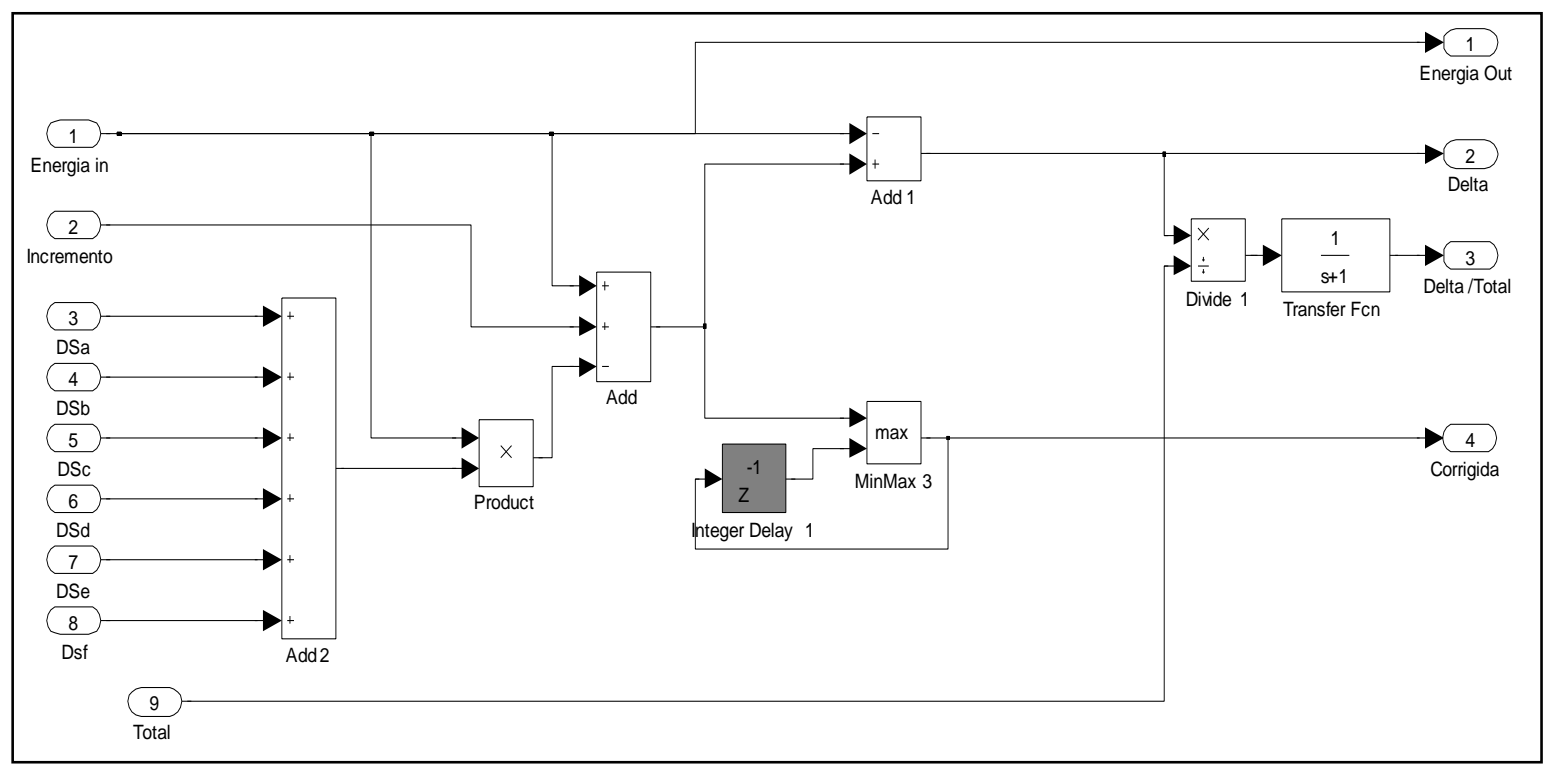

FIGURA 46 - Diagrama dos blocos que calculam a energia corrigida.

Além da energia corrigida, neste subsistema, também é calculado o desvio de produção em relação à expressão da função obtida da evolução de produção do BEN. Esses valores são realimentados para as demais partes do sistema, criando uma configuração de equilíbrio dinâmico.

Dois pontos a ressaltar, neste subsistema, são os deltas das outras fontes de recursos que alimentam esta parte do sistema e têm origem nos blocos de matriz de influência e a geração, na saída do bloco, do quociente de delta de produção em relação à produção total que irá realimentar a própria matriz de influência.

\subsubsection{Subsistema de Obtenção dos Índices Emergéticos}

A ferramenta é modular, portanto passível de se incorporar novas funcionalidades. Uma importante característica é a possibilidade de exclusão, substituição ou inclusão de módulos que gerem indicadores a partir da produção de energia elétrica.

Assim, por exemplo, o subsistema de obtenção dos índices emergéticos poderia ser substituído por um subsistema para obtenção de quantidades de emissões de $\mathrm{CO}_{2}$ na atmosfera. 
A escolha do módulo de obtenção de índices emergéticos se deveu à relevância e abrangência na avaliação e qualificação dos quesitos ambientais que esses índices incorporam.

Para geração dos índices emergéticos, conforme a figura 47, a ferramenta utiliza a energia produzida corrigida e aplica a ela o conceito de transformidade, para cada fonte de recursos.

Os valores utilizados estão apresentados na tabela 17 e foram obtidos da literatura. O fator de conversão de seJ/J para seJ/tep é $4,18 \times 10^{10}$ J/tep, conforme o BEN2005. Os valores de emergia, para cada fonte de recursos, estão decompostos em três partes: uma componente renovável, uma não renovável e uma paga, advinda das operações econômicas e das importações. A tabela 17 apresenta ainda os componentes $R, N$ e $F$ normalizados e os índices EIS, ELR e EIS calculados.

TABELA 17 - Índices Emergéticos das fontes de recurso utilizadas.

\begin{tabular}{|c|c|c|c|c|c|c|c|c|c|}
\hline $\begin{array}{l}\text { Fonte de } \\
\text { Recurso }\end{array}$ & $\begin{array}{l}\text { Transfor- } \\
\text { midade } \\
{[\mathrm{sej} / \mathrm{j}] \times 10^{3}}\end{array}$ & $\begin{array}{c}\text { Transfor- } \\
\text { midade } \\
\text { [sej/tep] } \times 10^{-6}\end{array}$ & $\mathbf{R}_{\text {normal }}$ & $N_{\text {normal }}$ & $\mathbf{F}_{\text {normal }}$ & $\begin{array}{c}\text { Carga } \\
\text { ambien- } \\
\text { tal }\end{array}$ & $\begin{array}{l}\text { Rendim } \\
\text { ento } \\
\text { emerge- } \\
\text { tico }\end{array}$ & $\begin{array}{c}\text { Susten- } \\
\text { tabilida- } \\
\text { de }\end{array}$ & Fonte \\
\hline $\begin{array}{l}\text { Gás } \\
\text { Natural }\end{array}$ & 170,0 & 4,06 & 0,078 & 0,770 & 0,152 & 11,82 & 6,58 & 0,56 & $\begin{array}{c}\text { Brown e Ulgiati } \\
\quad(2002)\end{array}$ \\
\hline $\begin{array}{l}\text { Carvão } \\
\text { Vapor }\end{array}$ & 171,0 & 4,09 & 0,088 & 0,729 & 0,182 & 10,32 & 5,49 & 0,53 & $\begin{array}{c}\text { Brown e Ulgiati } \\
(2002)\end{array}$ \\
\hline $\begin{array}{l}\text { Energia } \\
\text { Hidráulica }\end{array}$ & 62,3 & 1,49 & 0,688 & 0,181 & 0,131 & 0,45 & 7,63 & 16,83 & $\begin{array}{c}\text { Brown e Ulgiati } \\
\quad(2002)\end{array}$ \\
\hline $\begin{array}{l}\text { Produtos } \\
\text { de Cana }\end{array}$ & 69,7 & 1,67 & 0,677 & 0,026 & 0,297 & 0,45 & 3,36 & 7,46 & $\begin{array}{l}\text { Alonso-Pippo } \\
\text { (2004) }\end{array}$ \\
\hline $\begin{array}{l}\text { Energia } \\
\text { Eólica }\end{array}$ & 62,1 & 1,48 & 0,866 & 0,000 & 0,134 & 0,15 & 7,46 & 48,23 & $\begin{array}{l}\text { Brown e Ulgiati } \\
\quad(2002)\end{array}$ \\
\hline $\begin{array}{l}\text { Energia } \\
\text { Nuclear }\end{array}$ & 48,1 & 1,15 & 0,399 & 0,519 & 0,082 & 1,51 & 12,17 & 8,08 & $\begin{array}{c}\text { Kindberg } \\
\text { (2007); IAEA } \\
(2005)\end{array}$ \\
\hline
\end{tabular}

O anexo B apresenta o memorial de cálculo para os valores utilizados. 


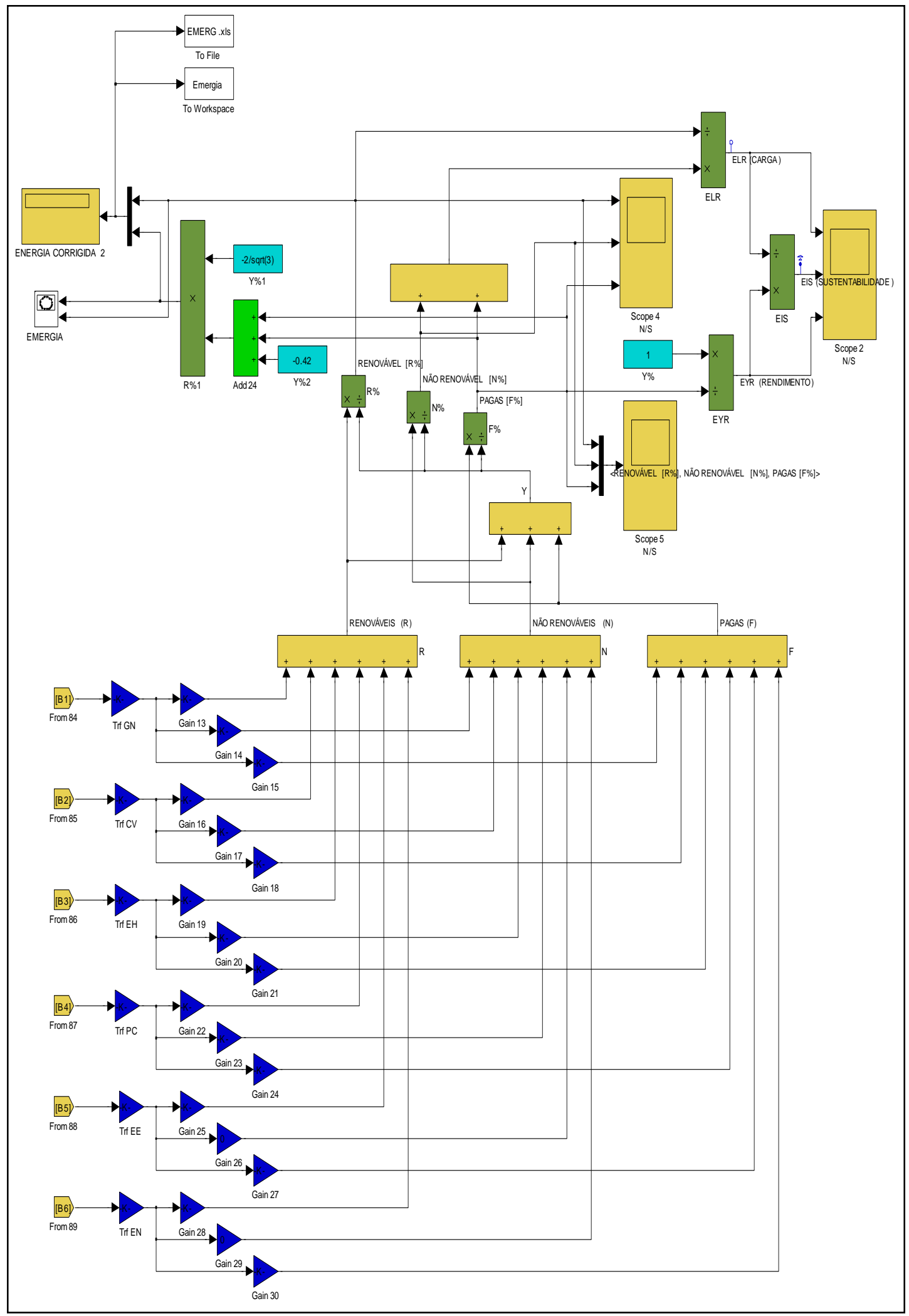

FIGURA 47 - Diagrama dos blocos gerador dos índices emergéticos. 
Além dos índices emergéticos são também geradas duas séries de dados para serem apresentadas em gráfico tipo dispersão $(x, y)$, em formato de diagrama ternário (BARRELLA, 2004).

Estes valores exportados para arquivo de dados padrão Excel®, permitem a apresentação do diagrama ternário de emergia, conforme a figura 48. Neste gráfico estão apresentados, para efeito de exemplo, pontos destacados com as respectivas identificações, em seus rótulos, a cada 10 anos, isto é, 1970, 1980, 1990, 2000, 2010, 2020, 2030 e 2040.

a)

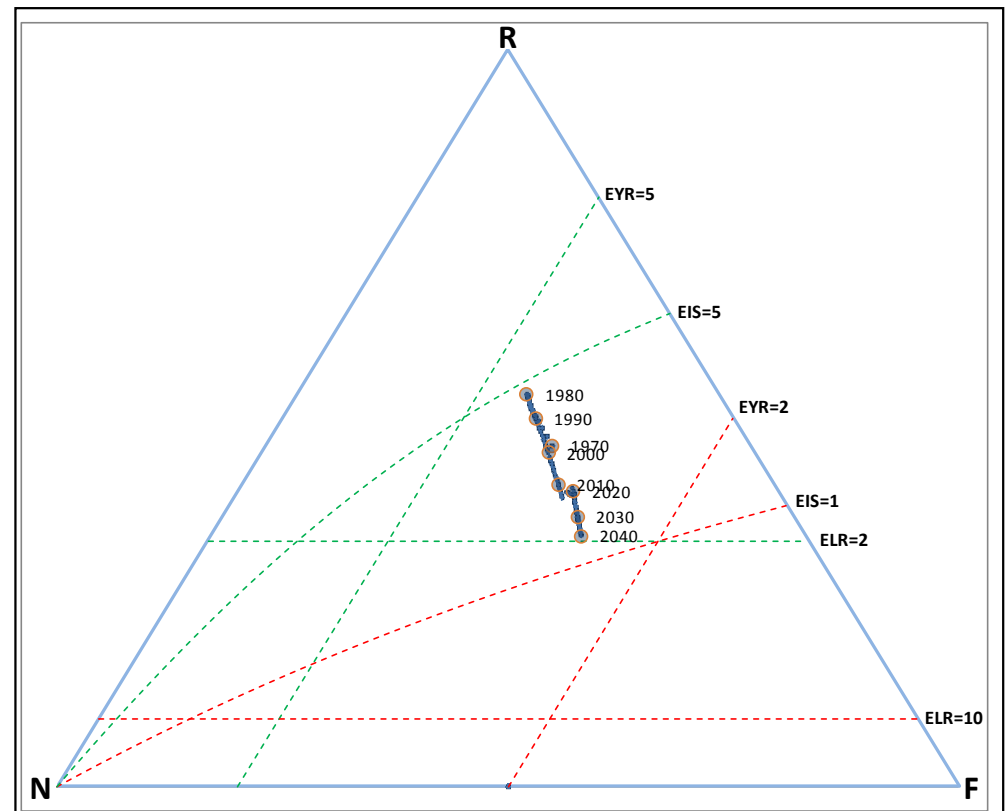

b)

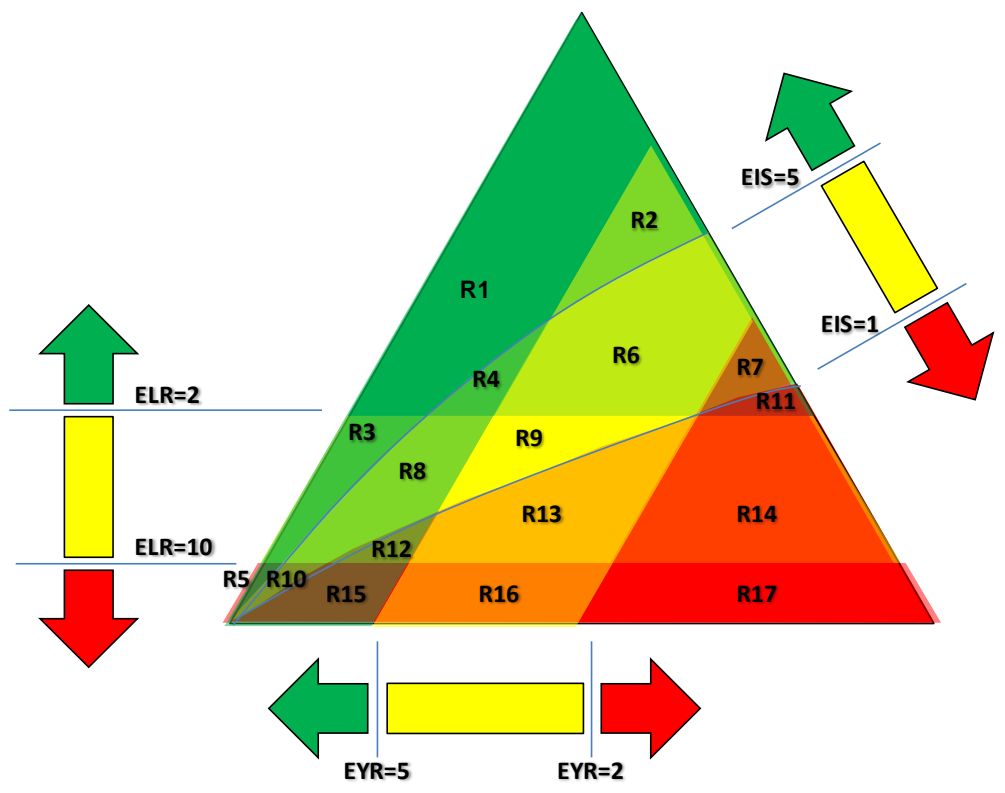

FIGURA 48 - Diagrama ternário a) percurso emergético b) regiões. 
No diagrama ternário, da figura 48a), são apresentadas as linhas de sustentabilidade com valores EIS $=1$ e EIS $=5$, as linhas de carga ambiental ELR $=2$ e ELR $=10$ e rendimento ambiental EYR $=2$ e EYR $=5$, que dividem o diagrama ternário em regiões:

Três regiões quanto à sustentabilidade - insustentabilidade, valores menores que 1 ; sustentabilidade a médio prazo, valores entre 1 e 5 ; e sustentabilidade, valores maiores que 5 .

Três regiões quanto à carga ambiental - baixos impactos, valores menores que 2; impactos moderados, valores entre 2 e 10 e altos impactos, valores acima de 10 .

Três regiões quanto ao rendimento ambiental - nenhuma contribuição, valores menores que 2 ; fontes de energia secundária e materiais primários, valores entre 2 e 5 e fontes de energia primária, valores acima de 5 (BROWN e ULGIATI, 2002).

A sobreposição dessas 9 regiões forma um conjunto de 17 subregiões que podem ser classificadas como desde regiões de péssimo desempenho dos índices, onde EIS $<1$, ELR $>10$ e EYR $<2$, área em vermelho no diagrama da figura 48b), até regiões ideais, onde EIS $>5$, ELR $<2$ e EYR $>5$, área em verde no diagrama da figura 48b).

A tabela 18 apresenta uma classificação das regiões do diagrama ternário. Foi utilizado um critério de desempate para regiões de mesma classificação com base na informação agregada que os índices carregam em si. Assim o EYR, que só depende da componente $F$, foi considerado o de menor peso (1); o ELR, que depende da relação $(N+F) / R$, foi considerado o de peso intermediário (2) e o EIS, que agrega os dois índices anteriores EYR/ELR, foi considerado o de maior peso (3). 
TABELA 18 - Classificação das regiões do diagrama ternário.

\begin{tabular}{ccccc}
\hline Região & EYR & ELR & EIS & Score \\
\hline R1 & +1 & +1 & +1 & 6 \\
R2 & +1 & +1 & 0 & 5 \\
R3 & +1 & 0 & +1 & 4 \\
R4 & 0 & +1 & +1 & 3 \\
R5 & +1 & -1 & +1 & 2 \\
R6 & 0 & +1 & 0 & 2 \\
R7 & 0 & +1 & -1 & 1 \\
R8 & 0 & 0 & +1 & 1 \\
R9 & 0 & 0 & 0 & 0 \\
R10 & 0 & -1 & 1 & -1 \\
R11 & -1 & +1 & -1 & -2 \\
R12 & -1 & 0 & +1 & -2 \\
R13 & -1 & 0 & 0 & -3 \\
R14 & -1 & 0 & -1 & -4 \\
R15 & -1 & -1 & +1 & -4 \\
R16 & -1 & -1 & 0 & -5 \\
R17 & -1 & -1 & -1 & -6 \\
\hline
\end{tabular}

\subsubsection{Cálculo dos valores e gráficos de simulações}

A figura 49 apresenta os blocos responsáveis pelos cálculos dos valores de energia produzida e deltas de cada uma das fontes de recursos e dos totais de energia com e sem perturbações.

Os valores de delta são obtidos a partir da diferença entre a produção de energia corrigida e a produção de energia sem correção, expressão da função que descreve o crescimento da fonte de energia.

Os totais são obtidos pela soma da parcela de energia de cada uma das fontes de recursos.

Os gráfico da figura 50a) apresenta um exemplo hipotético dos deltas de produção por tipo de fonte de recurso, 50b) as produções de energia para cada tipo de fonte de recurso e 50c) produções totais com e sem perturbação. 


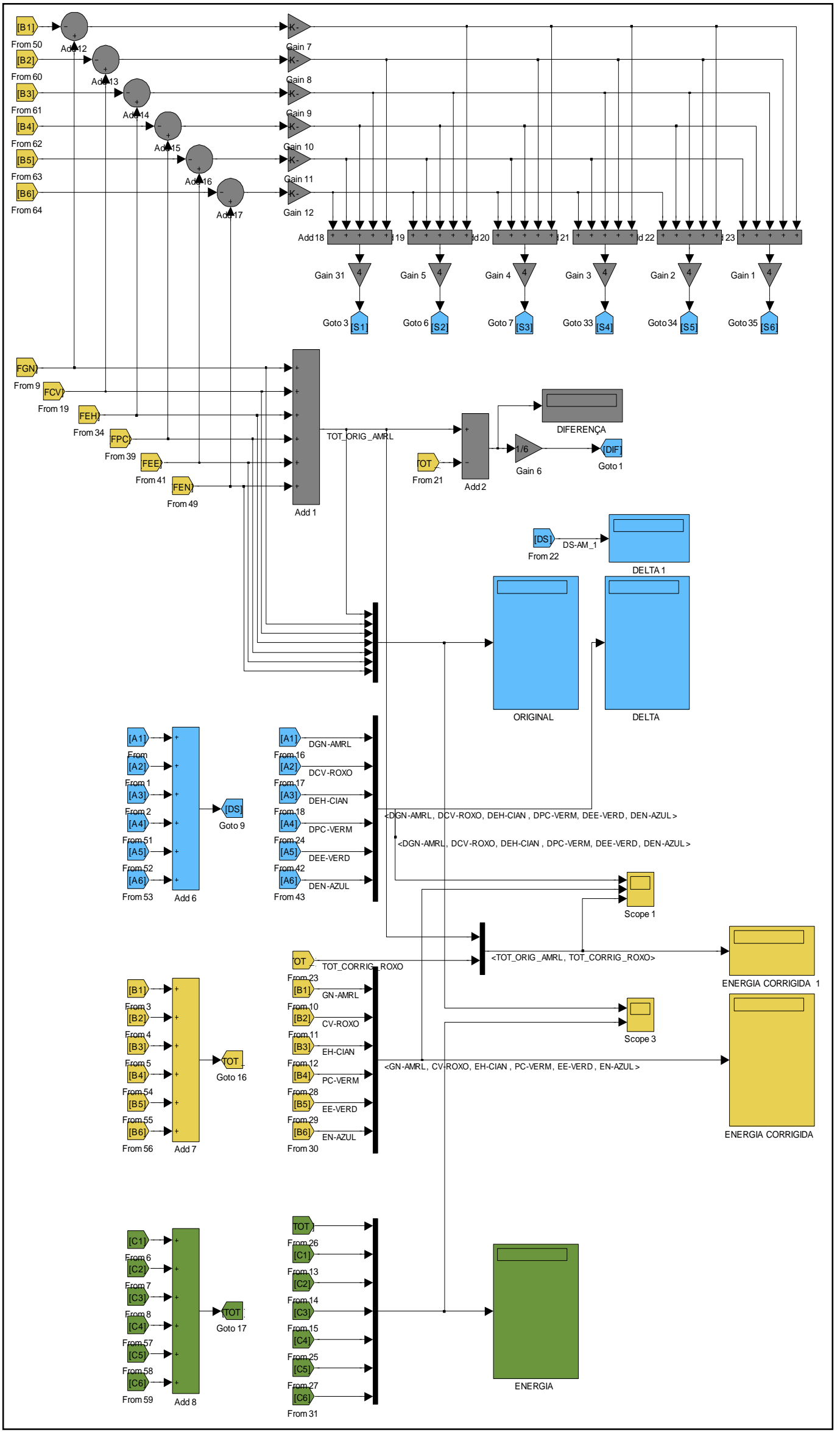

FIGURA 49 - Diagrama de blocos para cálculo dos valores energéticos. 
a)

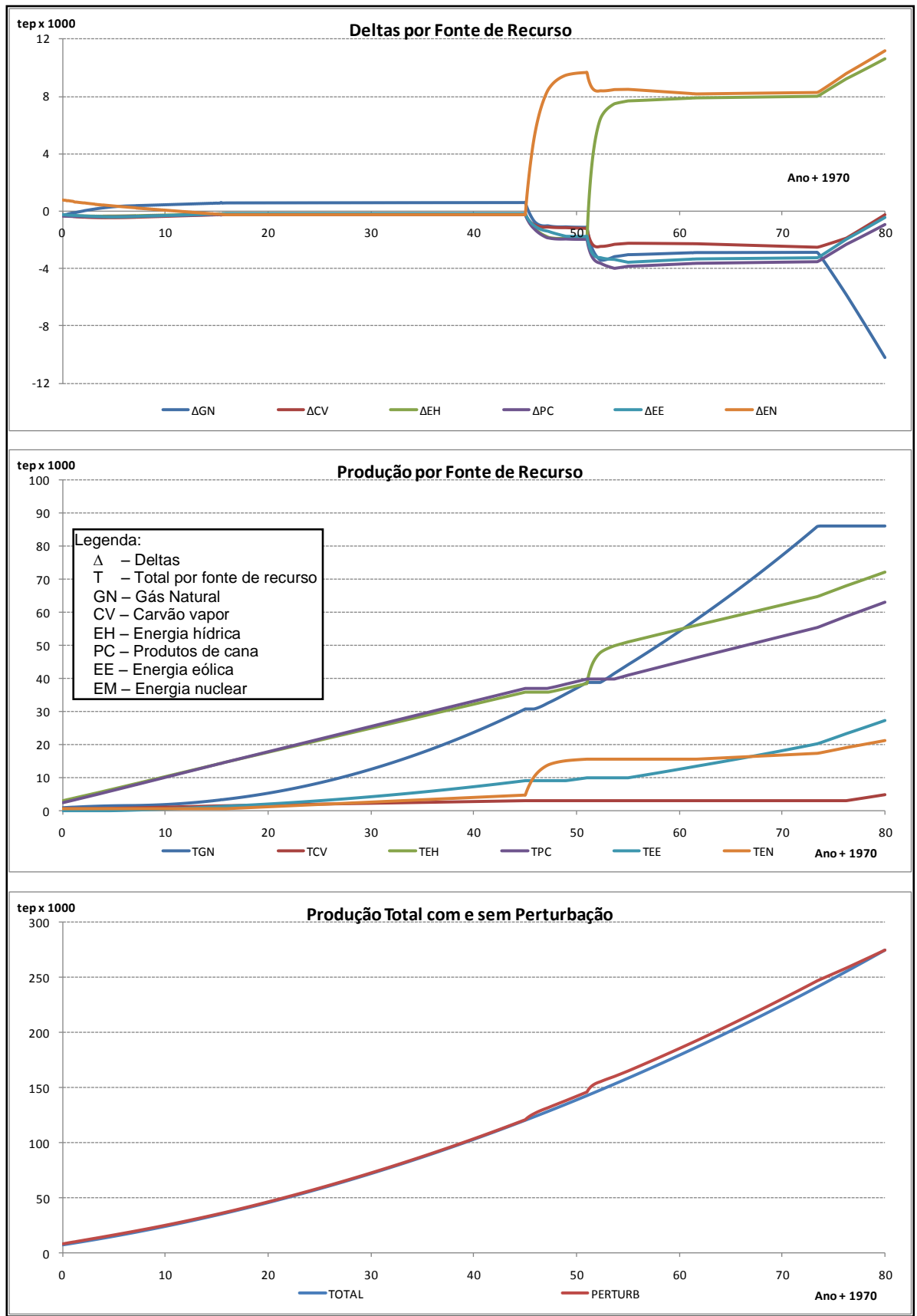

FIGURA 50 - Exemplo de gráfico de deltas de produção, produção por fonte de recurso e produções com e sem perturbação.

\subsubsection{Sistema Auto-Regulado}

O sistema de produção em uma abordagem global pode ser descrito como um sistema auto-regulado e conduzido pelo consumo. Assim, qualquer mudança interna na matriz energética não deve ter uma influência muito grande nos resultados globais. 


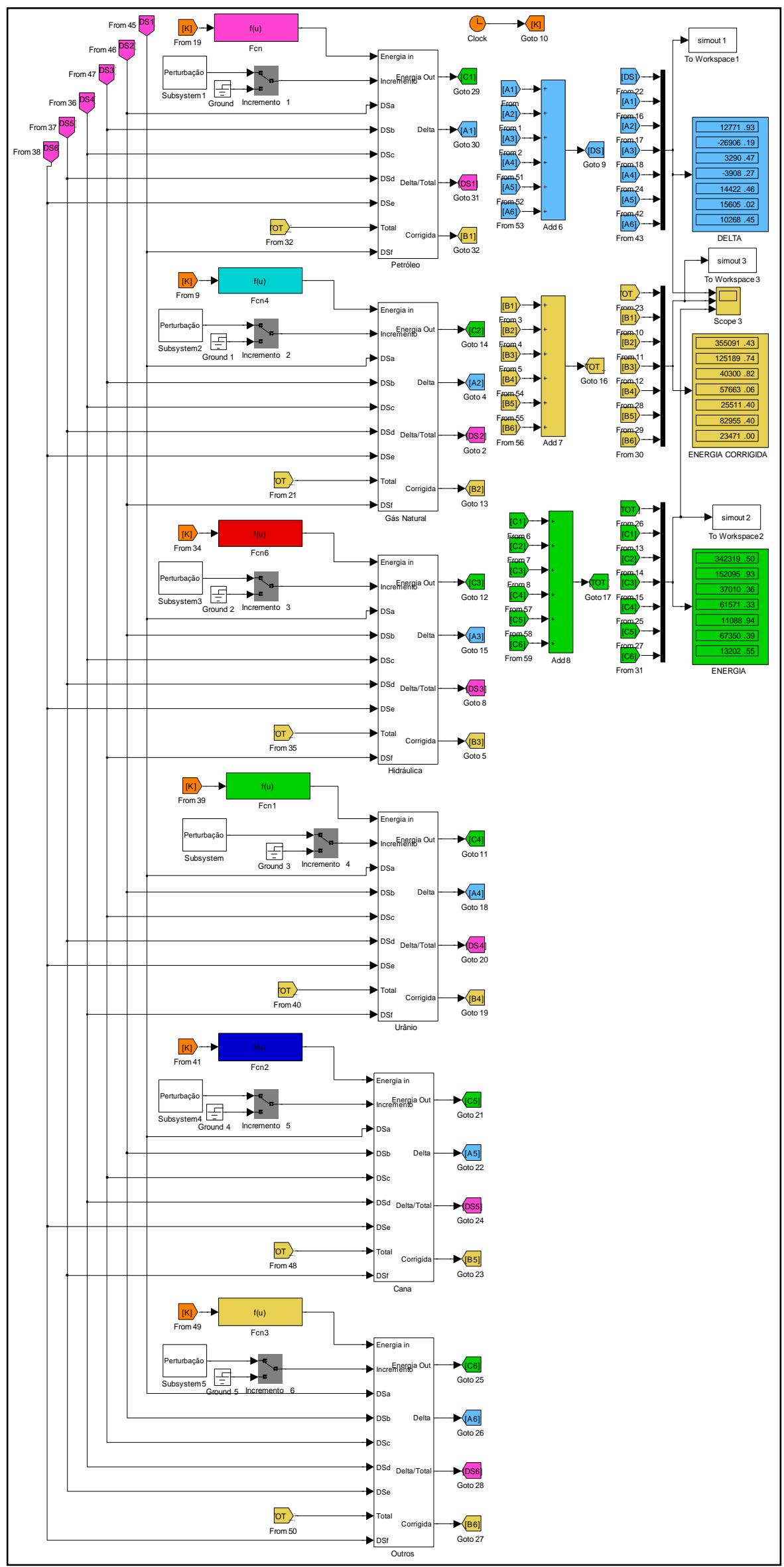

FIGURA 51 - Sistema auto-regulado 
No diagrama da figura 51 , estão apresentados os seis grupos de blocos referentes a fontes de recursos: gás natural, carvão vapor, energia hídrica, produtos de cana, energia eólica e energia nuclear.

Cada um desses blocos tem associado em suas respectivas entradas um bloco com a função de entrada, conforme a equação de curva tendência obtida da matriz $24 \times 47$ do BEN, e um bloco denominado perturbação, que pode ser ativado ou desativado através de chave manual.

A figura 52 mostra a caixa de diálogo para inserção dos valores de perturbação de produção. Podem ser especificadas até cinco tempos, em que ocorrem as perturbações na produção, com seus respectivos valores. No exemplo da figura 52 foram utilizados os ciclos de simulação 30 até $34 \mathrm{com}$ incrementos de produção de 5000 tep, nos ciclos 30 a 33, e zero no ciclo 34 .

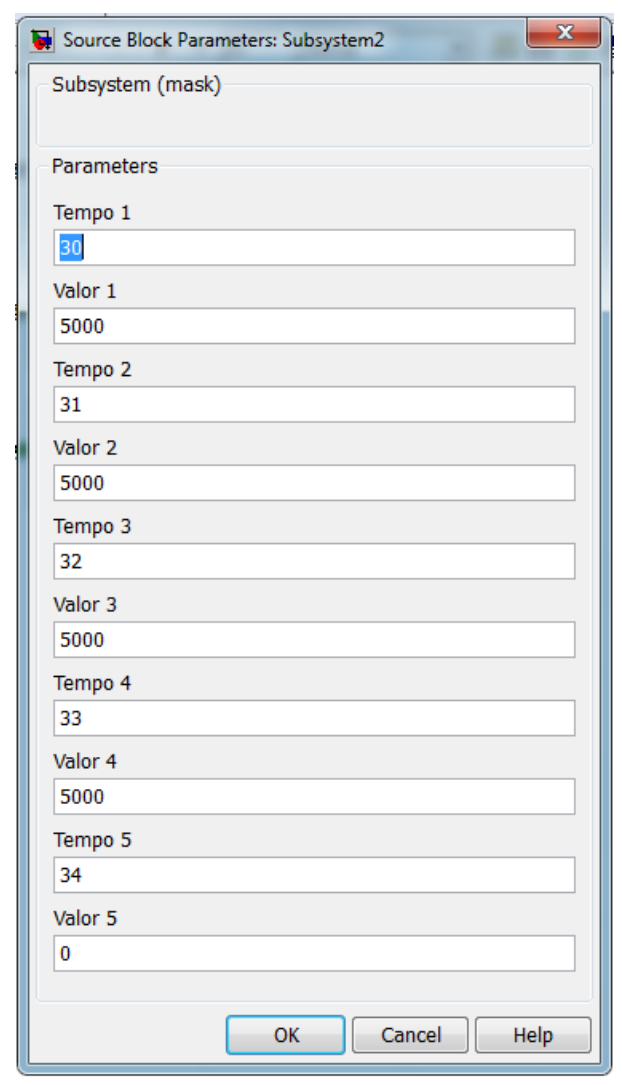

FIGURA 52 - Caixa de diálogo para entrada de perturbação no sistema

O detalhamento interno do bloco de cada recurso está mostrado na figura 46 e tem como entradas, a energia total, resultado do somatório das 
energias produzidas, e as variações percentuais de cada uma das fontes de energia.

Na saída do bloco têm-se: o delta de produção, que é definido como a diferença entre a energia que se teria produzido se o sistema não sofresse nenhuma perturbação e a energia corrigida como efeito de perturbações introduzidas no sistema; os deltas percentuais, que se referem a cada um dos deltas de todos os blocos dividido pela produção total do sistema e a produção de energia já corrigida.

A saída do sinal delta percentual passa por um bloco cuja função de transferência tem um pólo no ponto zero e um pólo no ponto menos um. A inserção desse bloco permite que o efeito da perturbação não seja do tipo degrau que poderia mascarar o crescimento real, mas sim tem a forma de uma curva exponencial decrescente, o qual é mais condizente com a realidade.

Na figura 53 apresentam-se os resultados de uma simulação com incremento no ciclo 45, referente ao ano de 2015, de 10000 tep, aproximadamente $10 \%$ da energia total no ano de aplicação da perturbação.

O gráfico da figura 53a) apresenta os deltas para cada uma das fontes de recursos, enquanto que no gráfico da figura 53b) estão apresentadas as produções por fonte de recurso, no gráfico da figura 53c) as produções totais com o efeito da perturbação e sem o efeito da perturbação respectivamente.

Para os casos de simulação com e sem perturbação, note-se que o aumento em uma das fontes de recursos causou o decréscimo das outras fontes, o que faz manter a produção total dentro de uma variação menor do que $1 \%$, não apresentando assim, variações significativas.

Ainda nos gráficos da figura 53, a partir do ano 73, devido ao esgotamento dos recursos de gás natural, houve acréscimos de produção das outras fontes mantendo constante a produção total. Esta simulação mostra o funcionamento da ferramenta tanto na introdução de perturbações forçadas ou naturais, quanto ao sentido da perturbação, por acréscimo ou decréscimo. O valor da correlação $\rho_{p, p c}$ está apresentado no gráfico da figura $53 c$ ). 
a)

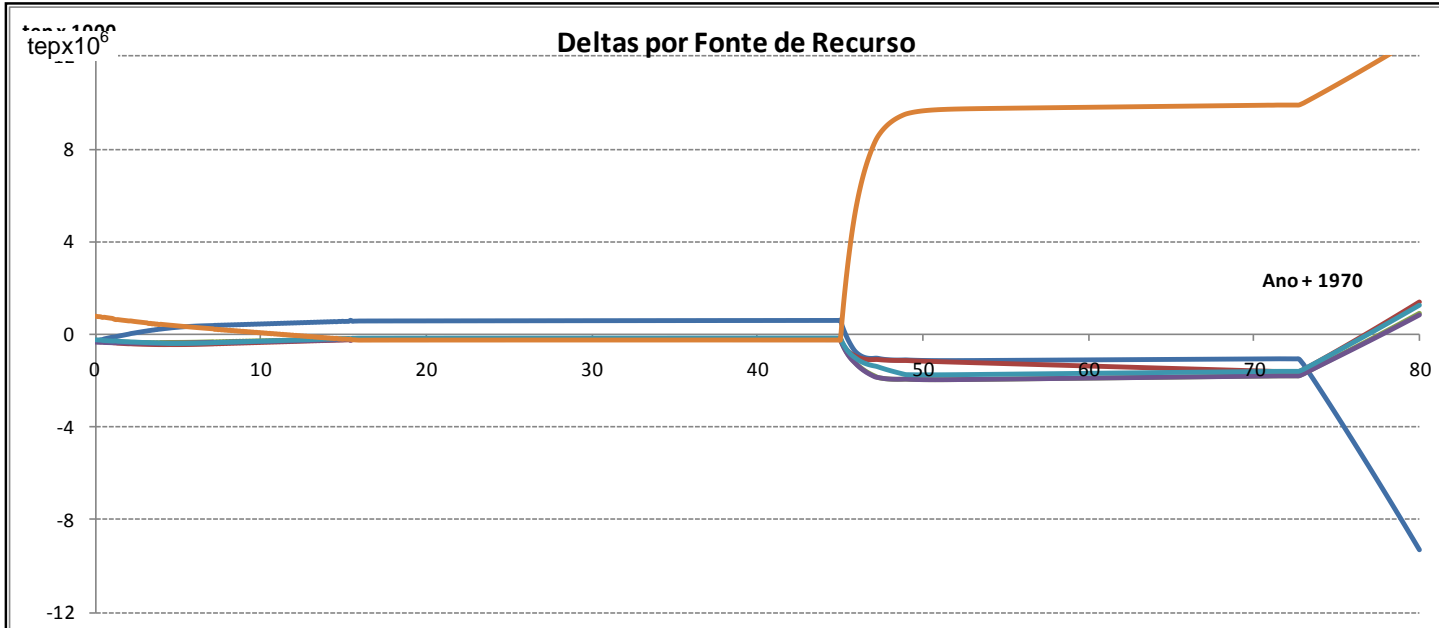

)

$-\triangle \mathrm{GN} \quad-\Delta \mathrm{CV} \quad-\Delta \mathrm{EH} \quad-\triangle \mathrm{PC} \quad-\triangle \mathrm{EE} \quad-\Delta \mathrm{EN}$

$\tan \times 10 n n$
tep $\times 10^{6}$$\quad$ Produção por Fonte de Recurso

b)

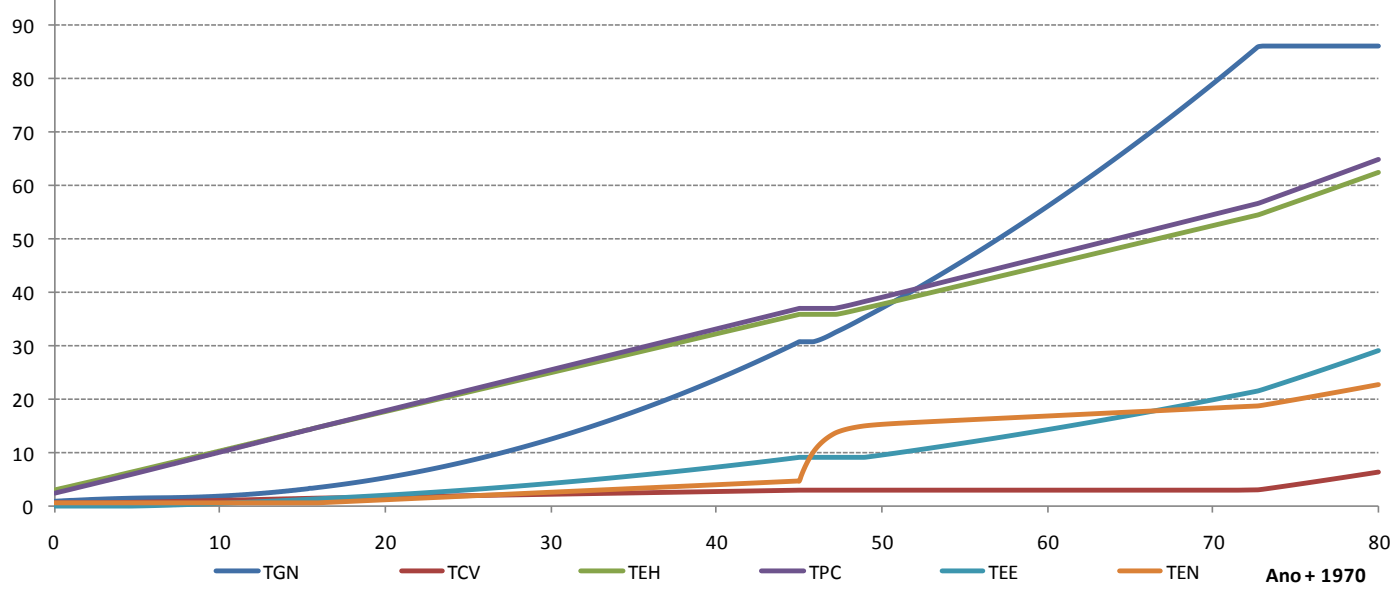

c)

$\operatorname{tan\times 10nn}$
tep $\times 10^{6}$$\quad$ Produção Total com e sem Perturbação

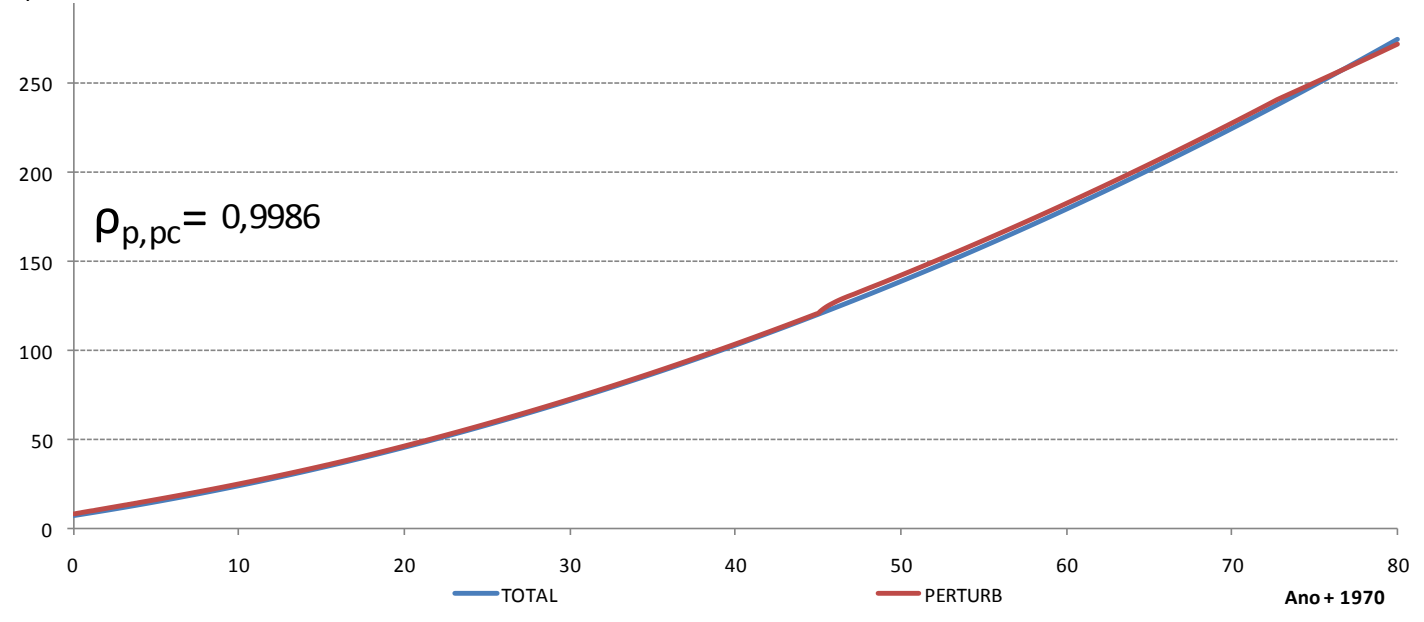

FIGURA 53 - Gráficos de produção com perturbação em somente uma fonte de recurso: a) delta de produção; b) produção por fonte de recursos e c) produção total com e sem perturbação. 
$\mathrm{Na}$ figura 54 estão mostrados os mesmos gráficos da figura 53 , porém, introduzindo-se perturbações diversas, em todas as fontes de recursos, em diferentes tempos.

a)

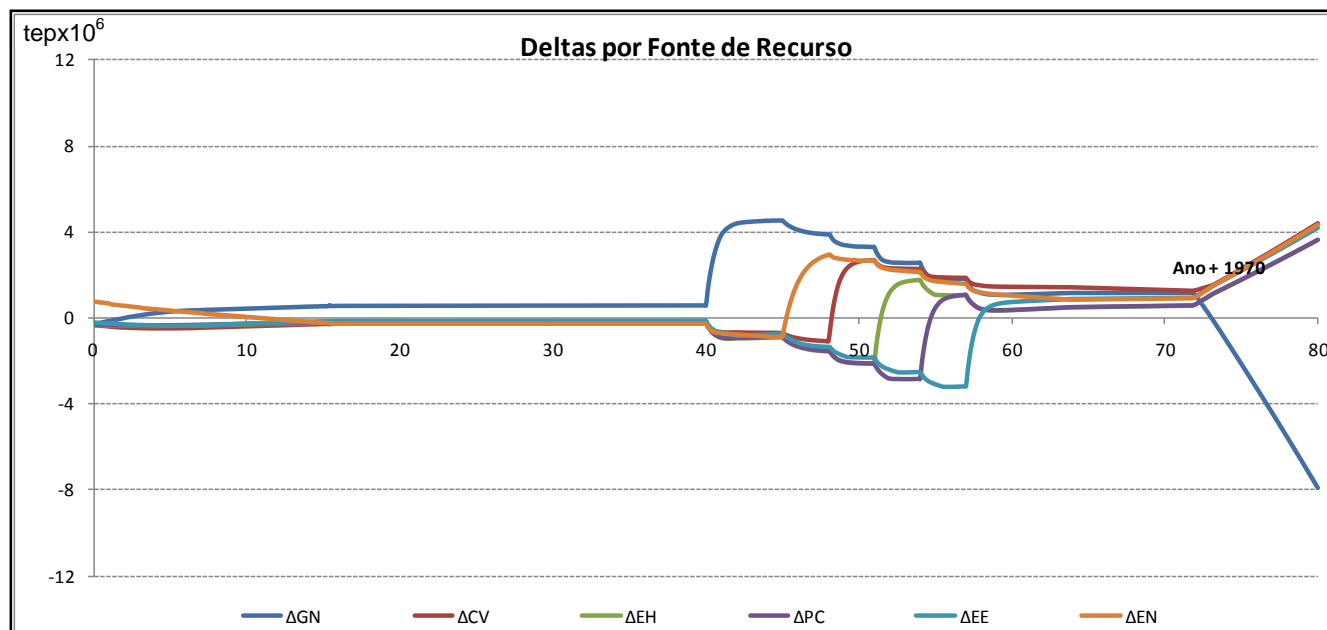

b)

$\operatorname{tep} \times 10^{6}$
100
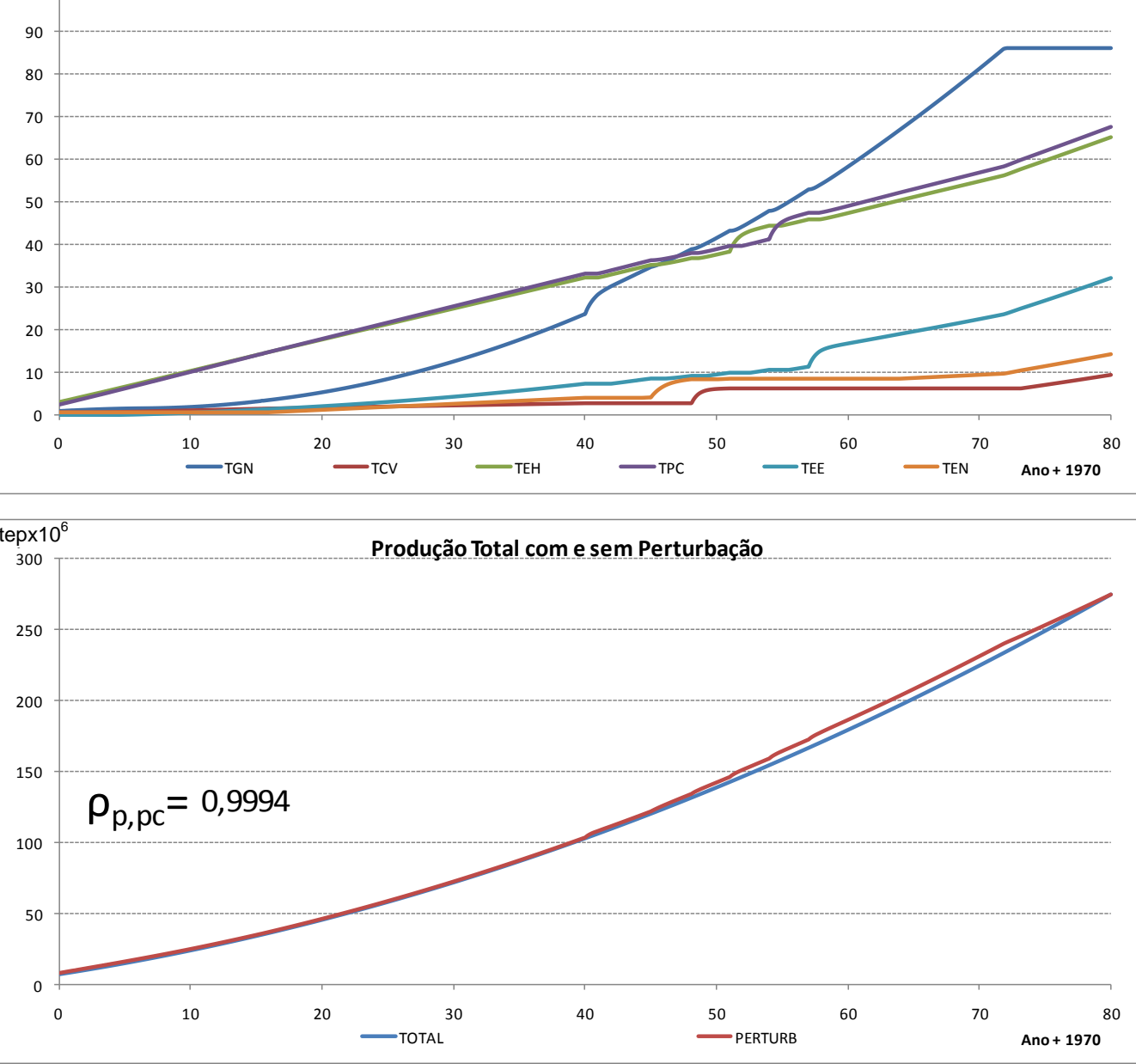

FIGURA 54 - Gráficos de produção com perturbação em todas as fontes de recurso: a) delta de produção; b) comportamento do sistema com perturbação e c) comportamento do sistema sem perturbação. 
Note-se que, mesmo neste caso em que se têm perturbações múltiplas, a variação da produção total ficou menor que $1 \%$. Depreende-se que o modelo é suficientemente robusto para que mantenha a tendência de crescimento coerente, conforme o esperado, e independa de variações de fontes de recursos individuais.

\subsection{Equacionamento Proposto}

O equacionamento do sistema apresentado na figura 46 , diagrama dos blocos que calculam a energia corrigida, é dado abaixo:

A energia total produzida na fonte de recursos i $\left(E_{T O T_{i}}\right)$, é calculada conforme a equação 15 .

$$
E_{T_{O O T}}=E_{i}+P_{i}
$$

onde $E_{i}$ é a energia produzida sem perturbação, para o recurso i e $P_{i}$ é a perturbação imposta ao recurso $\mathrm{i}$

O delta de produção de energia para a fonte de recursos i $\left(D_{i}\right)$ é obtido pela diferença entre a energia corrigida devido a perturbação $\left(E_{C O R_{i}}\right)$ e a energia sem perturbação $\left(E_{i}\right)$, conforme apresentado na equação (16).

$$
D_{i}=E_{C O R_{i}}-E_{i}
$$

O delta percentual de energia para a fonte de recursos i $\left(D S T_{i}\right)$ é obtido pela relação entre o delta de energia $\left(D_{i}\right)$ e o somatório das energias corrigidas de todas as fontes de recursos $\left(\sum_{i=a}^{f} E_{C O R_{i}}\right)$. Neste caso, o valor do desvio percentual ainda está multiplicado por uma exponencial amortecida, pois os efeitos são graduais, conforme apresentado na equação (17).

$$
D S T_{i}=\frac{1}{G} \cdot \frac{D_{i}}{\sum_{i=a}^{f} E_{C O R i}} \cdot \frac{1}{s \cdot(s+1)}
$$

A energia corrigida para a fonte de recursos i $\left(E_{C O R_{i}}\right)$ é dada pela diferença entre a energia sem perturbação $\left(E_{T O T_{i}}\right)$ e a energia corrigida, 
vezes o somatório dos deltas percentuais de todas as fontes de recursos. Note que essa expressão da energia corrigida é recursiva, o que na simulação faz com que se utilize o valor anterior da energia corrigida para se obter o valor futuro. Com uma série de transformações matemáticas, conforme apresentadas nas equações 18 a 22, obtém-se a expressão dada na equação 23.

$$
\begin{aligned}
& E_{C O R_{i}}=E_{T O T_{i}}-E_{C O R_{i}} \cdot \sum_{i=a}^{f} D S T_{i} \\
& E_{C O R_{i}}+E_{C O R_{i}} \cdot \sum_{i=a}^{f} D S T_{i}=E_{T O T_{i}} \\
& E_{C O R_{i}} \cdot\left(1+\sum_{i=a}^{f} D S T_{i}\right)=E_{T^{\prime} O T_{i}} \\
& E_{C O R_{i}}=\frac{E_{T O T_{i}}}{\left(1+\sum_{i=a}^{f} D S T_{i}\right)} \\
& E_{C O R_{i}}=\frac{E_{i}+P_{i}}{\left(1+\sum_{i=a}^{f} D S T_{i}\right)} \\
& E_{C O R_{i}}=\frac{E_{i}+P_{i}}{\left(1+\sum_{i=a}^{f} \frac{1}{G} \cdot \frac{D_{i}}{\sum_{i=a}^{f} E_{C O R i}} \cdot \frac{1}{s \cdot(s+1)}\right)}
\end{aligned}
$$

Este equacionamento do subsistema de ordem $\mathrm{i}$ indica que a energia total corrigida, relativa à fonte de recursos i $\left(E_{C O R_{i}}\right)$, é igual a energia de crescimento natural $\left(E_{i}\right)$ mais a perturbação $\left(P_{i}\right)$ provocada pelo investimento naquela fonte de recursos, dividido por um fator que considera todos os deltas de todas as fontes de recursos, inclusive a própria fonte i.

A energia total $\left(E_{T O T A L}\right)$ pode ser calculada a partir do somatório das energias corrigidas para cada fonte de recursos, conforme a equação 24 .

$$
E_{\text {TOTAL }}=\sum_{j=a}^{f} \frac{E_{i}+P_{i}}{\left(1+\sum_{i=a}^{f} \frac{1}{G} \cdot \frac{D_{i}}{\sum_{i=a}^{f} E_{C O R i}} \cdot \frac{1}{s \cdot(s+1)}\right)}
$$




\section{RESULTADOS}

Os resultados aqui apresentados são os mais significativos colhidos das simulações realizadas. Estão divididos basicamente em quatro partes: verificação do modelo; comportamento do modelo com perturbações; obtenção dos índices emergéticos com e sem perturbações e outras simulações.

\subsection{Verificação do Modelo}

Nesta fase de obtenção de resultados foram feitas simulações considerando a série histórica relativa ao BEN de 1970 até 2004, como base de dados e fez-se a projeção para os anos de 2005 a 2009, para validação do modelo (figura 55). Esta projeção, fonte a fonte de recursos, foi comparada com os dados reais nos anos de 2004 e de 2009 e foram verificados os desvios.

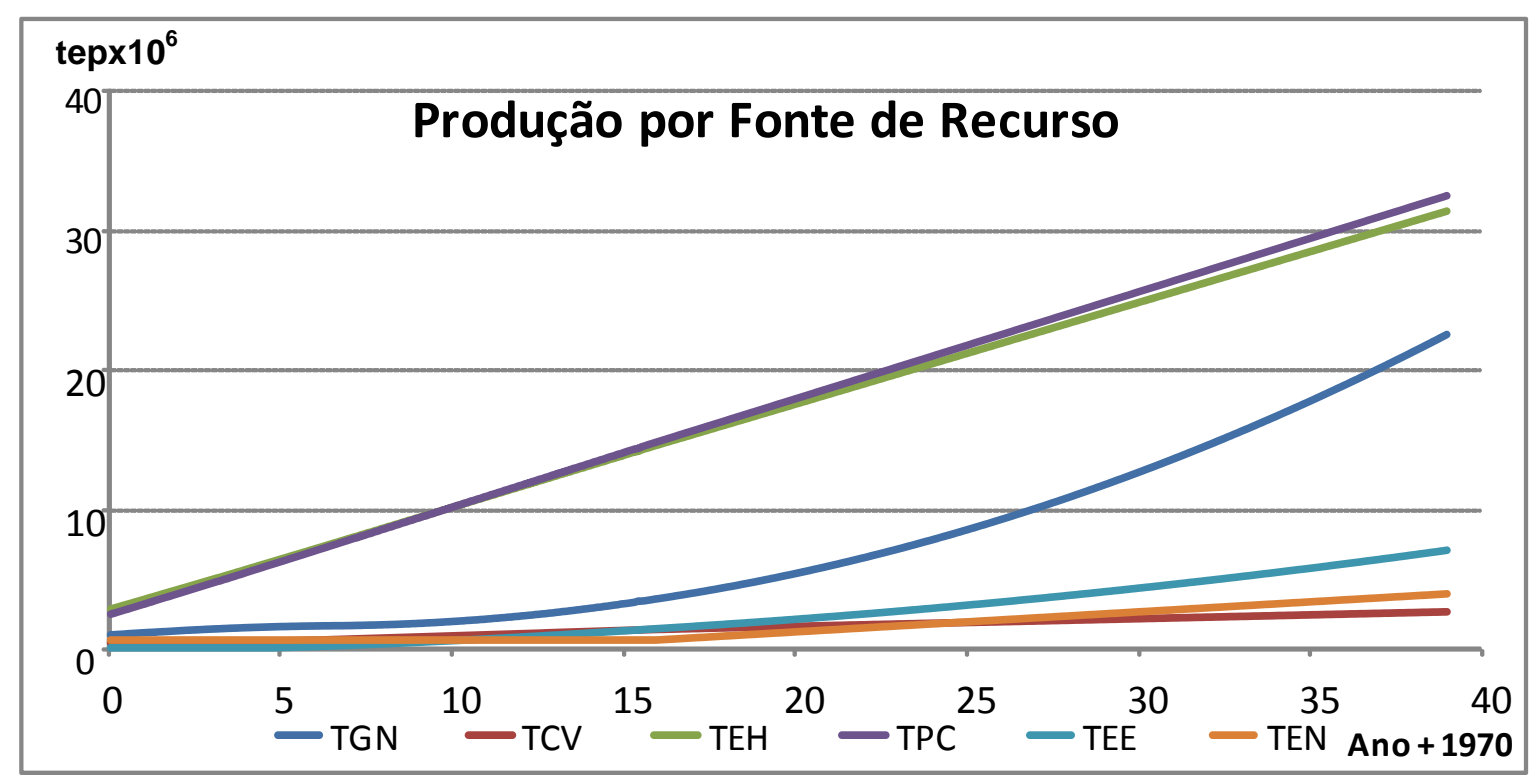

FIGURA 55 - Produção sem perturbação por fonte de recurso para validação do modelo (até 2009). 
As tabelas 19 e 20 apresentam os resultados das produções individuais para cada fonte de recursos e a totalização, para os anos 2004 e 2009, respectivamente.

$\mathrm{Na}$ tabela 19 verifica-se que os desvios, entre os valores calculados e os valores constantes no relatório BEN, estão na faixa de $5 \%$ para o ano de 2004, último ano calculado diretamente pelas funções selecionadas para cada fonte de recursos.

Na tabela 20 os valores calculados até o ano de 2004, e entre 2005 e 2009 estimados através da curva de tendência, continuam acompanhar os resultados do BEN, porém com diferenças um pouco maiores.

TABELA 19 - Comparação dos resultados BEN2004 e Projeção.

\begin{tabular}{lrrr}
\hline FONTE & BEN 2004 & SIMULAÇÃO & DESVIO\% \\
\hline GÁS NATURAL & 19.061 & 16.623 & $12,79 \%$ \\
CARVÃO VAPOR & 2.085 & 2.406 & $-15,37 \%$ \\
ENERGIA HIDRELÉTRICA & 27.589 & 27.848 & $-0,94 \%$ \\
PRODUTOS DE CANA & 29.385 & 28.663 & $2,46 \%$ \\
ENERGIA EÓLICA & 5.860 & 5.489 & $6,34 \%$ \\
ENERGIA NUCLEAR & 5.904 & 3.333 & $43,55 \%$ \\
\hline TOTAL & 89.885 & 84.362 & $\mathbf{6 , 1 4 \%}$ \\
\hline
\end{tabular}

TABELA 20 - Comparativo dos resultados BEN2009 e Simulação.

\begin{tabular}{lrrr}
\hline FONTE & BEN 2009 & SIMULAÇÃO & DESVIO\% \\
\hline GÁS NATURAL & 21.145 & 22.490 & $-6,36 \%$ \\
CARVÃO VAPOR & 1.886 & 2.666 & $-41,38 \%$ \\
ENERGIA HIDRELÉTRICA & 33.625 & 31.482 & $6,37 \%$ \\
PRODUTOS DE CANA & 45.252 & 32.471 & $28,24 \%$ \\
ENERGIA EÓLICA & 9.237 & 7.067 & $23,49 \%$ \\
ENERGIA NUCLEAR & 3.871 & 4.037 & $-4,30 \%$ \\
\hline TOTAL & $\mathbf{1 1 5 . 0 1 5}$ & $\mathbf{1 0 0 . 2 1 3}$ & $\mathbf{1 2 , 8 7 \%}$ \\
\hline
\end{tabular}

A diferença absoluta, na tabela 19, na fonte de recursos de gás natural, se deve ao ajuste do acordo de exportação de gás natural da Bolívia para o Brasil.

Nota-se ainda, na tabela 20 , que a maior diferença absoluta é nos produtos de cana. Esta diferença se deve a um crescimento acima do 
previsto de 2004 a 2009. Nos outros casos em que as diferenças relativas foram acentuadas, como os casos do carvão vapor e da energia nuclear, isto se deveu a diferença de uma ordem de grandeza nos valores absolutos de produção do carvão e urânio quando comparado com as outras fontes de recursos. Assim mesmo, a diferença de totalização é aproximadamente de $12 \%$.

Estas diferenças apresentadas na tabelas 19 e 20 se devem principalmente às incertezas contidas nos dados, tais como perdas na produção, perdas no armazenamento e ajustes estatísticos, que não estão considerados no equacionamento do modelo.

\subsection{Comportamento do modelo com perturbações}

Para análise do modelo foram feitas simulações com e sem perturbações nas fontes de recursos e obtidos os resultados que servem de avaliação do comportamento do modelo.

\subsubsection{Comportamento com perturbações de curto prazo}

Nesta fase, impuseram-se perturbações pontuais em fontes de recursos individualmente ou em grupos e verificaram-se os desvios da produção total com e sem perturbações, para o período de 2010 a 2027.

A figura 56 apresenta a simulação até 2027 sem perturbações no sistema e a figura 57 apresenta a simulação com perturbação na fonte de recursos nuclear no ano de 2020 de um valor de 15000 tep, que é um valor significativamente grande para que os efeitos sejam percebidos com clareza.

Os gráficos das figuras 56a) e 57a) apresentam os deltas de cada fonte de recurso, os gráficos das figuras 56b) e 57b) os valores de produção individuais e os gráficos das figuras 56c) e 57c) os valores totais com e sem perturbação. 
a)

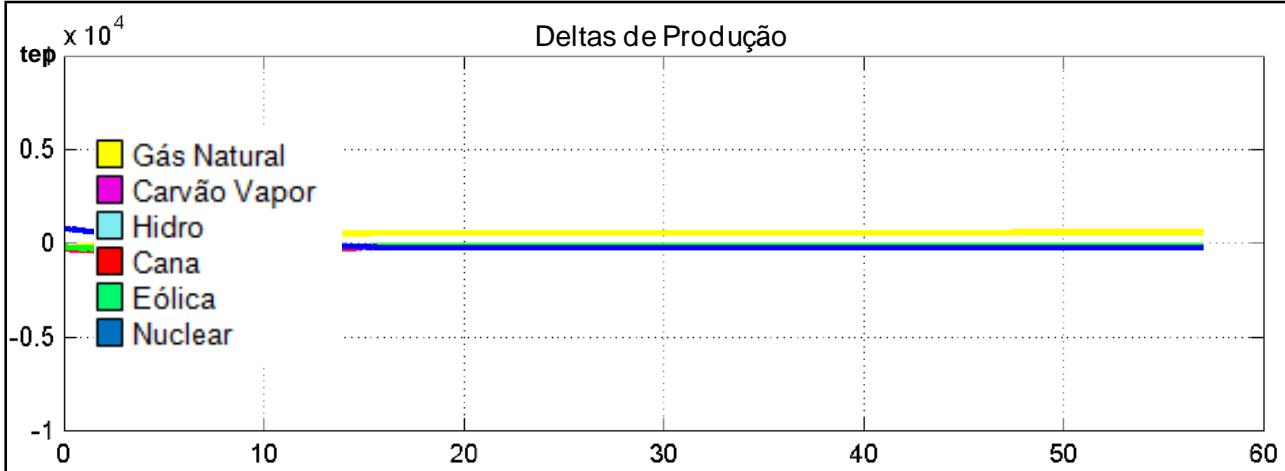

b)

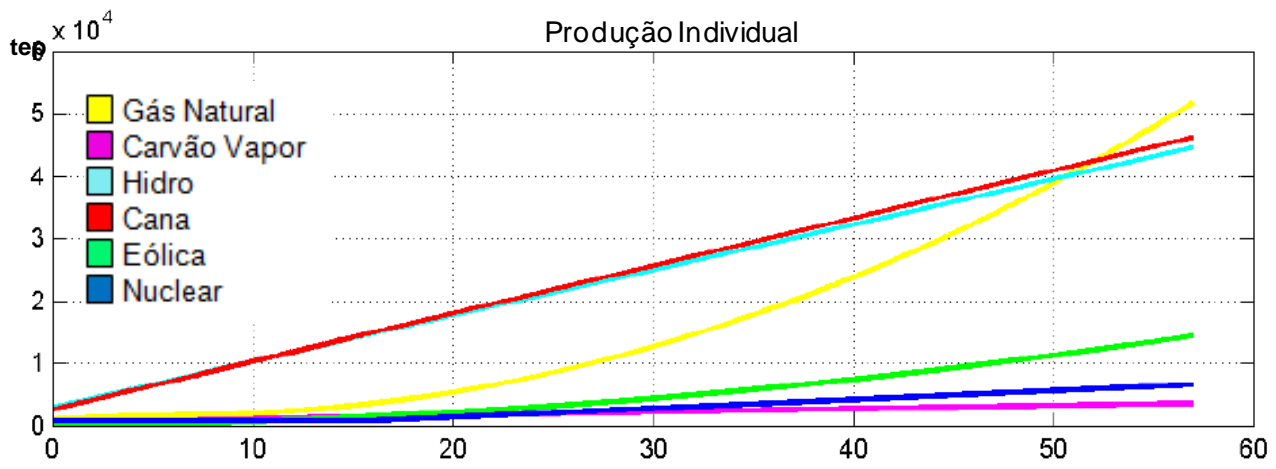

c)

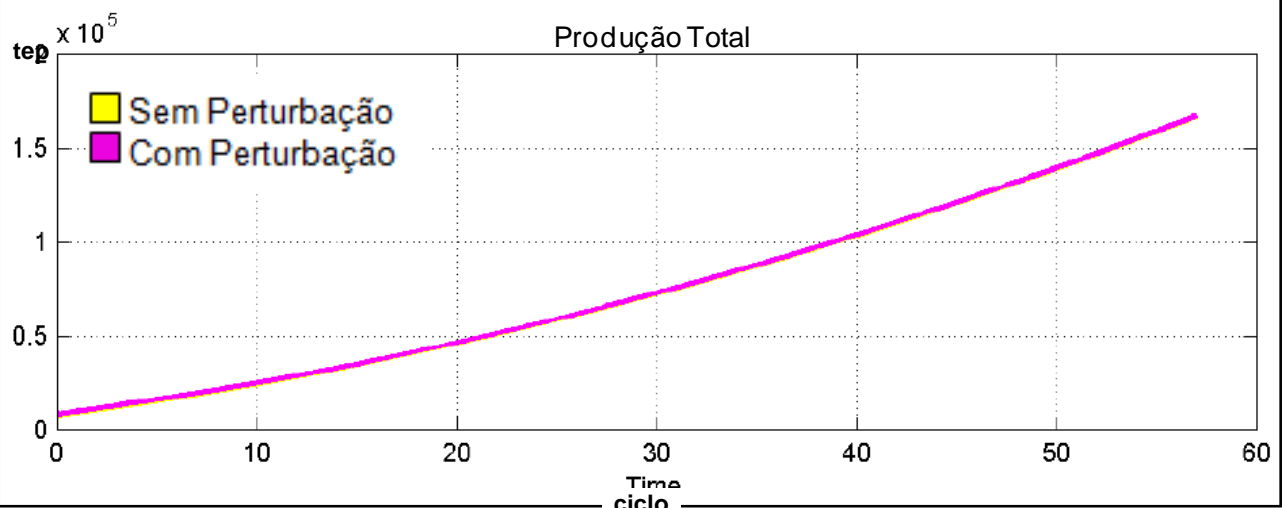

FIGURA 56 - Gráficos de produção sem perturbação (até 2027): a) delta de produção; b) produção por fonte de recurso e c) comportamento do sistema sem perturbação.

Nos gráficos da figura 57 as produções totais com e sem perturbação mantiveram-se muito próximas, mesmo com a aplicação de uma grande perturbação numa das fontes de recursos, 15000 tep na fonte de energia nuclear, no ano de 2015.

No gráfico da figura 57a) dos desvios e 57b) das produções individuais, pode-se observar que o acréscimo numa das fontes de recursos tende a ser compensado pelo decréscimo dos valores das demais, como esperado. 
A diferença entre a produção total sem perturbação e a produção corrigida, com perturbação, de menos de 5000 tep, se deve aos ajustes de produção individuais e também eram esperados.

a)

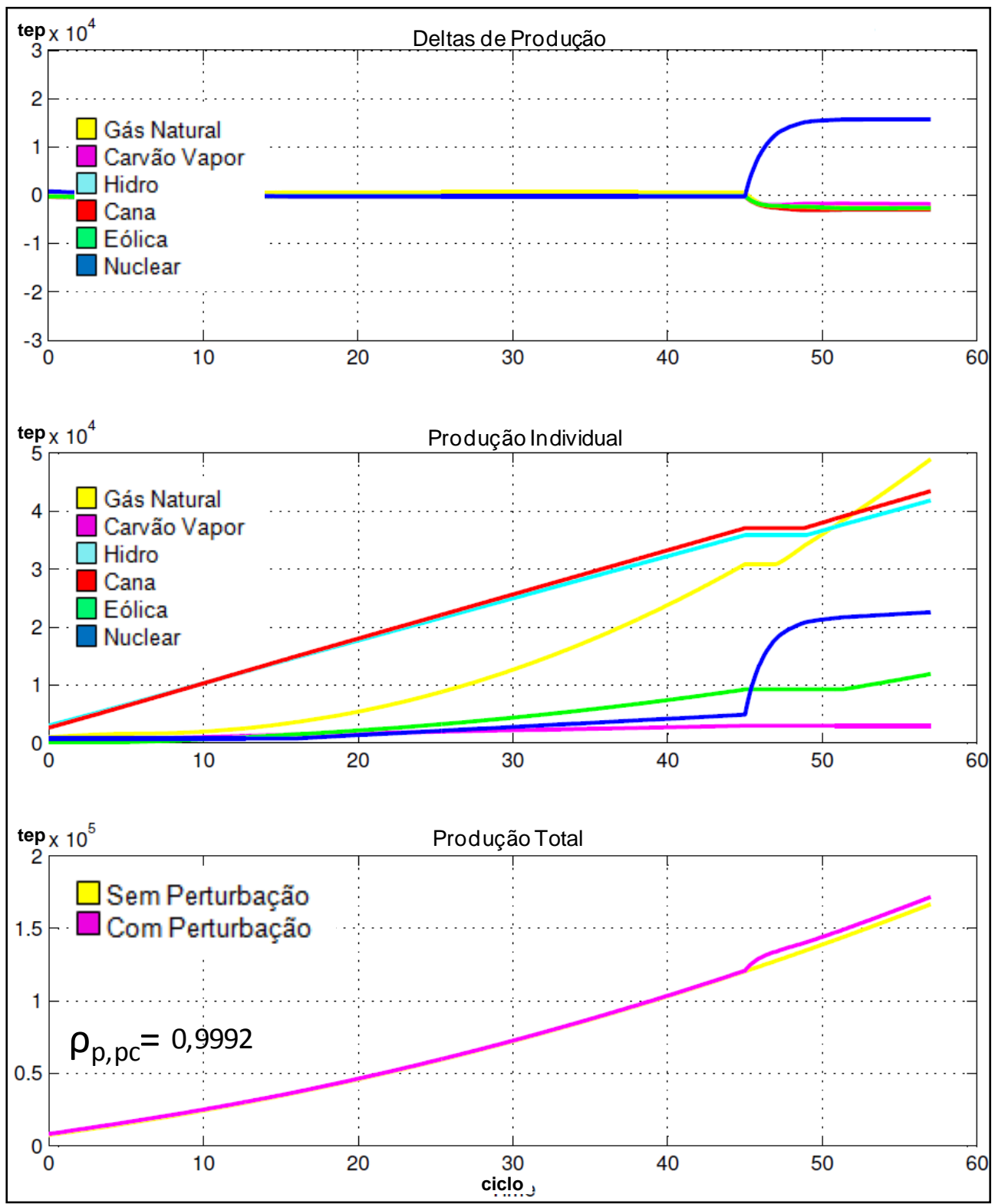

FIGURA 57 - Gráficos de produção com perturbação de 15000 tep, na fonte nuclear, em 2020 (até 2027): a) delta de produção; b) produção individual e c) comportamento do sistema com perturbação.

Comparando-se os gráficos das figuras 56a) e 57a) observa-se que, embora haja mudanças nos deltas de produção, após o ciclo 45, referente ao ano 2015, quando foi gerada a perturbação na fonte de recurso de energia nuclear, as outras fontes de recursos decresceram 
proporcionalmente aos seus próprios valores de produção e assim, o valor da produção total não apresentou mudanças significativas, conforme apresentados nos gráficos das figuras 56c) e 57c).

Os desvios observados efetivamente retratam a introdução do bloco $F(s)=\frac{k}{s+a}$, sugerindo que qualquer perturbação tem um tempo de acomodamento.

O valor final do sinal de saída da função, no tempo, é obtido pela expressão $f(\infty)=\lim _{s \rightarrow 0} s . F(s)$, dado pelo teorema do valor final, redundando, no caso, em um valor final $f(\infty)=0$. O erro estacionário não nulo observado indica que o sistema é de segunda ordem, portanto com erro de velocidade, e de acordo com os resultados esperados.

\subsubsection{Comportamento do modelo com perturbações de médio} prazo

O resultado desta fase foi obtido estendendo-se o tempo de observação até o ciclo 70 , referente ao ano de 2040, nas simulações sem e com perturbações nas várias fontes de recursos.

Os gráficos da figura 58 apresentam a evolução dos deltas de produção (figura 58a), das produções individuais (figura 58b) e das produções totais (figura 58c), sem perturbações, até o ano de 2040. 
а)

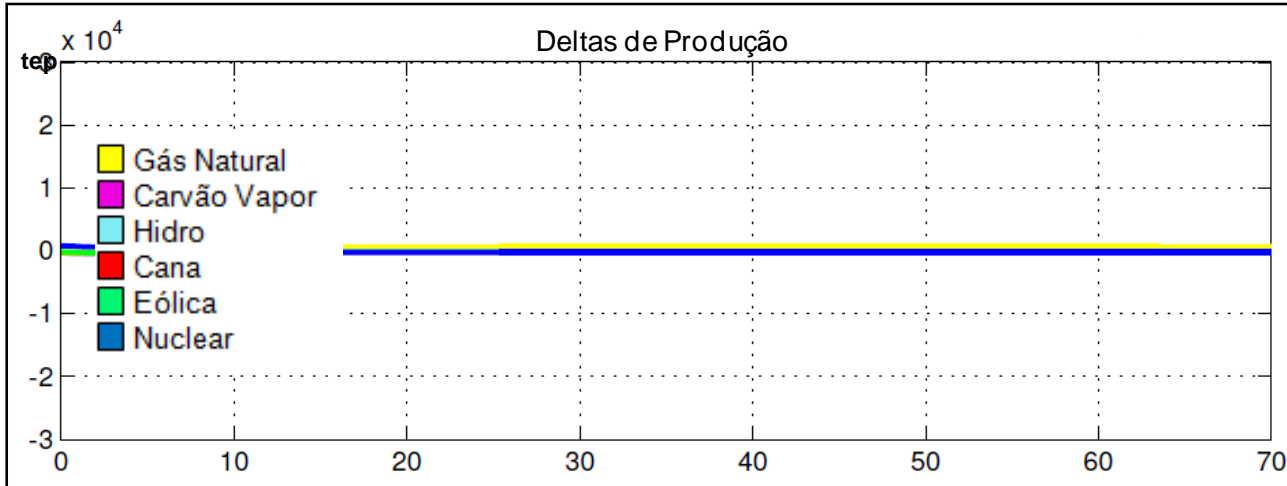

b)

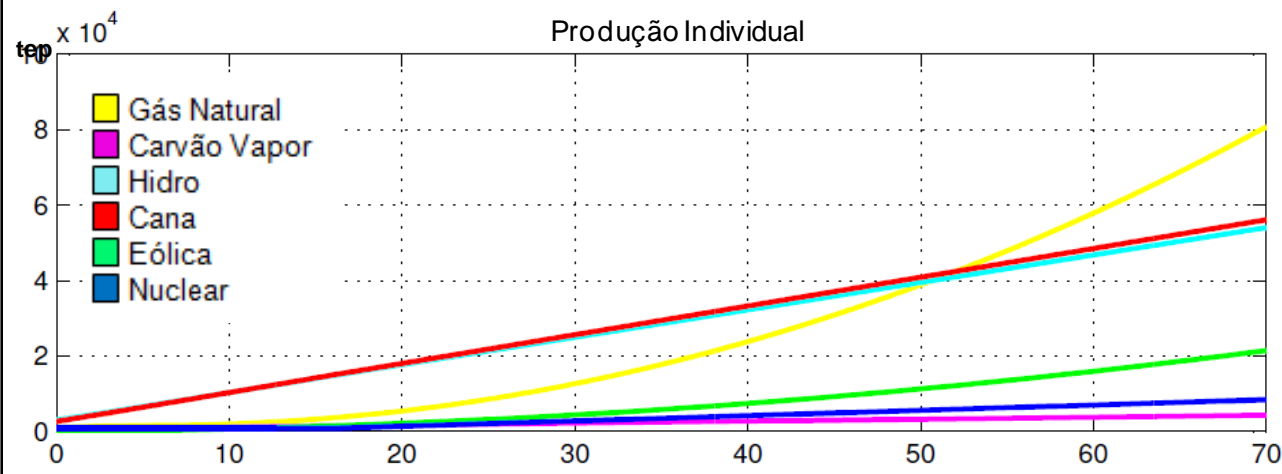

c)

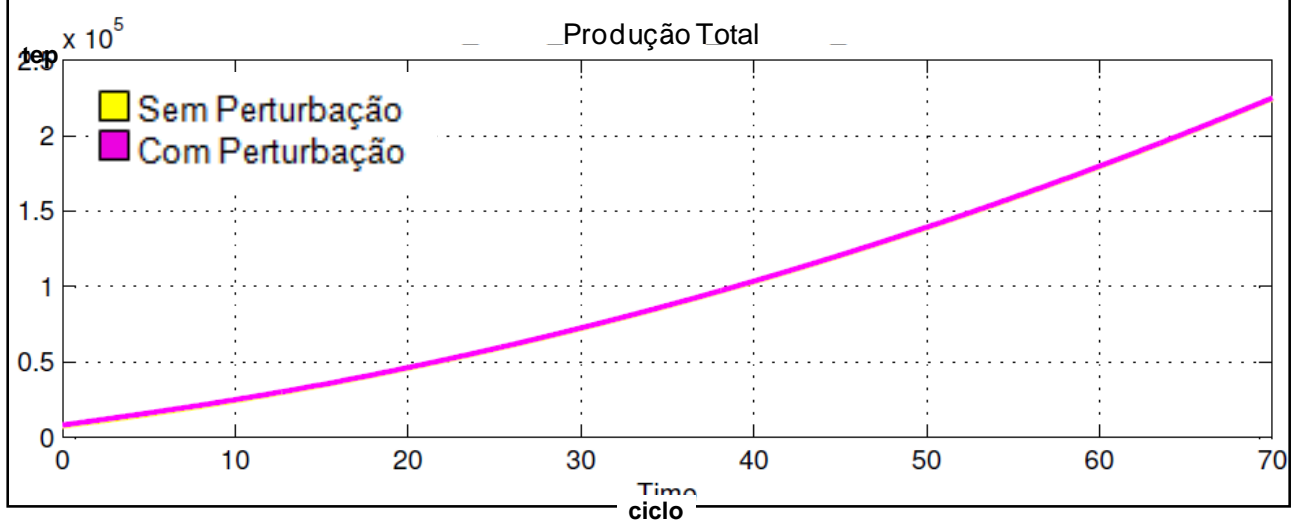

FIGURA 58 - Gráficos de produção sem perturbação: a) delta de produção; b) produção individual e c) comportamento do sistema sem perturbação.

Os gráficos das figuras 59 e 60 apresentam as evoluções de produção com perturbações, no ciclo 45 , referente ao ano de 2015 , de um valor de 15000 tep, nas fontes de recursos nuclear e hídrico, respectivamente. 
a)

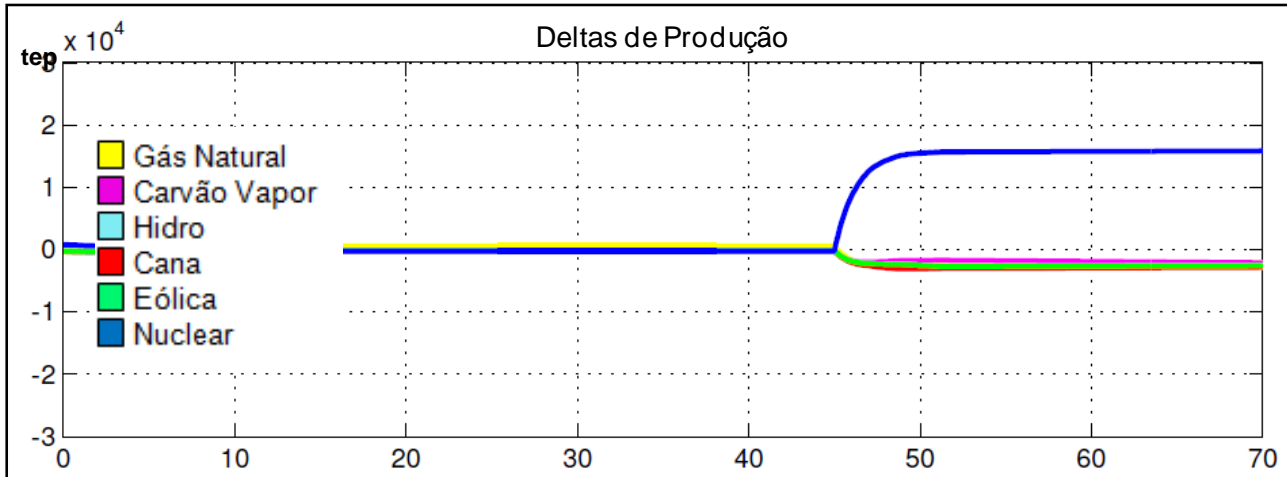

b)

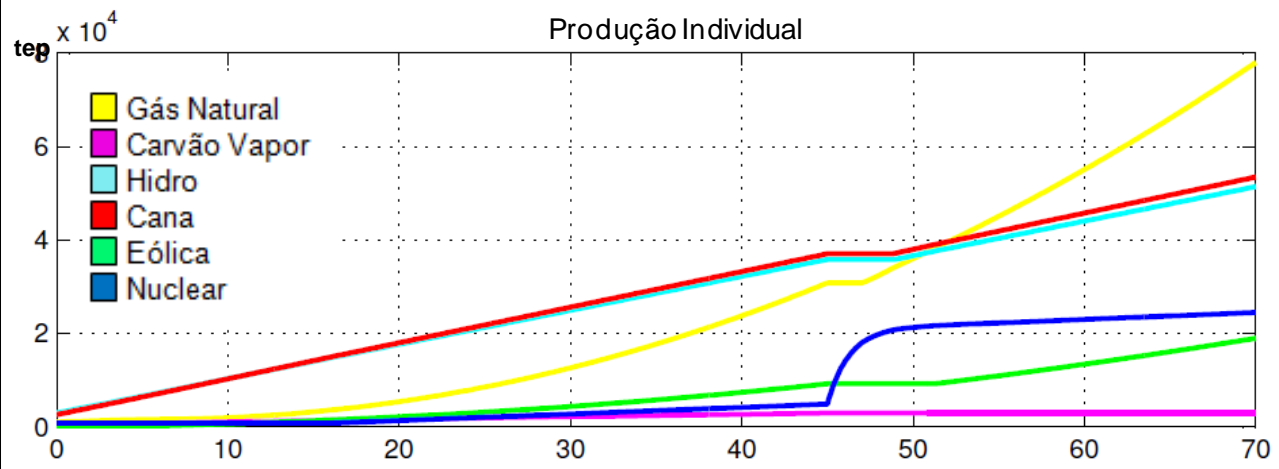

c)

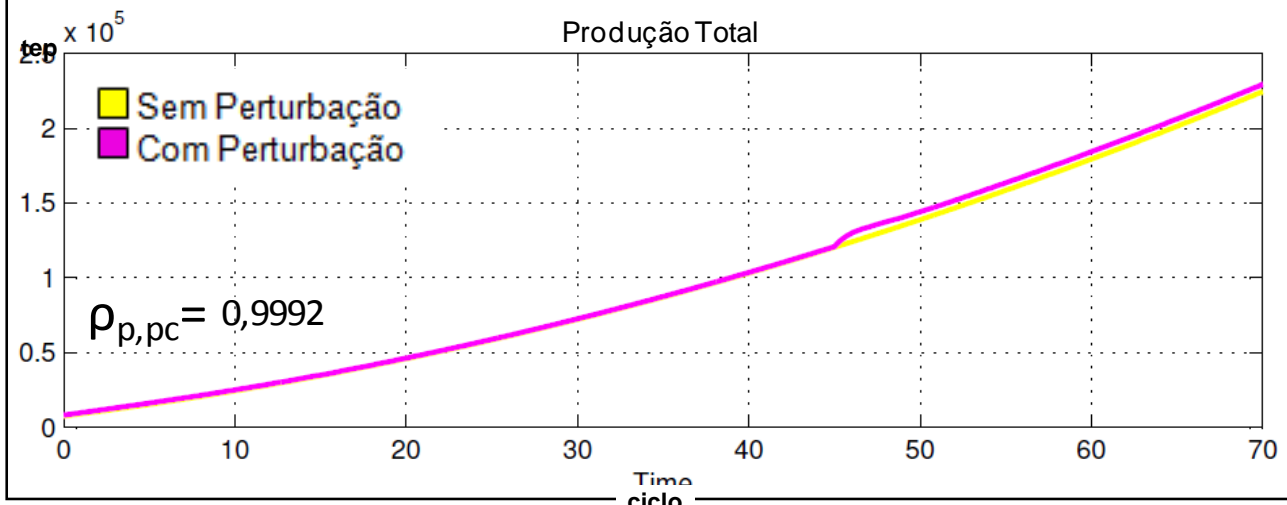

FIGURA 59 - Gráficos de produção com perturbação de 15000 tep, na fonte nuclear, em 2015 (até 2040): a) delta de produção; b) produção individual e c) comportamento do sistema com perturbação.

Para uma perturbação de 15000 tep, na fonte de recursos nuclear, observou-se uma diferença total na produção de menos de 5000 tep, entre os valores com e sem perturbação. 
a)

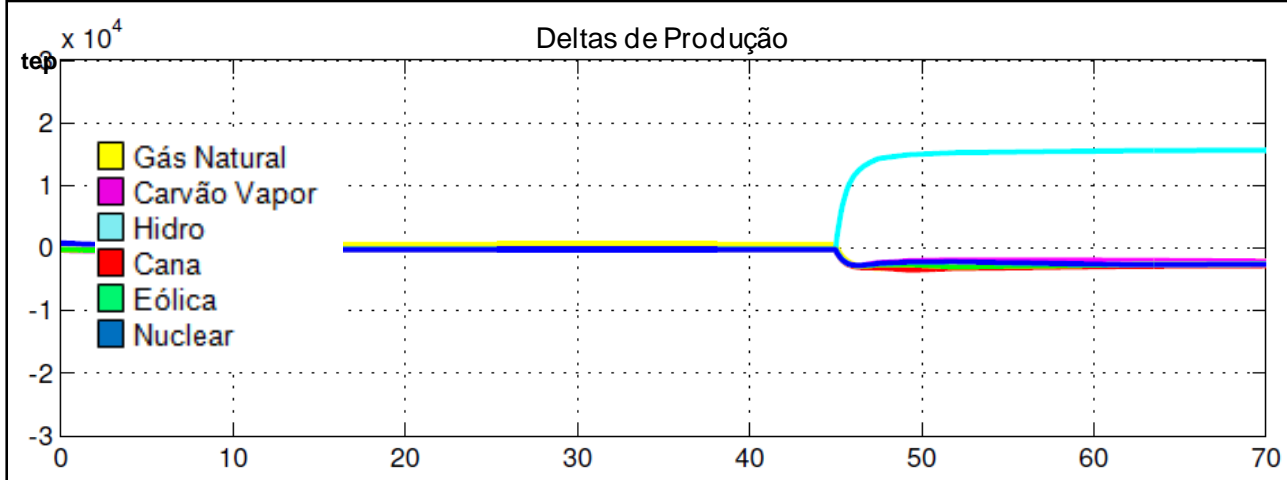

b)

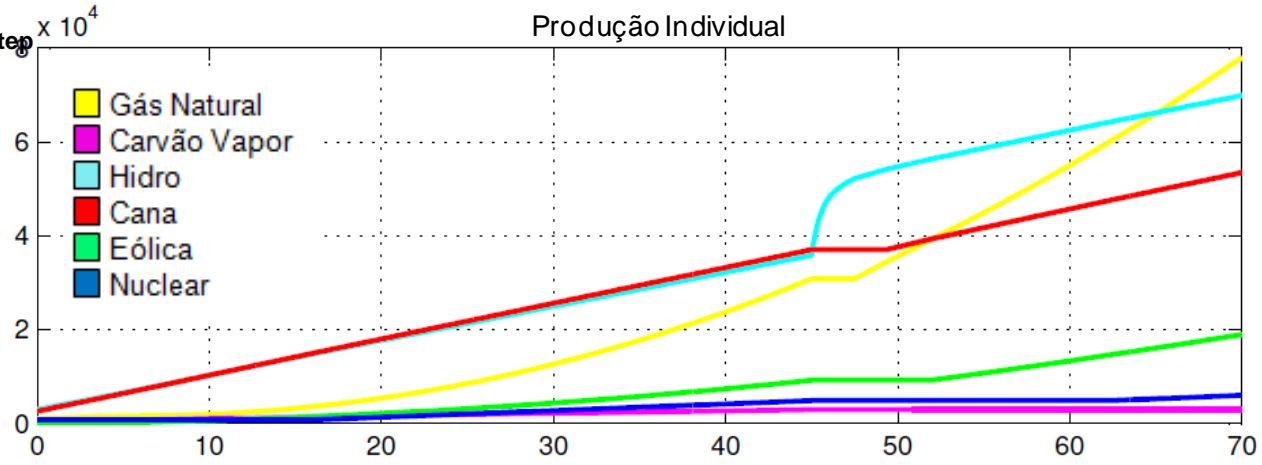

c)

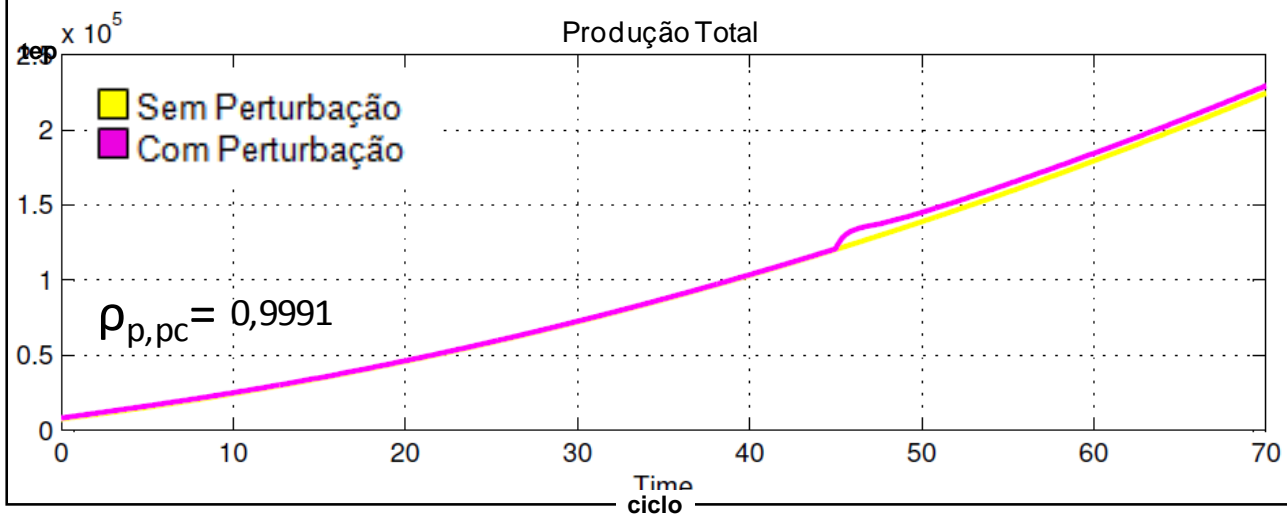

FIGURA 60 - Gráficos de produção com perturbação de 15000 tep, na fonte hídrica, em 2015 (até 2040): a) delta de produção; b) produção individual e c) comportamento do sistema com perturbação.

Para uma perturbação de 15000 tep, na fonte de recursos hídricos, observou-se também uma diferença total na produção de menos de 5000 tep, entre os valores com e sem perturbação.

Os gráficos da figura 61 apresentam a evolução da produção, para o período de observação de 70 ciclos, até o ano 2040, com perturbações de 5000 tep em todas as fontes de recursos, escalonadas de 3 em 3 anos a partir do ano 2015. 
a)

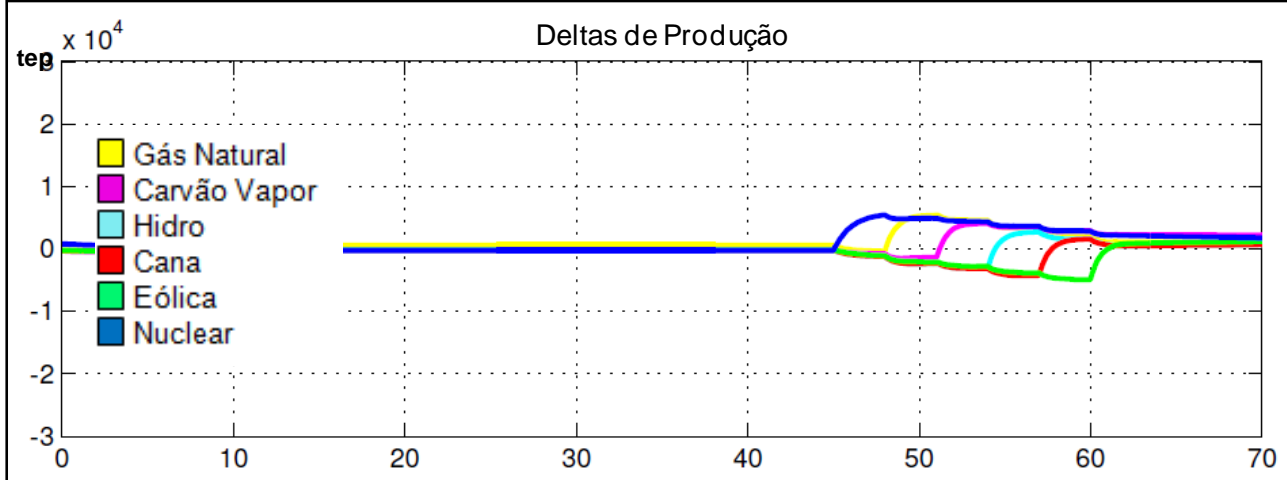

b)

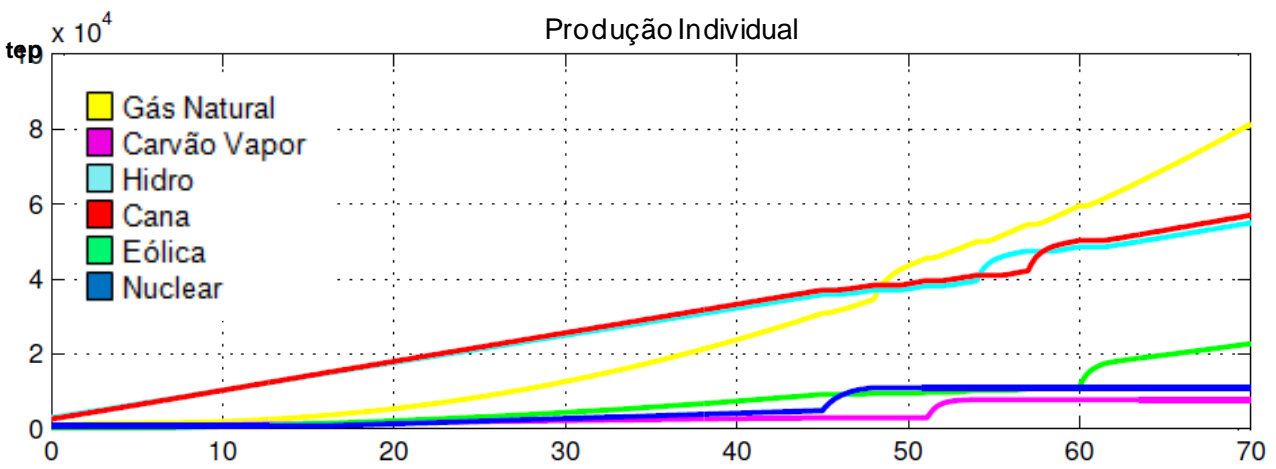

c)

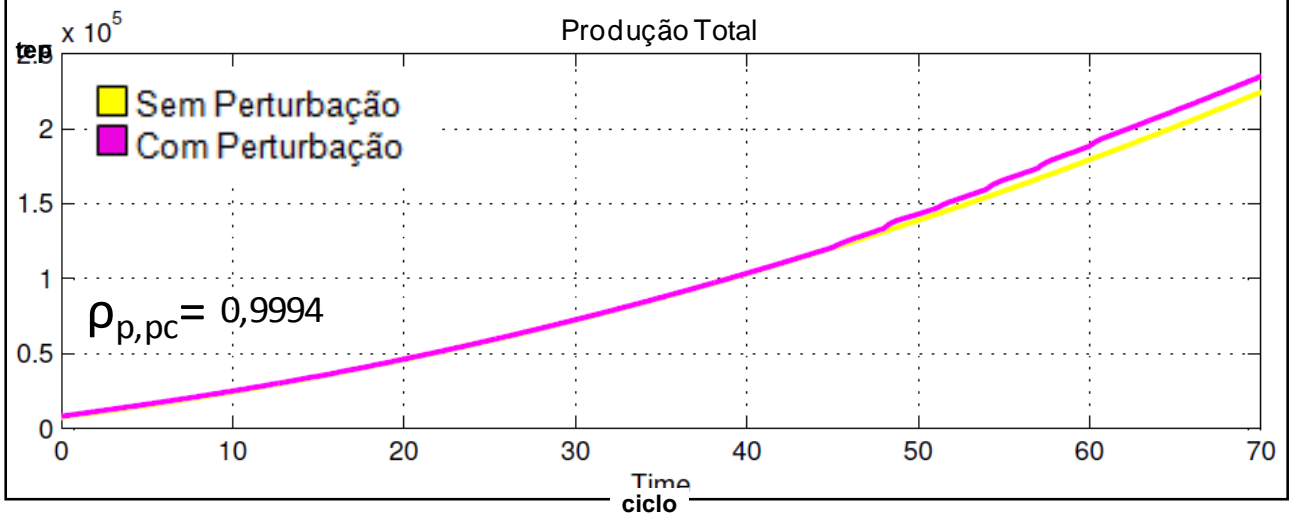

FIGURA 61 - Gráficos de produção com perturbações individuais entre 2015 e 2030 (até 2040): a) delta de produção; b) produção individual e c) comportamento do sistema com perturbação.

A diferença entre as produções totais, no final do ano 2040, é de aproximadamente 10000 tep, para uma perturbação total de 30000 tep.

Note-se que, independentemente da fonte de recurso em que se aplicou a perturbação, os valores de produção total mantiveram-se (gráfico da figura 61c), sendo corrigida pelas variações individuais de cada uma das outras fontes de recurso. 
Para os gráficos da figura 62 aplicou-se uma perturbação de 15000 tep no ciclo 45 , referente ao ano de 2015 , na fonte de recursos de gás natural.

а)

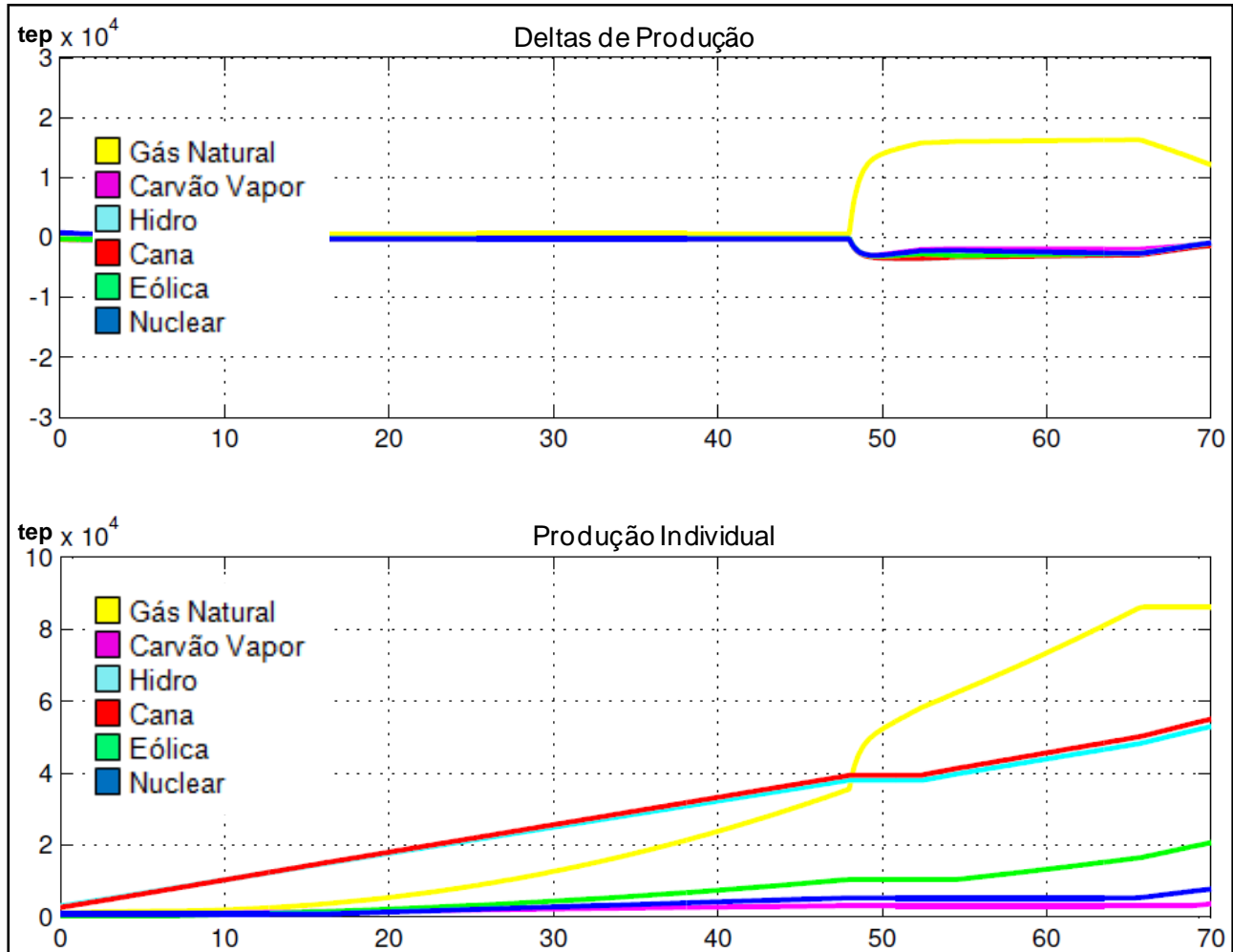

c)

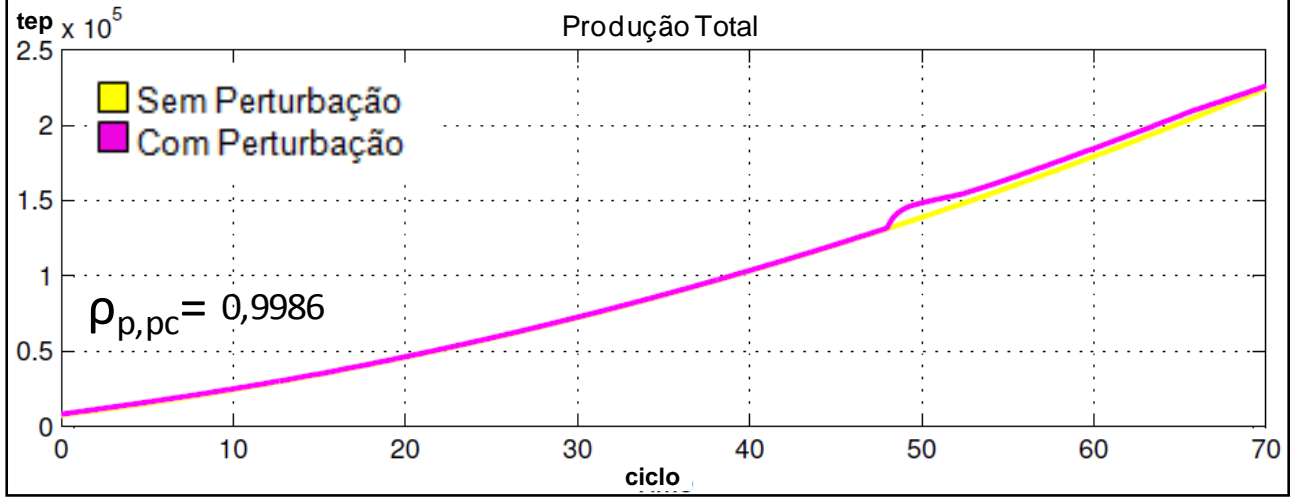

FIGURA 62 - Gráficos de produção com perturbação de 15000, na fonte gás natural, em 2018 (até 2040): a) delta de produção; b) produção individual e c) comportamento do sistema com perturbação.

Neste caso, verificou-se que a partir do ciclo 66 não há acréscimo na produção de gás natural (gráfico da figura 62b). Isso também pode ser verificado pelos gráficos de deltas de produção (gráfico da figura 62a) que, no 
caso do gás natural, começa a decrescer, indicando deltas negativos por ciclo.

Esse efeito se deve ao esgotamento das reservas de gás natural que aparece no ano 2046, com o aumento da sua utilização. Ainda, impõe aumento de produção das outras fontes de recursos para compensar os níveis de consumo, e mesmo com o decréscimo da produção de gás natural, (figuras 62a e 62b), a produção total, (figura 62c), se mantém.

a)

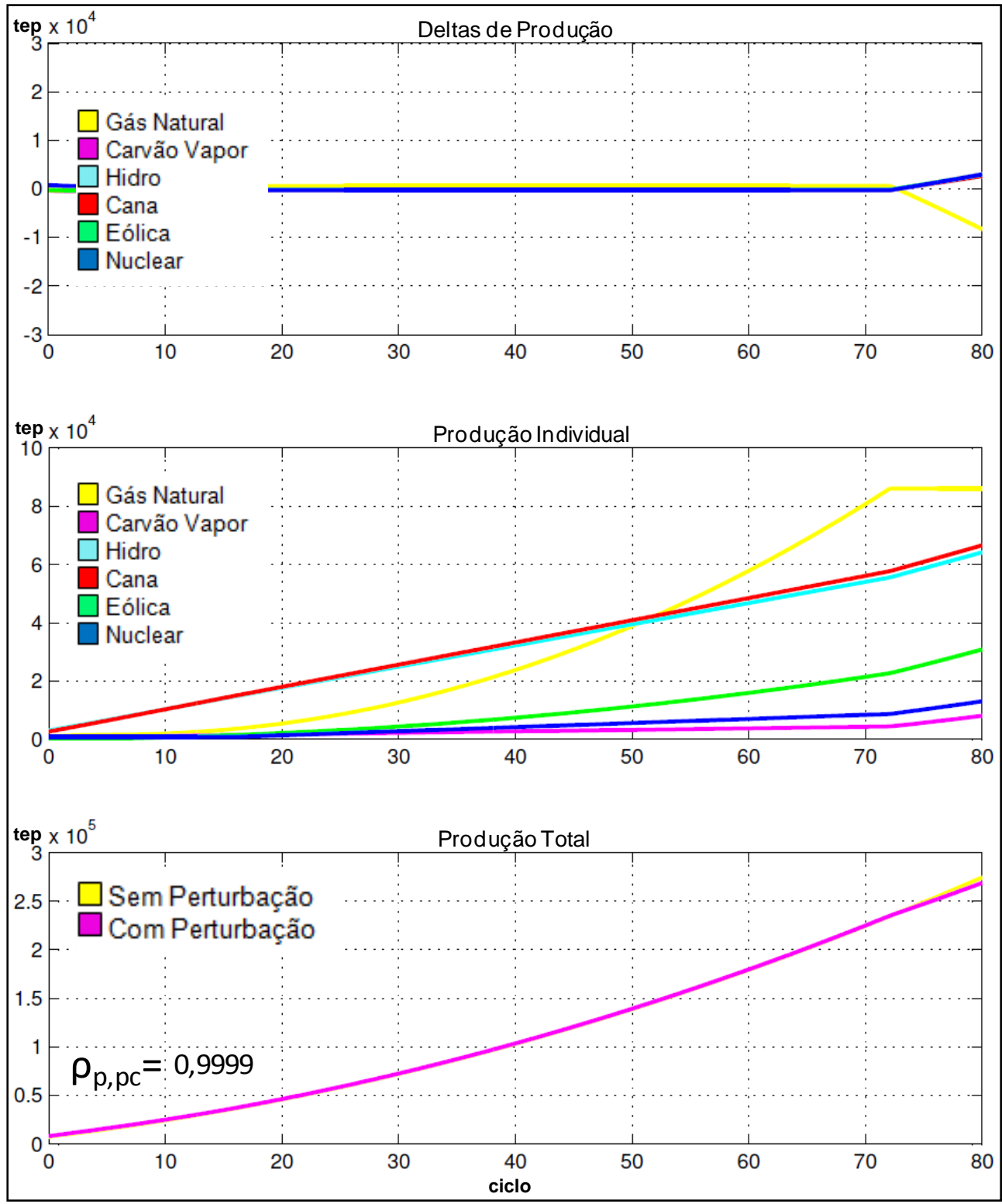

FIGURA 63 - Gráficos de produção sem perturbação, com esgotamento de gás natural: a) delta de produção; b) produções individuais e c) comportamento do sistema sem perturbação. 
Para verificação desse efeito de esgotamento da fonte de recurso de gás natural, estendeu-se o período de simulação até o ciclo 80 , referente ao ano de 2050, sem perturbações. Pode-se notar, pelos gráficos da figura 63, que a partir do ciclo 73 as reservas de gás natural esgotam-se e a produção estaciona no patamar máximo.

A matriz de influência colocada na ferramenta permite que uma diminuição de produção de uma determinada fonte de recursos influencie mais ou menos na variação de cada uma das outras fontes de recursos. Embora a matriz esteja já implementada na ferramenta optou-se por utilizá-la com todos os coeficientes neutros, valores iguais a unidade, isto é, as influências de uma fonte de recursos sobre as outras é proporcional ao valor da produção atual de cada uma delas.

\subsection{Obtenção dos índices com e sem perturbações}

Nesta fase fez-se a projeção para os anos de 2009 até 2040. Obteve-se os índices ambientais para os vários cenários apresentados. Fezse ainda análises comparativas entre os vários cenários propostos.

Os gráficos apresentados, nesta sessão, mostram o desempenho dos índices de sustentabilidade (EIS), impacto ambiental (ELR) e rendimento emergético (EYR) ao longo do tempo, conforme o modelo do exemplo da figura 64.

Ao lado do gráfico dos três índices, aparecem novamente os índices, porém em três gráficos separados, onde estão assinalados os limites recomendados, conforme Broen e Ulgiati (2002). 


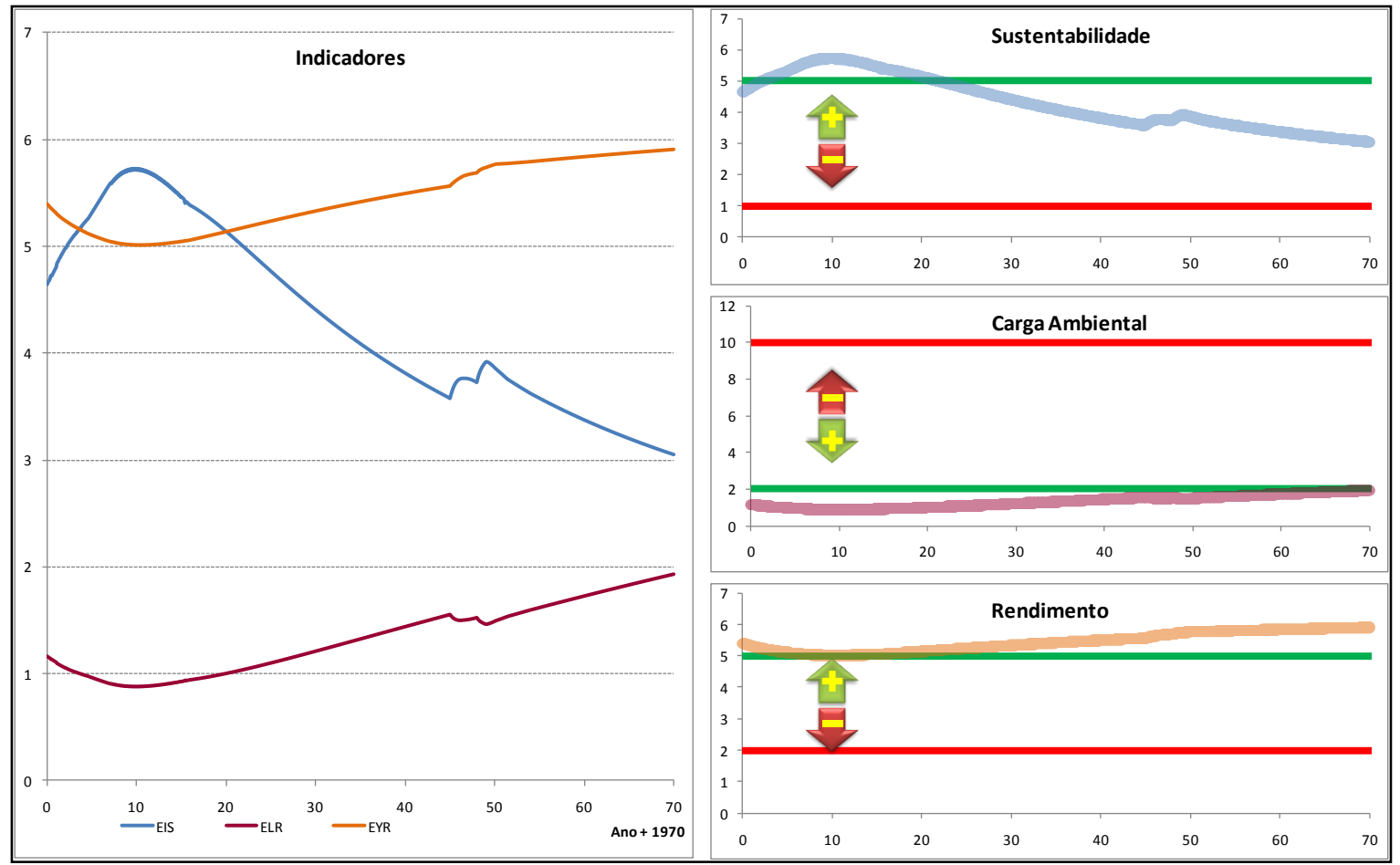

FIGURA 64 - Gráficos dos índices de desempenho (esquerda) e índices de desempenho com marcação dos limites (direita).

Apresenta-se também, o diagrama ternário com 0 percurso emergético. Foi escolhida a indicação de pontos a cada 10 anos para que se tenha a percepção do caminho emergético ao longo do tempo, conforme figura 65a), e a sua versão ampliada, conforme o exemplo da figura 65b).

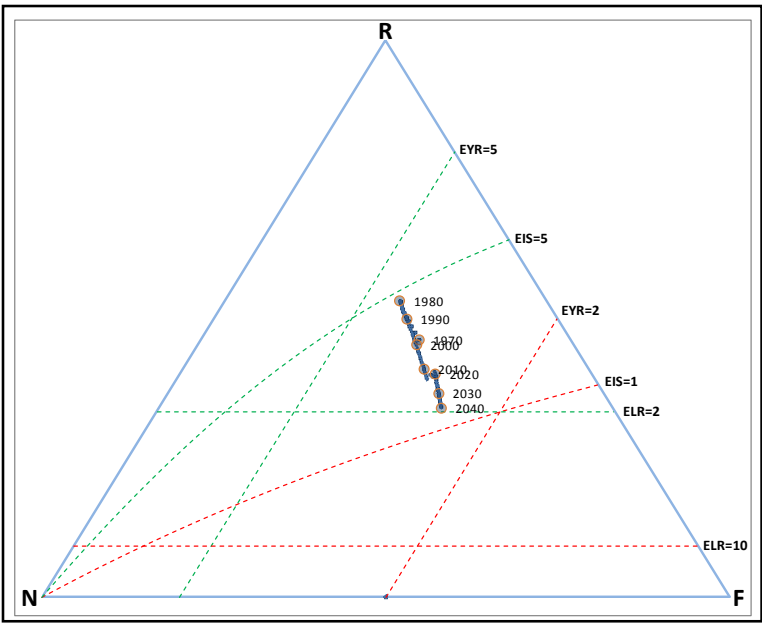

a)

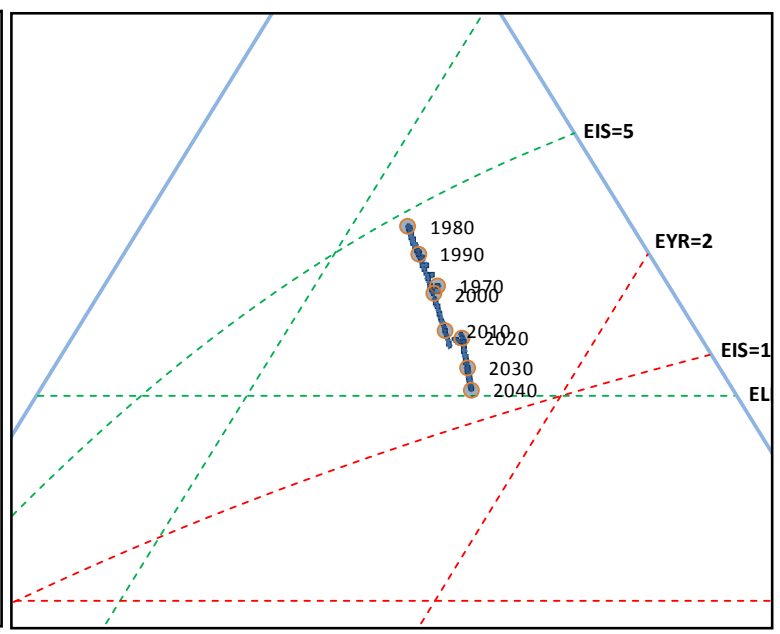

b)

FIGURA 65 - a) Diagrama ternário e b) Diagrama ternário ampliado. 


\subsection{1 Índices: sem Perturbação}

Os gráficos das figuras 66 e 67 apresentam o desempenho dos índices para a simulação, para o caso da remoção de qualquer perturbação individual nas fontes de recursos.

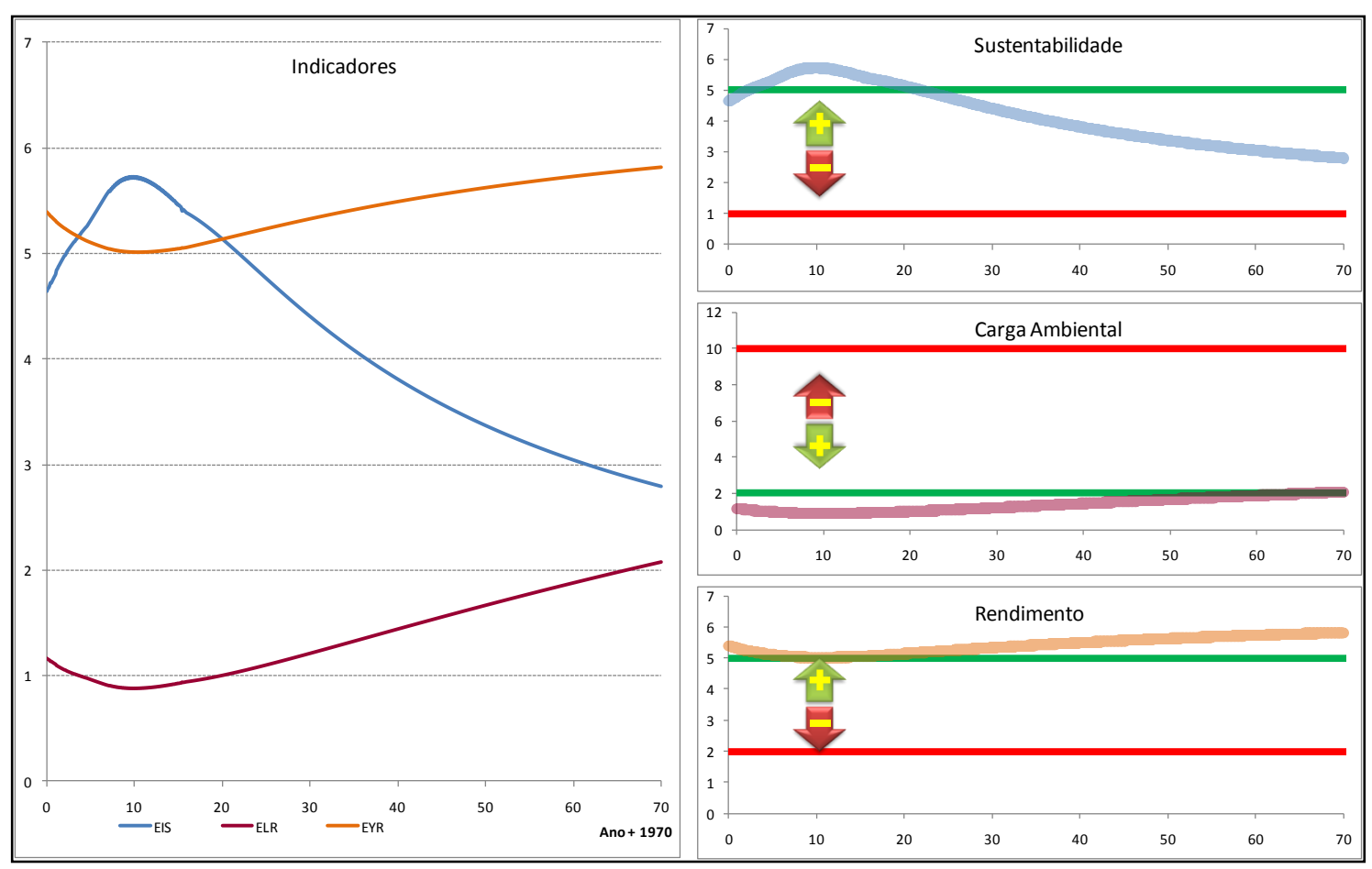

FIGURA 66 - Índices: Sustentabilidade, Impacto Ambiental e Rendimento, sem perturbação.

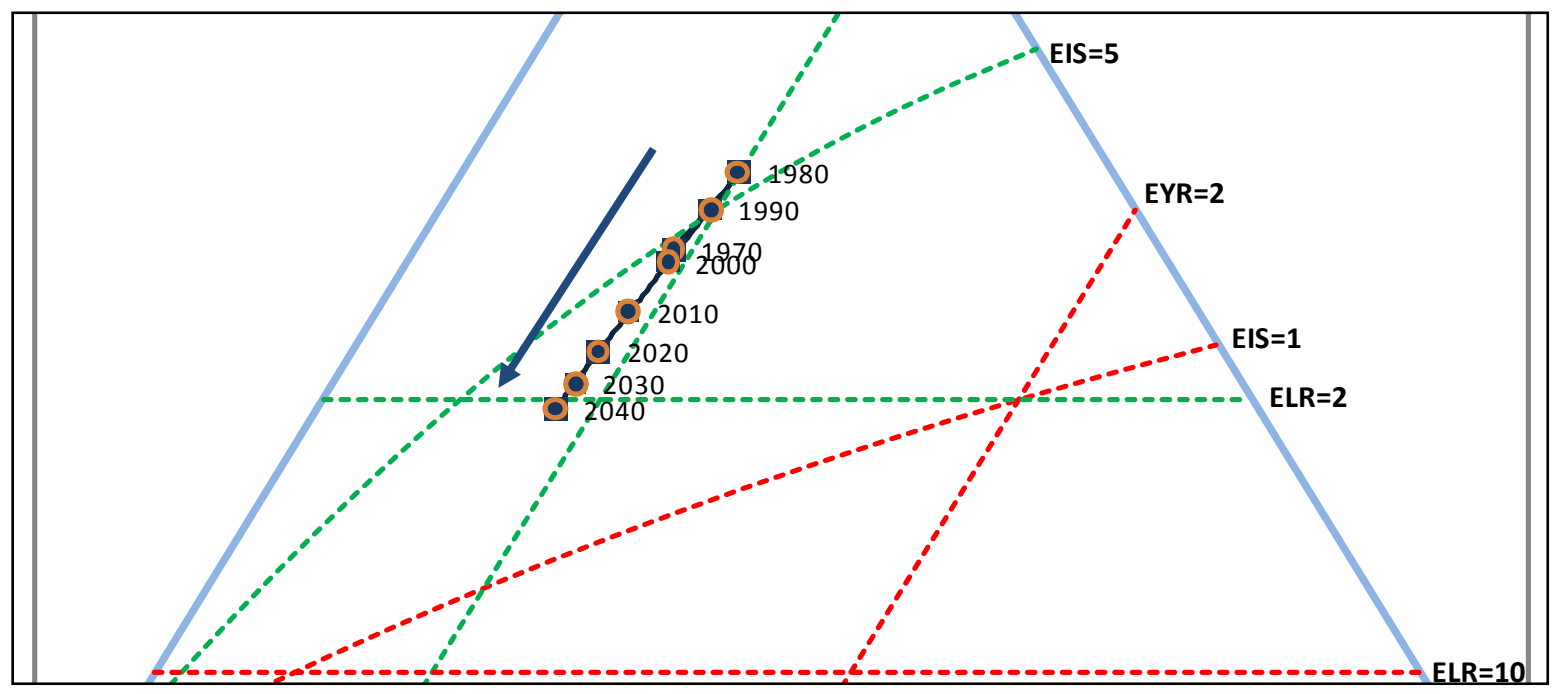

FIGURA 67 - Percurso Emergético sem perturbação. 


\subsection{2 Índices: Perturbação na fonte de Gás Natural}

Os gráficos das figuras 68 e 69 apresentam o desempenho dos índices, para o caso de uma perturbação individual na fonte de recursos de gás natural, de um valor de 10000 tep, no ciclo 45, referente ao ano de 2015.

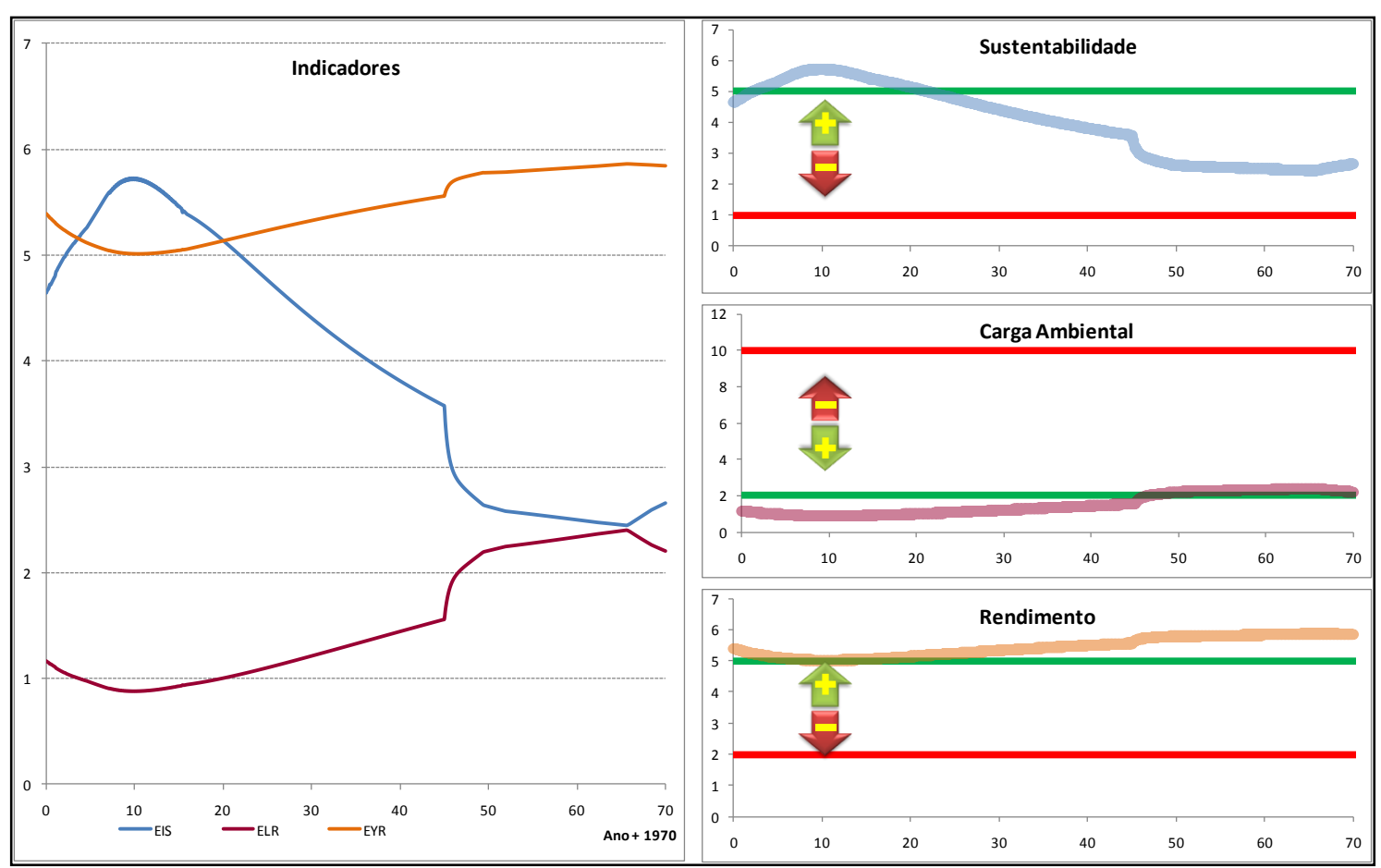

FIGURA 68 - Índices: EIS, ELR e EYR, com perturbação na fonte de Gás Natural de 10000 tep.

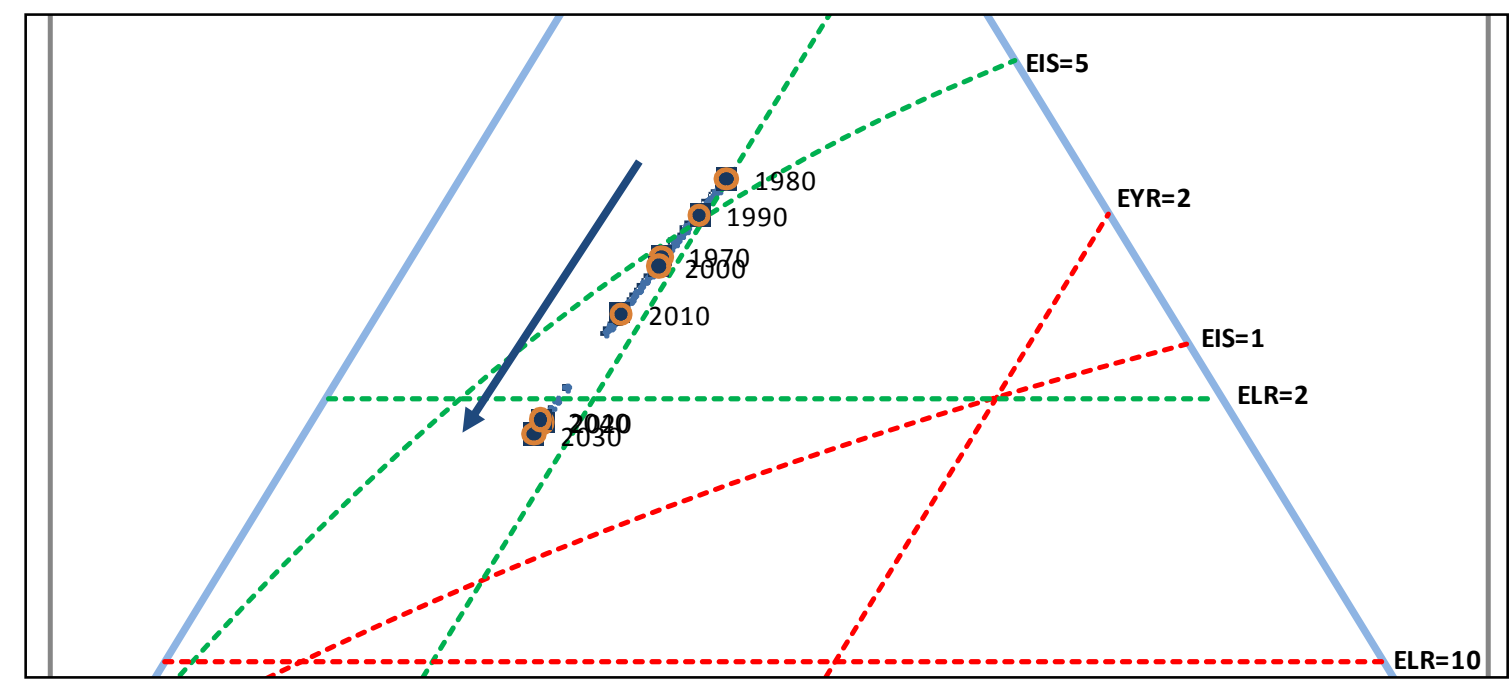

FIGURA 69 - Percurso Emergético com perturbação na fonte de Gás Natural de 10000 tep. 


\subsection{3 Índices: Perturbação na fonte de Carvão Vapor}

Os gráficos das figuras 70 e 71 apresentam o desempenho dos índices, para o caso de uma perturbação individual na fonte de recursos de carvão vapor, de um valor de 10000 tep, no ciclo 45, referente ao ano de 2015.

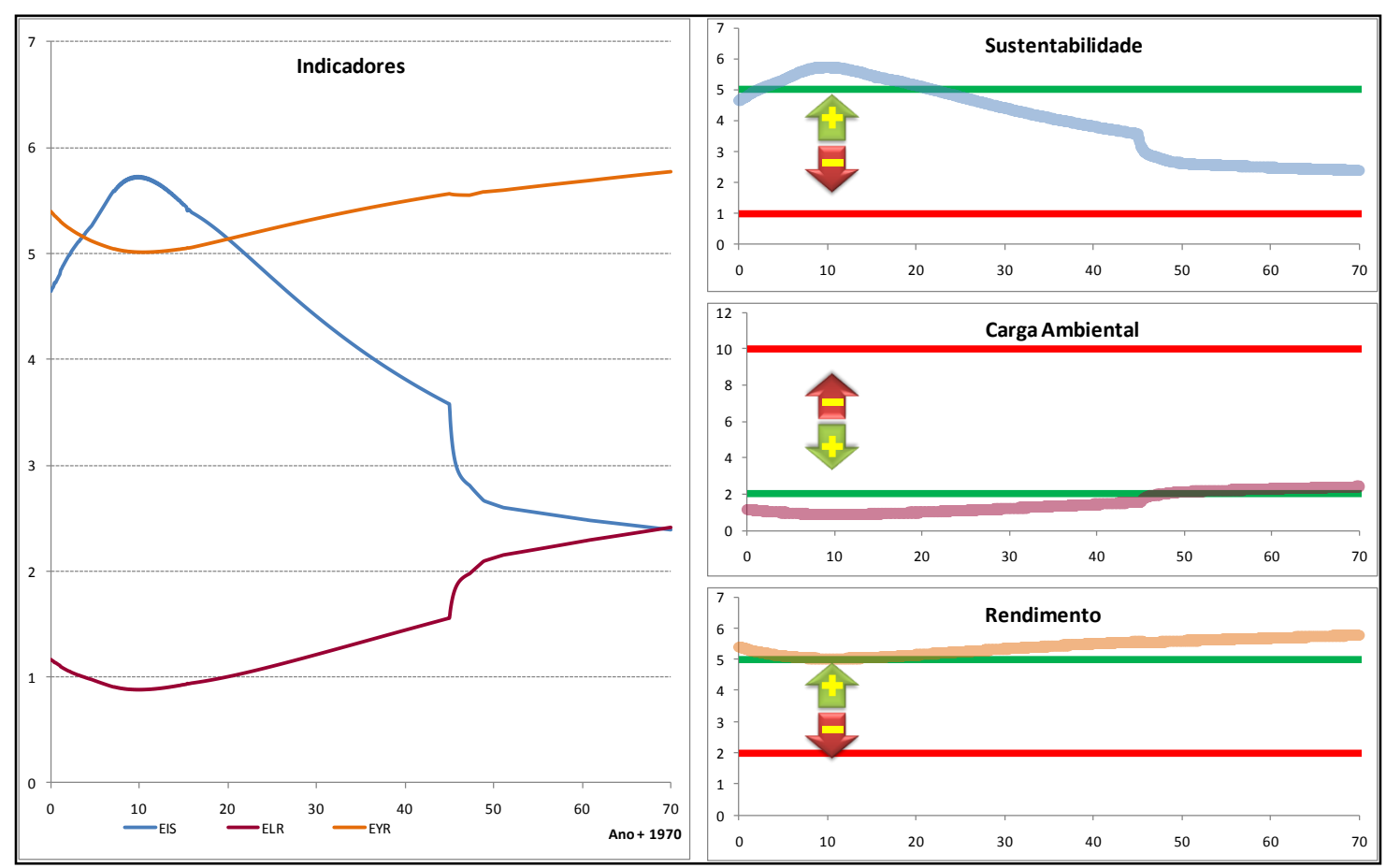

FIGURA 70 - Índices: EIS, ELR e EYR, com perturbação nas fonte de recurso Carvão de 10000 tep.

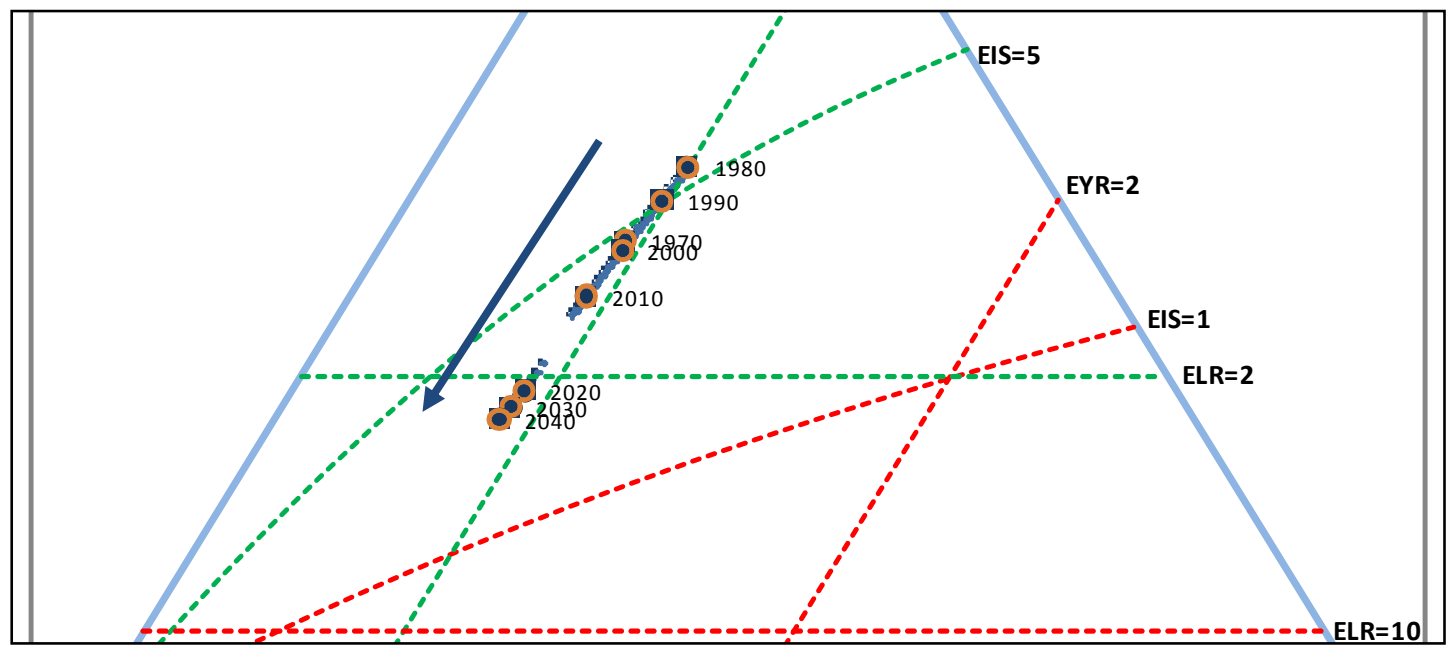

FIGURA 71 - Percurso Emergético com perturbação na fonte de energia Carvão de 10000 tep. 


\subsection{4 Índices: Perturbação na fonte de recursos Hídricos}

Os gráficos das figuras 72 e 73 apresentam o desempenho dos índices, para o caso de uma perturbação individual na fonte de recursos de hídricos, de um valor de 10000 tep, no ciclo 45, referente ao ano de 2015.

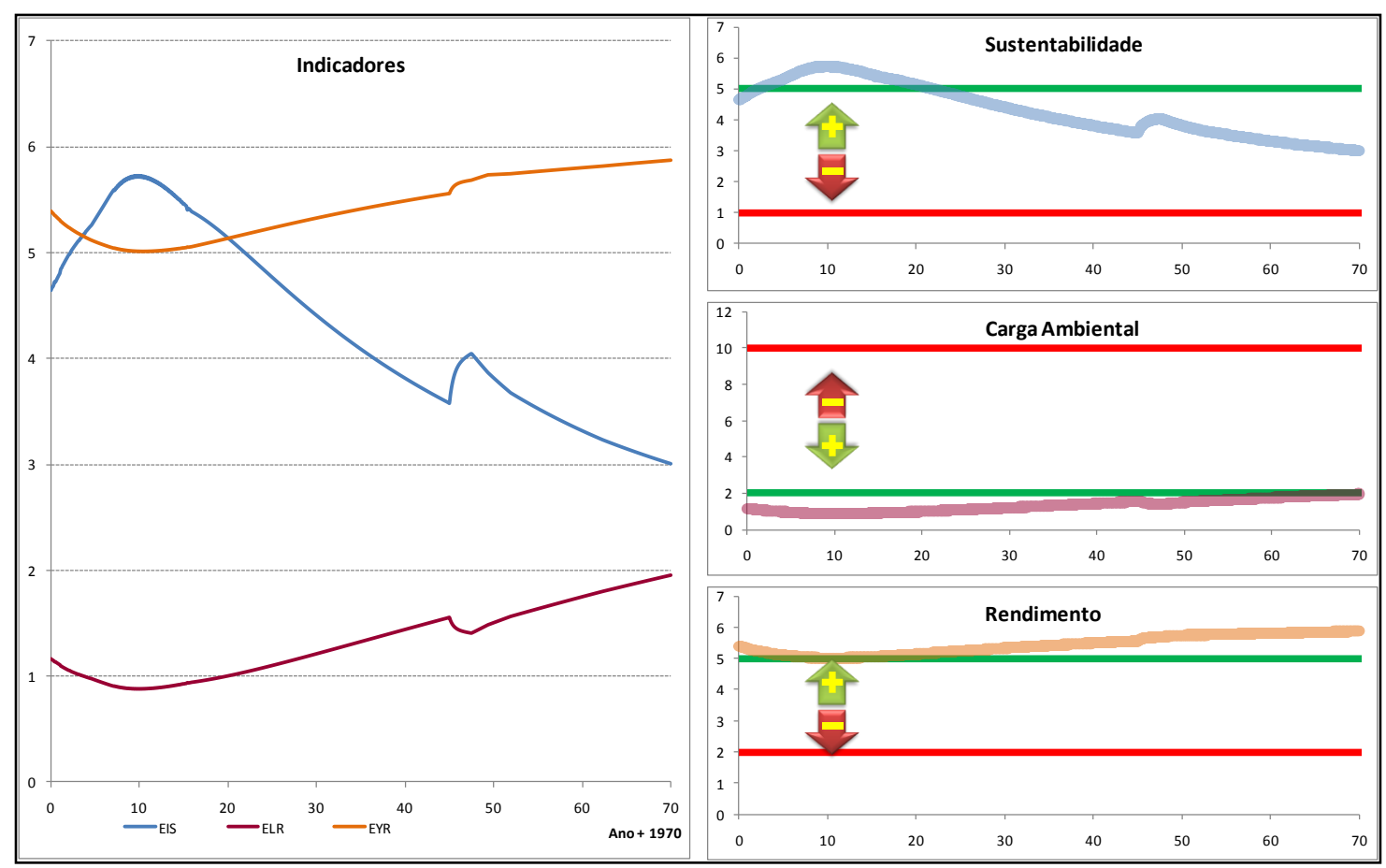

FIGURA 72 - Índices: EIS, ELR e EYR, com perturbação na fonte de energia hídrica de 10000 tep.

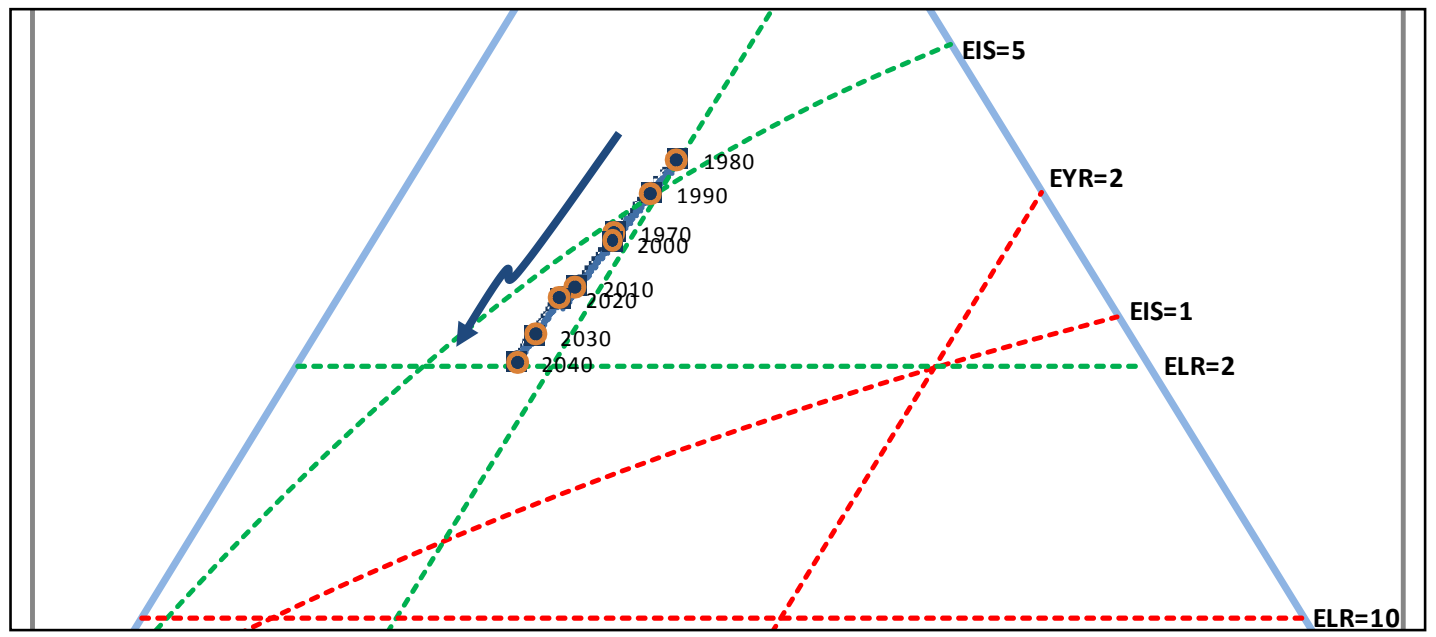

FIGURA 73 - Percurso Emergético com perturbação na fonte de energia hídrica de 10000 tep. 
3.3.5 Índices: Perturbação na fonte de recursos Produtos de Cana

Os gráficos das figuras 74 e 75 apresentam o desempenho dos índices, para o caso de uma perturbação individual na fonte de recursos de produtos de cana, de um valor de 10000 tep, no ciclo 45, referente ao ano de 2015.

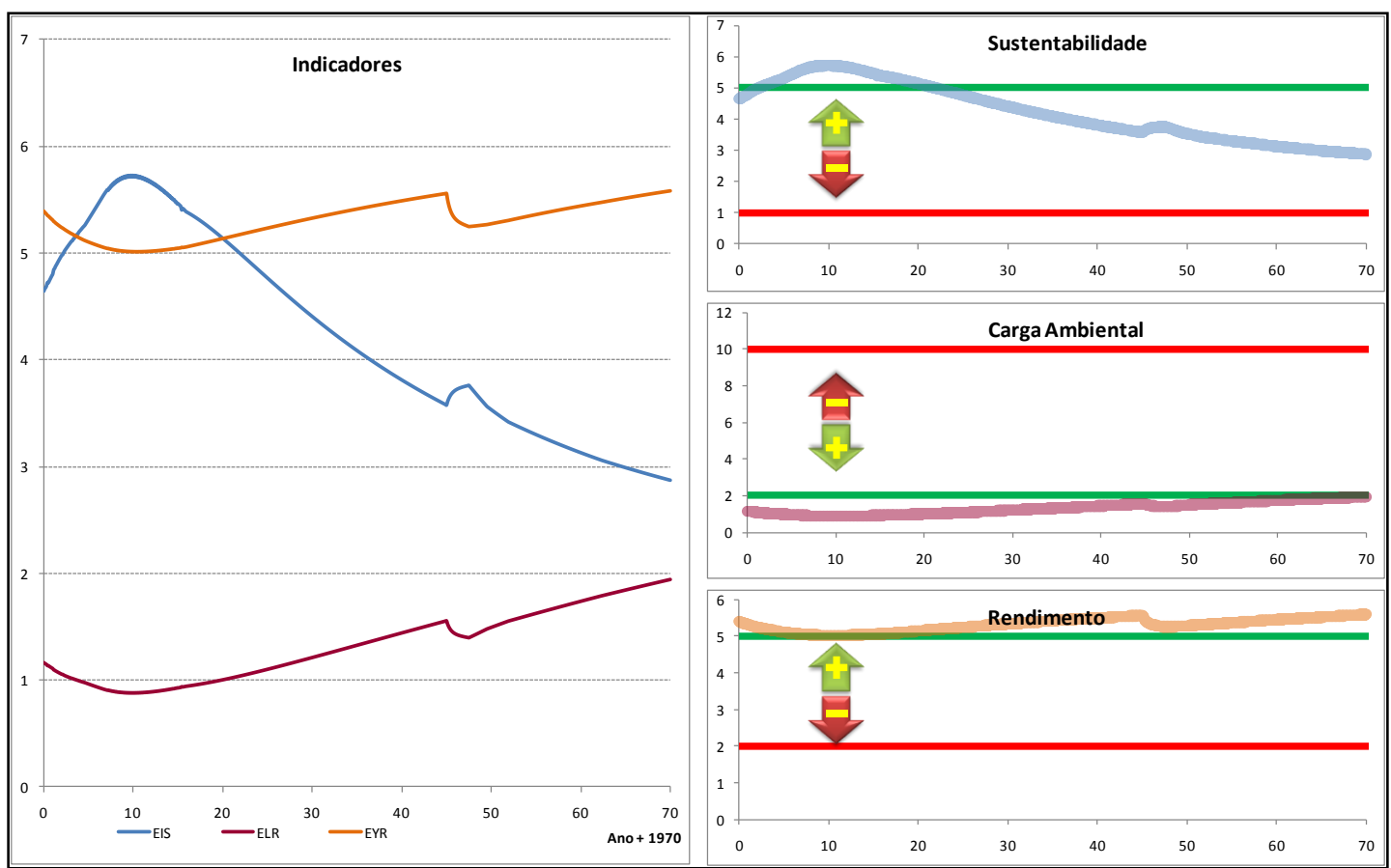

FIGURA 74 - Índices: EIS, ELR e EYR, com perturbação nas fonte de recurso Cana de 10000 tep.

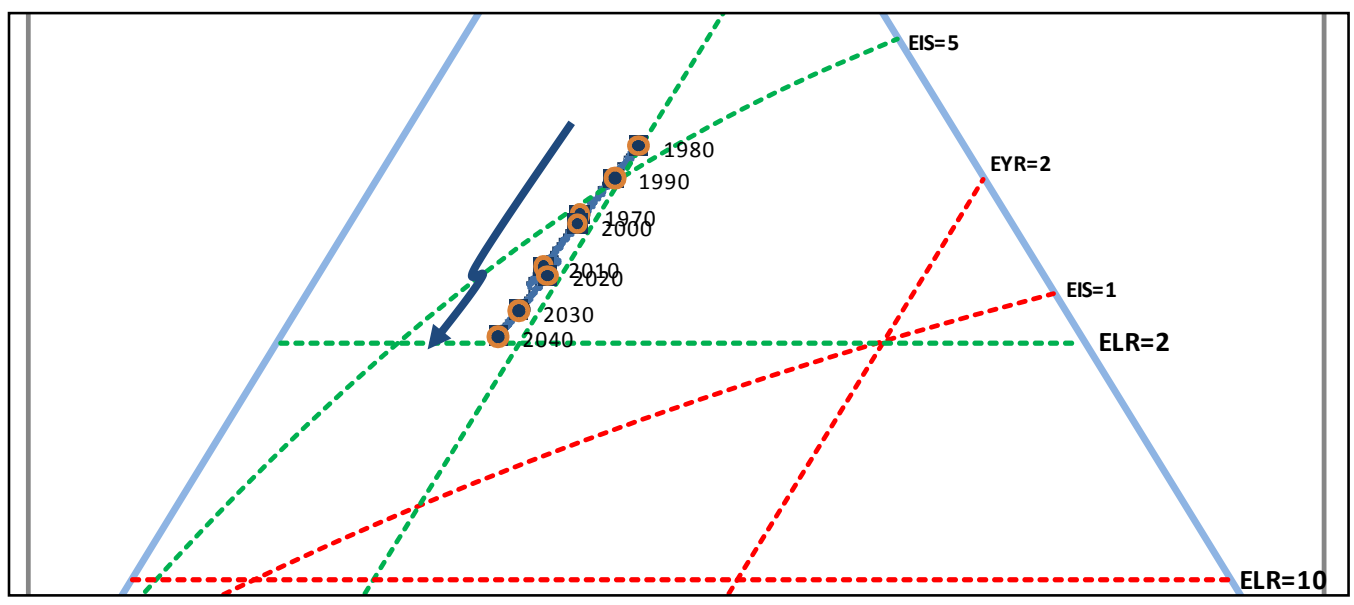

FIGURA 75 - Percurso Emergético com perturbação na fonte de energia Cana de 10000 tep. 


\subsection{6 Índices: Perturbação na fonte de recursos Eólica}

Os gráficos das figuras 76 e 77 apresentam o desempenho dos índices, para o caso de uma perturbação individual na fonte de recursos eólicos, de um valor de 10000 tep, no ciclo 45, referente ao ano de 2015.

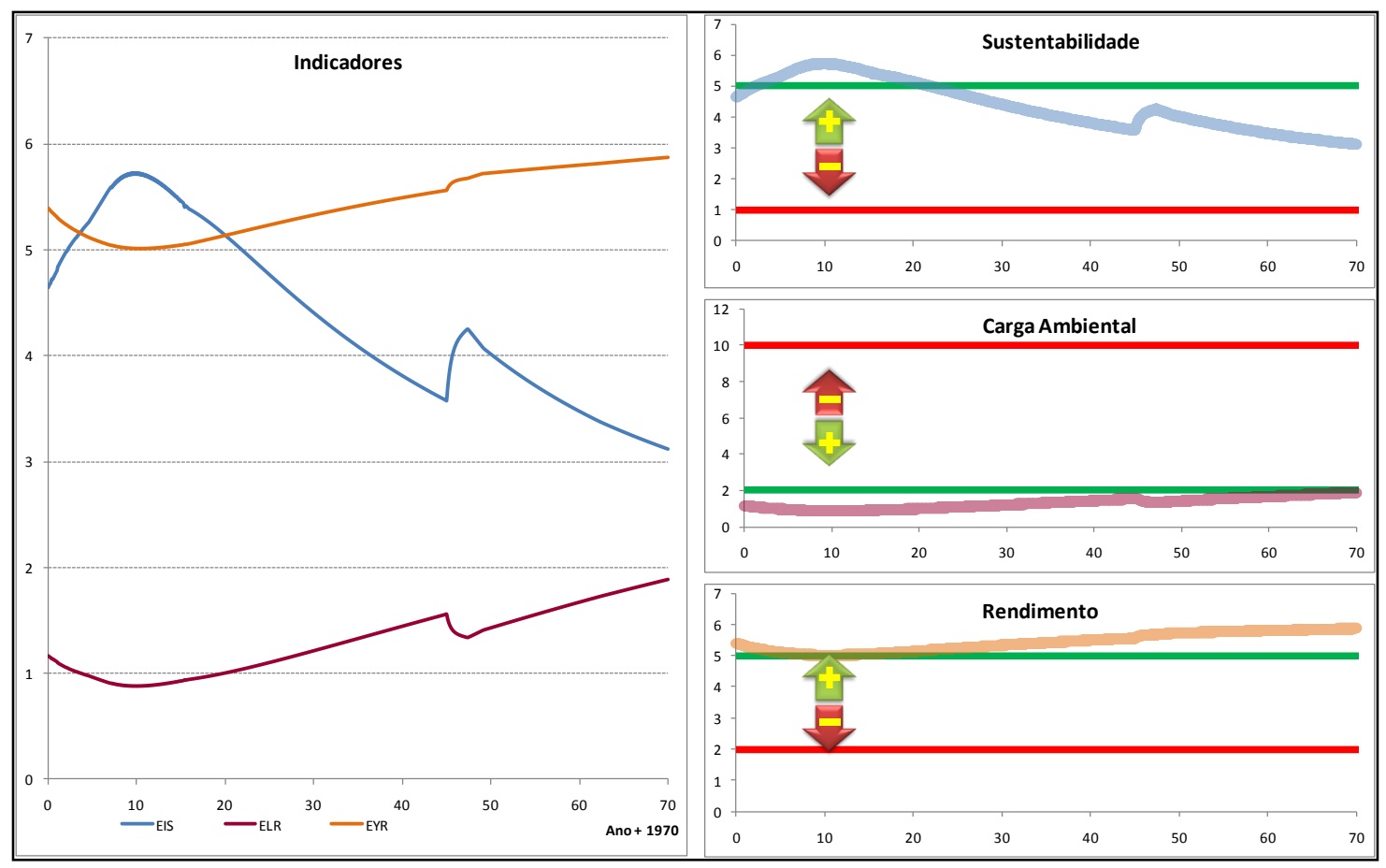

FIGURA 76 - Índices: EIS, ELR e EYR, com perturbação nas fonte de recurso Eólico de 10000 tep.

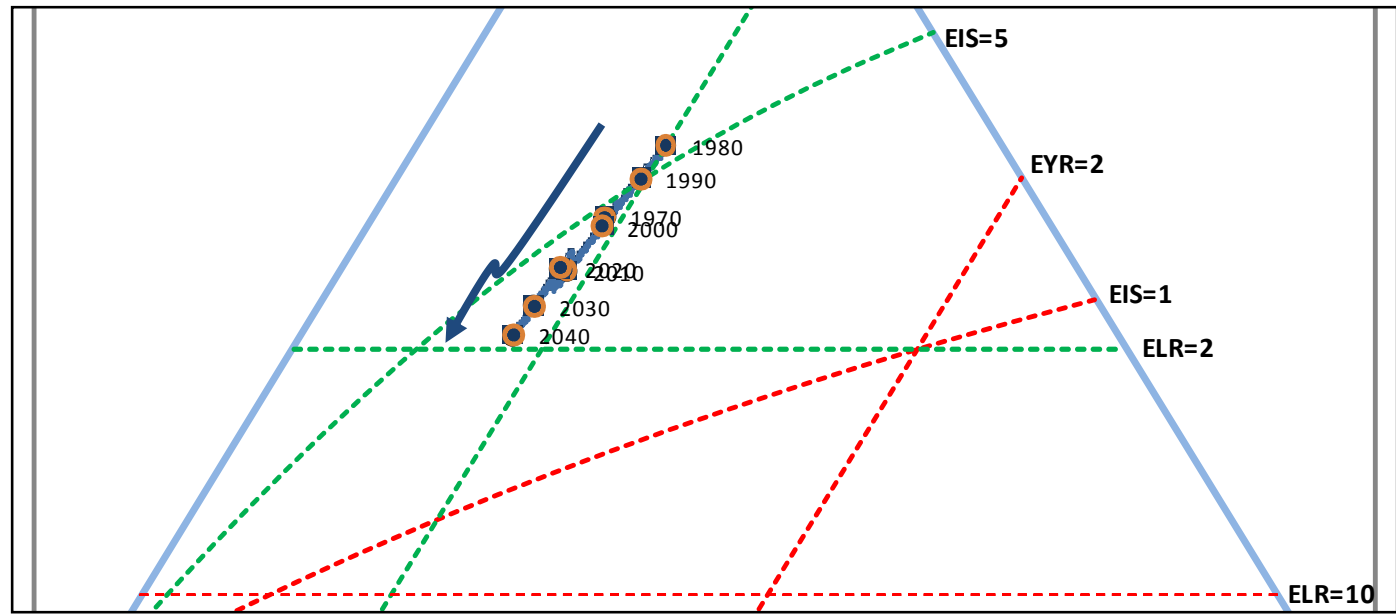

FIGURA 77 - Percurso Emergético com perturbação na fonte de energia Eólica de 10000 tep. 


\subsection{7 Índices: Perturbação na fonte de recursos Nucleares}

Os gráficos das figuras 78 e 79 apresentam o desempenho dos índices, para o caso de uma perturbação individual na fonte de recursos nucleares, de um valor de 10000 tep, no ciclo 45, referente ao ano de 2015.

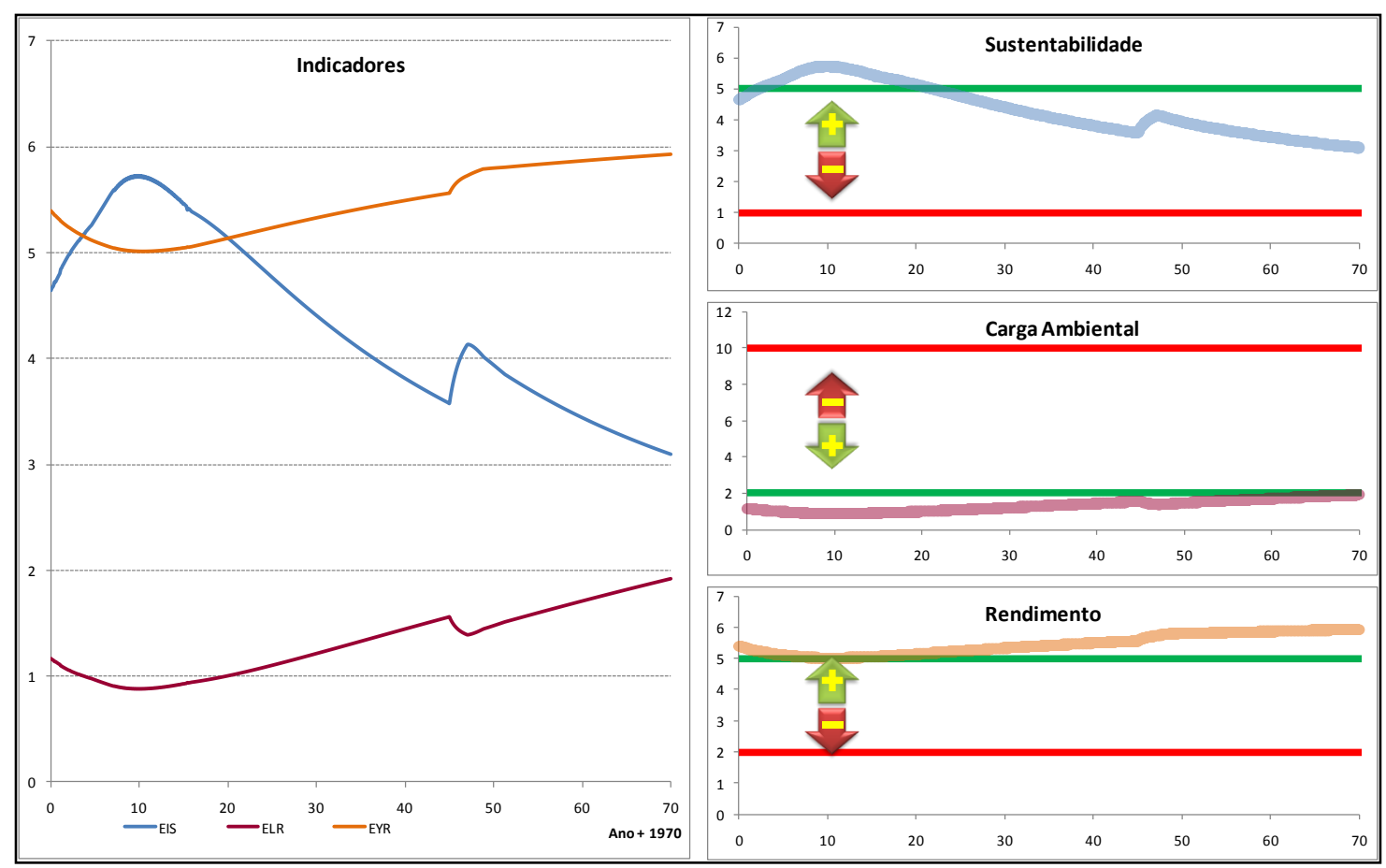

FIGURA 78 - Índices: EIS, ELR e EYR, com perturbação na fonte de recursos nuclear de 10000 tep.

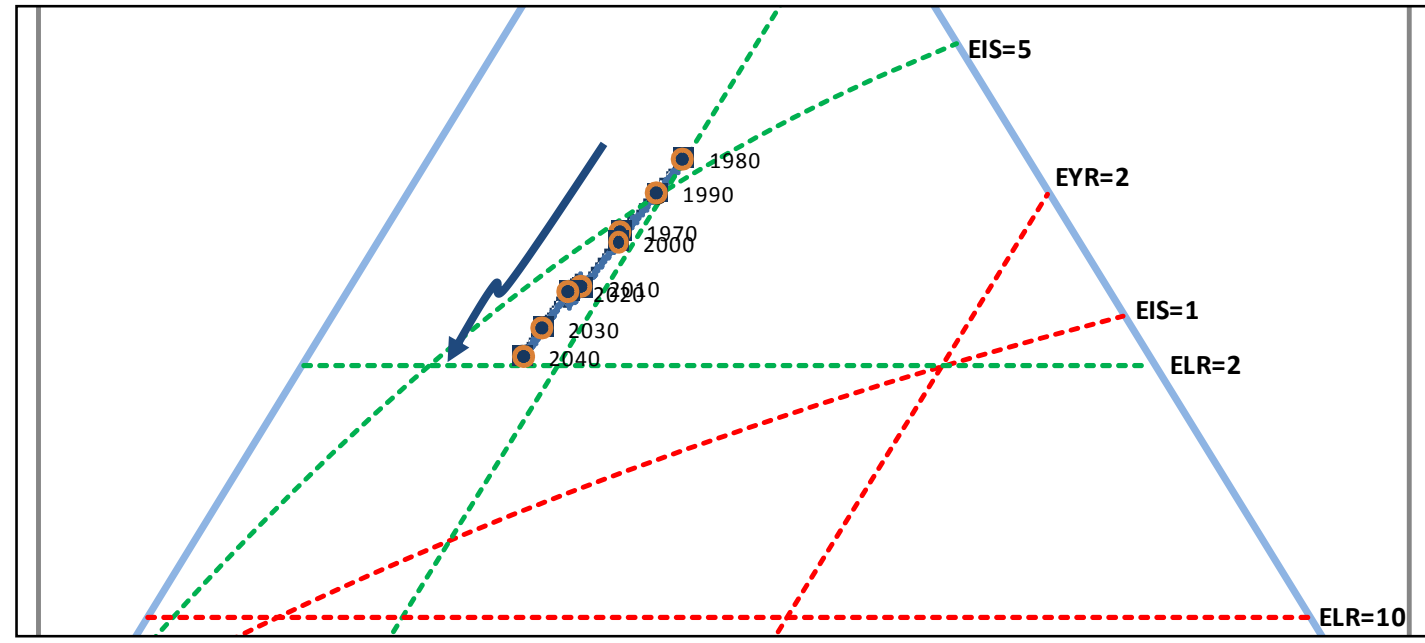

FIGURA 79 - Percurso Emergético com perturbação na fonte de energia nuclear de 10000 tep. 


\subsection{8 Índices: Perturbação combinada Hídrica e Nuclear 1}

Os gráficos das figuras 80 e 81 apresentam o desempenho dos índices, para o caso de uma perturbação individual na fonte de recursos nucleares e hídricos, de um valor de 10000 tep, no ciclo 45 e 48 respectivamente, referentes aos anos de 2015 e 2018.

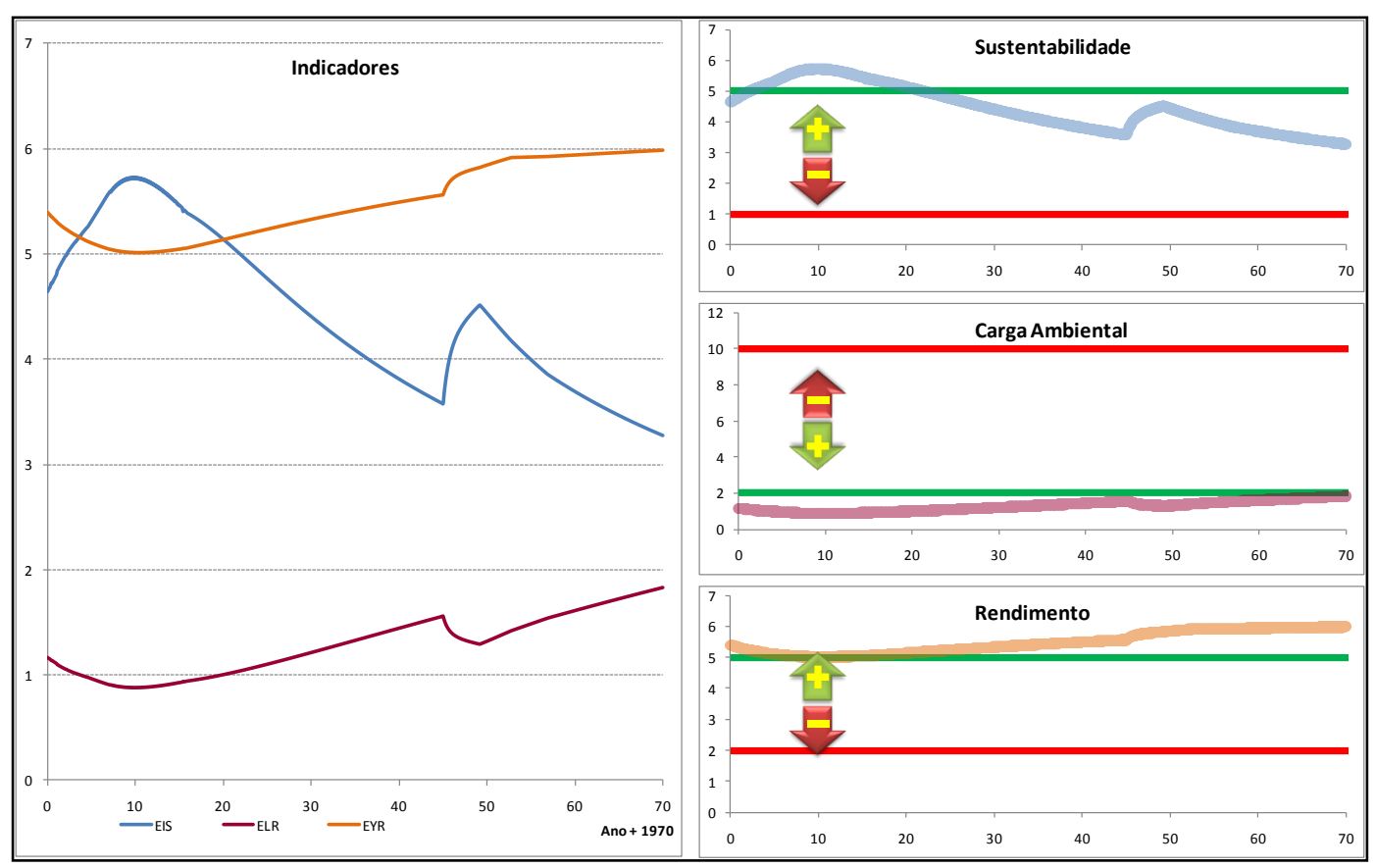

FIGURA 80 - Índices: EIS, ELR e EYR, com perturbação combinada nas fontes de recursos Hídrica de 10000 tep e Nuclear de 10000 tep.

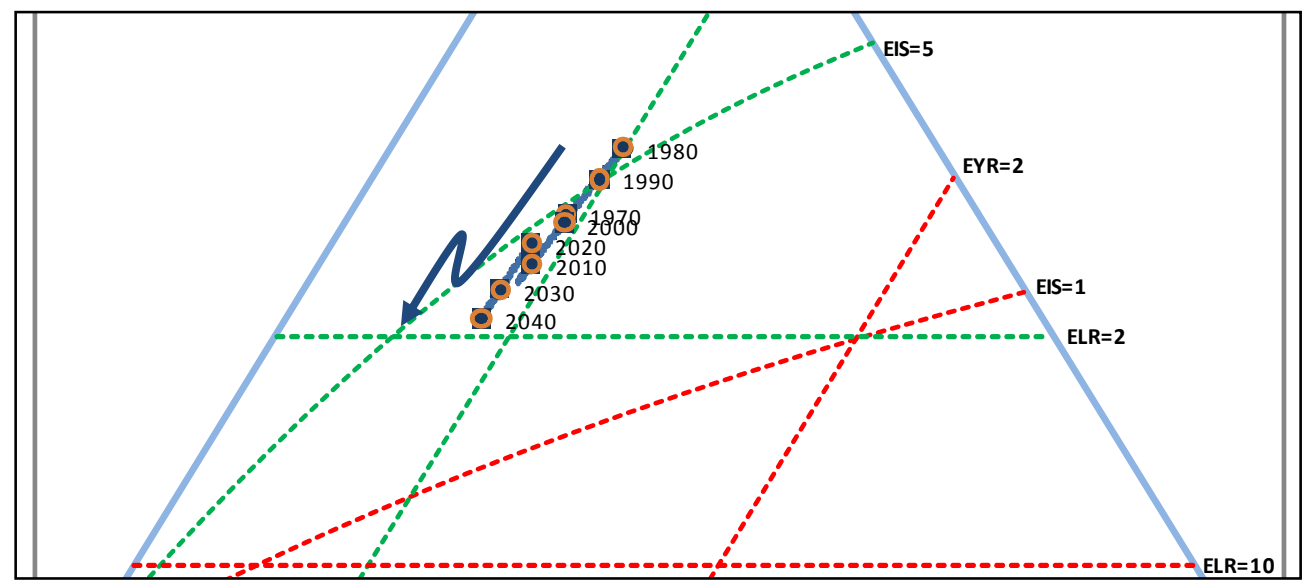

FIGURA 81 - Percurso Emergético com perturbações nas fontes de energia hídrica de 10000 tep e nuclear de 10000 tep. 


\subsection{9 Índices: Perturbação combinada Hídrica e Nuclear 2}

Os gráficos das figuras 82 e 83 apresentam o desempenho dos índices, para o caso de uma perturbação individual na fonte de recursos nucleares e hídricos, de um valor de 5000 tep, no ciclo 45 e 48 respectivamente, referentes aos anos de 2015 e 2018

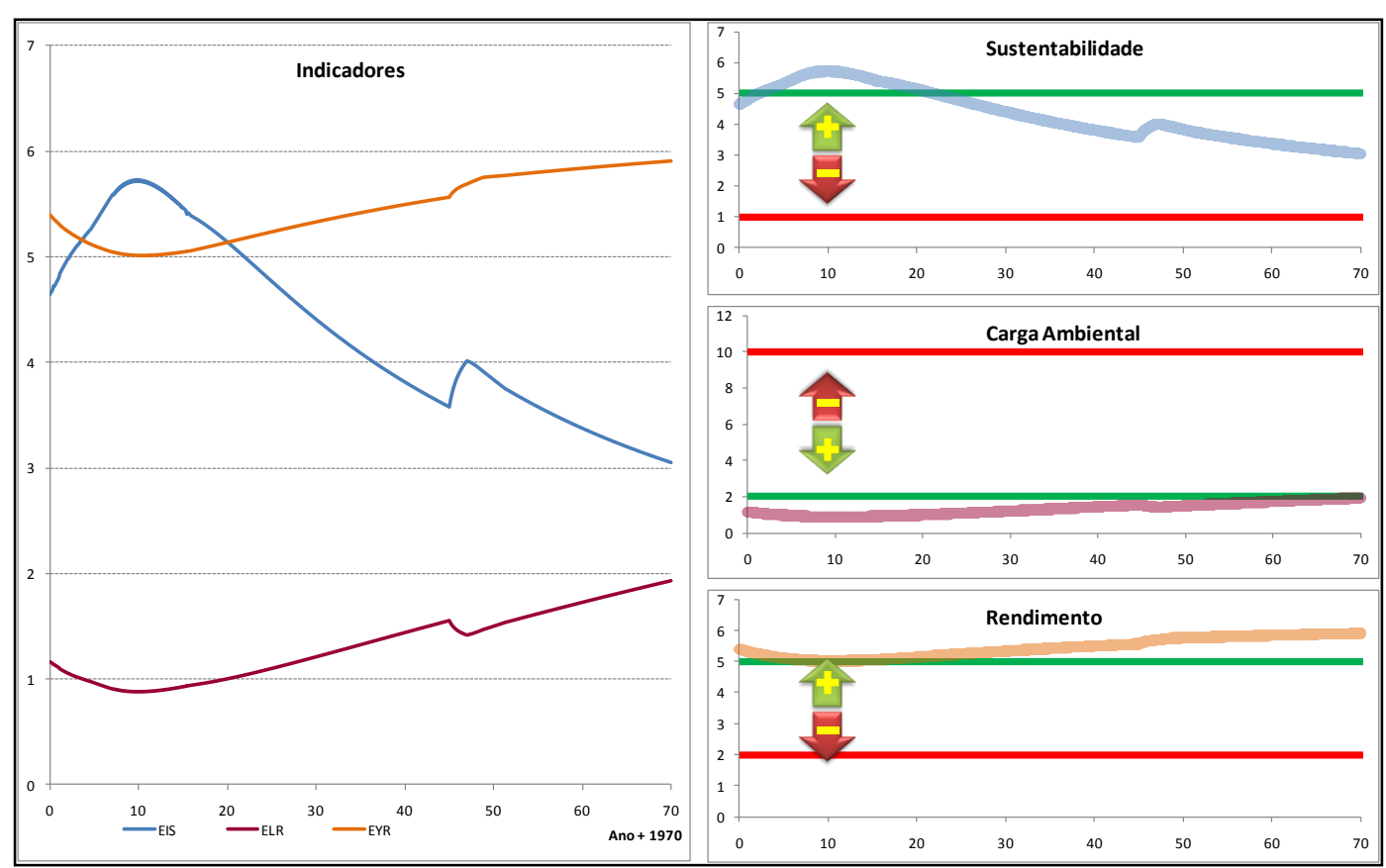

FIGURA 82 - Índices: EIS, ELR e EYR, com perturbação combinada nas fontes de recursos Hídrica de 5000 tep e de Nuclear 5000 tep.

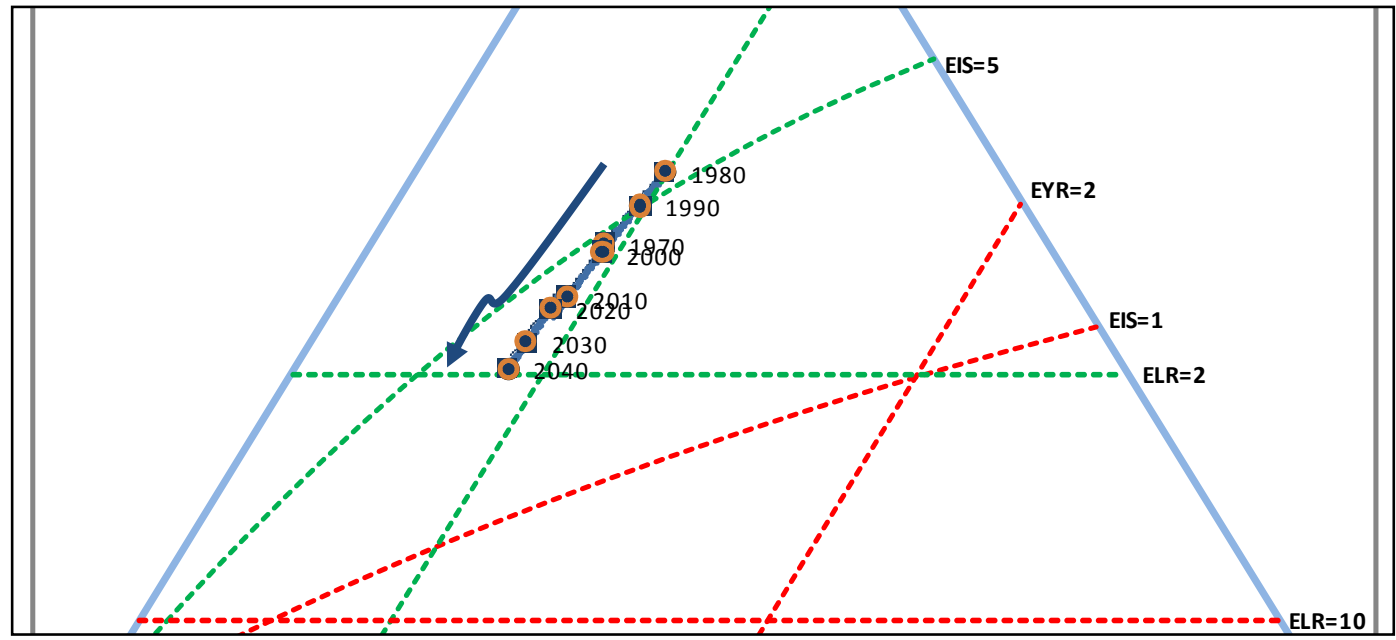

FIGURA 83 - Percurso Emergético com perturbações nas fontes de energia hídrica de 5000 tep e nuclear de 5000 tep. 


\subsection{Comparação entre simulações}

Apresenta-se na tabela 21 um quadro comparativo entre as várias simulações com relação aos índices de sustentabilidade (EIS), impacto ambiental (ELR) e rendimento emergético (EYR).

TABELA 21 - Resultados de simulação: sem perturbação; com perturbações individuais e combinadas.

\begin{tabular}{lcccc}
\hline Tipo de Perturbação & EIS & ELR & EYR & Desempenho \\
\hline Sem Perturbação & 2,80 & 2,08 & 5,82 & Referência \\
Energia Eólica & 3,12 & 1,88 & 5,87 & 1 \\
Energia Nuclear & 3,10 & 1,92 & 5,93 & 2 \\
Energia Hídrica & 3,00 & 1,96 & 5,88 & 3 \\
Produtos de Cana & 2,87 & 1,94 & 5,59 & 4 \\
Gás Natural & 2,66 & 2,20 & 5,85 & 5 \\
Carvão Vapor & 2,39 & 2,42 & 5,77 & 6 \\
Hidro e Urânio combinados 1 & 3,28 & 1,83 & 5,99 & - \\
Hidro e Urânio combinados 2 & 3,05 & 1,94 & 5,90 & - \\
\hline
\end{tabular}

$\mathrm{Na}$ coluna de observação da tabela 21 apresenta-se uma classificação de desempenho dos índices que utiliza o critério das regiões do diagrama ternário.

\subsection{Simulações com Índices Agregados}

Nesta fase foram executadas simulações com os índices agregados médios, pois os índices não agregados carregam em seus valores o histórico ao longo do tempo. Lembrando que as fontes de recursos têm históricos muito diferentes, alguns resultados e avaliações temporais poderiam ser mascarados.

Ainda, embora seja importante avaliar o histórico de benefícios ou malefícios de cada fonte de recursos, a preocupação inerente a este estudo volta-se para os resultados futuros e em relação às tendências na utilização deste ou daquele recurso. 
Dessa maneira, foram feitas simulações com os índices agregados médios, tomando-se como ponto de partida o ano 2000 e finalizando no ano 2040 .

\subsection{1 Índices Agregados Médios: sem Perturbação}

Os gráficos da figura 84 apresentam o desempenho dos índices agregados médios em função do tempo, para a simulação sem perturbações individuais, nas fontes de recursos.
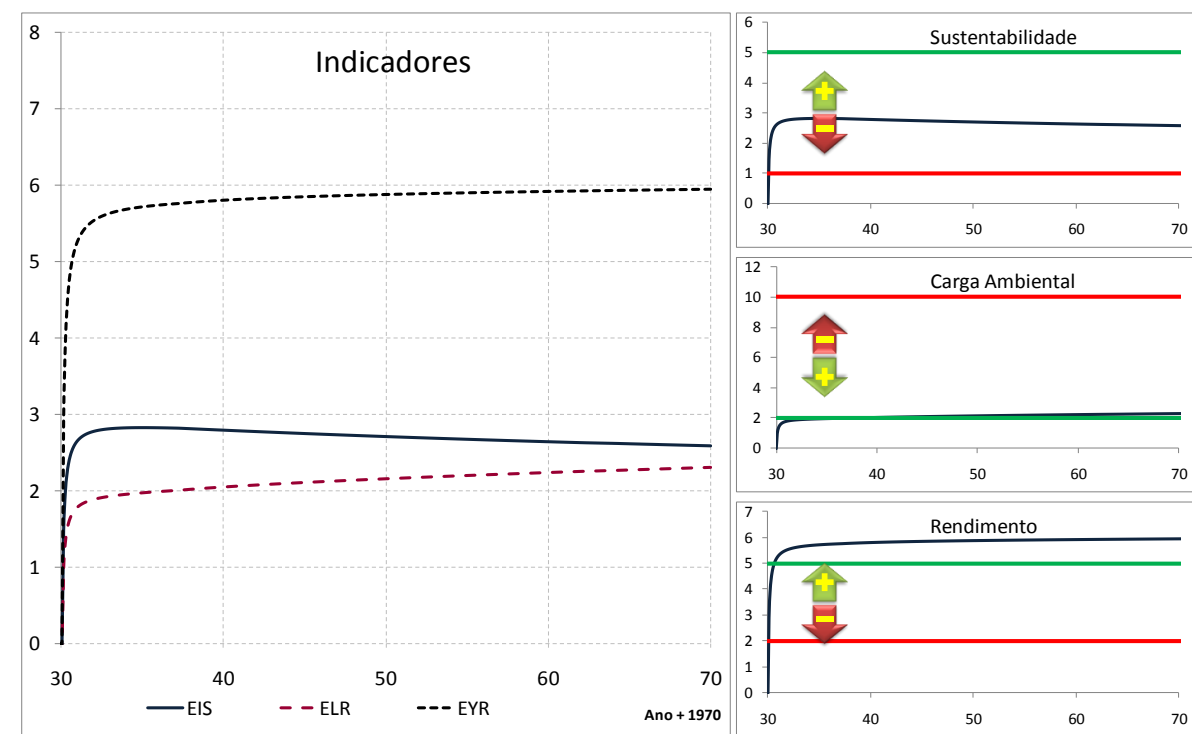

FIGURA 84 - Índices Agregados: EIS, ELR e EYR, sem perturbação.

3.5.2 Índices Agregados Médios: Perturbação na fonte de Gás Natural

Os gráficos da figura 85 apresentam o desempenho dos índices agregados médios em função do tempo, para a simulação com perturbação individual, na fonte de recurso de gás natural, de um valor de 10000 tep, no ciclo 45, referente ao ano 2015. 


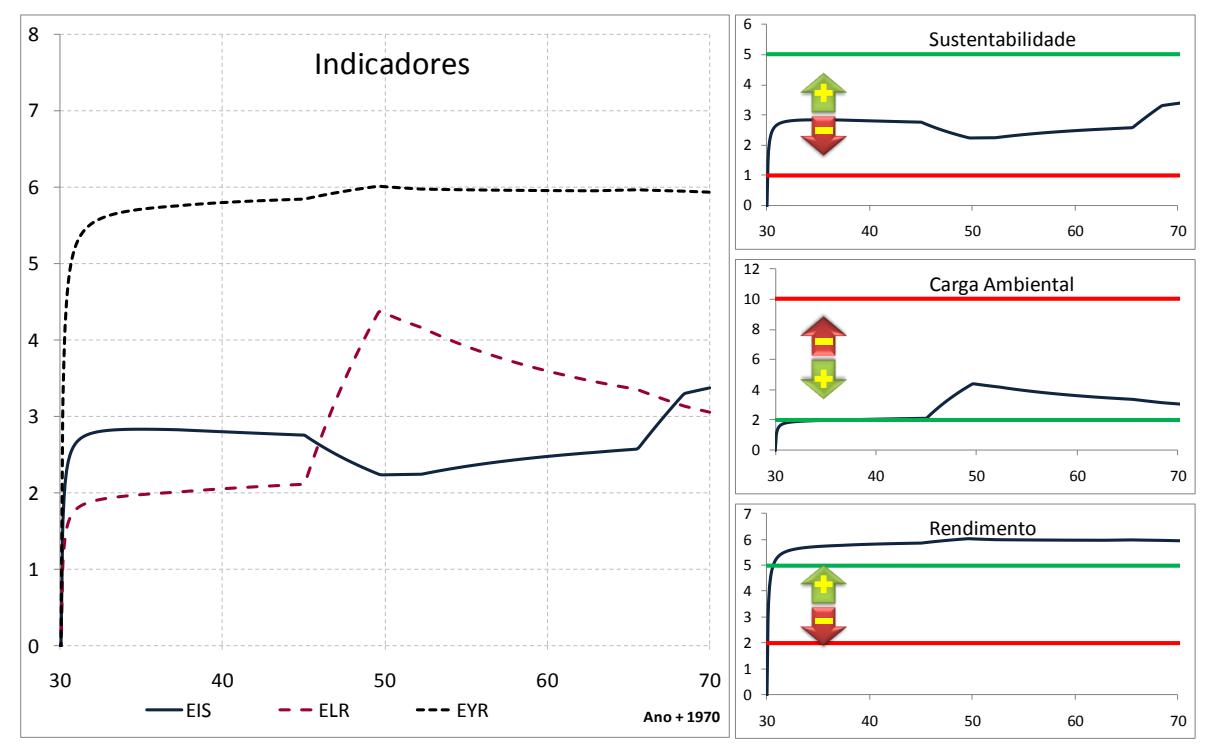

FIGURA 85 - Índices Agregados: EIS, ELR e EYR, com perturbação nas fonte de recurso Gás Natural de 10000 tep.

\subsection{3 Índices Agregados Médios: Perturbação na fonte de Carvão Vapor}

Os gráficos da figura 86 apresentam o desempenho dos índices agregados médios em função do tempo, para a simulação com perturbação individual, na fonte de recurso de carvão vapor, de um valor de 10000 tep, no ciclo 45, referente ao ano 2015.
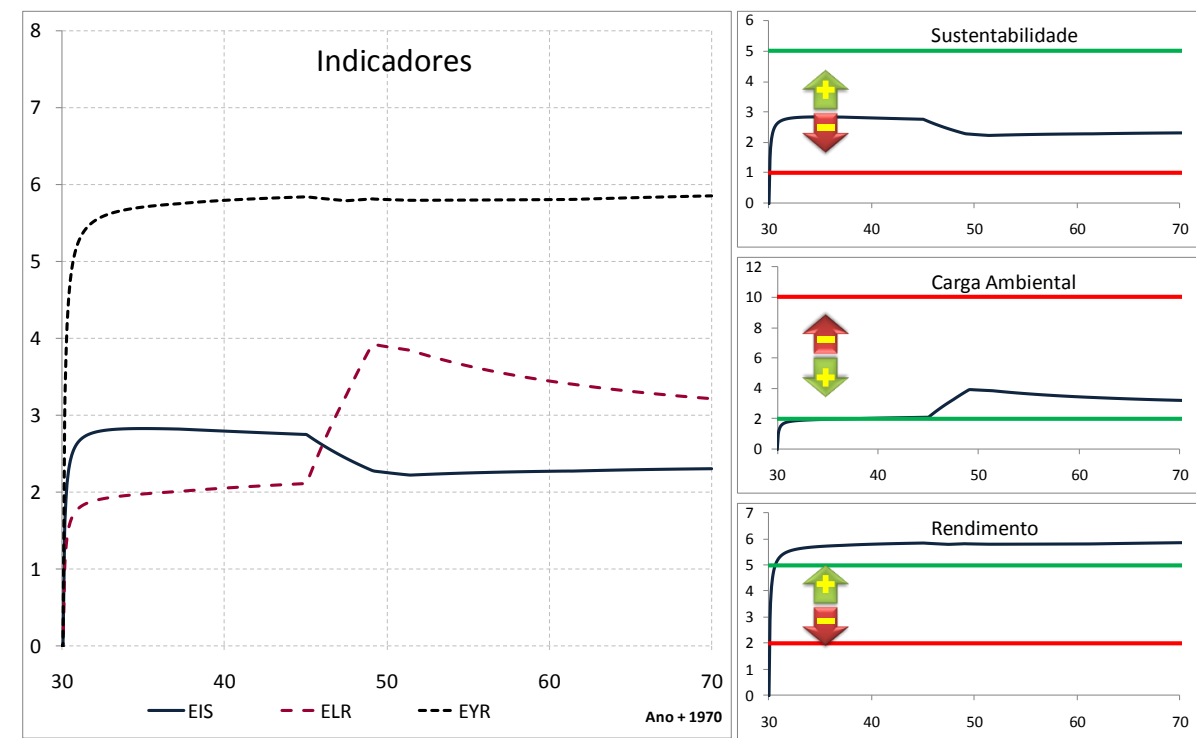

FIGURA 86 - Índices Agregados: EIS, ELR e EYR, com perturbação na fonte de Carvão, de 10000 tep. 
3.5.4 Índices Agregados Médios: Perturbação na fonte de recursos Hídricos

Os gráficos da figura 87 apresentam o desempenho dos índices agregados médios em função do tempo, para a simulação com perturbação individual, na fonte de recursos hídricos, de um valor de 10000 tep, no ciclo 45, referente ao ano 2015.

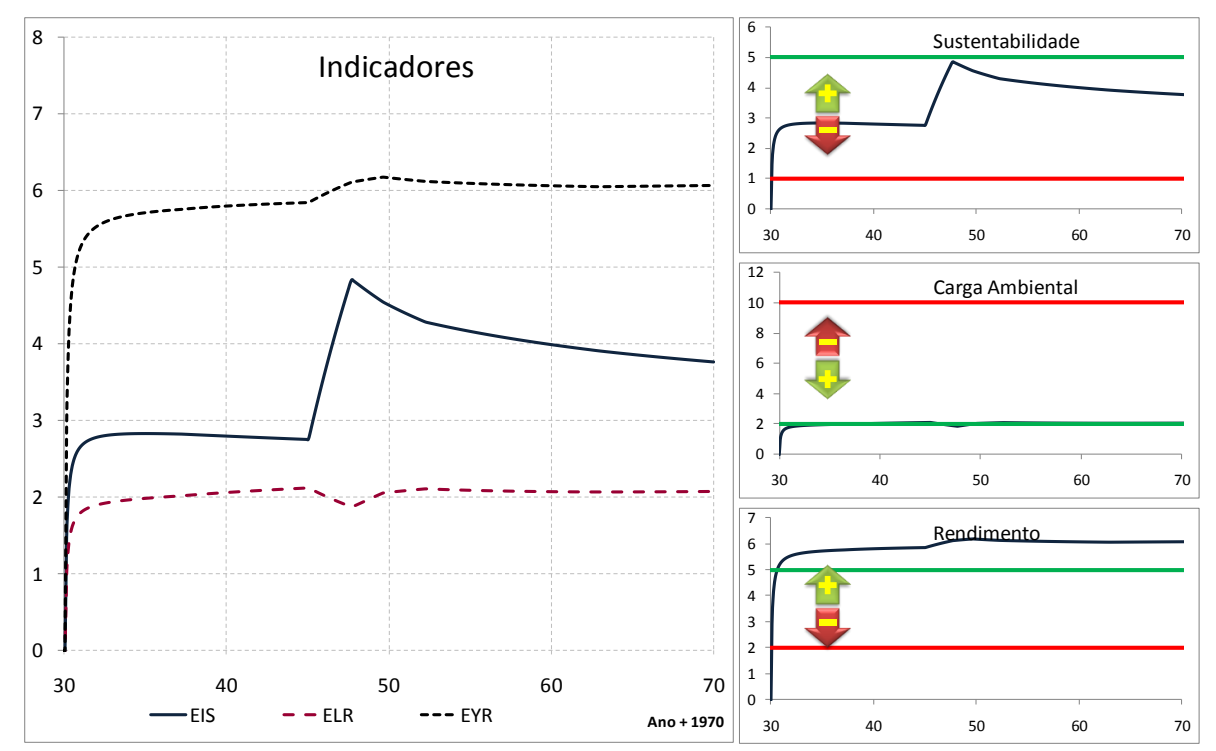

FIGURA 87 - Índices Agregados: EIS, ELR e EYR, com perturbação na fonte hídrica, de 10000 tep.

3.5.5 Índices Agregados Médios: Perturbação na fonte de Produtos de Cana

Os gráficos da figura 88 apresentam o desempenho dos índices agregados médios em função do tempo, para a simulação com perturbação individual, na fonte de recurso de produtos de cana, de um valor de 10000 tep, no ciclo 45, referente ao ano 2015. 


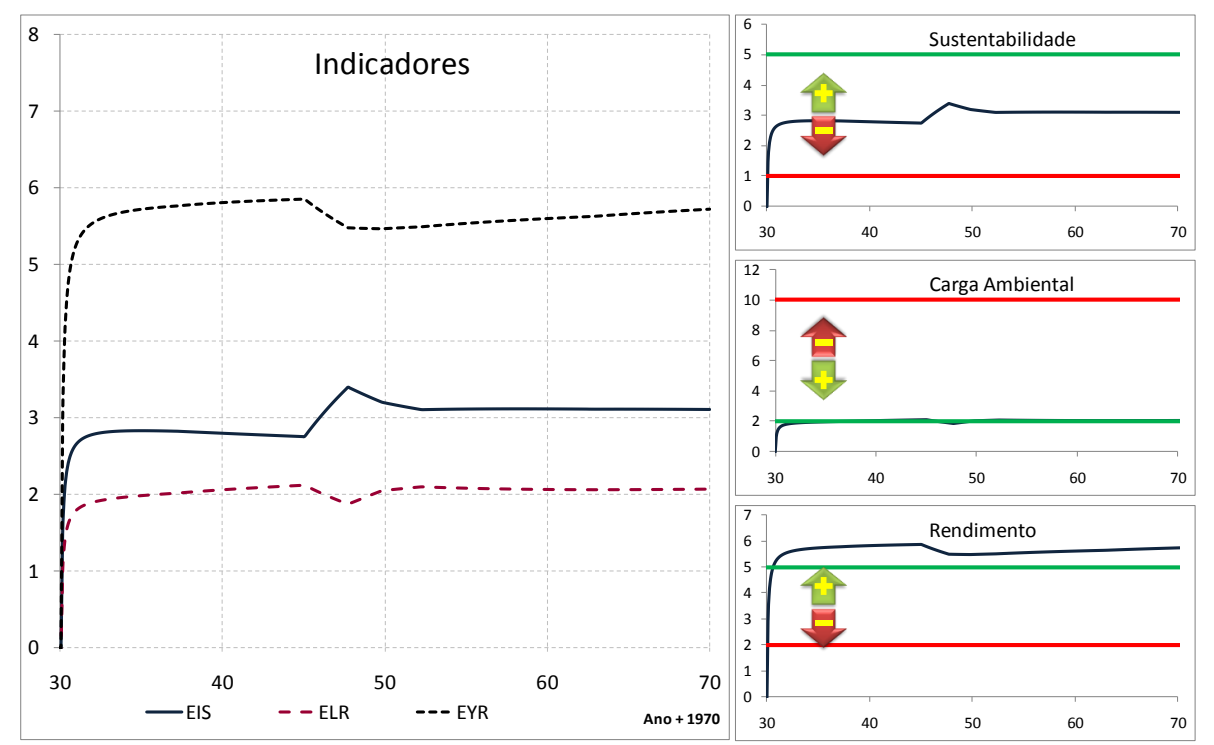

FIGURA 88 - Índices Agregados: EIS, ELR e EYR, com perturbação na fonte de Cana, de 10000 tep.

\subsection{6 Índices Agregados Médios: Perturbação na fonte de recursos Eólica}

Os gráficos da figura 89 apresentam o desempenho dos índices agregados médios em função do tempo, para a simulação com perturbação individual, na fonte de recurso eólica, de um valor de 10000 tep, no ciclo 45, referente ao ano 2015 .
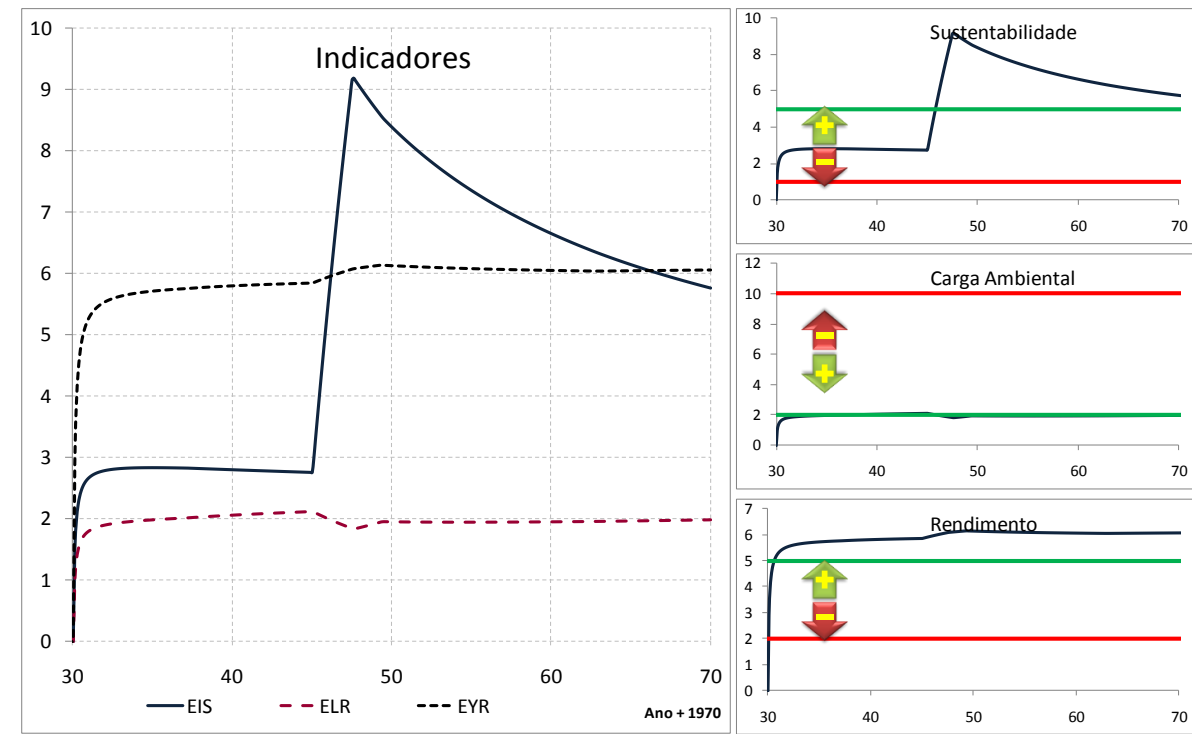

FIGURA 89 - Índices Agregados: EIS, ELR e EYR, com perturbação na fonte Eólica, de 10000 tep. 
3.5.7 Índices Agregados Médios: Perturbação na fonte de recursos Nucleares

Os gráficos da figura 90 apresentam o desempenho dos índices agregados médios em função do tempo, para a simulação com perturbação individual, na fonte de recursos nucleares, de um valor de 10000 tep, no ciclo 45, referente ao ano 2015.

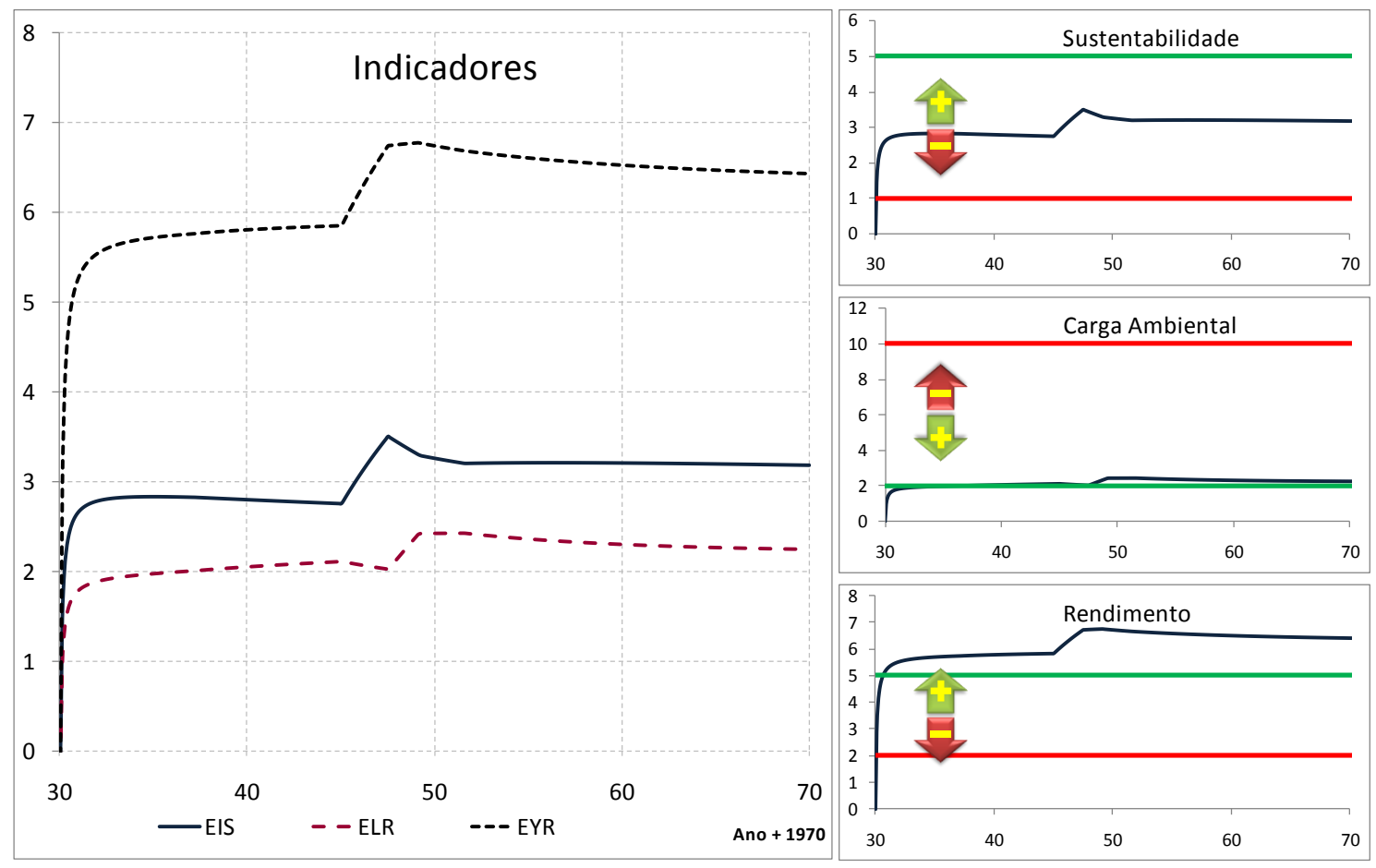

FIGURA 90 - Índices Agregados: EIS, ELR e EYR, com perturbação na fonte nuclear, de 10000 tep.

Pela análise dos gráficos das figuras de 84 à 90, mais uma vez, pode-se constatar que pelo desempenho dos índices agregados médios, a ordem de classificação se mantém igual ao da tabela 21 .

\subsection{Outras Simulações}

\subsubsection{Detalhamento no Gás Natural}

Especificamente na simulação do gás natural após o ano de 2033, ciclo 63, os desempenhos dos índices começam a melhorar. Em razão de 
que, neste ano, as reservas de gás natural esgotam-se e, portanto, deixa de ser produzida energia com gás natural, sendo assim substituída pelas outras fontes de recursos. Para uma melhor avaliação dos resultados foram realizadas mais duas simulações.

Na primeira, aplicou-se um falso aumento no valor das reservas de gás natural, de maneira que as reservas não se esgotem, durante o período de simulação. Os gráficos dos índices e do percurso emergéticos estão apresentados nas figuras 91 e 92 . Os valores dos índices, para o ano 2040, são EIS $=2,41, E L R=2,45$ e EYR $=5,89$.

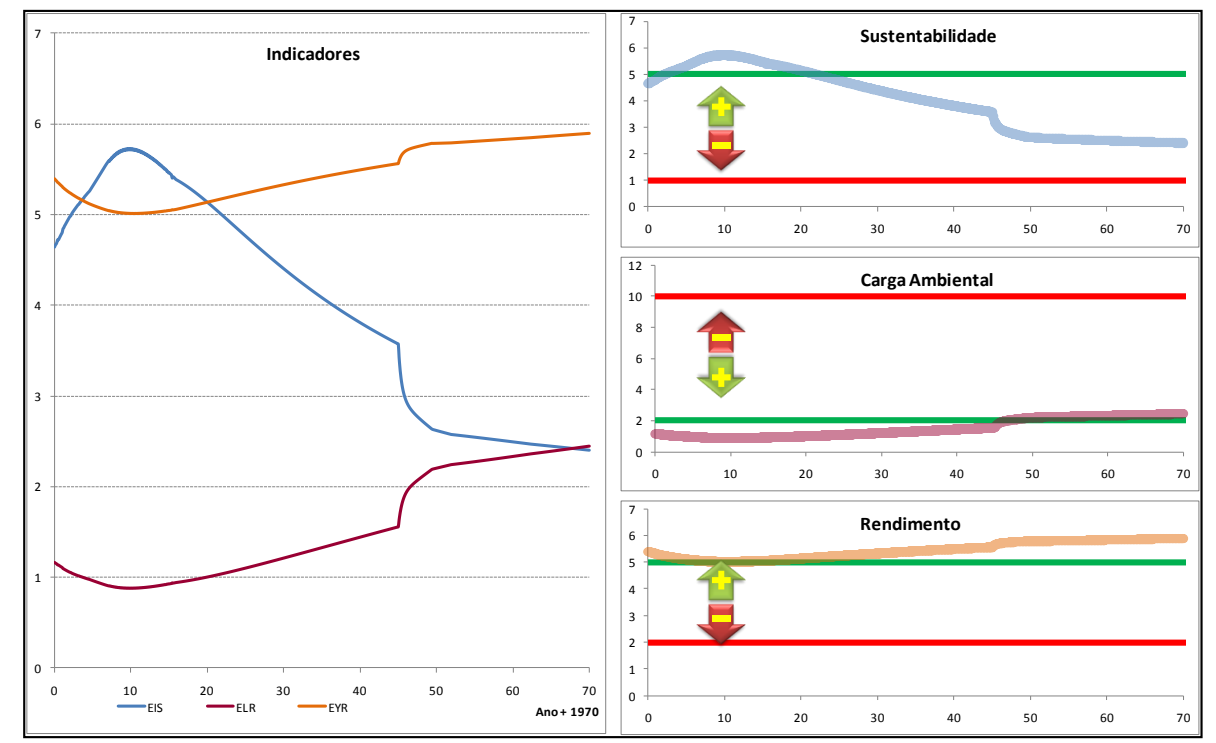

FIGURA 91 - Índices: EIS, ELR e EYR, com perturbação na fonte de gás natural de 10000 tep e falso aumento de reservas.

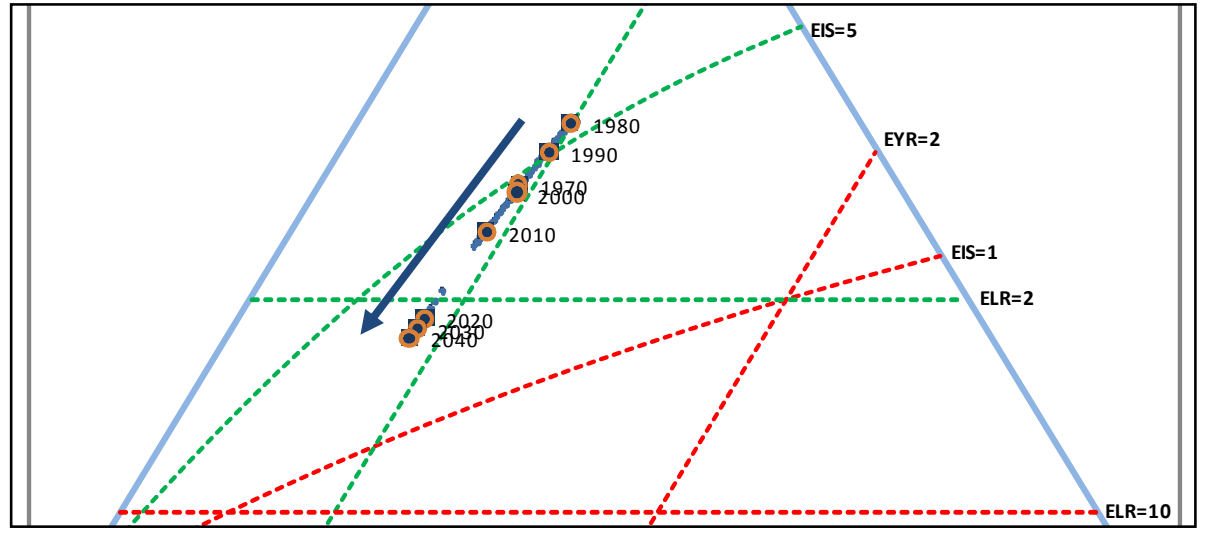

FIGURA 92 - Percurso Emergético: perturbação no gás natural de 10000 tep e falso aumento de reservas. 
$\mathrm{Na}$ segunda, adotou-se o aumento do tempo de simulação até o ciclo 80 , referente ao ano 2050, retornando as reservas para os valores reais. Este grupo é composto de uma simulação sem perturbação e outra com perturbação de 10000 tep na fonte de gás natural no ciclo 45, referente ao ano de 2015, conforme apresentados nas figuras de 93 a 96.

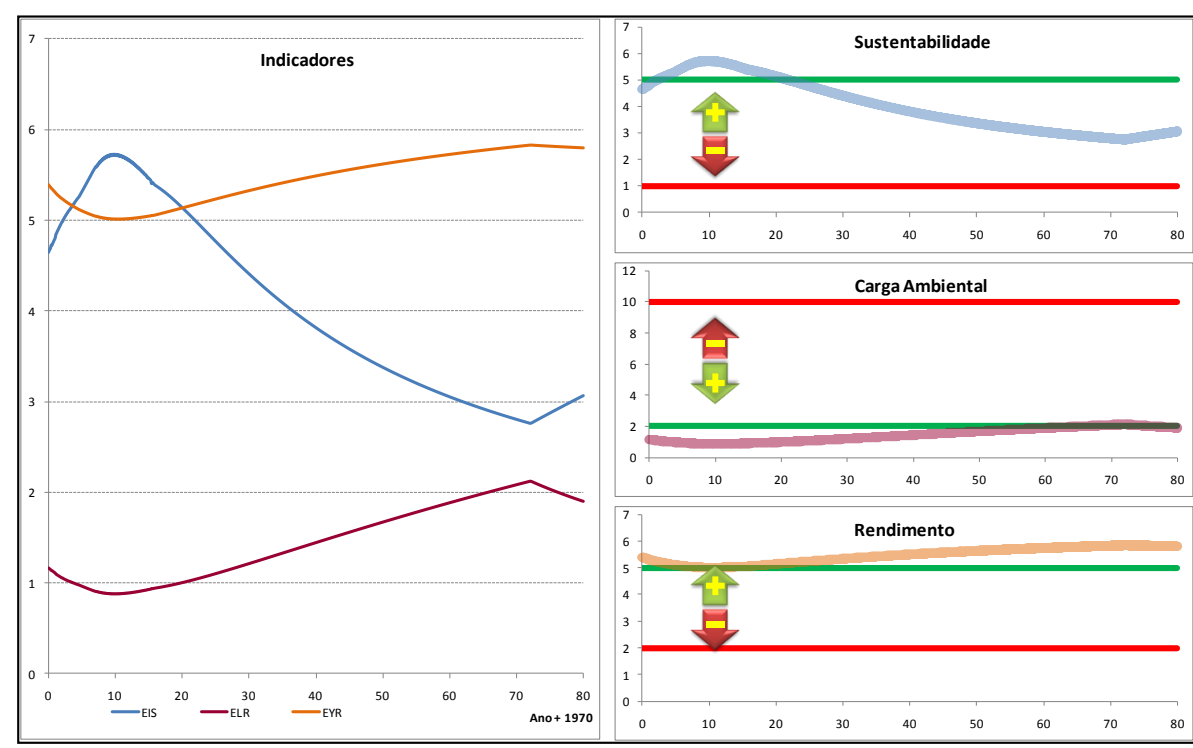

FIGURA 93 - Índices: EIS, ELR e EYR, sem perturbação até 2050 para o gás natural.

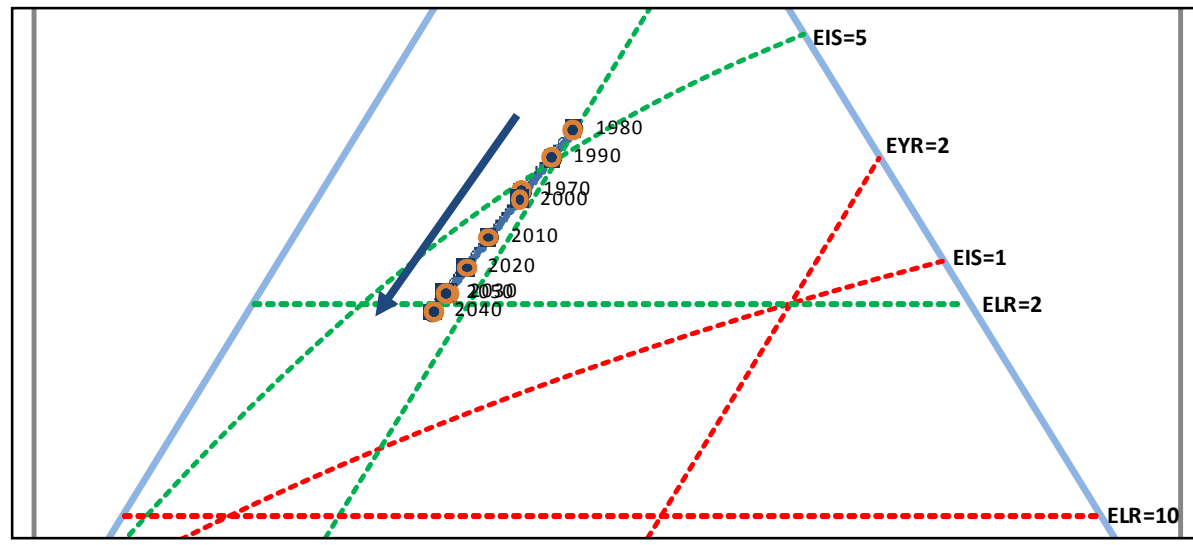

FIGURA 94 - Percurso Emergético: sem perturbação até 2050, para o gás natural. 


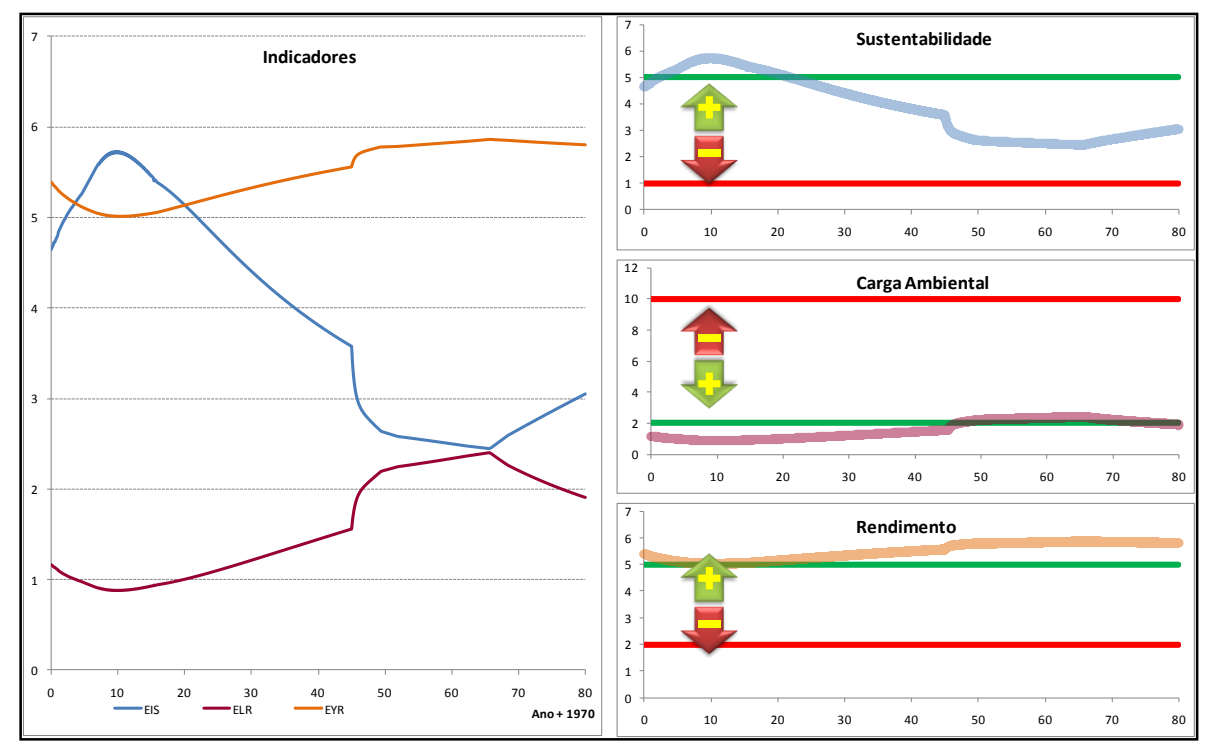

FIGURA 95 - Índices: EIS, ELR e EYR, com perturbação de 10000 tep no ano de 2015 e simulação até 2050 para o gás natural.

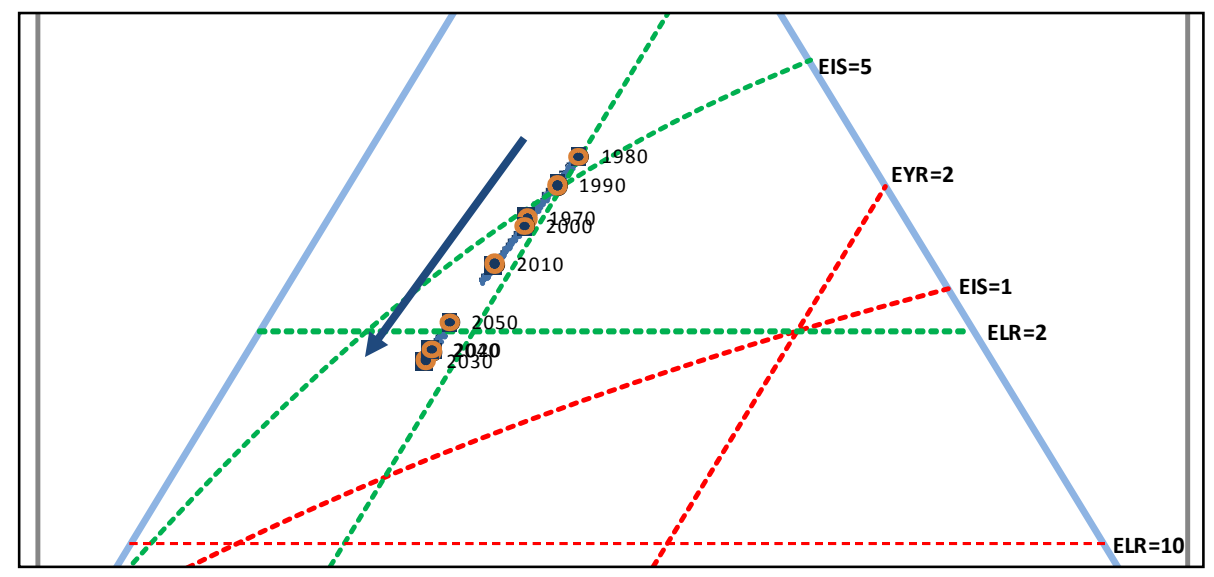

FIGURA 96 - Percurso Emergético: perturbação de 10000 tep no ano de 2015 e simulação até 2050, para o gás natural.

Novamente, com o aumento do tempo de observação, mesmo sem perturbação na fonte de gás natural, aparece o esgotamento das reservas, agora no ciclo 73 , referente ao ano 2043.

\subsection{2 Índices Agregados Médios: Gás Natural com Reserva llimitada}

Nos gráficos da figura 97 são apresentados o desempenho dos índices agregados médios, os quais também melhoram o desempenho na simulação, a partir do ciclo 63. Dessa forma, da mesma maneira que no item 
anterior e para se evitar uma falsa conclusão, foi executada mais uma simulação considerando as reservas do gás natural inesgotáveis. Simulação executada com perturbação individual na fonte de recursos de gás natural com valor de 10000 tep, no ciclo 45, referente ao ano de 2015.
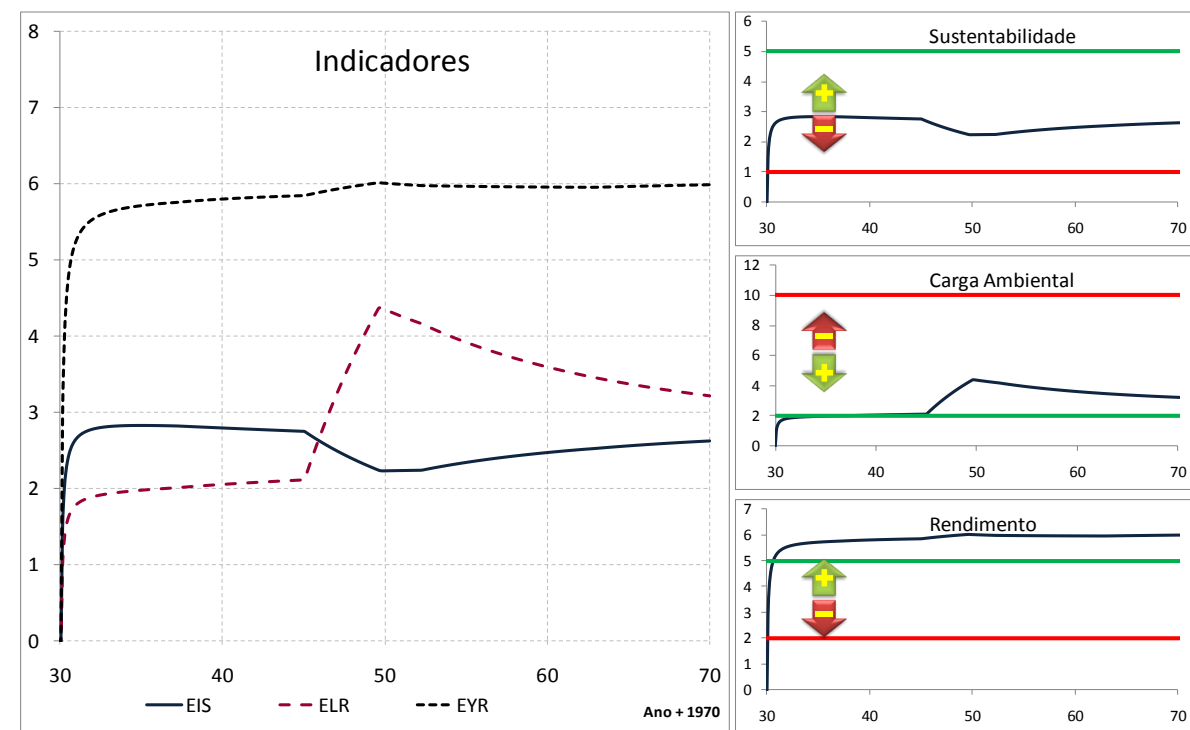

FIGURA 97 - Índices: EIS, ELR e EYR, com perturbação combinada nas fontes de recursos Hídrica de 10000 tep e Nuclear de 10000 tep.

Foram obtidos assim os valores dos índices agregados médios para todas as simulações individuais, com reservas limitadas e ilimitadas para o gás natural. Os valores dos índices agregados médios, no ano 2040 com e sem perturbação, estão apresentados na tabela 22.

TABELA 22 - Índices Agregados: Resultados de simulação com e sem perturbação.

\begin{tabular}{lcccc}
\hline Tipo de Perturbação & EIS & ELR & EYR & Observação \\
\hline Sem Perturbação & 2,596 & 2,312 & 5,949 & Referência \\
EÓLICO & 5,764 & 1,980 & 6,064 & 1 \\
HíDRICA & 3,770 & 2,069 & 6,074 & 2 \\
GÁS & 3,375 & 3,057 & 5,941 & - \\
NUCLEAR & 3,185 & 2,251 & 6,430 & $3 x$ \\
CANA & 3,112 & 2,064 & 5,719 & $3 x$ \\
GÁS Ilimitado & 2,631 & 3,217 & 5,993 & 5 \\
CARVÃO & 2,311 & 3,218 & 5,864 & 6 \\
\hline
\end{tabular}


A tabela 22 foi ordenada do melhor para pior desempenho dos índices, com base no critério das regiões.

As fontes de recurso Nuclear e Produtos de Cana, tiveram a mesma classificação, embora o EIS da fonte nuclear tenha um desempenho levemente superior ao dos produtos de cana, este último apresenta o ELR melhor do que o da fonte nuclear.

Nos casos das duas simulações, a reserva de gás natural esgotouse, no primeiro caso mais tarde e no segundo caso mais cedo. No caso sem perturbação, os índices tiveram um desempenho decrescente até o esgotamento das reservas de gás natural, quando começam a recuperar os seus desempenhos.

No caso com perturbação, na fonte de recursos de gás natural, o desempenho dos índices apresenta um salto negativo, porém as reservas se esgotam também antes, por volta do ano 2036, e a partir daí os índices permanecem por mais tempo no sentido da melhora.

Portanto, não foi feita a classificação para a fonte de recursos Gás Natural, e em seu lugar está apresentada a fonte de recursos de Gás Natural com reservas ilimitadas.

Esse resultado confirma que o esgotamento de um recurso de desempenho ruim leva a uma melhoria no desempenho geral.

Ainda pode-se verificar nos gráficos de percurso emergético, que embora o valor final dos índices, no ano 2050, sejam praticamente iguais, o percurso emergético foi bem diferente.

\subsubsection{Recursos Hídricos e de Produtos de Cana}

Tanto da utilização das fontes de recursos hídricos quanto na dos produtos de cana, a questão se refere ao uso intensivo das reservas e como a composição entre as componentes $\mathrm{R}, \mathrm{N}$ e $\mathrm{F}$ se comportam.

Nos dois casos, os resultados mostram que o uso intensivo desses recursos faz com que as explorações das reservas desloquem-se para a 
região amazônica, conseqüentemente, incorrendo em um impacto maior que pode ser associado com um custo maior advindo dos recursos pagos.

Este é o custo necessário para que os impactos sejam mitigados por medidas de recuperação na área ambiental afetada, isto é, caso se queira mitigar os efeitos desse impacto deve-se aumentar a parcela dos recursos pagos, mantendo-se as proporções entre recursos renováveis e não renováveis (ULGIATI e BROWN, 2002).

\subsubsection{Recursos Hídricos}

A proposta de alteração na parcela de recursos pagos, mantendose a proporção de recursos renováveis e não renováveis decorre em razão de que os recursos hídricos tendem ao aproveitamento de bacias localizadas nas regiões de floresta amazônica.

A implicação direta é que a utilização de recursos hídricos nesta região impacta o meio ambiente, de forma mais significativa que em outras regiões e, portanto, deveria ser gasto uma parcela maior de recursos pagos para que esse impacto fosse minimizado.

$\mathrm{Na}$ simulação, foi feita a alteração do valor das parcelas de recursos renováveis, não renováveis e pagos toda vez que a produção atingir um determinado valor. A ferramenta de simulação foi configurada para que durante a execução, toda vez que a produção corrigida no ciclo ultrapassar o valor de 100 tep, as componentes renováveis e não renováveis diminuam de 0,688 para 0,562 e de 0,181 para 0,148 respectivamente e a componente de recurso pago aumente de 0,131 para 0, 290. Esses valores têm como base o custo dos serviços do meio ambiente para a mitigação dos impactos, segundo Ulgiati e Brown (2002).

O efeito dessa simulação pode ser verificado nos gráficos das figuras 98 e 99 . 


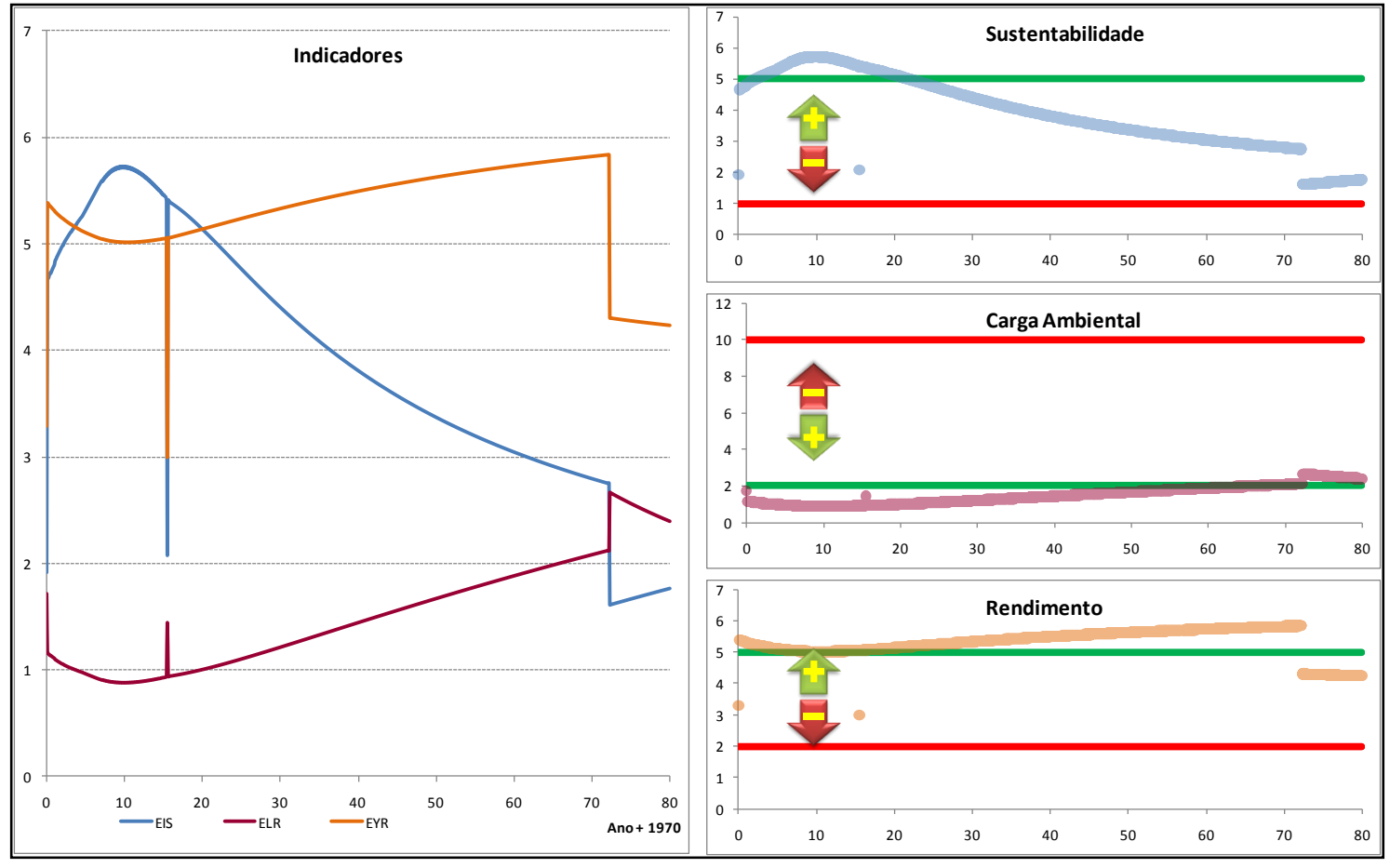

FIGURA 98 - Índices: EIS, ELR e EYR, com o serviço do meio ambiente para recursos hídricos.

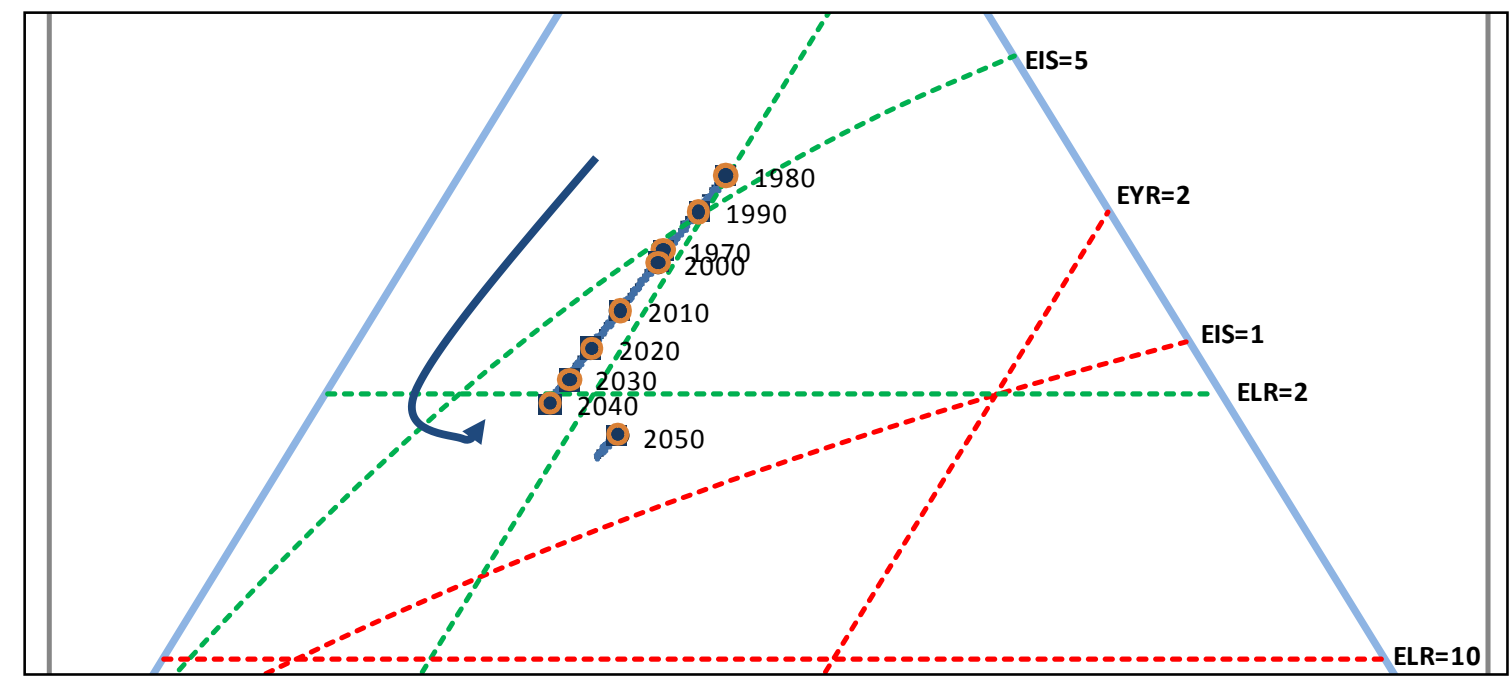

FIGURA 99 - Percurso Emergético com serviço do meio ambiente, recursos hídricos. 
Os resultados numéricos obtidos para os índices estão apresentados na tabela 23.

TABELA 23 - Resultados com e sem os serviços do meio ambiente para os recursos hídricos.

\begin{tabular}{lcccc}
\hline Serviço do Meio Ambiente & EIS & ELR & EYR & Observação \\
\hline SEM & 3,061 & 1,896 & 5,804 & \\
COM & 1,769 & 2,393 & 4,234 & \\
\hline
\end{tabular}

Nota-se que os índices, para os recursos hídricos, obtidos considerando o serviço do meio ambiente para mitigar o efeito floresta, apresentaram desempenho abaixo do que sem a consideração do serviço do meio ambiente.

\subsubsection{Produtos de Cana}

Da mesma forma que no caso de recursos hídricos, alterou-se a parcela de recursos pagos, mantendo-se a proporção de recursos renováveis e não renováveis, para o caso dos produtos de cana.

Nesse caso a justificativa se deve a dois fatores: (i) a invasão da floresta amazônica, direta ou indiretamente, isto é, ou por cultura de cana em área florestal, ou por deslocamento de outras culturas, como por exemplo, a soja, para a área amazônica ou áreas de pastagens e (ii) a concorrência pela área agriculturável, entre a cultura de cana para utilização como recurso como gerador de energia e o de plantações destinadas ao suprimento de alimentação.

As implicações dessa utilização de produtos de cana, direta ou indiretamente, nesta região, diminuem a permanência de recursos renováveis naturais da floresta.

A ferramenta, para execução das simulações, adota procedimento de correção automática de $\mathrm{R}, \mathrm{N}$ e $\mathrm{F}$, e toda vez que a produção corrigida no ciclo ultrapassa o valor de 110 tep, as componentes renováveis e não renováveis diminuem de 0,677 para 0,553 e de 0,026 para 0,021 
respectivamente, e a componente de recurso pago aumenta de 0,297 para 0,426 . Esses valores têm como base o custo dos serviços do meio ambiente para a mitigação dos impactos (ULGIATI e BROWN, 2002). O efeito dessa simulação pode ser verificado nos gráficos das figuras 100 e 101.

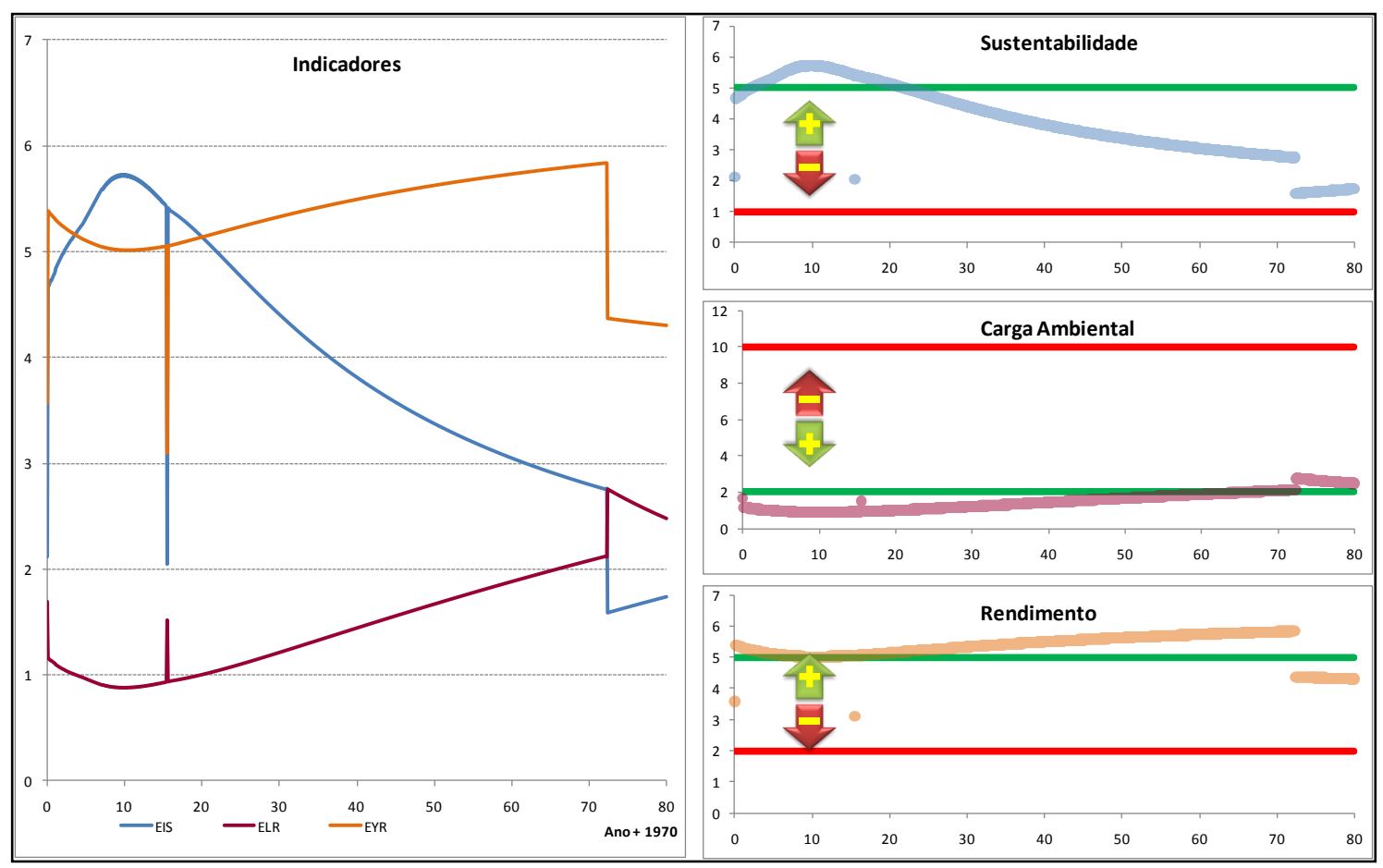

FIGURA 100 - Índices: EIS, ELR e EYR, com serviço do meio ambiente para produtos de cana.

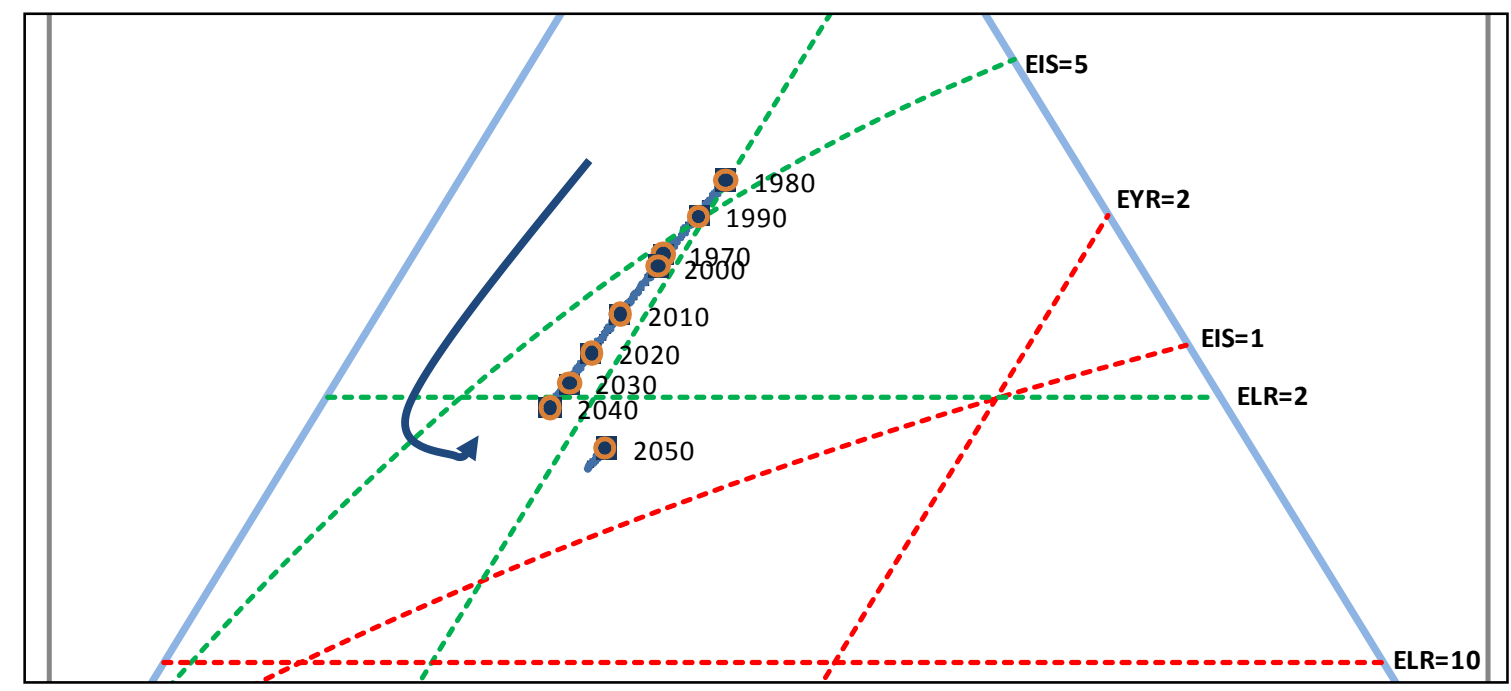

FIGURA 101 - Percurso Emergético com serviço de meio ambiente, recurso de produto de cana. 
Os resultados numéricos obtidos para os índices estão apresentados na tabela 24 .

TABELA 24 - Resultados com e sem os serviços do meio ambiente para os produtos de cana.

\begin{tabular}{lcccc}
\hline Serviço do Meio Ambiente & EIS & ELR & EYR & Observação \\
\hline SEM & 3,061 & 1,896 & 5,804 & \\
COM & 1,737 & 2,478 & 4,305 & \\
\hline
\end{tabular}

Nota-se que os índices, para os produtos de cana, obtidos considerando o serviço do meio ambiente para mitigar o efeito floresta, apresentaram desempenho abaixo do que sem a consideração do serviço do meio ambiente. 


\section{$4 \quad$ ANÁLISE E DISCUSSÃO DOS RESULTADOS}

A partir dos resultados obtidos no capítulo 3 observa-se que a ferramenta fornece informações confiáveis. O grau de precisão, conforme a análise de correlação efetuada, mostra uma distorção aceitável, pois as faixas de correlação superiores a 0,99 determinam que os desvios presentes não são significativos.

\subsection{Análise da Verificação do Modelo}

Na Verificação do Modelo - item 3.1. - foi utilizado um período de observação de apenas cinco anos. Caso seja de interesse obter menores descolamentos das curvas de tendências em relação aos dados reais, poderse-á utilizar a ferramenta para períodos com maior duração e ajustar os equacionamentos, os parâmetros de reservas, de absorções e de recuperações.

Cabe observar que o descolamento não interfere nas avaliações dos índices, pois as análises têm como base as variações de valores quando impostas perturbações nas fontes de recursos.

Ainda quanto à questão da validade das fontes dos dados utilizados, a ferramenta se mostra muito flexível e adaptável a quaisquer novas contextualizações necessárias.

A manipulação da ferramenta é ainda um tanto trabalhosa e de operacionalidade difícil, porém muitas partes podem ser automatizadas, devendo para isso serem feitos desenvolvimentos adicionais na área de sistemas e software, o que não é o objeto principal deste trabalho.

Optou-se por manter a ferramenta com capacidade para seis fontes de recursos, embora na realidade existam muito mais de seis, pois o intuito é fazer comparações específicas, destacando uma fonte em relação a algumas das outras.

As fontes de recursos contempladas neste trabalho são: gás natural, carvão vapor, produtos de cana, energia hídrica, energia eólica e 
energia nuclear. Entende-se que com o uso destas fontes de recursos o presente estudo fica completamente caracterizado, pois, conforme explanado no item 2.2, são as fontes de recursos mais significativas no país.

Tanto o gráfico da figura 55 quanto os valores obtidos e apresentados nas tabelas 19 e 20 confirmam que o modelo e a ferramenta desenvolvidos são válidos e atendem aos objetivos almejados.

\subsection{Análise do Comportamento do modelo com perturbações}

No comportamento do modelo com perturbações - item 3.2. foram evidenciados o comportamento da metodologia quando sujeito a perturbações externas e ainda potencializou as possíveis análises desses mesmos cenários, fornecendo novas percepções de contexto.

$\mathrm{Na}$ primeira parte, fruto da análise das figuras 56 e 57, o aparecimento de uma diferença em estado estacionário sugere que 0 comportamento do caso real apresenta uma diferença entre as simulações sem perturbação e com perturbação, advinda da própria indução ao aumento do consumo e ainda, ao aumento das perdas por mudança do ponto de trabalho em regime permanente.

Esse fenômeno pode ser comprovado nas séries históricas do relatório $\mathrm{BEN}$, que quando há uma variação muito grande de uma das fontes de recursos, há uma produção maior do que o esperado nos anos seguintes.

Além disso, comprova o descolamento, da curva de tendência para os valores reais, para fontes de recursos com grandes variações em um curto período.

Quando as simulações foram estendidas em seus tempos de observação, ficou mais claro que o descolamento inicial tende a um erro estacionário de regime, mantendo-o para sempre, independente da fonte de recurso que sofreu a perturbação, conforme apresentado nos gráficos das figuras 60 e 61. Este erro estacionário de posição está de acordo com o esperado, já que o sistema, conforme já discutido, é de segunda ordem. 
$\mathrm{Na}$ aplicação de perturbações sucessivas em várias, ou todas, as fontes de recursos, os efeitos de compensação também podem ser sentidos, porém o descolamento se mantém dentro da mesma ordem de grandeza, como apresentado na figura 61.

Fato imprevisto inicialmente, porém muito importante para a análise de cenários, obteve-se com a perturbação na fonte de recursos gás natural, que mostrou um esgotamento de recursos precoce, conforme a figura 62.

Isto permite que vários cenários possam ser simulados no intuito de se verificar a validade de um alongamento de utilização de tal fonte de recursos. Ou ainda, realizar previsões do tempo restante para o seu esgotamento, caso se intensifique a sua utilização.

Pode-se ainda fazer a análises de cenários para os casos de crescimentos naturais, sem perturbações, em que se obtém em quais, em que medida e quando serão necessários investimentos, em fontes de recursos para substituir a fonte que se esgota.

O refinamento dessas análises pode ser alcançado pela utilização da matriz de influência com coeficientes diferentes dos neutros. Para isso deve ser realizado um estudo específico das influências entre fontes de recursos, umas sobre as outras, com efeitos positivos e com efeitos negativos.

\subsection{Análise da Obtenção dos índices com e sem perturbações}

Na obtenção dos índices com e sem perturbações - item 3.3. objeto principal deste trabalho, as análises permitem que se atinjam conclusões de grande valor quanto à tomada de decisões, para direcionamento de investimentos do setor de geração de energia elétrica.

Em princípio, a análise dos resultados da aplicação de perturbações nas fontes de recursos individualmente, apresentado nas figuras 66 a 83 e na tabela 21 , fornece uma idéia geral de quais as fontes de 
recursos e em que medida impacta para melhor ou pior a combinação atual de recursos da matriz energética.

A tabela 21 foi ordenada de modo que na primeira linha está a combinação atual de recursos e nas subseqüentes, em ordem, as fontes de recursos que melhor desempenho tem, quando houver incrementos de utilização.

Nota-se ainda, pela análise dos gráficos e da tabela, que as fontes de recursos eólica, nuclear, hídrica e produtos de cana, tendem a melhorar o desempenho dos índices, ao passo que as fontes de recursos gás natural e carvão vapor, com a intensificação de sua utilização, tendem a piorar o desempenho dos índices. Esta constatação não traz surpresas em si, pois essas tendências já são de consenso geral, mas as confirmam.

Fato novo foi a constatação de que, nos exemplos simulados, a fonte de recursos advinda da energia nuclear está muito próxima da energia eólica e tem um desempenho de índices muito acima das fontes de recursos hídrica e de produtos de cana.

Outra constatação de muito interesse é com relação à aplicação de perturbações combinadas, como por exemplo, a nuclear em conjunto com a hídrica, apresentados nas figuras 80 a 83 e nas duas últimas linhas da tabela 21 , onde se observa que o desempenho dos índices podem ser melhorados com a aplicação de investimentos em várias fontes de recursos diferentes.

Ainda com base nessas observações, nota-se que o sistema apresenta uma característica de linearidade, pois o aumento de recursos, mesmo combinado, aumenta na mesma proporção o desempenho dos índices.

Uma observação inesperada, porém muito importante, foi na análise dos gráficos das figuras 91 e 92, que apresentou uma melhora de desempenho de índices após o ciclo 66, quando aplicada uma perturbação na fonte de recursos gás natural.

A melhora do desempenho dos índices, neste caso, foi evidenciada, pois, nesse ciclo, esgotam-se as reservas de gás natural e as outras fontes de recursos passam a compensar essa lacuna. 
Esse fato sugere duas conclusões adicionais: a metodologia e a ferramenta se mostram úteis para análises de esgotamento de reservas e as perturbações, naturais ou impostas, têm sua aplicação tanto no sentido de intensificar o uso de uma determinada fonte de recursos, como também para a análise de redução do uso de uma fonte de recursos, na busca de um alongamento do período de uso desse recurso.

Em qualquer dos dois casos, descritos no parágrafo anterior, decisões estratégicas quanto ao uso de reservas desta ou daquela fonte de recursos esgotável pode ter, nesta ferramenta, um aliado valoroso.

Os aspectos encontrados na observação de cenários da intensificação do uso de recursos hídricos e de produtos de cana, quando consideradas alterações das proporções das componentes renovável, não renovável e pagos, pela aplicação do conceito de mitigação dos efeitos nocivos ao meio ambiente através do valor do serviço da natureza, se mostraram elucidativos, conforme apresentados nas figuras de 98 a $101 \mathrm{e}$ nas tabelas 23 e 24 .

Confirma-se assim, que a invasão da Amazônia, tanto pelo uso da terra para a agricultura, quanto pelo uso da água e desmatamento para o uso da energia hídrica, traz como conseqüência uma piora significativa no desempenho dos índices emergéticos.

Há certo desconforto quanto aos fatores utilizados nesses cenários, dado que foram adaptados de usos em outras fontes de recursos, porém, fato esse que não invalida a verificação da tendência clara de piora do desempenho dos índices emergéticos. 


\section{CONCLUSÃO}

O modelo original proposto, para análise e auxilio à tomada de decisões, mostrou-se robusto e pertinente ao contexto de produção de energia elétrica nacional.

A ferramenta funcionou, conforme o esperado, inclusive trazendo durante suas análises novas percepções, as quais sem ela seriam de difícil visualização.

Nos cenários de simulações apresentados, torna-se claro que as opções de se utilizar, mais intensivamente, desta ou daquela fonte de recursos, redunda em vantagens e desvantagens do ponto de vista ambiental.

Embora não utilizada, todas as fontes de recursos, mesmo aquelas aqui não focadas, por fugir do escopo deste estudo, a ferramenta e a metodologia se mostraram flexíveis e passíveis de serem utilizadas para observação de cenários futuros.

Nas simulações que consideram a mitigação dos malefícios ambientais, foram obtidos parâmetros importantes para auxílio na tomadas de decisões.

E por fim, note-se que a análise do desempenho dos índices mostra que o exercício de simulação fornece uma variedade de informações para a tomada de decisões. Critérios como a minimização da agressividade ao meio ambiente, a sustentabilidade nas situações que consideram a composição da matriz energética e a esgotabilidade de fontes de recursos, podem ser amplamente utilizados. 


\section{Sugestões de continuidade do trabalho}

Apresentam-se a seguir, como sugestão de aprimoramento da metodologia e da ferramenta, alguns passos que poderão ser executados no seu desenvolvimento.

\subsection{Matriz de Influência}

Estudo das relações de crescimento e decréscimo entre as fontes de recursos individuais, para definição dos parâmetros da matriz de influências.

\subsection{Abrangência de Aplicação}

Aplicação da metodologia em outras áreas de abrangência de aplicação, como por exemplo, para toda a produção de energia e não somente na produção de energia elétrica.

\subsection{Abrangência Geográfica}

Aplicação da metodologia em outras áreas de abrangência geográfica, como por exemplo, para regiões como América Latina ou Global.

\subsection{Ampliação de Capacidade da Ferramenta}

Aproveitar a característica modular da ferramenta e ampliar 0 número de fontes de recursos para cobrir a totalidade da matriz energética reportada no BEN. 


\subsection{Novos Índices}

Propor novos índices que possam ser incorporados à metodologia e implementados na ferramenta, como por exemplo, um que indique a relação da quantidade de reservas disponíveis em relação a intensidade de uso e sua variação ao longo do tempo (ESGOTABILIDADE DINÂMICA), fornecendo o conceito de renovabilidade e associando-a ao tempo que resta para sua exploração.

\subsection{Interface Homem-Máquina - IHM}

Criar uma interface homem-máquina - IHM, na ferramenta, para entrada e saída de dados mais amigável com o operador e que gere relatórios padronizados. 


\section{REFERÊNCIAS BIBLIOGRÁFICAS}

ALMEIDA, C. M. V. B. et al. Avaliação ambiental e diagrama triangular: estudo de sistema operacional alternativo para distribuição de chapas de aço. In: J.P.FUSCO, Tópicos de Engenharia de Produção III. São Paulo: Arte \& Ciência, 2004.

ALMEIDA, C. M. V. B.; BARRELLA, F. A.; GIANNETTI, B. F. Emergetic ternary diagrams: five examples for application in environmental accounting for decisionmaking. Journal of Cleaner Production, p. 50-52, 19 September 2005.

ALONSO-PIPPO, W. et al. Emergy Evaluation of Bio-Oil Production using Sugarcane Bio-Mass Residues at Fast Pirolysis Pilot Plant in Brazil. in Proceeding of Biennal International Workshop: Advances in Energy Studies, Campinas, p. 401-408, Junho 2004.

ALVIN, C. F.; EIDELMAN, F.; FERREIRA, O. C. Energia nuclear num cenário de trinta anos. Estudos Avançados, São Paulo, v. 21, n. 59, Jan./Apr 2007.

BARRELLA, F. A. Ferramenta Gráfica para Análise Emergética: Avaliação Ambiental e Tomada de Decisão. Dissertação de Mestrado. Universidade Paulista. São Paulo, SP, p. 120. 2004.

BARRELLA, F. A.; ALMEIDA, C. M. V. B.; GIANNETTI, B. F. Ferramenta para Tomada de Decisão Considerando a Interação dos Sistemas de Produção e o Meio Ambiente. Revista Produção, v. 15, n. 1, p. 87-101, Jan/Abr 2005.

BASTIANONI, S.; MARCHETTINI, N. Emergy/exergy ratio as measure of the level of organization of systems. Ecological Modelling, n. 99, p. 33-40, 1997.

BASTIANONI, S.; MARCHETTINI, N. The problem of co-production in environmental accounting by emergy analysis. Ecological Modelling, n. 129, p. 187-193, 2000.

BROWN, M. T.; ULGIATI, S. Emergy-based indices and ratios to evaluate sustainability: monitoring economies and technology toward environmentally sound innovation. Ecological Engineering, n. 9, p. 51-69, 1997.

BROWN, M. T.; ULGIATI, S. Emergy Evaluations and Environmental Loading of Electricity Production System. Journal Cleaner Production, n. 10, p. 321-334, 2002.

BUSICO, A. Energia. Presidenza del Consiglio dei Ministri. Roma. 2003.

CICCHI, C. ALSTOM at a glance. Simpósio sobre a Matriz Energética. São Paulo: Instituto de Engenharia. 2006.

CLEVELAND, C. J.; KAUFMANN, R. K.; STERN, D. I. Aggregation and the role of energy in the economy. Ecological Economics, n. 32, p. 301-317, 2000.

DORF, R. C.; SVOBODA, J. A. Introdução aos Circuitos Elétricos. 7ª . ed. [S.I.]: LTC, 2008.

GIANNETTI, B. F.; ALMEIDA, C. M. V. B. Ecologia Industrial: Conceitos, Ferramentas e Aplicações. São Paulo: Edgard Blücher, 109 p. 2006.

GIANNETTI, B. F.; BARRELLA, F. A.; ALMEIDA, C. M. V. B. A combined tool for environmental scientists and decision makers: ternary diagrams and emergy accounting. Journal Cleaner Production, v. 14, n. 2, p. 201-210, 2006. 
GRAEDEL, B. F.; ALLENBY, B. R. Industrial Ecology. 1ª Ed. ed. Chicago: Prentice Hall, 412 p. 1995.

HEIZER, J.; RENDER, B. Production and operation management: strategic and tactical decisions. Englewood Cliffs: Prentice Hall, 428p.1996.

HORNBORG, A. Comentary: Towards en ecological theory of unequal exchange: articulating world system theory and ecological economics. Ecological Economics, $n$. 25, p. 127-136, 1998.

IAEA - INTERNATIONAL ATOMIC ENERGY AGENCY. An annual report to the General Conference concerning the aff airs of the Agency and any projects approved by the Agency and any projects approved by the Agency. IAEA. [S.I.]. 2004.

IAEA - INTERNATIONAL ATOMIC ENERGY AGENCY. Energy Indicators For Sustainable Development: Guidelines and Methodologies. United Nations Department Of Economic and Social Affairs, International Energy Agency, Eurostat and European Environment Agency. [S.I.]. 2005.

JÖRGENSEN, S. E.; NIELSEN, S. N.; MEJER, H. Emergy, environ, exergy and ecological modeling. Ecological Modelling, n. 77, p. 99-109, 1995.

KINDBERG, A. Emergy Evaluation of a Swedish Nuclear Power Plant. Examensarbete, mars 20 p. 2007.

KUSTER, L. A.; SOUZA, S. Tecnologia de IGCC - Gaseificação Integrada com Ciclo Combinado - GE. Simpósio sobre a Matriz Energética. São Paulo: Instituto de Engenharia. 2006.

LAGANISA, J.; DEBELJAKB, M. Sensitivity analysis of the emergy flows at the solar salt production process in Slovenia. Ecological Modelling, n. 194, p. 287-295, 2006.

LOPES, E. E. A. Application of Life Cycle Assessment to the Portuguese Pulp and Paper Industry. Journal Cleaner Production, n. 11, p. 51-59, 2003.

MATHWORKS Matlab and Simulink R2008, versão 7.6: Software de Simulação: The MathWorks, Inc., Conjunto de programas. 1. CD-ROM. 2008.

MICROSOFT Office Excel 2007, versão 12.0: planilha eletrônica. [S.I.]: Microsoft Corporation, Conjunto de programas. 1 CD-ROM. 2008.

ODUM, H. T. Environmental Accounting - EMERGY and Environmental Decision Making. [S.I.]: John Wiley \& Songs Ltd., 370 p. 1996.

ODUM, H. T. Emergy evaluation of an OTEC electrical power system. Energy, n. 25, p. 389-393. 2000.

ODUM, H. T.; PETERSON, N. Simulation and evaluation with energy systems blocks. Ecological Modelling, n. 93, p. 155-173. 1996.

ORTEGA, E. Símbolos dos ícones usados na linguagem de fluxos de energia. Site da UNICAMP-FEA, 2004.2 Disponivel em: <http://www.unicamp.br/fea/ortega/ecologia/desafio-21.htm>. Acesso em: 19 maio 2004.

PATTEN, B. C. Network integration of ecological extremal principles: exergy, emergy, power, ascendency, and indirect effects. Ecological Modelling, n. 79, p. 7584. 1995. 
PINHEIRO DA SILVA, O. L. Energia Nuclear: Inserção no Sistema Elétrico Nacional ELETRONUCLEAR. Simpósio sobre a Matriz Energética. São Paulo: Instituto de Engenharia. 2006.

POPP, J.; HOAG, D.; HYATT, D. E. Sustainability indices with multiple objectives. Ecological Indicators, v. 1, p. 37-47, 2001.

PORTER, M.; LINDE VAN DER, C. Toward a new conception of the environment competitiveness relantionship. J. Econ. Perspect., n. 9, p. 97-118, 1995.

RONCHI, E.; FEDERICO, A.; MUSMECI, F. A system oriented integrated indicator for sustainable development in Italy. Ecological Indicators, n. 2, p. 197-210, 2002.

SALES, C. J. D. Desenvolvimento Sustentável - ACENDE. Simpósio sobre a Matriz Energética. São Paulo: Instituto de Engenharia. 2006.

SARKIS, J. Manufacturing strategy and environmental conciousness. Technovation, v. 15, n. 2, p. 79-97, 1995.

SEAGER, T. P.; THEIS, T. L. A uniform definition and quantitative basis for industrial ecology. Journal of Cleaner Production, n. 10, p. 225-235, 2002.

SHALDERS, A. N. Matriz Energética do Estado de São Paulo - Secretaria de Energia do Estado de São Paulo. Simpósio sobre a Matriz Energética. São Paulo: Instituto de Engenharia. 2006.

SHARMA, S.; VREDENBURG, H. Proactive corporate environmental strategy and the development of competitively valuable organizational capabilities. Strategic Management Journal, v. 19, n. 8, p. 729-753, 1998.

SHRIVASTAVA, P. Environmental technologies and competitive advantages. Strategic Management Journal, v. 19, n. 3, p. 183-200, 1995.

SILVA, B. A. Contabilidade e Meio Ambiente: Considerações teóricas e práticas sobre o controle dos gastos ambientais. São Paulo: Annablume. 2003.

SPALDING, E. C. Matriz Energética - ABRACE. Simpósio sobre a Matriz Energética. São Paulo: Instituto de Engenharia. 2006.

SPANGENBERG, J. H. Environmental space and the prism of sustainability: frameworks for indicators measuring sustainable development. Ecological Indicators, n. 2, p. 295-309, 2002.

SZWARC, A. Etanol - UNICA. Simpósio sobre a Matriz Energética. São Paulo: Instituto de Engenharia. 2006.

TORRES, M. A. Z. Matriz Energética - TRACTEBEL ENERGIA. Simpósio sobre a Matriz Energética. São Paulo: Instituto de Engenharia. 2006.

ULGIATI, S.; BARGIGLI, S.; RAUGEL, M. Uneven Distribuition of Benefits and Environmental Load. Site da UNICAMP-FEA, 2004. Disponivel em: <http://www.fea.unicamp.br/energy/SUlgiaty.ppt>. Acesso em: 26 jun. 2004.

ULGIATI, S.; BROWN, M. T. Monitoring patterns of sustainability in natural and manmade ecosystems. Ecological Modelling, n. 108, p. 23-36, 1998. 
ULGIATI, S.; BROWN, M. T. Quantifying the environmental support for diluition and abatement of process emissions - The case of electricity production. Journal Cleaner Production, n. 10, p. 335-348, 2002.

ULGIATI, S.; BROWN, M. T.; MARCHETTINI, N. Emergy-based indices and ratios to evaluate the sustainable use of resources. Ecological Engineering, n. 5, p. 519-531, 1995.

ULGIATI, S.; ODUM, H. T.; BASTIANONI, S. Emergy analysis, environmental loading sustainability. An emergy analysis of Italy. Ecological Modelling, n. 73, p. 215-268, 1994.

YANG, $H$. et al. Evaluating waste treatment, recycle and reuse in industrial system: an application of the eMergy approach. Ecological Modeling, n. 160, p. 13-21, 2003.

ZANCAN, F. L. ENERGIA: Carvão - ABCM. Simpósio sobre a Matriz Energética. São Paulo: Instituto de Engenharia. 2006.

ZIMMERMAN, M. P. Matriz Energética, Reservas de Combustíveis Não-Renováveis e Projeção da Matriz Energética - MME. Simpósio sobre a Matriz Energética. São Paulo: Instituto de Engenharia. 2006. 


\section{APÊNDICE A - Sensibilidade dos índices EYR, ELR e EIS em relação à $F$}

Na tabela A1 estão apresentados para os conjuntos de pontos 1, 3, 5, 7 e 2, 4, 6 e 8 as composições das parcelas R, N e F. As colunas Original e $\Delta F(F x 2)$ representam os valores iniciais e finais da simulação. Nas colunas de índices e de ranking observa-se que, embora os valores dos índices tenham se alterado, a classificação quanto ao desempenho se manteve.

Tabela A1 - Valores calculados dos índices EYR, ELR e EIS para uma variação de F de um fator de 2, para os pontos 1, 3, 5 e 7; resultando os pontos 2, 4, 6 e 8 .

\begin{tabular}{|c|c|c|c|c|c|c|c|c|c|}
\hline \multirow{2}{*}{$\begin{array}{c}\text { Recurso } \\
\text { TIPO } 1 \\
\end{array}$} & \multicolumn{2}{|c|}{ Original (Ponto 1 ) } & \multicolumn{2}{|c|}{$\Delta \mathrm{F}(\mathrm{Fx2})$ (ponto 2) } & \multirow[t]{2}{*}{ Índice } & \multicolumn{2}{|c|}{ Original } & \multicolumn{2}{|c|}{$\Delta F(F \times 2)$} \\
\hline & Valor & Parcela & Valor & Parcela & & Valor & Rank & Valor & Rank \\
\hline$R$ & $1,00 E+00$ & 0,333 & $1,00 E+00$ & 0,250 & EYR & 3,000 & 2 & 2,000 & 2 \\
\hline $\mathrm{N}$ & $1,00 E+00$ & 0,333 & $1,00 E+00$ & 0,250 & ELR & 2,000 & 2 & 3,000 & 2 \\
\hline $\mathrm{F}$ & $1,00 E+00$ & 0,333 & $2,00 E+00$ & 0,500 & ESI & 1,500 & 2 & 0,667 & 2 \\
\hline Y & \multicolumn{2}{|l|}{$3,00 E+00$} & \multicolumn{2}{|l|}{$4,00 E+00$} & & & & & \\
\hline Recurso & \multicolumn{2}{|c|}{ Original (Ponto3) } & \multicolumn{2}{|c|}{$\Delta F(F \times 2)$ (ponto 4) } & Índice & \multicolumn{2}{|c|}{ Original } & \multicolumn{2}{|c|}{$\Delta F(F \times 2)$} \\
\hline TIPO 2 & Valor & Parcela & Valor & Parcela & & Valor & Rank & Valor & Rank \\
\hline $\mathrm{R}$ & $3,00 E+00$ & 0,600 & $3,00 E+00$ & 0,500 & EYR & 5,000 & 1 & 3,000 & 1 \\
\hline $\mathrm{N}$ & $1,00 E+00$ & 0,200 & $1,00 E+00$ & 0,167 & ELR & 0,667 & 1 & 1,000 & 1 \\
\hline $\mathrm{F}$ & $1,00 E+00$ & 0,200 & $2,00 E+00$ & 0,333 & ESI & 7,500 & 1 & 3,000 & 1 \\
\hline Y & \multicolumn{2}{|l|}{$5,00 E+00$} & \multicolumn{2}{|l|}{$6,00 E+00$} & & & & & \\
\hline Recurso & \multicolumn{2}{|c|}{ Original (Ponto 5) } & \multicolumn{2}{|c|}{$\Delta F(F \times 2)$ (ponto 6) } & Índice & \multicolumn{2}{|c|}{ Original } & \multicolumn{2}{|c|}{$\Delta F(F \times 2)$} \\
\hline TIPO 3 & Valor & Parcela & Valor & Parcela & & Valor & Rank & Valor & Rank \\
\hline $\mathrm{R}$ & $1,00 E+00$ & 0,200 & $1,00 E+00$ & 0,167 & EYR & 5,000 & 1 & 3,000 & 1 \\
\hline $\mathrm{N}$ & $3,00 E+00$ & 0,600 & $3,00 E+00$ & 0,500 & ELR & 4,000 & 3 & 5,000 & 3 \\
\hline $\mathrm{F}$ & $1,00 E+00$ & 0,200 & $2,00 E+00$ & 0,333 & ESI & 1,250 & 3 & 0,600 & 3 \\
\hline Y & \multicolumn{2}{|l|}{$5,00 E+00$} & \multicolumn{2}{|l|}{$6,00 \mathrm{E}+00$} & & & & & \\
\hline Recurso & \multicolumn{2}{|c|}{ Original (Ponto 7) } & \multicolumn{2}{|c|}{$\Delta F(F \times 2)$ (ponto 8) } & Índice & \multicolumn{2}{|c|}{ Original } & \multicolumn{2}{|c|}{$\Delta F(F \times 2)$} \\
\hline TIPO 4 & Valor & Parcela & Valor & Parcela & & Valor & Rank & Valor & Rank \\
\hline $\mathrm{R}$ & $1,00 E+00$ & 0,167 & $1,00 E+00$ & 0,111 & EYR & 2,000 & 3 & 1,500 & 3 \\
\hline $\mathrm{N}$ & $2,00 E+00$ & 0,333 & $2,00 E+00$ & 0,222 & ELR & 5,000 & 4 & 8,000 & 4 \\
\hline $\mathrm{F}$ & $3,00 E+00$ & 0,500 & $6,00 E+00$ & 0,667 & ESI & 0,400 & 4 & 0,188 & 4 \\
\hline Y & $6,00 E+00$ & & $9,00 E+00$ & & & & & & \\
\hline
\end{tabular}

As expressões analíticas para a obtenção dos índices emergéticos a partir dos valores das componentes $\mathrm{R}, \mathrm{N}$ e $\mathrm{F}$, normalizados, podem ser escritas como segue: 
$E Y R=\frac{R+N+F}{F}$

$E Y R=\overline{E Y R}=\frac{\bar{R}+\bar{N}+\bar{F}}{\bar{F}}, \quad$ mas $\bar{R}+\bar{N}+\bar{F}=1 \quad \Rightarrow \quad E Y R=\frac{1}{\bar{F}}$

$E L R=\frac{N+F}{R}$

$E L R=\overline{E L R}=\frac{\bar{N}+\bar{F}}{\bar{R}}, \quad$ mas $\bar{N}+\bar{F}=1-\bar{R} \Rightarrow E L R=\frac{1-\bar{R}}{\bar{R}}$

$E I S=\frac{E Y R}{E L R}$

$E I S=\overline{E I S}=\frac{E Y R}{E L R}=\frac{\overline{E Y R}}{\overline{E L R}}=\frac{\bar{R}}{(1-\bar{R}) \times \bar{F}}$

Definindo a razão entre as componentes $\mathrm{N}$ e $\mathrm{R} ;\left(k=\frac{\bar{N}}{\bar{R}}\right)$, conforme em Laganisa e Debeljakb (2006), obtêm-se as seguintes expressões de $\bar{R}$ e $\bar{N}$ em função de $\bar{F}$ e $k$

$\bar{R}=\frac{1-\bar{F}}{1+k}$ e $\bar{N}=\frac{k \times(1-\bar{F})}{1+k}$

Fazendo a parametrização, por k, dos índices EYR, ELR e EIS em função da componente $F$, obtêm-se as seguintes expressões:

$E Y R=\frac{1}{\bar{F}}$, não dependente de $k$

$$
\begin{aligned}
& E L R=\frac{\bar{N}+\bar{F}}{\bar{R}}=\frac{\frac{k \times(1-\bar{F})}{1+k}+F}{\frac{1-\bar{F}}{1+k}}=\frac{k \times(1-\bar{F})+\bar{F} \times(1+k)}{1-\bar{F}} \\
& E L R=\frac{k-k \times \bar{F}+\bar{F}+\bar{F} \times k}{1-\bar{F}}=\frac{k+\bar{F}}{1-\bar{F}} \\
& E I S=\frac{E Y R}{E L R}=\frac{\frac{1}{\bar{F}}}{\frac{k+\bar{F}}{1-\bar{F}}}=\frac{1-\bar{F}}{\bar{F} \times(k+\bar{F})}
\end{aligned}
$$

Os gráficos das figuras $A 1$ a $A 3$, apresentam os resultados dos índices em função da componente $\mathrm{F}$, parametrizados por $\mathrm{k}$. 


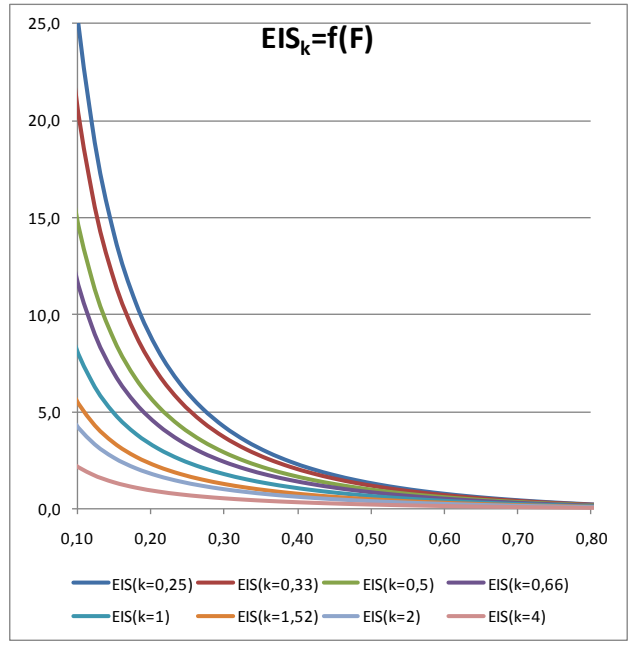

Figura $A 1$ - EIS x F com parametrização de $K=(N / R)$

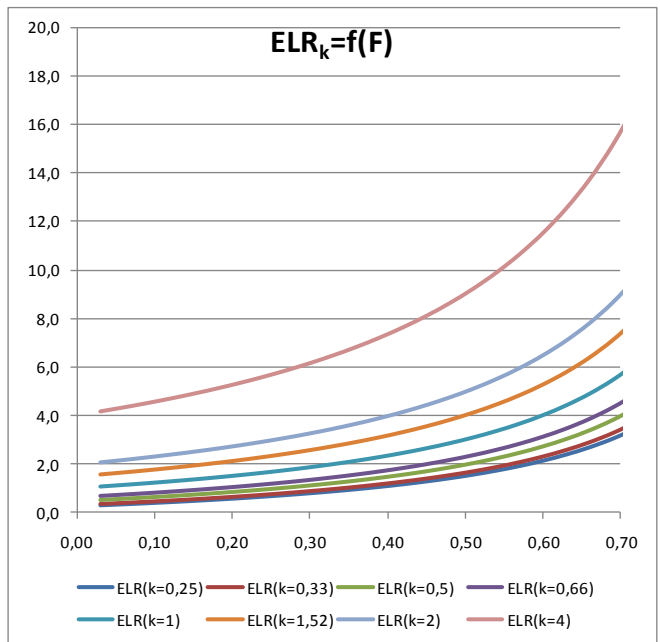

Figura A2 - ELR x F com parametrização de $K=(N / R)$

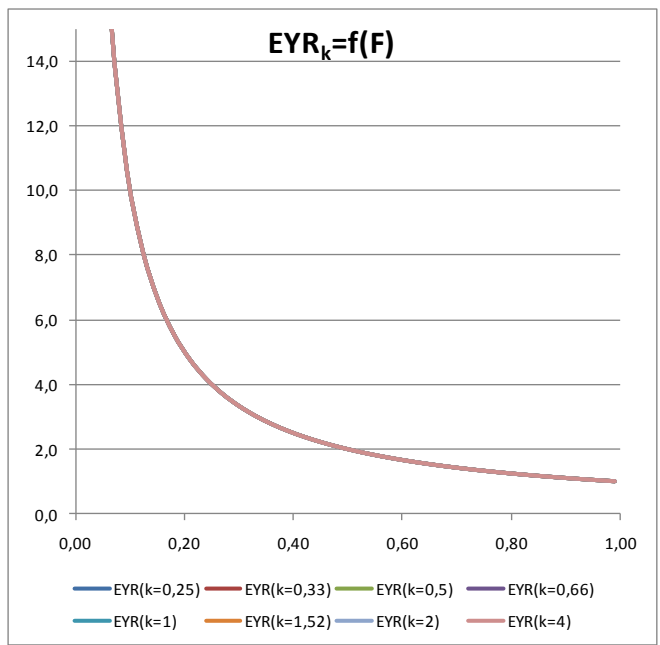

Figura A3 - EYR x F com parametrização de $K=(N / R)$ - curvas sobrepostas. 


\section{APÊNDICE B - Simulações Índices Agregados}

Este apêndice apresenta as simulações, em vários cenários, conforme os quadros apresentados a seguir. Para cada uma das simulações, estão apresentados os valores de EIS, ELR e EYR para os anos de 2040 e 2050 e os gráficos correspondentes.

Os cenários são sem e com perturbações para cada fonte de recursos, para os casos de:

- Sem o efeito floresta.

- Com o efeito floresta nos recursos Hídricos.

- Com o efeito floresta nos Produtos de Cana.

- Com o efeito floresta nos recursos Hídricos e Produtos de Cana, combinados.

Quadro B1 - Sem o efeito floresta

\begin{tabular}{|c|c|c|c|c|c|c|c|}
\hline Simulação & Floresta: & M EFE & & Início: & 2000 & Término: & 2050 \\
\hline PERTURBAÇÃO & \multicolumn{3}{|c|}{ no ano de 2040} & \multicolumn{4}{|c|}{ no ano de 2050} \\
\hline $10^{4}$ tep em 2015 & EIS & ELR & EYR & EIS & & ELR & EYR \\
\hline sem Perturbação & 2,596 & 2,312 & 5,949 & 2,987 & & 2,137 & 5,906 \\
\hline GÁS & 3,375 & 3,057 & 5,941 & 3,735 & & 2,669 & 5,881 \\
\hline GÁS Ilimitado & 2,631 & 3,217 & 5,993 & 2,708 & & 3,01 & 6,03 \\
\hline CARVÃO & 2,311 & 3,218 & 5,864 & 2,700 & & 2,894 & 5,846 \\
\hline HÍDRICA & 3,770 & 2,069 & 6,074 & 4,152 & & 1,924 & 6,026 \\
\hline CANA & 3,112 & 2,064 & 5,719 & 3,626 & & 1,920 & 5,742 \\
\hline EÓLICO & 5,764 & 1,980 & 6,064 & 5,749 & & 1,852 & 6,019 \\
\hline NUCLEAR & 3,185 & 2,251 & 6,430 & 3,684 & & 2,069 & 6,311 \\
\hline
\end{tabular}

Quadro B2 - Com o efeito floresta nos recursos Hídricos

\begin{tabular}{|l|l|l|l|l|l|l|l|}
\hline Simulação & Floresta: & \multicolumn{1}{|l|}{ HIDRO } & Início: & 2000 & Término: & $\mathbf{2 0 5 0}$ \\
\hline PERTURBAC̃O & \multicolumn{3}{|c|}{ no ano de 2040 } & \multicolumn{3}{c|}{ no ano de 2050 } \\
\hline $\mathbf{1 0}$ tep em 2015 & EIS & ELR & EYR & EIS & ELR & EYR \\
\hline sem Perturbação & 2,560 & 2,324 & 5,899 & 2,907 & 2,152 & 5,828 \\
\hline GÁS & 3,211 & 3,074 & 5,836 & 3,541 & 2,688 & 5,753 \\
\hline GÁS Ilimitado & 2,558 & 3,234 & 5,909 & 2,626 & 3,028 & 5,935 \\
\hline CARVÃO & 2,273 & 3,233 & 5,809 & 2,623 & 2,91 & 5,767 \\
\hline HÍ́RICA & 3,068 & 2,106 & 5,763 & 3,504 & 1,959 & 5,732 \\
\hline CANA & 3,039 & 2,08 & 5,635 & 3,481 & 1,938 & 5,63 \\
\hline EÓLICO & 5,692 & 1,994 & 5,983 & 5,604 & 1,869 & 5,909 \\
\hline NUCLEAR & 3,122 & 2,264 & 6,357 & 3,547 & 2,085 & 6,208 \\
\hline
\end{tabular}


Quadro B3 - Com o efeito floresta nos Produtos de Cana

\begin{tabular}{|c|c|c|c|c|c|c|c|}
\hline Simulação & Floresta: & NA & & Início: & 2000 & Término: & 2050 \\
\hline PERTURBAÇÃO & \multicolumn{3}{|c|}{ no ano de 2040} & \multicolumn{4}{|c|}{ no ano de 2050} \\
\hline $10^{4}$ tep em 2015 & EIS & ELR & EYR & EIS & & ELR & EYR \\
\hline sem Perturbação & 2,531 & 2,288 & 5,741 & 2,82 & & 2,117 & 5,611 \\
\hline GÁS & 2,983 & 3,039 & 5,569 & 3,279 & & 2,656 & 5,438 \\
\hline GÁS Ilimitado & 2,496 & 3,191 & 5,677 & 2,555 & & 2,983 & 5,677 \\
\hline CARVÃO & 2,249 & 3,184 & 5,644 & 2,547 & & 2,865 & 5,550 \\
\hline HÍDRICA & 3,634 & 2,044 & 5,758 & 3,831 & & 1,905 & 5,627 \\
\hline CANA & 2,724 & 2,035 & 5,300 & 3,102 & & 1,898 & 5,260 \\
\hline EÓLICO & 5,624 & 1,96 & 5,756 & 5,423 & & 1,837 & 5,625 \\
\hline NUCLEAR & 3,06 & 2,23 & 6,143 & 3,371 & & 2,054 & 5,935 \\
\hline
\end{tabular}

Quadro B4 - Com o efeito floresta nos recursos Hídricos e Produtos de Cana

\begin{tabular}{|c|c|c|c|c|c|c|c|}
\hline Simulação & Floresta: & $\mathrm{DRO}+$ & & Início: & 2000 & Término: & 2050 \\
\hline PERTURBAÇÃO & \multicolumn{3}{|c|}{ no ano de 2040} & \multicolumn{4}{|c|}{ no ano de 2050} \\
\hline $10^{4}$ tep em 2015 & EIS & ELR & EYR & EIS & & ELR & EYR \\
\hline sem Perturbação & 2,498 & 2,299 & 5,697 & 2,755 & & 2,131 & 5,549 \\
\hline GÁS & 2,874 & 3,054 & 5,493 & 3,145 & & 2,673 & 5,346 \\
\hline GÁS llimitado & 2,437 & 3,206 & 5,612 & 2,489 & & 2,999 & 5,604 \\
\hline CARVÃO & 2,214 & 3,198 & 5,597 & 2,485 & & 2,881 & 5,487 \\
\hline HÍDRICA & 2,946 & 2,080 & 5,466 & 3,225 & & 1,938 & 5,363 \\
\hline CANA & 2,664 & 2,050 & 5,235 & 3,000 & & 1,915 & 5,178 \\
\hline EÓLICO & 5,564 & 1,973 & 5,693 & 5,321 & & 1,853 & 5,544 \\
\hline NUCLEAR & 3,008 & 2,243 & 6,083 & 3,275 & & 2,068 & 5,857 \\
\hline
\end{tabular}


FLORESTA: SEM EFEITO

SEM PERTURBAÇÃO

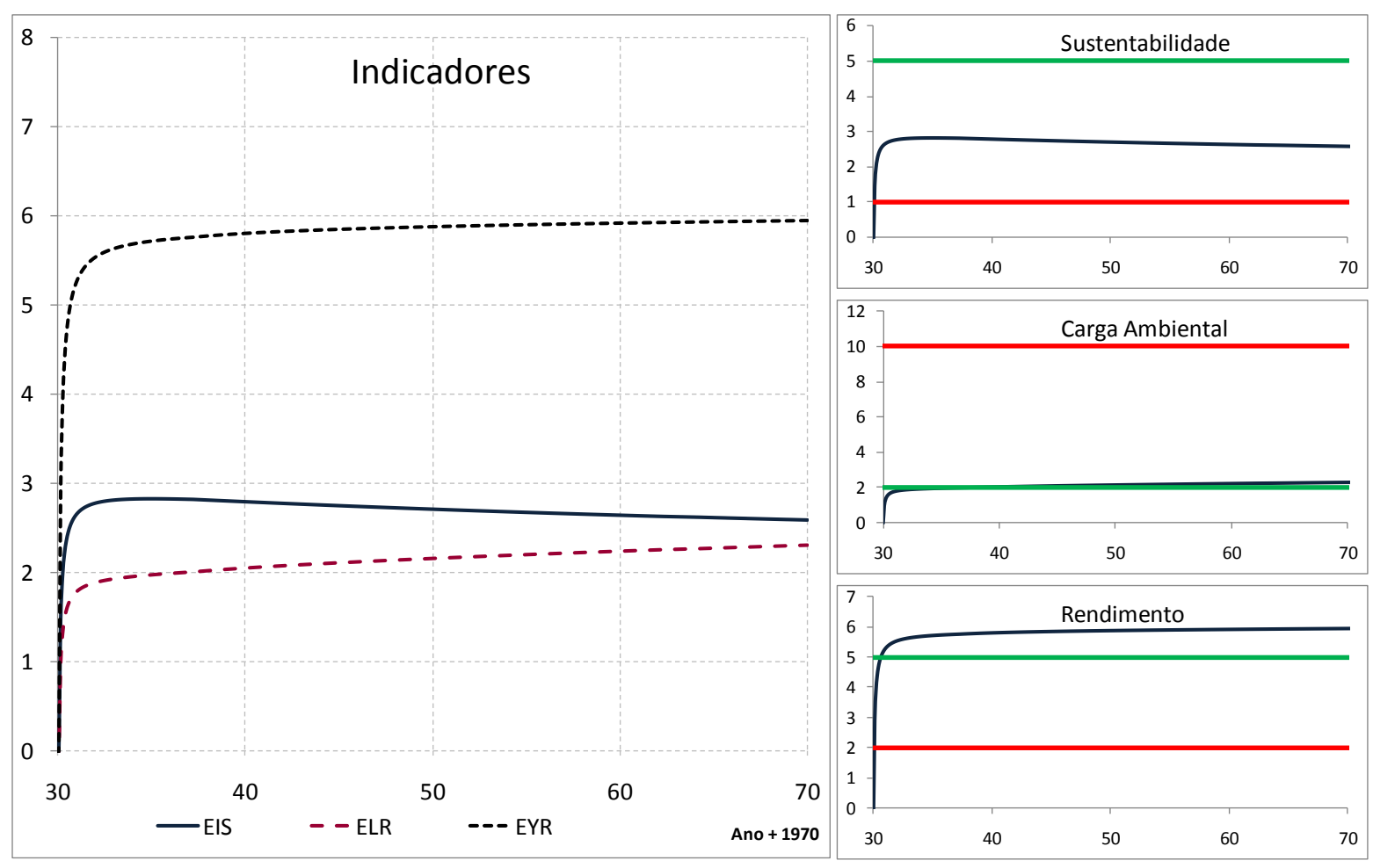

Figura B1 - Índices sem perturbação e sem efeito floresta (70 anos)

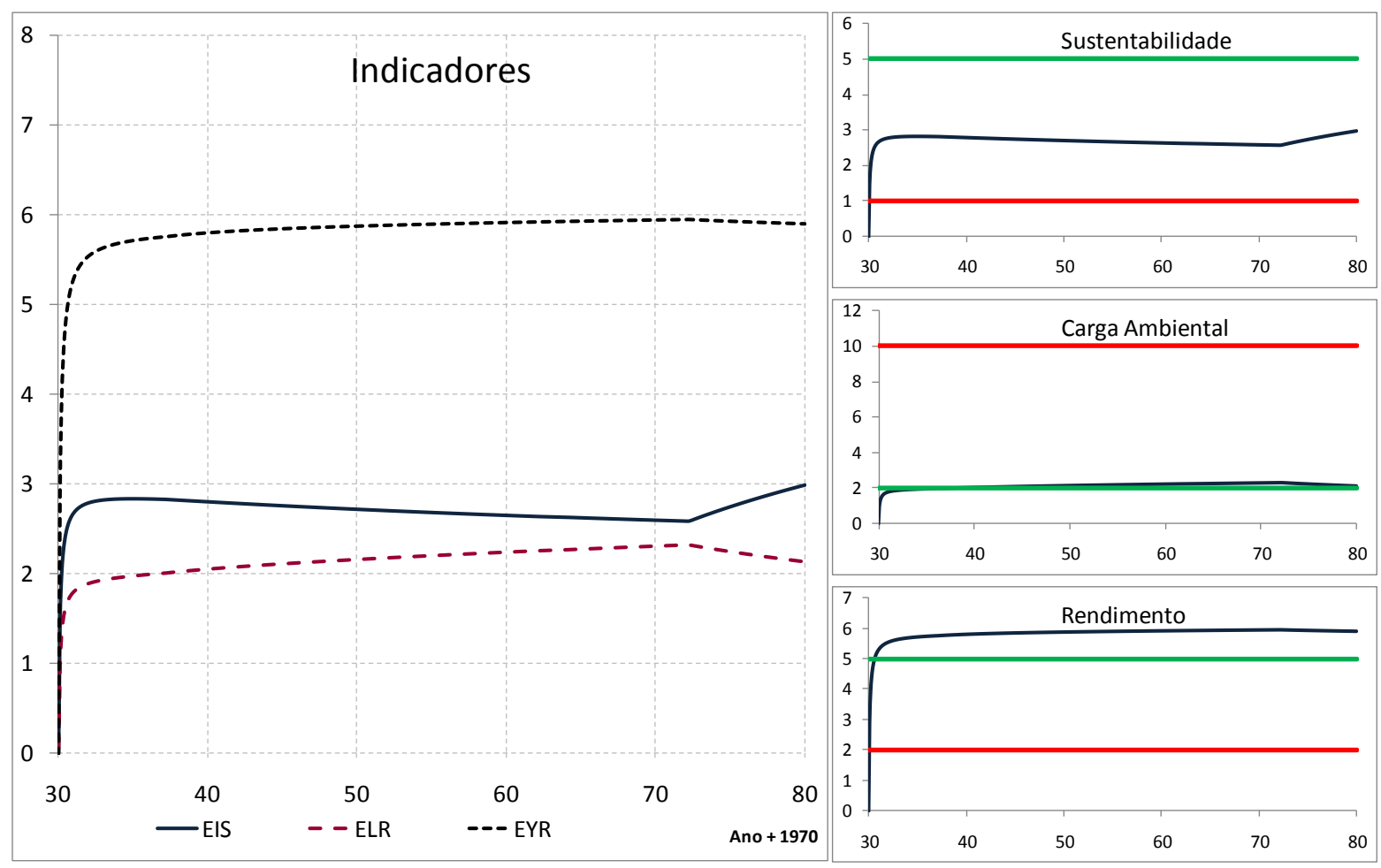

Figura B2 - Índices sem perturbação e sem efeito floresta (80 anos) 
GÁS NATURAL

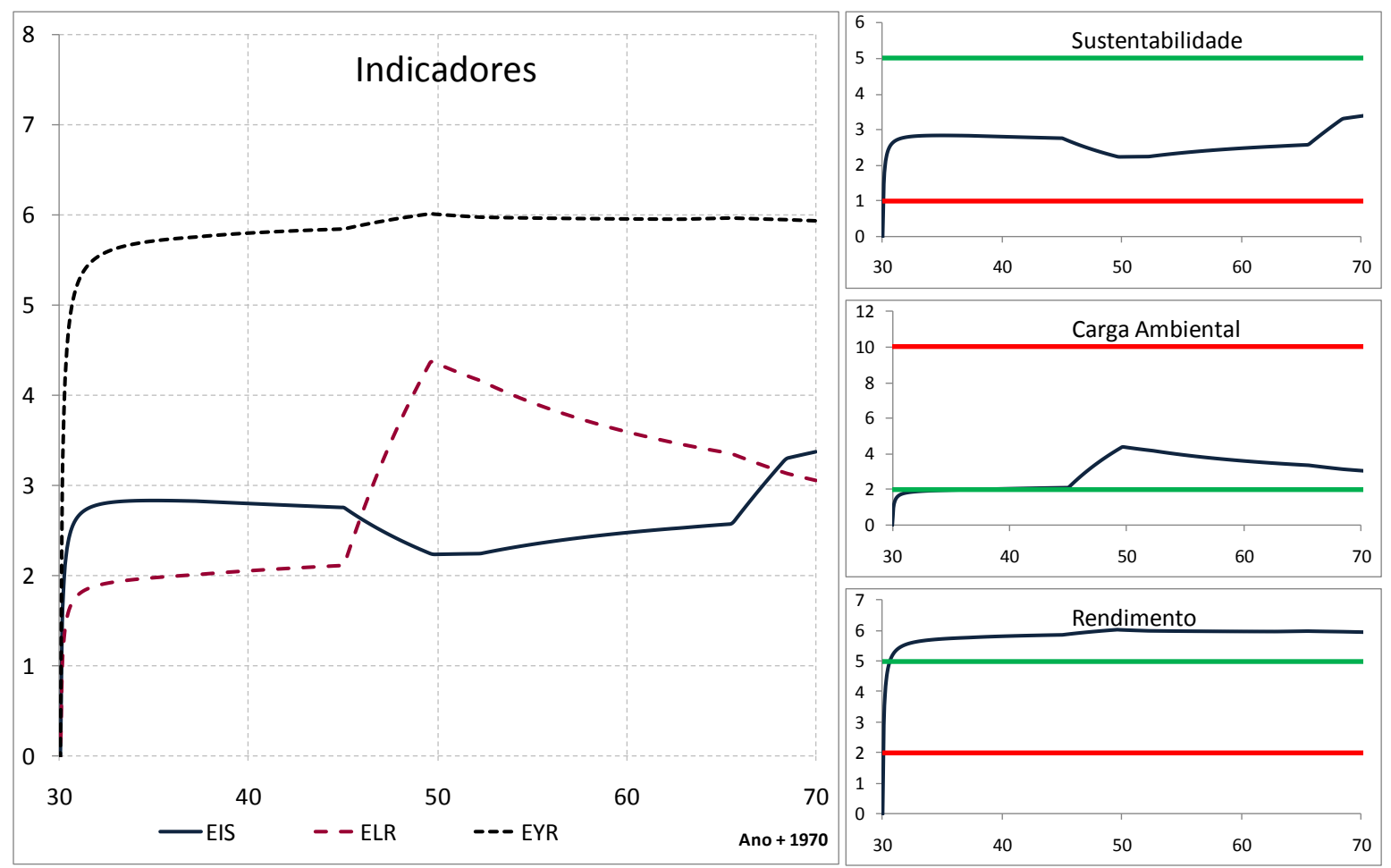

Figura B3 - Índices, perturbação no gás natural, sem efeito floresta (70 anos)

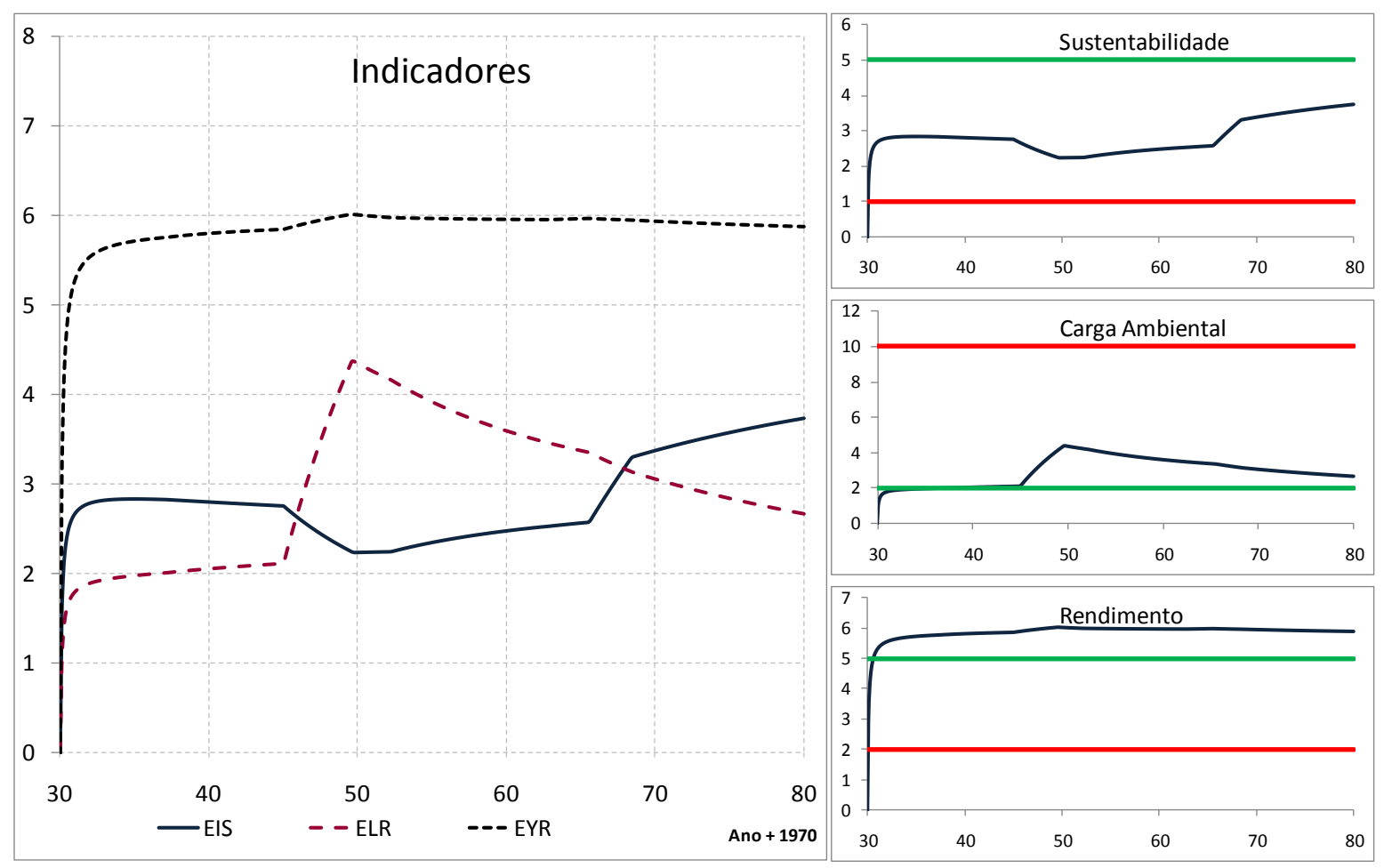

Figura B4 - Índices, perturbação no gás natural, sem efeito floresta (80 anos) 
GÁS NATURAL Ilimitado

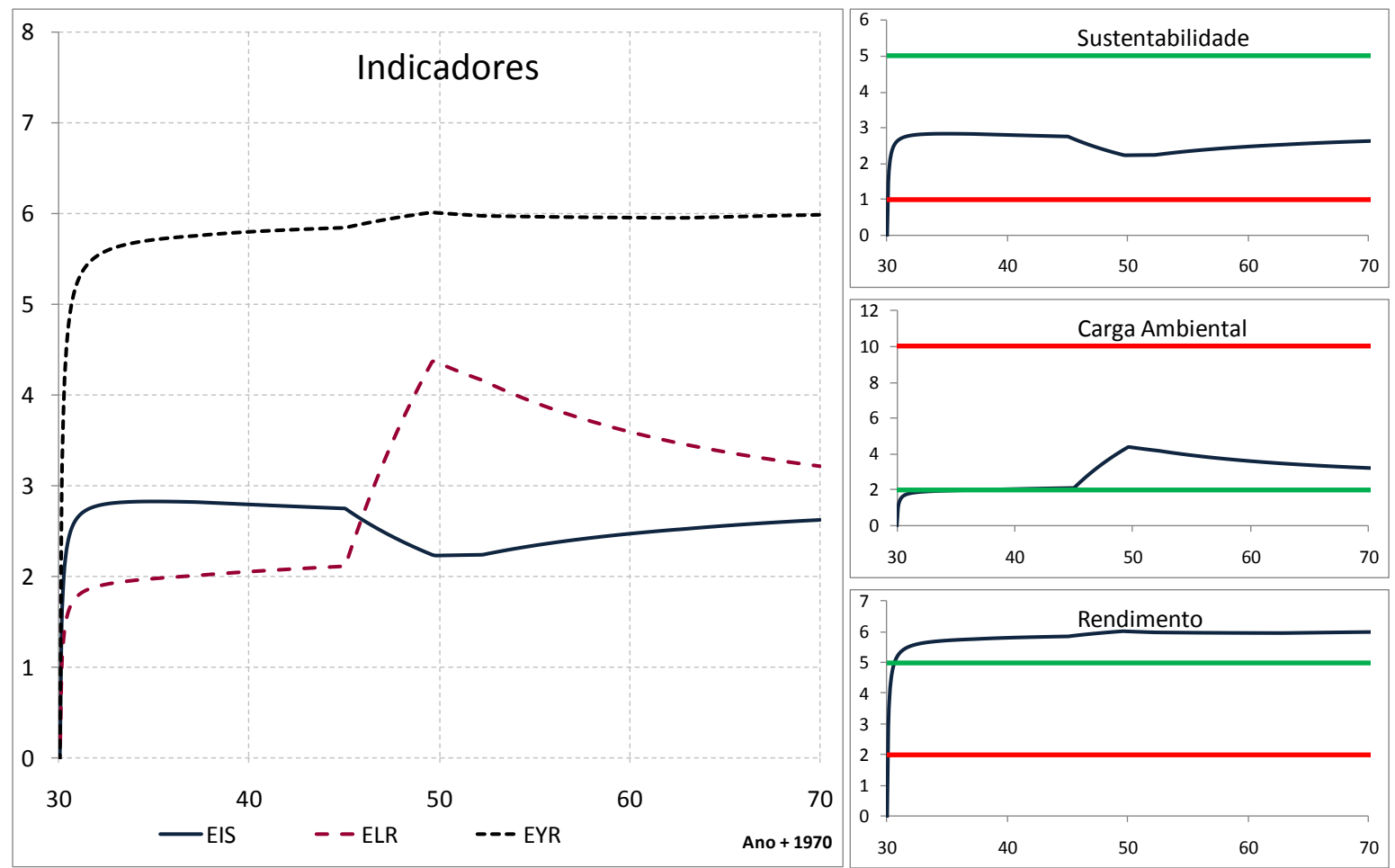

Figura B5 - Índices, perturbação no gás natural ilimitado, sem efeito floresta (70 anos)

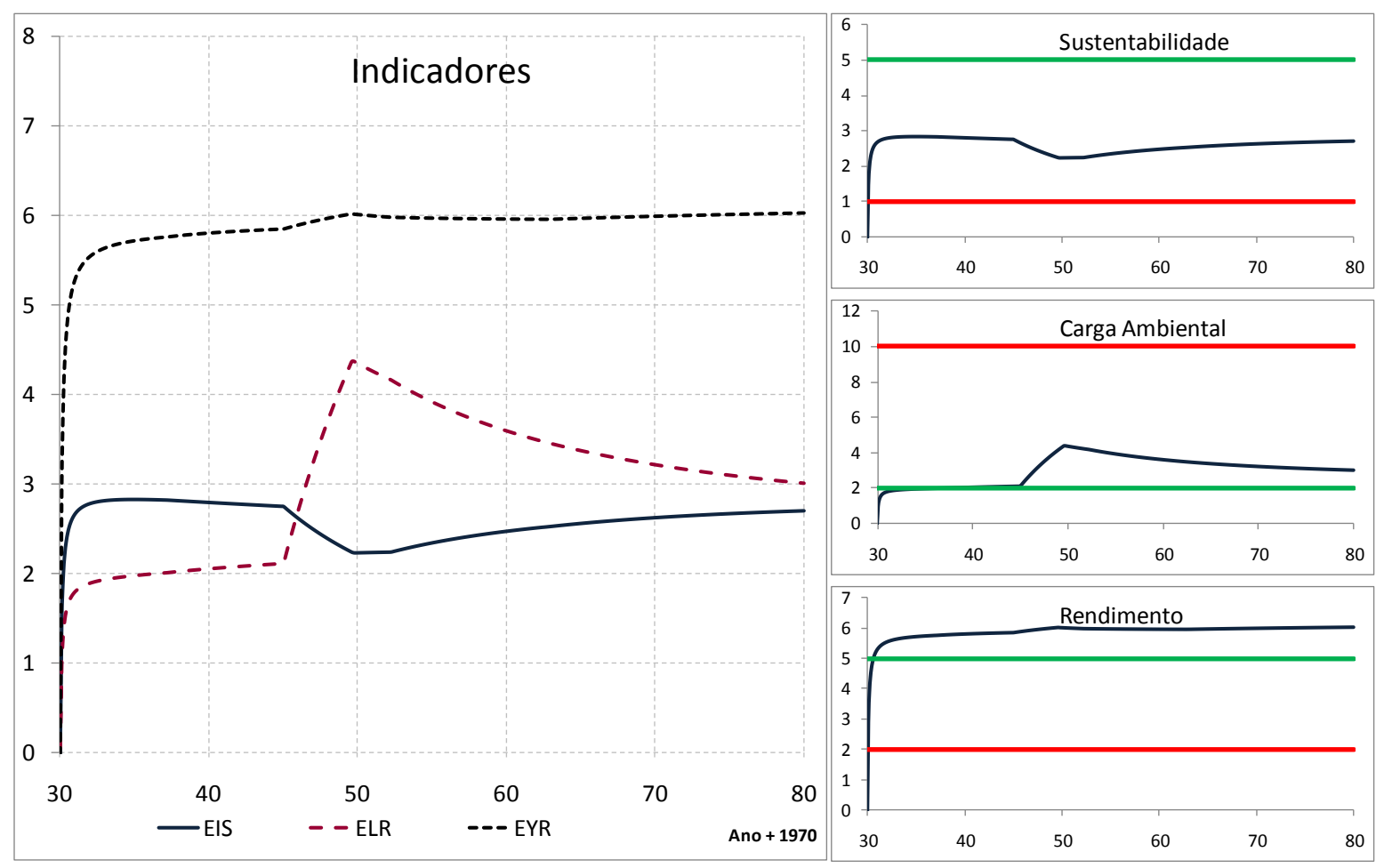

Figura B6 - Índices, perturbação no gás natural ilimitado, sem efeito floresta (80 anos) 
CARVÃO VAPOR

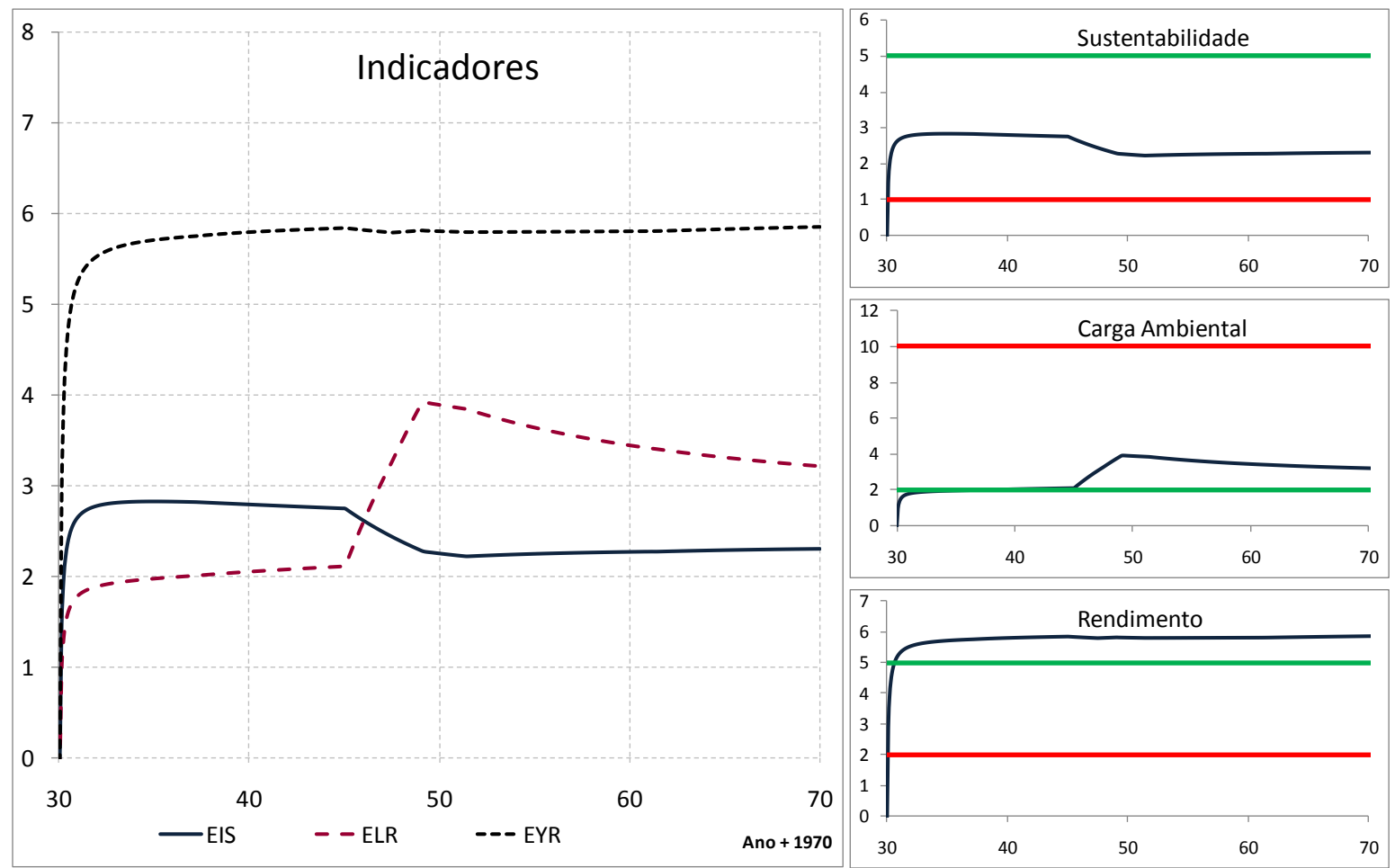

Figura B7 - Índices, perturbação no carvão vapor, sem efeito floresta (70 anos)

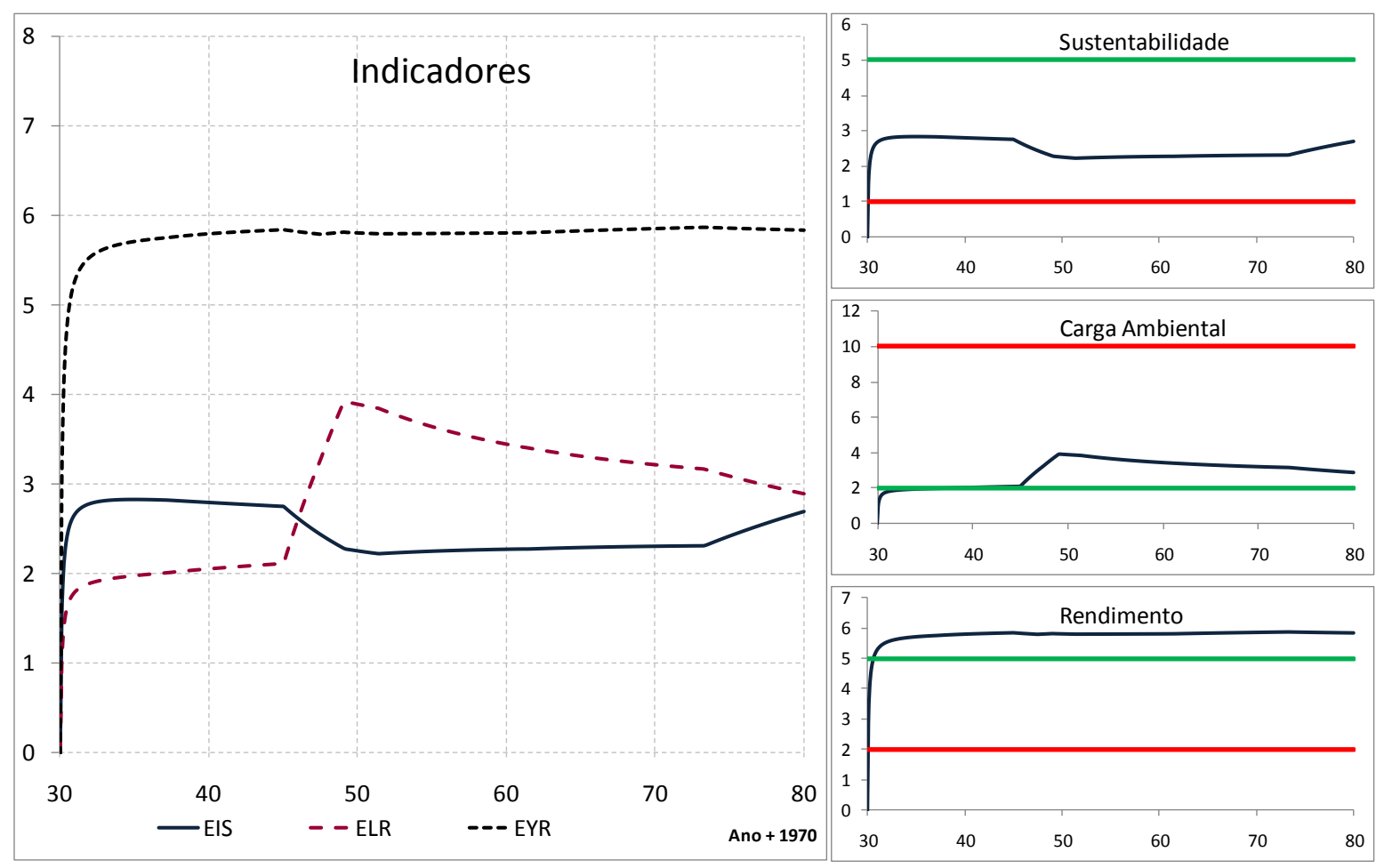

Figura B8 - Índices, perturbação no carvão vapor, sem efeito floresta (80 anos) 
ENERGIA HÍDRICA

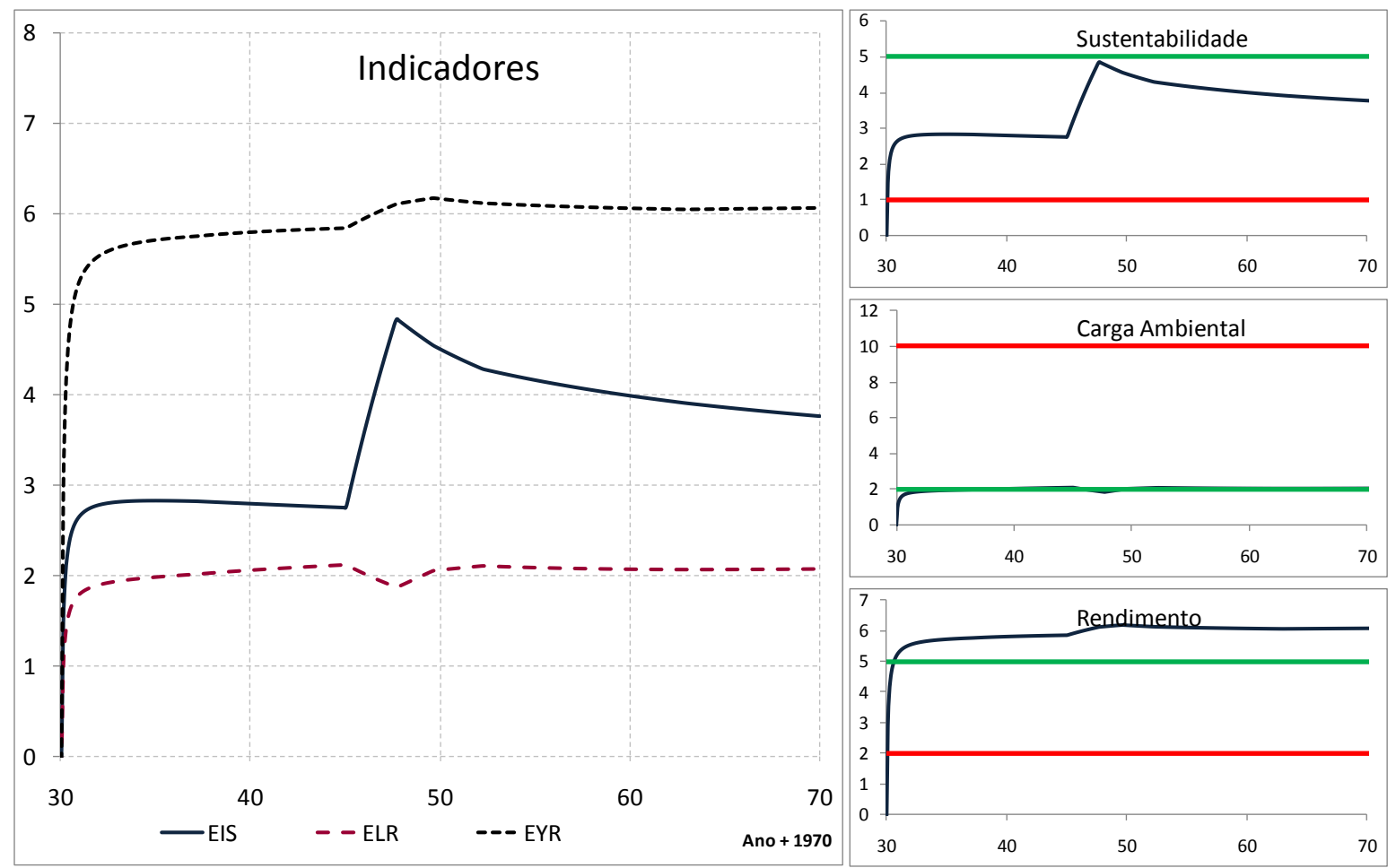

Figura B9 - Índices, perturbação no hídrico, sem efeito floresta (70 anos)

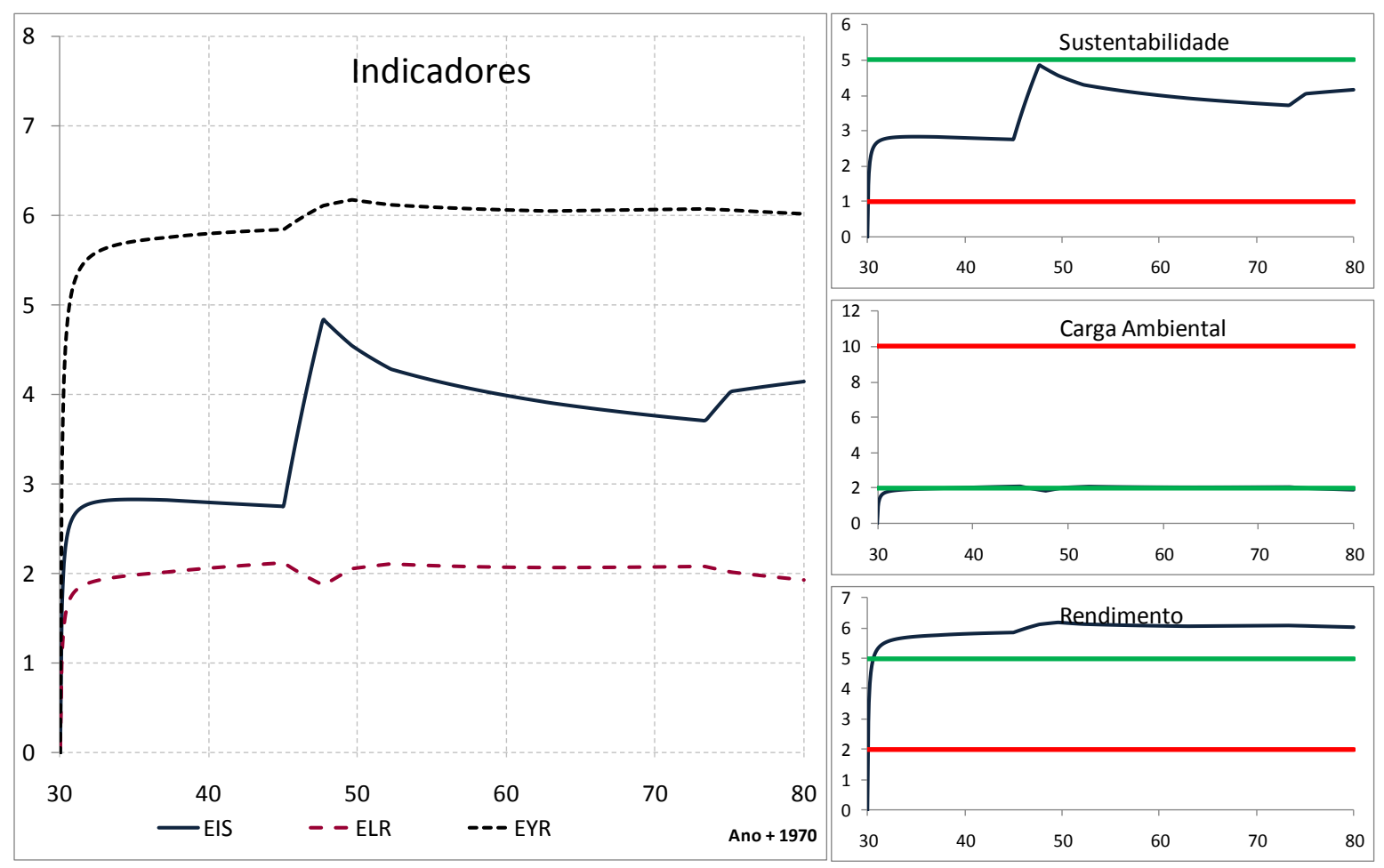

Figura B10 - Índices, perturbação no hídrico, sem efeito floresta (80 anos) 
PRODUTOS DE CANA

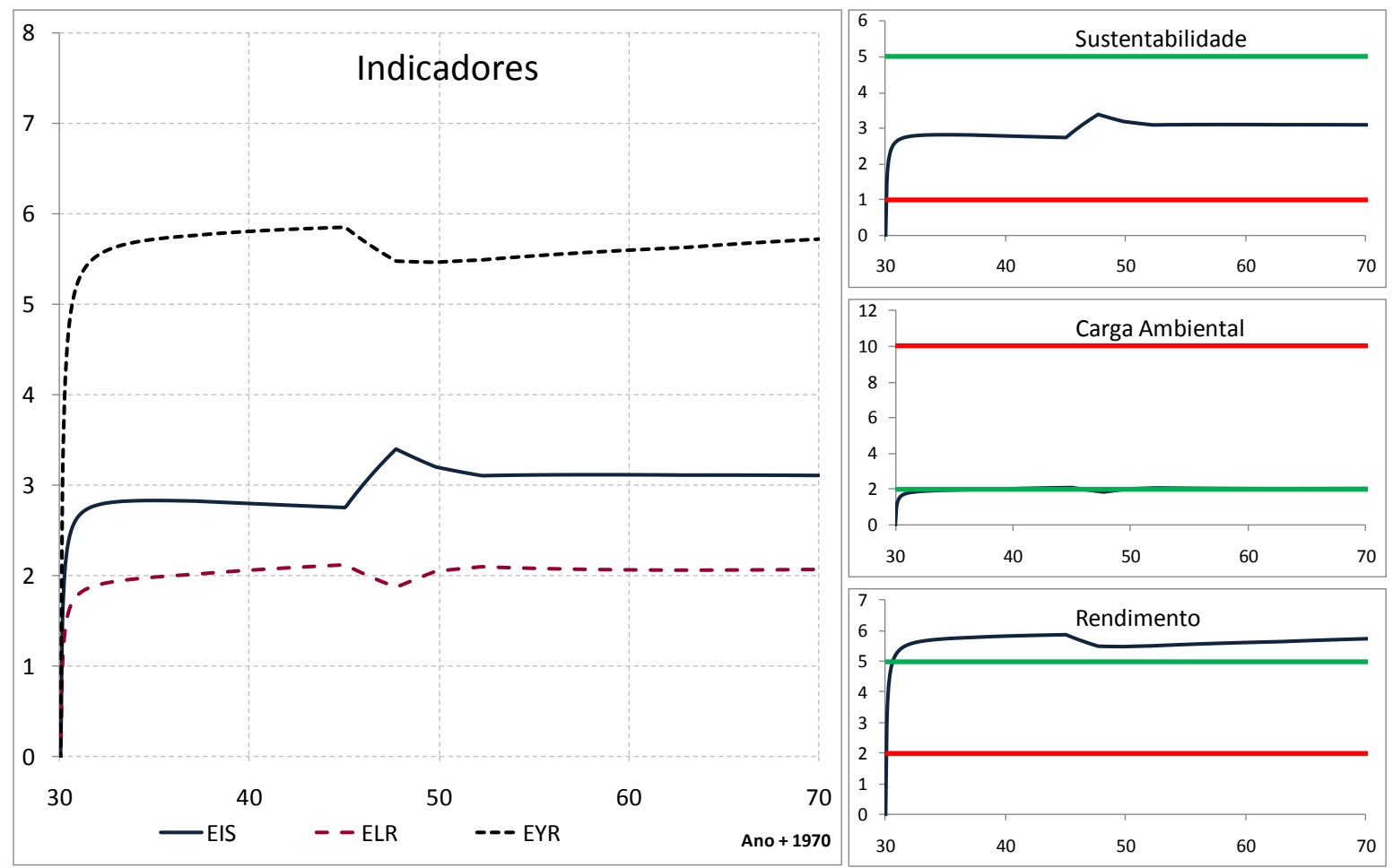

Figura B11 - Índices, perturbação nos produtos de cana, sem efeito floresta (70 anos)

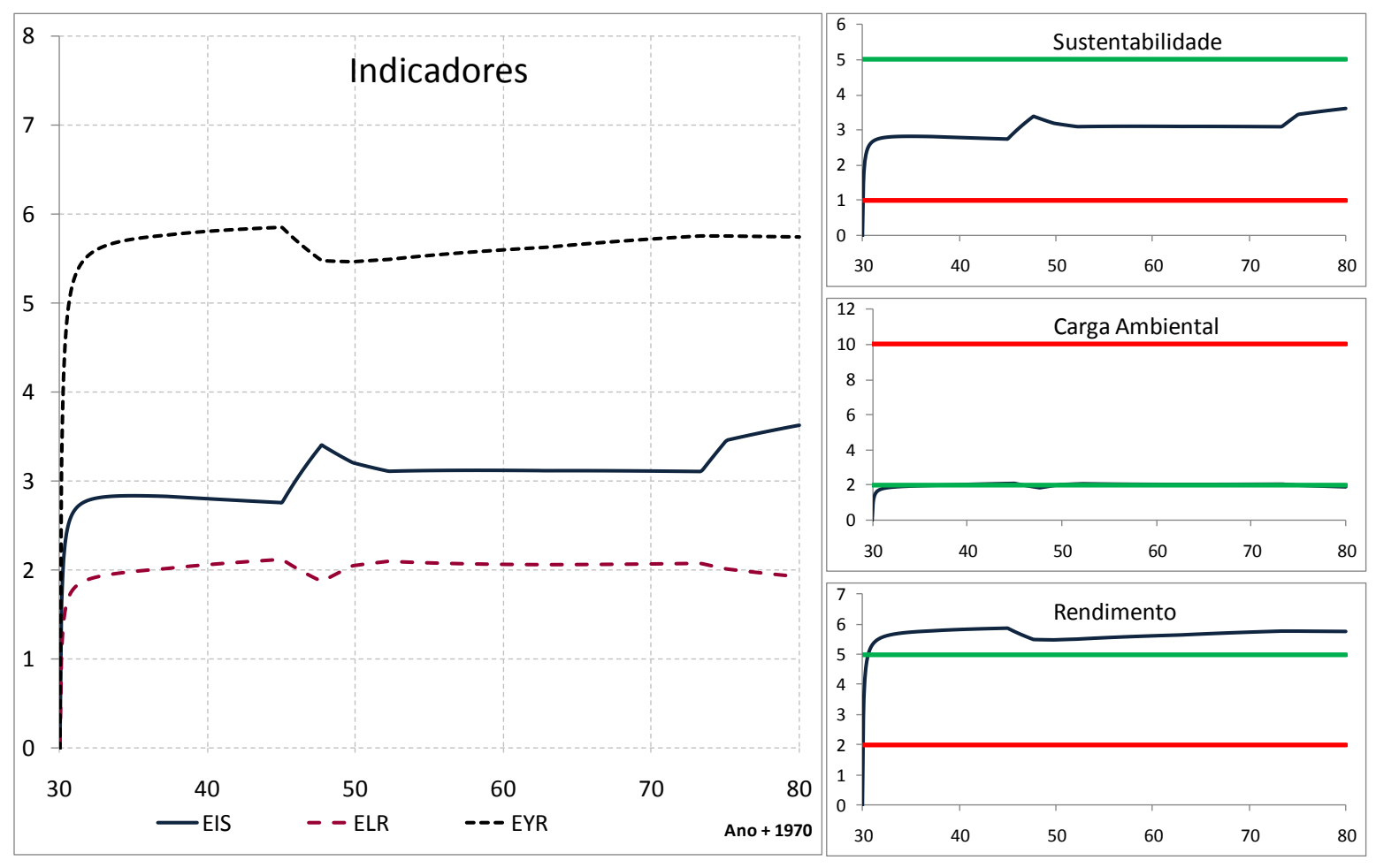

Figura B12 - Índices, perturbação nos produtos de cana, sem efeito floresta (80 anos) 
ENERGIA EÓLICA

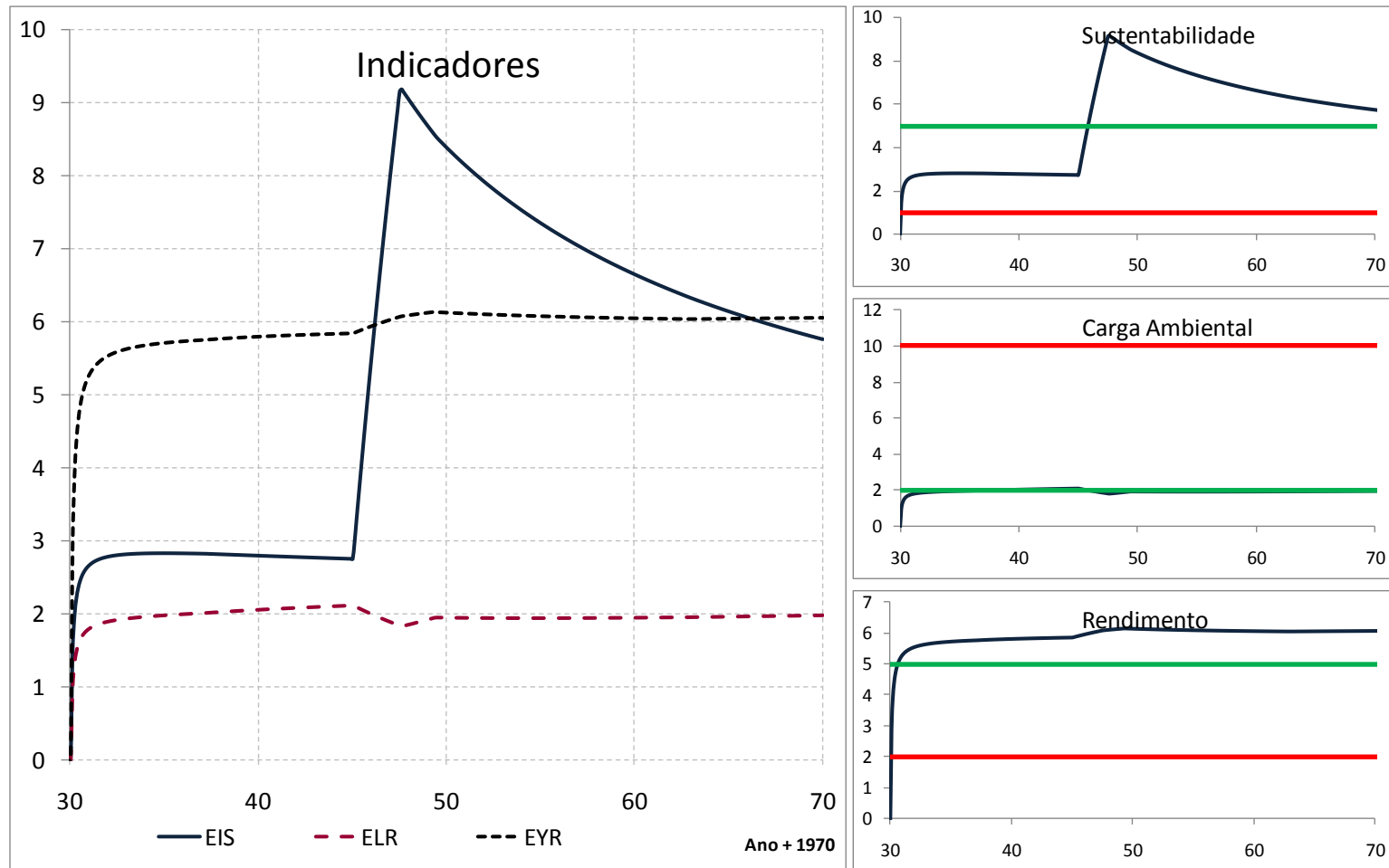

Figura B13 - Índices, perturbação na eólica, sem efeito floresta (70 anos)
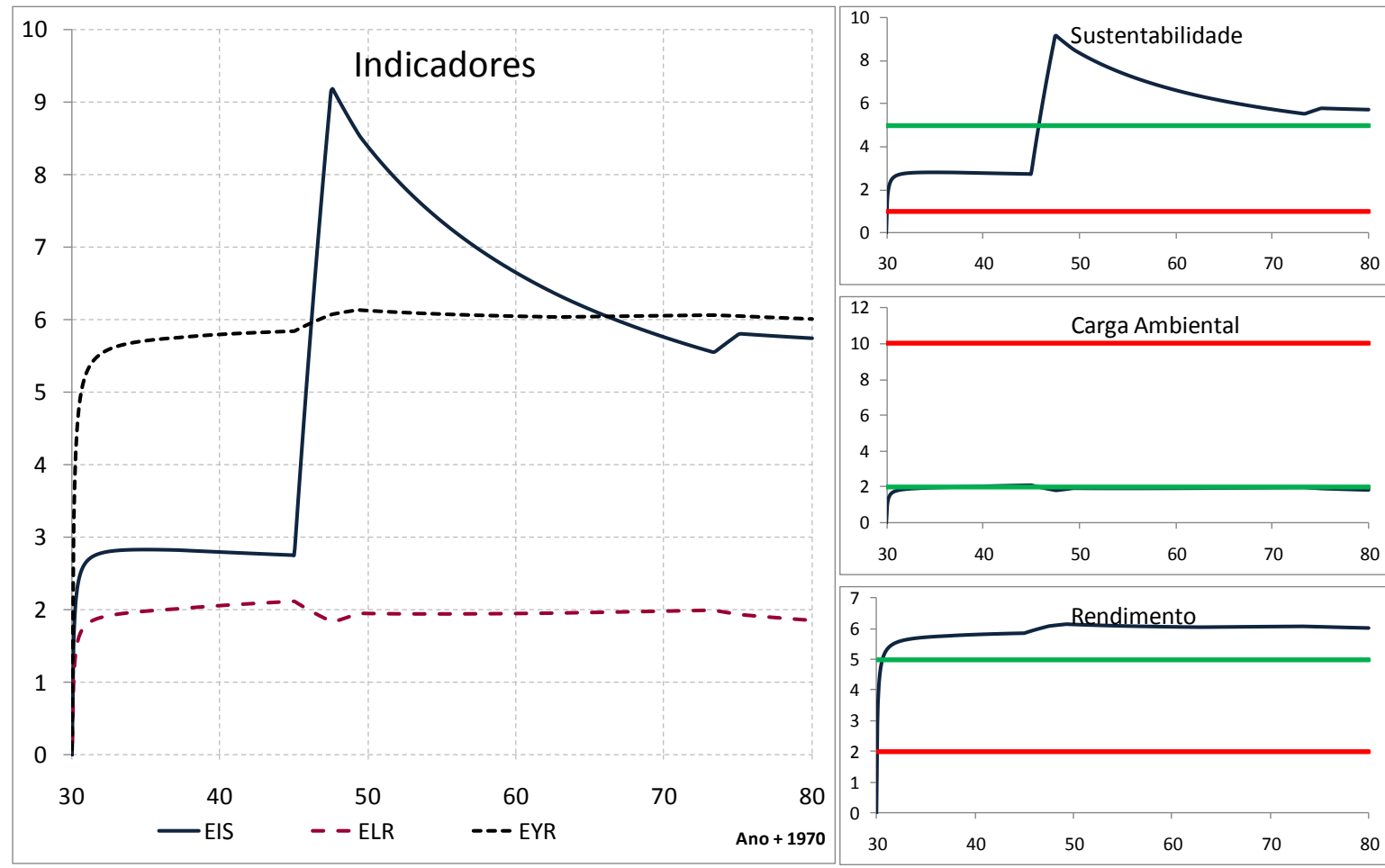

Figura B14 - Índices, perturbação na eólica, sem efeito floresta (80 anos) 
ENERGIA NUCLEAR

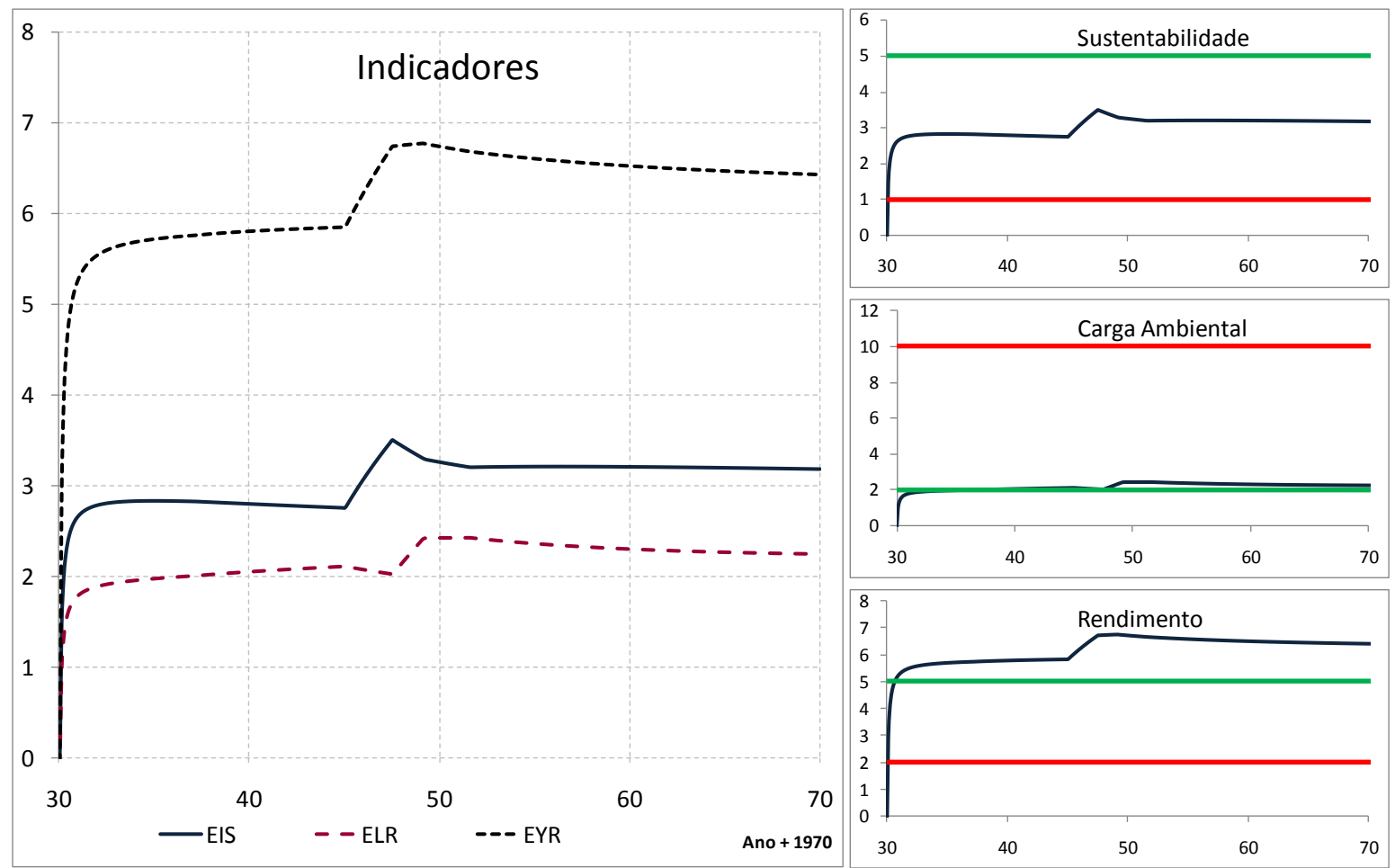

Figura B15 - Índices, perturbação na nuclear, sem efeito floresta (70 anos)
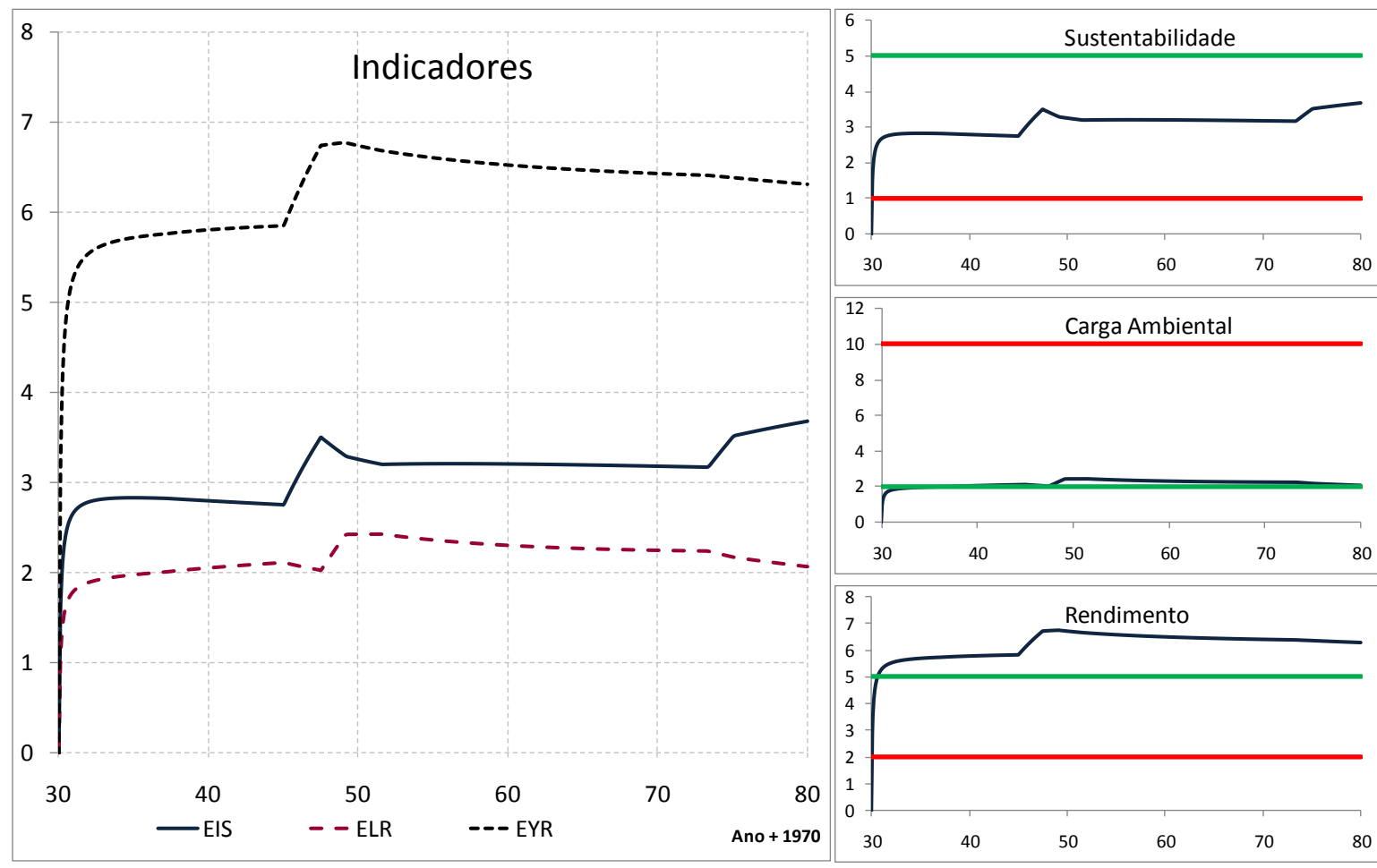

Figura B16 - Índices, perturbação na nuclear, sem efeito floresta (80 anos) 
FLORESTA: ENERGIA HÍDRICA

SEM PERTURBAÇÃO

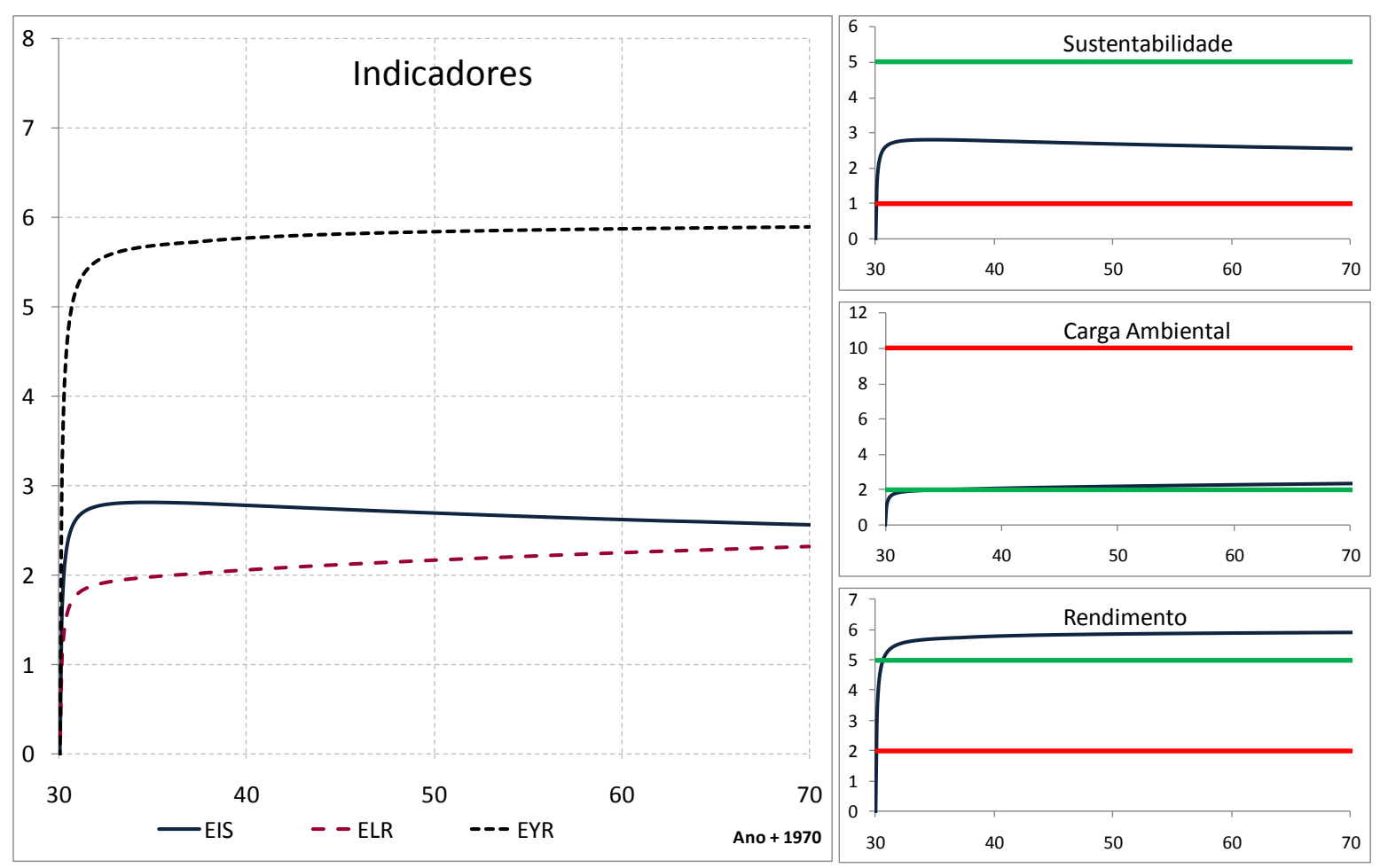

Figura B17 - Índices, sem perturbação, efeito floresta hídrica (70 anos)

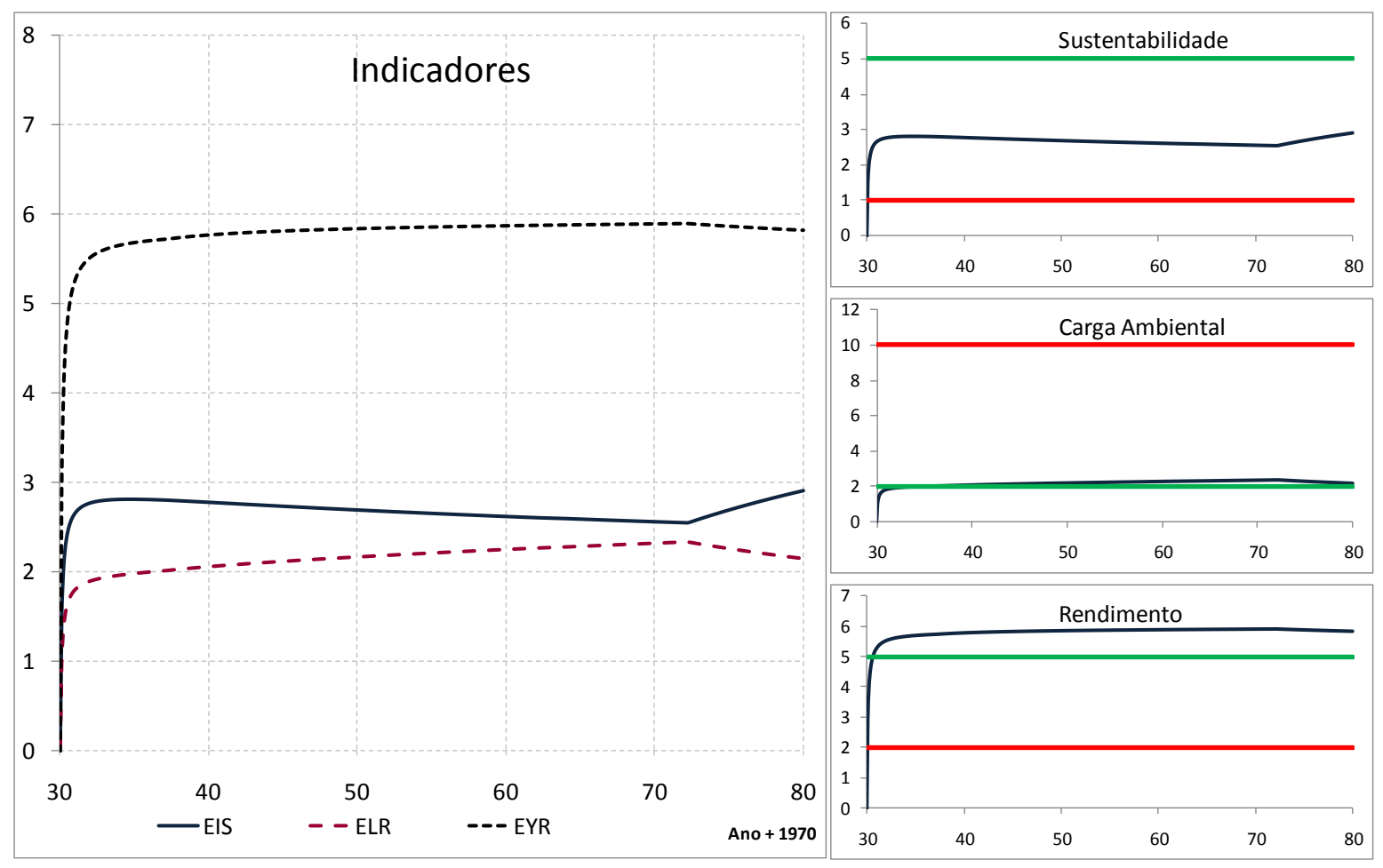

Figura B18 - Índices, sem perturbação, efeito floresta hídrica (80 anos) 
GÁS NATURAL

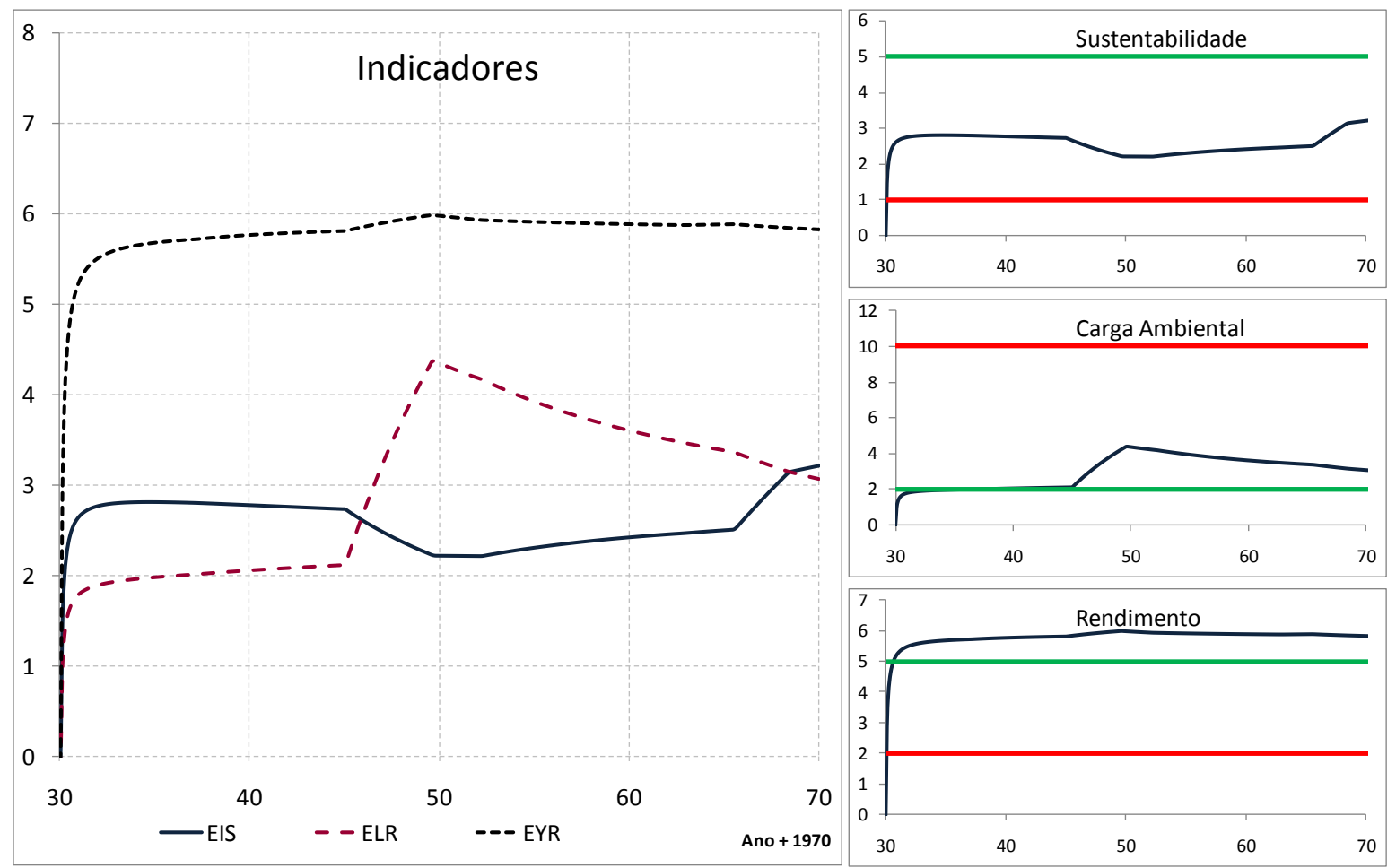

Figura B19 - Índices, perturbação no gás natural, efeito floresta hídrica (70 anos)

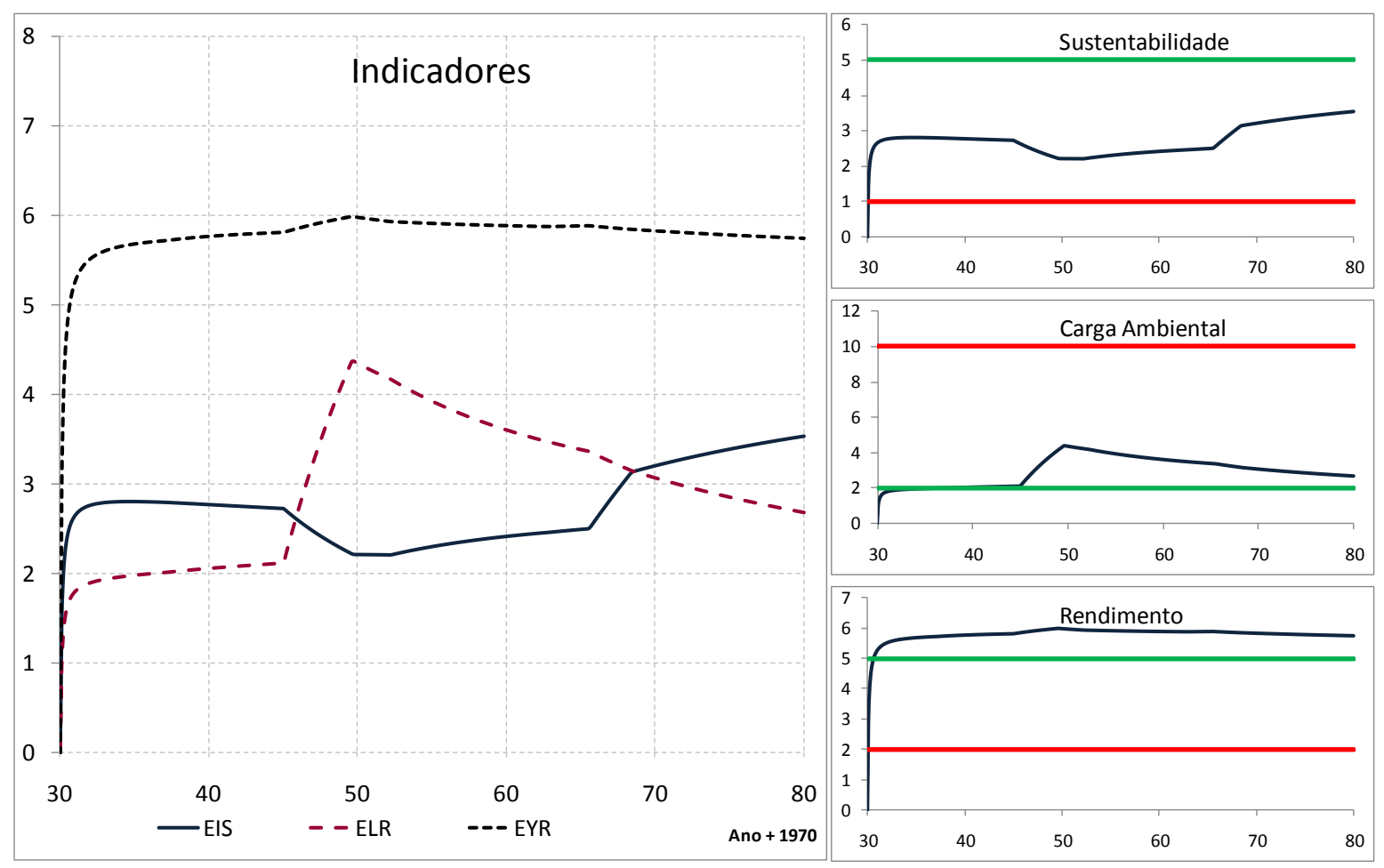

Figura B20 - Índices, perturbação no gás natural, efeito floresta hídrica (80 anos) 
GÁS NATURAL Ilimitado

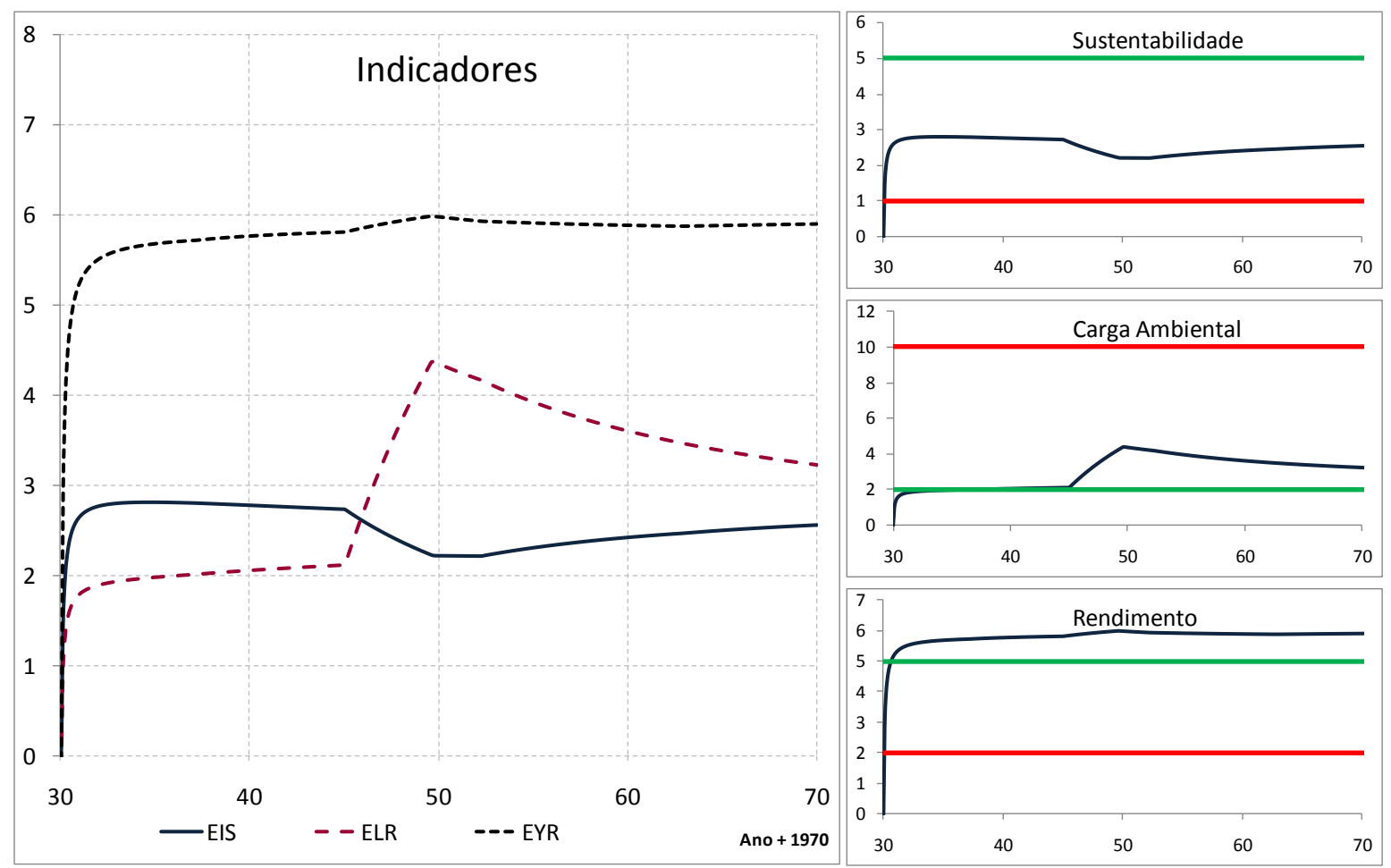

Figura B21 - Índices, perturbação no gás natural ilimitado, efeito floresta hídrica (70 anos)
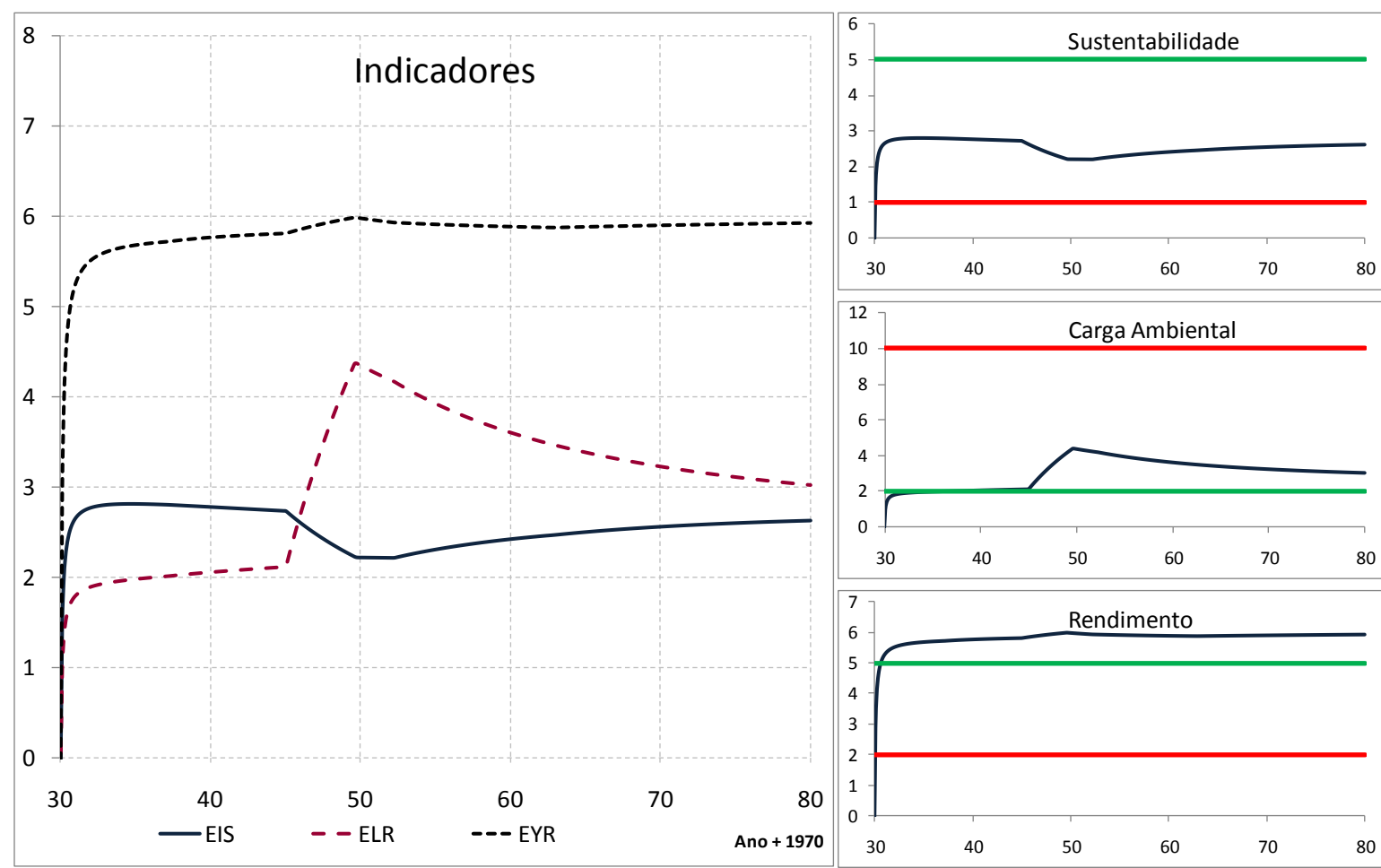

Figura B22 - Índices, perturbação no gás natural ilimitado, efeito floresta hídrica (80 anos) 
CARVÃO VAPOR

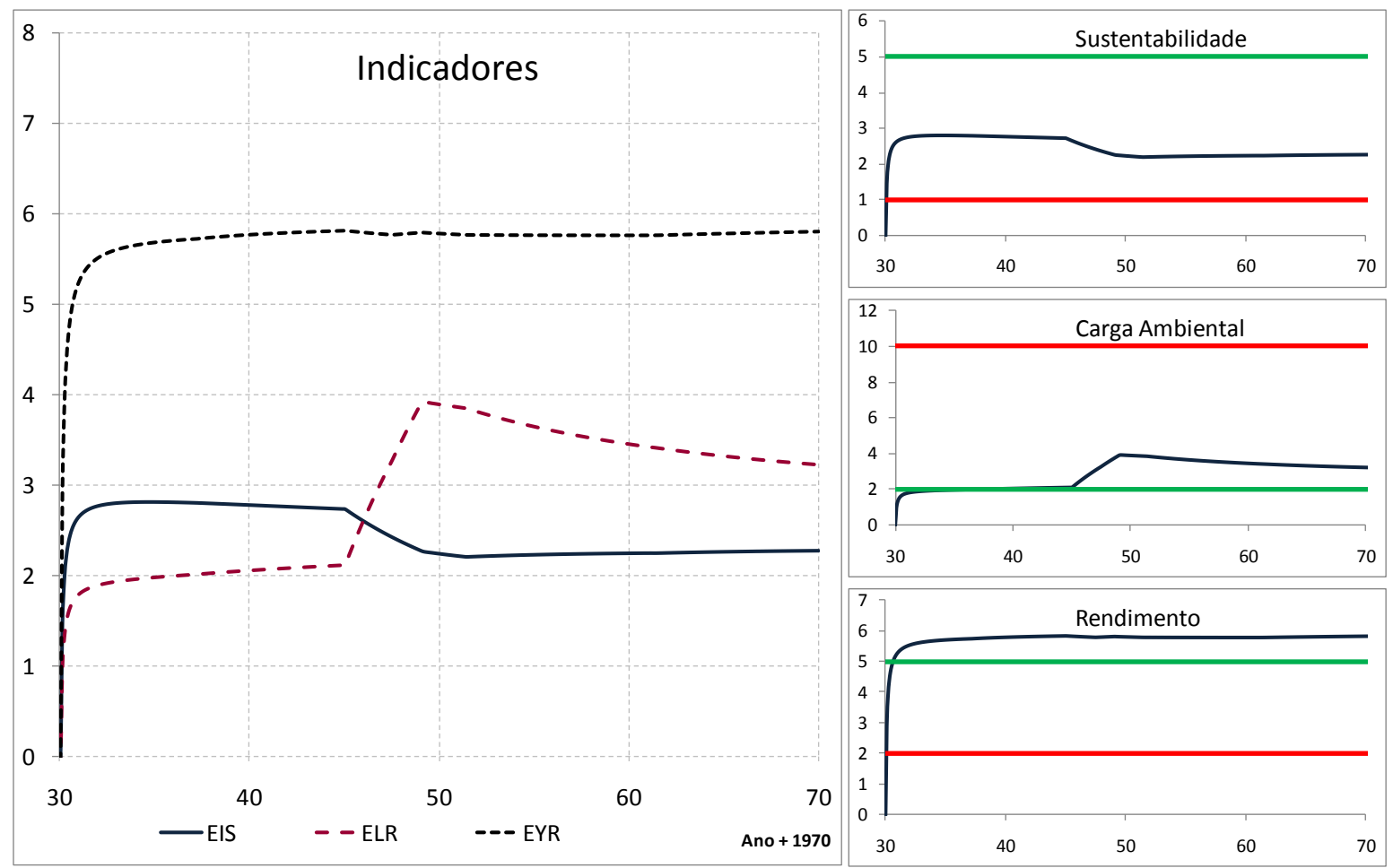

Figura B23 - Índices, perturbação no carvão vapor, efeito floresta hídrica (70 anos)

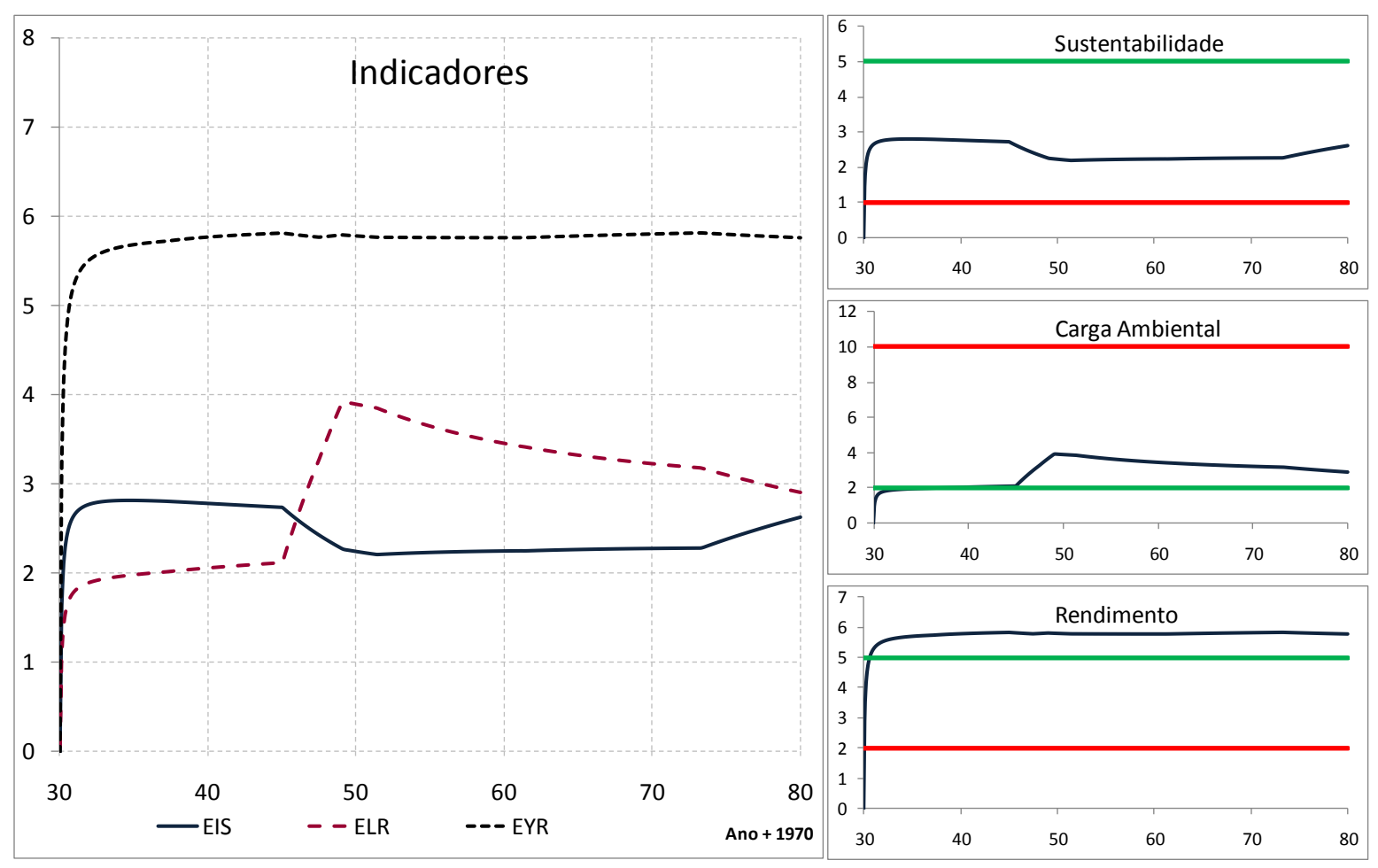

Figura B24 - Índices, perturbação no carvão vapor, efeito floresta hídrica (80 anos) 
ENERGIA HÍDRICA

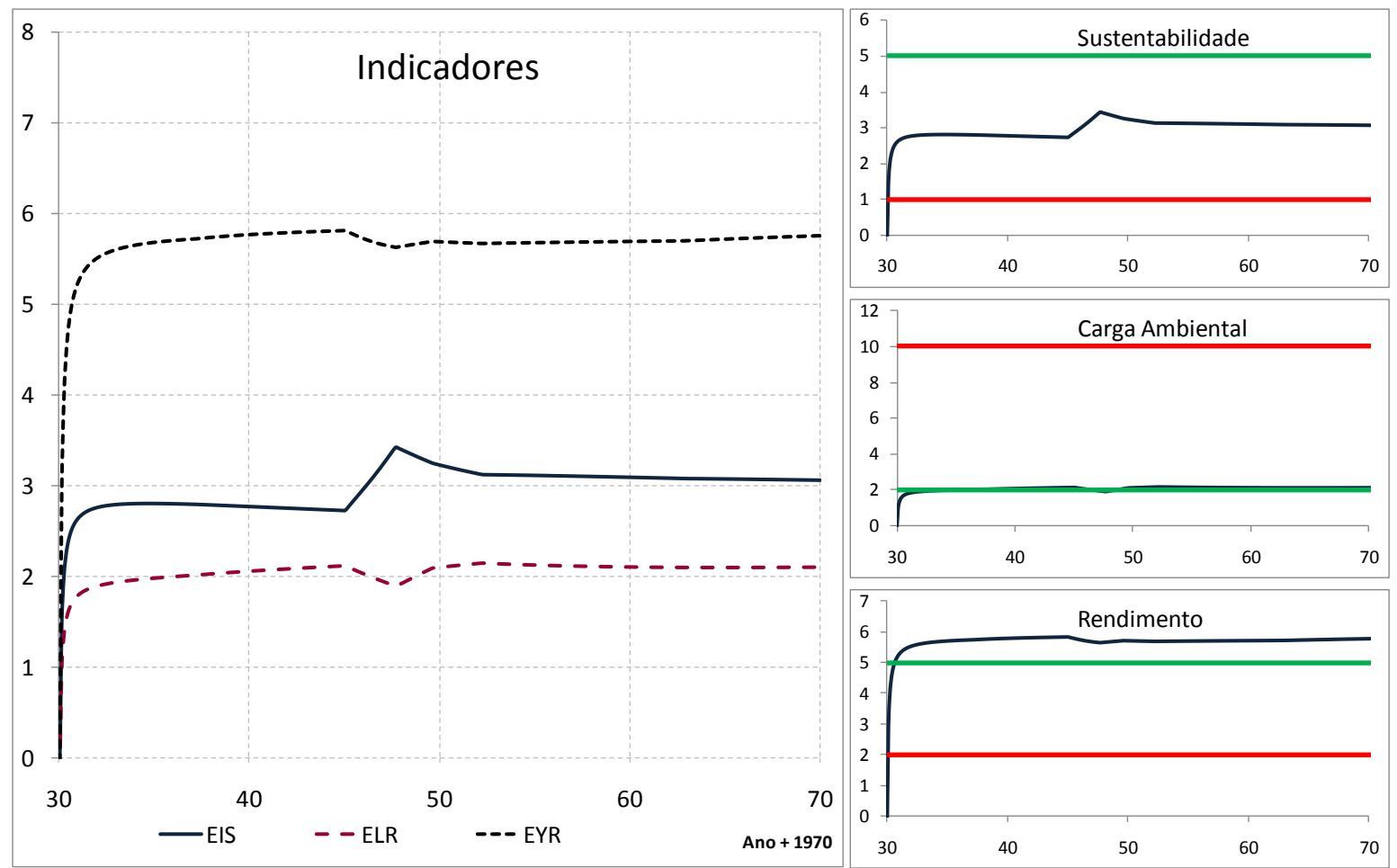

Figura B25 - Índices, perturbação na hídrica, efeito floresta hídrica (70 anos)
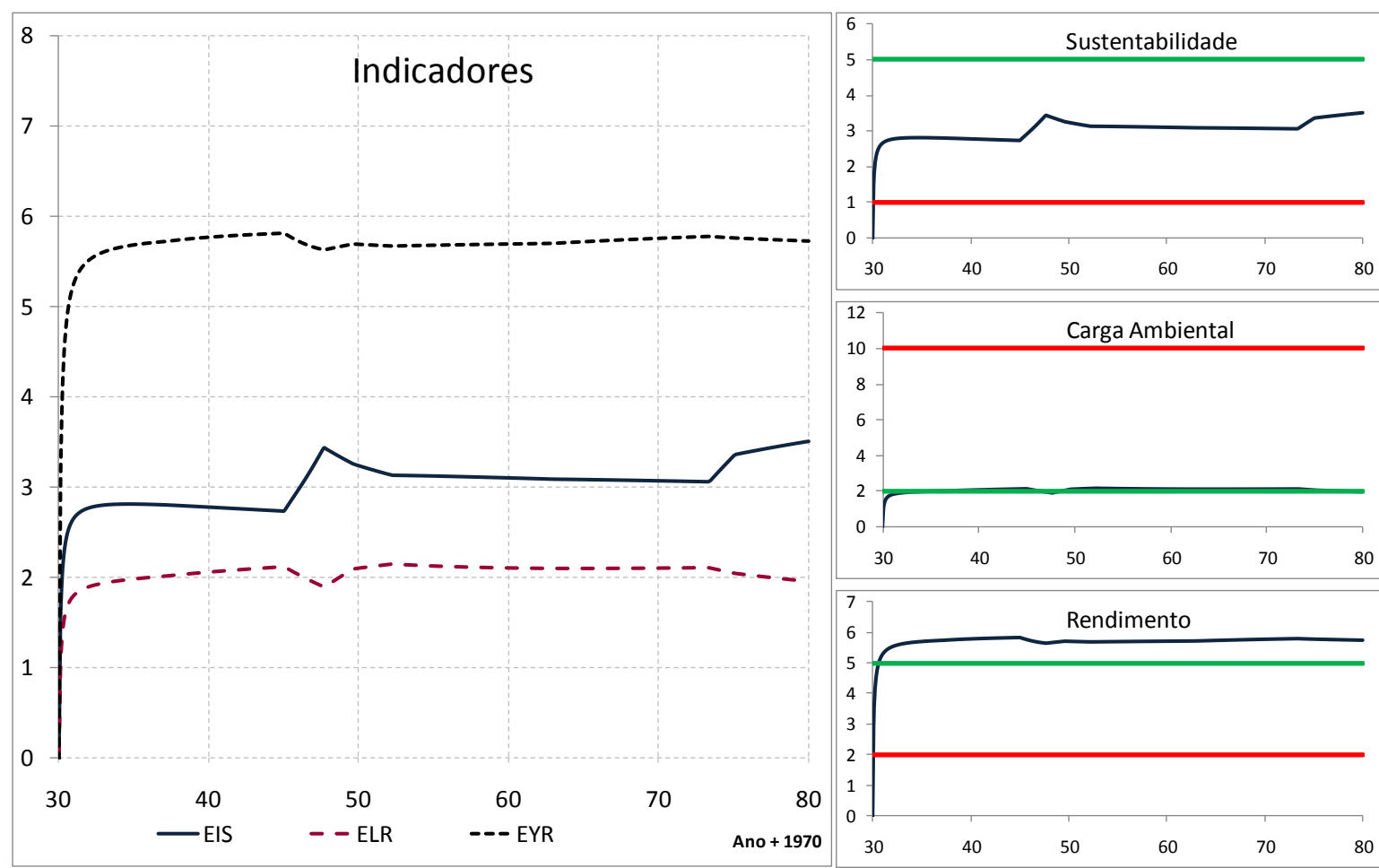

Figura B26 - Índices, perturbação na hídrica, efeito floresta hídrica (80 anos) 
PRODUTOS DE CANA

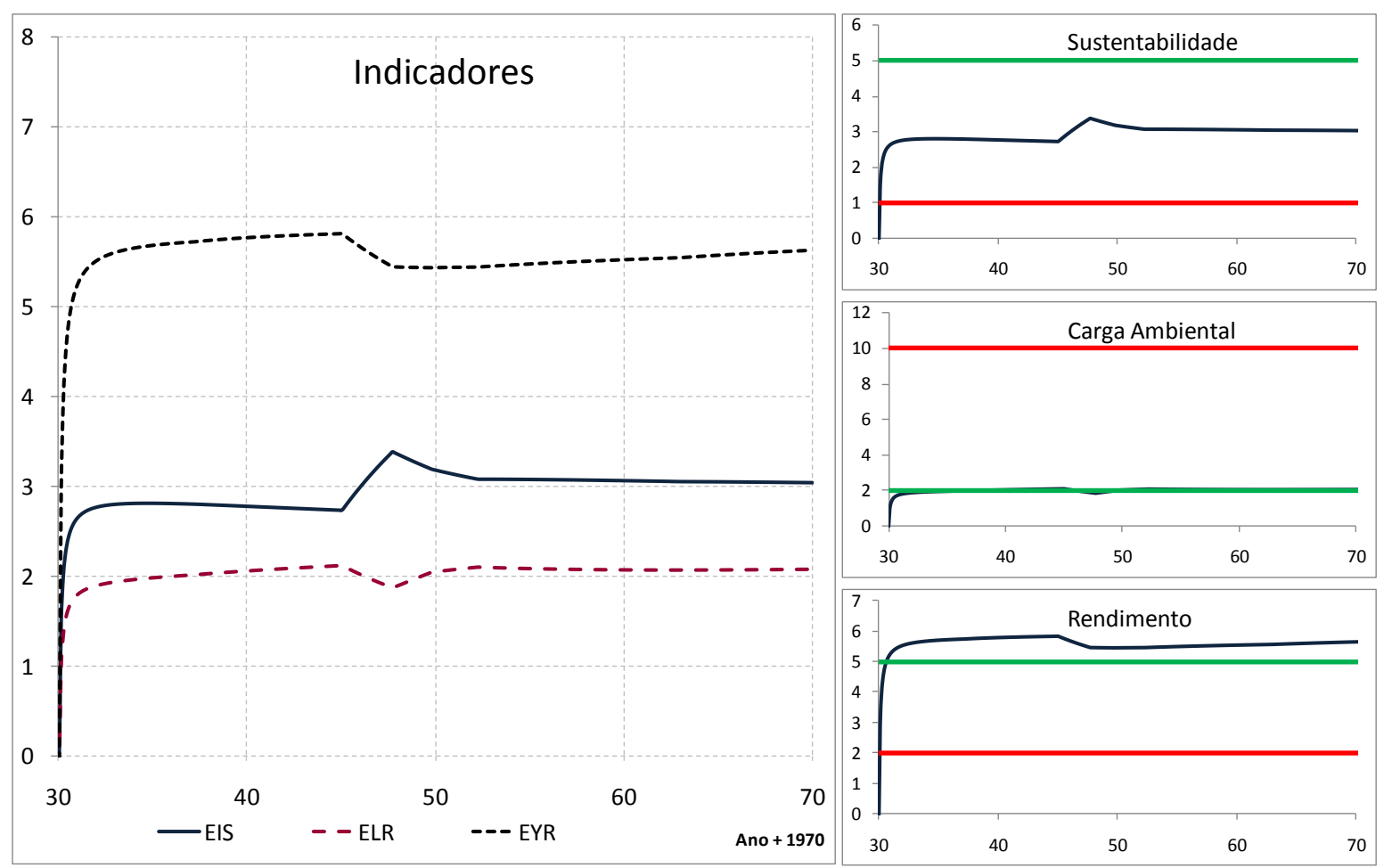

Figura B27 - Índices, perturbação nos produtos de cana, efeito floresta hídrica (70 anos)
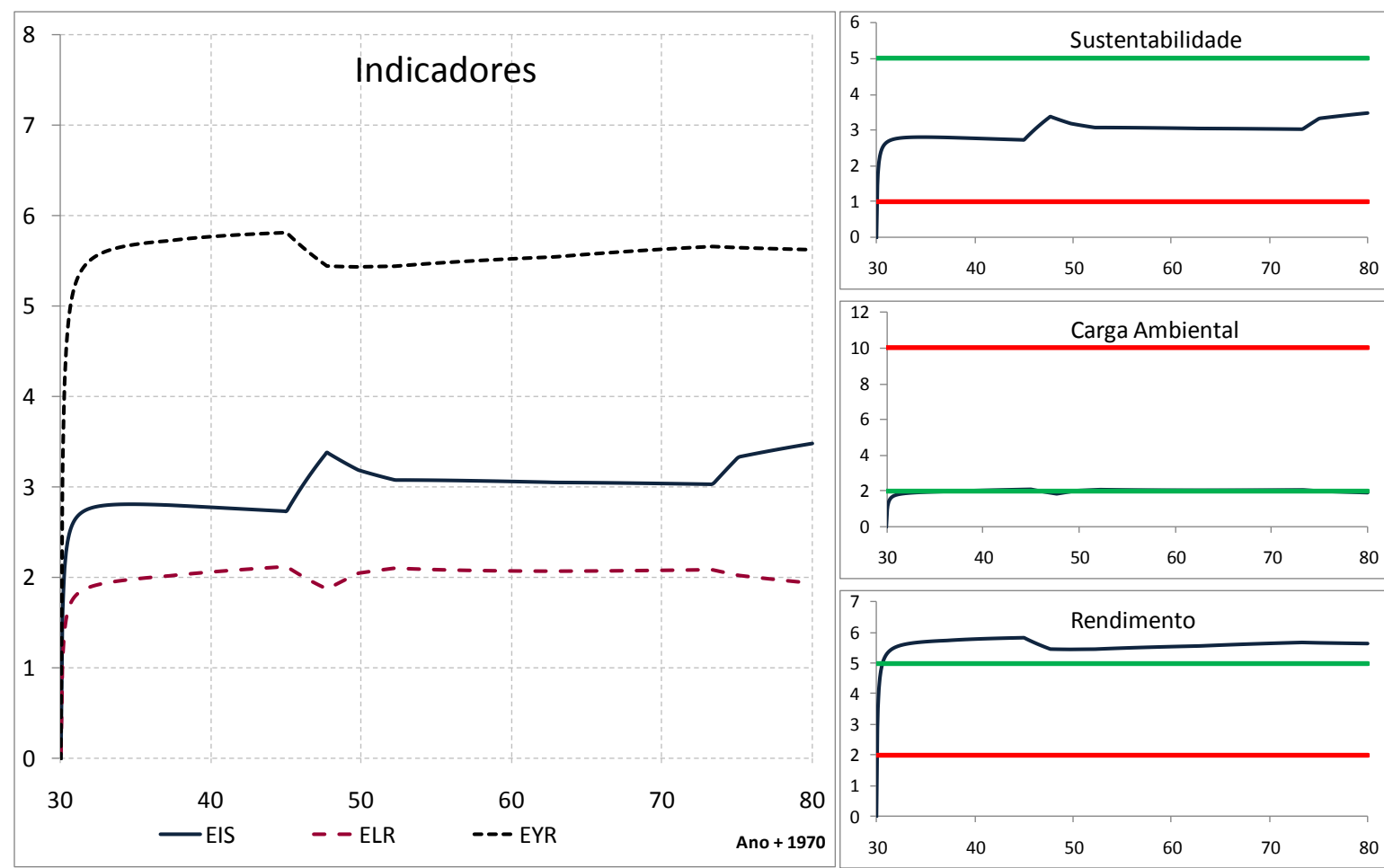

Figura B28 - Índices, perturbação nos produtos de cana, efeito floresta hídrica (80 anos) 
ENERGIA EÓLICA

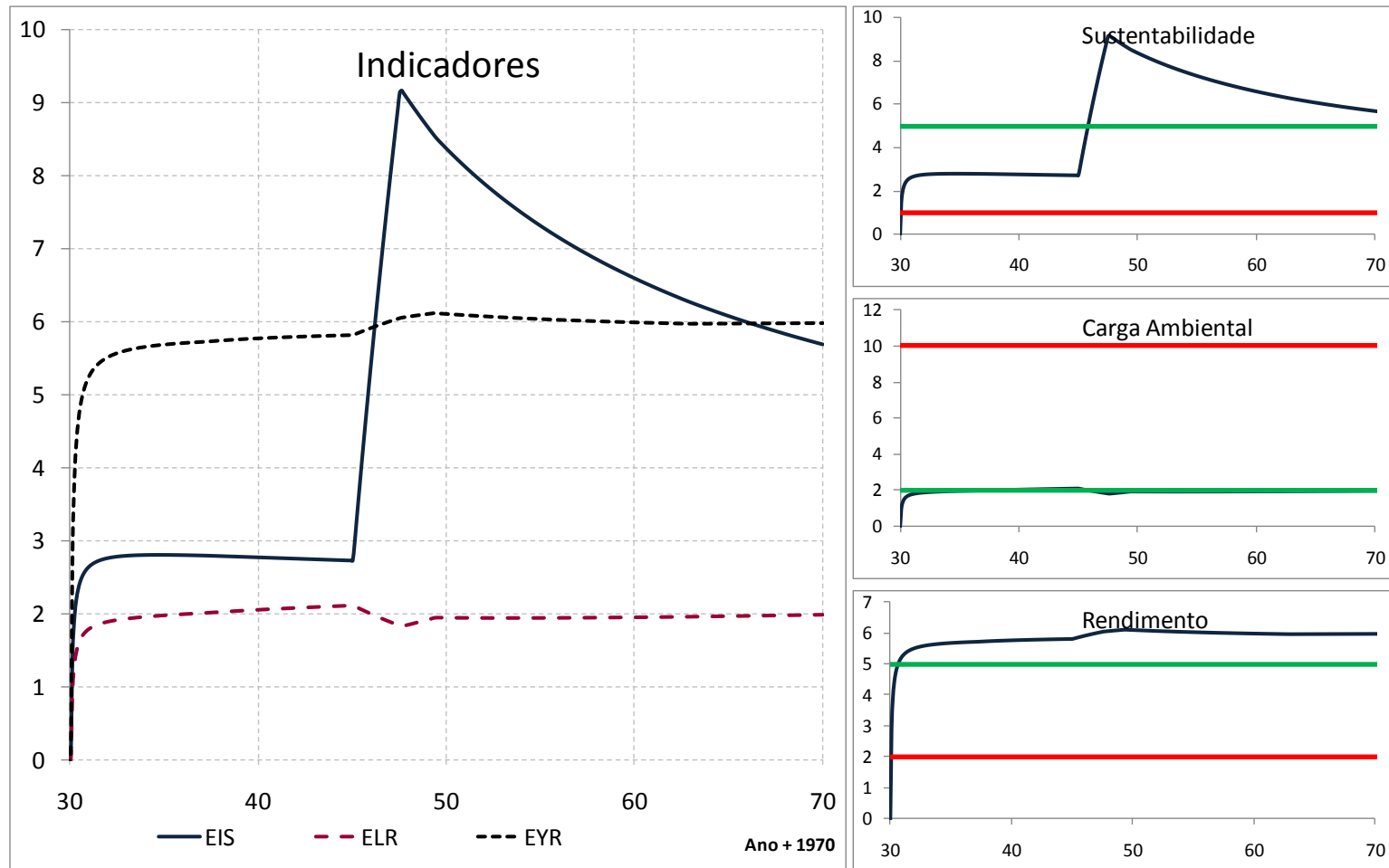

Figura B29 - Índices, perturbação na eólica, efeito floresta hídrica (70 anos)
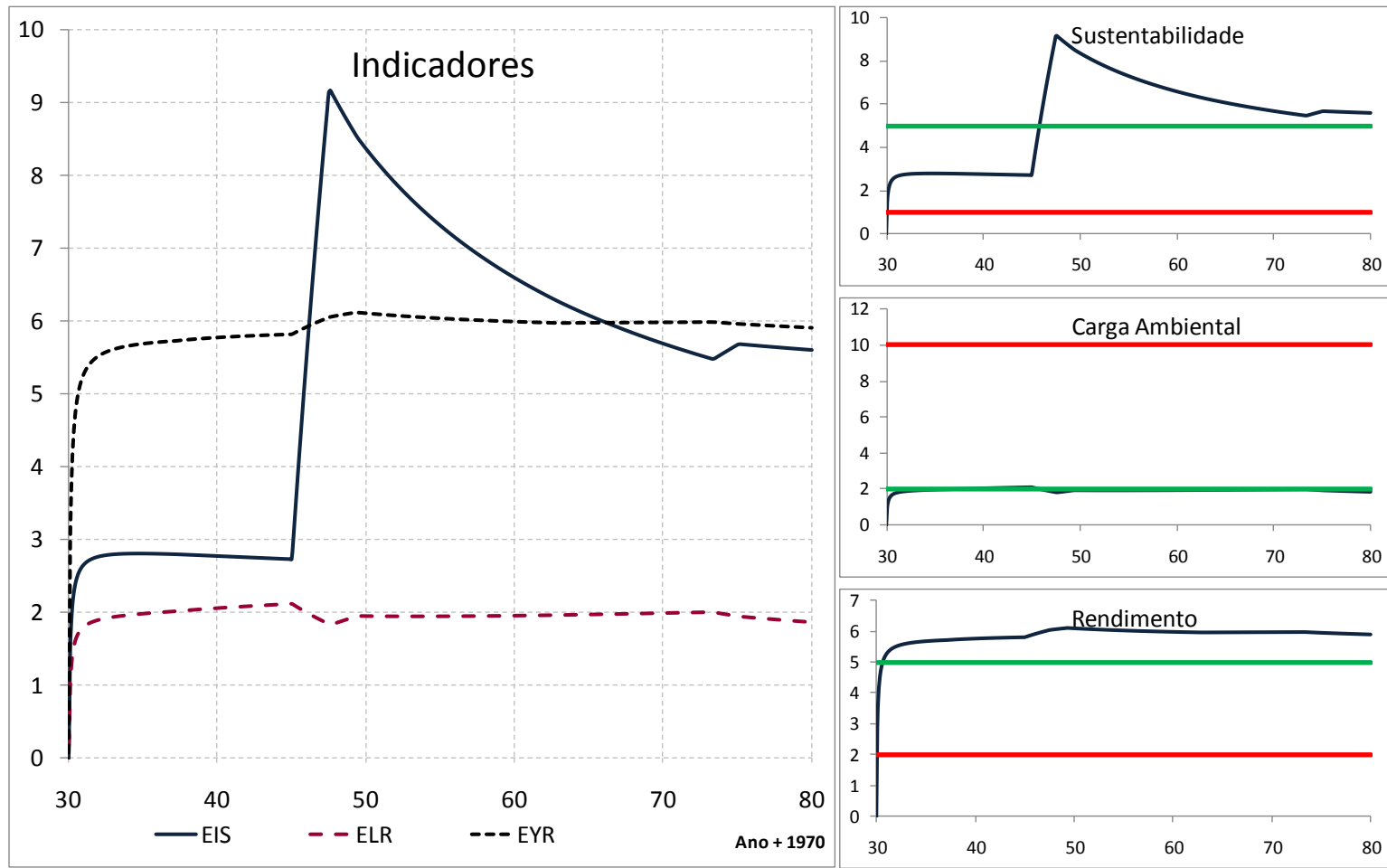

Figura B30 - Índices, perturbação na eólica, efeito floresta hídrica (80 anos) 
ENERGIA NUCLEAR

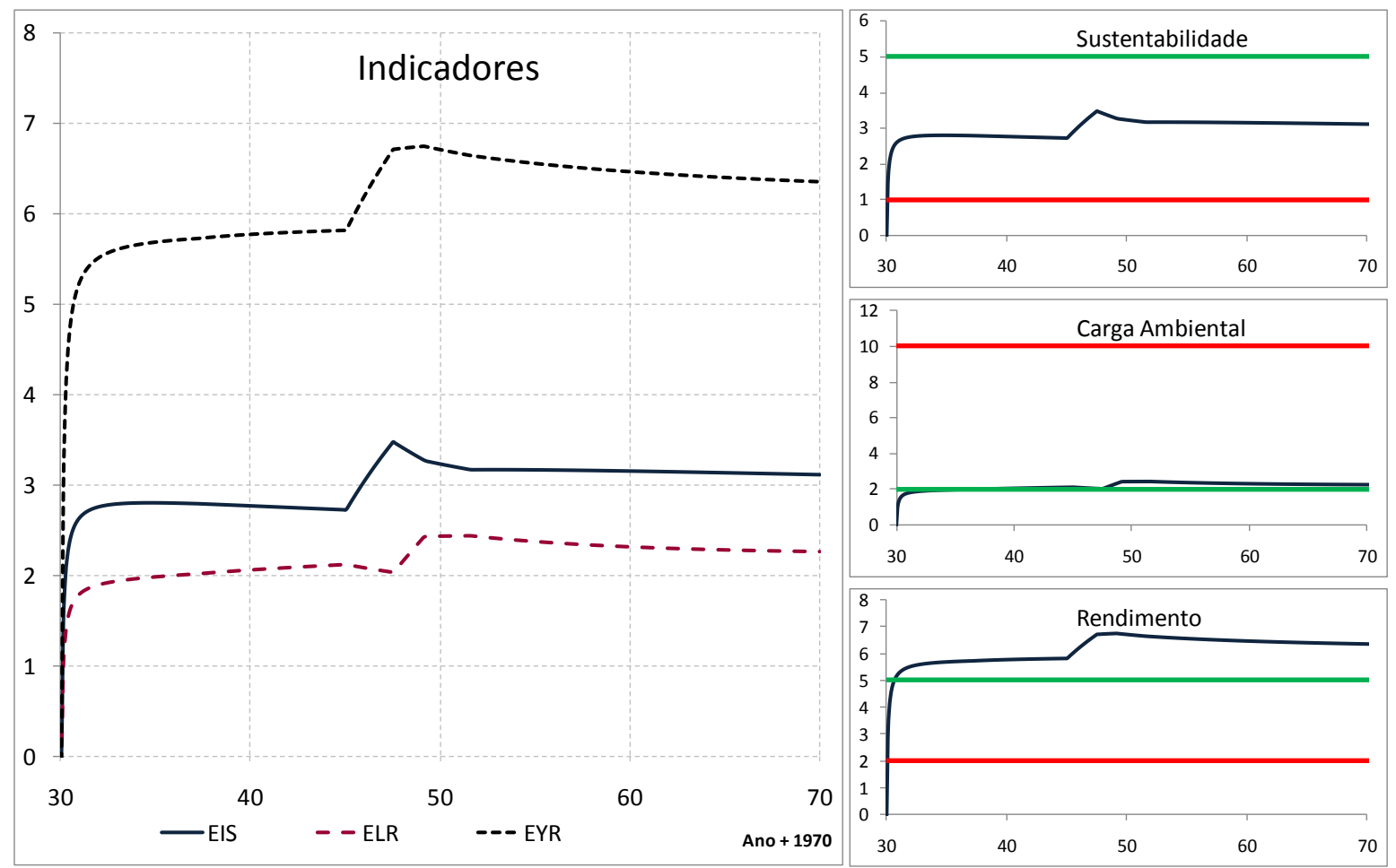

Figura B31 - Índices, perturbação na nuclear, efeito floresta hídrica (70 anos)

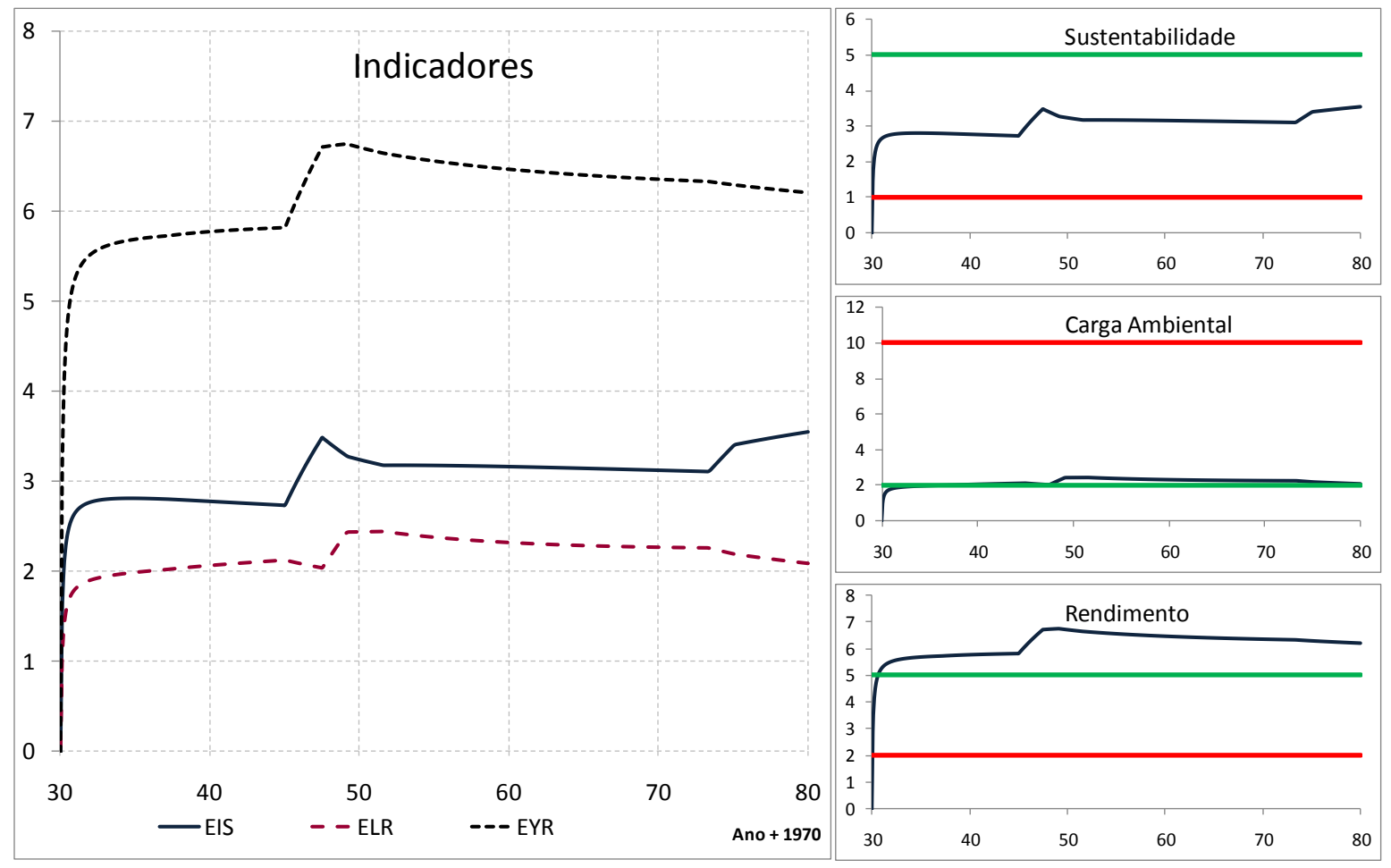

Figura B32 - Índices, perturbação na nuclear, efeito floresta hídrica (80 anos) 
FLORESTA: PRODUTOS DE CANA

SEM PERTURBAÇÃO

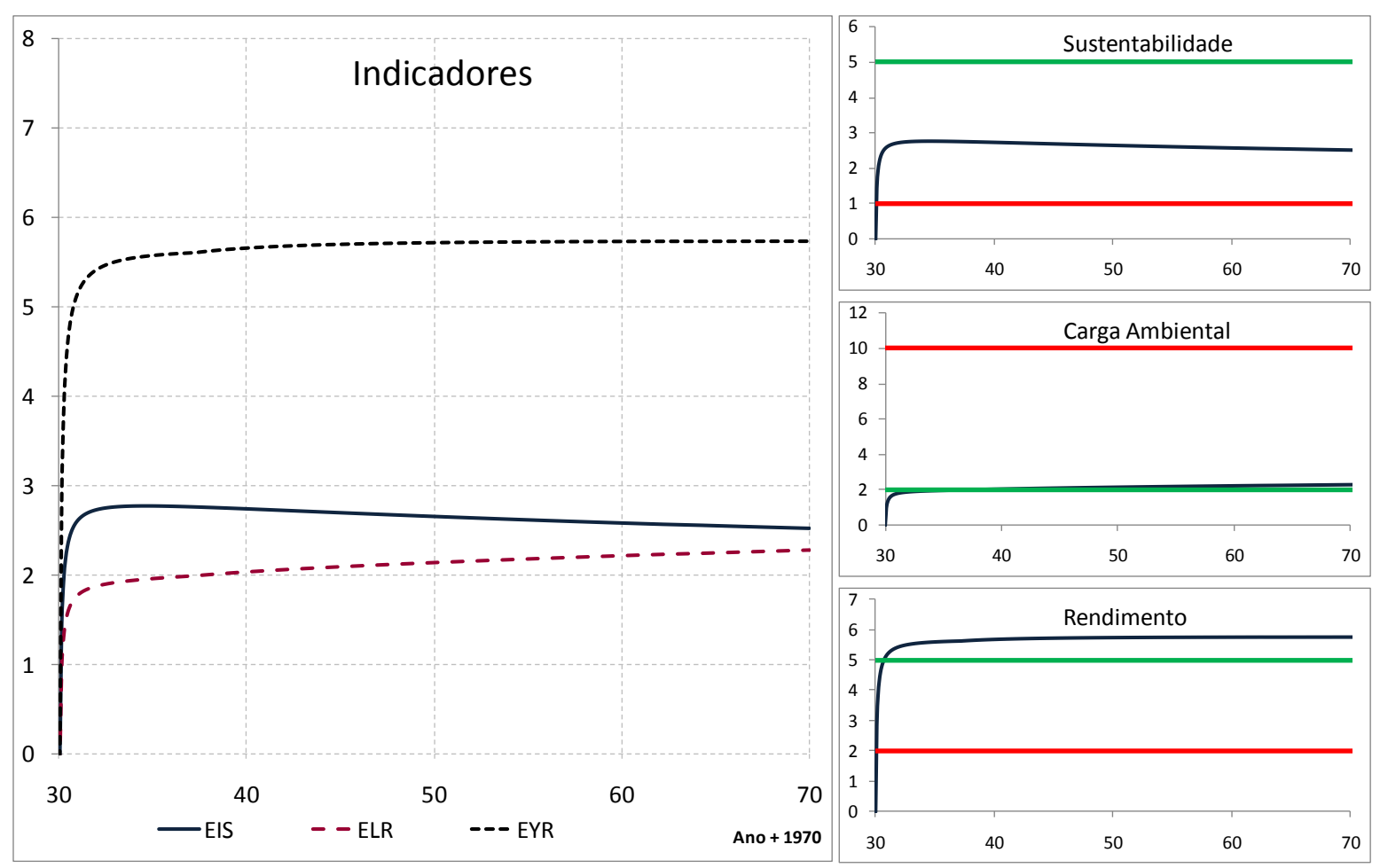

Figura B33 - Índices, sem perturbação, efeito floresta produtos de cana (70 anos)
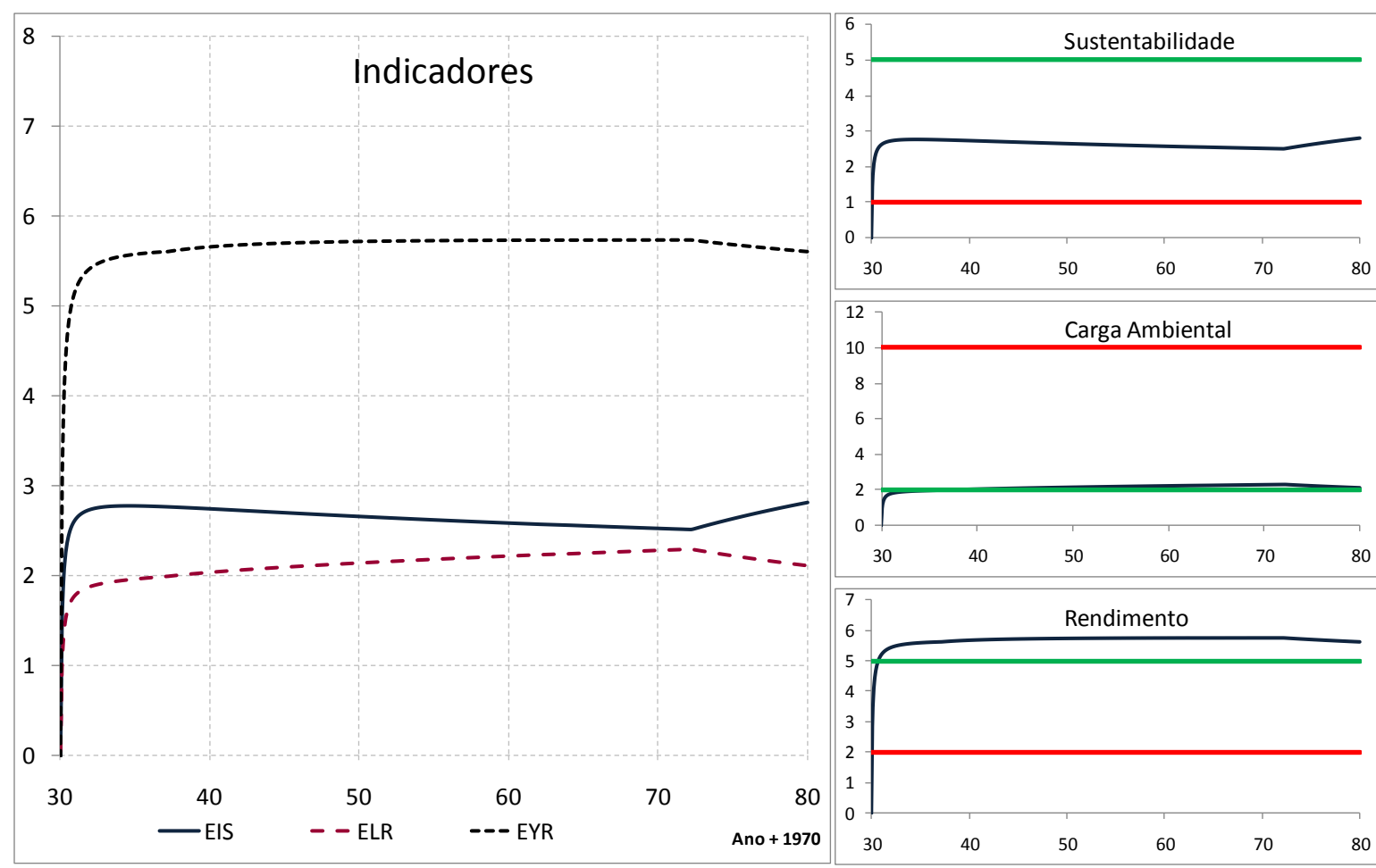

Figura B34 - Índices, sem perturbação, efeito floresta produtos de cana (80 anos) 
GÁS NATURAL

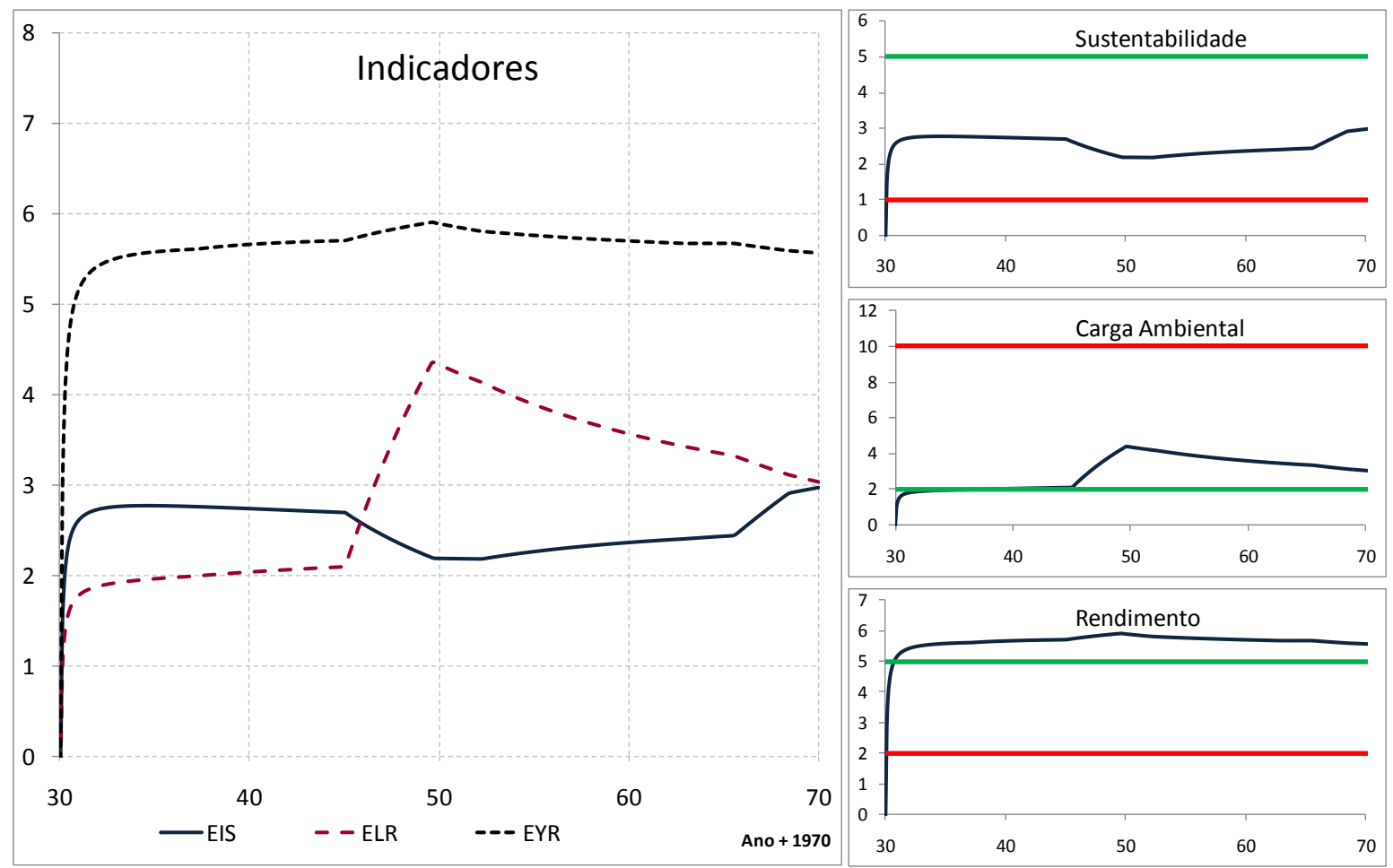

Figura B35 - Índices, perturbação no gás natural, efeito floresta produtos de cana (70 anos)
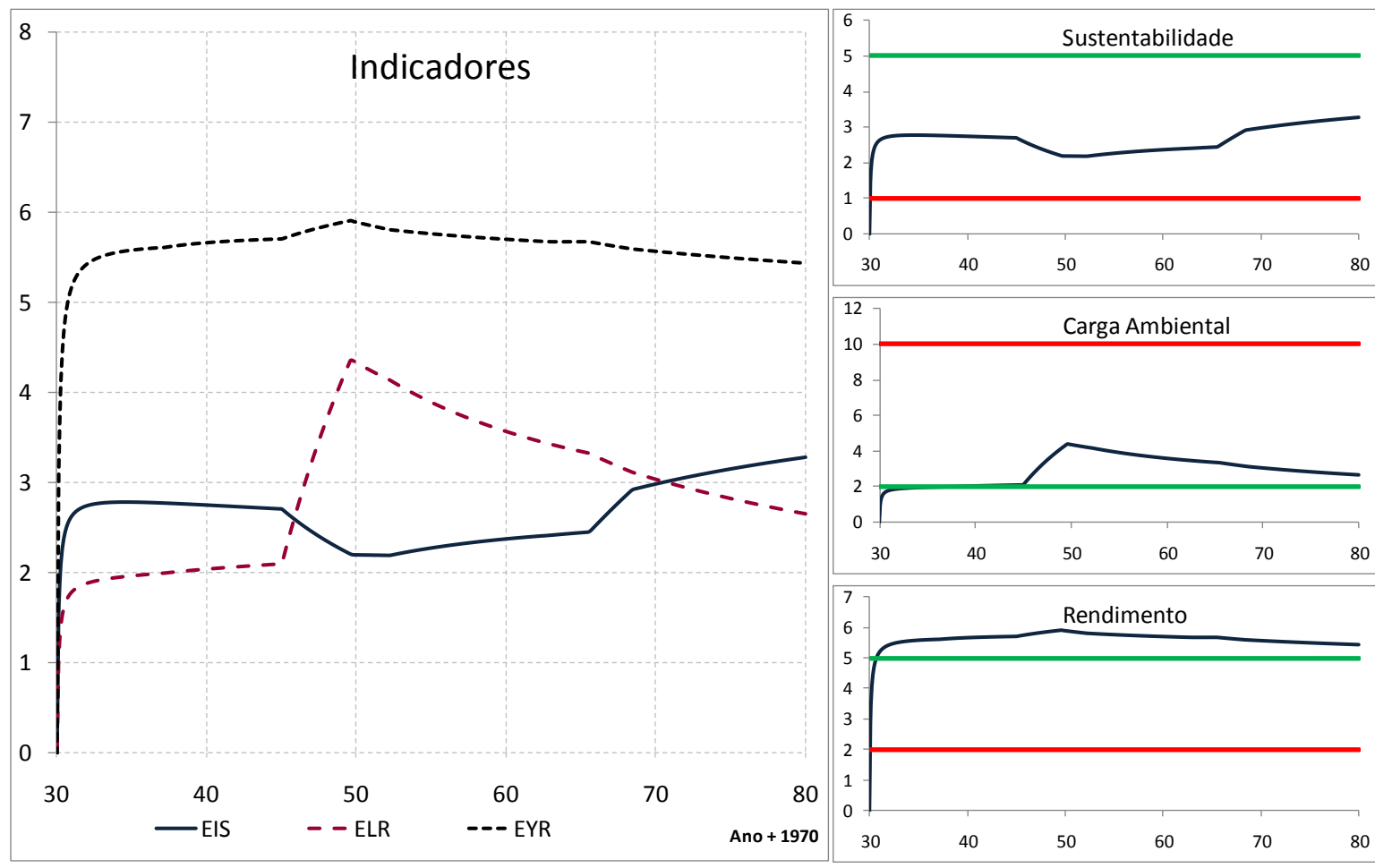

Figura B36 - Índices, perturbação no gás natural, efeito floresta produtos de cana (80 anos) 
GÁS NATURAL Ilimitado

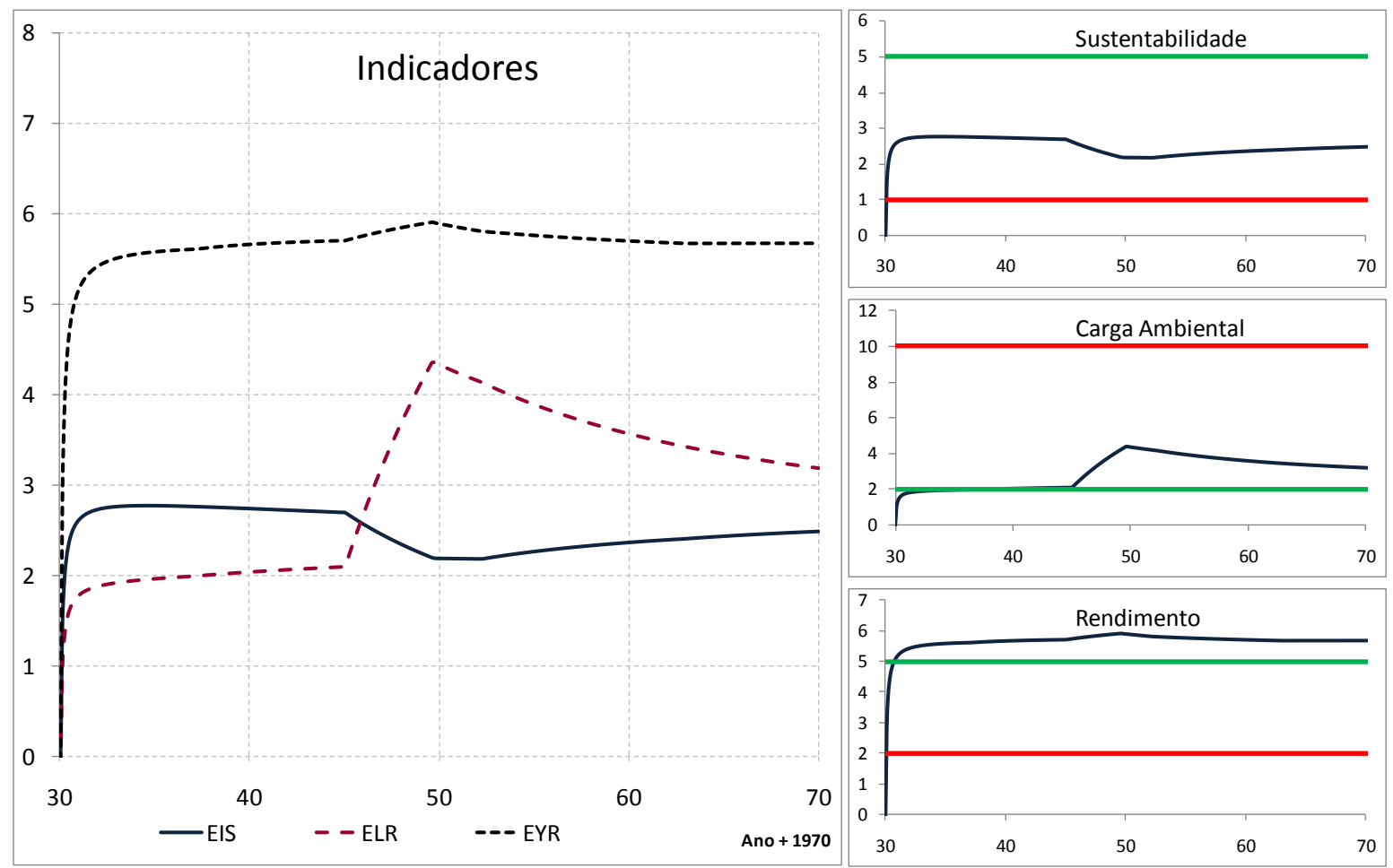

Figura B37 - Índices, perturbação no gás natural ilimitado, efeito floresta produtos de cana (70 anos)
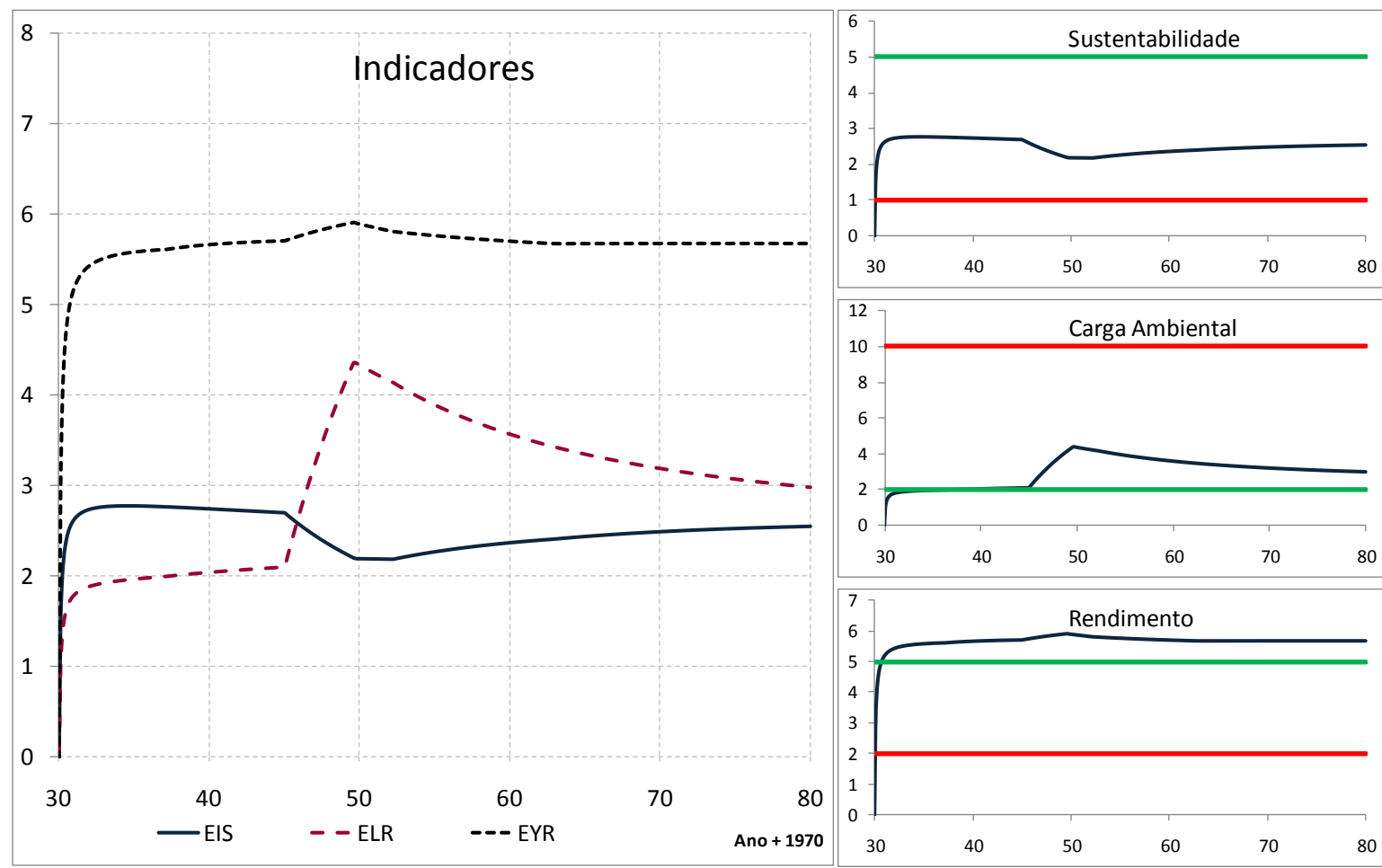

Figura B38 - Índices, perturbação no gás natural ilimitado, efeito floresta produtos de cana (80 anos) 
CARVÃO VAPOR

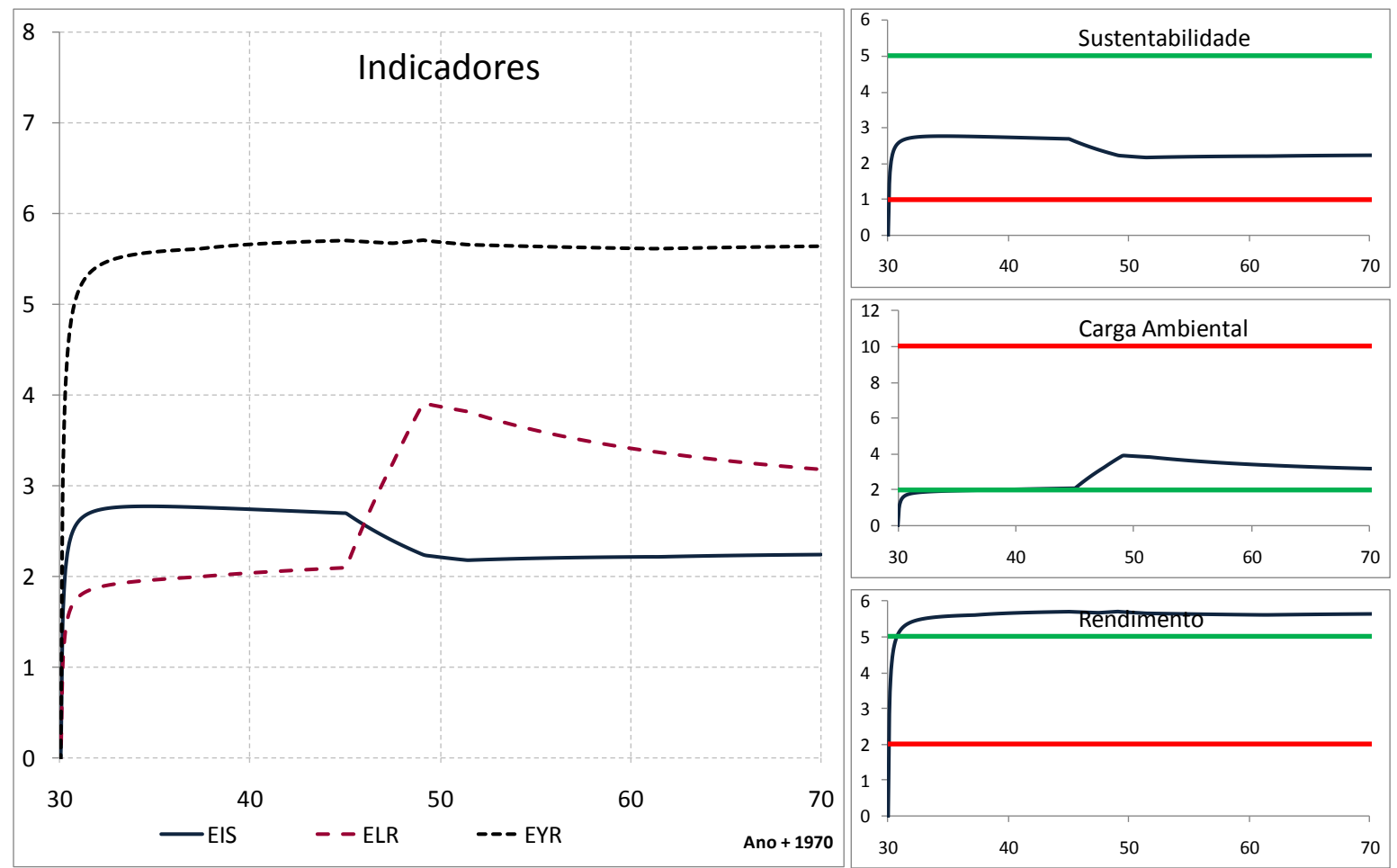

Figura B39 - Índices, perturbação no carvão vapor, efeito floresta produtos de cana (70 anos)

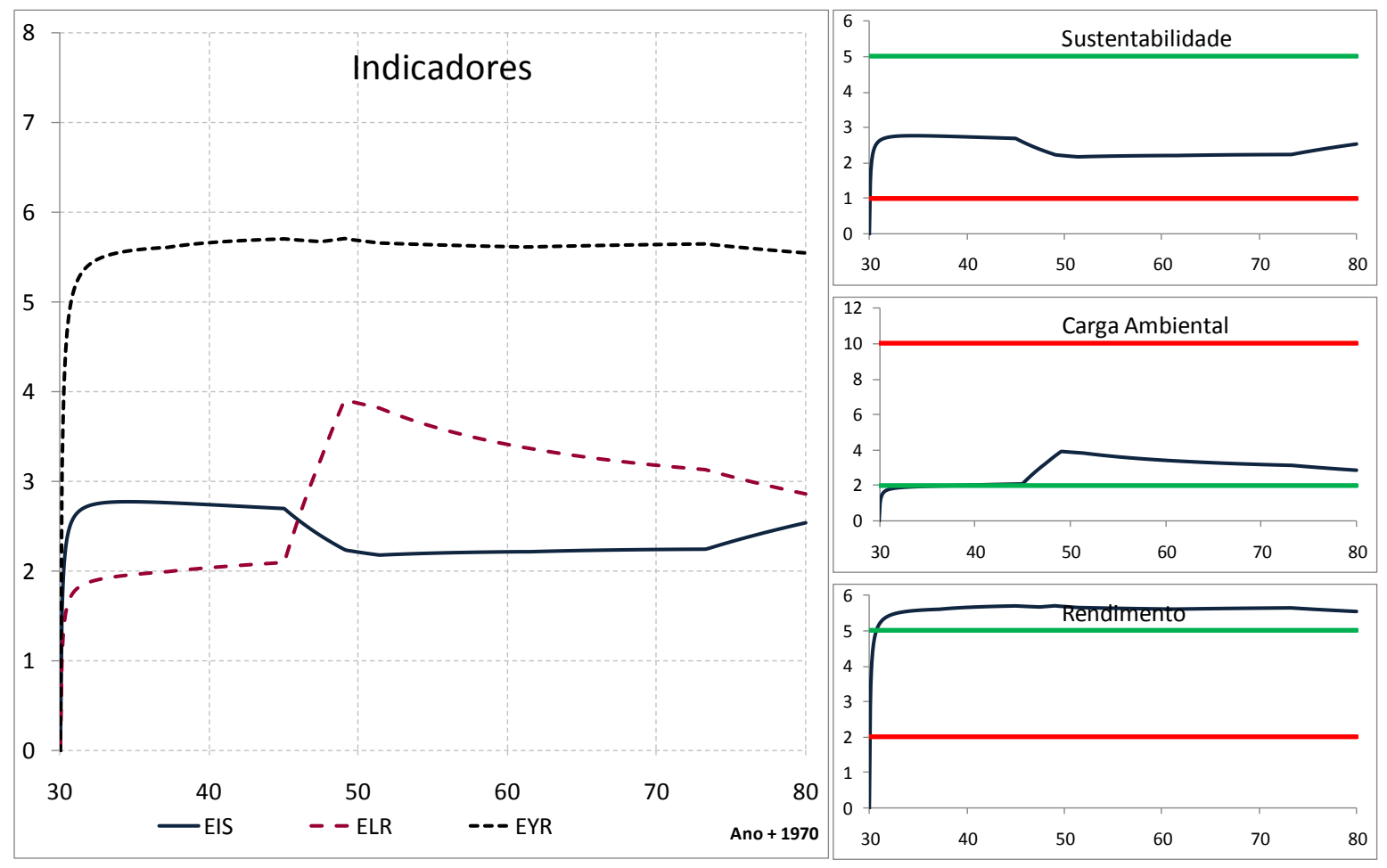

Figura B40 - Índices, perturbação no carvão vapor, efeito floresta produtos de cana (80 anos) 
ENERGIA HÍDRICA

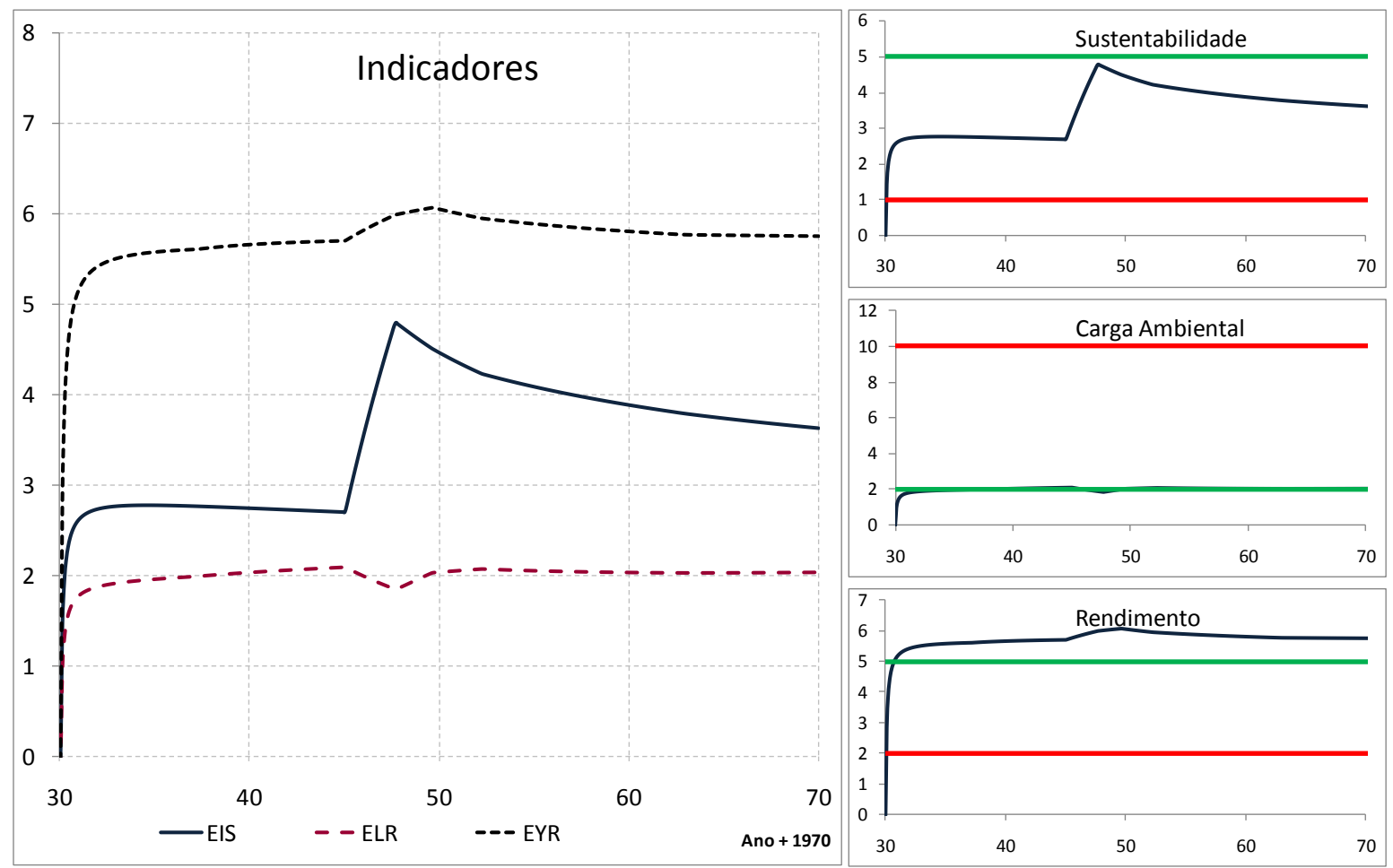

Figura B41 - Índices, perturbação na hídrica, efeito floresta produtos de cana (70 anos)
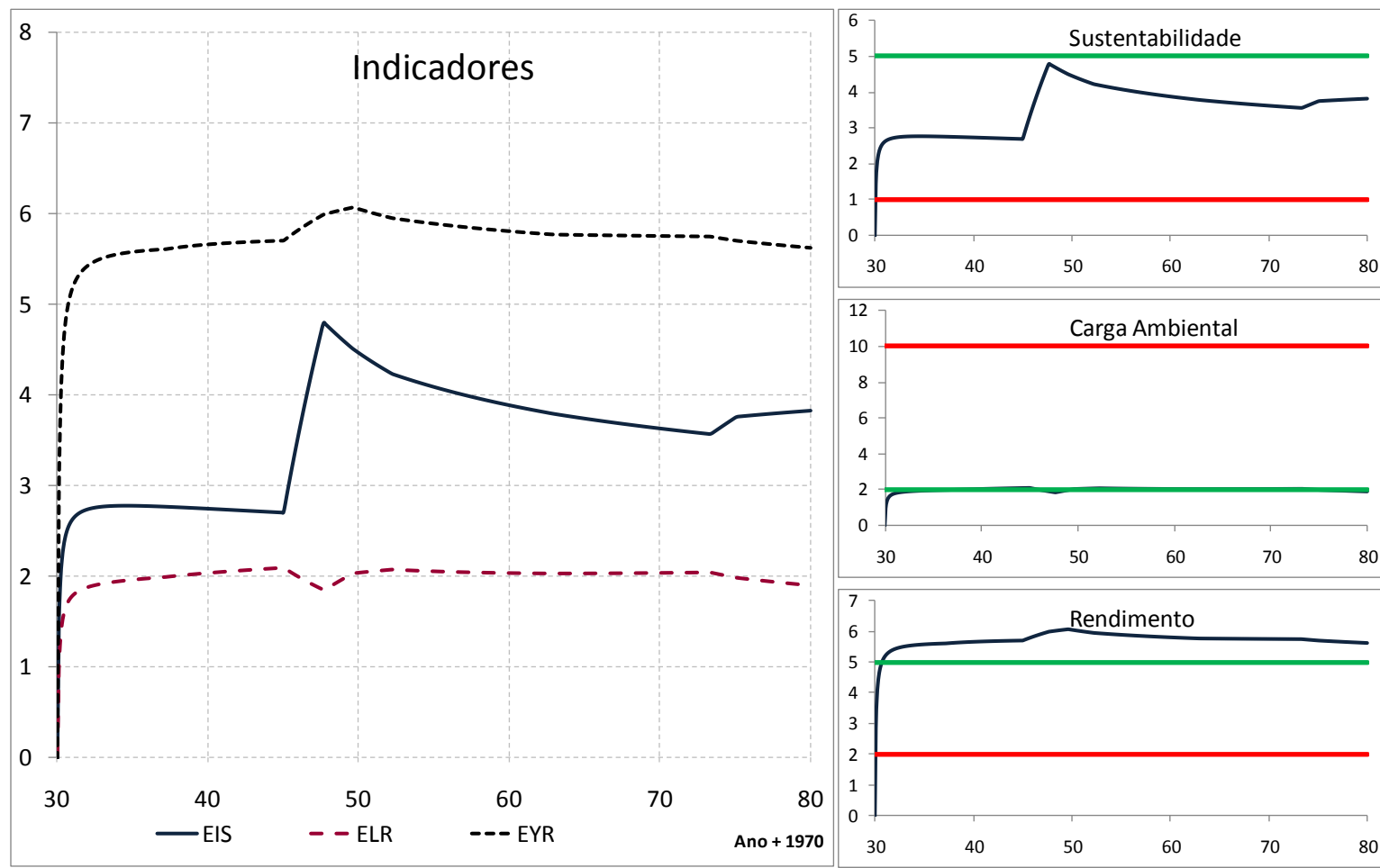

Figura B42 - Índices, perturbação na hídrica, efeito floresta produtos de cana (80 anos) 
PRODUTOS DE CANA

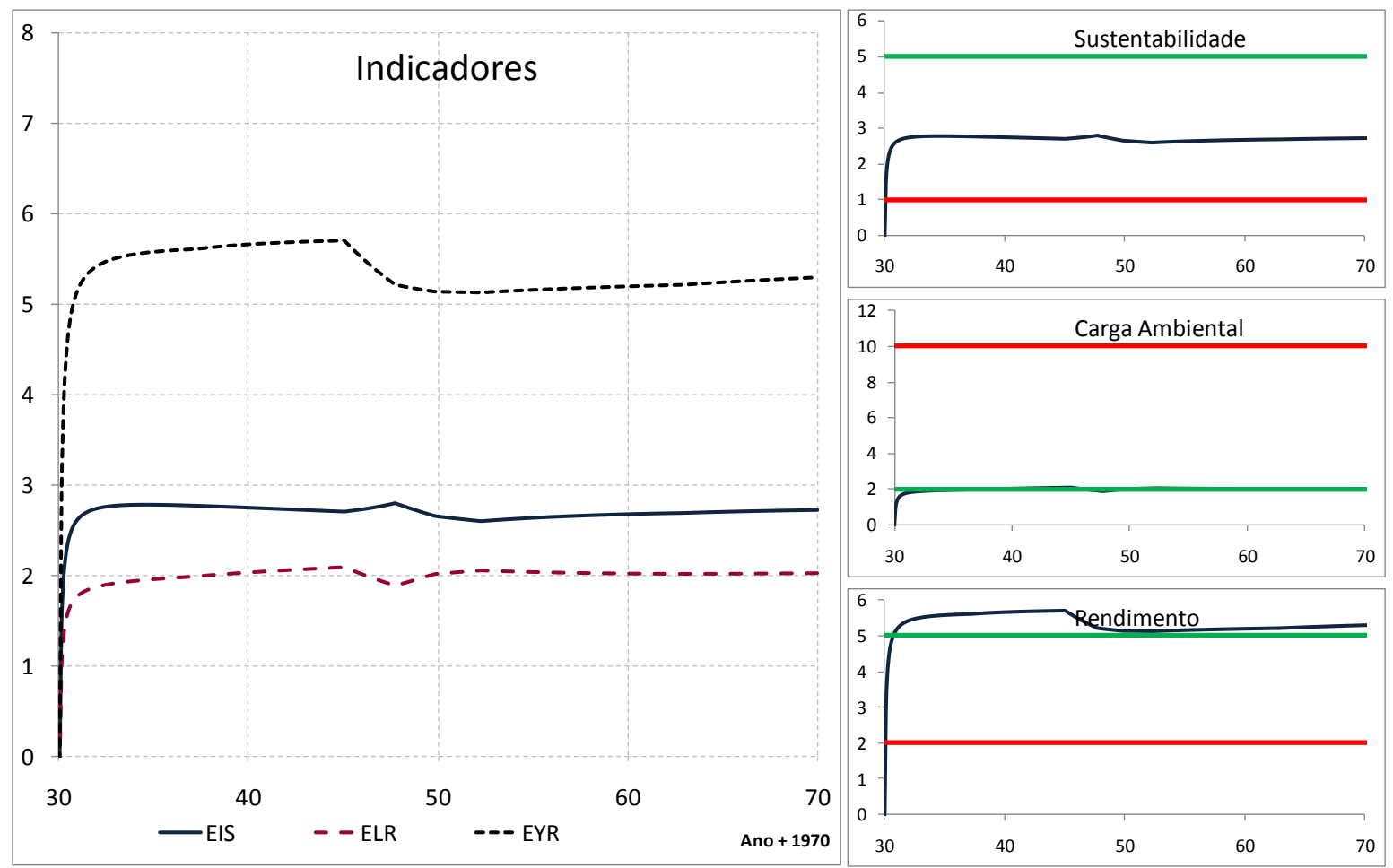

Figura B43 - Índices, perturbação nos produtos de cana, efeito floresta produtos de cana (70 anos)
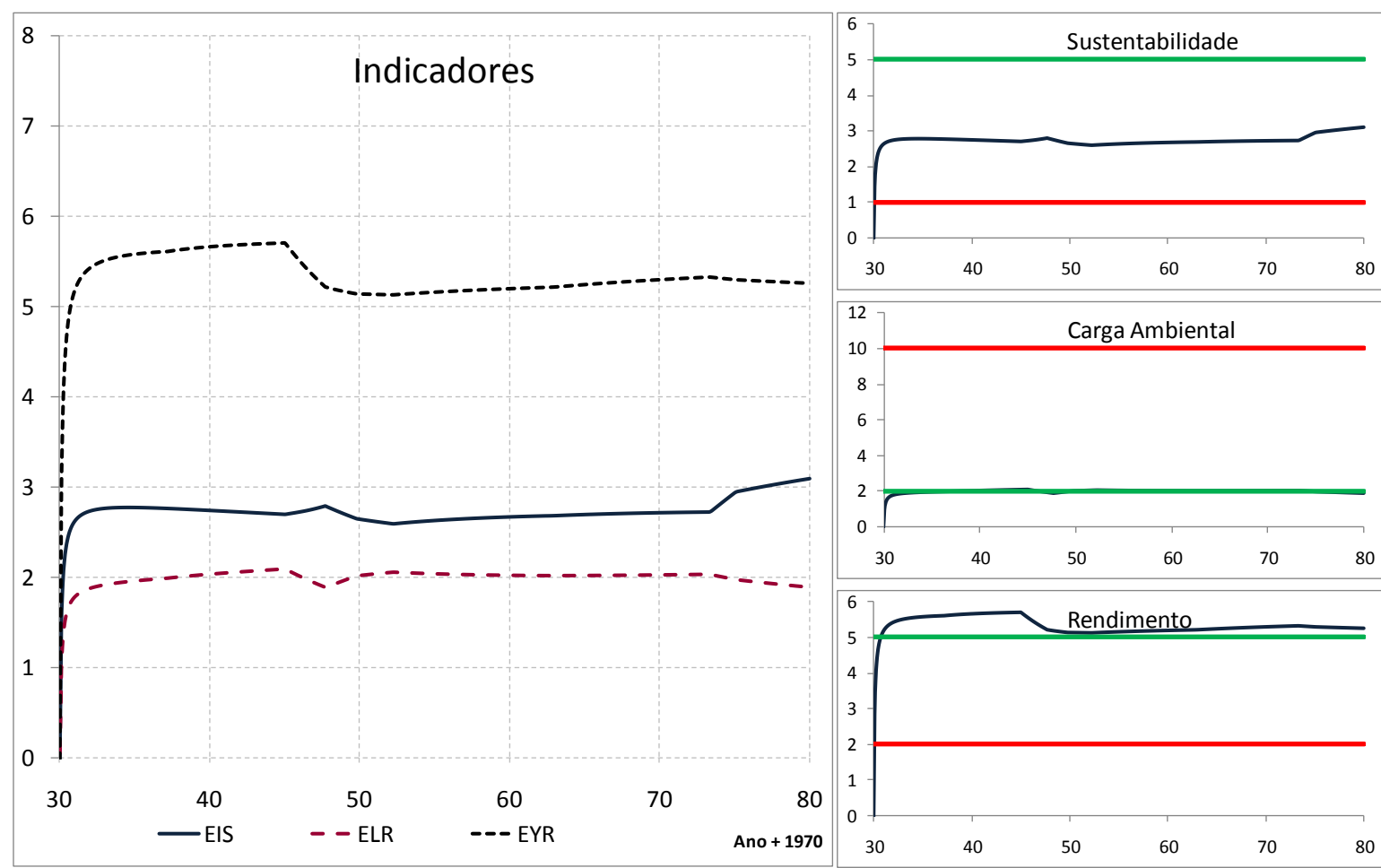

Figura B44 - Índices, perturbação nos produtos de cana, efeito floresta produtos de cana (80 anos) 
ENERGIA EÓLICA

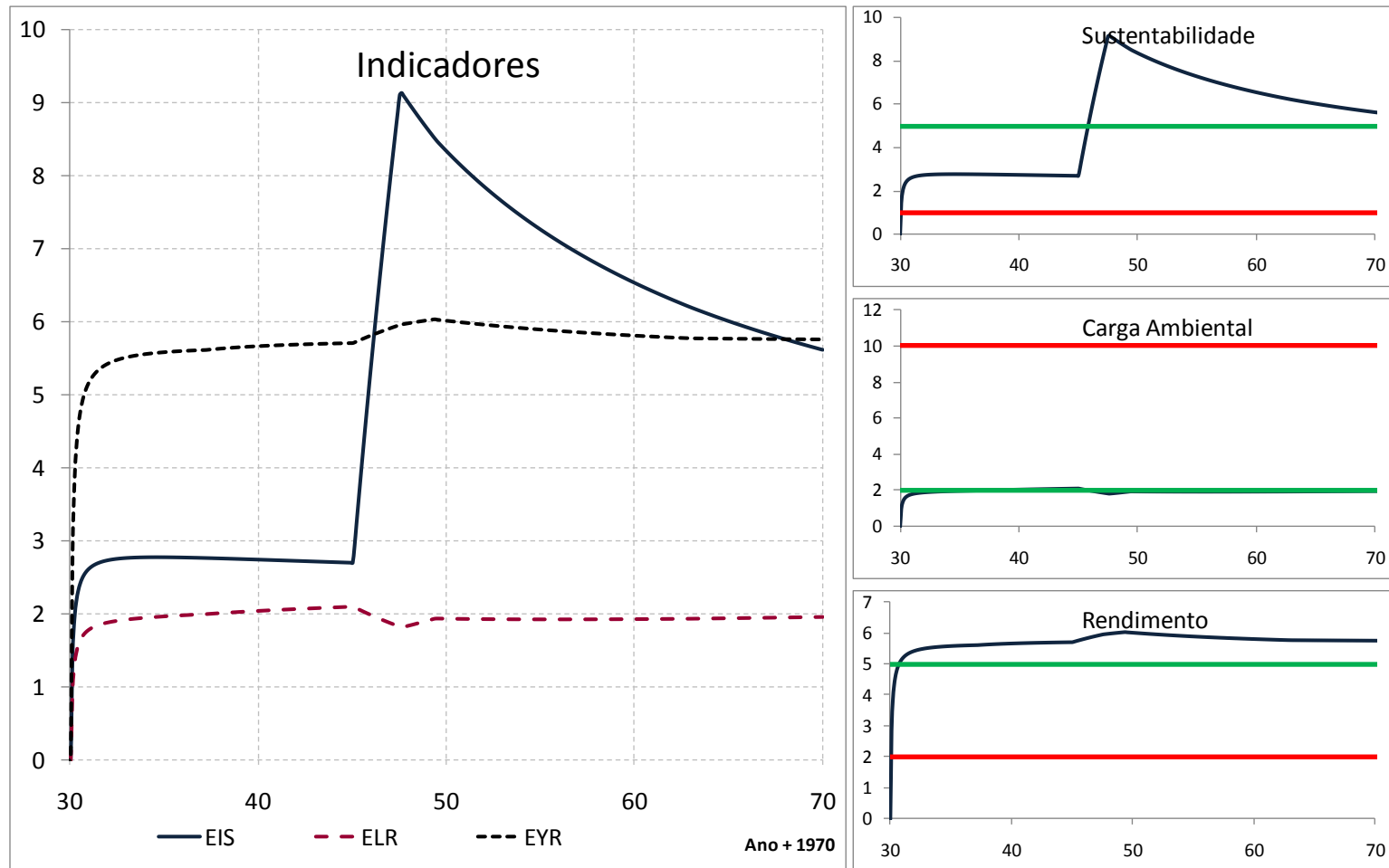

Figura B45 - Índices, perturbação na eólica, efeito floresta produtos de cana (70 anos)
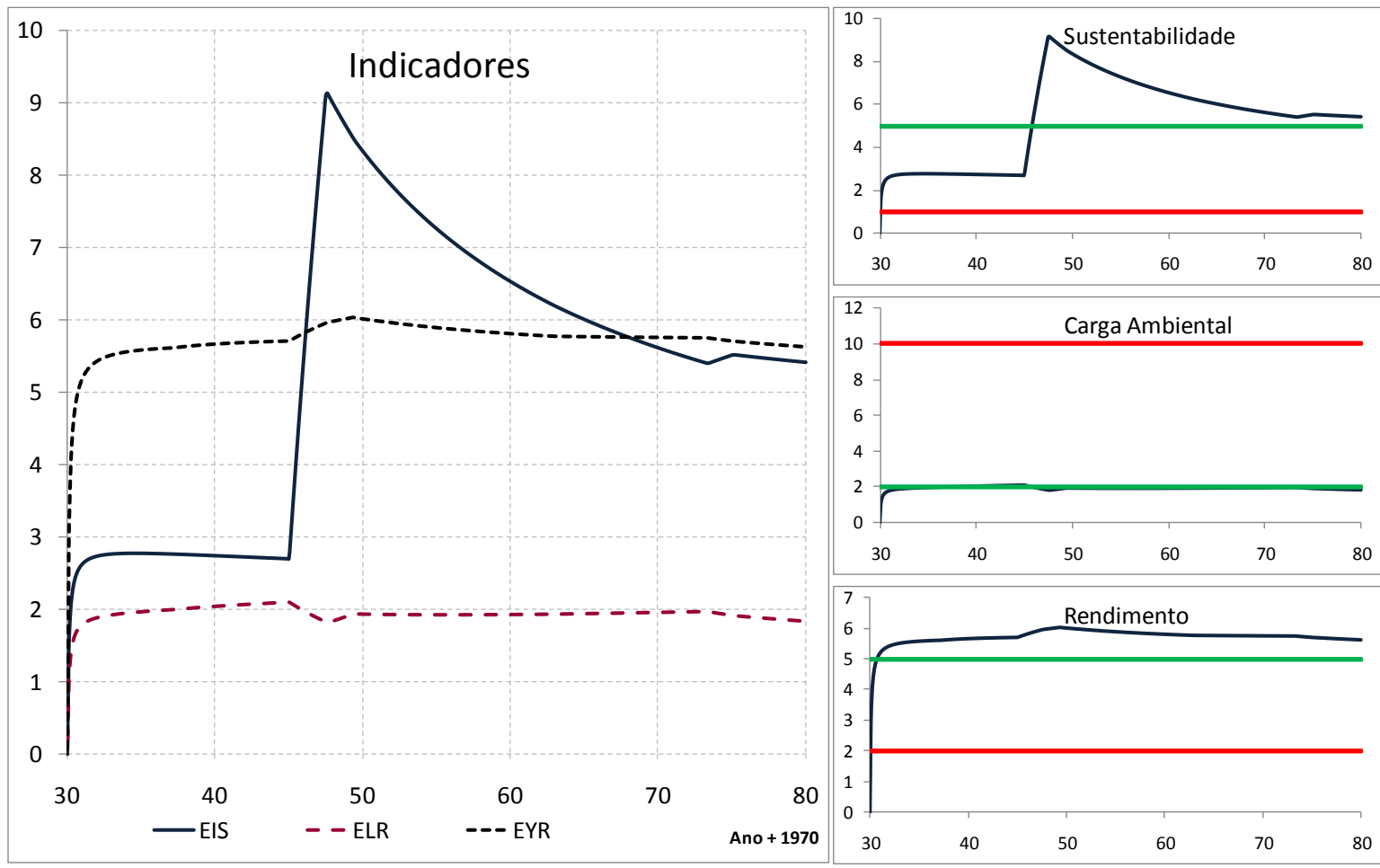

Figura B46 - Índices, perturbação na eólica, efeito floresta produtos de cana (80 anos) 
ENERGIA NUCLEAR

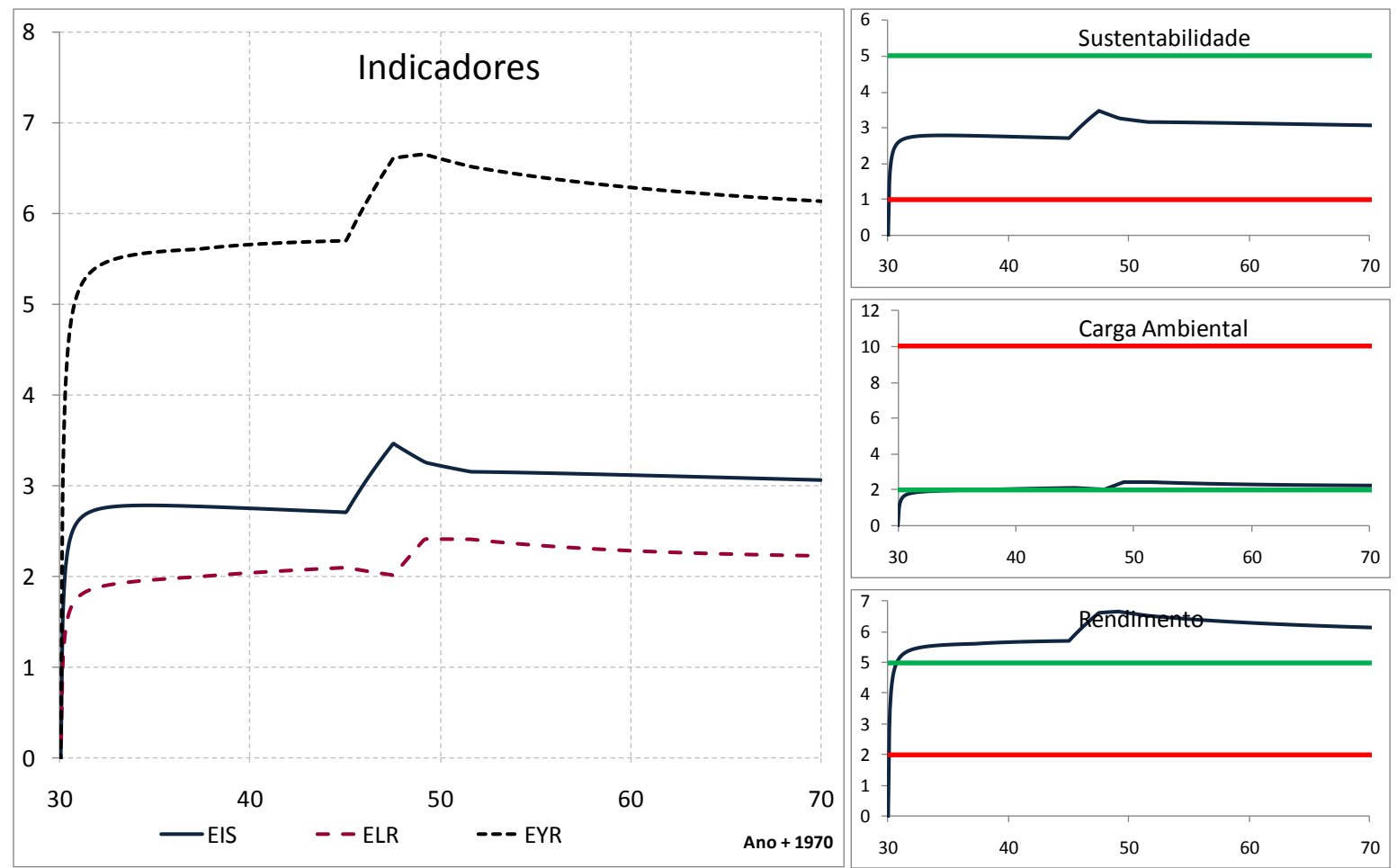

Figura B47 - Índices, perturbação na nuclear, efeito floresta produtos de cana (70 anos)
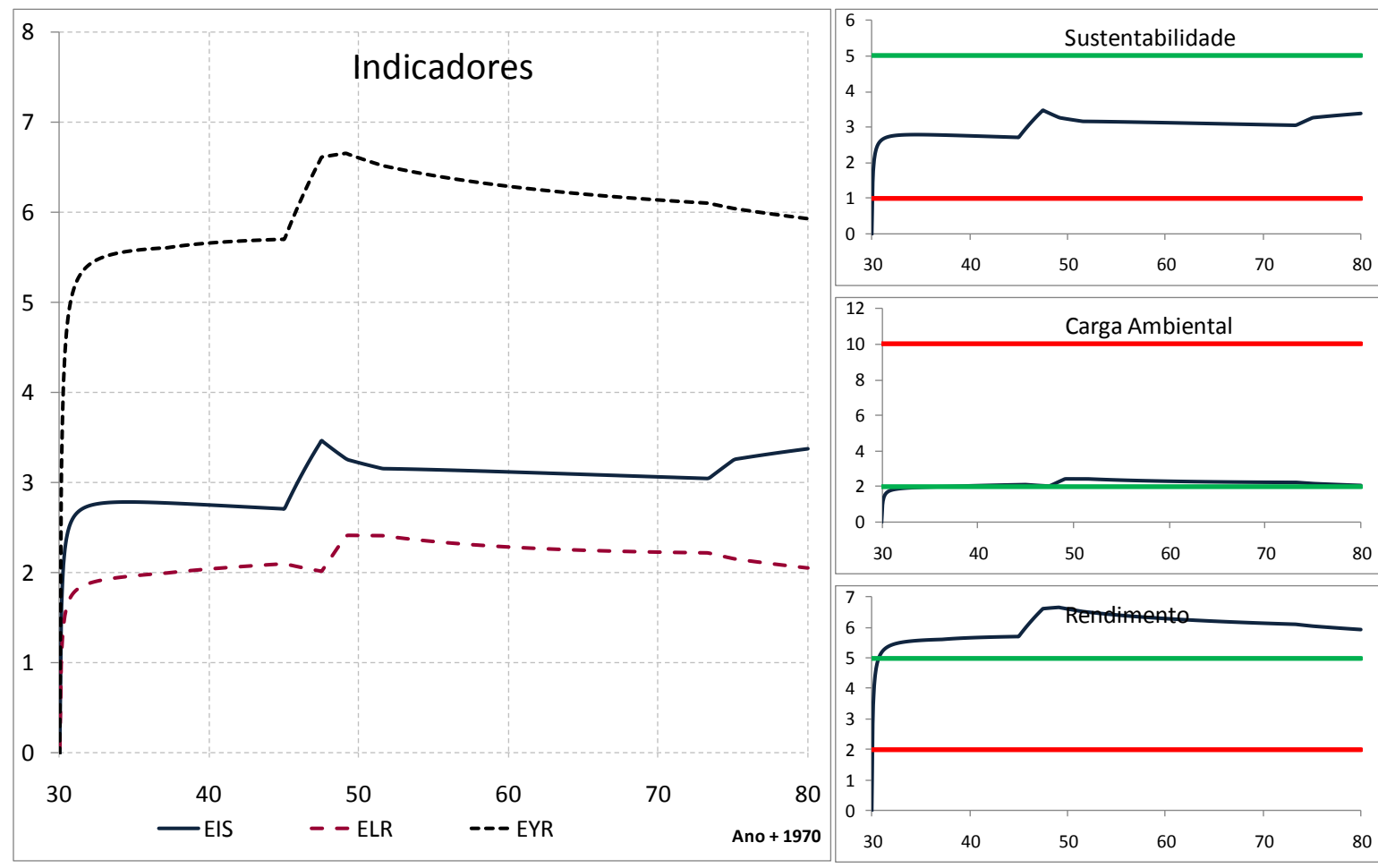

Figura B48 - Índices, perturbação na nuclear, efeito floresta produtos de cana (80 anos) 
FLORESTA: HÍDRICA + CANA

SEM PERTURBAÇÃO

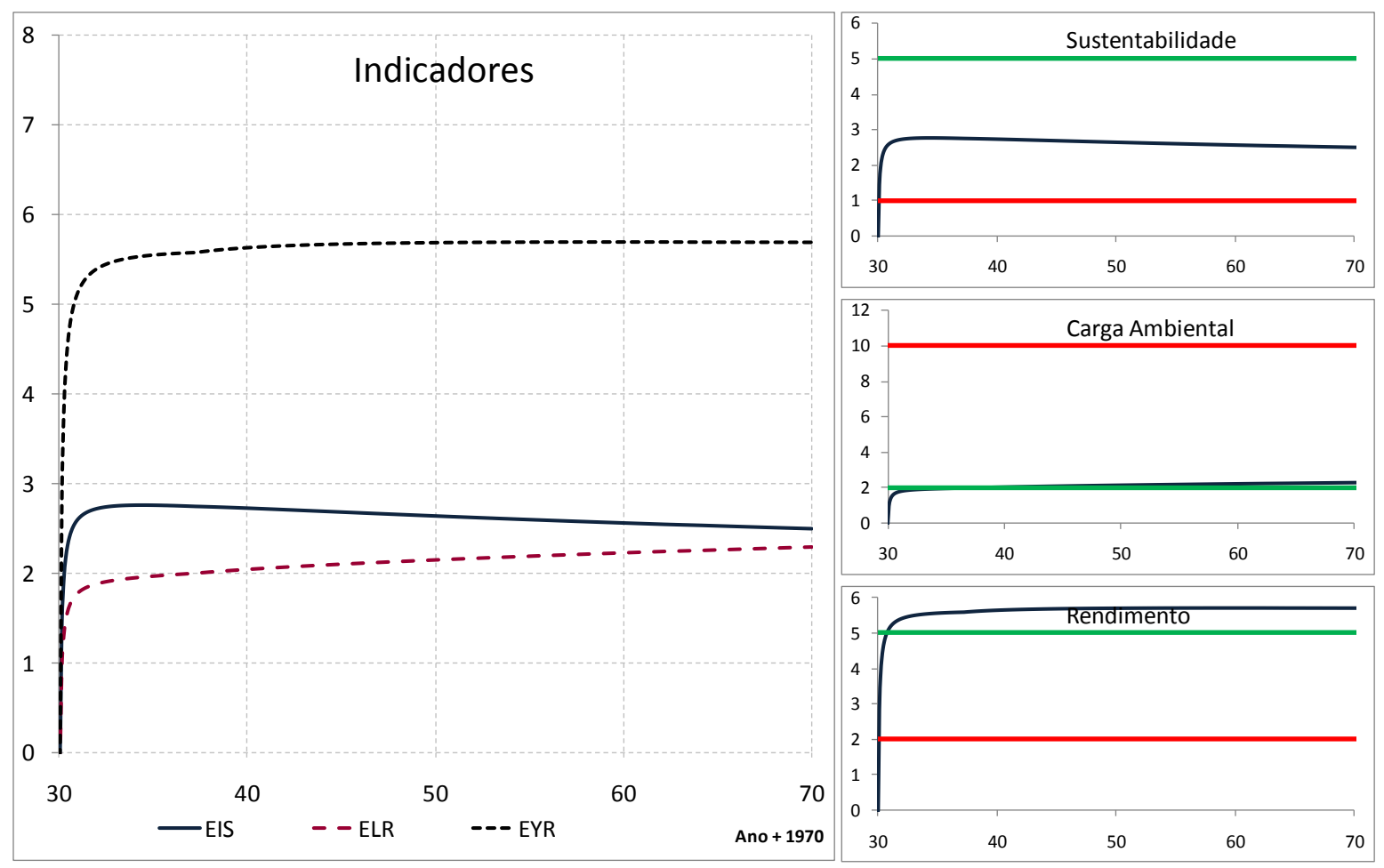

Figura B49 - Índices, sem perturbação, efeito floresta hídrica e produtos de cana (70 anos)
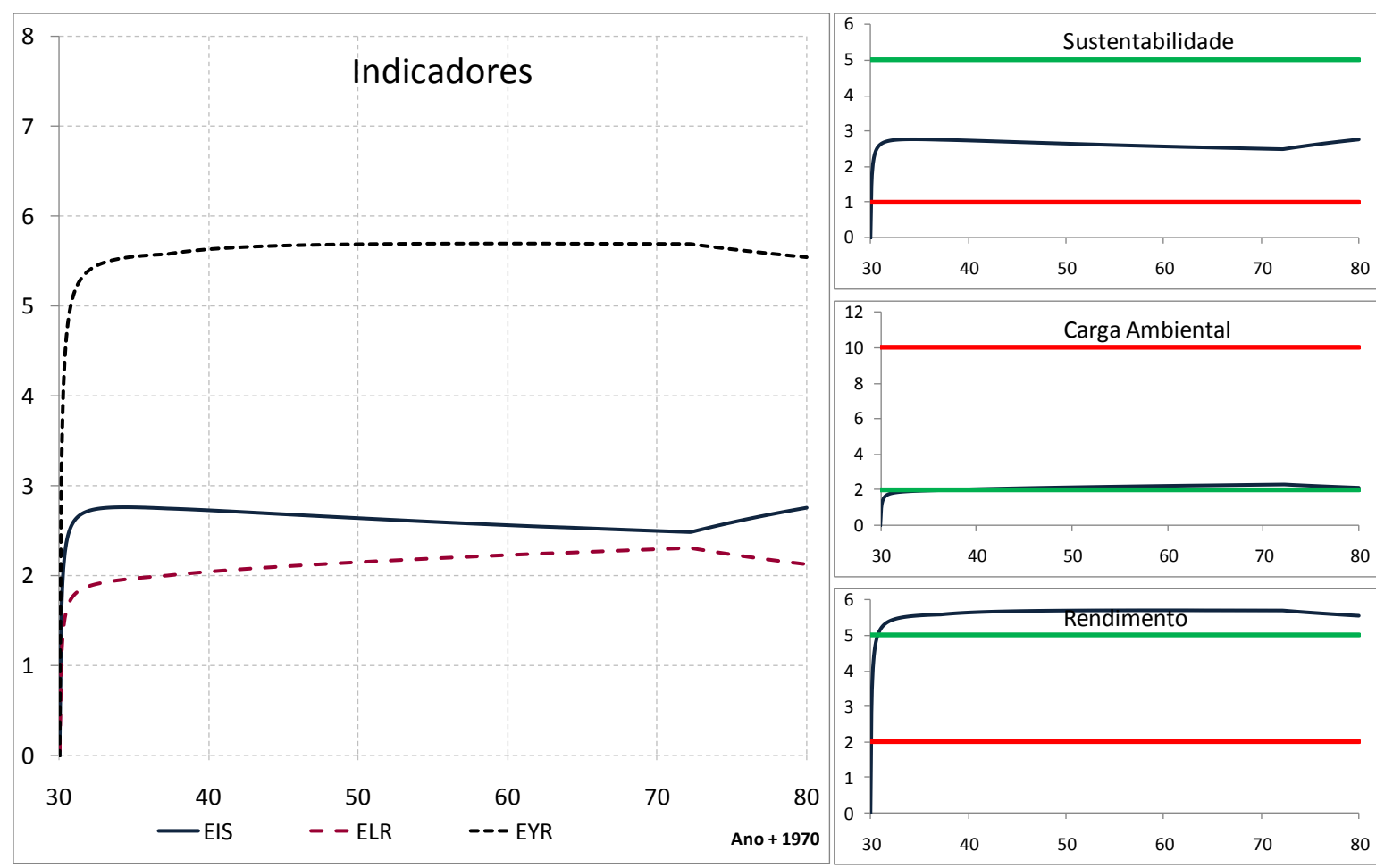

Figura B50 - Índices, sem perturbação, efeito floresta hídrica e produtos de cana (80 anos) 
GÁS NATURAL

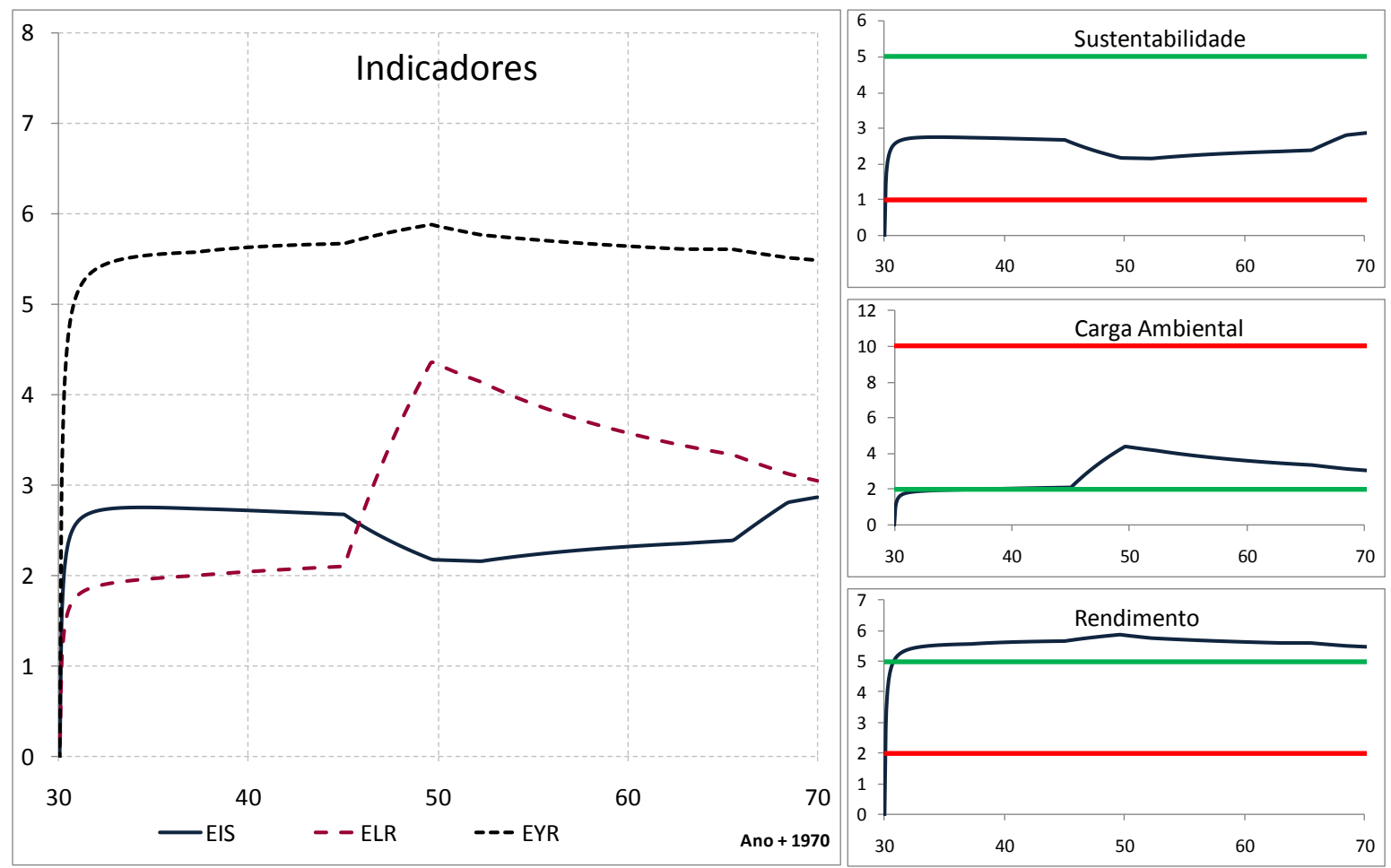

Figura B51 - Índices, perturbação no gás natural, efeito floresta hídrica e produtos de cana (70 anos)

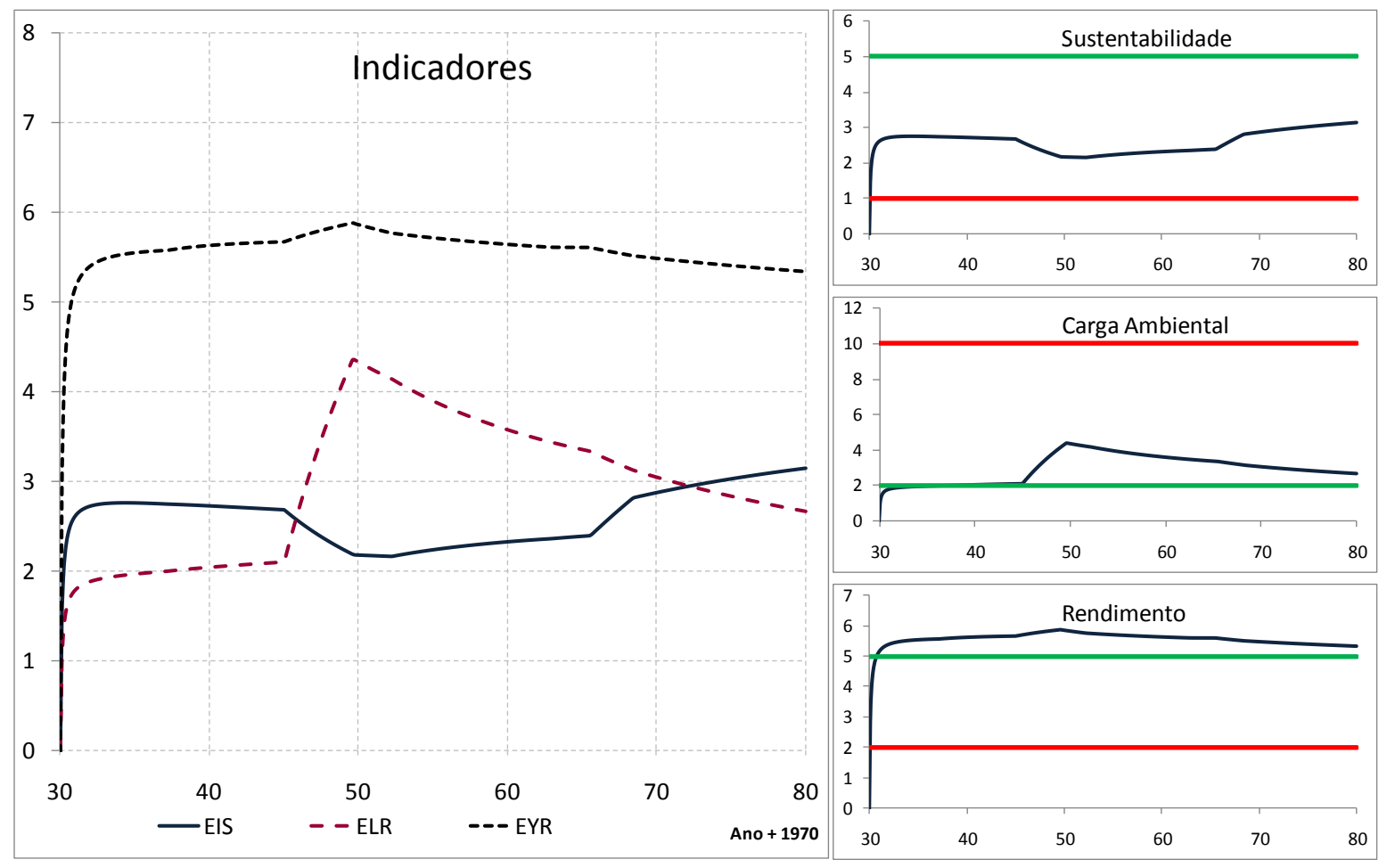

Figura B52 - Índices, perturbação no gás natural, efeito floresta hídrica e produtos de cana (80 anos) 
GÁS NATURAL Ilimitado

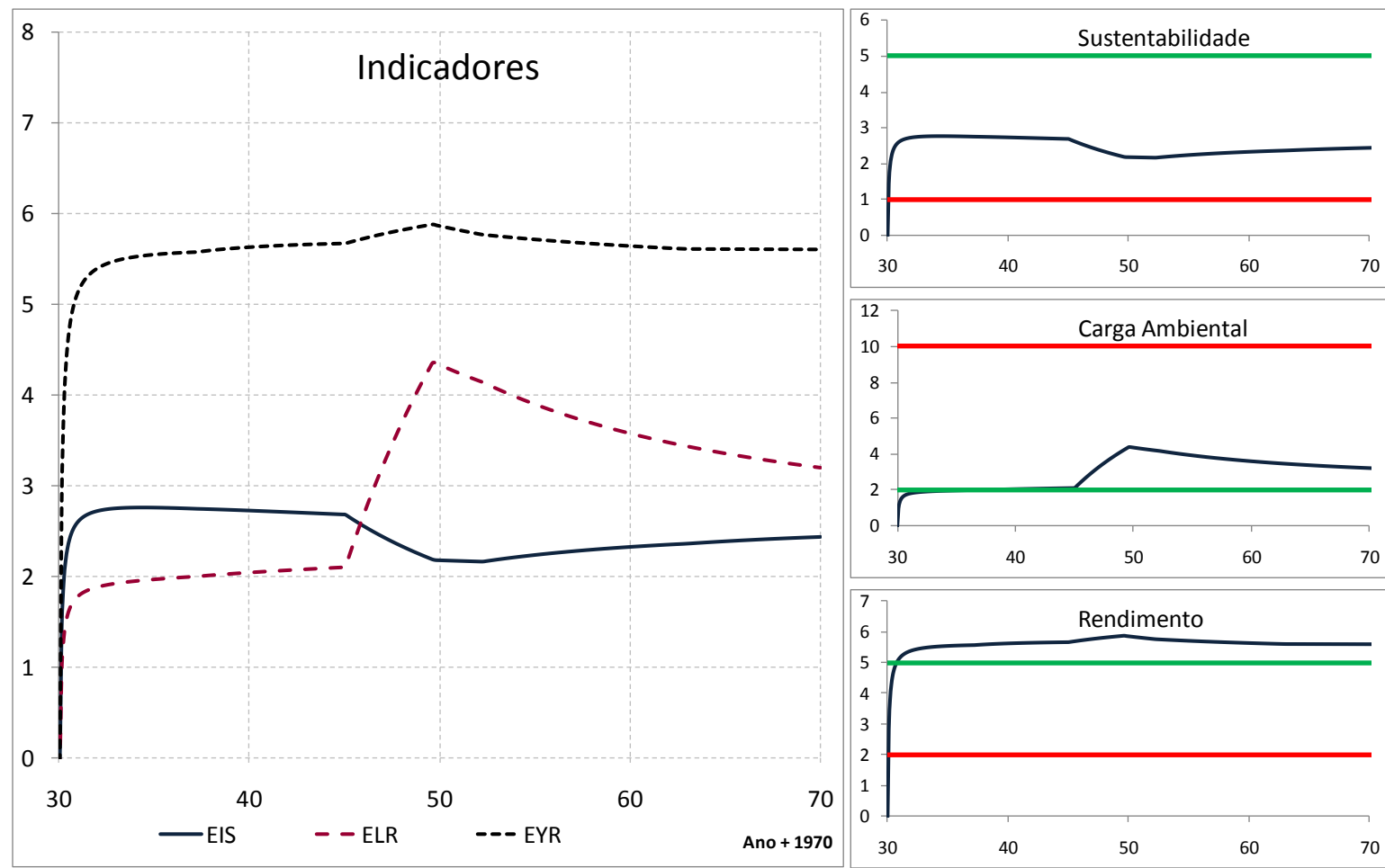

Figura B53 - Índices, perturbação no gás natural ilimitado, efeito floresta hídrica e produtos de cana (70 anos)
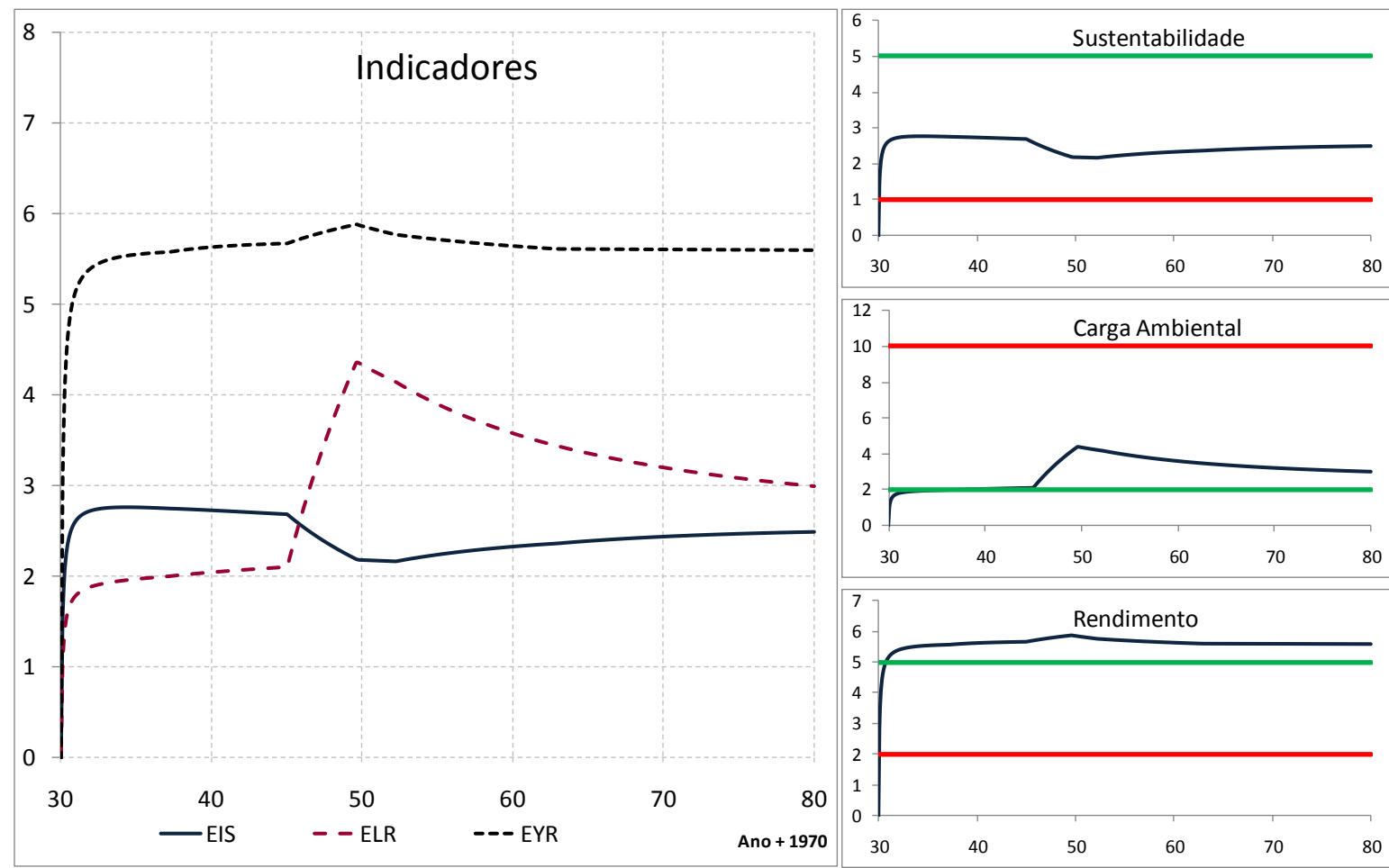

Figura B54 - Índices, perturbação no gás natural ilimitado, efeito floresta hídrica e produtos de cana (80 anos) 
CARVÃO VAPOR

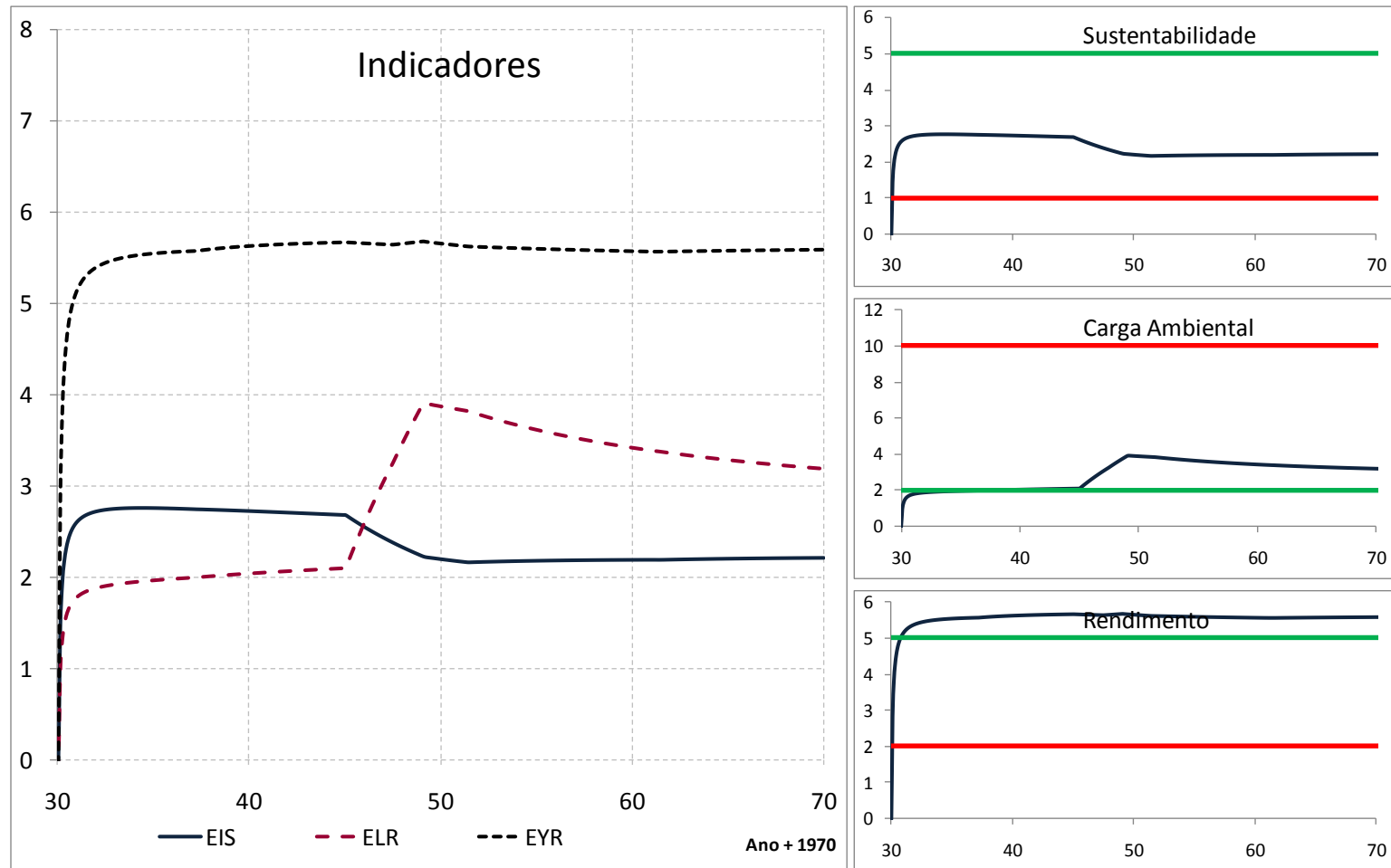

Figura B55 - Índices, perturbação no carvão vapor, efeito floresta hídrica e produtos de cana (70 anos)

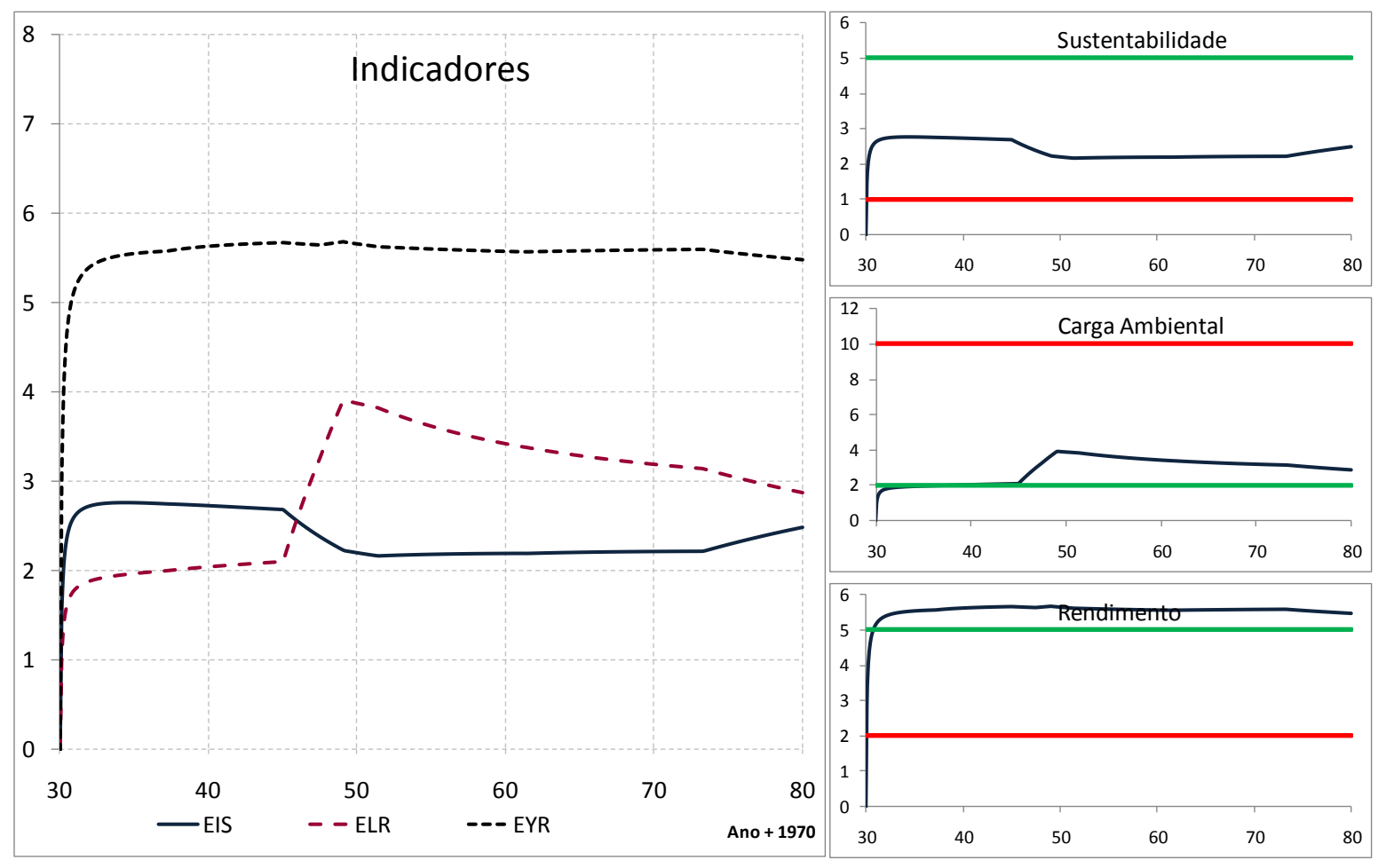

Figura B56 - Índices, perturbação no carvão vapor, efeito floresta hídrica e produtos de cana (80 anos) 
ENERGIA HÍDRICA

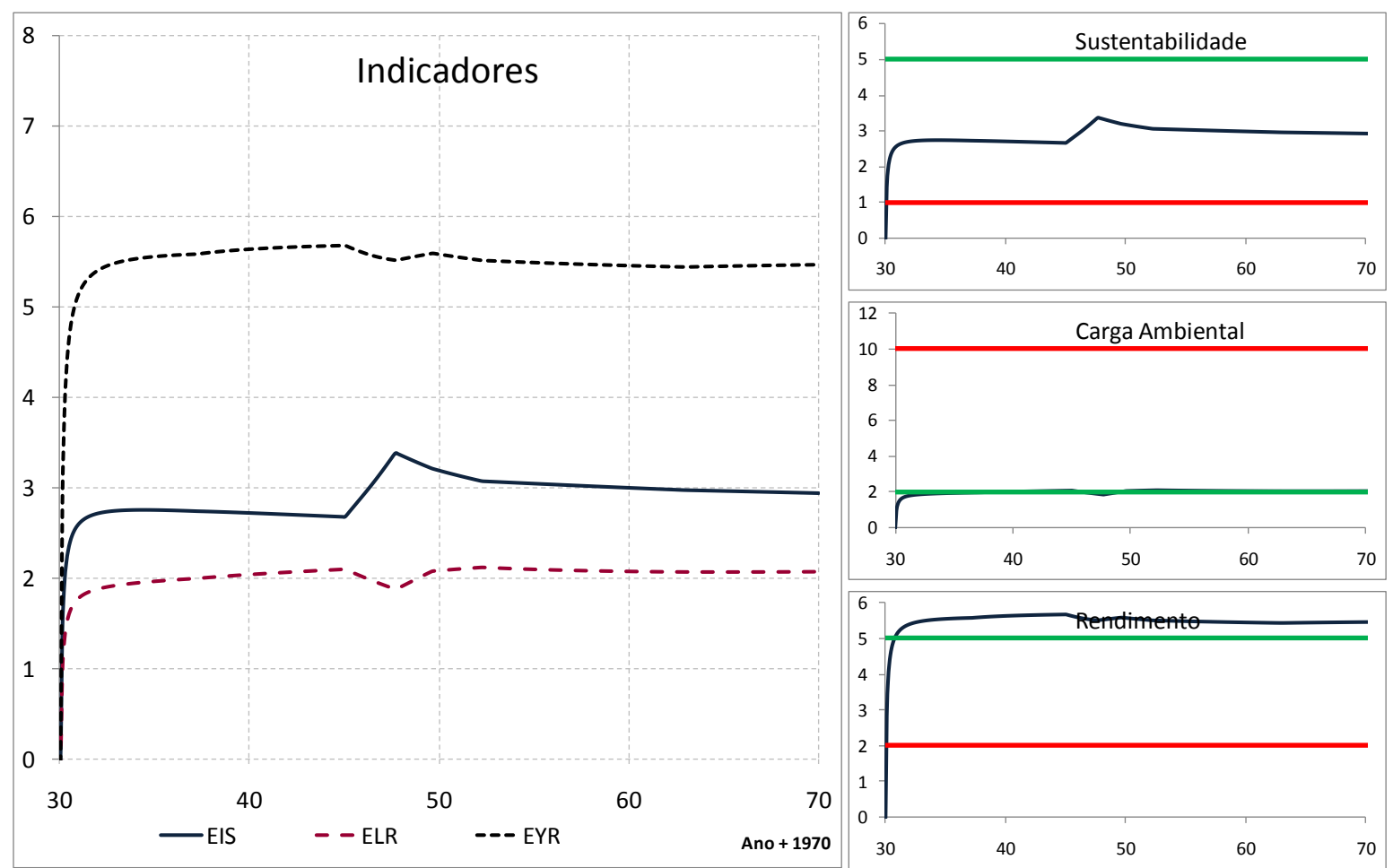

Figura B57 - Índices, perturbação na hídrica, efeito floresta hídrica e produtos de cana (70 anos)

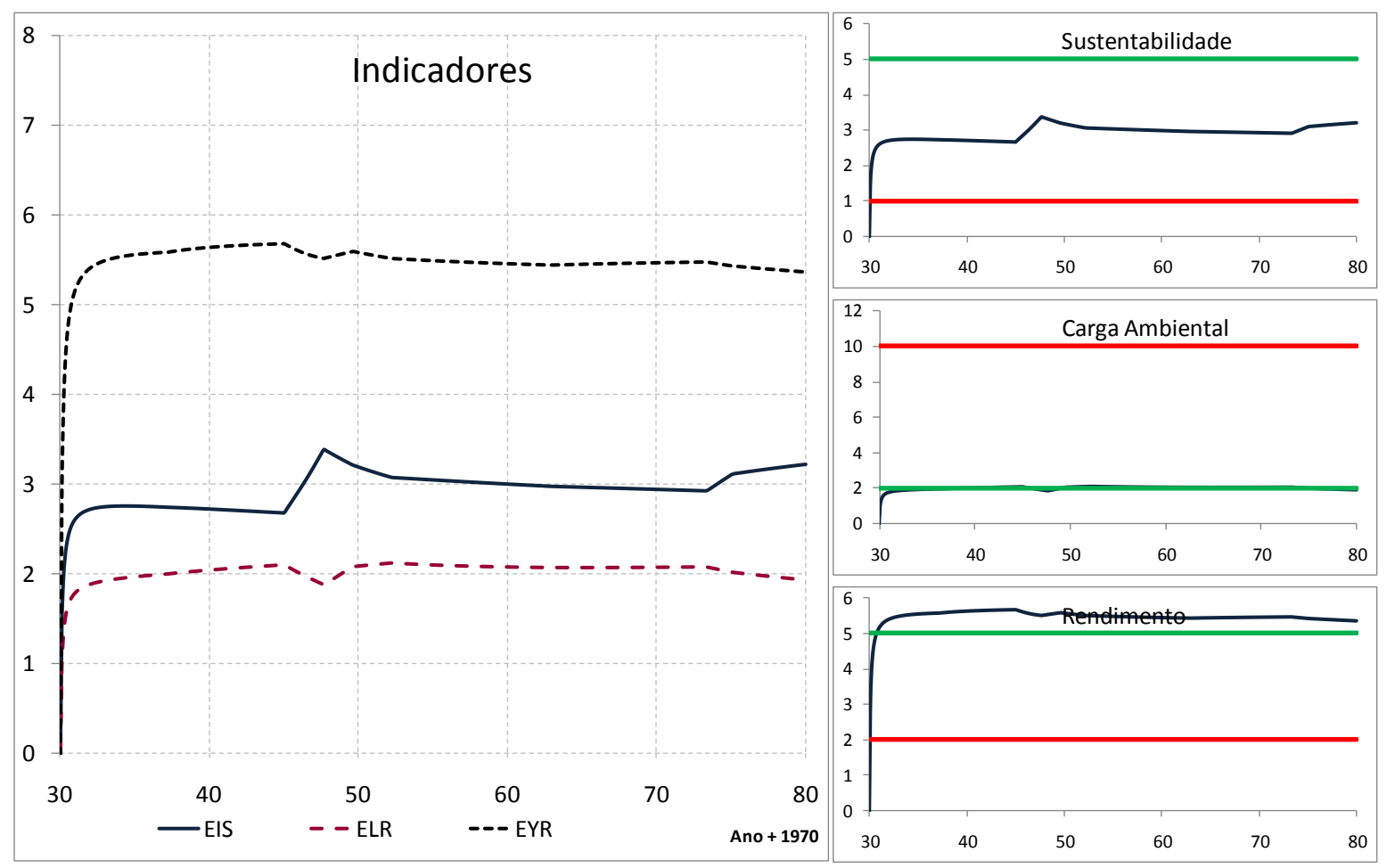

Figura B58 - Índices, perturbação na hídrica, efeito floresta hídrica e produtos de cana (80 anos) 
PRODUTOS DE CANA

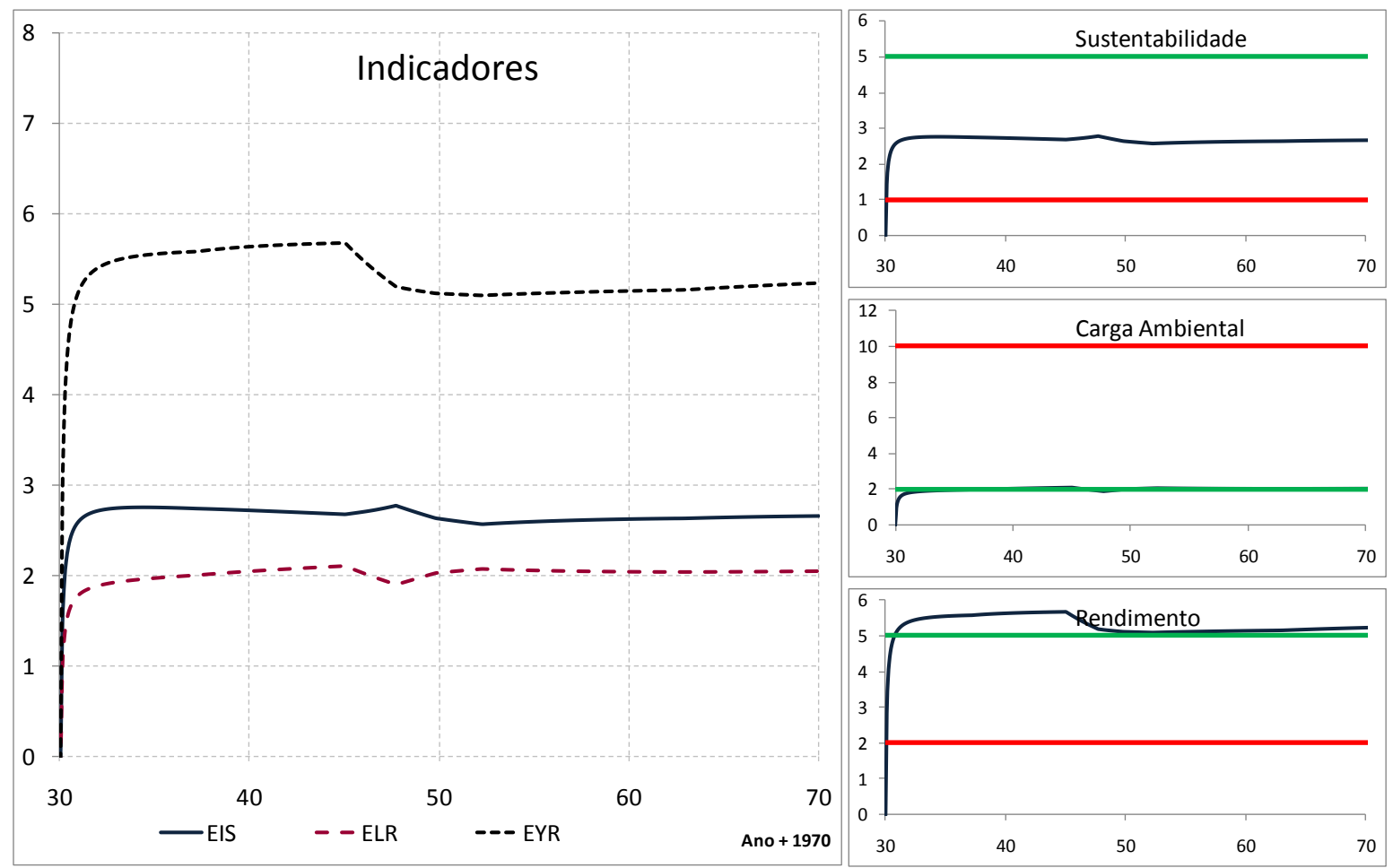

Figura B59 - Índices, perturbação nos produtos de cana, efeito floresta hídrica e produtos de cana (70 anos)
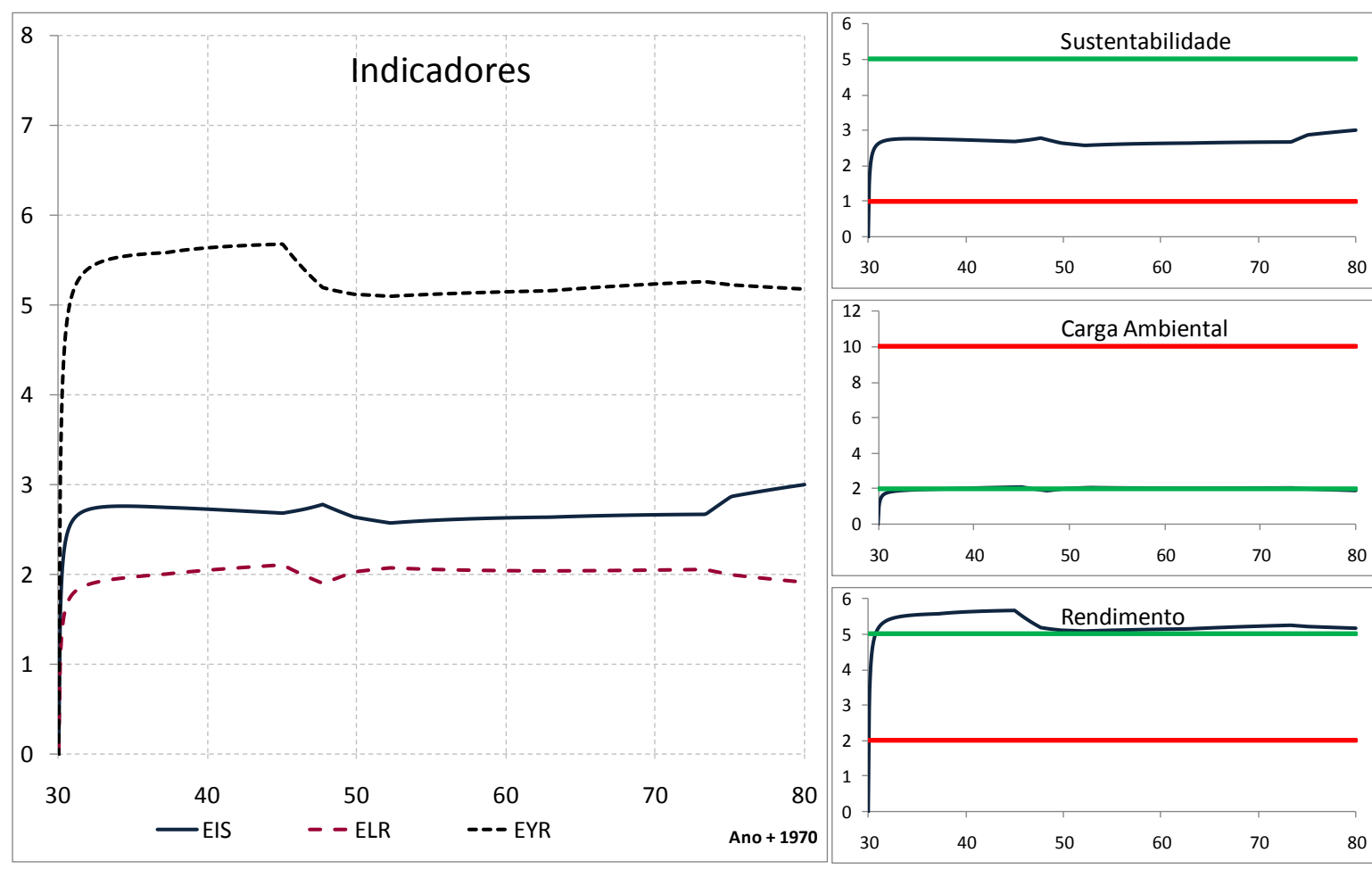

Figura B60 - Índices, perturbação nos produtos de cana, efeito floresta hídrica e produtos de cana (80 anos) 
ENERGIA EÓLICA

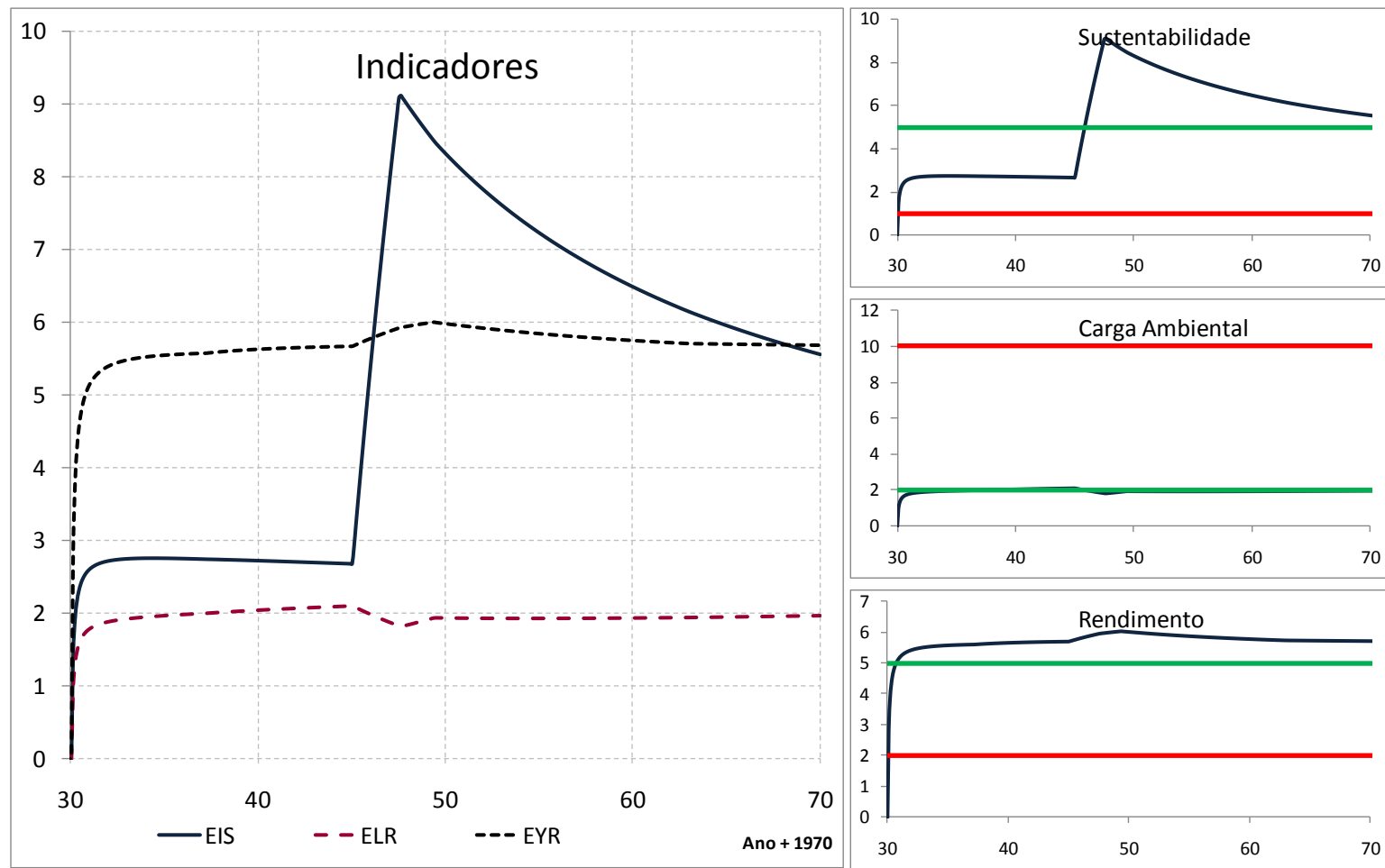

Figura B61 - Índices, perturbação na eólica, efeito floresta hídrica e produtos de cana (70 anos)
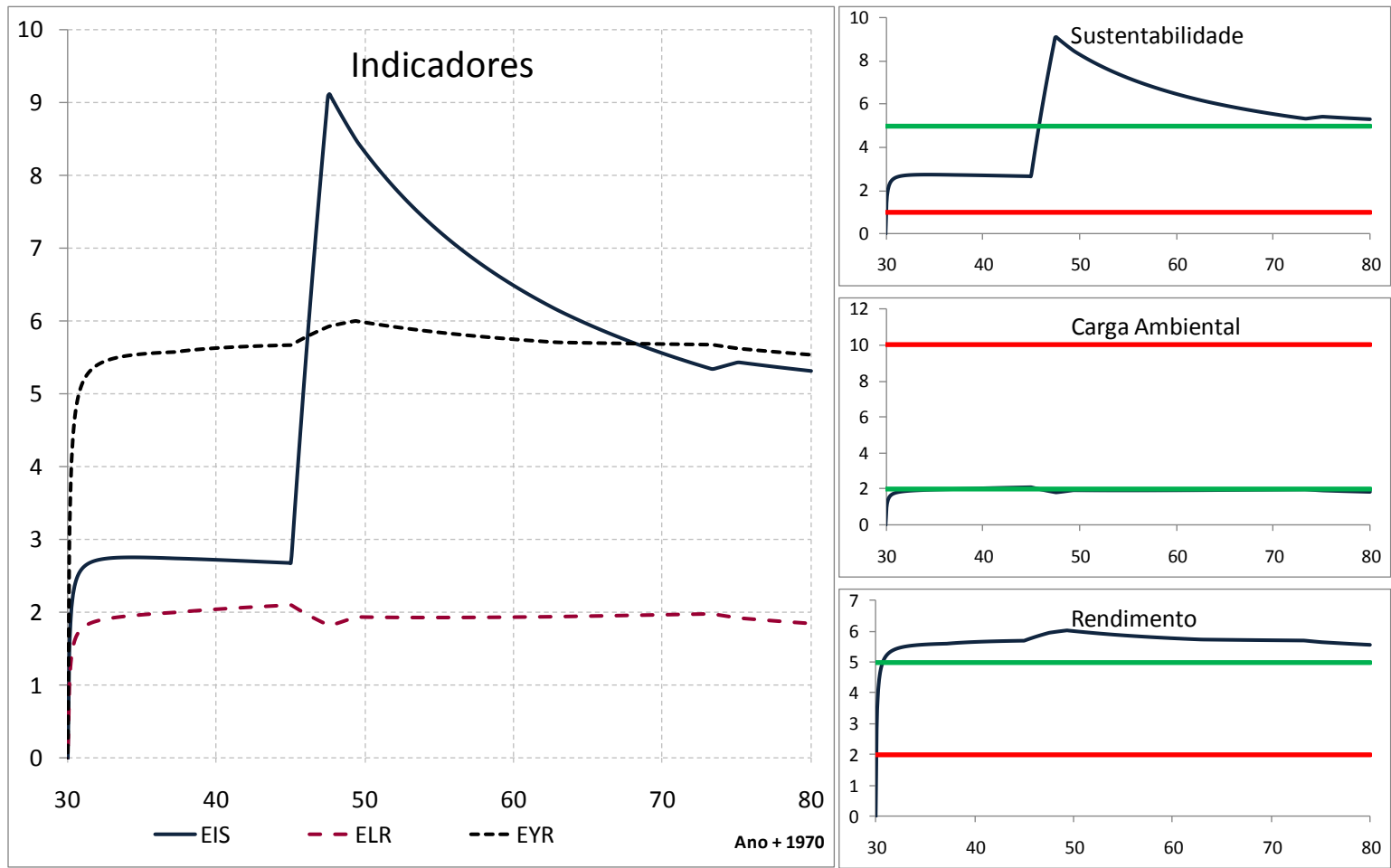

Figura B62 - Índices, perturbação na eólica, efeito floresta hídrica e produtos de cana (80 anos) 
ENERGIA NUCLEAR

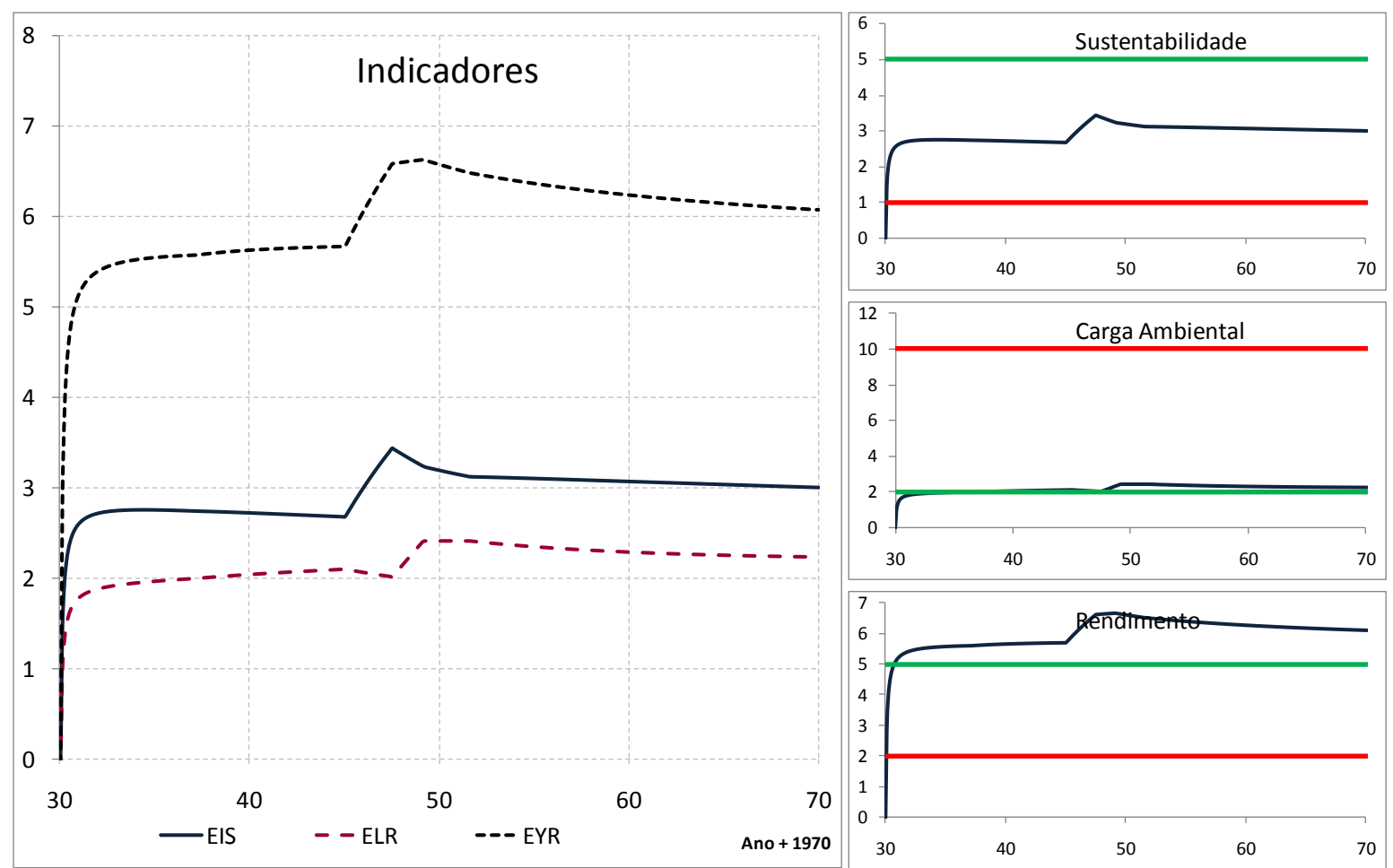

Figura B63 - Índices, perturbação na nuclear, efeito floresta hídrica e produtos de cana (70 anos)
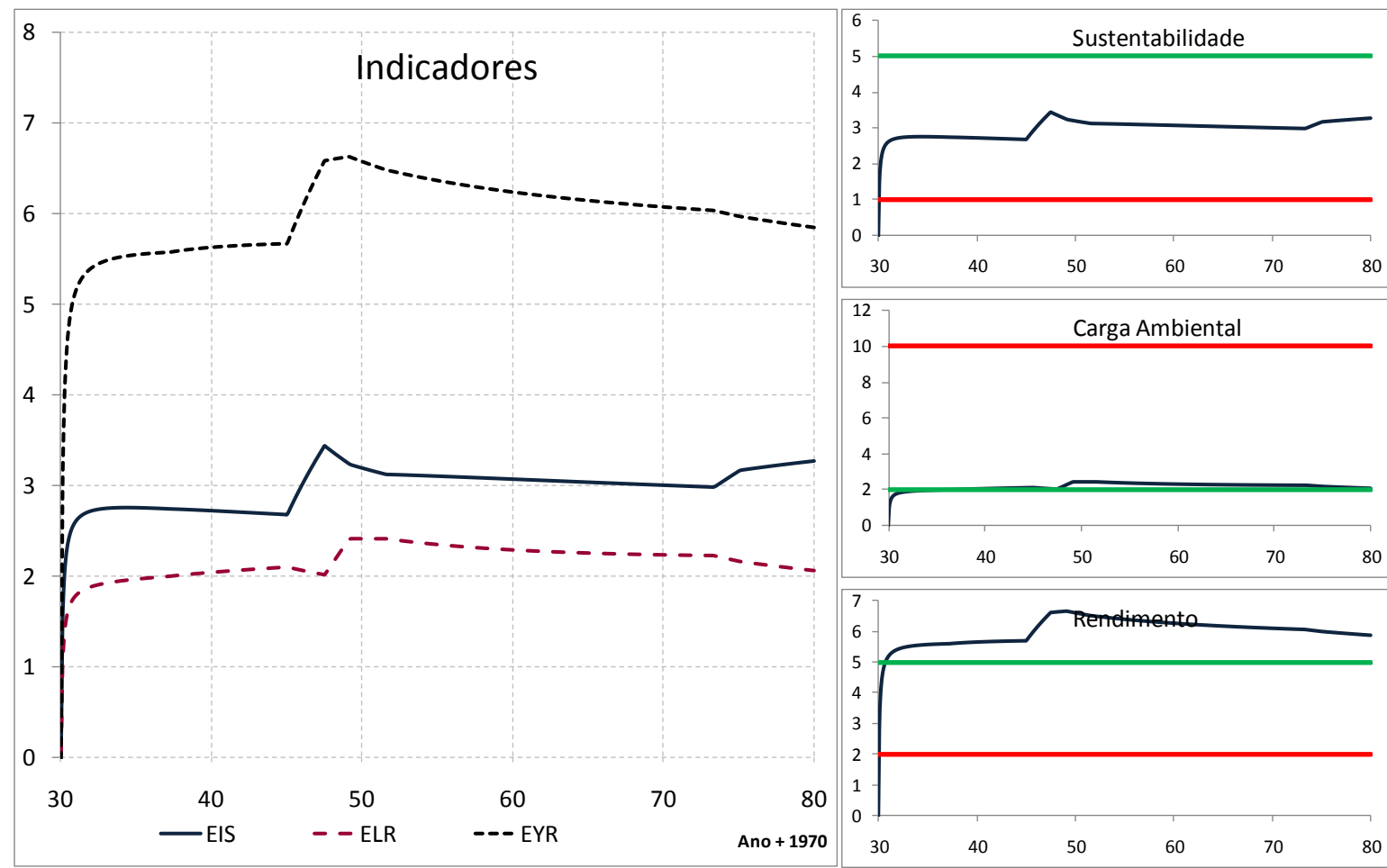

Figura B64 - Índices, perturbação na nuclear, efeito floresta hídrica e produtos de cana (80 anos) 


\title{
ANEXO A - Anexo E do capítulo 9 do BEN2005
}

\author{
ANEXO E: UNIDADES
}

\section{1 - UNIDADE BÁSICA ADOTADA}

Para expressar os fluxos que conformam balanços de energia deve-se adotar uma única unidade de medida na agregação das suas diversas variáveis.

A unidade básica adotada na composição do Balanço Energético Nacional - BEN é a "tonelada equivalente de petróleo - tep", uma vez que a mesma:

a) está relacionada diretamente com um energético importante;

b) expressa um valor físico;

Atenção: O BEN, a partir da edição de 2003, passou a adotar os critérios internacionais mais usuais para a conversão das unidades comerciais de energia em uma unidade comum de referência. Assim, (i) o petróleo de referência passou a ser o de $10000 \mathrm{kcal} / \mathrm{kg}$, (ii) todos os fatores de conversões passam a ser determinados com base nos poderes caloríficos inferiores das fontes de energia, e (iii) para a energia hidráulica e eletricidade passam a ser considerados os coeficientes de equivalência teórica, onde $1 \mathrm{kWh}=860$ kcal ( $1^{\circ}$ Princípio da Termodinâmica).

\section{2 - TRATAMENTO DAS UNIDADES POR PRODUTO}

\subsection{PETRÓLEO E DERIVADOS, GÁS NATURAL, ÁLCOOL E XISTO}

A PETROBRAS, por meio dos setores de controle de qualidade das suas refinarias de petróleo e do Centro de Pesquisas Leopoldo Américo Miguez de Mello - CENPES, mantém atualizadas as características físico-químicas de todos os seus produtos, estabelecendo ao final de cada ano, coeficientes médios para cada um. Dessa forma, são apresentados no balanço as massas específicas e poderes caloríficos inferiores observados em cada ano.

\subsection{CARVÃO VAPOR}

O carvão vapor nacional é produzido nas mais diversas formas quanto às suas características físicoquímicas, apresentando teores de cinzas de $20 \%$ até $54 \%$ e múltiplas variações de teores de enxofre, voláteis, carbono fixo e outros. A análise dos carvões é feita em algumas usinas de beneficiamento equipadas com laboratórios próprios, na Fundação de Ciência e Tecnologia - CIENTEC e no Centro de Tecnologia Mineral - CETEM.

Sua equivalência para tep é determinada a partir dos poderes caloríficos médios dos diversos tipos de carvões processados.

\subsection{CARVÃO METALÚRGICO}

a) Importado: adotado o poder calorífico fornecido pela Companhia Siderúrgica Nacional -CSN, que se situa dentro da faixa dos diversos carvões metalúrgicos importados.

b) Nacional: adotado o poder calorífico fornecido pela CSN.

\subsection{URÂNIO $-\cup_{3} \mathrm{O}_{8}$}

Adotado o coeficiente de equivalência informado pelas Indústrias Nucleares do Brasil.

\subsection{ENERGIA HIDRELÉTRICA E ELETRICIDADE}

O coeficiente de equivalência utilizado foi de 0,086 tep/MWh, decorrente de uma equivalência calórica de $860 \mathrm{kcal} / \mathrm{kWh}$. Este coeficiente foi determinado pela equivalência da energia potencial da água (energia mecânica) em calor.

\subsection{LENHA}

A unidade primária da lenha é o metro cúbico estereo $\left(\mathrm{m}^{3} \mathrm{st}\right)$. Para a lenha de uso residencial (vulgarmente 
identificada como "catada"), foi adotada densidade de $300 \mathrm{~kg} / \mathrm{m}^{3} \mathrm{st}$, valor médio identificado em pesquisa realizada pela Fundação Centro Tecnológico de Minas Gerais - CETEC em localidades do Estado de Minas Gerais.

Para a lenha comercial, foi utilizada a densidade de $390 \mathrm{~kg} / \mathrm{m}^{3} \mathrm{st}$, segundo dados fornecidos pela BRACELPA. A Nota Técnica COBEN 04/88, mencionada no item 5 do Anexo D, contém maiores detalhes sobre $O$ assunto.

\subsection{PRODUTOS DA CANA-DE-AÇÚCAR}

O conteúdo calórico da cana-de-açúcar, considerando os seus componentes (sacarose, fibras, água e outros),é de, aproximadamente, $1060 \mathrm{kcal} / \mathrm{kg}$. Retirando desta quantidade a energia contida nas fibras (bagaço), o poder calorífico para o caldo de cana alcança cerca de $620 \mathrm{kcal} / \mathrm{kg}$. Quanto ao melaço, com cerca de $55 \%$ de açúcares redutores em peso e capaz de produzir em torno de 350 litros de álcool/t, chega-se a um valor próximo de $1.930 \mathrm{kcal} / \mathrm{kg}$. Para o bagaço de cana foi utilizado o poder calorífico calculado experimentalmente pelo antigo Instituto do Açúcar e do Álcool -IAA.

\subsection{OUTRAS FONTES PRIMÁRIAS}

Incluem-se neste item resíduos vegetais e industriais utilizados para geração de calor e vapor. A equivalência para tep foi estabelecida a partir de poderes caloríficos médios estimados. Para a lixívia, foi empregado o poder calorífico adotado pela BRACELPA.

\subsection{GÁS CANALIZADO E DE COQUERIA}

Foram adotados os poderes caloríficos utilizados pela Companhia Estadual de Gás do Rio de Janeiro - CEG e pela Companhia Estadual de Gás de São Paulo - COMGAS.

\subsection{COQUE DE CARVÃO MINERAL}

Foi utilizado o poder calorífico obtido teoricamente com o emprego da Equação de Dulong, a partir da análise química de uma amostragem média de coque.

\subsection{URÂNIO CONTIDO NO UO,}

Foi empregado o coeficiente de equivalência adotado pelas Indústrias Nucleares do Brasil.

\subsection{CARVÃO VEGETAL} e Acesita.

O poder calorífico empregado foi de pesquisas efetuadas nas Companhias Siderúrgicas Belgo Mineira TABELA E.1: RELAÇÕES ENTRE UNIDADES

\begin{tabular}{|c|c|c|}
\hline EXPONENCIAIS & EQUIVALÊNCIAS & RELAÇÕES PRÁTICAS \\
\hline (k) kilo $=10^{3}$ & $1 \mathrm{~m}^{\mathrm{s}}=6,28981$ barris & \\
\hline (M) $\operatorname{mega}=10^{6}$ & 1 barril $=0,158987 \mathrm{~m}^{\mathrm{s}}$ & 1 tep ano $=7,2$ bep ano \\
\hline (G) giga $=10^{\circ}$ & 1 joule $=0,239$ cal & 1 bep ano $=0,14$ tep ano \\
\hline (P) peto $=10^{15}$ & $1 \mathrm{~m}^{3}$ de petróleo $=0,872 \uparrow(\mathrm{em} \mathrm{1994)}$ & 1 bep dia $=50$ tep ano \\
\hline (E) $\mathrm{exo}=10^{18}$ & 1 tep $=10000 \mathrm{Mcal}$ & \\
\hline
\end{tabular}

TABELA E.2 - COEFICIENTES DE EQUIVALÊNICA CALÓRICA

\begin{tabular}{|c|c|c|c|c|c|c|}
\hline $\begin{array}{l}\text { Multiplicar por } \\
\text { Unidade Fisica }\end{array}$ & $\begin{array}{c}\text { Olèo } \\
\text { Combustivel }\left(m^{3}\right)\end{array}$ & $\begin{array}{l}\text { Gás } \\
\text { Natural } \\
\text { Seco } \\
\left(\mathrm{mil} \mathrm{m} \mathrm{m}^{3}\right)\end{array}$ & $\begin{array}{l}\text { Carvão } \\
\text { Mineral } \\
5200 \\
(t)\end{array}$ & $\begin{array}{l}\text { GLP } \\
\left(\mathrm{m}^{3}\right)\end{array}$ & Lenha & Carvão Vegetal \\
\hline Óleo Combustível $\left(\mathrm{m}^{3}\right)$ & 1,00 & 1,09 & 1,94 & 1,56 & 3,06 & 1,48 \\
\hline Gás Natural Seco (mil ms) & 0,92 & 1,00 & 1,78 & 1,43 & 2,80 & 1,36 \\
\hline Carvõo Mineral 5200 (t) & 0,52 & 0,56 & 1,00 & 0,80 & 1,58 & 0,76 \\
\hline $\operatorname{GLP}\left(m^{s}\right)$ & 0,64 & 0,70 & 1,25 & 1,00 & 1,97 & 0,95 \\
\hline Lenha (t) & 0,33 & 0,36 & 0,63 & 0,51 & 1,00 & 0,49 \\
\hline Carvõo Vegetal (t) & 0,67 & 0,73 & 1,31 & 1,05 & 2,06 & 1,00 \\
\hline
\end{tabular}


TABELA E.3 - FATORES DE CONVERSÃO PARA MASSA

\begin{tabular}{|c|c|c|c|c|c|}
\hline Multiplicar por & kg & $t$ & tl & tc & lb \\
\hline quilograma (kg) & 1,0 & 0,001 & 0,000984 & 0,001102 & 2,2046 \\
\hline tonelados métricos (t) & 1000,0 & 1,0 & 0,984 & 1,1023 & 2204,6 \\
\hline tonelados longas (tt) & 1016,0 & 1,016 & 1,0 & 1,120 & 2240,0 \\
\hline toneladas curtas (tc) & 907,2 & 0,9072 & 0,893 & 1,0 & 2000,0 \\
\hline libros (lb) & 0,454 & 0,000454 & 0,000446 & 0,0005 & 1,0 \\
\hline
\end{tabular}

TABELA E.4 - FATORES DE CONVERSÃO PARA VOLUME

\begin{tabular}{|c|c|c|c|c|c|c|}
\hline Multiplicar por & $\mathrm{m}^{3}$ & I & gal (EUA) & gal (RU) & bы & $\mathbf{p e}^{3}$ \\
\hline litros (I) & 0,001 & 1,0 & 0,2642 & 0,22 & 0,0063 & 0,0353 \\
\hline galöes (EUA) & 0,0038 & 3,785 & 1,0 & 0,8327 & 0,02381 & 0,1337 \\
\hline barris (bbl) & 0,159 & 159,0 & 42,0 & 34,97 & 1,0 & 5,615 \\
\hline pés cúbicos (pế) & 0,0283 & 28,3 & 7,48 & 6,229 & 0,1781 & 1,0 \\
\hline
\end{tabular}

TABELA E.5 - FATORES DE CONVERSÃO PARA ENERGIA

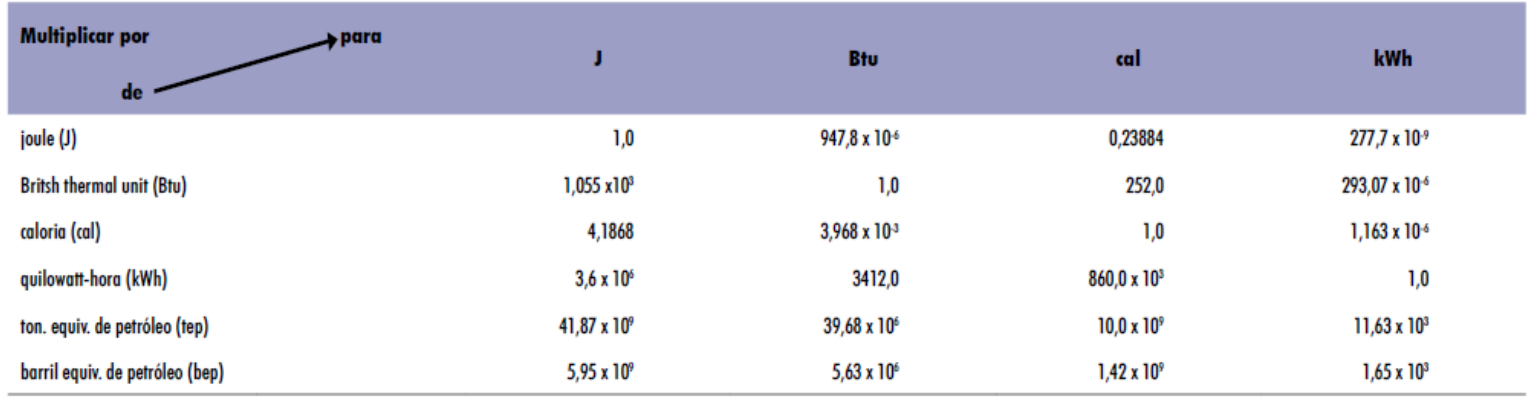

TABELA E.6 - COEFICIENTES DE EQUIVALÊNCIA MÉDIOS PARA OS COMBUSTIVVEIS GASOSOS

\begin{tabular}{|c|c|c|c|c|c|c|c|}
\hline $\begin{array}{l}\text { Multiplicar por } \\
\text { de } 1000 \mathrm{~m}\end{array}$ & giga-caloria & $\begin{array}{c}\text { tonelada } \\
\text { equivalente de } \\
\text { petrobleo (10000 } \\
\text { kcal } / \mathbf{k g})\end{array}$ & $\begin{array}{c}\text { baril } \\
\text { equivalente de } \\
\text { petroleo }\end{array}$ & $\begin{array}{l}\text { tonelada } \\
\text { equivalente de } \\
\text { carvão mineral } \\
(7000 \mathrm{kcal} / \mathrm{kg})\end{array}$ & giga-joule & milhöes Btu & $\begin{array}{l}\text { megawatt-hora } \\
(860 \mathrm{kcal} / \mathrm{kWh})\end{array}$ \\
\hline Gás Natural Úmido & 9,93 & 0,993 & 6,99 & 1,419 & 41,58 & 39,40 & 11,55 \\
\hline Gás de Coqueria & 4,30 & 0,430 & 3,03 & 0,614 & 18,00 & 17,06 & 5,00 \\
\hline Gás Conalizado Rio de Janeiro & 3,80 & 0,380 & 2,68 & 0,543 & 15,91 & 15,08 & 4,42 \\
\hline Gás Canalizado Sõo Paulo & 4,50 & 0,450 & 3,17 & 0,643 & 18,84 & 17,86 & 5,23 \\
\hline
\end{tabular}


TABELA E.7 - COEFICIENTES DE EQUIVALENCIA MEDIOS PARA OS COMBUSTIVEIS LIQUIDOS

\begin{tabular}{|c|c|c|c|c|c|c|c|}
\hline $\begin{array}{l}\text { Mulfiplicar por } \\
\qquad \text { de } \mathrm{m}^{3}\end{array}$ & giga-caloria & $\begin{array}{c}\text { tonelada } \\
\text { equivalente de } \\
\text { petróleo (10000 } \\
\text { kcal } / \mathrm{kg})\end{array}$ & $\begin{array}{c}\text { baril } \\
\text { equivalente de } \\
\text { petroleo }\end{array}$ & $\begin{array}{l}\text { tonelada } \\
\text { equivalente de } \\
\text { carvão mineral } \\
\text { (7000 kcal } / \mathrm{kg})\end{array}$ & giga-joule & milhöes Btu & $\begin{array}{l}\text { megawatt-hora } \\
\text { (860 kcal/kWh) }\end{array}$ \\
\hline Petroléo & 8,90 & 0,890 & 6,27 & 1,271 & 37,25 & 35,30 & 10,35 \\
\hline Óleo Diesel & 8,48 & 0,848 & 5,97 & 1,212 & 35,52 & 33,66 & 9,87 \\
\hline Gasolina Automotiva & 7,70 & 0,770 & 5,42 & 1,099 & 32,22 & 30,54 & 8,95 \\
\hline Gasolina de Aviação & 7,63 & 0,763 & 5,37 & 1,090 & 31,95 & 30,28 & 8,88 \\
\hline Gás Linquefeito de Petróleo & 6,11 & 0,611 & 4,30 & 0,872 & 25,56 & 24,22 & 7,10 \\
\hline Nafta & 7,65 & 0,765 & 5,39 & 1,093 & 32,05 & 30,37 & 8,90 \\
\hline Álcool Etilico Hidratado & 5,01 & 0,510 & 3,59 & 0,728 & 21,34 & 20,22 & 5,93 \\
\hline Gás de Refinaria & 6,55 & 0,655 & 4,61 & 0,936 & 27,43 & 26,00 & 7,62 \\
\hline Coque de Petróleo & 8,73 & 0,873 & 6,15 & 1,247 & 36,53 & 34,62 & 10,15 \\
\hline Outros Energéticos de Petróleo & 8,90 & 0,890 & 6,27 & 1,271 & 37,25 & 35,30 & 10,35 \\
\hline Asfaltos & 10,18 & 1,018 & 7,17 & 1,455 & 42,63 & 40,40 & 11,84 \\
\hline Lubrificantes & 8,91 & 0,891 & 6,27 & 1,272 & 37,29 & 35,34 & 10,36 \\
\hline Solventes & 7,81 & 0,781 & 5,50 & 1,115 & 32,69 & 30,98 & 9,08 \\
\hline Outros nõo Energ. de Petróleo & 8,90 & 0,890 & 6,27 & 1,271 & 37,25 & 35,30 & 10,35 \\
\hline
\end{tabular}

TABELA E.8 - COEFICIENTES DE EQUIVALÊNCIA MÉDIOS PARA OS COMBUSTIVEIS SÓLIDOS

\begin{tabular}{|c|c|c|c|c|c|c|c|}
\hline C. VAPOR $3100 \mathrm{KCAL} / \mathrm{KG}$ & 2,95 & 0,295 & 2,08 & 0,421 & 12,35 & 11,70 & 3,43 \\
\hline C. VAPOR $4200 \mathrm{KCAL} / \mathrm{KG}$ & 4,00 & 0,400 & 2,82 & 0,571 & 16,75 & 15,87 & 4,65 \\
\hline C. VAPOR $4500 \mathrm{KCAL} / \mathrm{KG}$ & 4,25 & 0,425 & 2,99 & 0,607 & 17,79 & 16,86 & 4,94 \\
\hline C. VAPOR $4700 \mathrm{KCAL} / \mathrm{KG}$ & 4,45 & 0,445 & 3,13 & 0,636 & 18,63 & 17,66 & 5,18 \\
\hline C. VAPOR $5200 \mathrm{KCAL} / \mathrm{KG}$ & 4,90 & 0,490 & 3,45 & 0,700 & 20,52 & 19,44 & 5,70 \\
\hline CARVÃO METALÚRGICO NACIONAL & 6,42 & 0,642 & 4,52 & 0,917 & 26,88 & 25,47 & 7,47 \\
\hline CARVÃO METALÚRGICO IMPORTADO & 7,40 & 0,740 & 5,21 & 1,057 & 30,98 & 29,36 & 8,61 \\
\hline LENHA & 3,10 & 0,310 & 2,18 & 0,443 & 12,98 & 12,30 & 3,61 \\
\hline CALDO DE CANA & 0,62 & 0,062 & 0,44 & 0,089 & 2,61 & 2,47 & 0,72 \\
\hline MELAÇO & 1,85 & 0,185 & 1,30 & 0,264 & 7,75 & 7,34 & 2,15 \\
\hline BAGAÇO DE CANA & 2,13 & 0,213 & 1,50 & 0,304 & 8,92 & 8,45 & 2,48 \\
\hline LIXIVIA & 2,86 & 0,286 & 2,01 & 0,409 & 11,97 & 11,35 & 3,33 \\
\hline COQUE DE CARVÃO MINERAL & 6,90 & 0,690 & 4,86 & 0,986 & 28,89 & 27,38 & 8,02 \\
\hline CARVÃO VEGETAL & 6,46 & 0,646 & 4,55 & 0,923 & 27,05 & 25,63 & 7,51 \\
\hline
\end{tabular}


TABELA E.9: DENSIDADES E PODERES CALORÍFICOS INFERIORES - 2004

\begin{tabular}{|c|c|c|}
\hline FONTES & $\begin{array}{l}\text { DENSIDADE } \\
\mathbf{k g} / \mathrm{m}^{3} \\
\text { (1) }\end{array}$ & $\begin{array}{c}\text { PODER } \\
\text { CALORIFICO } \\
\text { INFERIOR } \\
\mathbf{k c a l} / \mathbf{k g}\end{array}$ \\
\hline PETRÓLEO & 874 & 10200 \\
\hline GÁS NATURAL ÚMIDO (2) & - & 9930 \\
\hline GÁS NATURAL SECO (2) & - & 8800 \\
\hline CARVÃO VAPOR $3100 \mathrm{KCAL} / \mathrm{KG}$ & - & 2950 \\
\hline CARVÃO VAPOR $3300 \mathrm{KCAL} / \mathrm{KG}$ & - & 3100 \\
\hline CARVÃO VAPOR $3700 \mathrm{KCAL} / \mathrm{KG}$ & - & 3500 \\
\hline CARVÃO VAPOR $4200 \mathrm{KCAL} / \mathrm{KG}$ & - & 4000 \\
\hline CARVÃO VAPOR 4500 KCAL/KG & - & 4250 \\
\hline CARVÃO VAPOR $4700 \mathrm{KCAL} / \mathrm{KG}$ & - & 4450 \\
\hline CARVÃO VAPOR $5200 \mathrm{KCAL} / \mathrm{KG}$ & - & 4900 \\
\hline CARVÃO VAPOR $5900 \mathrm{KCAL} / \mathrm{KG}$ & - & 5600 \\
\hline CARVÃO VAPOR $6000 \mathrm{KCAL} / \mathrm{KG}$ & - & 5700 \\
\hline CARVÃO VAPOR SEM ESPECIFICAÇÃO & - & 2850 \\
\hline CARVÃO METALÚRGICO NACIONAL & - & 6420 \\
\hline CARVÃO METALÚRGICO IMPORTADO & - & 7400 \\
\hline ENERGIA HIDRÁULICA (3) & - & 860 \\
\hline LENHA CATADA & 300 & 3100 \\
\hline LENHA COMERCIAL & 390 & 3100 \\
\hline CALDO DE CANA & - & 623 \\
\hline MELAÇO & - & 1850 \\
\hline BAGAÇO DE CANA (4) & - & 2130 \\
\hline LXXIVIA & - & 2860 \\
\hline ÓLEO DIESEL & 840 & 10100 \\
\hline $\begin{array}{ll}\text { (1) } & \text { A temperatura de } 20^{\circ} \mathrm{C} \text {, para } \\
\text { (2) } & \mathrm{kcol} / \mathrm{m} 3 \\
\text { (3) } & \mathrm{kcol} / \mathrm{kWh} \\
\text { (4) } & \text { Bagaço com 50\% de umidade } \\
\text { No } & \end{array}$ & s de petróleo e & \\
\hline
\end{tabular}

\begin{tabular}{|c|c|c|}
\hline FONTES & $\begin{array}{l}\text { DENSIDADE } \\
\mathbf{k g} / \mathbf{m}^{3} \\
\text { (1) }\end{array}$ & $\begin{array}{c}\text { PODER } \\
\text { CALORIFICO } \\
\text { INFERIOR } \\
\text { kcal/ } / \mathrm{kg}\end{array}$ \\
\hline ÓLEO COMBUSTÍVEL & 1000 & 9590 \\
\hline GASOLINA AUTOMOTIVA & 740 & 10400 \\
\hline GASOLINA DE AVIAÇÃ̃O & 720 & 10600 \\
\hline GÁS LIQUEFEITO DE PETRÓLEO & 550 & 11100 \\
\hline NAFTA & 720 & 10630 \\
\hline QUEROSENE ILUMINANTE & 790 & 10400 \\
\hline QUEROSENE DE AVĨ̃̃ & 790 & 10400 \\
\hline GÁS DE COQUERIA (2) & - & 4300 \\
\hline GÁS CANALIZADO RIO DE JANEIRO (2) & - & 3800 \\
\hline GÁS CANALIZADO SÃ̃ PAULO (2) & - & 4500 \\
\hline COQUE DE CARVÃO MINERAL & - & 6900 \\
\hline ELETRICIDADE (3) & - & 860 \\
\hline CARVÃO VEGETAL & 250 & 6460 \\
\hline ÁLCOOL ETÍLICO ANIDRO & 791 & 6750 \\
\hline ÁLCOOL ET́LICO HIDRATADO & 809 & 6300 \\
\hline GÁS DE REFINARIA & 780 & 8400 \\
\hline COQUE DE PETRÓLEO & 1041 & 8390 \\
\hline OUTROS ENERGÉTICOS DE PETRÓLEO & 872 & 10200 \\
\hline OUTRAS SECUNDÁRIAS - ALCATRÃ0 & - & 8550 \\
\hline ASFALTOS & 1040 & 9790 \\
\hline LUBRIFICANTES & 880 & 10120 \\
\hline SOLVENTES & 740 & 10550 \\
\hline OUTROS NÃO-ENERGÉTICOS DE PETRÓLEO & 873 & 10200 \\
\hline
\end{tabular}


TABELA E.10: FATORES DE CONVERSÄO PARA tep MEDIO

\begin{tabular}{|c|c|c|c|c|c|c|c|c|c|c|c|c|c|c|c|c|c|}
\hline FONTES & UNIDADE & 1888 & 1889 & 1990 & 1991 & 1992 & 1993 & 1994 & 1995 & 1996 & 1997 & 1998 & 1999 & 2000 & 2001 & 2002 & 2003 \\
\hline GÁS NATURAL ÚMIDO & $10^{3} \mathrm{~m}^{3}$ & 0,993 & 0,993 & 0,993 & 0,993 & 0,993 & 0,993 & 0,993 & 0,993 & 0,993 & 0,993 & 0,993 & 0,993 & 0,993 & 0,993 & 0,993 & 0,993 \\
\hline CARVÃO VAPOR $3100 \mathrm{kcol} / \mathrm{kg}$ & $t$ & 0,295 & 0,295 & 0,295 & 0,295 & 0,295 & 0,295 & 0,295 & 0,295 & 0,295 & 0,295 & 0,295 & 0,295 & 0,295 & 0,295 & 0,295 & 0,295 \\
\hline CARVÃO VAPOR $3300 \mathrm{kcol} / \mathrm{kg}$ & $t$ & 0,310 & 0,310 & 0,310 & 0,310 & 0,310 & 0,310 & 0,310 & 0,310 & 0,310 & 0,310 & 0,310 & 0,310 & 0,310 & 0,310 & 0,310 & 0,310 \\
\hline CARVÃo VAPOR $4200 \mathrm{kcol} / \mathrm{kg}$ & $t$ & 0,400 & 0,400 & 0,400 & 0,400 & 0,400 & 0,400 & 0,400 & 0,400 & 0,400 & 0,400 & 0,400 & 0,400 & 0,400 & 0,400 & 0,400 & 0,400 \\
\hline CARVÃ0 VAPOR $4500 \mathrm{kcol} / \mathrm{kg}$ & $t$ & 0,425 & 0,425 & 0,425 & 0,425 & 0,425 & 0,425 & 0,425 & 0,425 & 0,425 & 0,425 & 0,425 & 0,425 & 0,425 & 0,425 & 0,425 & 0,425 \\
\hline CARVÃO VAPOR $4700 \mathrm{kcol} / \mathrm{kg}$ & $t$ & 0,445 & 0,445 & 0,445 & 0,445 & 0,445 & 0,445 & 0,445 & 0,445 & 0,445 & 0,445 & 0,445 & 0,445 & 0,445 & 0,445 & 0,445 & 0,445 \\
\hline CARVÃO VAPOR $5200 \mathrm{kcol} / \mathrm{kg}$ & $t$ & 0,490 & 0,490 & 0,490 & 0,490 & 0,490 & 0,490 & 0,490 & 0,490 & 0,490 & 0,490 & 0,490 & 0,490 & 0,490 & 0,490 & 0,490 & 0,490 \\
\hline CARVÃO METALÚRGICO NACIONAL & $t$ & 0,642 & 0,642 & 0,642 & 0,642 & 0,642 & 0,642 & 0,642 & 0,642 & 0,642 & 0,642 & 0,642 & 0,642 & 0,642 & 0,642 & 0,642 & 0,642 \\
\hline CARVÃ̃ METALÚRGICO IMPORTADO & $t$ & 0,740 & 0,740 & 0,740 & 0,740 & 0,740 & 0,740 & 0,740 & 0,740 & 0,740 & 0,740 & 0,740 & 0,740 & 0,740 & 0,740 & 0,740 & 0,740 \\
\hline URÂNI0 U308 & $\mathrm{kg}$ & 10,139 & 10,139 & 10,139 & 10,139 & 10,139 & 10,139 & 10,139 & 10,139 & 10,139 & 10,139 & 10,139 & 10,139 & 10,139 & 10,139 & 10,139 & 10,139 \\
\hline OUTRAS RENOVÁVEIS & tep & 1,000 & 1,000 & 1,000 & 1,000 & 1,000 & 1,000 & 1,000 & 1,000 & 1,000 & 1,000 & 1,000 & 1,000 & 1,000 & 1,000 & 1,000 & 1,000 \\
\hline HIDRÁULICA & MWh & 0,086 & 0,086 & 0,086 & 0,086 & 0,086 & 0,086 & 0,086 & 0,086 & 0,086 & 0,086 & 0,086 & 0,086 & 0,086 & 0,086 & 0,086 & 0,086 \\
\hline LENHA COMERCIAL & $t$ & 0,310 & 0,310 & 0,310 & 0,310 & 0,310 & 0,310 & 0,310 & 0,310 & 0,310 & 0,310 & 0,310 & 0,310 & 0,310 & 0,310 & 0,310 & 0,310 \\
\hline CALDO DE CANA & $t$ & 0,060 & 0,060 & 0,060 & 0,060 & 0,060 & 0,060 & 0,060 & 0,060 & 0,060 & 0,060 & 0,060 & 0,060 & 0,061 & 0,062 & 0,062 & 0,062 \\
\hline MELAÇO & $t$ & 0,180 & 0,180 & 0,180 & 0,180 & 0,180 & 0,180 & 0,180 & 0,180 & 0,180 & 0,180 & 0,180 & 0,181 & 0,183 & 0,184 & 0,185 & 0,185 \\
\hline GASOLINA DE AVIAÇ̧̃̃O & $\mathrm{m}^{3}$ & 0,763 & 0,746 & 0,770 & 0,770 & 0,770 & 0,770 & 0,770 & 0,770 & 0,770 & 0,770 & 0,763 & 0,763 & 0,763 & 0,763 & 0,763 & 0,763 \\
\hline GÁS LIQUEFEITO DE PETRÓLEO & $m^{3}$ & 0,616 & 0,618 & 0,616 & 0,616 & 0,616 & 0,616 & 0,616 & 0,616 & 0,616 & 0,616 & 0,613 & 0,613 & 0,612 & 0,611 & 0,611 & 0,611 \\
\hline NAFTA & $\mathrm{m}^{3}$ & 0,754 & 0,763 & 0,763 & 0,763 & 0,763 & 0,763 & 0,763 & 0,763 & 0,763 & 0,769 & 0,769 & 0,765 & 0,765 & 0,765 & 0,765 & 0,765 \\
\hline QUEROSENE ILUMINANTE & $\mathrm{m}^{3}$ & 0,821 & 0,825 & 0,832 & 0,832 & 0,832 & 0,832 & 0,832 & 0,832 & 0,832 & 0,832 & 0,826 & 0,822 & 0,822 & 0,822 & 0,822 & 0,822 \\
\hline QUEROSENE DE AVIAÇÃO & $m^{3}$ & 0,823 & 0,829 & 0,833 & 0,833 & 0,833 & 0,833 & 0,833 & 0,833 & 0,833 & 0,833 & 0,826 & 0,822 & 0,822 & 0,822 & 0,822 & 0,822 \\
\hline GÁS DE COQUERIA & $10^{3} \mathrm{~m}^{3}$ & 0,430 & 0,430 & 0,430 & 0,430 & 0,430 & 0,430 & 0,430 & 0,430 & 0,430 & 0,430 & 0,430 & 0,430 & 0,430 & 0,430 & 0,430 & 0,430 \\
\hline GÁS CANALIZADO RIO DE JANEIRO & $10^{3} \mathrm{~m}^{9}$ & 0,380 & 0,380 & 0,380 & 0,380 & 0,380 & 0,380 & 0,380 & 0,380 & 0,380 & 0,380 & 0,380 & 0,380 & 0,380 & 0,380 & 0,380 & 0,380 \\
\hline GÁS CANALIZADO SÃO PAULO & $10^{3} \mathrm{~m}^{3}$ & 0,450 & 0,450 & 0,450 & 0,450 & 0,450 & 0,450 & 0,450 & 0,450 & 0,450 & 0,450 & 0,450 & 0,450 & 0,450 & 0,450 & 0,450 & 0,450 \\
\hline COQUE DE CARVÃO MINERAL & $t$ & 0,690 & 0,690 & 0,690 & 0,690 & 0,690 & 0,690 & 0,690 & 0,690 & 0,690 & 0,690 & 0,690 & 0,690 & 0,690 & 0,690 & 0,690 & 0,690 \\
\hline URÂNI0 CONTIDO NO U02 & $\mathrm{kg}$ & 73,908 & 73,908 & 73,908 & 73,908 & 73,908 & 73,908 & 73,908 & 73,908 & 73,908 & 73,908 & 73,908 & 73,908 & 73,908 & 73,908 & 73,908 & 73,908 \\
\hline ELETRICIDADE & MWh & 0,086 & 0,086 & 0,086 & 0,086 & 0,086 & 0,086 & 0,086 & 0,086 & 0,086 & 0,086 & 0,086 & 0,086 & 0,086 & 0,086 & 0,086 & 0,086 \\
\hline CARVÃO VEGETAL & $\dagger$ & 0,646 & 0,646 & 0,646 & 0,646 & 0,646 & 0,646 & 0,646 & 0,646 & 0,646 & 0,646 & 0,646 & 0,646 & 0,646 & 0,646 & 0,646 & 0,646 \\
\hline ÁLCOOL ETÍLICO ANIDRO & $m^{3}$ & 0,534 & 0,534 & 0,534 & 0,534 & 0,534 & 0,534 & 0,534 & 0,534 & 0,534 & 0,534 & 0,534 & 0,534 & 0,534 & 0,534 & 0,534 & 0,534 \\
\hline ÁLCOOL ETILICO HIDRATADO & $\mathrm{m}^{3}$ & 0,510 & 0,510 & 0,510 & 0,510 & 0,510 & 0,510 & 0,510 & 0,510 & 0,510 & 0,510 & 0,510 & 0,510 & 0,510 & 0,510 & 0,510 & 0,510 \\
\hline GÁS DE REFINARIA & $m^{3}$ & 0,655 & 0,655 & 0,655 & 0,655 & 0,655 & 0,655 & 0,655 & 0,655 & 0,655 & 0,655 & 0,655 & 0,655 & 0,655 & 0,655 & 0,655 & 0,655 \\
\hline COQUE DE PETRÓLEO & $\mathrm{m}^{3}$ & 0,871 & 0,873 & 0,873 & 0,873 & 0,873 & 0,873 & 0,873 & 0,873 & 0,873 & 0,873 & 0,873 & 0,873 & 0,873 & 0,873 & 0,873 & 0,873 \\
\hline $\begin{array}{l}\text { OUTROS ENERGÉTICOS DE } \\
\text { PETRÓLEO }\end{array}$ & $m^{3}$ & 0,882 & 0,887 & 0,890 & 0,889 & 0,889 & 0,889 & 0,889 & 0,890 & 0,889 & 0,893 & 0,893 & 0,886 & 0,889 & 0,890 & 0,890 & 0,890 \\
\hline
\end{tabular}




\section{ANEXO B - Cálculos das Componentes Emergéticas}

Table 1

Emergy flows in a geothermal electricity production plant. (data on a yearly basis. Plant Cornia 2, sited at Castelnuovo V.C., Pisa, Italy)

\begin{tabular}{|c|c|c|c|c|c|}
\hline Item & Unit & Amount & $\begin{array}{l}\text { Solar transformity } \\
\text { (sej/unit) }\end{array}$ & $\begin{array}{l}\text { Ref. for } \\
\text { transf. }^{\text {a }}\end{array}$ & Solar emergy \\
\hline
\end{tabular}

Items 19, 21, 22 and 23 are free renewable. All other input flows are nonrenewable.

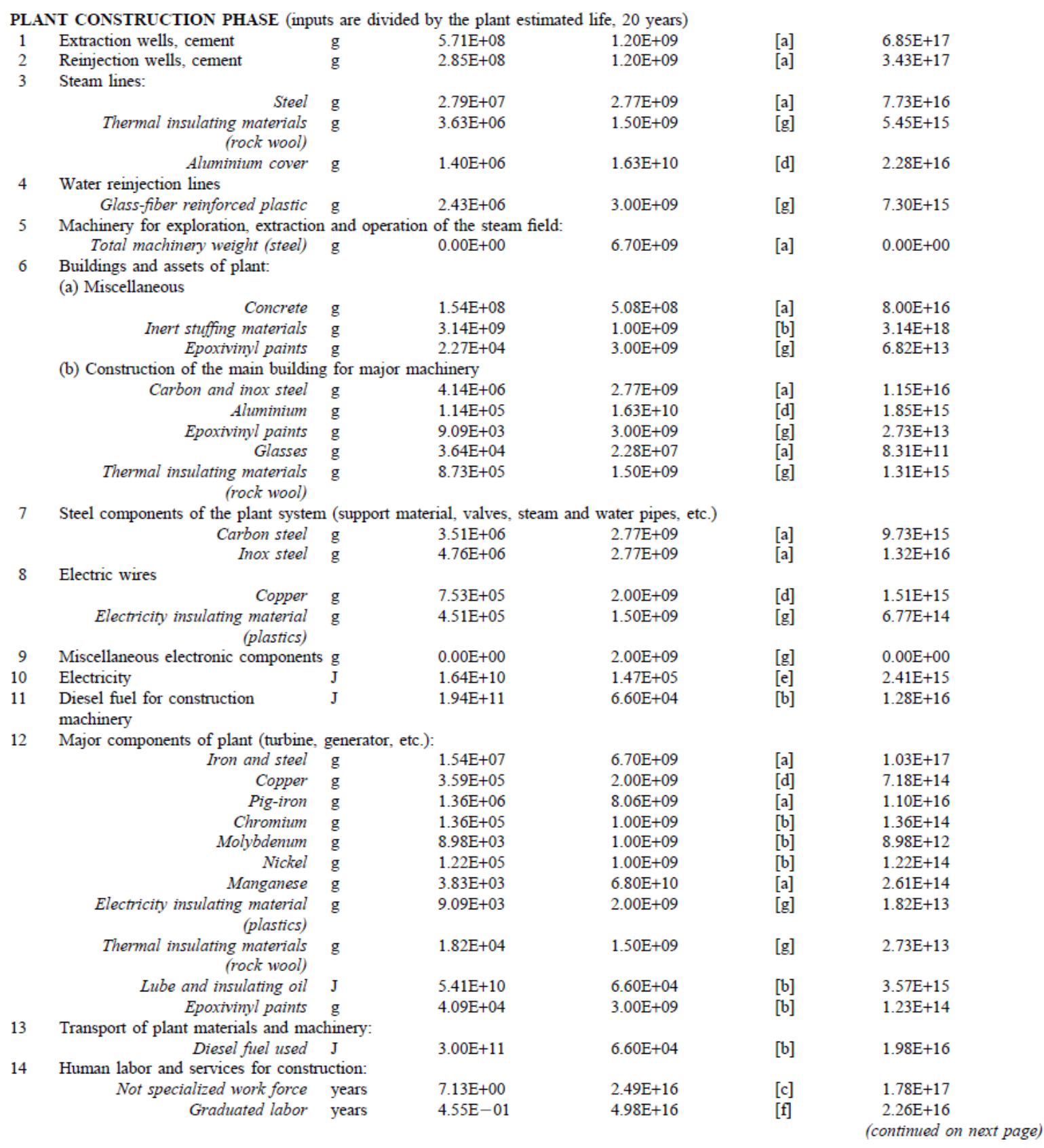


Table 1 (contimued)

\begin{tabular}{|c|c|c|c|c|c|c|}
\hline$\#$ & Item & Unit & Amount & $\begin{array}{l}\text { Solar transformity } \\
\text { (sej/unit) }\end{array}$ & $\begin{array}{l}\text { Ref. for } \\
\text { transf.[a] }\end{array}$ & Solar emergy \\
\hline \multicolumn{7}{|c|}{$\begin{array}{l}\text { PLANT OPERATING PHASE (inputs are } \\
\text { calculated on an annual basis) }\end{array}$} \\
\hline 15 & Annual electricity input & $\mathrm{J}$ & $2.53 \mathrm{E}+13$ & $1.47 \mathrm{E}+05$ & {$[e]$} & $3.73 \mathrm{E}+18$ \\
\hline \multirow[t]{5}{*}{16} & Human labor and services: & & & & & \\
\hline & Graduated & $\mathrm{J}$ & $2.60 \mathrm{E}-01$ & $4.98 \mathrm{E}+16$ & {$[\mathrm{f}]$} & $1.30 \mathrm{E}+16$ \\
\hline & Technical and administrative & $\mathrm{J}$ & $1.20 \mathrm{E}+00$ & $2.49 \mathrm{E}+16$ & {$[\mathrm{c}]$} & $2.98 \mathrm{E}+16$ \\
\hline & Not specialized & $\mathrm{J}$ & 4.17E+00 & $2.49 \mathrm{E}+16$ & [c] & $1.04 \mathrm{E}+17$ \\
\hline & Other technical services & $\mathrm{J}$ & $5.21 \mathrm{E}+01$ & $2.49 \mathrm{E}+16$ & [c] & $1.30 \mathrm{E}+18$ \\
\hline \multirow[t]{6}{*}{17} & Maintenance materials & & & & & \\
\hline & Lube oil & $\mathrm{J}$ & $4.61 \mathrm{E}+10$ & $6.60 \mathrm{E}+04$ & [b] & $3.04 \mathrm{E}+15$ \\
\hline & Epoxivinyl paints & $\mathrm{g}$ & $5.00 \mathrm{E}+05$ & $3.00 \mathrm{E}+09$ & {$[\mathrm{~b}]$} & $1.50 \mathrm{E}+15$ \\
\hline & Steel & $\mathrm{g}$ & $8.00 \mathrm{E}+05$ & $2.77 \mathrm{E}+09$ & [a] & $2.22 \mathrm{E}+15$ \\
\hline & Alumimum & $\begin{array}{l}5 \\
g\end{array}$ & $3.00 \mathrm{E}+05$ & $1.63 \mathrm{E}+10$ & [d] & $4.89 \mathrm{E}+15$ \\
\hline & $\begin{array}{r}\text { Thermal insulating materials } \\
\text { (rock wool) }\end{array}$ & $\mathrm{g}$ & $2.00 \mathrm{E}+05$ & $1.50 \mathrm{E}+09$ & {$[\mathrm{~g}]$} & $3.00 \mathrm{E}+14$ \\
\hline 18 & $\begin{array}{l}\text { Additional human services for plant } \\
\text { manufacture }\end{array}$ & US \$ & $5.92 \mathrm{E}+04$ & $1.81 \mathrm{E}+12$ & [i] & $1.07 \mathrm{E}+17$ \\
\hline \multicolumn{7}{|c|}{ ENVIRONMENTAL INPUTS (inputs are calculated on an annual basis) } \\
\hline 19 & Geothermal heat & $\mathrm{J}$ & $2.25 \mathrm{E}+15$ & $1.49 \mathrm{E}+04$ & {$[\mathrm{~h}]$} & $3.35 \mathrm{E}+19$ \\
\hline 20 & Underground water used up & $\mathrm{J}$ & $2.53 \mathrm{E}+12$ & $1.82 \mathrm{E}+06$ & [h] & $4.61 \mathrm{E}+18$ \\
\hline 21 & Cooling service at towers (wind) & $\mathrm{J}$ & $1.02 \mathrm{E}+14$ & $1.50 \mathrm{E}+03$ & {$[\mathrm{~b}]$} & $1.52 \mathrm{E}+17$ \\
\hline 22 & $\begin{array}{l}\text { Oxygen for combustion processes } \\
\text { occurring in the manufacture of } \\
\text { components }\left(^{*}\right)\end{array}$ & $\mathrm{g}$ & $1.22 \mathrm{E}+09$ & $5.16 \mathrm{E}+07$ & [i] & $6.32 \mathrm{E}+16$ \\
\hline \multicolumn{7}{|c|}{ INDIRECT ENVIRONMENTAL INPUTS (inputs are calculated on an annual basis) } \\
\hline 23 & $\begin{array}{l}\text { Dispersal of released chemicals } \\
\text { (wind) }(* *)\end{array}$ & $\mathrm{J}$ & $3.50 \mathrm{E}+13$ & $1.50 \mathrm{E}+03$ & [b] & $5.26 \mathrm{E}+16$ \\
\hline \multicolumn{7}{|c|}{ ANNUAL PRODUCTION OF ELECTRICITY } \\
\hline 24 & Electricity delivered & $\mathrm{J}$ & $3.28 \mathrm{E}+14$ & $1.47 \mathrm{E}+05$ & {$[\mathrm{~h}]$} & $4.83 \mathrm{E}+19$ \\
\hline
\end{tabular}

[a] Haukoos, 1995

[b] Odum, 1996

[c] Labor evaluation in the year 1995. [Ulgiati and Russi, unpublished report, University of Siena]

[d] Lapp, 1991

[e] Assumed the value resulting from this plant itself (item 24), by means of iterative calculations

[f] From [3], assuming that trained labor requires 2 more times emergy inflow than untrained.

[g] Our estimate.

[h] From calculation performed in this work

[i] Ulgiati and Tabacco, 2001

[i] Emergy intensity in the year 1995 (emergy/GNP, sej/Italian lira converted to seJ/US \$) [Ulgiati and Russi, unpublished report, University of Siena]

(*) Oil combustion releases $\mathrm{CO}_{2}$, but needs a free renewable input of oxygen from the environment. According to the reaction stoichiometry, with a theoretical $100 \%$ efficiency, an approximate amount of oxygen equal to $3.25 \mathrm{~g}$ is needed to react with one gram of fuel.

$(* *)$ Emergy associated with the environmental services for the dilution of combustion emissions down to their biosphere background concentration.

Fonte: Ulgiati e Brown (2002)

Table 2

Summary of the main emissions from the geothermal and fossil powered plants investigated ${ }^{\mathrm{a}}$

\begin{tabular}{|c|c|c|c|c|c|c|}
\hline & $\mathrm{CO}_{2}$ & $\begin{array}{l}\mathrm{SO}_{2} \\
\mathrm{~g} / \mathrm{yr}\end{array}$ & $\begin{array}{l}\mathrm{NO}_{\mathrm{s}} \\
\mathrm{g} / \mathrm{yr}\end{array}$ & $\begin{array}{l}\mathrm{CO} \\
\mathrm{g} / \mathrm{yr}\end{array}$ & $\begin{array}{l}\text { Unburnt } \\
\text { hydrocarbons } \\
\mathrm{g} / \mathrm{yr}\end{array}$ & $\begin{array}{l}\text { Ash } \\
\mathrm{g} / \mathrm{yr}\end{array}$ \\
\hline Methane, $171 \mathrm{MW}$ & $3.32 \mathrm{E}+11$ & $2.40 \mathrm{E}+06$ & $9.59 \mathrm{E}+08$ & $2.50 \mathrm{E}+02$ & $9.28 \mathrm{E}+07$ & $6.00 \mathrm{E}+04$ \\
\hline Coal, $1280 \mathrm{MW}$ & $7.47 \mathrm{E}+12$ & $3.85 \mathrm{E}+10$ & $2.54 \mathrm{E}+10$ & $1.49 \mathrm{E}+11$ & $9.26 \mathrm{E}+08$ & $2.19 E+09$ \\
\hline Oil, $1280 \mathrm{MW}$ & $5.99 \mathrm{E}+12$ & $3.42 \mathrm{E}+10$ & $7.33 \mathrm{E}+09$ & $7.56 \mathrm{E}+06$ & $3.78 \mathrm{E}+08$ & $1.82 \mathrm{E}+09$ \\
\hline
\end{tabular}

Indirect emissions from construction phase are not included

b Sulphur emissions as $\mathrm{H}_{2} \mathrm{~S}$ and hydrocarbon emissions as $\mathrm{CH}_{4}$. 


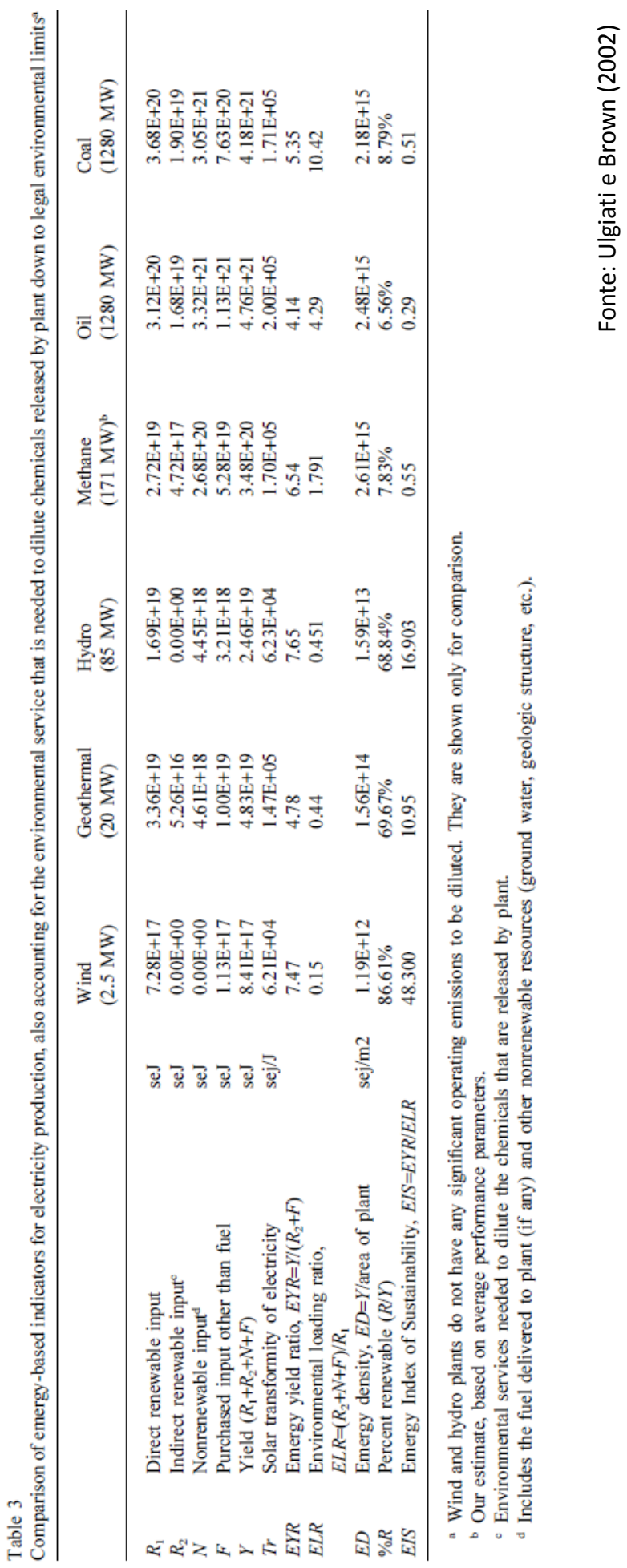




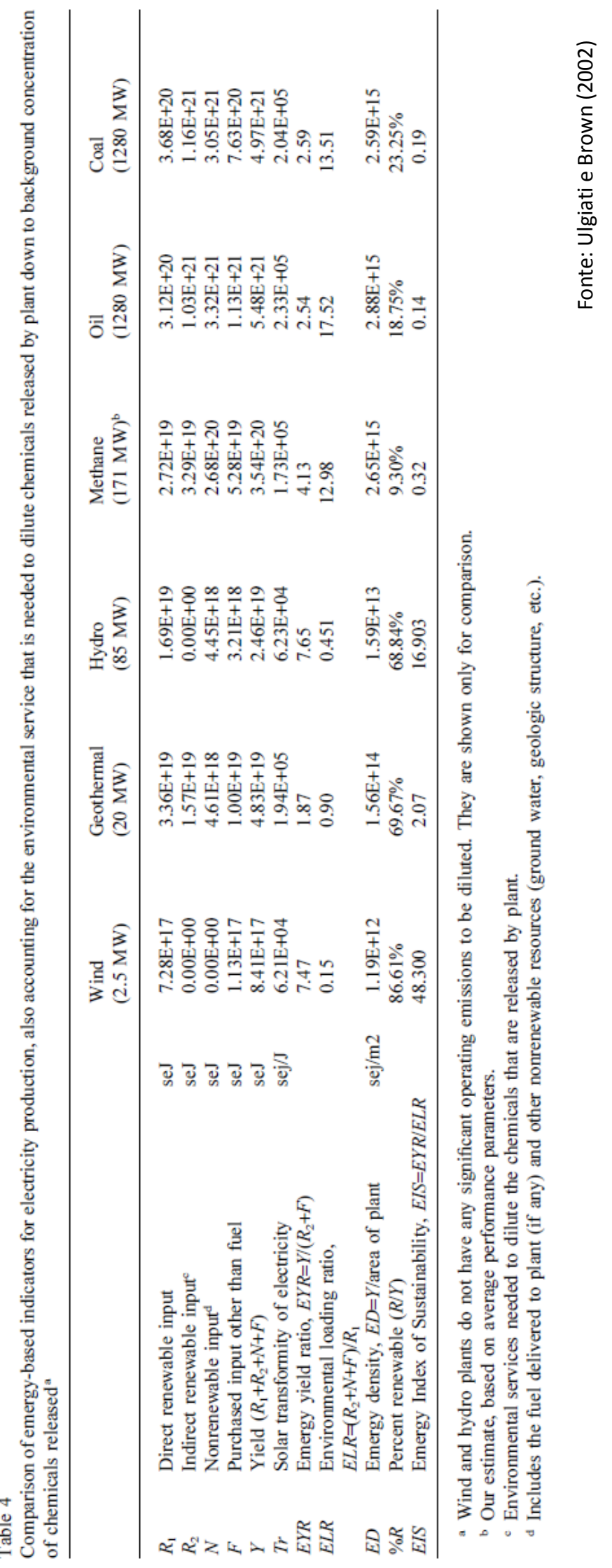


Retorno de Investimento Emergético e outros índices

\begin{tabular}{lccc}
\hline & Yield ratios Calculations Results & & \\
Descrição & Expressão & Cálculo & Valor \\
\hline $\begin{array}{l}\text { Transformidade da eletricidade para o total } \\
\text { emergético da energia nuclear }\end{array}$ & $Y$ & & $2,92 \mathrm{Jemb} / \mathrm{J}$ \\
Emergia da Economia & $F$ & $\frac{2,06 \times 10^{16}}{8,66 \times 10^{16}}$ & 0,24 Jemb/J \\
Entradas do Meio Ambiente (I) & $I=Y-F$ & $2,92-0,24$ & $2,68 \mathrm{Jemb} / \mathrm{J}$ \\
Rendimento Emergético (EYR) & $E Y R=\frac{Y}{F}=\frac{I}{F}+1$ & $\frac{2,92}{0,24}$ & 12,3 \\
Retorno de Investimento Emergético (EIR) & $E I R=\frac{I}{F}$ & $\frac{2,68}{0,24}$ & 11,3 \\
\hline
\end{tabular}

Fonte: Kindberg (2007)

Transformidade Atualizada da Eletricidade advinda de Energia Nuclear

\begin{tabular}{lc}
\hline Item & seJ/ano \\
\hline Emergia da economia & $9.128 \times 10^{23}$ \\
Emergia do meio ambiente & $4.900 \times 10^{22}$ \\
Emergia do urânio & $6.370 \times 10^{22}$ \\
Emergia total & $1.030 \times 10^{24}$ \\
Na base 9.26 & $1.010 \times 10^{24}$ \\
Joules de eletricidade gerada & $2.090 \times 10^{19}$ \\
Transformidade da eletricidade nuclear & $4.81 \times 10^{4} \mathrm{sej} / \mathrm{J}$ \\
\hline
\end{tabular}

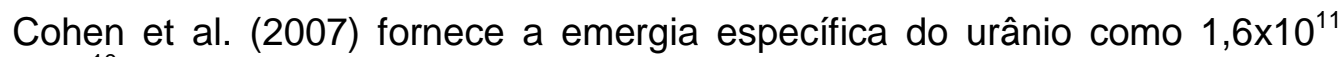
$\mathrm{seJ} / \mathrm{g}=9,36 \times 10^{10} \mathrm{sej} / \mathrm{g}$ na base 9.26. Itens na tabela são de Lapp (1991) contabilizadas em Odum (1996) na p.154. 
Tabela de cálculo de valores emergéticos para produtos de cana

\begin{tabular}{|c|c|c|c|c|c|c|c|}
\hline \multicolumn{2}{|c|}{ Notas } & $\begin{array}{l}\text { Energia (J/ano) } \\
\text { Massa (kg/ano) } \\
\text { Dinheiro (\$/ano) }\end{array}$ & & $\begin{array}{c}\text { Transformidade } \\
\text { se } / \mathrm{J} \\
\text { se } / \mathrm{kg}\end{array}$ & $\begin{array}{c}\text { Fluxo } \\
\text { Emergético }\end{array}$ & & $\mathrm{Em} \$$ \\
\hline \multicolumn{4}{|c|}{ Recursos Naturais } & & seJ/ano & $\%$ & US\$ 2004 \\
\hline \multicolumn{5}{|c|}{ Renováveis } & $1,17 \times 10^{17}$ & 68 & $5,37 \times 10^{4 *}$ \\
\hline 1 & Biomassa de Cana & $6,44 \times 10^{12}$ & J/ano & 24600 & $1,58 \times 10^{17}$ & 63 & $4,98 \times 10^{4}$ \\
\hline 2 & $\begin{array}{l}\text { Água (sistema de } \\
\text { refrigeração) }\end{array}$ & $1,56 \times 10^{10}$ & J/ano & $6,66 \times 10^{5}$ & $1,04 \times 10^{16}$ & 4 & $3,28 \times 10^{3}$ \\
\hline 3 & Carvão vegetal & $1,71 \times 10^{10}$ & J/ano & 107000 & $1,83 \times 10^{15}$ & 1 & $5,77 \times 10^{2}$ \\
\hline \multicolumn{5}{|c|}{ Não Renováveis } & $6,59 \times 10^{15}$ & 2,6 & $2,08 \times 10^{3}$ \\
\hline 4 & Areia & $3,29 \times 10^{8}$ & J/ano & 20000000 & $6,58 \times 10^{15}$ & 2,6 & $2,08 \times 10^{3}$ \\
\hline 5 & Material Cerâmico & $1,02 \times 10^{-6}$ & $\mathrm{Kg}$ /ano & $330,0 \times 10^{11}$ & $3,37 \times 10^{\prime}$ & 0 & $1,06 \times 10^{-5}$ \\
\hline \multicolumn{5}{|c|}{ Materiais da Economia } & $7,32 \times 10^{16}$ & 29 & $2,31 \times 10^{4}$ \\
\hline \multirow[t]{4}{*}{6} & Equipamentos (Aço) & & & & & & \\
\hline & Reator & 1900 & Kg/ano & $18 \times 10^{11}$ & $3,42 \times 10^{15}$ & 1 & $1,08 \times 10^{3}$ \\
\hline & Resfriador & 250 & Kg/ano & $18 \times 10^{11}$ & $4,50 \times 10^{14}$ & 0 & $1,42 \times 10^{2}$ \\
\hline & Reservatório & 325 & $\mathrm{Kg}$ /ano & $18 \times 10^{11}$ & $5,85 \times 10^{14}$ & 0 & $1,85 \times 10^{2}$ \\
\hline 7 & Eletricidade kwh & $4,07 \times 10^{11}$ & J/ano & 165000 & $6,71 \times 10^{17}$ & 27 & $2,12 \times 10^{4}$ \\
\hline \multirow[t]{2}{*}{8} & Químicos & & & & & & \\
\hline & ISOPAR & 445 & $\mathrm{Kg}$ /ano & $38,0 \times 10^{11}$ & $1,69 \times 10^{15}$ & 1 & $5,33 \times 10^{2}$ \\
\hline \multicolumn{5}{|c|}{ Serviços } & $1,43 \times 10^{15}$ & 0,6 & $4,50 \times 10^{2}$ \\
\hline \multirow[t]{4}{*}{9} & Trabalho & & J/ano & & & & \\
\hline & Técnicos & $2,5 \times 10^{8}$ & J/ano & $4 \times 10^{6}$ & $1,0 \times 10^{15}$ & 0,4 & $3,15 \times 10^{2}$ \\
\hline & Mecânicos & $2,5 \times 10^{8}$ & J/ano & 1200000 & $3,0 \times 10^{14}$ & 0,1 & $9,46 \times 10^{1}$ \\
\hline & Operários & $3,2 \times 10^{8}$ & J/ano & 400000 & $1,28 \times 10^{14}$ & 0,1 & $4,04 \times 10^{1}$ \\
\hline \multicolumn{5}{|c|}{ Emergia Total } & $2,51 \times 10^{17}$ & 100 & $7,92 \times 10^{4}$ \\
\hline
\end{tabular}

${ }^{*} 3,17 \times 10^{12}$ seJ/US $\$$

Fonte: adaptado de Alonso-Pippo, Rocha, et al., (2004) 